This item is held in Loughborough University's Institutional Repository (https://dspace.lboro.ac.uk/) and was harvested from the British Library's EThOS service (http://www.ethos.bl.uk/). It is made available under the following Creative Commons Licence conditions.

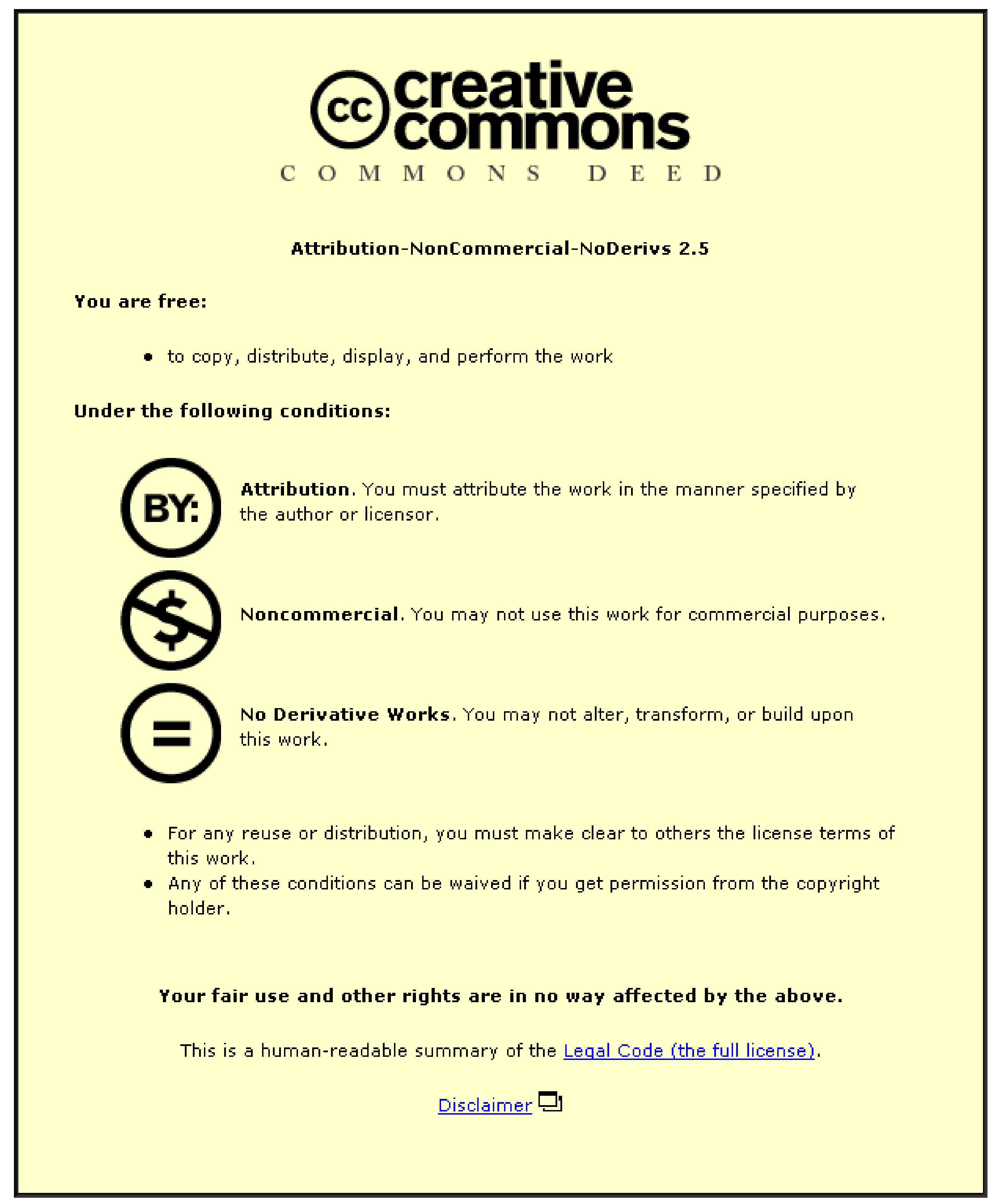

For the full text of this licence, please go to: http://creativecommons.org/licenses/by-nc-nd/2.5/ 


\title{
Microbiological Risk Assessment and Management of Shallow Groundwater Sources in Lichinga Mozambique
}

\author{
by \\ SAM GODFREY \\ BA, M.Sc., MCIWEM, MIWA \\ Chartered Water and Environmental Manager \\ Member International Water Association
}

A Doctoral Thesis submitted in partial fulfilment of the requirements for the award of Doctor of Philosophy of Loughborough University

(C) Sam Godfrey 2006

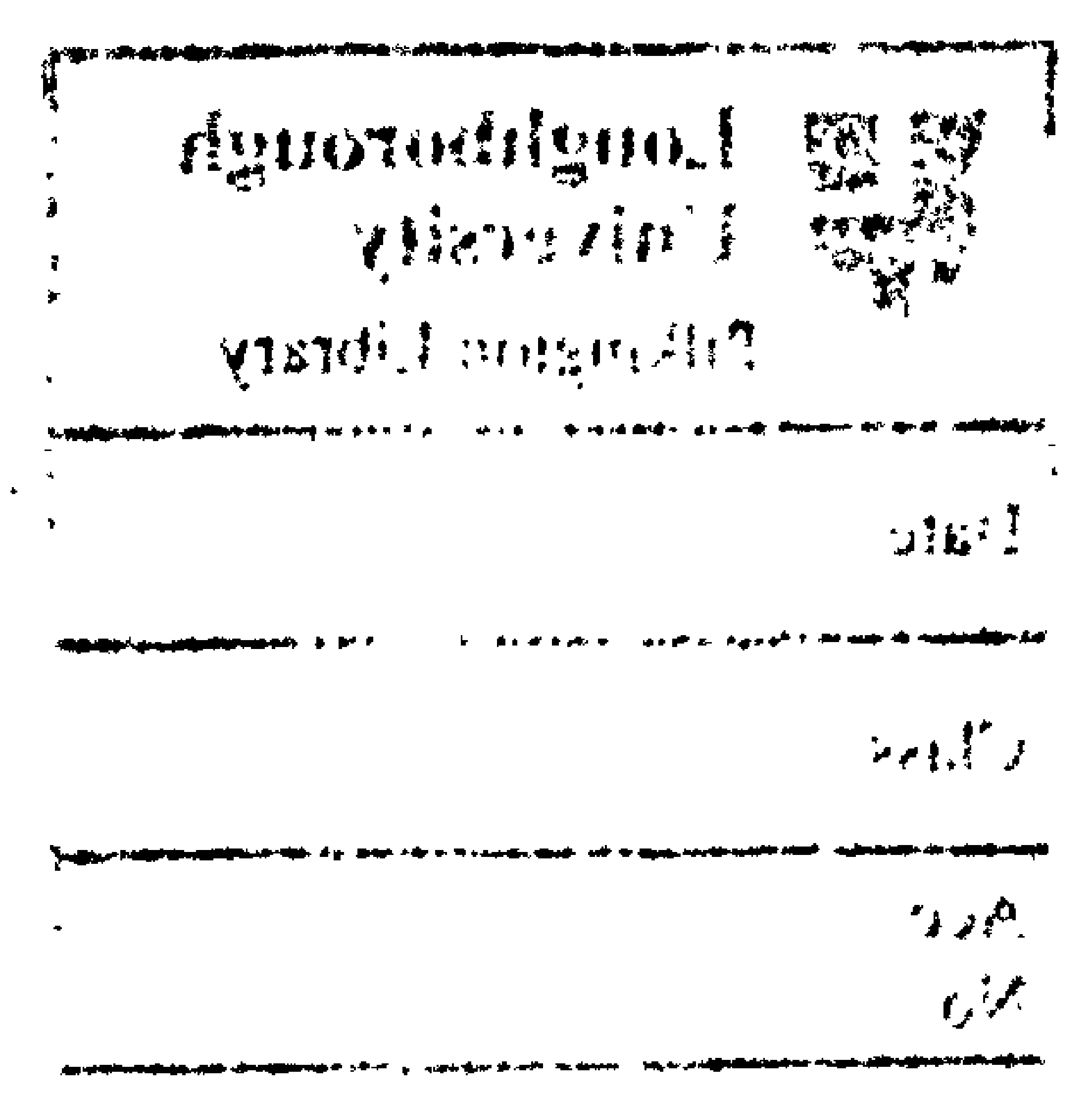




\section{Acknowledgements}

Firstly, I would like to thank my supervisor, Mike Smith, for giving me such clear and precise guidance in the development of this thesis. Additionally, I would like to acknowledge Dr Guy Howard for providing me the inspiration and ideas before, during and after the research period and for helping me redirect my $\mathrm{PhD}$ research in 2002. I am deeply grateful to both for tolerating such a head strong student such as myself. At the field level, I would specifically like to acknowledge members of the three study communities (Nomba, Lulimile and Ceramica) in Lichinga, Mozambique. The thesis was only possible due to their cooperation in allowing me access to their water supplies. Specifically, however I would like to recognize the input of Felix Agosto Timo from the Estação Agraria de Lichinga. His assistance during the data collection phase of the research was invaluable and I am deeply grateful for his patience and commitment to his work. Further, I would like to thank Rebecca Van Der Meulen for volunteering to undertake quality control of the data collection and to James Gibson and Ned Breslin of WaterAid Mozambique for their help and support.

In the UK, I would like to acknowledge the UK CIWEM Water Conservators Company for awarding me the 2004 Tony Drake Scholarship. The research award enabled me to complete the field data collection and write up the findings in time. In addition, I would like to acknowledge Neil Durham of WagTech International for supporting the research with additional field water quality testing equipment and Steve Pedley and Kali Johal of the Robens Centre for Environmental Health, Surrey University and John Watkins of CREH Analytic for providing expert microbiological analytical input when required.

From Loughborough University, I would like to thank Ian Smout (Director-WEDC) for providing me with the flexibility to complete the $\mathrm{PhD}$ whilst working full time as a WEDC staff and to Dr Mohammed Khan (Sohail), Dr Margaret Ince, Dr Sam Kayaga, Dr Kala Vairavamoorthy and (of course) Trisha Jackson for their intellectual and logistical advice. Additionally, I would like to thank David Coates from the Loughborough University Business School for providing specialist statistical input.

Last, but no means least, I would like to thank my devoted wife (Amaka) and family (Mum and Dad) who have supported me throughout those dark long winter nights. 


\section{Abstract}

The principal Water target of the Millennium Development Goals (MDG) is to Ensure environmental sustainability by halving the proportion of people without access to safe water by 2015. Although great strides have been made in meeting this challenge in terms of provision of services since the year 2000 , the safety of many these water supplies remains unknown. One of the biggest challenges therefore facing water development professionals is how to ensure sufficient levels of both quantity and quality of safe water. One of the principal mechanisms for monitoring the progress towards attaining the MDG goals for access to safe water is the UNICEF/WHO Joint Monitoring Programme (JMP).

However, the JMP acknowledges that one of its current weaknesses is in assessing safety related to different technology types. In acknowledgement of these weaknesses and of the weakness of reliance on "end product testing" as a means of assuring microbiological safety, the thesis proposes improved methods of assessment and management of microbiological water safety based on a "risk" paradigm. Coinciding with proposed new risk based methods of assessing water safety outlined in the $3^{\text {rd }}$ edition of the World Health Organization Guidelines for Drinking Water Quality (2004), the thesis researches the risk to three well technology types in Mozambique. Principal pathways to microbiological contamination of shallow groundwater were assessed which included both the conventional aquifer pathways and preferential or localised pathways.

The research adopted an experimental design that uses a mix of qualitative and quantitative data collection techniques. Data were collected over 12 months in 25 well sites in Lichinga, Mozambique. Findings from the research demonstrated that risk assessment and management are effective tools in understanding the level of safety associated with the well technologies under study. The research indicated firstly that risk assessment aids the identification of specific risk variables (of which animal faeces is a predominant risk), secondly that the use of alternative indicator organisms (e.g. enterococci) may improve risk understanding, thirdly that there is a strong statistical correlation between use of surrogates (e.g. turbidity) and microbes and fourthly that Water Safety Plans are an appropriate method of risk management. Furthermore, the research supports the JMP definitions of improved water sources, 
which suggest that upgraded wells are not an improved source due to their high vulnerability to contamination through localised pathways.

The recommendations from the thesis include; non-inclusion of upgraded wells in the JMP in Mozambique, greater use of enterococci and turbidity as surrogate indicators of faecal pollution, the need for the development of rapid risk assessment and management techniques for rural areas in developing countries and the inclusion of localised pathways as a principal route of assessment. Potential areas of further research include field-based studies of assessment of faecal sources of Enterococci bacteria, and rapid methods for the development of model Water Safety Plans.

Key words: Microbiology, Bacteria, Groundwater, Hydrogeology, Localised Pathways, Mozambique, Rainfall, Risk, Virus, Wells 
Table of Contents

Acknowledgements.......................................................................................................... II

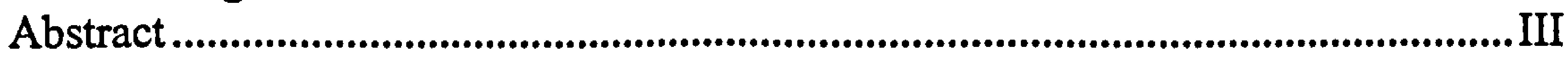

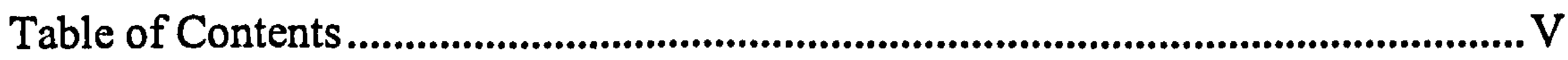

List of Figures .......................................................................................................... VIII

List of Tables ..................................................................................................................

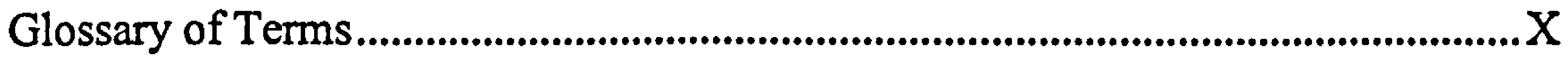

Abbreviations .................................................................................................................... XII

Chapter 1: Introduction ......................................................................................................... 1

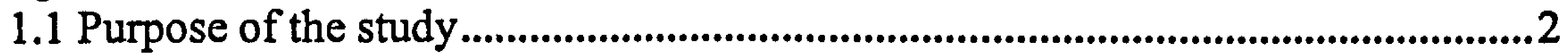

1.2 Methodology and Conceptual Design....................................................................3

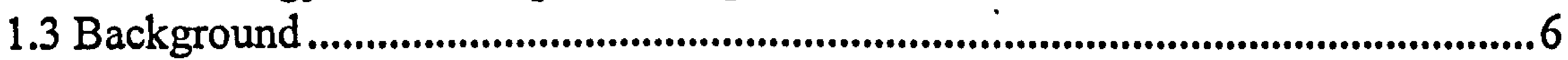

1.3.1 Hydrogeological risk assessment..............................................................6

1.3.2 Water quality risk assessment ..................................................................7

1.4 Justification and Originality.............................................................................9

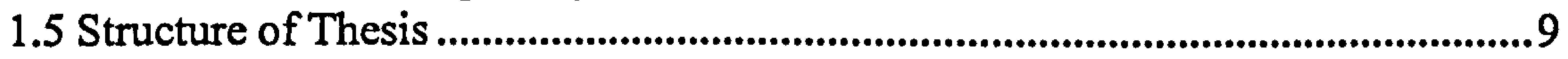

Chapter 2: Literature review ..................................................................................10

2.1 Chapter Introduction .....................................................................................11

2.1.1 Literature review methodology ..................................................................11

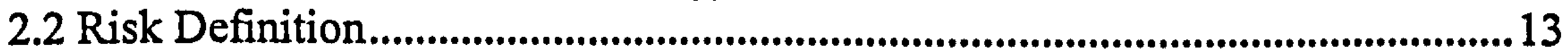

2.2.1 Risk Assessment and Risk Management ................................................14

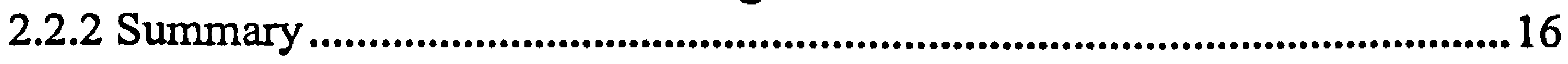

2.3 Microbiological/Chemical Pollutant Source.......................................................17

2.3.1 Chemical sources of contamination ...............................................................17

2.3.2 Microbiological sources of contamination................................................19

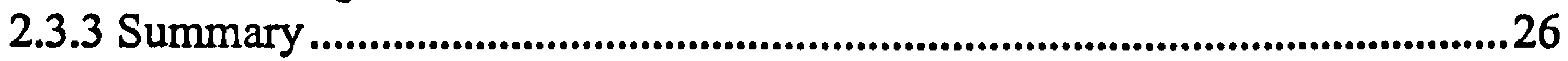

2.4 Pathways to Contamination ......................................................................27

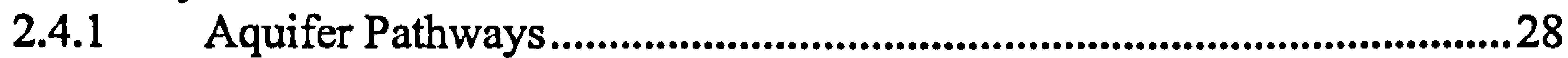

2.4.1 Localised Pathways.......................................................................35

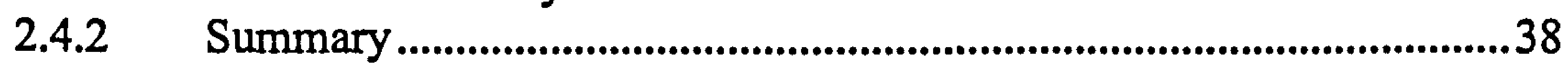

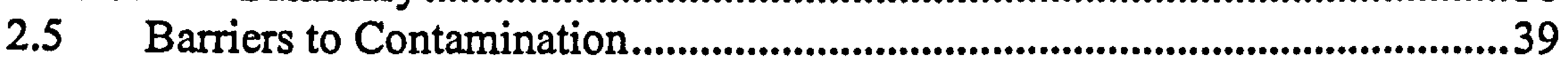

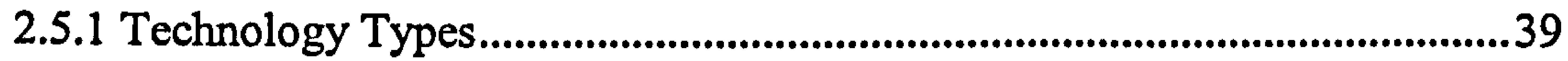

2.5.2 Effectiveness of Technologies ..........................................................51

2.5.3 Variables ....................................................................................5

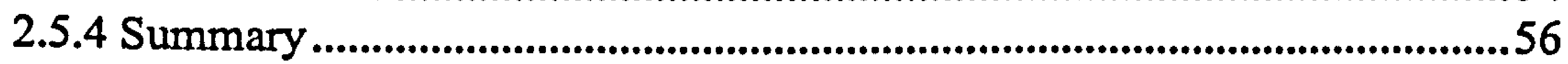

2.6 Literature Review Summary and Identified Research Gaps...............................57

Chapter 3: Selection of Risk Variables.....................................................................58

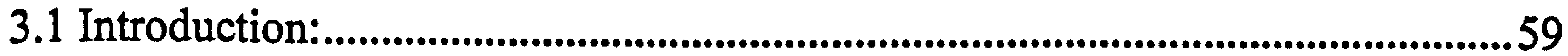

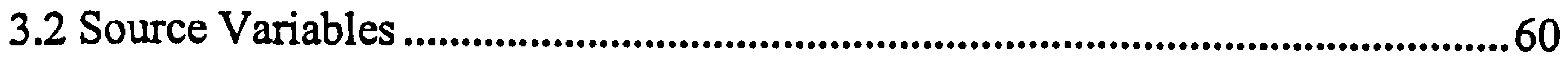

3.3 Pathway Variables - Meteorological ..............................................................63

3.4 Pathway Variables - Hydrogeological .................................................................63

3.5 Receptor - Engineering Variables.....................................................................67

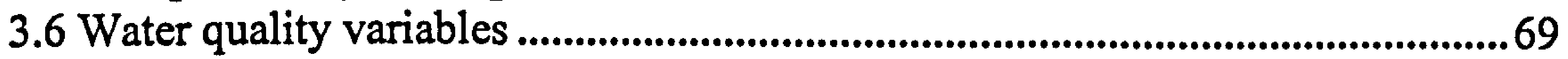

Microbiological variables ...............................................................................69

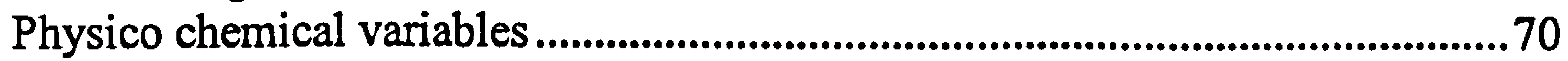

3.7 Selected Variables..........................................................................................................71

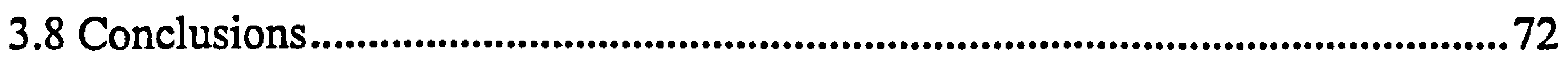

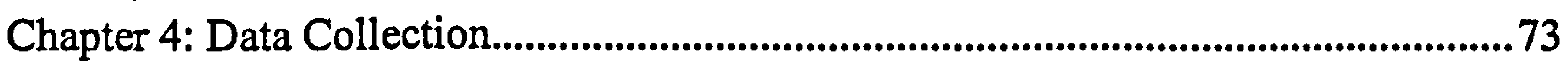

4.1 Introduction...................................................................................................................74

4.2 Selection of Study Areas and Sample Size .............................................................74 


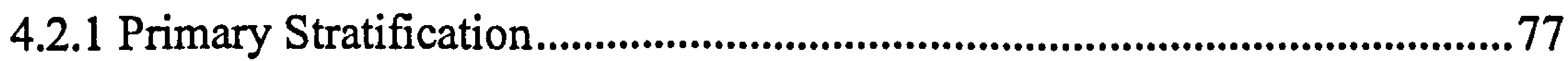

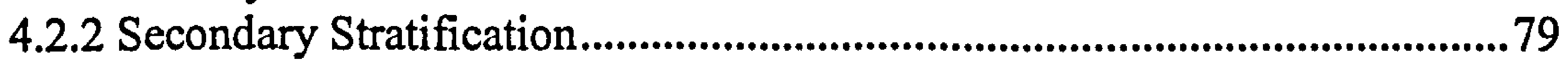

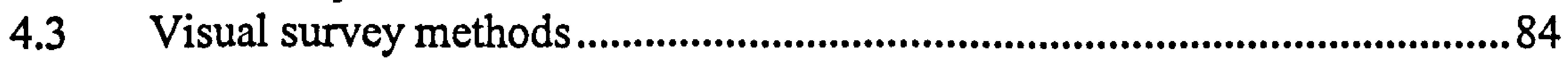

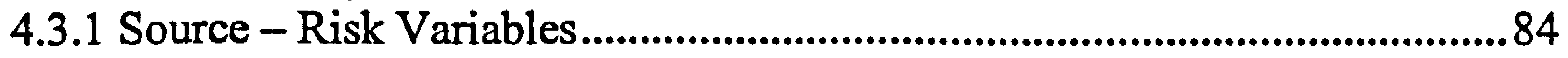

4.3.2 Pathway - Meteorological and Hydrogeological Variables ..........................8.87

4.3.3 Receptor - Engineering Barriers .................................................................99

4.3.4 End Product - Water quality variables ...............................................................91

4.4 Physical/Non destructive field methods.............................................................92

4.4.1 Source - Risk Variables......................................................................992

4.4.2 Pathway - Meteorological and Hydrogeological Variables ........................92

4.4.3 Receptor - Engineering Variables ...............................................................99

4.4.4 End Product - Water quality variables ......................................................98

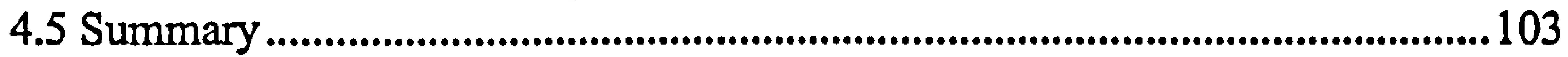

Chapter 5: Data Analysis ...................................................................................104

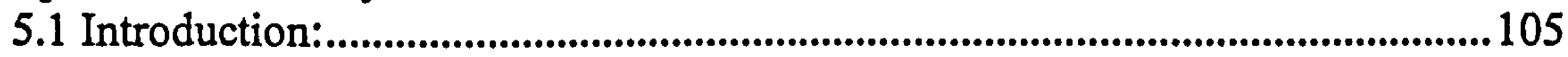

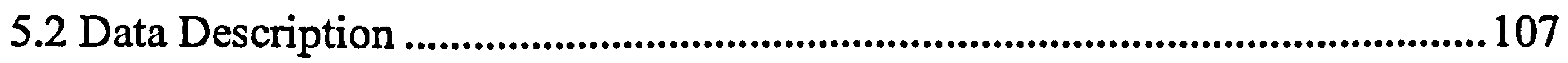

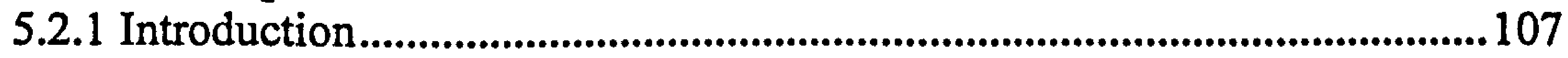

5.2.2 Source of anthropogenic contamination .......................................................... 107

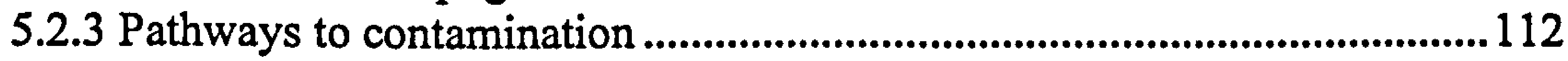

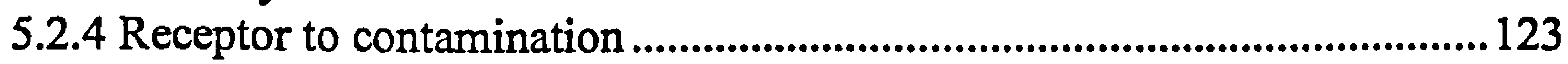

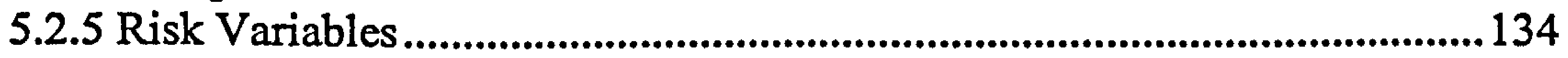

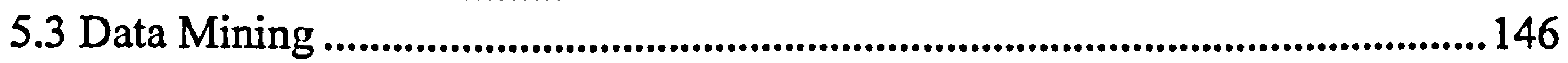

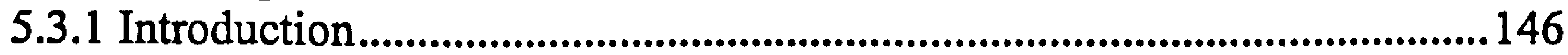

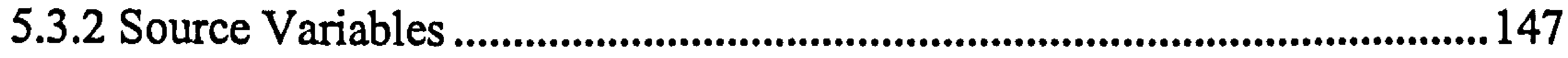

5.3.3 Pathway Variables ................................................................................148

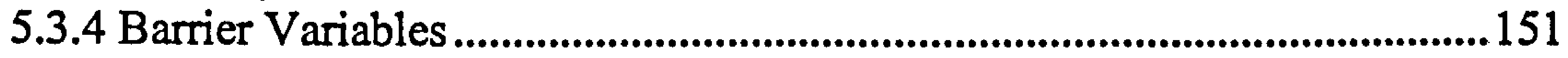

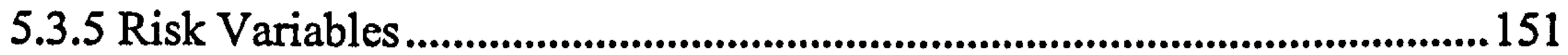

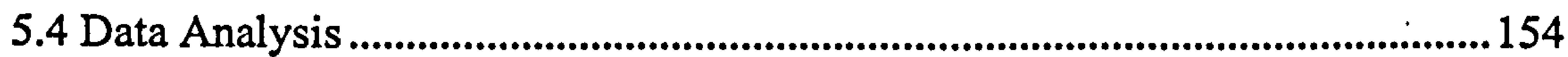

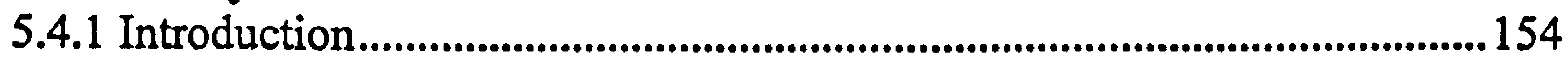

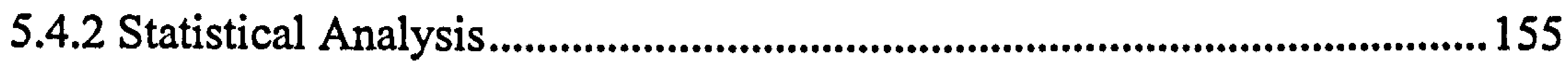

5.4.3 Analysis 1 - source, pathway, receptor ..................................................157

5.4.4 Analysis 2 - Sanitary Inspection..........................................................160

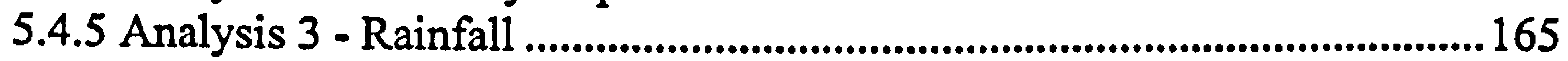

5.4.6 Analysis 4 - Turbidity ...........................................................................168

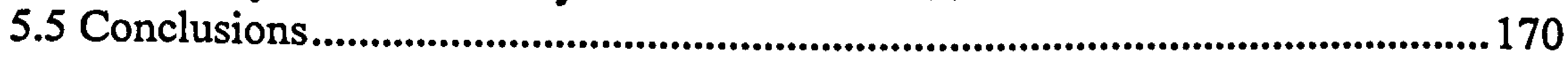

Chapter 6: Risk Management........................................................................173

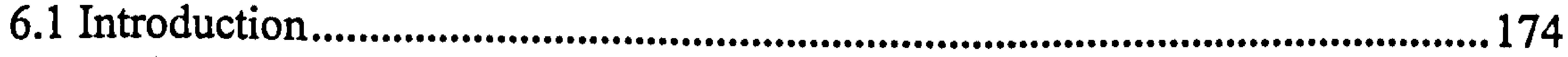

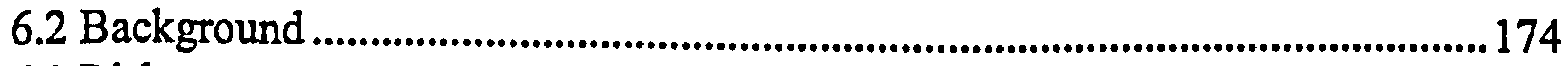

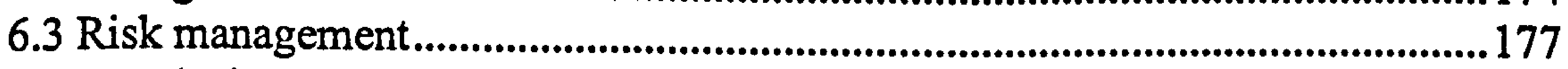

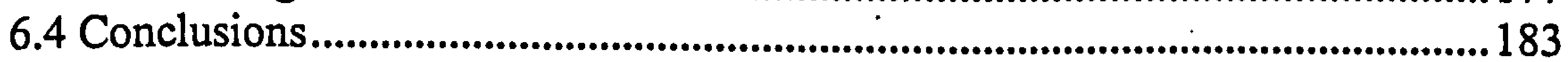

Chapter 7: Conclusions and Recommendations ...................................................184

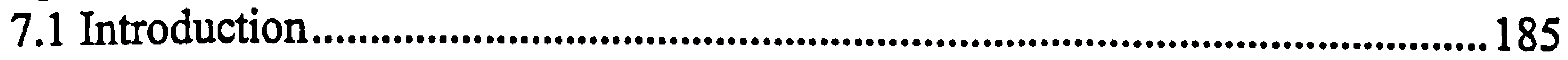

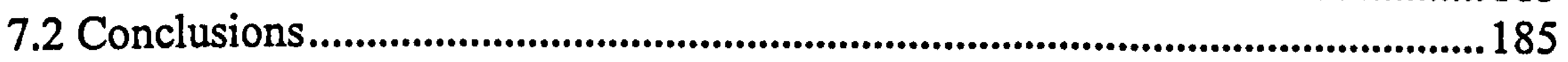

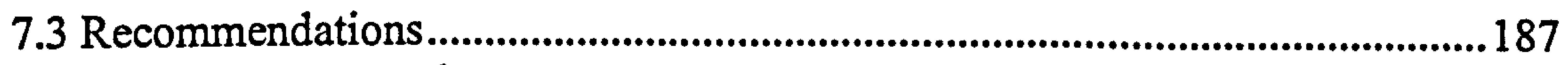

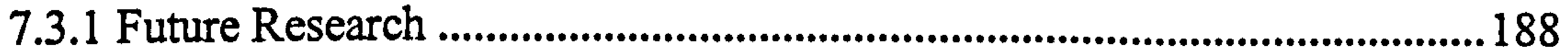

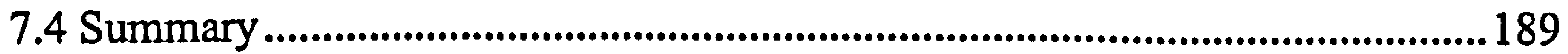

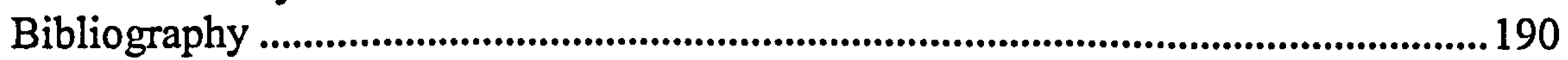

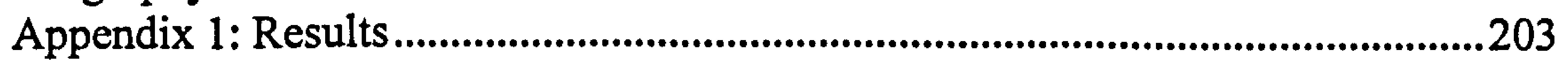

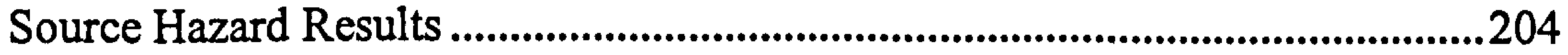

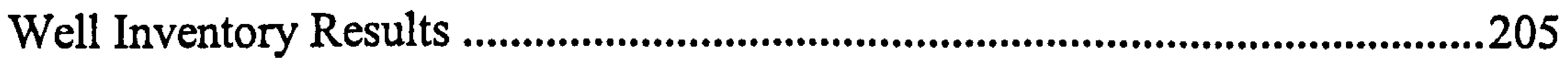


Schmidt Hammer Results

Appendix 2: Analytic Hierarchy Process (AHP) .....................................................207

Appendix 3: Paper Publications ...............................................................................210

Appendix 4: Statistical Methods ..................................................................................227 


\section{List of Figures}

Figure 1: Experimental design framework ................................................................4

Figure 2: Research Methodology................................................................................5

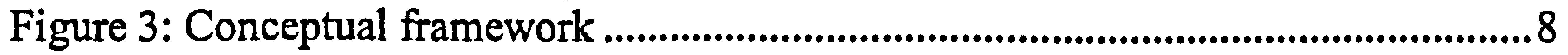

Figure 4: Source, pathway, receptor relationship ................................................................ 12

Figure 5: Pathogen size compared to groundwater matrix properties .............................20

Figure 6: Pathways to Contamination.......................................................................27

Figure 7: Time distance graph ................................................................................34

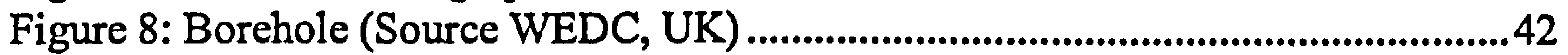

Figure 9: Hand dug well (Source WEDC, UK) .......................................................45

Figure 10: Location of Lichinga, Mozambique .......................................................75

Figure 11: Sample Design....................................................................................................76

Figure 12: Location of communities and sample points in Lichinga.............................78

Figure 13: Soil Identification Test ...............................................................................89

Figure 14: Enthusiastic community participation during soil sampling .......................99

Figure 15: Sieve Analyses equipment...................................................................95

Figure 16: Geovision Borehole Camera .....................................................................96

Figure 17: Surface Hardness testing by the author ....................................................98

Figure 18: Duplicate sampling routine (duplicates shown as shaded area)................103

Figure 19: Conceptual framework ....................................................................105

Figure 20: Geographical location of Lichinga ............................................................107

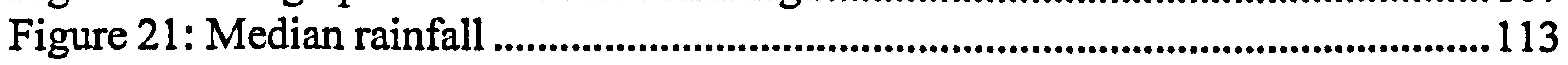

Figure 22: Groundwater levels..........................................................................113

Figure 23: Geological Map of Mozambique....................................................................115

Figure 24: Soil Ternary diagram....................................................................................116

Figure 25: Coefficient of permeability $(\mathrm{m} / \mathrm{s})$.......................................................118

Figure 26: Particle Size Distribution analysis for Lichinga......................................118

Figure 27: Well Lining Hierarchy.......................................................................129

Figure 28: Thermotoloerant Coliform Data.............................................................135

Figure 29: Enterococci data ............................................................................136

Figure 30: thermotolerant coliform compliance ......................................................137

Figure 31: Percentage compliance of enterococci .......................................................138

Figure 32: EF and TTC results per technology.....................................................139

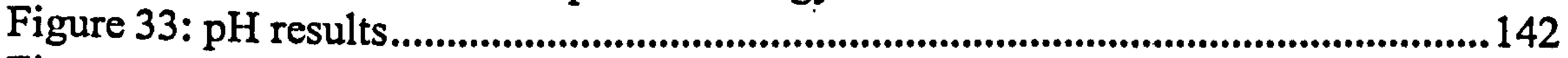

Figure 34: Turbidity Results ............................................................................143

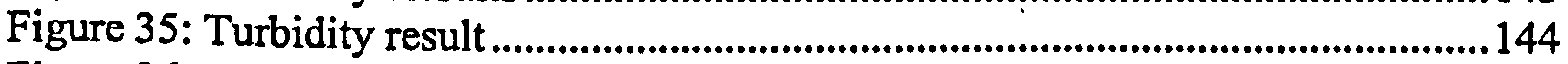

Figure 36: POSH method variables ...........................................................................147

Figure 37: Vulnerability categories based on modified Swartz method.......................149

Figure 38: Vulnerability and source loading categorisations .....................................150

Figure 39 Traditional Well Sanitary Inspection Results............................................161

Figure 40: Improved well Sanitary Inspection records.............................................163

Figure 41 Upgraded wells sanitary inspection records.................................................164

Figure 42: EF/TTC contamination and Rainfall - Nov/Dec 2003 ..............................167

Figure 43: TTC v Turbidity ...................................................................................168

Figure 44: Framework for safe drinking water (WHO 2004).....................................176

Figure 45: Historical and WSP approach.............................................................176 


\section{List of Tables}

Table 1: JMP definitions ........................................................................................................2

Table 2: Pathogenic micro organisms.............................................................................21

Table 3: Aquifer vulnerability assessment methods ...................................................64

Table 4: Justification for variable selection ................................................................67

Table 5: Selected Variables ......................................................................................72

Table 6: Selected Water Points by Technology ............................................................81

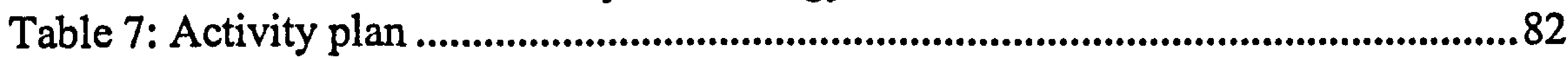

Table 8: Data collection methods .......................................................................................83

Table 9: Selected source variables.....................................................................................8 84

Table 10: Sanitary Inspection Question Categories.......................................................85

Table 11: Land use categorisation ...................................................................86

Table 12: Selected Hydrogeological Variables.............................................................87

Table 13: Selected Engineering Barrier Variables............................................................90

Table 14: Selected meteorological variables ...................................................................92

Table 15: Selected hydrogeological variables ...........................................................93

Table 16: Selected Engineering Variables .......................................................................97

Table 17: Selected water quality variables .....................................................................99

Table 18: Classification of pollution sources using an adapted POSH method .........109

Table 19: Pollution load characterisation .......................................................................110

Table 20: Subsoil vulnerability based on hydrogeological characteristics..................117

Table 21: Vulnerability Index ......................................................................................121

Table 22: Wellhead design criteria .......................................................................124

Table 23: Scale of measurement for AHP ...................................................................127

Table 24: AHP Composite Weightings........................................................................131

Table 25: Receptor Risk.........................................................................................133

Table 26: Subsurface contaminant load potential......................................................148

Table 27: Vulnerability ratings Lichinga .......................................................................149

Table 28: Risk to barrier ratings Lichinga .............................................................151

Table 29: Sanitary inspection variables ..............................................................152

Table 30: Omnibus - thermotolerant coliform Non Compliance ................................157

Table 31: Omnibus - Thermotolerant Non Compliance..............................................159

Table 32: Omnibus - Thermotolerant Non Compliance................................................159

Table 33 Rainfall............................................................................................................. 166

Table 34: Condition and weighting of hazard events (WHO 2004) ............................178

Table 35 Final risk ratings for potential combinations (WHO 2004)............................178

Table 36: Model Water Safety Plan - Traditional Wells.............................................180

Table 37: Model Water Safety Plan - Improved Wells with handpump......................181

Table 38: Model Water Safety Plan - Upgraded well with windlass............................182

Table 39 Risk Scores by technology....................................................................................... 183 


\section{Glossary of Terms}

\section{Aquifer pathway}

Pathways permitting flow of water that occur naturally in the subsurface due to openings and cracks in the soil and rock.

\section{enterococci}

Subgroup of larger group of organisms known as Faecal Streptococci, comprising of the genus Streptococcus. Gram-positive and relatively tolerant to temperature.

\section{Hazard}

Biological, physical or chemical agents with the potential to cause an adverse health affect

\section{Improved Well}

Concrete caisson lined hand dug well with handpump

\section{Indicator bacteria}

Bacteria that normally live in the intestinal tract of man and other warm-blooded animals without necessarily causing disease. They are always and naturally present in faeces and their presence in drinking water indicates faecal pollution.

\section{Indicator Organism}

Organisms that point to the likely presence of pathogenic organisms

\section{Localised pathway}

Man-made pathways permitting flow of water that occur as a consequence of the design and construction of the receptor

\section{Logistic Regression}

Multivariate analysis of two or more single variates against a dependent variable.

\section{Microbial}

Belonging to or relating to microorganisms

\section{Microbiological}

Study of biological microorganisms

\section{Pathogen bacteria}

Those that cause disease are transmitted through direct contact with an infected host, by ingestion of contaminated food or water, or by action of an intermediate host or disease vector.

\section{Pathway}

Routes by which contaminants reach a receptor (e.g. aquifer)

\section{Quantitative Microbial Risk Assessment (QMRA)}

Risk assessment tool to determine health based targets

\section{Receptor}


Risk

Combination of the probability or frequency of particular event occurring and consequences of its occurrence

\section{Somatic Coliphage}

Bacteriophage (phage) are viruses that use bacteria as hosts with Somatic Coliphage being an ideal indicator virus of contamination from warm blooded animals.

\section{Shallow groundwater}

The water bearing materials that are strongly influenced by physical and chemical processes on the surface (topography, precipitation, man-induced negative changes), because the water is relatively close to the ground surface.

\section{Source}

Anthropogenic Source of contamination (e.g. pit latrine)

\section{Surrogate}

Suitable alternative or substitute

\section{thermotolerant coliforms}

Escherichia coli (or alternatively thermotolerant coliforms) is an indicator bacteria that occur in high numbers in human and animal faeces, sewage and water subject to faecal pollution. These organisms grow at 44 or $44.5^{\circ} \mathrm{C}$ and are able to ferment lactose to produce acid and gas.

\section{Traditional Well}

Unlined well with no constructed headworks

\section{Unsaturated zone}

Zone below the soil layer in which pores are only partially filled with water. The remainder of the pore spaces are filled with air.

\section{Upgraded Well}

Brick lined well with windlass

\section{Vulnerability}

Susceptibility of the physical properties of groundwater systems to a hazard event

\section{Water Safety Plan}

Comprehensive risk assessment and management approach that encompasses all steps in water supply from the catchment to the consumer.

\section{Water level}

The level below which a geological formation is completely saturated with water.

\section{Windlass}

Rope and bucket form of extraction with winch. 


\section{Abbreviations}

- AHP - Analytic Hierarchy Process

- BGS - British Geological Survey

- CFU - Colony Forming Units

- EF - Enterococci Faecalis

- JMP - Joint Monitoring Programme

- MBG - Metres Below Ground

- MDG-Millennium Development Goals

- QMRA - Quantitative Microbial Risk Assessment

- TTC - thermotolerant coliforms

- UN - United Nations

- UNICEF - United Nations Children's Fund

- WHO - World Health Organization

- WSP - Water Safety Plans 
Chapter 1: Introduction 


\subsection{Purpose of the study}

The principal Water target of the Millennium Development Goals (MDG) is to Ensure environmental sustainability by halving the proportion of people without access to safe water by 2015 (WHO/UNICEF 2004). In the year 2000, the WHO/UNICEF stated that $47 \%$ of the population of rural areas in Africa, $62 \%$ in Latin America and $75 \%$ in Asia had access to improved water (WHO/UNICEF, 2004). Although great strides have been made in meeting the MDG water target in terms of provision of services since the year 2000 , the safety of many water supplies remains unknown. One of the biggest challenges therefore facing water development professionals is how to ensure sufficient levels of both quantity and quality of safe water.

Current debates within the water and sanitation sector focus on the means of addressing the Millennium Development Goals. One of the principal mechanisms for monitoring the progress towards attaining the goals for access to safe water is the WHO/UNICEF Joint Monitoring Programme (JMP). In the 2004 JMP Interim Report, WHO/UNICEF presented findings on levels of access to "safe" water from improved and unimproved water supplies. In the JMP Interim report, access to water-supply services is defined as "the availability of at least 20 litres per person per day from an "improved" source within 1 kilometre of the user's dwelling." Furthermore, improved water supply is defined as "a source is one that is likely to provide "safe" water" (WHO/UNICEF 2004). This includes the technologies outlined in Table 1:

Table 1: JMP definitions

\begin{tabular}{|c|c|}
\hline Improved & Unimproved \\
\hline $\begin{array}{ll}\text { - } & \text { Household connection } \\
\text { - } & \text { Public standpipe } \\
\text { - } & \text { Borehole } \\
\text { - } & \text { Protected dug well } \\
\text { - } & \text { Protected spring } \\
\text { - } & \text { Rainwater collection }\end{array}$ & $\begin{array}{l}\text { - Unprotected well } \\
\text { - Unprotected spring } \\
\text { - } \quad \text { Vendor provided water } \\
\text { - } \quad \text { Bottled water } \\
\text { - } \\
\text { Tanker truck water }\end{array}$ \\
\hline
\end{tabular}

Source: WHO/UNICEF 2004

Technologies are considered to be unimproved if the quantity or quality cannot be assured. However, as recognised by WHO/UNICEF, "current information does not allow us to establish a relationship between access to safe water and access to 
improved sources" (WHO/UNICEF 2004). Although WHO and UNICEF are examining this relationship, any correlation will be country specific and dependent on definitions of improved and unimproved water sources in each country. This is the case in Mozambique where there is currently a high level debate being undertaken between the UN, Government Ministers, Non Government Organizations and Practitioners. The basis of this debate is whether an upgraded well (well with headwall and windlass) constitutes an improved water source under the definitions outlined in the JMP. Due to the high number of such water supplies in the North of Mozambique, the potential inclusion or exclusion of the technology would clearly bias coverage figures in the JMP for Mozambique.

In 2002, the JMP estimated that $42 \%$ of the population of Mozambique had access to safe water, with a $76 \%$ and $24 \%$ coverage in urban and rural areas respectively (WHO/UNICEF 2004). Due to these low levels in rural areas, the debate over the definition of improved water technologies in the JMP is evermore pertinent. Presently, upgraded wells (wells with headwall and windlass) are not included in the JMP definitions of an improved technology. The Government of Mozambique argues that this is correct. However, NGOs (including WaterAid) state that upgraded wells are the predominant form of safe water supply in Northern Mozambique and that their exclusion is drastically affecting coverage figures.

\subsection{Methodology and Conceptual Design}

In light of this debate, this research has the following methodology:

AIM: To assess the level of "safety" of upgraded wells as a water source in comparison to both traditional (unprotected wells) and improved (concrete caisson lined) wells with handpumps.

To achieve this, the research has two hypotheses:

H1: It is possible to determine the relative risk to microbiological groundwater quality by study of the source, pathway and receptor,

H2: It is possible to quantify the overall risk to microbiological groundwater quality by study of the collective risks from source, pathway and receptors.

In this research, the source is defined as the hazard event/environment (e.g. septic tank), the pathway as the vulnerability of the media (e.g. soil type) and the receptor as 
the receiving water infrastructure (e.g. hand dug well). Shallow groundwater is defined in this thesis as the water bearing materials that are strongly influenced by physical and chemical processes on the surface (topography, precipitation and maninduced negative changes) (Melian et al. 1999).

To address these hypotheses, the research has three specific objectives:

01: To assess the sources, pathways and receptors that present greatest risk to shallow groundwater,

02: To analyse levels of significance of individual risk variables,

03: To propose appropriate Water Safety Plans (WSPs) to manage and minimise existing and probable risks.

To research these aims and objectives, an experimental design framework will be used that follows the five step methodology outlined in Figure 1 (Allison, 1997).

Figure 1: Experimental design framework

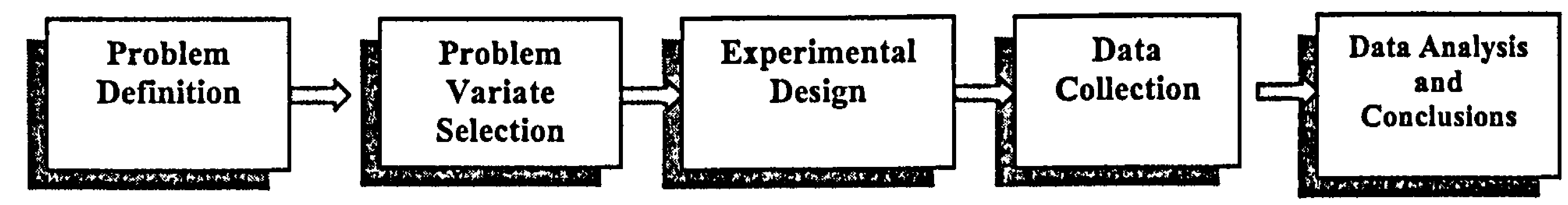

The basis of the experimental design is described as "the specification of the conditions at which experimental design will be observed" (Greenfield 2000). It begins with a defined problem or hypothesis and ends with a solution and conclusion.

The research question is addressed repeatedly throughout the research to question the what if? scenario. The defined problem in this research was;

How to assess the significance of variables affecting microbiological risk to shallow groundwater?

To answer the defined research problem, this study collected data from three sources:

1. Review of available literature from UK based libraries, internationally accessible academic journals and articles, relevant literature in the Loughborough University library and the WEDC Resources Centre. 
2. 12 months field work in Mozambique in collaboration with the UK charity WaterAid between November 2003 and October 2004 (the author was awarded a travel bursary for fieldwork by the Tony Drake Scholarship from CIWEM and the UK Water Conservators Company to finance the field work).

3. Interviews, discussions and communications with water sector professionals during the period of research.

These three sources are considered appropriate data sources as they combine both qualitative and quantitative information. In addition the data sources are likely to provide reliable information with opportunity for comparison and validation of data from different sources.

Initially, a review of background literature was undertaken. This was followed by a thorough review of available literature. The objective of the literature review is to identify gaps in the literature through an analysis of microbiological and chemical risk to infrastructure. On the basis of the review, specific risk variables affecting shallow groundwater was identified. Quantitative data will then be collected from a field site in Mozambique over a 12 month period for each of the required variables. Based on this, statistical and data analysis was result in the development of appropriate risk management strategies.

Figure 2: Research Methodology

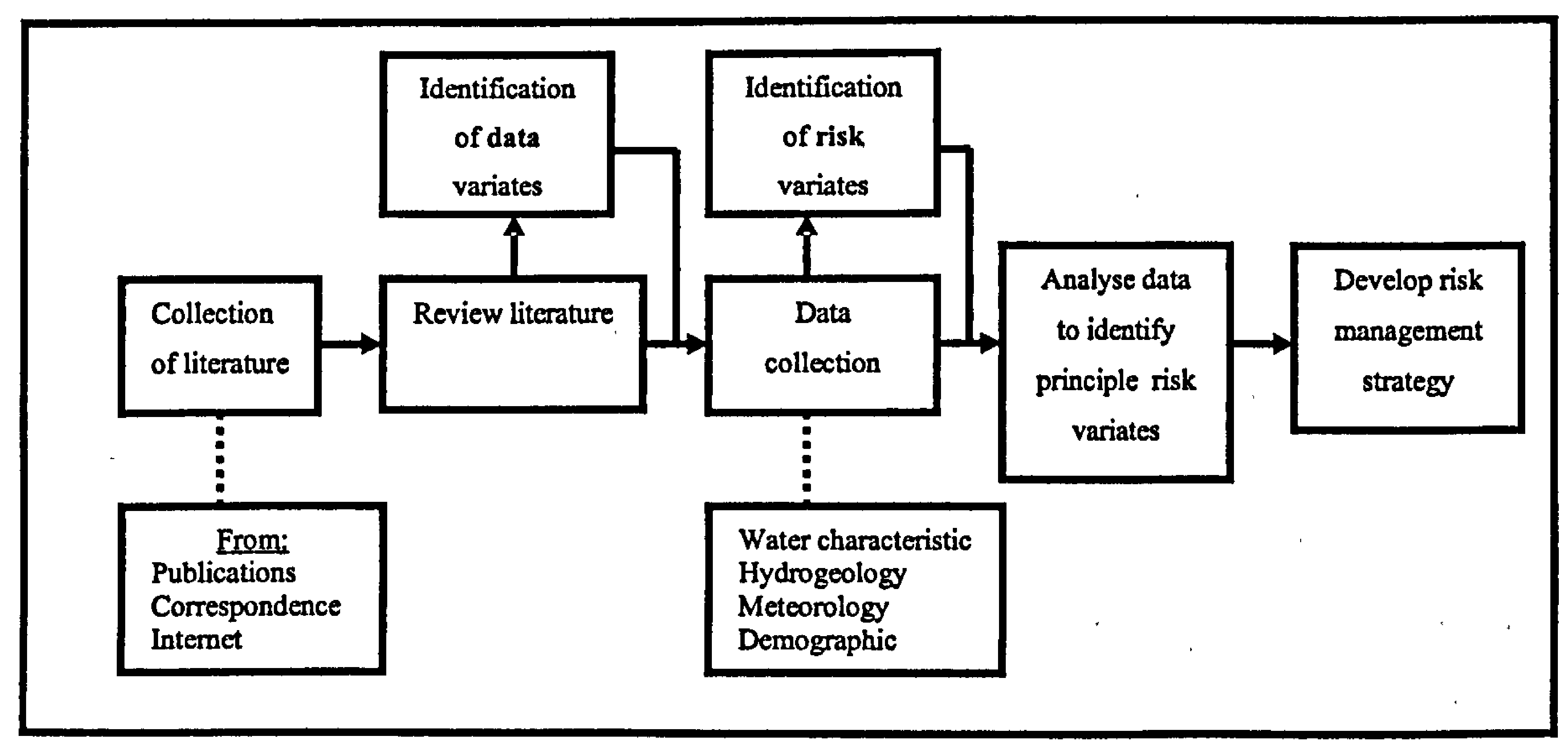




\subsection{Background}

\subsubsection{Hydrogeological risk assessment}

It is commonly known that hydrogeologists and water quality professionals have failed to reach a consensus on definitions, reference terms and methods of effective groundwater risk assessment (Doerfliger et al. 1999, Gogu et al. 2000). Terms such as vulnerability, hazard and risk are commonly used, but commonly misunderstood. Indeed, due to the numerous variables that contribute to groundwater risk, various overlay and index tools have been developed. Overlay and index methods are numerical, statistical, conceptual and computer-based multivariate models that are developed to improve groundwater risk assessment. They are commonly developed using Geographic Information System (GIS) formats in order to visually depict the multiple variables in GIS layers. Further information on overlay and index tools can be found in texts such as Doerfliger et al (1999) and Gogu et al. (2000).

For hydrogeologists, the understanding of risk has historically focussed on the assessment of possible pollution from faecal sources to a water supply receptor through movement of microbiological pathogens through aquifer pathways (Gogu et al. 2000). Hydrogeologists consider factors such as contaminant loading, soil permeability and porosity, ambient temperature of soil microbes relative to physiologic temperature and distance from source to receptor to develop overlay and index risk-based tools. Many of these tools are heavily reliant on quantitative data and are used to delineate the boundaries of groundwater supply protection areas (Foster et al. 2002).

There are, however, limitations in providing such guidance in developing countries. These include limited data availability, complex and dynamic traditional land tenure practices and adoption of unrealistic distances for siting water supply points from domestic dwellings (Gelinas et al. 1996). Indeed it can be argued that factors, other than the conventional hydrogeological factors, are of greater importance in developing countries in defining a "safe distance" from a faecal source (e.g. septic tank/pit latrine) to a water receptor (e.g. well/borehole). For example, research by the British Geological Survey (BGS) and the Robens Institute at Surrey University, UK on the Associated Risks to Groundwater from On Site Sanitation (ARGOSS) identified 
"engineering" variables such as poor workmanship as primary pathways to the short circuiting of the wellhead protection zone (ARGOSS 2001, Howard et al. 2003).

The ARGOSS study noted ingress of contaminants through localised pathways (short circuiting). These originated from diffuse surface faecal sources (associated with inadequate sanitation conditions) and through poorly sealed annuli of boreholes or cracks in surface aprons (associated with construction faults and inadequate maintenance of wells). This resulted in higher levels of microbiological contamination than from the conventional aquifer pathways (Howard et al. 2005). Studies by ARGOSS (2001) and Howard et al. (2003) further noted that to reduce risk of contamination of shallow groundwater, a more thorough understanding of the mechanisms affecting the formation of preferential flow paths through localised pathways is required.

\subsubsection{Water quality risk assessment}

In comparison to hydrogeologists, water quality professionals' assessment of safety of groundwater supplies has historically relied upon results from microbiological and chemical analysis. However, fundamental weaknesses in this approach have resulted in changes in recommended practices for water safety. In the World Health Organization Guidelines for Drinking Water Quality (GDWQ) edition 3, there is a move away from the reliance on end product testing of water quality as a means of assuring water safety and towards a risk based approach termed Water Safety Framework (Davison et al. 2005).

Since 2001, the author has advised on the development of parallel research into the application of an aspect of the Water Safety Framework termed Water Safety Plan in developing countries (Godfrey et al. 2005) The methodology adopted in that research formed an essential evidence base for the proposed new approaches outlined in the $3^{\text {rd }}$ edition of the World Health Organization (WHO) Guidelines for Drinking Water Quality (WHO 2004). This thesis therefore builds on the experience of the development of the principles of Water Safety Plans (WSPs) and provides examples of how to apply WSPs for risk management of shallow groundwater. 
Combining the principles of WSPs with improved hydrogeological risk assessment, this thesis provides further scientific and technical evidence to support the WSP approach. The WSP approach is designed to be a "holistic" approach to shallow groundwater risk assessment that considers the hydrogeological, microbiological, sociological and engineering principles of risk assessment.

Conceptually, the thesis follows the framework outlined in Figure 3.

Figure 3: Conceptual framework

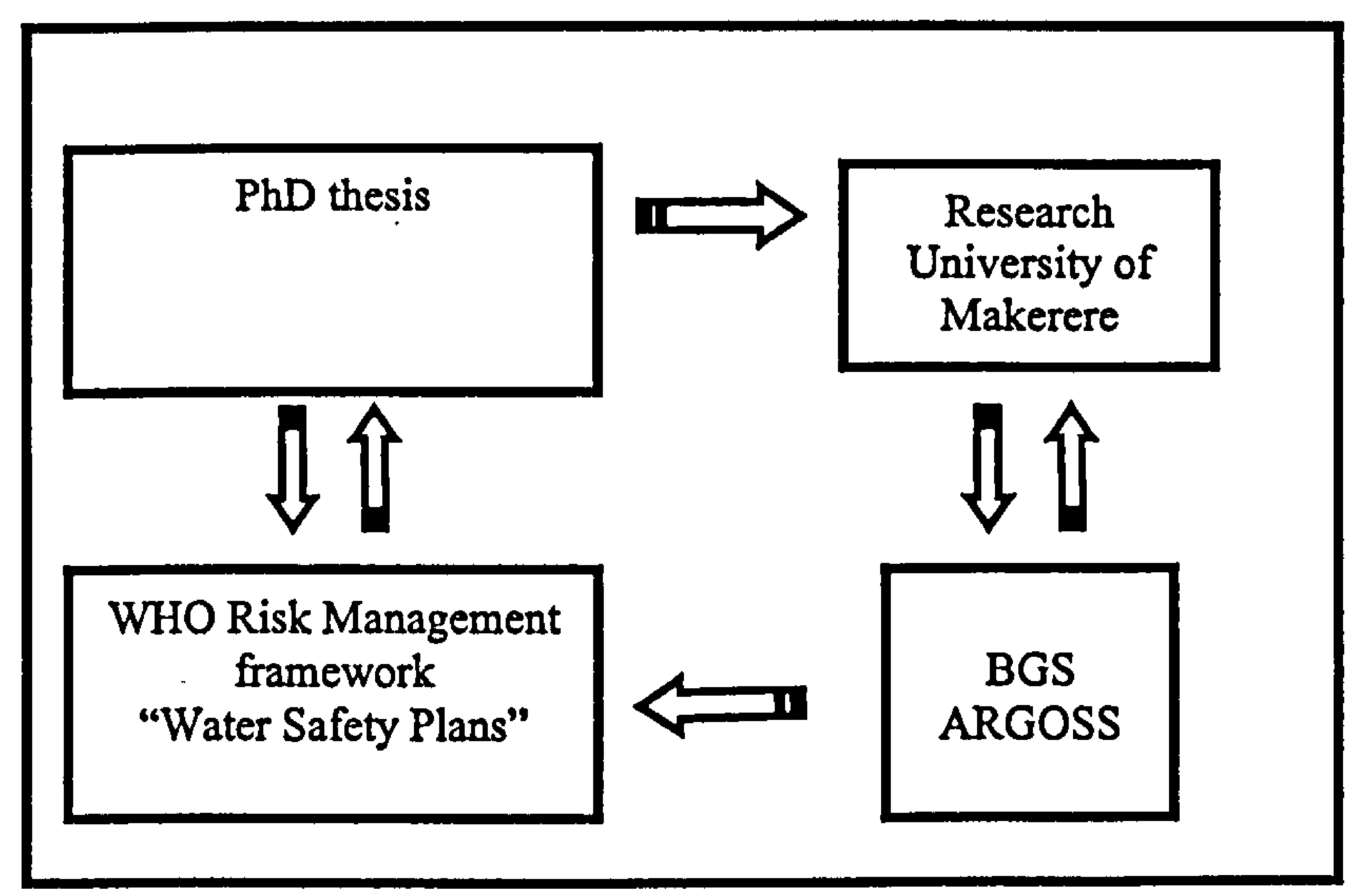

Where;

WHO $=$ World Health Organization

BGS $=$ British Geological Survey

ARGOSS = Associated Risk to Groundwater from On-Site Sanitation

This research uses the findings of the BGS and WHO as its point of departure (ARGOSS 2001, WHO 2004). The thesis focuses primarily on improved risk assessment and management techniques based on a study of 25 well sites in Northern Mozambique. The research complements a further, currently ongoing, piece of research by the University of Makerere, Uganda which is developing source specific models for assessing levels of anthropogenic pollution to shallow groundwater in periurban Kampala, Uganda. 


\subsection{Justification and Originality}

The original contributions of this thesis to academic research are therefore threefold.

1. Firstly, the research explores the area of localized pathways of groundwater contamination which to date have been greatly overlooked by the scientific community's emphasis on aquifer pathways of contamination. The research into localized pathways in the context of low-income communities in developing countries is, in the author's opinion, essential to gaining a greater understanding of safe water provision.

2. Secondly, this research identifies the key variables that define risk to shallow groundwater through localized pathways, and explores the statistical relationship or weighting of significance between the variables. Although the use of statistical methods to establish relationship between variables is not uncommon, its application in this context is original.

3. Thirdly, the research proposes risk management tools that follow the principles of Water Safety Plans for each of the three well technologies studied.

\subsection{Structure of Thesis}

The thesis is divided into 6 further chapters. Chapter 2 provides a systematic review of literature that is available in the area of groundwater risk assessment. The chapter is divided into three clear sections examining the source, the pathway and the receptors in groundwater contamination. The chapter concludes with the identification of key indicators or variables for groundwater risk assessment. Chapter 3 provides rationale for the selection of the variables required for further research and is followed by Chapter 4 which provides details of the sample design and methodology for field data collection for each of these variables in Mozambique. Chapter 5 then presents results from the fieldwork and analysis of those results. The analysis identifies specific risk variables and then Chapter 6 provides sample Water Safety Plans for risk management of these variables for each of the well technologies studied. Finally, Chapter 7 presents the conclusions from this work and identifies potential areas of future research. 
Chapter 2: Literature review 


\subsection{Chapter Introduction}

Chapter 1 provided an introduction to the research. This chapter establishes the conceptual and theoretical foundation for the research by reviewing relevant literature to identify key research issues. Specifically, this chapter has three objectives:

1. to distinguish what has been done and what has not been done in the groundwater risk assessment and management sector,

2. to identify specific sources and principal pathways of risk to shallow groundwater to be researched in the thesis, and,

3. to evaluate effectiveness of varied engineering barriers in reducing risk of contamination to shallow groundwater.

As outlined in Chapter 1, the aim of this thesis is to determine the relative risk of microbiological groundwater quality by a study of the source, pathway and receptor.

In many developing countries, the majority of small-scale groundwater supplies are community managed. This thesis bases its research on the premise that small scale water supplies are community managed and that the technology choices made by communities are based on Demand Responsive Approaches (DRA). The objective of this research is therefore to complement the DRA approach by providing both water supply agencies and communities with greater informed choice of the effectiveness of selected technologies in reducing risk of shallow groundwater to contamination. This will be achieved through a scientific analysis of available literature of risk reduction measures in the shallow groundwater supply sector followed by a selection of appropriate indicators that require further research to improve risk assessment and management.

\subsubsection{Literature review methodology}

The importance of this research for the water sector in developing countries is emphasised through the declaration of both the International Drinking Water Supply and Sanitation Decade in the 1980s and the recently authorised Millennium Declaration Goals (MDGs) (UN 2005) As previously noted in the UN Conference at Mar del Plata, 1977 at the launch of the Drinking Water Supply and Sanitation decade "All people, whatever their stage of development and social and economic condition, have the right to have access to drinking water in quantities and of a quality equal to their basic needs" (UN 1977). To date this goal has not been achieved. 
To address these UN goals, greater consideration is being given to the quality of water. Historically, since the work of John Snow (1854) in the United Kingdom, there has been recognition of the importance of microbiological safety of drinking water and its risk to public health. Methodologically, the achievement of safe water has historically relied upon quality control procedures through end product testing of selected indicator bacteria. A number of recent scientific studies suggest that this process of water quality monitoring is ineffectual. For example studies undertaken in North America provide evidence that a 35\% occurrence of Gastro Intestinal (GI) illness was related to water consumed meeting E.coli standards (Payment et al 1991, Payment 2003). Further work has also linked indicator bacteria presence and turbidity with a rise in the number of cases of infant gastroenteritis (Schwartz et al 1997). As noted in Chapter 1, there is therefore increasing recognition of the importance of assuring the "safety" of water based on a range of multiple barriers. It is recommended that these are controlled through quality assurance procedures that rely on a thorough understanding of the management of risk in a water supply from the catchment to the consumer (WHO, 2004, Davison et al. 2005).

Central in applying these quality assurance procedures to shallow groundwater sources is an appreciation of the SOURCE - PATHWAY - RECEPTOR relationship ARGOSS 2002). This relationship is commonly applied in hydrogeological analysis of groundwater. This chapter bases its literature review on this relationship (as noted in Figure 4).

Figure 4: Source, pathway, receptor relationship

\section{Groundwater Contamination Model}

Source Pathway Receptor

- Source - Hazard event/environment (e.g. septic tank)

- Pathway - Vulnerability of media (e.g. soil type)

- Receptor - Receiving water infrastructure (e.g. hand-dug well)

with consideration of time dimension and consumer aspects (Household level storage)

The literature review begins with a review of generic risk management principles and then focuses on the identification and differentiation between chemical and microbiological hazard sources. The relevance of each in the context of risk reduction 
measures is discussed, and selected parameters are highlighted for further research. Secondly, the review identifies pathways to contamination, reviewing the importance of localised as well as aquifer pathways of contamination of shallow groundwater in a developing country context. Thirdly, the chapter reviews existing evidence in the literature of both the design and effectiveness to contamination of existing engineering barriers. Combining these three principles, the final section of the literature review focuses on identifying appropriate risk variables that require further study and may be used to compose a multivariate risk model.

\subsection{Risk Definition}

To assess or manage risk to potable water supplies, clarity of definition of risk is required. Conceptually, risk is often defined as a measure that combines the probability or frequency of a particular event occurring with the consequences of its occurrence (Dixon 2001).

Conventional definitions note that risk consists of three variables:

$R(A)=C(A) \cdot P(A)$

Where;

$R(A)$ is the magnitude of the risk associated with an event $A$

$C(A)$ is the consequence of the event

$\mathrm{P}(\mathrm{A})$ is the probability of occurrence of the event (Dixon et al., 2001)

The use of this definition is highly applicable to assessing risk of contamination to shallow groundwater to microbiological contamination where, as noted in Chapter 1 , shallow groundwater is defined in this thesis as the water bearing materials that are strongly influenced by physical and chemical processes on the surface (topography, precipitation, man-induced negative changes etc) (Melian et al 1999).

This literature review examined the applicability of risk models applied to varied infrastructure (including piped water supplies, sewers and groundwater) with the aim of identifying potential methodological commonalities. Using evidence from risk management tools developed for other infrastructure, the thesis will identify appropriate indicators of risk and then develop appropriate models for managing risk reduction. 


\subsubsection{Risk Assessment and Risk Management}

Due to the uncertainties in assessing public health risks derived from water quality, there is a recognition within the water and public health sector that comprehensive risk assessment and management tools founded upon the principles of quality assurance are required (Davison et al. 2005, Godfrey et al. 2005). These tools focus on both monitoring and controlling water safety through quality assurance processes such as the principles outlined in Water Safety Plans (WSPs) (WHO, 2004). There is an appreciation within these quality assurance approaches that there are a number of contributing variates to risk. These include, for example, establishing both potential pathways of contamination and approximating survival time of pathogens in a specific environment (Fourie et al 1995, Van Ryneveld et al, 1995). Evidence therefore suggests that risk should be considered in a broader context where contributing variates are considered as multivariates that contribute to a risk model (Fewtrell et al. 2001). The literature suggests that in isolation each variate gives a limited point of reference for assessing risk and that they must be considered together as multivariates in order to scientifically assess their impact (Haas et al. 2001).

The importance of recognising risk as a multifaceted or multivariate entity is essential in assessing risk to infrastructure. For example, in assessing risk of piped distribution to bursts, Woodward et al (2001) identifies uncertainties stating that "until recently there has been limited understanding as to why mains fractures occur. A number of different factors such as ground movement, rapid changes in air temperature, traffic loadings, have been suggested as causes, however the degree to which each factor has an influence on mains failure has not been established." Similarly, lessons may also be learnt from vulnerability assessment of sewers (Horold et al. 1997). Horold et al (1997) note that due to uncertainties in forecasting the risk of sewer failure, a multivariate model approach that includes pipe material, diameter, age and period of construction and location is required.

There are further examples of the use of multivariate models in assessing the vulnerability of groundwater to a risk event (e.g. chemical pollution, microbiological contamination). In the groundwater sector, these have included extensive development of vulnerability maps, most notably DRASTIC and EPIK and these approaches are discussed in more detail in chapter 3 (Doerfliger et al 1999, Rupert 2001). 
In assessing the vulnerability of Karst aquifers, Doerfliger et al. (1999) used a multivariate method of vulnerability mapping which considered specific hydrogeological behaviour of Karst aquifers known as EPIK. The EPIK method is an overlay weighting and rating method similar to that of DRASTIC. It considers both the intrinsic vulnerability of aquifers (i.e. the risks associated with non-point sources of pollution) and the specific vulnerability (considering all types of contamination).

Indeed, to overcome the uncertainties in microbiological risk assessment, Havellar in Fewtrell (2001) recognises the importance of "the development of structured, transparent methods to precipitate expert opinion in the risk assessment process." Such methods may include the use of Quantitative Microbiological Risk Assessment (QMRA) methods, decision-making tools, developing predictive models and the use of Geographical display systems such as Geographical Information Systems (GIS).

The use of a multivariate model is of particular relevance in assessing the risk of both microbiological and chemical contamination to groundwater from both point and diffuse sources of industrial, agricultural and other anthropogenic pollution. The occurrence and transport of these pollutants in groundwater is however complex and one that requires significant further research. This is of particular importance in developing countries where unregulated discharge of pollutants from multiple sources results in high levels of risks of groundwater contamination. The use of a multivariate risk model to predict and control this risk is critical for shallow groundwater sources due to their inherent vulnerability. Indeed, the early work by Foster et al (1991) in South America, highlights the importance of specific assessment of the vulnerability of shallow groundwater sources as opposed to deep groundwater sources to contamination.

There is further consensus as to the multiplicity of sources of this contamination, with studies acknowledging the importance of both point and diffuse sources of contamination from agricultural, anthropogenic and industrial activity (Melian et al 1999). Lewis et al (1980) highlights the need of a "pollution risk array" which not only acknowledges the multiplicity of hazard sources but also the physical variables 
(such as soil porosity) that affect the vulnerability of groundwater to contamination. This is supported by more recent research by ARGOSS 2002 and Howard et al. 2003 emphasising the need to evaluate a multiplicity of pathways.

This approach is supported by Gerba et al (1975) who note that minimum distances of a shallow groundwater source from a hazard that solely conforms to hypothetical hydrogeological profiles will be affected by varying permeabilities and be dependent on die off rates of specific microorganisms at specific locations. Crucial to the establishment of these distances are processes of contaminant transport based on the movement of the contaminant from SOURCE through a geological PATHWAY to a groundwater RECEPTOR.

This source pathway receptor relationship is commonly used in the hydrogeological field to assess risk of groundwater to pollution. It is however a complex process and one that involves a number of key data sets ranging from the key characteristics of the microbe or source (i.e. contaminant loading, size of microbe, inactivation - die off rate and surface electrostatic properties), the physical determinants of the aquifer or pathway (i.e. physiological flow velocity, porosity, temperature and aquifer grain pore size) and the type of receptor (i.e. lined/unlined well, tubewell or spring). The theoretical justification for using the Source-Pathway-Receptor model as the methodological basis of this research relates to its acknowledgement of the multivariate nature of risk reduction in shallow groundwater. Other risk models used in the groundwater sector include establishing groundwater protection zones based on theoretical travel distances and multivariate vulnerability models (e.g. DRASTIC and EPIK) that assume the presence and concentration of a hazard source (Foster et al. 2002). In a developing country context where there are a number of uncertainties in estimating risk, it is important to establish a relationship between the source, the pathway and the receptor. This thesis therefore uses this relationship as a guide to reviewing literature on the subject.

\subsubsection{Summary}

In summary, the literature suggests a multivariate approach to risk assessment and management is required that considers risk as multifaceted entity. The critical components in this risk definition are the source of the contaminant, the pathway from 
which it reaches the receiving groundwater and the effectiveness of the receptor in reducing overall risk of contamination. The subsequent sections will consider each of these components in turn; section 2.3 will review relevant literature on the source of contamination, section 2.4 will review the pathways of transmission and section 2.5 will review the types of receptors that receive these sources.

\subsection{Microbiological/Chemical Pollutant Source}

Specification of the type of hazardous source can be divided into three categories defined as "a biological, physical or chemical agent with the potential to cause an adverse health effect" (WHO, 2004). The assessment of these hazards involves "collecting and interpreting information on hazards, and events leading to their presence, to decide which are significant for water safety." (Davison et al. 2005). Deere et al (2001) note that the identification of the sources of these hazards provides an easier means of developing an understanding of hazards that may affect groundwater, than attempting to isolate specific contaminants within supplies.

These contaminants of public health concern are broadly subdivided into chemical and microbiological contaminants. The consumption of water polluted with chemical or microbiological contaminants is associated with both acute and chronic health problems, whose impact range from mild symptoms to fatality (Murray et al. 1996). The following subsections will discuss both the persistence and public health impact of both the chemical and microbiological sources of contamination.

\subsubsection{Chemical sources of contamination}

There is increasing concern regarding the public health significance of both naturally occurring and synthetic sources of chemical pollutants. These pollutants occur in shallow groundwater through two sources:

1. Naturally occurring contamination occurs where chemical evolution of groundwater and solution of minerals can be aggravated by manmade pollution and/or excessive abstraction (Foster et al 2002),

2. Synthetic contaminants introduced to groundwater through anthropogenic, industrial or agricultural sources (Foster et al 2002). 
Of increasing global concern is the presence of inorganic chemicals in groundwater. The WHO (2004) consider the greatest concern to be associated with the presence of inorganic arsenic and fluoride in groundwater and their inherent public health effects. The presence of this contamination is not a problem solely affecting developing countries. Studies in the USA and Northern Ireland support global concern regarding the significance of excessive fluoride levels in causing dental or skeletal fluorosis, extensive studies undertaken in Bangladesh, India and China further emphasise the importance of arsenic and its associated public health effect (arsenicosis) (Robins 1998).

The management of the risk of naturally occurring chemical contamination can be achieved through varied engineering measures such as treatment of water at source or at household level. Of particular relevance for both arsenic and fluoride mitigation are the use of dilution, source substitution, appropriate coagulation and flocculation techniques, safe disposal of treated sludge and more long term engineered remedial measures such as deepening of boreholes to unpolluted aquifers. Although of relevance in the management of risk reduction in shallow groundwater, due to the scope of this research, these mitigation options will not be considered in this thesis.

As well as naturally occurring contamination, there is further concern regarding the risk of shallow groundwater to synthetic pollutants. The United States Environment Protection Agency (USEPA) note that at least 63,000 synthetic organic chemicals are in common industrial and commercial use in the United States alone (USEPA 1994). Of this total number, 200 have been found present in groundwater of which many could have a potential adverse health effect. The presence of many of these synthetic chemical pollutants is related to land use practices. For example Fourie et al (1995) noted great uncertainty regarding pollution loads of nitrates during a study of the fate of subsurface contaminants associated with on site sanitation.

This view is supported by a study of risks to groundwater from onsite sanitation by the British Geological Survey and the Robens Institute (ARGOSS 2002). The study noted that of principal importance are nitrate and chloride and their associated health effects of methaemoglobiminia (or blue-baby syndrome) and possible links to stomach cancers. Further studies undertaken in Central Nigeria and the Gambia 
indicate a significant correlation between the proximity of shallow wells to settlements and nitrate contamination (Langenegger 1981). These studies outline how nitrate is derived from multiple sources such as indiscriminate disposal of human waste and decomposing organic matter or fertilisers (Amuzu 1993). Results from these surveys indicate that high nitrate levels in groundwater originate from naturally occurring wastes of both plant refuse as well as human and animal excrement.

The management of the risks of these pollutants to shallow groundwater relate to informed policy making, application of legislation and enforcement of clear licensing laws (Zoller 1993). Many of the solutions for risk reduction of chemical pollutants require international legislation and are not locally specific. As noted by Zoller (1993) in a study of groundwater contamination in Israel by detergents and polycyclic aromatic hydrocarbons, risk reduction can only be achieved through long term international cooperation. The detail of these measures of chemical risk reduction measures are beyond the scope of this research.

\subsubsection{Microbiological sources of contamination}

Since John Snows' work in the $19^{\text {th }}$ Century, numerous studies of the impact of microbiologically contaminated drinking water and its associated impact on health in developing countries have been undertaken (Esrey et al. 1990). Appropriately, a controlled case study of the impact of improved water sources in Sri Lanka by the London School of Tropical Hygiene and Medicine noted a 46\% reduction in episodes of diarrhoea in children from families drinking water from protected handpump sources as opposed to unprotected sources (Mertens et al. 1990). This is supported by a small scale epidemiological investigation undertaken in Kanpur, India where an overall incidence rate of 80.1 per 1000 population was recorded in population consuming water from unprotected sources (Pedley et al. 1997).

The priority in water quality control has therefore focussed on the elimination of pathogenic micro-organisms. There is a wide variety of micro organisms that may be found in water (Mara 2003). These include pathogenic (can lead to infection of human hosts) and non pathogenic (WHO 2004). Listed in order of size these include viruses, bacteria, protozoa and helminths (see Figure 5 below). 
Figure 5: Pathogen size compared to groundwater matrix properties

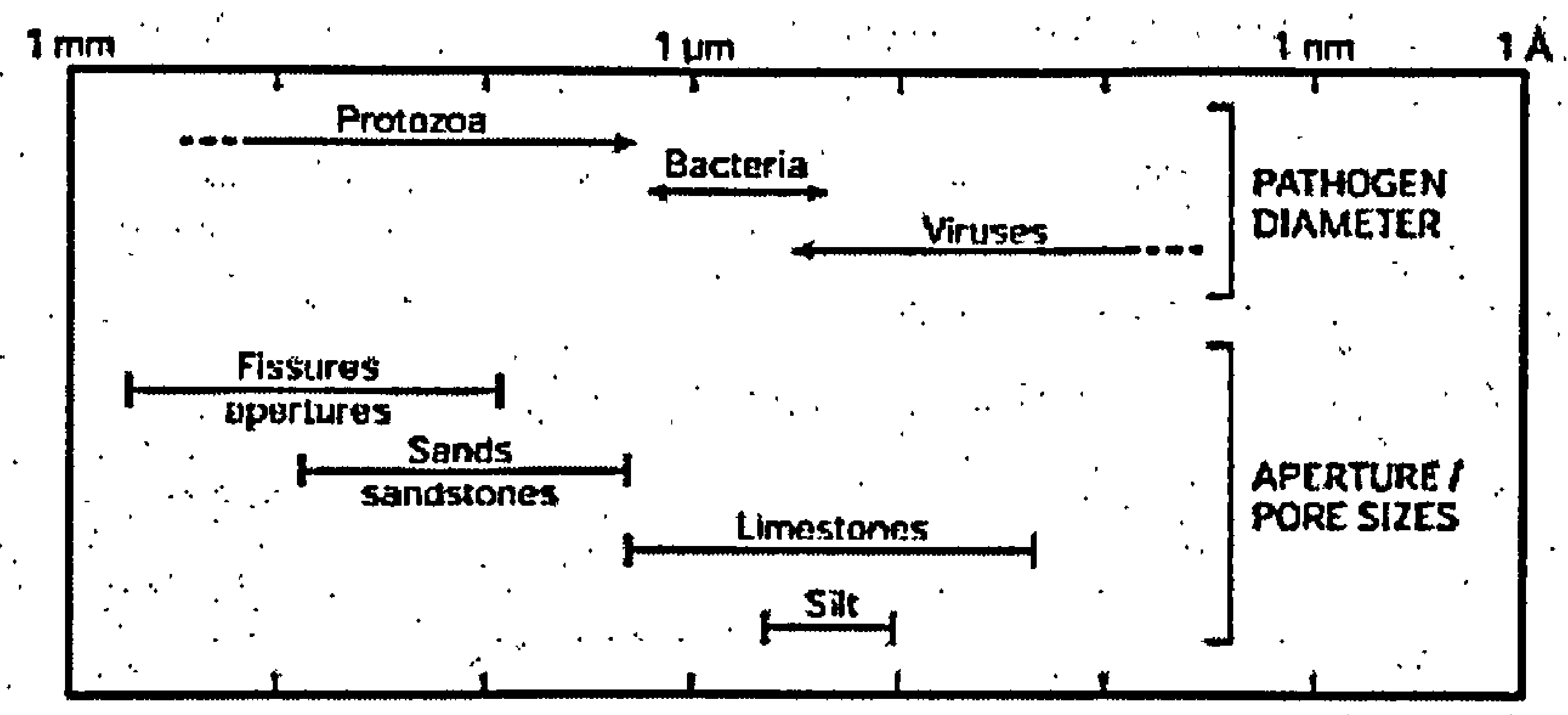

(Source: ARGOSS 2002)

As noted in Figure 5, the transmission of helminths in groundwater is unlikely due to the size of the micro organism at $>25 \mu \mathrm{m}$ (ARGOSS 2002). Unless there is direct ingress of surface water into the groundwater source, the majority of the helminths are efficiently removed through physical filtration in the soil (Cave et al. 1999). For this reason and because public health risks from waterborne diseases transmitted through groundwater focus on the ingestion of other groups of micro organisms, helminths will not be considered in this thesis.

Table 2 outlines the primary pathogenic micro organisms of concern in groundwater (Macler et al. 2000). The occurrence of these specific micro organisms is dependent on varied factors including incidence of disease in the community, known seasonality of human infections, characteristics of both the water supply and aquifer and hydrological patterns. 
Table 2: Pathogenic micro organisms

\begin{tabular}{|l|l|}
\hline Organism & Associated Health Effect \\
\hline Bacteria & \\
\hline Escherichia coli & Gastroenteritis \\
\hline Salmonella spp. & $\begin{array}{l}\text { Enterocolitis, endocarditis, meningitis, pericarditis, reactive } \\
\text { arthritis, pneumonia }\end{array}$ \\
\hline Campylobacter jejuni & Gastroenteritis, Guillain-Barre syndrome \\
\hline Yersinia spp & Diarrhoea, reactive arthritis \\
\hline Legionella spp & Legionnaire's disease, Pontiac fever \\
\hline Vibrio cholerae & Cholera \\
\hline Virus & \\
\hline Coxsackievirus & $\begin{array}{l}\text { Fever, pharangitis, rash, respiratory disease, diarrhoea, } \\
\text { haemorrhagic conjunctivitis, myocarditis, pericarditis, aseptic } \\
\text { meningitis, encephalitis, reactive insulin dependent diabetes, hand, } \\
\text { foot and mouth disease }\end{array}$ \\
\hline Echovirus & Respiratory disease, aseptic meningitis, rash, fever \\
\hline Norwalk & Gastroenteritis \\
\hline Hepatitis A & Fever, Nausea, Jaundice, Liver Failure \\
\hline Hepatitis E & Fever, Nausea, Jaundice, Death \\
\hline Rotavirus A and C & Gastroenteritis \\
\hline Calicivirus & Gastroenteritis \\
\hline Astrovirus & Gastroenteritis \\
\hline Enteric Adenovirus & Respiratory Disease, Haemorrhagic Conjunctivitis, Gastroenteritis \\
\hline Protozoa & Diarrhoea \\
\hline Giardia lamblia & Chronic diarrhoea \\
\hline Adapted from Maridium parvum & 2000 , \\
\hline
\end{tabular}

(Adapted from Macler et al. 2000)

Of greatest concern to contamination of groundwater are bacteria, viruses and protozoa (Gale 2001). Due to their size and high concentration in wastewater discharge, viruses and bacteria pose the greatest risk to contamination of groundwater sources (Pedley et al 2005). According to Fourie et al (1995) there are two major considerations affecting the mobility of these pathogens in soils; namely their physical size and mobility. Studies of outbreaks of Cryptosporidium and Giardia protozoa in both Milwaukee and Las Vegas in the USA indicate that these organisms are more than 100 times greater in linear size than viruses. Therefore, viruses would be an effective surrogate for monitoring the potential for their breakthrough. 
To pollute the receiving groundwater these organisms must have a source and pathway. Pathways to contamination of groundwater will be discussed in greater detail in the subsequent section; this section will address the hazardous source.

The identification of these hazard sources is essential in the estimation of potential levels of contamination. Evidence from assessing risk of contamination to potable water supplies by the American Water Works Association Research Foundations (AWWARF, 2002) suggest that hazard identification of pathogens in water supply should involve linking each pathogenic agent to a specific health effect. This, note AWWARF, will direct the water professionals to focus on agents of highest pathogenic priority to limit any further specific risk analysis as well as to prioritise remedial actions.

However, Deere et al. (2001) note limitations of assessing hazards based on an assessment of health effects. Deere provides the example of assessing pathogen loading in the piped water supplies where he states that the nature of movement of pathogens, microbiological die off, extent of human exposure and the likely dilution of pathogens create wide uncertainties in establishing appropriate pathogen levels. Instead, Deere proposes the use of hazard event scenarios that are assessed based on the potential sources of hazard and the pathways of the hazard into the water supply.

The approached adopted by Deere et al (2001) is of particular relevance for assessing risks to groundwater from both animal and human faeces. Research indicates that both animals and humans harbour bacteria in their gastro-intestinal tract that are of risk to human health. Varied methods for distinguishing between the risks of the two have been undertaken. Early investigations explored the use of ratios between enterococci (EF) and faecal coliforms (FC) as indicators of both animal and human derived faecal sources respectively (Lewis et al 1984). Research indicated that human faeces have a ratio of $4.0 \mathrm{FC} / \mathrm{EF}$ as compared to 0.7 or less of $\mathrm{FC} / \mathrm{EF}$ in faeces derived from livestock or poultry. The use of these ratios assists in the identification of what Deere et al (2001) refer to as häzard events.

There is however doubt in the use of these ratios for hazard determination. Studies undertaken by Wright (1986) on the seasonality of bacterial quality of water in Sierra 
Leone noted distinct limitations in this method. The study highlights that the ratios apply only to fresh faecal contamination and do not consider the die off kinetics of the specific microbes. The study observed that enterococci survive longer in human faeces after defecation (but before entering a water source) than faecal coliforms. The ratios were therefore only applicable for the source of faeces and not at the point of contamination.

Alternative approaches in identifying hazard events were adopted for distinguishing between human and animal faecal sources of pollution. Field research in Nigeria and Zimbabwe demonstrated that sorbitol fermenting bifidobacteria - SFBs (unique to human faeces) and Rhodococcus coprophilus (unique to animal faeces) could be used to distinguish between hazard sources (Barret et al. 2000). Nonetheless, limitations were identified in the application of analysis of these indicators in developing countries. Firstly, the identification of Rhodococcus coprophilus requires a minimum of 18 to 22 days incubation time, a period that precludes the use of the indicator during epidemics due to the requirement of rapid results. Secondly, the positive identification of Rhodoccus coprophilus post incubation requires a good understanding of microbe morphology as the description of the expected colonies is rather imprecise and complex in available papers (Howard et al. 2000). These problems preclude the use of Rhodoccus coprophilus as a routine indicator. The analysis of Sorbitol Fermenting Bifidobacteira (SFB) in comparison is a more realistic indicator to be used in hazard assessment and as a possible indicator in epidemic investigation. The study concluded that although anaerobic conditions are required for analysis, a shortened period of 48 hours incubation combined with clearer available guidance on colony identification resulted in SFB as a more reliable indicator in developing countries.

Further studies reinforce the point that both on site and off site sanitation systems in developing countries pose varied degrees of pollution threats. Studies by Hoffman (1994) of off site sanitation on surface water recorded high levels of E.coli and phosphates in a surface water source downstream from overflow from a blocked sewer with a reduction in levels of concentration of these pollutants downstream due to natural processes of purification and dispersion. Studies by Hoffman (1994) and 
Fourie et al (1995) concluded that definition of pollution from sanitation is complex and requires consideration of three main factors:

1. Varying subsurface conditions - including a number of subsurface soils with distinction between saturated and unsaturated layers,

2. Varying contaminants - varied contaminants with different characteristics (e.g. mobility and persistence) affected by differing subsurfaces,

3. Varying mechanisms of movement - through varied materials.

The literature suggests a consensus as to the importance of on site sanitation as a primary cause of microbiological pollution of groundwater. However, the majority of evidence presented relates to point source pollution from water-borne sanitation (such as septic tanks, sewers) in the developed world (Cogger 1988). In this case, the hydraulic loading exceeds the saturation capacity of the topsoils resulting in percolation of pathogenic micro organisms into the groundwater. Studies by Fourie $e t$ al (1995) note that where hydraulic loading exceeds soil saturation capacity, breakthrough of pathogenic material may occur. For example studies by Cogger (1988) of the risk of groundwater contamination from on site sanitation from a high rise apartment complex in Long Island, New York, viruses leached through approximately $3 \mathrm{~m}$ of unsaturated soil. The study concluded that extensive viral movement was only possible due to the design of the on site system used for the apartment complex that experienced heavy hydraulic loading.

In contrast, on site sanitation systems in developing countries associate less significance to sanitation as a potential source of contamination (MacDonald et al.1999). In many developing countries, a large percentage of on site sanitation is provided through pit latrines where the potential hydraulic loading is less than from water borne sanitation. Where the hydraulic loading is less, studies indicate the subsurface leaching can provide a very effective means of attenuating contaminants. Studies by Lewis et al (1984) indicate that the risk to groundwater from onsite sanitation is minimal. They state where the thickness of fine unconsolidated strata is at least $2 \mathrm{~m}$ between base of latrine and groundwater, adequate filtration of pathogenic micro-organisms is achieved. 
Supporting the theories of Lewis, findings from catchments in South Africa (Fourie et al 1995) and Kampala, Uganda (Howard et al 2003) suggest that pollution derived from water-borne sanitation (off site sanitation) is of greater concern than that from basic unimproved pit latrines (on site sanitation). Fourie et al concluded that the microbiological risks associated with helminths and protozoa from on site sanitation are minimal due to either absorption in clayey soils or physical filtration restricting movement of helminths and protozoa in alluvial soils. The potential risk of contamination from viruses and bacteria was concluded as being only significant when either the water table or a horizon of fractured or karst bedrock occurs at shallow depths. The study concluded that risks from pit latrines are minimal where an unsaturated layer underlain pit latrines acting as a barrier to reduce hydraulic conductivity. For water-borne sewerage the potential of breakthrough in the unsaturated zone increased due to its greater hydraulic loading.

Pedley et al (1997) emphasise that the greatest risk posed by on site sanitation to groundwater occurs at depth where engineering works meaningfully penetrate the unsaturated zone. The studies indicate that where a pit latrine is greater than 3 metres in depth, the potential risk to groundwater increases as the pit bypasses the most active attenuating layer in the unsaturated zone. This, note Pedley et al (1997), results in a higher concentration of faecal loading as opposed to conventional water -borne sanitation systems such as septic tanks. This is supported by, Sutton et al (1994), who argue that in sparsely populated rural areas, existing practices of shallow burial of faeces close to the ground surface may present less risk to groundwater pollution than pit latrines as disposal of faeces in shallow pits allows decomposition of faeces through exposure with direct sunlight resulting in solar injury of pathogenic bacteria.

In support of Pedley et al (1997), studies of the risk of microbiological contamination to groundwater supplies in Bangladesh, Ghana, Malawi, Mozambique, and Uganda, indicate that direct ingress of contaminants through insanitary well completion is the primary route of contamination (Amuzu 1993). The studies note that where engineered insertions such as wells, springs and boreholes are made to access groundwater sources, increased risk of groundwater contamination occurs. The studies note that of greater concern than sub surface leaching of contaminants in developing countries, is the potential of localised pathways of contamination. These include 
percolation of contaminants through poorly sealed wellheads, pollution from the use of contaminated water lifting mechanisms (such as rope and buckets, handpumps etc), ingress of contaminants through cracks in wellhead platforms and subsurface leaching of contaminants from poor drainage.

The studies conclude that insanitary practices in the proximity of a wellhead are primary causes of contamination of groundwater sources. Studies by Amuzu (1993) in Ghana note a direct correlation between microbiologically deteriorating water quality and scouring of contaminated storage containers and washing of faecal infested children's clothes on a cracked apron head. Similarly, studies of priming handpumps with contaminated water, and feeding cattle in close proximity to a water source create direct hazard sources (MacDonald et al. 1999). In support of MacDonald, Cronin et al (2002) note that studies from Mozambique indicate the primary hazardous sources relate to surface faecal matter (discarded faeces, flooded latrine contents) entering the wells through insanitary well protection.

\subsubsection{Summary}

The literature recognises microbiological contamination to be of greater health significance than chemical contamination as chemicals have been proved to cause adverse as opposed to acute health effects. Furthermore, it suggests that factors affecting the occurrence of pathogenic micro organisms in groundwater include environmental conditions, properties of the organisms, and survival and transport of micro organisms in the subsurface soils. For these reasons, the literature concludes that viruses and bacteria are of greatest significance as indicators of pathogenic contamination of groundwater. The literature further suggests that viruses (specifically coliphage) are also useful indicators.

The literature highlights the need to develop a multivariate risk model that can be used to both assess and manage risk of microbiological ingress to groundwater. Due to the scope of this research, the model will not include naturally occurring or synthetic chemicals, but will rather focus on the risk of microbiological contamination through localised and aquifer pathways. The relative significance of these factors as compared with current knowledge will be researched in section 2.4 with a view to identifying key indicators in the development of a multivariate risk model. 


\subsection{Pathways to Contamination}

Reviews of the source-pathway-receptor relating to the contamination of shallow aquifers from faecal sources suggest that reliance on hydro geological models alone is inadequate. As noted by Gelinas et al (1996) "although thorough hydro geological studies are needed to determine contaminant pathways there are other contaminant pathways such as insufficient well maintenance which appear to be the main factor contributing to bacteriological contamination." Review of available literature on this subject reveals two main pathways of contamination - see Figure 6 (ARGOSS 2002):

a) Aquifer pathway - where pathogens migrate through the subsoil from a faecal source to the water table,

b) Localised pathway - a rapid bypass mechanism where pathogens enter the intake of the water supply. This is due to poor design and/or construction of the water supply and surface cracking of unsaturated soils resulting in limited residence time of the microbes in the subsurface.

Figure 6: Pathways to Contamination

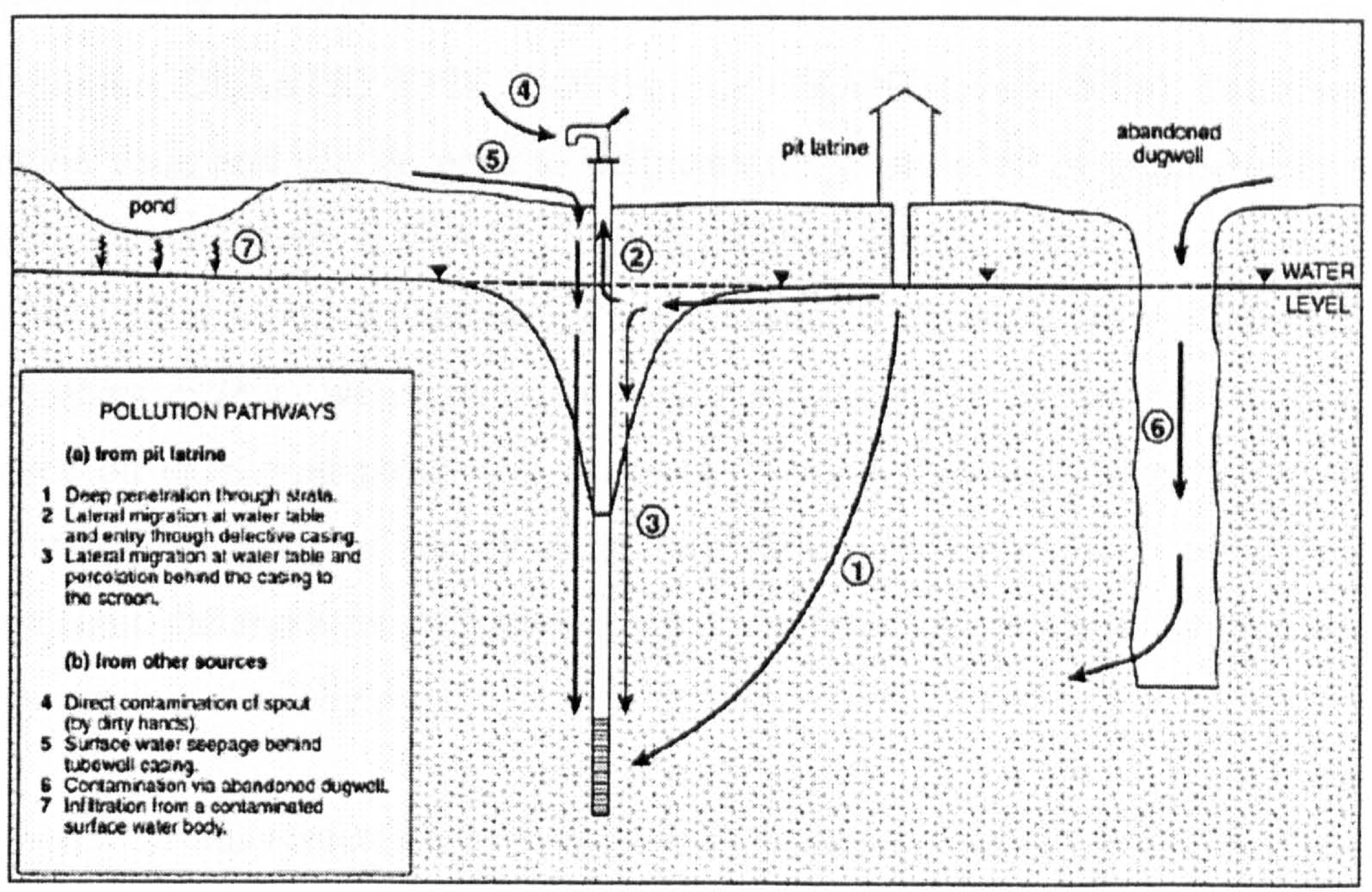

(Source: ARGOSS 2002)

The subsections 2.4.1 and 2.4.2 will review available literature on both aquifer and localised pathways. The review will begin with the inference of subsurface leaching of contaminants and specific aquifer properties on shallow groundwater pollution. It will then examine the significance of localised forms of contamination in developing countries. 


\subsubsection{Aquifer Pathways}

Comprehensive literature reviews have been undertaken on the topic of aquifer pathways of pollution in developing countries namely by Lewis (1980), Van Ryneveld (1997) and Howard et al (2003). These reviews observed that much of the scientific literature on pathogen behaviour in aquifer pathways related to the risk of contamination from septic tank effluent in the United States and not to the use of pit latrines in developing countries. More recently, the British Geological Survey and the Robens Institute have published findings from research to Assess the Risk to Groundwater from On Site Sanitation (ARGOSS) in developing countries. The ARGOSS (2002) research defines aquifer pathways as the "hydrogeological conditions that affect the migration pattern of a pathogen from a faecal source to the receiving water body."

These aquifer pathways consider factors such as contaminant loading, soil permeability and porosity, and distance from source to receptor. A number of multivariate groundwater vulnerability index tools have been developed to assess this risk including DRASTIC, EPIK, GOD and LE GRAND (Auge 2004). These tools are reliant on data, and can be used to delineate the boundaries of groundwater supply protection areas (Foster et al 2002). In a developing country context this may result in establishing safe distances between a faecal source (e.g. septic tank/pit latrine) and a water receptor (e.g. well/borehole). There are however limitations in providing guidance on supplying protection zones in developing countries including; limited data availability, complex and dynamic traditional land tenure practices and adoption of unrealistic distances for siting water supply points from domestic dwellings. These are discussed in detail below.

Of concern for this research are the specific hydrogeological conditions that determine extended risk to groundwater from both on-site sanitation and off-site sanitation systems. These specific hydrogeological conditions include flow velocity, porosity, temperature, aquifer grain (pore) size, solid organic carbon, temperature, $p H$, advection and hydrodynamic dispersion (USEPA 1994, Robertson et al. 1997). More specifically, the literature suggests that central to an understanding of aquifer pathways is a knowledge of specific die off kinetics of individual microbes. Foster et al (2002) notes that these are dependent on the size of the microbe as well as the 
matrix of the aquifer. Guidelines on specific die off kinetics however vary from virus survival of up to $400 \mathrm{~m}$ in silt or sand to $1600 \mathrm{~m}$ in Karst limestone aquifers (Robertson et al 1997, Doerfliger et al 1999).

Despite the aquifer-specific die off kinetics, there is a recognised consensus that primary attenuation of polluted groundwater occurs in the unsaturated soil surface. For example studies by Gebra et al 1975, note that straining of bacteria occurs at soil surface through the accumulation of retained bacteria. This is reinforced by further studies by Brown et al (1979) who noted that most faecal coliform bacteria and coliphage viruses were removed within the first $30 \mathrm{~cm}$ of unsaturated soil beneath absorption trenches in Texas, USA. Similarly, laboratory studies undertaken at the University of California by Regli et al. (1991) reported that in permeable alluvial soils, complete virus die off occurred within $1.0 \mathrm{~m}$ of subsurface. This is also applicable in developing countries, where studies undertaken in South Africa indicate virtually complete die off of both selected bacteria and viruses within $3 \mathrm{~m}$ of top soils (Fourie et al 1995).

Nonetheless, the majority of evidence suggests significant migration pathways are achieved where preferential pathways are created below the topsoil. This is of particular concern in chalk or karst aquifers where multiple preferential flow paths can be created. In comparison in the majority of confined clay topsoils, minimal migration pathways are present. Exceptions are montmorillonite clays that occur at ground level or at shallow depths. These clays are prone to fracturing due to their high shrinkage rates and the flat plate like structure of clay particles.

Studies by Preene et al (2003) in the United Kingdom have indicated that increased risk of aquifer pollution from surface activities occurs when the top soil is punctured by civil engineering works resulting in migration of polluted water along vertical preferential pathways. This is of particular relevance for developing countries where pit latrines frequently puncture top soil and place the pollutant below the top soil zone, leaving the unsaturated zone as the first line of defence to groundwater pollution (Howard et al. 2003). 
Evidence of the potential for micro organisms to pollute groundwater aquifers from pit latrines suggests that lessons cannot generally be learnt from pollution via aquifer pathways from water-borne sewerage. Studies undertaken in Nottingham, United Kingdom to estimate the risk to groundwater of leaking sewers in sandstone aquifers challenge conventional theory that states that "sewage exfiltration is mainly biological in nature and bacteria in the groundwater would render it harmless before it can reach the groundwater table" (Powell et al 2003, Reynolds et al 2003). The study assessed the microbiological quality of groundwater collected from depth at specific intervals using multilevel piezometers within a Permo-Triassic Sherwood sandstone aquifer. The study concluded that sewage-derived bacteria and viruses are observed to penetrate the entire thickness of the sandstone aquifer with the shallowest sampling interval near the water table being the least heavily contaminated. The investigations confirmed widespread contamination of shallow groundwater from a sewage derived source (Reynolds et al 2003). Limitations acknowledged in the study however note that the findings may be particular to sandstone geology and not be applicable to other geological formations where sandstone aquifers aid rapid dispersion through flow paths that allow near-surface flows to quickly reach depths.

The Nottingham study supports evidence that sewage derived micro organisms do not migrate from the water table at the sampling location but spread laterally at specific depths. Although true for water-borne sewerage, this is not the case for dry pit latrines due to the reduced hydraulic loading experienced in pit latrines. Estimations of the impact of pit latrine infiltration into groundwater undertaken in Epworth, Zimbabwe indicate that pit latrine contents leach downwards (vertically) and not laterally (horizontally) as in sewers (Chidavaenzi et al 2001). Results indicate that a minimum $5 \mathrm{~m}$ depth between the base of the latrine and the static groundwater level is required to reduce potential groundwater pollution. This ensures a thicker dry soil filtration buffer layer which reduces the potential for groundwater contamination. The study further emphasised the importance of refuse pits and unused wells as an additional means of short-circuiting potential groundwater protection. Nonetheless, studies undertaken into pollution of both deep and shallow aquifers in the weathered crystalline basement rock in Uganda, indicate no apparent relationship between the magnitude of contamination and the distance separating a shallow well from a 
contaminated scoop latrine (human excreta disposed of in open pits) (Howard et al 2003).

Conflicting evidence of die off rates of selected pollutants in aquifer pathways has therefore resulted in the creation of wellhead protection areas or setback distances from faecal sources of pollution. These areas are usually divided into wellhead operational zones, sanitary inspection zones, microbiological zones and total source capture areas (Foster et al 2002). The indicated set back distances from sources of faecal pollution to the groundwater sources is site specific and varies from country to country.

In a study of Groundwater Quality Protection, Foster et al (2002) note varied distances from 10 to 400 days travel time at flow velocities of $1 \mathrm{~m}$ per day as a suitable size for the total source capture areas. In contrast, the USEPA (2001) have indicated distances of between 210-325 days travel time from septic tanks to achieve a minimum $11 \mathrm{log}$ reduction at a travel velocity of $1 \mathrm{~m}$ per day in risk of viruses to groundwater. In comparison for protection zones established for the coral limestone aquifers of Barbados, it is recommended that delineation distances of 600 travel time days should be used for total source protection. There are therefore various sizes of source protection zones for different aquifer properties.

Further research by Yates et al (1989) give estimations of appropriate set back distances from septic tanks that are not founded on numerical guidelines for distances but rather on statistical techniques for determining probability of faecal contamination. These distances are dependent on local hydro geological, climatic and land use categorisations. The study concluded that to maintain a $7 \mathrm{log}$ reduction in numbers of viruses in groundwater, a wide range of setback distances (from less than $15 \mathrm{~m}$ to greater than $300 \mathrm{~m}$ ) are required dependent on soil types. Further research by the University of Idaho (2003) support the views of Yates et al noting that delineation of protection zones is dependent on both prevailing soil conditions and topography.

In contrast to this research, Chilton et al (2003) note the research by Yates et al neglects two keys components in their estimation of protection zone, namely; intensity of pollutant and duration of application of pollutant load. In agreement with 
Chilton, Robertson et al (1997) note that the horizontal travel distance of pathogens is governed principally by the intensity of the pollutant load and its ability to varied flow velocity with in groundwater. This is of particular significance when estimating the potential for contamination of groundwater from on site sanitation. Due to the limited hydraulic loading of a pit latrine, a biological layer forms at the base of the latrine, which limits vertical contaminant movement. This is of great significance when approximating appropriate distances for enteric viruses, as they require a live host, such as a vertebrate animal, to reproduce. The lack of such a host, notes Robertson et al (1997) in a groundwater environment limits both the migration and life span of viral pathogens.

There is however a consensus that the delineation of zones based on hydraulic gradient is dependent on prevailing hydrological conditions. This is particularly pertinent in tropical countries where seasonal rainfall results in temporal variations in levels of contamination. Studies undertaken of springs in weathered crystalline aquifers in Kampala, Uganda indicate a significant deterioration in microbiological groundwater quality with in 12 hours of a rainfall event (Howard et al 2003). An important consideration for delineation of protection zones is that the study identified the spring to be fed from interflow (locally recharged waters moving laterally through unsaturated, heterogeneous material) and/or surface runoff infiltrating the hardcore behind the protected springs. The presence of this recharge contributes to spring water quality and must also be considered in approximating groundwater protection zones.

This is supported by evidence from studies undertaken in Gambia, Sierra Leone and Zambia regarding the seasonality of groundwater quality (Barrel et al 1979, Wright, 1986). In a study of wells in rural village in the Gambia, Barrel et al (1979) noted an increase of 10 orders of magnitude for bacteria following the onset of the rains over a period of 6 days. Further studies in Zambia concluded that peaks in faecal contamination of wells were associated with rainfall as a result of surface flushing of faecal material.

However in contrast to these views, studies by Wright (1986) of the seasonality of water quality in Sierre Leone noted consistently low rates of contamination during the wet season. The study examined levels of selected faecal indicator bacteria and incidence of Salmonella spp. over a one year period. The study concluded that counts 
were generally increasing during the dry season culminating in peaks at the transition from dry to wet season. This increase was attributed to lack of sanitation development and the sporadic nature of rainfall patterns in the study area. As a result much of the human and animal waste was deposited at the soil surface and flushed into the water sources during the rains. Additionally, due to the water sources diminishing in the dry season, a lower level of dilution or concentration effect of faecal contamination was observed in the dry season resulting in higher detection levels.

There are therefore limitations in providing guidance on source protection zones as a risk reduction measure for shallow groundwater in developing countries. Often the delineation of these zones requires extensive knowledge of the prevailing hydro geological, hydrological and geological conditions. This data is often not available in developing countries and can result in the adoption of unrealistic and unobtainable protection zones. Instead, alternative methods are required. As noted by Cave et al (1999), data from research undertaken into technology choice and risk reduction indicate that it may be cheaper to combine on-site sanitation with public water supplies drawn from outside the protection zone, than to combine on-site wells with off-site sanitation. Although of relevance to urban areas, financial and cultural constraints make such service levels difficult to achieve in remote rural communities.

Instead simplified approaches to estimation of groundwater protection zones are required. For example, Foster et al. (2002) proposed a simplified approach using a simple mass balance equation. The approach involved estimations of safe distances based on a theoretical relationship between population density, rainfall infiltration and resulting nitrate concentrations. Many other countries have adopted a similar simplified minimum distance approach. In South Africa for example standard minimum distances of construction of pit latrines $15 \mathrm{~m}$ from shallow water sources and $30 \mathrm{~m}$ from very shallow water sources are applied (Van Ryneveld et al 1997). Studies by BGS and the Robens Institute on the Associated Risks to Groundwater from On-Site Sanitation also developed minimum distance and depth guidelines for latrines and wells based on specific aquifer media (ARGOSS 2001).

Gerba et al (1975) however note limitations in adopting a minimum distance approach as they do not confirm to hypothetical hydrogeological profiles, do not consider die 
off rates of specific micro organisms and make limited distinction between permeability in saturated and unsaturated zones. Gerba states the importance of consideration of survival of enteric bacteria in soil. Factors affecting greater survival time include soils with high moisture content during peak periods of rainfall, longer survival in cooler temperatures with high $\mathrm{pH}$ and in soils in the unsaturated zone.

The applicability of these groundwater protection zones in developing countries is questionable for a number of reasons. The first is that safe distances for siting a water source are dependent on changing land use practise. In a developed country context, public land tenure acts may result in the development of dynamic groundwater protection zones. In developing countries this is less feasible as many private owned lands have traditional land laws that do not conform to civilian law. Furthermore, the application of protection zones in developing countries will inevitably increase the distance between a domestic dwelling and a water source. In rural areas, where in house or yard water connections are uncommon, water usage patterns will be affected. Studies undertaken in the 1970s and 1980s indicate that where water is further away or involves a return trip travel time exceeding half an hour, water consumption significantly decreases (see figure 7). Although there are limitations in the size and shape of the graph, it offers a guide to the time and distance relationship, showing that for short journey times large volumes of water will be used; for journey times of between about 5 and 30 minutes water use does not change significantly and for longer journey times (round trip times of more than 30 minutes) water use decreases.

Figure 7: Time distance graph

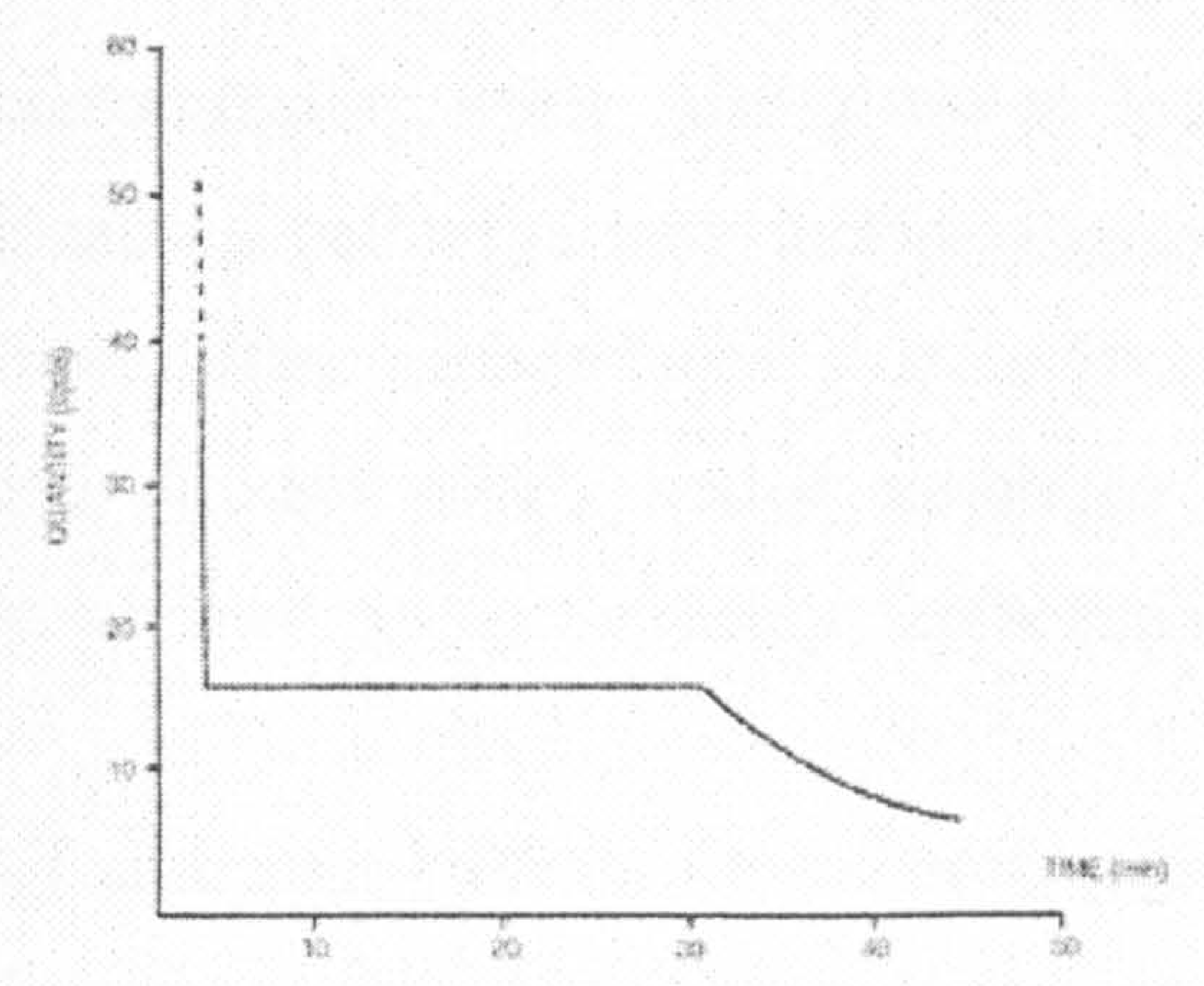

Studies by Lewis et al (1984) state the application of stringent groundwater protection measures may result in communities in developing countries siting boreholes or wells 
in areas outside of village boundaries. For example in Malawi the application of a minimal distance of $100 \mathrm{~m}$ from water source to pit latrine resulted in communities reverting back to the use of more polluted unprotected sources. Therefore the application of groundwater protection zones that require extensive travel times for microbiological die off will discourage the collection of the recommended 20 litres per person per day and result in negative public health outcomes.

In summary, the literature suggests uncertainty in estimating appropriate methods for establishing wellhead or set back distance protection zones. Methods to estimate these distances range from standard distances of construction, site-specific detailed hydro geological setback distance calculations and statistical probability methods. Despite discrepancies over the most appropriate methods for groundwater protection delineation, the literature provides agreement on the importance of both topsoils as a means of increasing residence time and in limiting potential aquifer contamination and of the impact of localised pathways of contamination. It furthermore emphasises the risk of aquifer pollution when civil engineering works such as water well or sanitation construction punctures the confining bed or topsoil. These forms of localised pathways are discussed in greater detail in the following section.

\subsubsection{Localised Pathways}

Shallow groundwater is generally assumed to be of good quality due to the filtration, absorption, advection, hydrodynamic dispersion and inactivation of pathogenic micro organisms in the sub soil. Nonetheless, as noted in section 2.4.1 the creation of preferential flow paths through forced abstraction can increase the risk of contaminating water quality due to localised pollution (Gelinas et al 1996). These localised pathways may include ingress of contaminants along localised pathways from diffuse surface faecal sources (associated with inadequate sanitation conditions), and through poorly sealed annuluses of boreholes and cracks in surface aprons (associated with construction faults and inadequate maintenance of wells).

Of particular relevance to microbiological contamination of shallow groundwater is direct contamination of groundwater at the point of abstraction or resulting from rapid recharge pathways close to the source. As noted by Robertson et al (1997), where contamination is allowed to enter the groundwater source via localised pathways, the 
travel time may be too limited to ensure adequate die-off and processes of attenuation may not be effective to reduce risk of microbiological contamination.

A number of recent studies highlight the importance of localised pathways of contamination as a primary route of microbiological contamination of shallow groundwater in developing countries (Gelinas et al 1996, MacDonald et al 1999). The studies point to localised pathways being of particular relevance for microbiological contamination due to direct ingress at the point of abstraction. This is of particular relevance in boreholes and wells where poor design, construction and operation and maintenance of headworks and pumping mechanisms can result in the creation of preferential flow paths and rapid bypass mechanisms to the intake of the water supply (Amuzu 1993, Barret et al. 1999).

Furthermore, the importance of localised pathways is not a problem solely affecting developing countries. Examples from both Nottingham, UK and Walkerton, Canada emphasise importance of localised pathways as primary routes of contamination (Hrudey et al. 2002, Powell et al 2003). Studies of the impact of leaking sewers on shallow groundwaters in Nottingham, UK by Powell et al (2003) indicated that the insertion of piezometers provided preferential pathways for bacteria and viruses to penetrate the aquifer. This resulted in significant short circuiting of vertical groundwater flow around the annuli of each bundled multilevel piezometer. Similar results were found from a study of an outbreak of disease caused by the presence of Cryptosporidium in water supplies in April 2001 in North Battleford, Canada (Hrudey et al. 2002). In total between 5800 and 7100 people were affected with severe gastro intestinal illness resulting from contamination from disposed sewage effluent $3 \mathrm{~km}$ upstream of the drinking water intake. It led to a legal enquiry (known as the Walkerton enquiry) as to the specific cause of the outbreak. The study concluded that lack of management of source protection of shallow wells $(5-8 \mathrm{~m})$ within the vicinity of the main water intake resulted in cross contamination from livestock faeces (Hrudey et al. 2002).

Further studies in the literature from developing countries support the views that traditional (shallow) sources are prone to contamination through direct ingress of contaminated water from localised pathways. For example scoping studies of 
groundwater quality in Dar Es Salaam, Tanzania revealed more than $70 \%$ of samples taken from traditional sources indicated faecal contamination (Hepworth 2001). The study identified livestock /human faecal polluted water seeping in through poorly sealed well heads as the principle cause of contamination (Hepworth 2001). In agreement with Hepworth, a study of the effects of on site sanitation on groundwater in Kampala, Uganda, (Howard et al 2003), noted that high levels of localised contamination from surface pollution were recorded in water sources with poor headworks protection. The study concluded the quality of water from point water supplies is largely technology dependent.

Similarly, studies by (MacDonald et al 1999) in peri urban communities in Dhaka, Bangladesh point to localised contamination of the tubewells as the primary pathway of contamination. The contamination was attributed to three sources; firstly the use of poor quality of water for the priming of the handpump. The study recorded counts of $>500 \mathrm{FC} / 100 \mathrm{ml}$ during the first round of sampling. Secondly, the percolation of contaminated shallow water down the back of the casing. This was of particular concern in tubewells drilled with the manual "sludging" technique where the method of construction often precludes the sealing of the annulus between the borehole and casing with a gravel pack. The third possible pathway of contamination was seepage from contaminated surface water through cracked (or missing) platforms.

A comparison of field based observational sanitary inspections and water quality monitoring in studies in Guinea by Gelinas et al (1996) indicated a strong correlation between unsanitary wellhead completion and the magnitude of faecal contamination. Specific localised pathways such as lack of adequate plinths and limited grouting of upper well walls correlated with increases in contaminated water.

In contrast to these findings, Sutton (1994) suggests that, although a primary route of contamination, localised pathways alone are not the primary cause of faecal contamination of unprotected wells (Sutton 1994). In a study of more than 1000 wells in Zambia, only one in three traditional wells were polluted. Sutton (1994) suggests that other routes such as poor hygiene practice at household level are of greater significance. 
Studies by Bartram (1996) and Howard (2003) identify some of the contributing hazards and vulnerability factors and tools used for the assessment of risk to shallow groundwater from faecal contamination. The studies noted that the collection and analysis of water quality monitoring and sanitary inspection data could be an effective means of establishing the source of contamination of shallow groundwater. In relation to risks from on-site sanitation, BGS and the Robens Institute further note that the use of these tools "offers the potential for countries and organizations that lack detailed hydrogeological data to develop an understanding of the relative risk to groundwater contamination".

\subsubsection{Summary}

A review of available scientific literature suggests there are high incidences of microbiological contamination of shallow groundwater in developing countries. Global studies suggest that this contamination is derived from a number of sources including:

- On and off site sanitation,

- Polluted surface water intrusion from anthropogenic/livestock surface activity,

- Surface leaching within groundwater protection zone.

Due to the construction of sanitation facilities below the subsurface, the literature emphasises the importance of various barriers to reducing risk of shallow groundwater to microbiological contamination.

The first of these is subsurface soil filtration as an effective means of pathogen removal. The literature emphasises the importance of the topsoil as the first line of natural defence to reduce the risk of microbiological contamination of groundwater. The second barrier to contamination is related to localised pathways of contamination. The literature suggests that the pathway provides rapid bypass mechanisms to the intake of the water supply limiting the residence time of the microbes in the subsurface levels.

Factors affecting the potential for ingress through localised pathways include poor design, construction and maintenance of water supply headworks, linings and pumping mechanisms. The literature suggests that localised pathways are of increasing concern and require further research. However, the literature reveals 
limited information on the effectiveness of these varied engineering barriers to contamination through localised pathways. Section 2.5 will therefore review the effectiveness of varied engineering barriers in reducing the risk of microbiological contamination of shallow groundwater through localised pathways.

\subsection{Barriers to Contamination}

The severity of contamination of shallow groundwater is closely related to the design and construction of the protective engineering barriers. As noted in studies by Lewis et al (1984) "inadequate sanitary protection measures during construction allow pollutants to bypass the natural soil protection normally given to the aquifer." Sub section 2.5.1 will review the available literature on engineering barriers to microbiological contamination of shallow groundwater through localised pathways. Sub section 2.5.2 will then discuss various studies undertaken in developing countries as to the effectiveness of these engineering barriers in reducing risk of contamination followed by sub section 2.5.3 that will select appropriate indicators or control measures required to manage risk reduction of the varied engineering barriers.

\subsubsection{Technology Types}

Roberston et al (1997) note four basic principles in the protection of groundwater from faecal contamination:

1. Minimizing existing potential surface source of contamination within the watershed,

2. Protecting the water collection system and the immediate areas,

3. Minimising mobility/persistence of microbes and chemical contaminants in the soil, and,

4. Monitoring the resource for early signs of problems.

This section will focus on the protection of the water collection system and the immediate area with specific reference to varied engineering barriers to reduce risk of microbiological contamination of shallow groundwater through localised pathways. Engineering barriers in this context are defined as "the protective barriers that prevent direct ingress of pollutants through localised pathways." (Howard et al 2005). Similar to processes adopted in environmental risk assessment models, it is 
essential to identify these protective barriers as indicators during the risk assessment stage (Gale 2001). These barriers then serve as indicators for effective prediction of failure during the risk management stage.

Of particular importance is the barrier of wellhead protection and sanitary completion. Wellhead completion is defined within the WHO Groundwater Monograph as "the underground and over ground construction of the abstraction facility as well as the immediate area surrounding the abstraction point." (Howard et al 2005) This wellhead protection prevents direct ingress of contamination through localised pathways. This chapter will review specific wellhead protection and sanitary completion measures used in hand dug well and borehole construction in shallow groundwater. The specific wellhead completion measures include varied materials for well lining, well grouting and sealing, types of sanitary seals, designs of headworks and types of pumping mechanisms. Each of these can be considered an engineering barrier to contamination.

More specifically, these barriers may be considered control measures to contamination. Adopting the WHO recommended Water Safety Plan (WSP) approach to the assessment and management of microbiological risk to groundwater; specific control measures may be identified for each technology (WHO 2004, Davison et al 2005 , Godfrey et al 2005). For example a specific control measure for an apron of a hand dug well is:

\section{- Good drainage around wellhead,}

This may be achieved through:

- Construction of diversion ditches to direct run off away from wellhead.

To identify appropriate control measures, this section will firstly review the available technologies and then establish appropriate control measures for each technology.

The protection of shallow groundwater sources is designed to enable the extraction of a sufficient quantity of uncontaminated drinking water for public consumption. Crucial to achieving this are both underground and overground construction technologies. Each are protective measures employed to reduce the possibility for contaminants to migrate into the groundwater source. Robertson et al (1997) highlight four guiding principles in the establishment of these protection measures: 
1. Increase travel time of groundwater and/or microbes from the source area to the well,

2. Increase degree of physical filtration,

3. Increase physical interception of microbiologically contaminated water, and,

4. Alter chemical environment to decrease subsurface mobility/longevity of microbes.

The selection of appropriate technology options to achieve effective protection measures must firstly consider the prevailing hydro geological environment - depth and extent of aquifer, attenuation capacity of topsoil, expected yields, depth and nature of overburden, degree of inter-connection between different aquifers (Pedley et al 2005). Based on these conditions, appropriate technological choices can be made. Protection of shallow groundwater in developing countries often involves the use of three technologies; boreholes, hand dug wells and spring protection. The third of these (spring protection) involves the protection of a natural groundwater source by providing protection measures around the 'eye' of the spring (where the water emerges) (Morgan 1990). Assessment of microbiological risk to springs often involves a broader understanding of the prevailing hydrogeological conditions and is less dependent on the specifics of the engineering barriers at the point of abstraction. Recent studies by Howard et al (2003) however emphasise the importance of the immediate surroundings and engineering barriers but acknowledge the overriding importance of hydrogeological conditions for springs. For these reasons, springs are excluded from this study. Focus will be given specifically to a comparison of the effectiveness of wellhead protection for both hand dug and borehole wells.

\subsubsection{Boreholes and Wells}

Definition and terminology applied to both boreholes and wells are country specific with the United States referring to boreholes as water wells and the United Kingdom referring to shallow boreholes as tubewells (Clark 1992). For the purpose of this thesis, the following standard definitions will be used:

- Borehole - a drilled well constructed for the principal purpose of obtaining a water supply

- Hand dug well - a large-diameter shallow water well constructed by manual labour. 
Both are manmade insertions from surface to groundwater level, constructed with the principal aim of protecting and extracting groundwater sources. The wells are constructed using varied lining techniques and materials (see section 2.5.1.3 for details) and are protected using appropriate methods of wellhead protection (see section 2.5.1.2). The methods for abstracting water include levels of complexity of water lifting which (see section 2.5.1.4). This section will focus on the design of hand dug well and borehole.

\section{Boreholes:}

Boreholes are drilled or sunk holes constructed in the ground using drilling techniques and lined to prevent collapse. The most common drilling techniques for accessing shallow groundwater include rotary mud flush and percussion (cable tool) drilling of a small diameter hole $(<200 \mathrm{~mm}$ ) to a depth of 10 to $40 \mathrm{~m}$ (Driscoll 1995). The choice of appropriate drilling technology and the depth and diameter of the borehole drilled is dependent on whether the aquifer is confined or unconfined and in what given geological formation it is located. Detailed hydrogeological investigation is therefore required before any drilling commences. Figure 8 : shows a vertical section through a borehole.

Figure 8: Borehole (Source WEDC, UK)

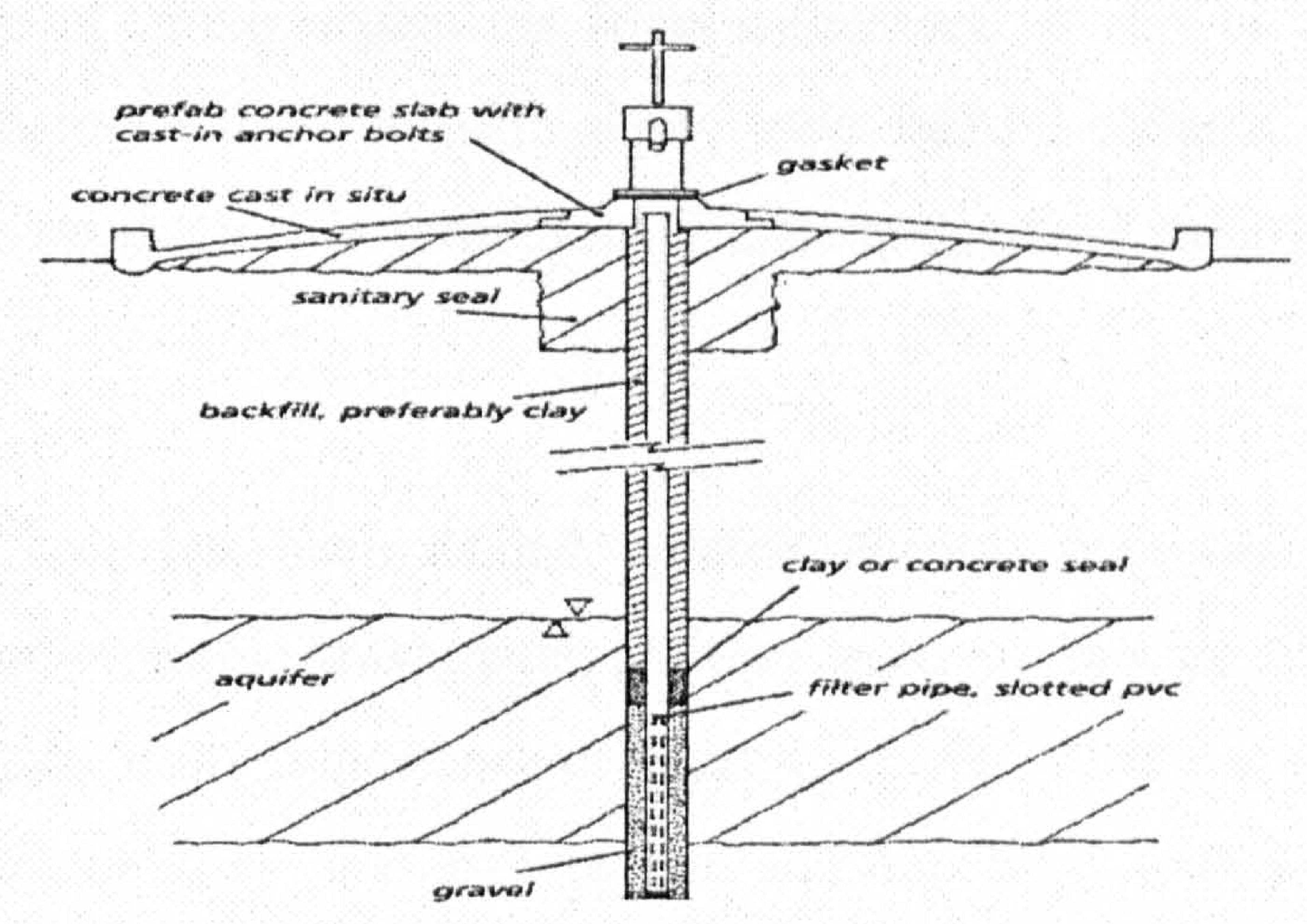


Following the construction of a shallow borehole, the borehole is then lined with a uPVC or metallic borehole casing with an adequate annulus left between the screen and bored hole for the insertion of a gravel pack or filter. A filter media is then inserted to fill the annulus to above the slotted area and developed/cleaned using compressed air or water until uniformity in the gravel pack is achieved (Driscoll 1995). Design of sanitary completion of wells varies between backfilling of remaining annuli with puddle clay/cement slurry or the use of bentonite seals. The top $1-2 \mathrm{~m}$ is then sealed using concrete grout to ensure sanitary protection.

The literature highlights uncertainty in reducing microbiological risks throughout the process of borehole design and construction. These include the importance of observing hygiene codes of construction as well as appropriate design of boreholes to minimise ingress of contaminated water post construction. For example, Robertson et al (1997) highlight the importance of using clean drilling mud during rotary flush drilling. This is of particular importance in developing countries where, due to cost and availability, cow dung may be used as an additive to bentonite or chemical/natural polymer drill mud (Ball 2001). The use of this medium can result in the introduction of microbiological pollutants. Furthermore, the use of the sludging form of drilling in South Asia often precludes the use of a gravel pack within the annulus of the borehole. Studies undertaken in Bangladesh indicate increased presence of micro organisms in boreholes constructed using the sludging method due to downward percolation of micro organisms from subsurface. It should be noted however that where sludging is undertaken in sandy soils, natural collapse of the soils around the well point results in the formation of a natural gravel pack and increased filtration efficacy.

Once the hole has been drilled, microbiological risks can be further introduced through inappropriate gravel pack and casing/screen design. Studies by Godfrey et al (2003) highlight the importance of appropriate design of a graded gravel pack within the annulus between the drill screen and the bore wall to minimise ingress of contaminated fine material. These appropriate designs include the use of appropriately double casing construction with grout between inner and outer casing, appropriate grades and thickness of gravel packs, use of geotextile stockings and insertion of internal filters within screens. The use of these measures reduces risk of 
microbiological contamination via aquifer pathways. Specific mitigation of localised pathways of contamination may include the use of a puddle clay grout inserted above the gravel pack or the use of a cement slurry.

The materials and methods used for borehole casing pose further risks of microbiological contamination For example the use of corroded galvanised iron screen may result in excessive pitting and the formation of biofilms. Studies of the deterioration mechanisms in metallic pipes by Rajani et al (2001) indicate that metallic fatigue occurs due to electrochemical decay and results in excessive corrosion and graphitisation. The formation of these corrosive pits support increased biofilm formation as well as the depositing of graphite flakes in borehole water. In comparison, uPVC casing is glued, and potential openings occur either where the solvent based cement deteriorates with age or where the casing cracks due to excessive pressure when the casing is inserted into the bore.

\section{Hand dug wells:}

Watt et al (1979) define a well as "a device for extracting water from the ground.". Wells can be broadly classified into:

a) Improved sealed wells that are lined and equipped with a pump,

b) Protected wells with concrete plinth and windlass with drainage channel

c) Traditional wells without concrete plinth. Water is collected by bucket.

Various other definitions are used for hand dug wells including scoop wells, a traditional water source constructed at a shallow depth to access subsurface water (Sutton 1994) and upgraded wells that are periodically chlorinated (Godfrey et al 2003).

Hand dug wells are often only constructed to a depth of $20 \mathrm{~m}$, although wells have been constructed to $120 \mathrm{~m}$ (Watt et al 1979). The well shaft is often dug to the water level and then deepened using a motor driven dewatering pump or manual suction lift pump. Where a suction lift pump is employed, a maximum of $6.5 \mathrm{~m}$ depth can be achieved which limits the total depth of the well constructed in shallow groundwater to $7 \mathrm{~m}$. The use of centrifugal pumps can facilitate the deepening of the well to $20 \mathrm{~m}$ but requires additional cost and for both pump fuel and lining materials. 
Collins (2000) state wells can be considered in three distinct parts: the intake, the shaft and the wellhead. The intake is the part of the well constructed within the aquifer and is designed to support the exposed section of the aquifer and permit water to flow into the well acting as a subsurface reservoir. The intake also reduces the risk of fine suspended material entering the well that may increase potential turbidity of the well water. The rate and means of infiltration is dependent on the choice of lining material and type of soil. In highly permeable soils, reinforced concrete caisson intake linings are used with infiltration through a filter layer placed at the base of the well. In less permeable aquifers a perforated or permeable concrete caisson may be used comprising spaced perforations to facilitate the inflow of water through the sides of the caisson.

Figure 9: Hand dug well (Source WEDC, UK)

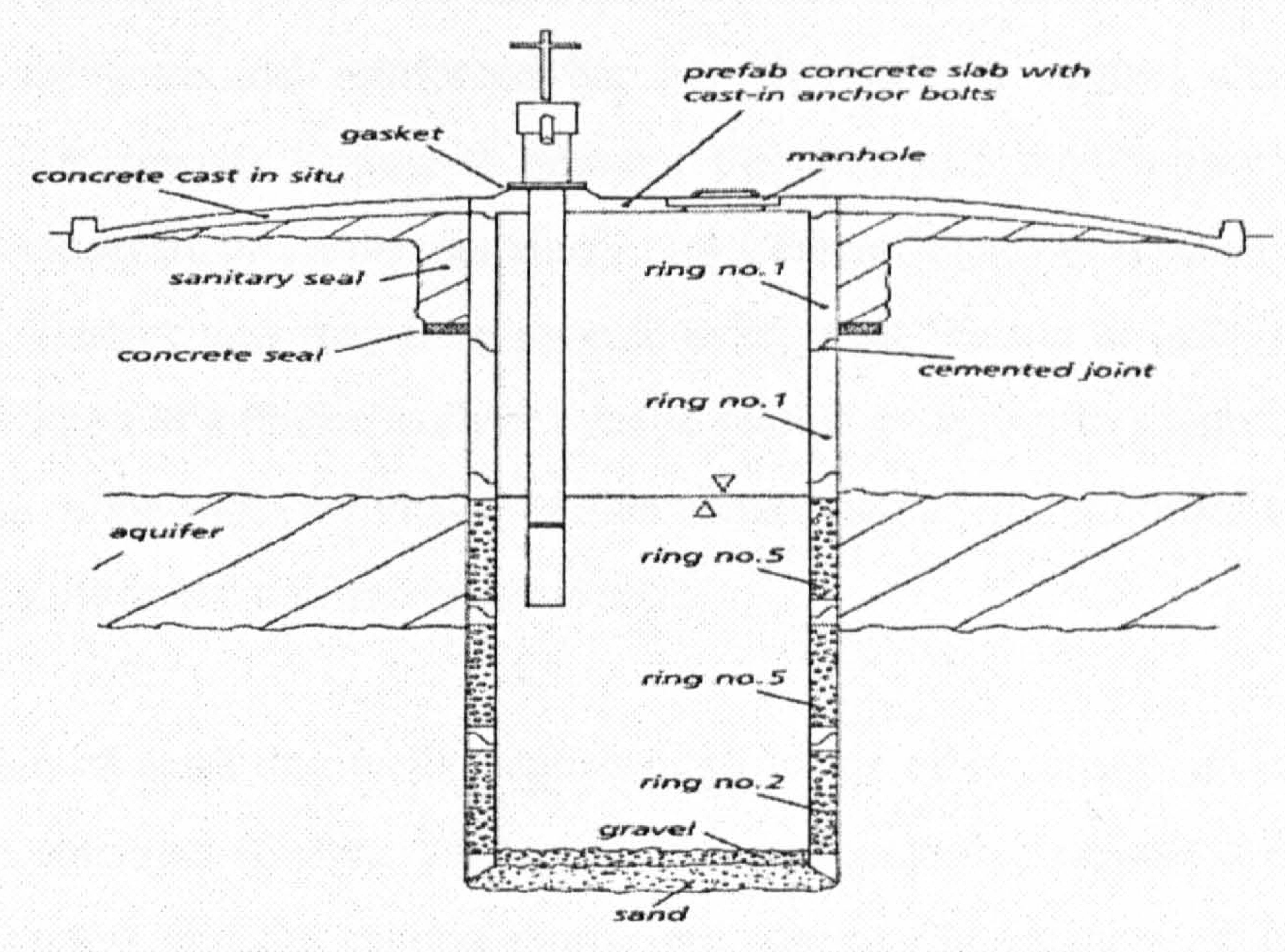

The shaft is defined as the "section of the well between the head and the intake" (Collins 2000). It is designed to prevent the ingress of polluted subsurface leaching into the intake and to provide structural support to the headworks. Various methods are used to construct the shaft including in situ, caissoning, parpen, Modified Chicago Method, cribbing and steining lining (Godfrey 2004). These involve the use of various 
lining materials including reinforced concrete, stone, bricks, wood and plastic. The comparative effectiveness of each of these lining methods and materials in reducing risk of microbiological contamination of shallow groundwater is highly under researched and is an area that require substantial further research. As noted by Gorter et al (1995) in a review of upgrading of hand dug wells "it is not known however how effective are the individual components of the upgrading in reducing contamination or whether their combined effect is greater or smaller than the sum of the separate effects."

Evidence suggests that where in situ concrete linings are used, preferential flow pathways often form through cracks in cement slurry due to insufficient cement strength or mixing In situ linings are often only used in consolidated soils where a shaft is dug to the point of intake and then lined using a "dig and line" technique. In less stable soils, the shaft is lined at $1 \mathrm{~m}$ intervals with $0.5 \mathrm{~m}$ deep internal steel moulds (formwork) (Koegel 1977). The shuttering is oiled at the surface and lowered and assembled using vertical reinforced bar into the well. A cement slurry of 1:2:5 (cement: sand: gravel) is poured between the well and the "formwork." Where shuttering is unavailable, a cement slurry (1:4 Cement: Sand) is splashed on the well wall. Both constructions may be supported using what Watt et al (1979) describe as curbing (addition of a thicker curb or outside section every $5 \mathrm{~m}$ to support shaft).. The final section of the well (the intake) is then either lined using reinforced caisson rings in unstable soils or left unlined in stable soils.

In situ lining of hand dug wells requires high levels of expertise and often is very complex to construct (Collins 2000). Due to poor quality of cement and inadequate mixing, cracks within the cement mortar are common and can result in ingress of contaminated water. Additionally, the seal between the base of the shaft and the intake often allows further ingress of contaminated water reaching the groundwater sources through downward percolation of micro organisms from the surface.

Alternatively reinforced concrete caissons are used. These involve the sinking of a preformed caisson on a cutting ring. Each of the caissons are precast on the surface with solid rings constructed for the shaft and porous rings for the intake. The caisson rings are sealed using a $10 \mathrm{~mm}$ cement mortar layer and are sealed using a porous base 
plug. The plug is precast at the surface from porous cement of 1:1:4 (cement: sand: gravel). Studies of the effectiveness of well protection suggest caisson lined wells significantly reduce the risk of microbiological contamination when properly constructed (Collins 2000). In cases where poor codes of construction are observed, severity of ingress of contaminated water is severe as the caisson provides a highly preferential flow path from hazard source to receptor. Examples of where this occurs include at the joints between caissonings.

Other methods of lining the shaft include use of plastic pipe, wood, brick or stone linings. Lewis et al (1984) notes that the irregular annular spacing used in brick linings results in adequate seal and limit reduction in risk of microbiological pollution. Similarly, studies on use of wood linings note the occurrence of undue rotting off intake lining resulting in increased instability in the well. Studies of the effectiveness of backfilled wells constructed using a $200 \mathrm{~mm}$ rising pipe backfilled with excavated material to ground level and connected to a reinforced concrete caisson intake in Malawi, noted a $31 \%$ reduction in microbiological contamination during the rainy season compared to previous years data (Lewis et al 1984). The use of the backfilled material increased travel times of microbiological pollutants through the subsurface therefore increased inactivation of pathogenic micro organisms. However, despite reduction in risk of microbiological contamination, deepening of the well during drought periods or maintenance of below surface pump components were difficult to achieve due to minimal access to the caisson intake.

\subsubsection{Wellhead}

Wellhead completion is defined as encompassing "the underground and overground construction of the abstraction facility as well as the immediate surface area surrounding the construction point." (Howard et al 2005). Watt et al (1979) note that a properly designed wellhead has two essential features: firstly a headwall that rises sufficiently high above ground surface to prevent anything "washing or blowing into the well mouth and narrow enough to discourage the users from standing on it and secondly an impervious $2 m$ wide apron that slopes away from the well allowing sufficient drainage." Many designs of aprons exist, this section outlines the guiding principles of these design. 
It is recommended that headworks involve the sealing of the top $1-3 \mathrm{~m}$ of the well with a cement or puddle clay sanitary seal either inserted into the annulus between the well/borehole lining and outer wall or the excavation of $50-100 \mathrm{~cm}$ wide shaft (Watt et al 1979). This is an essential component of well design. As noted by Olanrewaju (1990) in a study of groundwater pollution from soak away tanks, the use of clay sanitary seals help absorb charged colloidal particles such as viruses. The study concludes that virus absorption increases with the clay content in the sanitary seal.

If the well is to remain open, the final section of the shaft lining should be built up at least $80 \mathrm{~cm}$ above ground level and if the well is to be closed, $20 \mathrm{~cm}$ of shaft lining is built above ground and then a top slab or well cover is cemented onto a the shaft (Collins 2000): Where a sanitary seal is not used the open backfill area is subject to extensive erosion and potential pollution from surface run off (Nyanchaga 1994)

The well cover should be built with a $15 \mathrm{~cm}$ thick reinforced cement slab (8 or $6 \mathrm{~mm}$ rebar at $15 \mathrm{~cm}$ spacing) and a minimum circular or square opening of $50 \mathrm{~cm} \times 50 \mathrm{~cm}$ inspection hole for access to the well for essential maintenance. Due to additional stresses around the inspection hole, extra diagonal rebars are used at each corner to prevent cracks developing in the concrete, as cracks may allow infiltration of contaminated water into the well. If a mechanical pump is used, the well cover is designed to facilitate the bolting of the pump on a raised pedestal

The well is surrounded by a concrete apron or plinth. The literature highlights various designs of apron. Common to each of these is the importance of both an impermeable concrete platform around the well to prevent ingress of contaminated water and a soakway channel to remove stagnant discharged water. The diameter of the apron will be dependent on whether it is an apron for a borehole or a hand dug well. A general rule of thumb adapted from Watt et al (1979) is a minimum drainage apron of $2 \mathrm{~m}$ from outer diameter of well or borehole. This is clearly technology specific as for a borehole of $0.2 \mathrm{~m}$ diameter, a $2.5 \mathrm{~m}$ diameter apron is sufficient and for a hand dug well of $1.7 \mathrm{~m}$ diameter, an apron of at least $6 \mathrm{~m}$ may be required (Oxfam 1998).

A drainage channel and fence are constructed to minimise potential hazards in the immediate proximity of the source. The fence should enclose an area of at least $10 \mathrm{~m}$ 
around the well, but care should be taken to construct it with locally available material in order to achieve sustainability in maintenance. The drainage or water run off channel should be at least $3 \mathrm{~m}$ in length and should be constructed to divert discharged and stagnant water away from the source (Collins 2000). In contrast to Collins, Morgan (1990) recommends a water run off channel between 6 to $10 \mathrm{~m}$ and states that the length of the run off should be dependent on local hydrogeological conditions. The method of construction of this channel may include the use of interlocked $1 \mathrm{~m}$ length reinforced concrete slabs or cement mortared stabilised/cement blocks. Care should be taken to reduce potential ingress of contaminants at the weak jointing between the drainage channel and the apron base.

A soak away pit at the end of the channel can be used to collect wastewater from the run off in the drainage channel. Spilled water is often used for irrigation of vegetable gardens (Morgan 1990). However, Howard et al (2003) note this may reduce possibility of animals being attracted to the source but may also increase potential infiltration of contaminated water into the source via aquifer pathways.

Many wells are constructed with out an apron and use only a rope and bucket. These are commonly termed protected or traditional wells. The literature notes varying degrees of protection offered by traditional wells (discussed in detail in section 2.5.2). Watt et al (1979) note that wells without headwalls are susceptible to microbiological contamination due to ingress of contaminated water through eroded sections to the sides of the wells.

Traditional or protected wells are in their simplest form "a water hole, which is hand dug down into the water table." (Morgan 1990). Traditional methods of upgrading the well include the lining of the well shaft with stones or burnt bricks to prevent well collapse, and the addition of cover slabs made of wood or concrete to prevent children/animals falling into the well. Protected wells often involve the use of a raised hygienic apron with a water run off or drainage channel for discarded or stagnant water.

Contamination of wellheads can occur due to poor design and construction. Care must therefore be taken to ensure appropriate design and monitoring of specific control 
measures within the wellhead. This may include addition of clean inert clay or other fine-grained material into the upper $50 \mathrm{~cm}$ of sanitary seal to reduce permeability or use of cut off or curtain walls may be installed

\subsubsection{Water lifting}

A variety of water lifting mechanisms are used for extracting water from shallow groundwater for potable purposes. These range from simple rope and bucket pumps, shallow suction pumps functioning to $7 \mathrm{~m}$ depth to direct action and deep well reciprocating handpumps (Morgan 1990). Varied levels of theoretical risk of microbiological contamination are known to be associated with each of these pumps. Outlined below is a review of the published studies on the implications of risk of varied levels of water lifting technologies.

In a study in Kenya, Nyanchaga (1994) notes a direct correlation between an increase in faecal contamination and an increase in the number of buckets used for water lifting. The study observed a $70 \%$ increase in levels of contamination in wells with more than 3 families due to the percentage increase in numbers of families using their own buckets. These, note Nyanchaga, became contaminated whilst left lying on the polluted ground surrounding the wellhead resulting in the direct introduction of contaminants into the well.

A comprehensive review of the risk posed by the rope and washer handpump in Nicaragua by Gorter et al (1995) indicates a reduction in levels of contamination. The study compared the effectiveness of an unimproved well with a rope and bucket to both wells with a windlass and wells with a rope pump. Results indicated a $62 \%$ reduction of the geometric mean of faecal contamination in wells using a rope pump. The study further compared the difference on the impact of water quality of using a rope pump either with or without concrete headworks concluding that the headworks had a minimal effect on the fluctuations in water quality. Conclusions drawn from the study agreed with Nyanchaga (1994) stating that levels of contamination increased with number of users as the potential for cross contamination from polluted buckets increases. 
The Swiss Appropriate Technology Centre (SKAT) further recognise the current weakness in non standard handpump base plate design (Baumann 2003). The majority of handpumps require an individual well cover design to facilitate the use of the varied pumps. Although many of these pumps require the use of a rubber gasket placed between the pump base and the well cover, there is limited evidence in the literature to suggest how effective these gaskets are in preventing the ingress of stagnant water gathered at the base of the pump. Indeed, experience has shown that often poor concrete formwork results in the sheer pins being placed at unsymmetrical distances resulting in poor pump fitting. This view is supported by Jenkins (1984) who states that to ensure adequate protection of water sources, an off set pump is required. In a study of the use of off set handpumps in Nepal, Jenkins (1984) concluded that the pumps are effective in improving water quality as they reduce the level of human and animal activity at or around the well site. The disadvantage however of this method is that it is difficult to use with deep well pumps due to the type of rising rods and mechanism used for lifting.

Further studies of the maintenance of village Level Operation and Maintenance (VLOM) pumps such as the Afridev or Kanzee pumps plastic indicate that where spare parts are unavailable or unaffordable, sever deterioration of water quality can be observed (Breslin 2002). Studies by Breslin (2002) indicated high levels of faecal contamination $(>180 \mathrm{cfu} / 100 \mathrm{ml})$ in Afridev handpumps. The study concluded that principal route of contamination came from ingress of contaminants at the outlet nozzle of the pump.

Conclusively, the studies note varying effectiveness of water lifting devices in reducing risk of contamination. There is however a consensus that the risk of contamination is dependent on both the age and regularity of maintenance of the water lifting device. There is however, limited consensus as to the effectiveness of each of the water lifting devices in reducing risk of contamination. This is an area that requires significant further research.

\subsubsection{Effectiveness of Technologies}

Conflicting evidence exists over the effectiveness of varied levels of water source protection. Nonetheless, there is a consensus that the design and type of source 
construction has a major impact on water quality. This section reviews existing literature on the effectiveness of the varied levels of technologies for shallow groundwater source protection in developing countries. As well as highlighting the potential public health benefits of water source protection, this review indicate that low cost improvements to traditional sources can have as great (and in some cases greater) effect in reducing risk of microbiological contamination.

Studies undertaken in the 1970s into the effectiveness of varied engineering measures of source improvement, highlight the importance of rainfall as key determinant of well water pollution (Barrel et al 1979). A study by Barrel et al (1979) of 6 wells in a Gambian village indicates a 4 log increase in microbiological pollution during 1 to 6 days of rainfalls. Two of the wells were improved wells constructed with caisson concrete linings and equipped with a sanitary wellhead and windlass. The remaining wells were either protected or traditional wells with poorly constructed plinths. The study noted an increase in levels of microbiological contamination (thermotolerant coliforms and enterococci) to $10 \% / 100 \mathrm{ml}$ in both lined and unlined wells with the onset of rains with a limited difference in the degree of protection The isolation of Salmonella bacteria in a non lined well with a defective concrete plinth indicated a correlation between washing of clothes and cooking pots on concrete plinths and presence of Salmonella.

This can be compared to studies by Lewis et al (1984) on the performance of sanitary completion measures in wells and boreholes and onset of rain in Malawi. A total of 68 wells were analysed in 2 villages in Malawi between October 1983 and January 1984. The wells were divided into shallow boreholes, backfilled wells and improved wells. The boreholes were constructed using cable tool percussion drilling to between 10$40 \mathrm{~m}$ in depth and lined with $110 \mathrm{~mm}$ uPVC borehole casing, gravel pack, sanitary seal, wellhead and handpump. The dug wells were constructed using reinforced concrete caissoning for the intake and brick lining for the shaft. The backfilled well intakes were caissoned and then the shaft consisted of a $11 \mathrm{~mm}$ uPVC guide pipe backfilled with excavated material. Wells were equipped with sanitary seal headworks and handpump. Results in the dry season indicated only $63 \%$ of dug wells, $81 \%$ of 
backfilled wells and $80 \%$ boreholes had numbers of thermotolerant coliforms in excess of $20 \mathrm{cfu} / 100 \mathrm{ml}$ In comparison results in the wet season indicated only $50 \%$ of backfilled wells and $19 \%$ of non backfilled wells at $20 \mathrm{cfu} / 100 \mathrm{ml}$, a dramatic increase in contamination in all well types. The results were more striking with the use of enterococci bacteria that indicated a significant increase in all well types. The study concluded that borehole water was better than from wells (backfilled or not) and that "good sanitary completion of boreholes and wells cannot guarantee total absence of contamination, this can only be achieved by disinfection."

Further studies by Gelinas et al 1996 undertaken in two districts of Conakry, Guinea further emphasised the importance of localised pathways of contamination through insufficient well maintenance. The study by Gelinas et al (1986) compared well water quality from both traditional and protected wells with water from the piped water system. The study indicated that after long periods of dryness, elevated levels of nitrate contamination were in the unsaturated soil layer. This resulted in high leaching of nitrate into wells during the wet season through localised pathways such as in wells with no sanitary seal. Nonetheless, of greater significance were levels of microbiological contamination which were noted as higher during the wet season than during the dry season with levels recorded as $>100 \mathrm{cfu} / 100 \mathrm{ml}$. The study concluded that lack of well designed wellheads (including drainage channels) contributed significantly to microbiological contamination with limited variance between traditional and protected wells due to poor sanitary completion and design.

In a study of water quality from a variety of water sources including traditional, protected and improved sealed wells in Mozambique, Breslin (2002) concluded that there was "no measurable difference between water in protected wells or handump (improved sealed wells)." In a detailed study of one community, results of $>180$ $\mathrm{cfu} / 100 \mathrm{ml}$ of thermotolerant coliforms were recorded in an improved well with handpump as compared to $<30 \mathrm{cfu} / 100 \mathrm{ml}$ in a protected well. The study noted that of equal importance to the engineering intervention to improve water quality were the hygiene messages regarding where, how and when to maintain the wells. Furthermore the study concluded that handpump wells provide limited improvement in water quality and are not a sustainable option for rural water supplies in the Mozambique context. 
This view is supported by Sutton (1994) and Mbewe et al (1999) in research undertaken by the Ministry of Health and Department of Water Affairs in Zambia. An inventory of over 1500 traditional sources (including scoopholes, unlined wells and springs) using semi qualitative techniques was undertaken. The study observed that in over half of the sources, faecal coliform counts were $<10 \mathrm{cfu} / 100 \mathrm{ml}$. The study concluded that minimal improvements to traditional sources can improve both quality and availability of safe water.

Detailed studies undertaken by Howard et al (2003) highlight the specific risk factors that contribute to microbiological contamination of shallow groundwater in Kampala, Uganda. The study was undertaken over 12 months and involved the collection of rainfall, population density and water quality data related to risk of contamination of shallow spring water sources. Results indicated significant correlation between the poor sanitary condition of many of the springs and faecal contamination. Limited evidence pointed to aquifer pathways of contamination with greater emphasis placed on localised forms of contamination.

Although the study by Howard et al (2003) is of significance for this research, it should be noted that the study focussed on contamination of shallow spring water sources and not hand dug wells or boreholes. There are limitations in this approach such as the distinction in levels of recharge due to the difference in depths to water table in both springs and wells as well as the obvious variance in design of appropriate engineering barriers. Methodologically however the study further highlights the importance of establishing a statistical association between individual variables (such as presence/absence of sanitary protection) and the risk of contamination of shallow groundwater. Section 2.5.3 explores this idea further and attempts to identify appropriate risk variables applicable to assessing risk of contamination of shallow groundwater in wells and boreholes.

\subsubsection{Variables}

In line with section 2.5.2, this section will build on the principle of dealing with risk as a multi-attribute or multivariable concept. A multivariate concept is a concept that requires numerous variables. This section identifies the key variables required to 
develop a multivariate decision making tool to reduce risk of microbiological contamination of shallow groundwater. The means of comparing, presenting and using these variables as a decision support tool are described in greater detail in chapter 3.

\section{Hazard Source/Events}

The literature highlights the importance of sanitary risks located in proximity to water sources. It furthermore, states that location of on site sanitation facilities should not be considered as a primary hazard source due to minimal potential hydraulic movement in dry sanitation systems. Instead, research indicates that primary hazards from surface leaching of both animal and human faecal matter results in direct ingress of contaminants. This is further reinforced by studies of clothes washing in proximity of the well and presence of bacteria in shallow groundwater.

\section{Rainfall}

The literature emphasises the importance of a measurement of rainfall to estimate of the travel distance within the contaminant pathway. The literature suggests that one key determinant in this movement is rainfall. It is therefore important to consider rainfall as an indicator within the multivariate model.

\section{Soil Conditions}

The literature further suggests that a key to minimising risk to shallow groundwater is a thorough understanding of the attenuation processes taking place with in the topsoil or surface media. A thorough understanding of its attenuation properties is key in assessing risk of groundwater to contamination. It should further be noted that where the top soil is thin or absence, the vulnerability of groundwater to contamination greatly increases. For example, numerous studies reviewed in this section indicate that

primary routes of contamination occur through localised pathways such as poor wellhead construction.

\section{Engineering Barriers}

In assessing the potential for microbiological risk of contamination through localised pathways on wells/boreholes, limited evidence is available on the effectiveness of individual engineering barriers. The majority of published studies focus on a direct 
comparison of technology types (e.g. between a protected well and a sealed lined well) with limited attention as to the effectiveness of each component (e.g. well lining, water lifting device, sanitary seal or wellhead). A statistical study into the effectiveness of these components of the well would be a useful tool in aiding decision makers to select the most appropriate form of well technology.

\section{Water Quality}

The literature also emphasises the importance of microbiological water quality testing. Appropriate indicators for this include selected indicator micro organisms for presence of bacterial and viral contamination. These may include thermotolerant coliforms, Enterococci, E.coli, Coliphages and Clostridia Perfringens but suitable organisms are subject to further field validation. Each of these indicators will be discussed in greater detail in Chapter 3.

\subsubsection{Summary}

In summary, this section has reviewed a selection of engineering barriers currently used to reduce risk of microbiological contamination of shallow groundwater in developing countries. Due to the scope of the research not all technologies have been reviewed. Nonetheless, the reviews concluded that there remains great uncertainty in assessing the effectiveness of each technology. Some studies suggest that traditional wells are more cost effective, reach adequate levels of safe water for a greater number of people and are more sustainable due their lack of reliance of imported spare parts and skills. Other studies highlight the need for sealed, lined wells with handpumps stating that only with proper design and construction can safe water be assured. Possible construction options include the use of off set handpumps and cut off walls to increase travel time of contaminant water through topsoils resulting in a greater microbial die off.

Consensus was however raised in the literature for the need for further research into risk assessment and management of technological options. To achieve this, the literature has identified the following key indicators of:

- Hazard Source,

- Soil Condition,

- Rainfall, 
- Engineering barriers, and,

- Water quality.

\subsection{Literature Review Summary and Identified Research Gaps}

The literature review has assessed literary evidence on the risks of shallow groundwater to contamination. Using the SOURCE - PATHWAY - RECEPTOR relationship, the review highlights:

a. importance of microbiology (as opposed to chemical, sources of contamination),

b. localised pathways (as opposed to aquifer pathways of contamination),

c. analysis of individual variates of engineering barriers as a means of minimising risk of contamination through groundwater receptors.

Of significance, the review has identified a significant gap in the literature related to the statistical association between individual risk variates and deterioration in shallow groundwater quality. Although recent studies by Howard et al (2003) explore this idea for shallow springs, there are few other identified studies related to contamination of shallow wells or boreholes. The following chapters will therefore expand on this and present data collection, analysis and management tools to improve academic understanding of the risk of microbiological contamination of shallow groundwater. 
Chapter 3: Selection of Risk Variables 


\subsection{Introduction:}

Chapter 2 highlighted the importance of the three principal patterns of groundwater pollution, namely the source, pathway and receptor routes to contamination. Review of available literature highlighted a consensus that microbial (as opposed to chemical) contamination is of greater significance due to its rapid adverse impact on public health. It further stated the importance of localised as opposed to aquifer pathways of contamination as of significance in a developing country context, and finally focused on wells as opposed to boreholes as the selected technology to be used for shallow groundwater exploration in this research.

In reference to the research methodology outlined in Chapter 1, this thesis follows an Experimental Design research method. Within this design, the defined problem within the research is repeated continuously to remind the reader of the research aims and objectives. The defined problem of this research is, How to assess the significance of variables affecting microbiological risk to shallow groundwater? In line with Chapter 2 , this section will build on the principle of dealing with risk as a multi attribute or multi variable concept or model.

This chapter identifies the key variables in the multivariate model. Variables or attributes were selected from a variety of sources including literature, interviews, discussions and communications with other professionals in the sector and were selected for the following reasons;

- Firstly the literature review provided evidence of the significance of variables at a generic level (i.e. in defining risk to shallow groundwater at a catchment level).

- Secondly the discussions/communications provide sound observations in the area; although they may not follow rigorous scientific methodology and have not been published they are of significant value in identifying the risk variables, and are based on professional experience.

This chapter explores the variables identified from these sources. The chapter researches in greater detail the specific factors that must be monitored in the field to gain a better understanding of the significance of each of the risk variables. The chapter is therefore divided into sections that correspond to the groupings of each of the variables: 
- Section 3.2: Source variables

- Section 3.3: Pathway Variables-Meteorological

- Section 3.4: Pathway Variables - Hydrogeological

- Section 3.5: Receptor - Engineering variables

- Section 3.6: Water Quality Variables

The final section of the chapter summarises the selected variables that were identified from each section and that will be considered in this research. It is acknowledged that additional variables such as hygiene practices are of great significance when assessing the microbial risk to shallow groundwater. However, as the focus of this research is on physical interventions, the scope of the research was not extended to include a human study of human hygiene practices and behaviour.

\subsection{Source Variables}

The literature highlights the importance of sanitary risks located in the proximity of water sources. These are identified as sanitation facilities, solid waste dumps and diffuse pollution from open defecation. The literature furthermore states that location of on-site sanitation should not be considered as a primary hazard source due to minimal potential hydraulic movement around dry sanitation systems (Barret et al. 2000). Instead, research indicates that primary hazards should be considered from surface leaching of both animal and human faecal matter through localised pathways. These result in direct ingress of contaminants into water sources. For example, studies of clothes washing in proximity to wells and the presence of Salmonella in shallow groundwater by Barrel et al (1979) note that faecal materials leach into the well through localised pathways such as cracks in the well apron.

The literature further makes a critical distinction between human and animal faecal hazard sources. For example, studies of the source types in Kampala, Uganda by Barret et al (2000) emphasised the importance of human over animal sources due to the severe adverse health risks associated with ingestion of water contaminated by human faeces. The assessment of the precise origin of this human faecal source in developing countries is however difficult to achieve due to the multiplicity of possible faecal pollution sources in the environment. As an alternative Deere et al (2001) highlight the use of hazard events as a means of assessing the origin of the source. 
Research undertaken on the assessment of these hazard events in developing countries by Bartram (1996) and Howard (2002) emphasises the importance of sanitary inspections as a key tool in grouping hazard events. Sanitary inspections are qualitative methods that include visual assessments of the source of sanitary risk. The WHO (2004) recommend that sanitary inspections are applied each time a water sample is collected in order to correlate water quality results with identified risk variables. The risk variables commonly identified as part of the sanitary inspection include a minimum safe distance from a faecal source to a water point. This is indicated as $30 \mathrm{~m}$ in the WHO (2004) Guidelines for Drinking Water Quality (GDWQ) due to the potential attenuation processes in most common topsoil types. A similar distance of $30 \mathrm{~m}$ is also used for a safe distance from other potential sources of contamination. In addition, the sanitary inspection also identifies potential pathways of contaminant movement. For example, visual inspections of the headworks around a well site can reveal if there are cracks in the headworks that may result in ingress of the contaminant and or if the drainage channel or seepage pit could result in seepage of contaminants into the well.

For a more detailed assessment of the sanitary risk, quantitative methods (that combine physical measurements with survey data) are often used. For example, Hartley (2000) in studies to assess the risk to groundwater from on site sanitation in South Africa, notes the need to identify flag situations. These flag situations include circumstances where conditions are unfavourable for shallow groundwater due to the increased possibility of groundwater contamination. To ascertain where conditions are unfavourable, it is recommended that a selected number of the water sources being monitored are identified as flag situations and are then assessed in further detail. This assessment may include an analysis of the depth of a randomly selected number of faecal sources in order to ascertain if the depths intersect with the groundwater table. This is supported by studies by Chidavaenzi et al (2001) where the precise number of latrines (of varying depth) were monitored against the aquifer depth. The location of these latrines can assist in reducing the formation of horizontal preferential flowpaths through the aquifer. This is of particular importance if the distance from the faecal source to the water source is not considered to be a risk factor, and that instead the potential for subsurface leaching may be the predominant source of contamination. 
In agreement with Hartley and Chidavaenzi, Rupert (2001) concluded that due to difficulties of precise pathogen loading assessments, land use categorisation of urban, irrigated agriculture, rangeland, dry land agriculture and forest may also be used Rupert (2001) developed a hazard source ranking using land categorisations. His categorisation is supported by studies undertaken in Sweden and Ireland by Stejmar (1998) and Swartz et al (2003) respectively, where land use categorisations were used to approximate hazard sources. The objective of the land use categorisations was to determine the relative level of hazard source in proximity to selected well sites. To achieve this, Rupert (2001) proposed the use of the following methods to assess land use practices.

- Detailed direct on-ground inspection of the zone/area/catchment,

- Fly-over inspection from aircraft,

- Detailed examination of current and historical aerial photographs,

- Review of land ownership and use from title and other historical records,

- Investigation of current and historical characteristics of abutting properties,

- Interviews with knowledgeable people,

- Sampling and testing of suspect areas (Robertson et al. 1997)

These methods were subsequently used in the United States where they were considered successful in estimating pathogen loading associated with land use over a large area or catchment. Indeed, detailed studies by the USEPA and by the British Geological Survey on pathogen load estimation found close statistical correlations between predictions of levels of microbial pollution and land use categorisations (BGS 1994, USEPA 2001).

The literature therefore suggests that a combination of routine monitoring of parametric variables through the use of sanitary inspection as well as more detailed monitoring of categorical variables should be undertaken. This research will therefore focus on this combination. Data will be collected through monthly sanitary inspections as well as detailed sanitary inventories on the following variables:

- Human/Animal and Solid Waste Hazardous Sources,

- Population Density,

- Distance to and depth of latrine,

- Land use. 


\subsection{Pathway Variables - Meteorological}

The movement of contaminants in the subsoil requires a time/distance estimation of the travel distance from the hazard source to the water receptor. The literature suggests that one key determinant in this movement is rainfall. It is therefore important to consider rainfall as an indicator within the multivariate model (Wright 1986). Additionally, the literature identifies the depth to the groundwater table as a critical variable in determining the die-off of microbes in the vadose zone (Gogu et al. 2000, Pedley et al. 2005).

\subsection{Pathway Variables - Hydrogeological}

The literature suggests that the key to minimising risk to shallow groundwater is a thorough understanding of the attenuation processes taking place within the topsoil or surface media in the close vicinity of the wellhead (ARGOSS 2001, Pang et al. 2003). As noted by Robertson et al (1997) and Foster et al (2002), the soil is a very important first line of defence against contamination. A thorough understanding of its attenuation properties is key in assessing the risk to groundwater of contamination (Chilton et al. 2003). It should further be noted that where the topsoil is thin or absent, the vulnerability of groundwater to contamination greatly increases. For example, around the wellhead, preferential flowpaths may form resulting in increased risk of contamination (ARGOSS 2001, MacDonald et al.1999).

The assessment of the vulnerability of these topsoils is a well researched discipline. Methods developed include vulnerability matrices, vulnerability mapping and vulnerability/risk tabulation (Daly et al. 2002). It should however be noted that the majority of these methods have been developed to be applied at the "macro" level i.e. for the management of vulnerability/risk within groundwater catchments. The challenge of this research is to select or adapt an appropriate existing model for application in the assessment of risk from localised pathways in the close vicinity of the wellhead. To select the appropriate method, this section reviews the existing "catchment" methods and then selects the key variables which will be assessed in this research. Table 3 below provides a summary of the most common methods used for assessing aquifer vulnerability. The information only contains the principal groundwater vulnerability methods as identified by (Auge 2004). Individual approaches are described briefly below. 
Table 3: Aquifer vulnerability assessment methods

\begin{tabular}{|c|c|c|c|}
\hline DRASTIC & GOD & EPIK & $\begin{array}{l}\text { Hydrogeological } \\
\text { settings }\end{array}$ \\
\hline$D=$ Depth to water & $\begin{array}{l}\mathrm{G}=\text { Groundwater } \\
\text { occurrence }\end{array}$ & $\mathrm{E}=$ Epikarst formation & Subsoil thickness \\
\hline $\mathrm{R}=$ Recharge & $\begin{array}{l}0=\text { Overall aquifer } \\
\text { vulnerability class }\end{array}$ & $\mathrm{P}=$ Protective cover & Subsoil permeability \\
\hline $\mathrm{A}=$ Aquifer media & \multirow{5}{*}{$\begin{array}{l}\mathrm{D}=\text { Depth to water } \\
\text { table }\end{array}$} & \multirow{5}{*}{$\begin{array}{l}I=\text { Infiltration cover } \\
\mathrm{K}=\text { Karst network } \\
\text { development }\end{array}$} & \multirow[t]{5}{*}{ Unsaturated zone } \\
\hline$S=$ Soil media & & & \\
\hline$T=$ Topography & & & \\
\hline $\begin{array}{l}\text { I }=\text { Impact on } \\
\text { unsaturated zone media }\end{array}$ & & & \\
\hline $\begin{array}{l}C=\text { Hydraulic } \\
\text { conductivity }\end{array}$ & & & \\
\hline
\end{tabular}

Source: Adapted from Auge (2004)

Common to many of these approaches is an acknowledgement that risk is a multivariate concept consisting of a number of contributing variables (Thirumalaivasan et al 2001). Literature review highlights extensive examples of the use of these multivariate models in assessing vulnerability of groundwater to a risk event (e.g. to microbial contamination). For example Thirumalaivasian et al (2001) examined the application of assessing vulnerability of groundwater using the DRASTIC model developed for assessing aquifer vulnerability by the United States Environmental Protection Agency (USEPA). Critics of the DRASTIC model note that the DRASTIC model is a poor predictor of areas of groundwater contamination. Rupert (2001) proposed that instead of the use of the DRASTIC models that are solely reliant on hydrogeological variables, consideration should be given to anthropogenic and above ground factors such as land use and vegetation. In application of the model to the Idaho Snake River Basin in the United States, Rupert (2001) notes that hazard assessment could be effectively achieved through solely assigning probability ratings to land use types. Similarly, studies by Lee et al. (1992) suggest that vegetation is a useful secondary indicator for levels of subsoil permeability.

Further methods for assessing groundwater vulnerability include the EPIK method which is an overlay weighting and rating method similar to that of DRASTIC (Doerfliger et al. 1999). It considers both the intrinsic vulnerability of aquifers (i.e. the risks associated with non point sources of pollution) and the specific vulnerability (considering all types of contamination). EPIK was adapted by Ibe et al. (2001) when developing groundwater protection strategies in Owerri, South Eastern Nigeria. Ibe et 
al. (2001) used the triple variable GOD (Groundwater Occurrence, Overall Aquifer Vulnerability Class and Depth to Water Table). Conclusions from this study noted that hydrogeological variables alone are insufficient and that an additional variable that should be considered is the topography of the study site (topographical features include drainage features, soil distribution characteristics, slope variations and ground surface elevations). In agreement with Ibe et al, Secunda et al. (1998) note that topography is a key variable in estimating percolation times from the ground surface to water tables. In a study of groundwater vulnerability in the Sharon region of Israel, they note that although the study site was relatively flat, approximate estimates of topography based relative slopes was key to understanding risk potential. This is of equal importance in assessing risk through localised pathways of contamination, as increased slope will result in increased percolation of contaminated run off around a wellhead.

Further variables in reducing or preventing the inflow of contaminated water at the wellhead are the specific soil types or aquifer properties. However, the literature suggests that few available studies have been documented that use a composite multivariate method of comparing soil types to assess risk of microbial contamination through localised pathways. Developing the principle of multivariate analysis, this research explores the use of an established visual method termed hydrogeological settings to provide answers on how to visually assess subsoil types. The hydrogeological settings method was developed by Swartz et al. (2003) and Stejmar (1998) and uses visual techniques to provide uniform assessments of groundwater vulnerability through aquifer pathways but is equally applicable for assessing vulnerability through localised pathways. Research undertaken in Sweden and Ireland by Stejmar and Swartz et al respectively highlights the reliability of these visual techniques to assess the properties of top soil. The method used for this categorisation is known as hydrogeological settings. It is useful for the assessment of the subsoil described in the Irish groundwater protection scheme by Swartz et al. (2003) as the "sediment between the topsoil and bedrock". This term was first used by LeGrand (1970) and has since been used by the USEPA in the DRASTIC model. Stejmar outlines the application of hydrogeological settings in the Södermanland and Östergötland regions of Sweden. He describes the process as "a quick and useful 
means of discerning the principles and processes in a particular environment" which enables the ease of transferral of information from one area to another.

Hydrogeological settings are composed of elements affecting the character of groundwater. Specifically they include precipitation, geological factors and processes acting when the water moves through the ground. To facilitate the identification of hydrogeological settings, general geologic stratigraphy can be used based on a concept developed by Bengtsson et al. (1996). Building on the concept of visual categorisation through hydrogeological settings, Swartz et al. proposed a qualitative method of categorising subsoils based on the British Standard BS5930:1999. In the Swartz method, assessment of the vulnerability of groundwater is determined by a combination of the thickness and permeability of the subsoil. The study by Swartz et al indicated a correlation between descriptions of subsoil based on BS5930, in situ permeability measurements and the three subsoil permeability categories of high, medium and low permeability. This is highly applicable for this research as it only requires the collection of data for subsoil thickness and permeability. The research was undertaken in Lichinga in the remote Niassa region of Northern Mozambique where there are limited electricity supplies, laboratory facilities, technical skills and equipment. The selection of the hydrogeological settings methods is therefore considered appropriate for the following reasons:

- Limited technical equipment available in study site - for example use of generators, mechanised pumps, compressors or contaminant tracers is not logistically feasible,

- Lack of an adequate soil laboratory which would permit the testing of more complex soil characteristics and variables such as soil organic matter (SOM) content of top soils,

- Social considerations - limited access to operational private/communal wells precludes the use of tests that would disrupt service provision such as the use of coloured tracers.

In addition, if the findings from this research are to be developed further, practical approaches using limited resources will again be needed. It is therefore proposed that the hydrogeological settings method is applied with minor modifications (see Chapter 5. for details). 
Consequently non destructive and/or visual techniques are required to ensure minimal disruption to operational service. Table 4 below outlines the priority weighting and justification for selection of the selected variables to be researched.

Table 4: Justification for variable selection

\begin{tabular}{|l|l|l|}
\hline Variable & Priority & Justification \\
\hline Topography & Low & $\begin{array}{l}\text { Research focussed on local pathways where } \\
\text { topography has minimal effect }\end{array}$ \\
\hline Vegetation & Low & Considered as a secondary indicator \\
\hline Hydraulic conductivity & Medium & Calculated using permeability readings \\
\hline Permeability & High & Controls flow to water table \\
\hline Soil Composition & High & Link to permeability \\
\hline Subsoil thickness & High & Controls flow in soil \\
\hline Rainfall & High & Influences transport \\
\hline Depth to Groundwater & High & Proximity to risk \\
\hline
\end{tabular}

The variables given a high priority rating were selected for this research. Chapter 4 outlines how data will be collected at each of the 25 wells during this research in Lichinga, Mozambique.

\subsection{Receptor - Engineering Variables}

As noted by Howard et al. (2003), the headworks are defined as "the underground and over ground construction of the abstraction facility as well as the immediate area surrounding the abstraction point." In assessing the potential for microbial risk of contamination through localised pathways on wells/boreholes, limited evidence is available on the effectiveness of individual engineering barriers. The majority of published studies focus on a direct comparison of technology types (e.g. comparison between a protected well and a sealed lined well) with limited attention as to the effectiveness of each component (e.g. well lining, water lifting device, sanitary seal or wellhead).

Amongst the most comprehensive is that by Lewis et al. (1980). The Lewis et al study, although thorough, is outdated due to advances in analytical methods for assessing engineering variables. The study by Howard et al. (2003), although more recent, focuses on the effectiveness of spring protection rather than wells. Common to both of these, however, is an acceptance that each of the components of the engineering barrier must be assessed. In the case of well construction, these can be divided into the following variables: 
- Concrete apron (e.g. age/strength/design of apron)

- Extraction mechanism (e.g. pump type)

- Well design (e.g. depth/type of lining and protection)

The justification for each of these variables was discussed in detail in Chapter 2. However, as very few studies have been documented in this area, the author consulted with UK based experts, Mozambique field staff and Loughborough University civil engineering laboratory technicians, to decide on the key criteria for selecting variables. Based on these discussions, three key criteria were selected. The variables when selected should;

- provide sufficient data to demonstrate the relevance of the variable,

- follow British Standard methods of non destructive testing,

- provide an acceptable degree of accuracy when physically tested in remote conditions in Mozambique.

Based on these criteria, a combination of variables and testing methods was selected. These include visual assessments of the quality of construction, type of pump/rising main and sanitary condition of the well. They also include selected physical tests in order to provide a comparison. As noted in the British Standards, a combination of different methods has the advantages that "one method can be used as a preliminary to another" (BS1881-201, 1986). Based on this principle, the review selected visual and non destructive physical tests for the chosen variables.

There are a range of non destructive tests to assess the strength of concrete including density, elastic modulus, strength, reinforcement location, cover and corrosion risk (BS1881-201,1986). The advantage of non destructive tests is that they are quick, low cost and often cause minimal damage. The strength of concrete is determined by a combination of factors. The principal factors include the moisture, surface hardness and reinforcement spacing in the concrete. Moisture content is commonly tested under field conditions using a Speedy Moisture Tester (Mastrad 2004). Although it is considered accurate $( \pm 0.5 \%)$ the test has a disadvantage in that it requires Calcium Carbide to provide a gas reaction. The availability of Calcium Carbide is limited and international transportation of this substance is strictly prohibited due to its highly explosive properties. Surface hardness can, however, be tested. 
Due to the possibility of limited access into wells at field level, the author also researched "expert judgement" systems - i.e. systems based on expert choice. These are discussed in greater detail in Chapter 5.

\subsection{Water quality variables}

\section{Microbiological variables}

To assess the effectiveness of the barrier to reduce risk of contamination, microbial water quality testing for selected parameters is required. Due to the broad range of microbological parameters (bacterial, viral and protozoan), microbiologists conventionally select indicator organisms as evidence of faecal contamination in water (Mara 2003). These faecal indicator organisms have the following properties:

1. Suitable for all categories of water,

2. Present in wastewaters and polluted waters whenever pathogens are present,

3. Present in greater numbers than pathogens,

4. Having similar survival characteristics as pathogens in waters and wastewater treatment processes,

5. Non-pathogenic,

6. Able to be detected in low numbers reliably, rapidly and at low-cost. Adapted from Mara (2003)

The indicator organisms selected for this study were enterococci, thermotolerant coliforms and somatic coliphage.

\section{Indicator Bacteria}

Although studies undertaken by the World Health Organization (WHO) have noted that less than $95 \%$ of thermotolerant coliforms in temperate climates are E.coli, studies in tropical climates indicate a higher percentage (Barret et al. 2000, WHO 2004). The persistence of thermotolerant coliforms in shallow groundwater is however questionable. As noted by Bitton et al (1983) in sampling of 6 shallow wells for bacterial indicators during periods of intermittent sewage contamination, both thermotolerant coliforms and enterococci remained stable in the groundwater environment for up to 70 days. Nonetheless, the study noted that enterococci displayed a higher survival than thermotolerant coliforms, and did not multiple in polluted environments. 
These findings are in agreement with studies which state that enterococci display a higher survival at depth than thermotolerant coliforms and so they are a more robust indicator organism as they are less vulnerable to die-off, dilution or filtration (Bitton et al. 1983, Fujioka et al. 1984, Macler et al. 2000, Massa et al. 2001, Melian et al. 1999). Evidence from analysis of polluted waters by Massa et al. suggests that enterococci may be "a more reliable indicator of faecal pollution than faecal coliforms in raw water." Their greater survival at depth in this study suggests that enterococci may be an ideal indicator organism for bacterial contamination of shallow groundwaters. Limitations in the use of enterococci as an indicator organism include limited availability of selective media and potential variance in growth rates of enterococci when exposed to variable temperatures and/or times (Godfrey et al. 2005).

\section{Viral Indicators}

The selected pathogenic organism for viral presence used in this study was Somatic Coliphage. This was selected as studies have indicated incidence of coliphage presence even when coliforms are absent (Sivaborvorn et al. 1989). Studies undertaken on various water sources in Thailand indicated that coliphage was the sole contaminating organism in the 10 different wells tested even where coliform was not identified (Sivaborvorn et al. 1989). This study is supported by various studies including Petrivicova et al (1988) who noted that "presence of coliphages in drinking waters is an indication for aimed microbiological examination." These combined studies indicate that somatic coliphage is an ideal indicator of viral presence.

For each of these indicators, target levels must be established in order to assess risk reduction. For example, a target level of $<10 \mathrm{cfu} / 100 \mathrm{ml}$ may be established as an indicator of bacteriological water quality. Each of these indicators and target levels will be discussed in greater detail in Chapter 5 .

\section{Physico chemical variables}

pH

The $\mathrm{pH}$ of the water is related to the geological formation from which the water is extracted. Of interest to this study however is the linkage between $\mathrm{pH}$ and microbiological contamination. In an overview of the relationship between $\mathrm{pH}$ and 
microbial growth, Kinsey et al. (2003) note that microbes grow over a wide range of pH values between 2 and 11. More detailed studies by Nola et al. (2002), note a correlation between $\mathrm{pH}$ and microbial growth where $\mathrm{pH}$ modifies the assimilation of different mineral or organic nutrients by the bacteria. The study further notes that at lower $\mathrm{pH}$ values (1-4), the Streptococcus lactis strain of enterococci is able to multiply. The inclusion of $\mathrm{pH}$ as an additional surrogate is therefore of importance.

\section{Turbidity}

Turbidity is the result of suspended particles that are too small to settle out readily under quiescent conditions (Taylor 2003). These particles include both organic and inorganic material. Due to the mixture of particles, some pathogenic microorganisms may be "masked" or protected by the particles. This prolongs the longevity of the microbe and may permit longer survival times. The use of turbidity is recommended by WHO as an operational monitoring parameter and is listed as one of the "critical parameters of drinking water quality" (WHO 2004). Justification for its inclusion however requires further empirical research. It is therefore included in this research as a variable to be monitored at field level.

\subsection{Selected Variables}

The variables selected for study are divided into four categories:

1. Source Variables - Hazard/vulnerability analysis, distance from latrines, depth of latrines, animal presence and land use are selected to assess the extent of the source of contamination in the study site.

2. Pathway Variables - Meterological and hydrogeological variables are selected to measure the impact of the pathway on contamination.

3. Receptor Variables - Condition of the headworks through non destructive tests are selected to assess the contribution of the receptor to risk of groundwater contamination.

4. Risk (water quality) Variables - Selected microbiological and physicochemical parameters are selected.

Table 5 shows the selected categories and variables for study. 
Table 5: Selected Variables

\begin{tabular}{|c|l|l|l|l|}
\hline Variable & Source & Pathway & Receptor & Risk \\
\hline $\mathbf{1}$ & Hazard analysis & Meteorological & Surface hardness & $\begin{array}{l}\text { Turbidity } \\
\mathrm{pH}\end{array}$ \\
\hline $\mathbf{2}$ & $\begin{array}{l}\text { Distance from } \\
\text { latrines }\end{array}$ & $\begin{array}{l}\text { Rainfall } \\
\text { Precipitation }\end{array}$ & Water lifting & $\begin{array}{l}\text { thermotolerant } \\
\text { coliforms }\end{array}$ \\
\hline $\mathbf{3}$ & Depth of latrines & Hydrogeological & Headwork Survey & Enterococci \\
\hline $\mathbf{4}$ & Land use & $\begin{array}{l}\text { Depth to } \\
\text { water/water level }\end{array}$ & Well Design/lining & Somatic Coliphage \\
\hline $\mathbf{5}$ & & Aquifer media & & \\
\hline $\mathbf{6}$ & & $\begin{array}{l}\text { Hydrogeological } \\
\text { survey }\end{array}$ & & \\
\hline
\end{tabular}

\subsection{Conclusions}

This chapter has provided further justification for the selection of variables for inclusion in this study. Further literature has been cited and variables have been selected. Chapter 4 will review methods of collecting data for each of these variables at field level. 
Chapter 4: Data Collection 


\subsection{Introduction}

Chapter 3 provided scientific rationale for the selection of the risk variables of greatest significance in this research. This chapter outlines the methods used to collect data for each of these variables. It is divided into three sections:

- Section 4.2 - Methods used for definition of sample site and sample size

- Section 4.3-Visual field methods (qualitative surveys)

- Section 4.4-Physical/Non destructive field methods (quantitative methods) Justification for the methods selected is provided in sections 4.2, 4.3 and 4.4 respectively.

The objectives of this chapter are therefore:

1. To explore variables (identified in chapter 3 ) that affect risk of microbiological contamination of shallow groundwater,

2. To develop appropriate methods of data collection,

3. To provide a means of triangulation of results and

4. To develop means of independent verification for data quality control.

It should be noted that the visual and physical methods selected are designed to be complementary. They are not designed to be used in isolation. For example, data collected on the quality of workmanship of the headworks consist of visual survey methods and physical tests to quantify the visual survey methods. The precise use of each of these methods and the statistical validity is discussed in detail in Chapter 5.

\subsection{Selection of Study Areas and Sample Size}

The study was undertaken in Niassa province in Northern Mozambique through joint research between the UK Water, Engineering and Development Centre (WEDC), the Mozambique Estação Agraria de Lichinga (Agricultural Research Centre) and the UK charity WaterAid. The study area was selected for the following reasons:

- Previous interest and work undertaken by WaterAid in the area of groundwater risk assessment,

- Local availability of trained human resources,

- Local availability of equipment,

- Combination of groundwater technologies,

- Financial and logistic support from WaterAid. 
The precise study area selected was the town of Lichinga, the capital of Niassa province (selected due to the strong presence of WaterAid, and WaterAids long relationship with WEDC), located at $13^{\circ} 18^{\prime} \mathrm{S}, 35^{\circ} 15^{\prime} \mathrm{E}$. Figure 10 below shows the location of the town.

Figure 10: Location of Lichinga, Mozambique

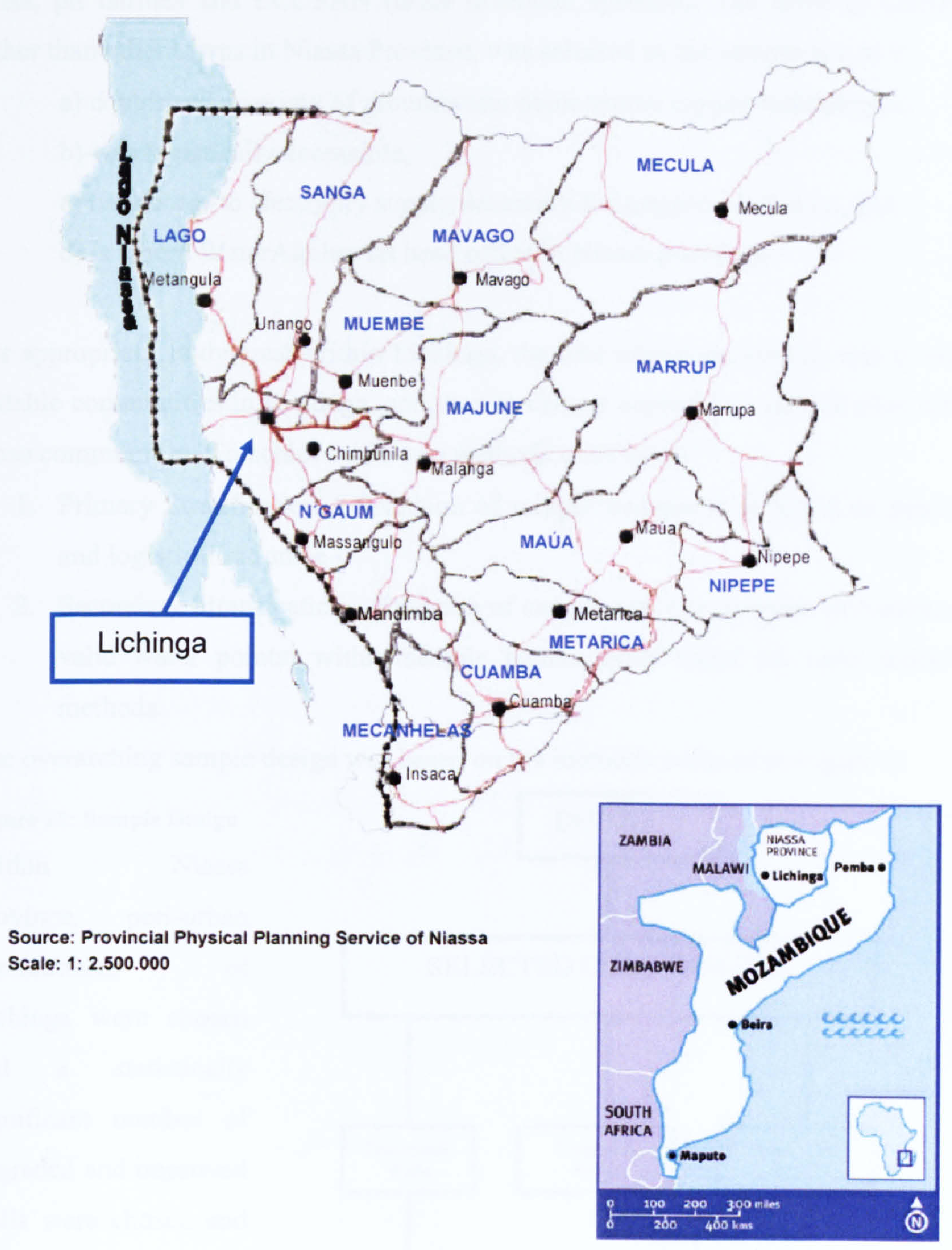


Lichinga is a town with a population of 110,000 people (GoM, 2003). The town was first constructed by the Portuguese as a market trading town for agricultural goods. To date, agriculture remains the main economic activity due to its temperate climate, abundant rainfall and high altitude. The water supply within Lichinga town consists of a centralised water distribution system combined with point source groundwater supplies (wells) in the peri-urban areas. Sanitation facilities in the town include septic tanks, pit latrines and ECOSAN (urine diversion systems). The town of Lichinga, rather than other towns in Niassa Province, was selected as the sample site as it:
a) comprised a variety of groundwater point source supply technologies,
b) was logistically accessible,
c) has access to electricity supply necessary for sample incubation, and
d) is where WaterAid has its head office in Niassa province.

For appropriate study areas within Lichinga, the first important activity was to select suitable communities in Lichinga, and then to choose appropriate sample sites within those communities. To achieve this, two methods were used:

1. Primary Stratification - Selection of sample communities based on practical and logistical rationale

2. Secondary Stratification - Selection of sample size (i.e. number of statistically valid water points) within sample communities based on $t$-test statistical methods.

The overarching sample design was based on the methods outlined in Figure 11.

Figure 11: Sample Design

Within Niassa

Province, peri-urban communities of

Lichinga were chosen and a statistically significant number of upgraded and improved wells were chosen and compared to control traditional wells.

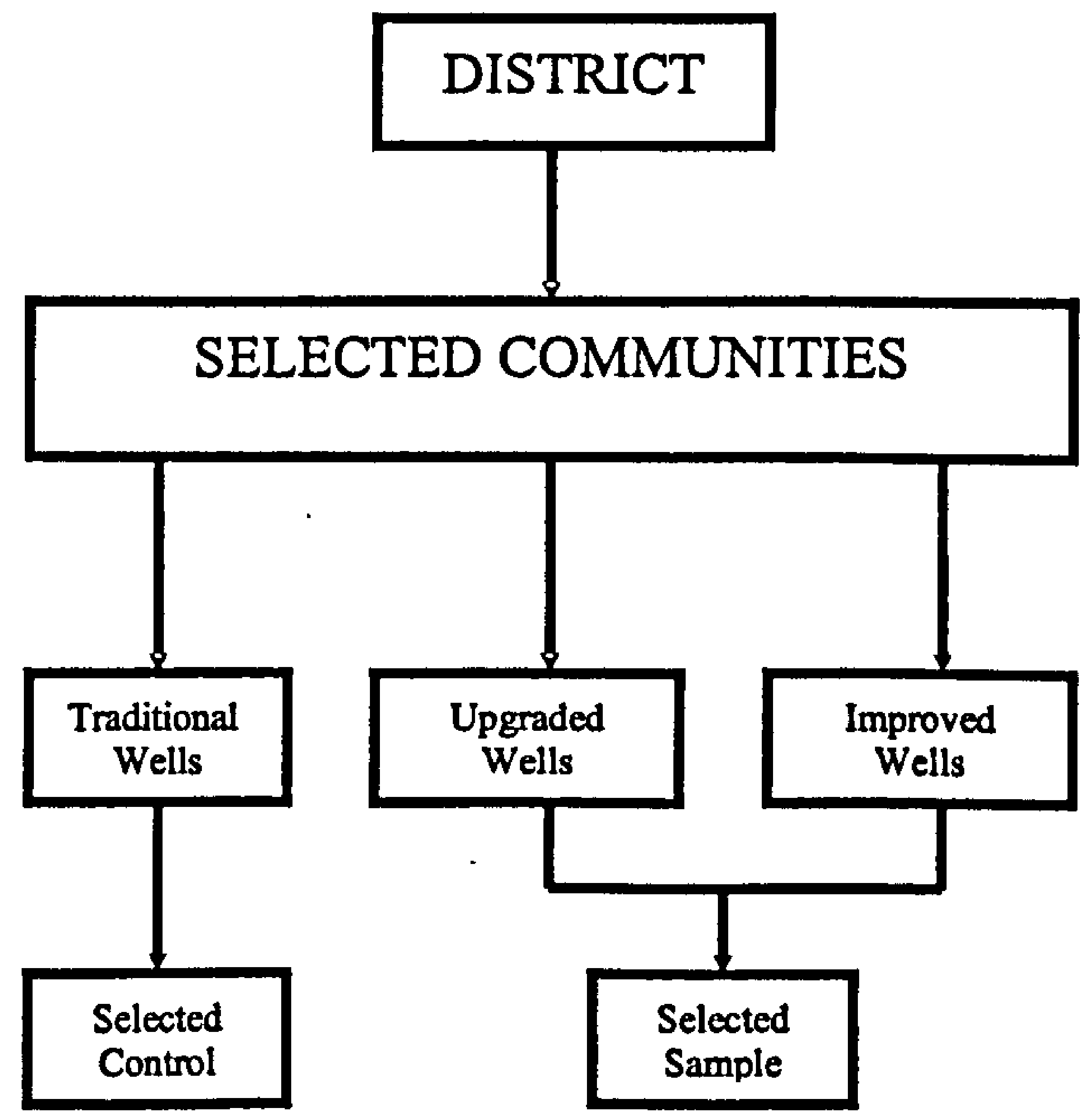




\subsubsection{Primary Stratification}

To select appropriate communities within Lichinga, a stratification approach based on the following selection criteria was used. Selected communities were those that:

1. have a combination of peri-urban and rural communities,

2. have more than one well technology,

3. have good links with WaterAid,

4. have available data,

5. contain low/middle income communities and

6. are close to Lichinga to facilitate safe handling and analysis of water samples. Communities were then stratified on the basis of the number of selection criteria. Stratification, in this context, can be described as a "means whereby specific characteristics of individuals (e.g. technology type and low economic status) are represented in the sample and the sample reflects the proportion of individuals with certain characteristics of the population" (Creswell, 2003).

Based on this stratification, it was concluded that the research should focus on communities surrounding the town of Lichinga. Data on each of these communities were verified during an initial field visit by the author. During a 5 day visit, the author (and local mobiliser/engineer) visited all the communities surrounding Lichinga and undertook a technical and social evaluation through visits to the wells and discussions with the communities. From the field visit, five communities fulfilled the majority of the selection criteria. However, only three fulfilled all the criteria. These three communities (Lulimile, Nomba and Ceramica) were therefore selected. They are located to the West and North of the city and their locations are shown in Figure 12. 
Figure 12: Location of communities and sample points in Lichinga

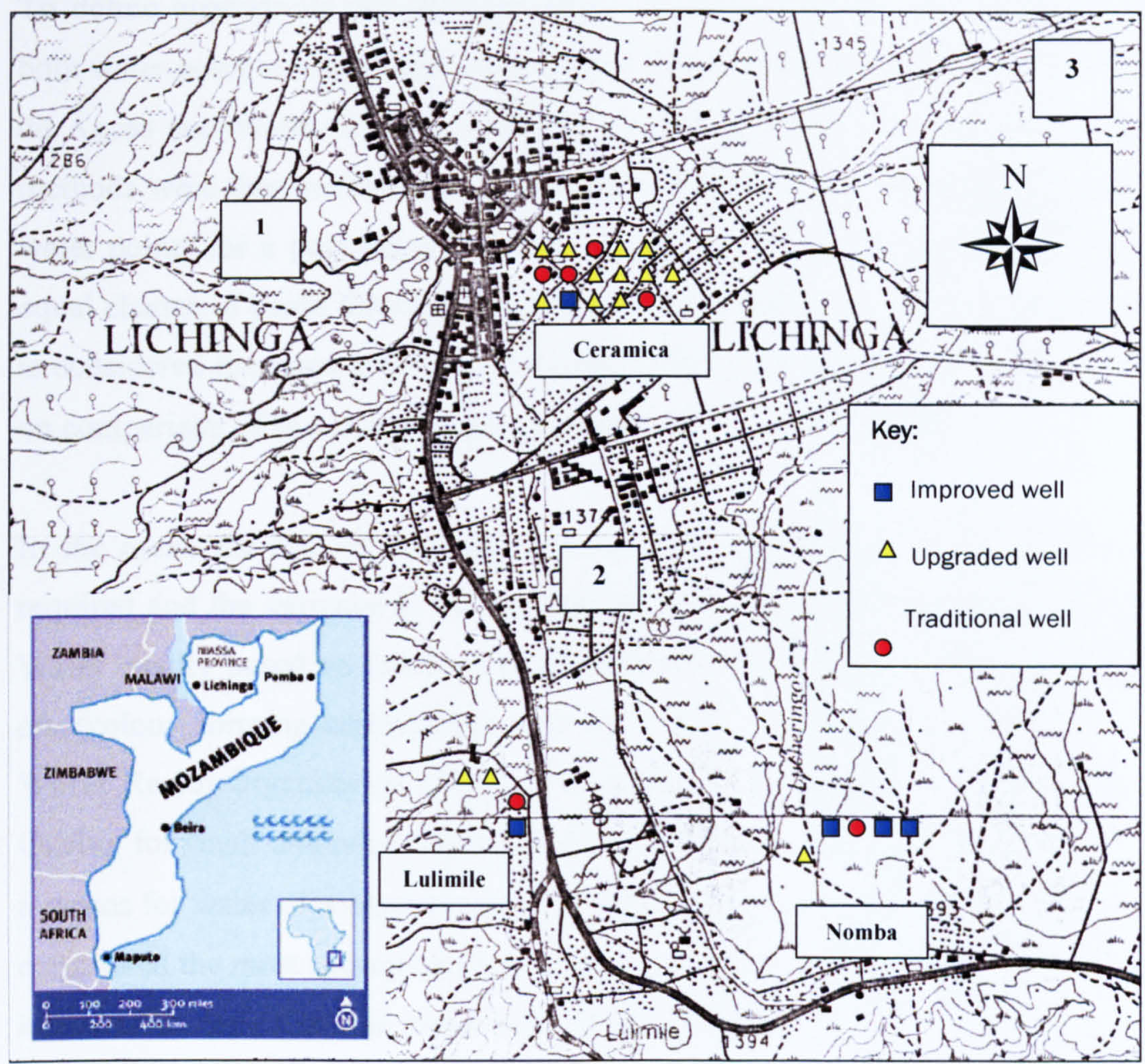

Where:

- Improved Well = concrete lined well with handpump

- Upgraded Well = Brick lined well with windlass

- Traditional Well = Unlined well with rope and bucket

- Raingauges 1,2 and 3 are identified by white squares

- Box Text $=$ Name of community

Both Nomba and Lumilile may be considered rural communities located $5-8 \mathrm{~km}$ to the South of the main Lichinga town. The principal sanitation type in these communities is pit latrines. In comparison, Ceramica is located in a peri urban area of Lichinga town. Pit latrines are the most common type of sanitation in this area although some ECOSAN (urine diversion) systems have been introduced (Breslin, 2002). Open defecation was noted as being uncommon in all three communities. 


\subsubsection{Secondary Stratification}

To define appropriate sample sizes within Nomba, Lulimile and Ceramica data on both water point coverage and water quality from the Mozambique Direcção Nacional de Águas and WaterAid were used (Mozambique, 2003). Simple random statistical methods were then reviewed to select the most appropriate method for calculating $n$ water points for a population of size $N$, so that each one of the water points has an equal chance of being drawn (Dziegielewski et al. 1996). The $t$-test was selected as it is considered the most appropriate test for defining an appropriate sample size based on comparison of two independent data groups (Helsel et al. 1992).

In the $t$-test, the size of the sample is dependent on the precision of measurement required and the variance in the parameters to be tested (Dziegielewski et al. 1996). Water quality based on levels of faecal (thermotolerant) contamination expressed as cfu (colony forming units) $/ 100 \mathrm{ml}$ was used as the key selection variable. Using the World Health Organization (WHO) relaxation of the Guidelines for Drinking Water Quality for small untreated water supplies, the level of $\leq 10 \mathrm{cfu} / 100 \mathrm{ml}$ was selected as a means for water of acceptable quality (WHO, 2004). Thermotolerant coliforms were considered the most appropriate key selection variable as they were the primary faecal indicator bacteria that was historically tested by WaterAid and they are more reliable than the use of turbidity, when tested at field level due to high error levels in the visual tube turbidity method (RCPEH, 2000).

The first approximation of the number of water supplies required for a representative sample was calculated using t-test statistics based on equations 1 and 2 (Dziegielewski et al. 1996).

$\mathrm{n}_{\mathrm{o}}=\frac{\{\mathrm{s}\}^{2}}{r \mathrm{Y}^{2}}$

Where,

$\mathrm{n}_{\mathrm{o}} \quad$ : first approximation of sample size

$t \quad:$ confidence probability ( $t$ statistics). This value is $1.64,1.96$ and 2.58 for confidence probabilities 90,95 and 99 percent respectively

S : population standard deviation

$r \quad:$ relative error 
$\mathrm{n}=\frac{\mathrm{n}_{\mathrm{o}}}{\left(1+\frac{\mathrm{n}_{\mathrm{o}}}{\mathrm{N}}\right)}$

Where,

n : sample size

$\mathrm{N} \quad$ : population size

$\mathrm{n}_{\mathrm{o}} \quad$ : first approximation sample size (see previous equation)

For example in Lichinga, data exist on 362 "improved" water points constructed up to November 2003. The analysis of these data indicates that average levels of contamination are $8 \mathrm{cfu} / 100 \mathrm{ml}$ and the standard deviation is $5 \mathrm{cfu} / 100 \mathrm{ml}$ (Mozambique, 2003). Using the $t$-test, the number of water points required with 90 percent confident of estimating average levels of contamination within 5 percent of the true value was calculated using equations 3 and 4 by substituting values in equations 1 and 2.

$$
\begin{aligned}
& n_{o}=\frac{\{t S\}^{2}}{r Y^{2}}=\left[\frac{(1.64)(5)}{(0.05)(8)}\right]^{2}=21.01 \\
& n=\frac{n_{o}}{\left(1+\frac{n_{0}}{N}\right)}=\frac{21.01}{\left(1+\frac{21.01}{362}\right)}=20
\end{aligned}
$$

Therefore, for a statistically valid sample of 362 water points, 20 water points would be required. These were selected from the above selected communities based on logistics, practicalities, ease of access, available data and inclusion in an existing monitoring framework.

In total, data were collected monthly from 20 water sources in 3 communities over 12 months. In 2002, the total populations in the three communities were 11988 in Ceramica, 8846 in Lulimile and $<1000$ in Nomba. 
Additional to the 20 water points were 5 control water points representing $20 \%$ of the sample size. The control sites selected at random from unprotected wells were prone to high levels of contamination. The objectives of choosing the control sites were;

a) to ensure field-testing equipment was functioning,

b) to act as a reference for comparative results, and

c) to assess improvements in trends of contamination from improved sources.

The sample and control sites were chosen from the three selected communities on the basis of criteria that included logistics, practicalities, ease of access, available data and inclusion in an existing WaterAid monitoring framework. A greater number of hand dug wells with bucket pumps were selected as they are representative of the (majority) of supplies in Lichinga.

Table 6: Selected Water Points by Technology

\begin{tabular}{|l|c|c|c|}
\hline Number & Site 1: Lulimile & Site 2: Nomba & Site 3: Ceramica \\
\hline $\begin{array}{l}\text { Hand dug wells with } \\
\text { handpump }\end{array}$ & 1 & 2 & 1 \\
\hline $\begin{array}{l}\text { Hand dug well with } \\
\text { rope pump }\end{array}$ & 0 & 1 & 0 \\
\hline $\begin{array}{l}\text { Hand dug well with } \\
\text { bucket pump }\end{array}$ & 2 & 1 & 11 \\
\hline Traditional well & 1 & 1 & 4 \\
\hline \multicolumn{1}{r}{ Total } & 4 & 5 & 16 \\
\hline
\end{tabular}

The primary data source for the research was based on field data collection from Lichinga, Niassa province, Northern Mozambique. Data were collected over a 12month period from November 2003 to October 2004. Historical data were made available to the researcher from August 2002 to October 2003 and were used to provide a rationale for the performance of each type of well prior to the start of the research. However, the historical data available were not quality controlled and had some evident errors.

Data were therefore collected monthly by the author at each of the same 25 wells between November 2003 and October 2004. A stratified approach to data collection was adopted during the 12-month period that included the collection of data on both categorical and parametric variables.

- Categorical Variables (or non changing data) were single measurements. These included a hazard assessment, soil characterisation study and an engineering assessment. 
- Parametric variables (or continuous data) were collected either daily or monthly over a 12-month period. These included daily rainfall readings, monthly microbiological and physico-chemical data, depth to water table and sanitary inspection data.

The dates when specific activities were undertaken are marked as shaded areas in table 7 below.

Table 7: Activity plan

\begin{tabular}{|c|l|l|l|l|l|l|l|l|l|l|l|l|}
\hline Activity & $11 / 03$ & $12 / 03$ & $01 / 04$ & $02 / 04$ & $03 / 04$ & $04 / 04$ & $05 / 04$ & $06 / 04$ & $07 / 04$ & $08 / 04$ & $09 / 04$ & $10 / 04$ \\
\hline $\begin{array}{c}\text { Set up rainfall gauges } \\
\text { Set up WQ }\end{array}$ & & & & & & & & & & & \\
\hline $\begin{array}{c}\text { laboratory/specialised } \\
\text { training for analyst }\end{array}$ & & & & & & & & & & & & \\
\hline WQ data collection & & & & & & & & & & & & \\
\hline $\begin{array}{c}\text { Historical } \\
\text { Rainfall/Precipitation } \\
\text { data }\end{array}$ & & & & & & & & & & & & \\
\hline $\begin{array}{c}\text { Rainfall data } \\
\text { collection }\end{array}$ & & & & & & & & & & & & \\
\hline Field Test SI forms & & & & & & & & & & & & \\
\hline $\begin{array}{c}\text { SI data collection } \\
\text { Identify wells }\end{array}$ & & & & & & & & & & & & \\
\hline $\begin{array}{c}\text { Hydrogeological } \\
\text { survey }\end{array}$ & & & & & & & & & & & & \\
\hline Headworks survey & & & & & & & & & & & & \\
\hline $\begin{array}{c}\text { Borehole camera } \\
\text { analysis }\end{array}$ & & & & & & & & & & & & \\
\hline $\begin{array}{c}\text { Particle size } \\
\text { distribution test }\end{array}$ & & & & & & & & & & & & \\
\hline Soil classification & & & & & & & & & & & & \\
\hline $\begin{array}{c}\text { Concrete Schmidt } \\
\text { Hammer Test }\end{array}$ & & & & & & & & & & & & \\
\hline $\begin{array}{c}\text { Analytic Hierarchy } \\
\text { Process (AHP) data }\end{array}$ & & & & & & & & & & & & \\
\hline
\end{tabular}

As the rainy season starts in Lichinga in December and ends in March, a large amount of the work was undertaken either before or after the rains in late 2003 and in early 2004. Specific training was required for a selected technician from the Lichinga Agricultural Research Centre before the work could commence, as he was not familiar with the water quality tests used during this research. This training was undertaken by the author but supported by both an American trained molecular biologist and a member of the WaterAid field staff (who had received prior training from the Robens Centre for Environmental Health). 
Outlined below (table 8) are the specific variables for which data were collected between November 2003 and October 2004. In the first and second columns are four categories of data: source, pathway, receptor and water quality. The source, pathway and receptor were selected as the study aims to investigate the following:

- Source - to investigate possible pollution risks

- Pathway - to investigate paths or obstacles to movement of pollutants

- Receptor - to study the effectiveness of engineering barriers

- Water quality - to study the extent of pollution in the groundwater.

Table 8: Data collection methods

\begin{tabular}{|c|c|c|c|}
\hline Variable Type & Variable & How? & Where? \\
\hline \multirow[t]{4}{*}{ Source: } & $\begin{array}{c}\text { Hazard/Vulnerability } \\
\text { analysis }\end{array}$ & Sanitary survey & On site \\
\hline & Distance from latrines & Field survey & On site \\
\hline & Depth of latrine & Field survey & $\overline{\text { On site }}$ \\
\hline & Land Use & Field survey & On site \\
\hline \multirow[t]{4}{*}{ Pathway: } & Rainfall/Precipitation & $\begin{array}{l}\text { Rainfall records } \\
\text { Daily monitoring }\end{array}$ & $\begin{array}{l}\text { Lichinga } \\
\text { On Site }\end{array}$ \\
\hline & Depth to water/water level & Dip Test & On site \\
\hline & Aquifer media & $\begin{array}{c}\text { Soil classification } \\
\text { Borehole camera } \\
\text { Field survey } \\
\text { Particle size } \\
\text { distribution }\end{array}$ & $\begin{array}{l}\text { On site } \\
\text { On site } \\
\text { On site } \\
\text { On site }\end{array}$ \\
\hline & Hydrogeological survey & $\begin{array}{l}\text { Field Survey } \\
\text { Visual soil } \\
\text { classification } \\
\text { Subsoil thickness } \\
\text { Geological } \\
\text { observations } \\
\end{array}$ & $\begin{array}{l}\text { On site } \\
\text { On site } \\
\text { On site } \\
\text { On site }\end{array}$ \\
\hline \multirow[t]{4}{*}{ Receptor: } & Surface hardness & $\begin{array}{l}\text { Schmidt Hammer } \\
\text { Test }\end{array}$ & On site \\
\hline & Water lifting & Structured survey & On site \\
\hline & Headwork Survey & $\begin{array}{l}\text { Borehole camera } \\
\text { Structured survey }\end{array}$ & $\begin{array}{l}\text { On site } \\
\text { On site }\end{array}$ \\
\hline & Well Design/lining & $\begin{array}{l}\text { Borehole camera } \\
\text { Structured survey }\end{array}$ & $\begin{array}{l}\text { On site } \\
\text { On site }\end{array}$ \\
\hline \multirow[t]{4}{*}{ Water Quality: } & $\begin{array}{c}\text { Turbidity } \\
\mathrm{pH}\end{array}$ & $\begin{array}{c}\text { Turbidity tube } \\
\text { Handheld comparator }\end{array}$ & $\begin{array}{l}\text { On site } \\
\text { On site } \\
\end{array}$ \\
\hline & thermotolerant coliforms & $\begin{array}{c}\text { PotaFlex portable test } \\
\text { kit }\end{array}$ & Lichinga Laboratory \\
\hline & Enterococci & $\begin{array}{l}\text { PotaFlex portable test } \\
\text { kit } \\
\end{array}$ & Lichinga Laboratory \\
\hline & Somatic coliphage & Laboratory Test & United Kingdom \\
\hline
\end{tabular}

Listed in the third column are the proposed field methods to collect information on each of the variables. Finally, the fourth column (marked Where?) outlines where the physical testing was done. In situ data collection was done at each of the 25 well sites. This included data collection on hydrogeology and hazard source. Water quality 
sampling was done in situ with microbiological samples being transported between 2 and $6 \mathrm{~km}$ to a laboratory established specifically for this research. Due to the complexity of testing for enterococci, laboratory testing, as opposed to on site field kit testing, was selected.

Outlined below are details of the methods used to collect data for each of the variables outlined in column 1 in Table 9. The sections are divided into two; visual and physical survey methods. Section 4.3 outlines the methods used for visual survey methods and section 4.4 outlines the physical methods.

\subsection{Visual survey methods}

This section discusses the survey methods used to collect qualitative data on the selected risk variables. The section is divided into the same categorisations of risk variables that were identified in Chapter 3, namely;

- 4.3.1: Source - Risk variables

- 4.3.2: Pathway - Meteorological and Hydrogeological Variables

- 4.3.3: Receptor - Engineering variables

- 4.3.4: End product - Water Quality Variables

\subsubsection{Source - Risk Variables}

To assess the source of a hazard, data on both categorical and parametric variables is required. Data were collected in this research for each of the hazard source variables outlined in Table 9.

Table 9: Selected source variables

\begin{tabular}{|c|c|c|c|}
\hline Source: & What & Where & Why \\
\hline Hazard/Vulnerability analysis & Sanitary survey & On site & Visual assessment of hazard source \\
\hline Distance from latrines & Field survey & On site & $\begin{array}{c}\text { Distance between faecal hazard } \\
\text { source and water supply }\end{array}$ \\
\hline Depth of latrine & Field survey & On site & $\begin{array}{c}\text { Assessment of potential of pit } \\
\text { latrine to bypass unsaturated soil } \\
\text { zone }\end{array}$ \\
\hline Land Use & Field survey & On site & $\begin{array}{c}\text { Categorisation of anthropogenic } \\
\text { pollution activities }\end{array}$ \\
\hline
\end{tabular}

Commonly, parametric variables such as hazard/vulnerability analysis are monitored using Sanitary Inspection (SI) forms. These SI forms are multiple question questionnaires with defined YES or NO answers. They combine questions on the identification of a hazard source as well as the identification of a specific localised 
pathway to contamination. A summary of these risk scores gives an overall risk associated with a particular infrastructure type. Levels of risk in an SI form typically have the following range:

- VERY HIGH = 10-12

- $\mathrm{HIGH}=7-9$

- $\mathrm{MEDIUM}=4-6$

- $\mathrm{LOW}=1-3$

- VERY LOW $=<1$

The target level is LOW or VERY LOW indicating limited pollution risk. Specific sanitary inspection forms were developed to identify sanitary risks associated with different technology types. The forms were developed through a round table discussion with project partners in Lichinga as to what specific risk factors should be considered for each technology. From there, draft sanitary inspection forms were developed. Following extensive field trialling of the forms, alterations were made and the final forms developed. A total of 4 sanitary inspection forms were developed for the following technologies:

1. Traditional well

2. Upgraded well with windlass

3. Improved well with rope and washer pump

4. Improved well with handpump

For each question, the nature of the potential risk was determined as being the source, pathway or indirect factor (receptor). Table 10 shows the nature of the potential risk for each question and SI form.

Table 10: Sanitary Inspection Question Categories

\begin{tabular}{|c|c|c|c|c|}
\hline Question & Traditional well & $\begin{array}{c}\text { Upgraded well } \\
\text { with windlass }\end{array}$ & $\begin{array}{c}\text { Improved well } \\
\text { with rope pump }\end{array}$ & $\begin{array}{c}\text { Improved well } \\
\text { with handpump }\end{array}$ \\
\hline $\mathbf{1}$ & Source & Source & Source & Source \\
\hline $\mathbf{2}$ & Source & Source & Source & Source \\
\hline $\mathbf{3}$ & Source & Source & Source & Source \\
\hline $\mathbf{4}$ & Pathway & Pathway & Pathway & Pathway \\
\hline $\mathbf{5}$ & Indirect factor & Indirect factor & Indirect factor & Indirect factor \\
\hline $\mathbf{6}$ & Pathway & Pathway & Pathway & Pathway \\
\hline 7 & Indirect factor & Pathway & Pathway & Pathway \\
\hline $\mathbf{8}$ & Pathway & Pathway & Indirect factor & Indirect factor \\
\hline 9 & Pathway & Indirect factor & Indirect factor & Indirect factor \\
\hline 10 & Pathway & Indirect factor & Pathway & Pathway \\
\hline 11 & & & Pathway & Indirect factor \\
\hline 12 & & & & Pathway \\
\hline TOTAL RISKS & 10 & 10 & 11 & 12 \\
\hline
\end{tabular}


Sanitary inspections were undertaken each time a sample was taken for analysis from a water point. In total 25 Sanitary Inspections were done once per month (1 per well). Two inspections were made for each well before the rains in November. Consequently, $25 * 2=50$ Sanitary Inspections were done in November and 25 in each of the next 11 months, giving a total of 325 sanitary inspections during the research.

Categorical variables can be monitored using singular detailed surveys. In this research detailed observations of land use were collected using a combination of a structured interview (with the village leaders) and visual survey techniques. The categorical variables discussed during the structured interviews included population density in a given area. Population density is taken for the immediate area around the water point. Subjective scorings of High (H), Medium (M) and Low (L) were assigned.

Further structured survey data were collected to gain information on land use in the vicinity of the well. Reference was made to work by Barret et al (2000). The study outlines methods for categorising sampling sites based on 5 main categories of land use. Table 11 outlines the specific land use categorisations. High/Medium and Low populations were calculated as $<50$ persons $\mathrm{km}^{2}, 50-100$ persons $\mathrm{km}^{2}$ and $>100$ persons per $\mathrm{km}^{2}$.

Table 11: Land use categorisation

\begin{tabular}{|c|c|c|c|c|c|}
\hline Site & $\begin{array}{c}\text { Population } \\
\text { Density }\end{array}$ & $\begin{array}{c}\text { Pit latrines } \\
\text { within } 30 \mathrm{~m}\end{array}$ & $\begin{array}{c}\text { Surface water } \\
\text { dump within } \\
30 \mathrm{~m}\end{array}$ & $\begin{array}{c}\text { Scattered waste } \\
\text { within } 50 \mathrm{~m}\end{array}$ & $\begin{array}{c}\text { Animal } \\
\text { husbandry } \\
\text { within } 100 \mathrm{~m}\end{array}$ \\
\hline & $\mathrm{H} / \mathrm{M} / \mathrm{L}$ & $\mathrm{Y} / \mathrm{N}$ & $\mathrm{Y} / \mathrm{N}$ & $\mathrm{Y} / \mathrm{N}$ & $\mathrm{Y} / \mathrm{N}$ \\
\hline
\end{tabular}

Other variables assessed included distance from hazard source and depth of hazard source, with guideline values based on scientific evidence presented by the British Geological Survey (2002) (ARGOSS, 2002). The distances were measured in the field by counting the number of paces of an average height male from the closest faecal or hazard source to the water point. Further in situ observations included the depth and type of latrines. Distances from faecal sources were then indicated as $\mathrm{Y}=\mathrm{Yes}$ and $\mathrm{N}=$ No. Data were collected between March and April 2004 and involved interviewing the latrine owner to determine the approximate latrine depth. Due to the sensitivities of 
human contact with faeces, it was inappropriate to take physical measurements of latrine depth within the communities.

Before undertaking the survey, the sanitary assessment forms were field tested by the author in each of the communities in order to gauge the relevance of each of the questions. It was noted that there was some overlap between questions in the survey and those in the Sanitary Inspection forms. Nonetheless, it was concluded that the same questions were required in order to clarify the purpose of the survey to those community members who were participating in the survey. A total of 25 surveys were undertaken equalling one per well, during April 2004.

\subsubsection{Pathway - Meteorological and Hydrogeological Variables}

Data collected for all meteorological parameters involved physical quantitative tests. No visual or qualitative survey methods were used. Full details can be seen in section 4.4.2. This section will outline the survey methods used in the research to collect data on the hydrogeological variables. The selected hydrogeological variables on which data were collected in this research are outlined in Table 12.

Table 12: Selected Hydrogeological Variables

\begin{tabular}{|c|l|l|l|}
\hline Pathway: & What & Where & \multicolumn{1}{|c|}{ Why } \\
\hline $\begin{array}{c}\text { Hydrogeological } \\
\text { survey: }\end{array}$ & Field Survey & On site & Site investigation \\
\cline { 2 - 4 } & $\begin{array}{c}\text { Visual soil } \\
\text { classification }\end{array}$ & On site & $\begin{array}{l}\text { Classification of soil } \\
\text { permeability }\end{array}$ \\
\cline { 2 - 5 } & Subsoil thickness & On site & $\begin{array}{l}\text { Classification of soil } \\
\text { porosity and permeability }\end{array}$ \\
\cline { 2 - 4 } & $\begin{array}{c}\text { Geological } \\
\text { observations }\end{array}$ & On site & $\begin{array}{l}\text { Vulnerability to } \\
\text { subsurface leaching of } \\
\text { contaminants }\end{array}$ \\
\hline
\end{tabular}

Data were collected on categorical variables using visual and simple field techniques.. $A$ total of 25 surveys were undertaken. Data were collected on subsoil thickness through visual observations of unlined traditional wells. These were logged as $0-1 \mathrm{~m}$, $1-3 \mathrm{~m}, 4-5 \mathrm{~m}$ and $>5 \mathrm{~m}$. Broad categorisations of the type of soil were undertaken and logged as the varied geological sections of each of the wells. These visual observations were supported by manual soil classification tests for soils. An augured sample was extracted from a depth of $0.5 \mathrm{~m}$ at a distance of $1 \mathrm{~m}$ from the well. This was done at each of the 25 well sites. A segment of soil was extracted from the 
sample and analysed by the author. The sample was placed between the thumb and finger and the soil was identified based on the methods outlined by CIBAGEIGY Agrochemicals in their Guide to Soil Identification. (CIBAGEIGY, 1986). Figure 13 below outlines the method used for identifying the soil. 


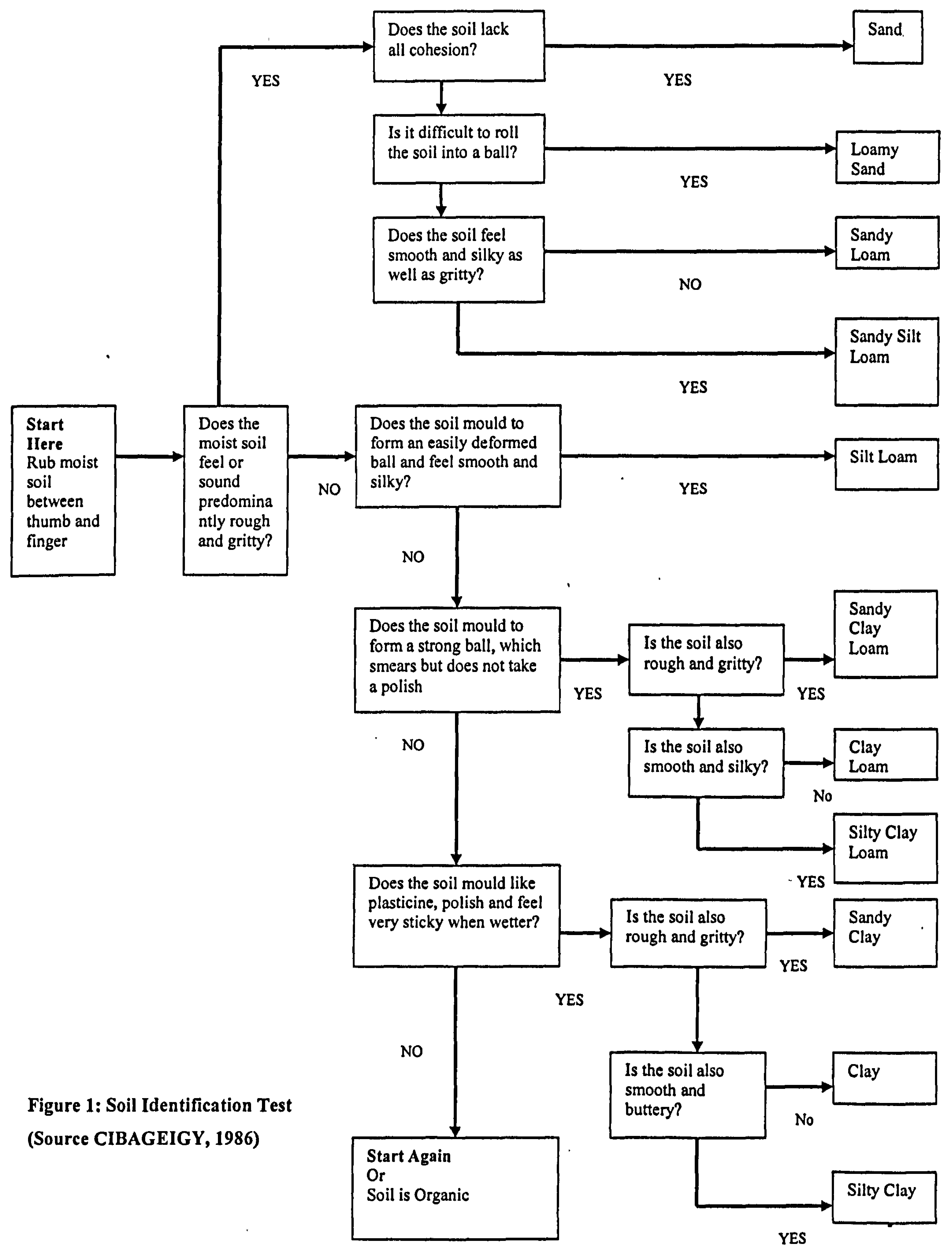




\subsubsection{Receptor - Engineering Barriers}

Combinations of methods were used to collect data on the effectiveness of the headworks in reducing risk of shallow groundwater to contamination. These included;

1. Visual inspections (structured surveys) - to understand the design and condition of the headworks structure.

2. Non-Destructive - selected tests to validate findings from the visual inspection. This section will discuss the visual inspection techniques used. Section 4.3.4 will outline the Non Destructive physical tests used. The variables for which data were collected in the structured survey are outlined in Table 13.

Table 13: Selected Engineering Barrier Variables

\begin{tabular}{|l|l|l|l|}
\hline Receptor: & What & Where & Why \\
\hline Water lifting & Structured survey & On site & $\begin{array}{l}\text { Assessment of possible ingress } \\
\text { through handpump annulus }\end{array}$ \\
\hline IIeadwork Survey & Structured survey & On site & $\begin{array}{l}\text { Assessment of possible ingress } \\
\text { through headworks annulus }\end{array}$ \\
\hline Well Design/lining & Structured survey & On site & $\begin{array}{l}\text { Assessment of possible ingress } \\
\text { through subsurface annulus }\end{array}$ \\
\hline
\end{tabular}

A structured survey approach was used for monitoring the technical quality of the headworks. This focused on principles of Total Quality Management (TQM), which emphasise the importance of quality assurance during the process of production as opposed to sole reliance on quality control of the end product. The survey assessed:

- Wellhead design - questions focused on the diameter, height of apron, depth of sanitary seal and methods of drainage,

- Pump type - questions focused on type of pump, rising main material used, appropriateness of pump for apron design used,

- Well/Pump age - questions were asked about well and pump age.

All the relevant measurements for this survey were gained from both the author's field experience and from the literature. The survey was undertaken once for each of the 25 wells during April 2004. The survey was undertaken by the author for all of the wells to provide consistency/uniformity of results through the use of different survey techniques.

Furthermore, the survey involved an assessment of the quality of workmanship. This focused on Total Quality Management principles using a combination of questions and structured observation techniques. The masons responsible for the construction of 
each of the wells were interviewed and their responses combined with survey data obtained from the field. It is appreciated that some of the responses to the questions were difficult to quantify. For example the depth/diameter of the sanitary seal or the size of aggregate used for construction could not be measured directly. Nonetheless, using a combination of survey and physical techniques, triangulation of results was possible to reduce potential errors and to validate individual variable results.

Structured surveys included assessment of the strength and integrity of the concrete using standard civil engineering practices. The variables that were visually monitored as indicators of construction were:

- Aggregate segregation - identification of large stones grouped together and visible at the concrete surface

- Honeycombing - where air bubbles have become trapped leaving voids at the concrete surface or within the concrete

- Dry joints - different layers applied after one concrete batch had started to dry

- Cracking - indicating excessive loading, shrinking during drying, expansion, and contraction.

Any faults in concrete could permit movement of pollutants through the concrete along paths of weakness. For concrete without faults, a non-destructive surface hardness test was undertaken to indicate the likelihood of water flowing through weak porous concrete (see section 4.4.4).

\subsubsection{End Product - Water quality variables}

Quantitative data collected for all water quality parameters involved physical tests of samples either in the field or in a laboratory. No visual or qualitative survey methods were used. Full details can be seen in section 4.4.5. 


\subsection{Physical/Non destructive field methods}

This section outlines the physical methods used for collecting data on the selected variables. The categories are the same as for section 4.3 but whereas section 4.3 considered qualitative data based on observation, this section considers complementary quantitative data. The section is also divided into five sub-sections, namely:

- 4.4.1: Source - Risk variables

- 4.4.2: Pathway - Meteorological and Hydrogeological Variables

- 4.4.3: Receptor - Engineering variables

- 4.4.4: End product - Water Quality Variables

\subsubsection{Source - Risk Variables}

Data for source parameters rely on visual survey methods (see section 4.3.1).

\subsubsection{Pathway-Meteorological and Hydrogeological Variables}

Data on rainfall were collected as daily readings throughout the 12 months of data collection (November 2003 - October 2004) in order to determine the correlation between rainfall and contamination (See Godfrey et al. 2005 Appendix 3). Daily records were compared to monthly historical data. Table 14 outlines the data collected for the meteorological variables.

Table 14: Selected meteorological variables

\begin{tabular}{|c|c|c|c|}
\hline Pathway: & What & Where & Why \\
\hline Rainfall & $\begin{array}{l}\text { Rainfall records } \\
\text { Daily monitoring }\end{array}$ & $\begin{array}{ll}\text { Lichinga } & \text { historical } \\
\text { records } & \\
\text { On Site } & \end{array}$ & Annual rainfall record \\
\hline
\end{tabular}

Daily rainfall was measured using two $40 \mathrm{~mm}$ capacity Dipflex raingauges (Sites 1 and 2 as shown on figure 12) during the 12 month period. These data were then compared to historical rainfall for the preceding 8 years. Number 1 raingauge was located to the West of the city in a low lying area for data comparison to rainfall measurements at a higher altitude. Number 2 raingauge was located in the Agricultural Research Centre of Lichinga approximately 500 to $1000 \mathrm{~m}$ from the project site. Each was positioned on a 1.5 to $2 \mathrm{~m}$ high pole in an open area with a clear distance between the gauge and the nearest and tallest tree being twice the height of that tree (Gunston, 1997). The rainfall was measured at 17:00 on a daily basis during 
the 12 month data collection period (Gunston, 1997). Historical data from 1995 to date were also collected from the Meteorological Centre of Lichinga (marked as number 3 on figure 12). Monthly average rainfall data or figures measured at Lichinga Airport for the period of 1995 to 2003 were also obtained from the Meteorological Centre of Lichinga.

This research selected three physical methods to test soil and aquifer properties. These included;

1. Particle size distribution tests (soil classification)

2. Borehole logging (variations in soil classification

3. Depth to water

Methods used to collect data for each are summarised in Table 15.

Table 15: Selected hydrogeological variables

\begin{tabular}{|l|l|l|ll|}
\hline Pathway: & What & Where & Why & table \\
\hline Depth to water/water level & Dip Test & On site & $\begin{array}{l}\text { Groundwater } \\
\text { monitoring }\end{array} \quad$ soil \\
\hline Aquifer media & $\begin{array}{l}\text { Soil classification } \\
\text { Borehole camera } \\
\text { Particle size distribution }\end{array}$ & $\begin{array}{l}\text { On site } \\
\text { On site } \\
\text { On site }\end{array}$ & $\begin{array}{l}\text { Determine characteristics } \\
\text { cher }\end{array}$ \\
\hline
\end{tabular}

\section{Particle Size Distribution}

Of critical importance in assessing subsoil vulnerability is permeability. Permeability is closely related to the more specific term hydraulic conductivity (Swartz et al. 2003). To test permeability, the grain size or particle size distribution within a sample should be recorded. Methods proposed for testing particle size distribution follow BS1377-2 (1990) and Barnes (2000). A single sample was taken at each of the 25 wells and analysed by the author in March 2004.

Specifically, $100 \mathrm{~g}$ undisturbed samples were taken from $0.5 \mathrm{~m}$ depth with a 4 " $(100 \mathrm{~mm})$ hand auger within $1 \mathrm{~m}$ of the well construction. The recommended sample weight in BS1377-2 (1990) is 200g when analysis is being undertaken on predominantly alluvial soils. However, due to the high concentration of fine material combined with the small size of sieve used, $200 \mathrm{~g}$ were difficult to riffle through the sieves. Following a field trial, it was therefore decided to sample $100 \mathrm{~g}$ only. Results showed consistency, with little variation, implying that accuracy was not compromised by used of a smaller sample than that recommended for alluvial soils. 
The sample $100 \mathrm{~g}$ was extracted from a depth of $0.5 \mathrm{~m}$. This depth was selected as it is the average depth of the sanitary seal constructed around the well. It is therefore important to compare the permeability of the surrounding subsoil to the material of the sanitary seal to understand the subsurface movement of contaminants around the well.

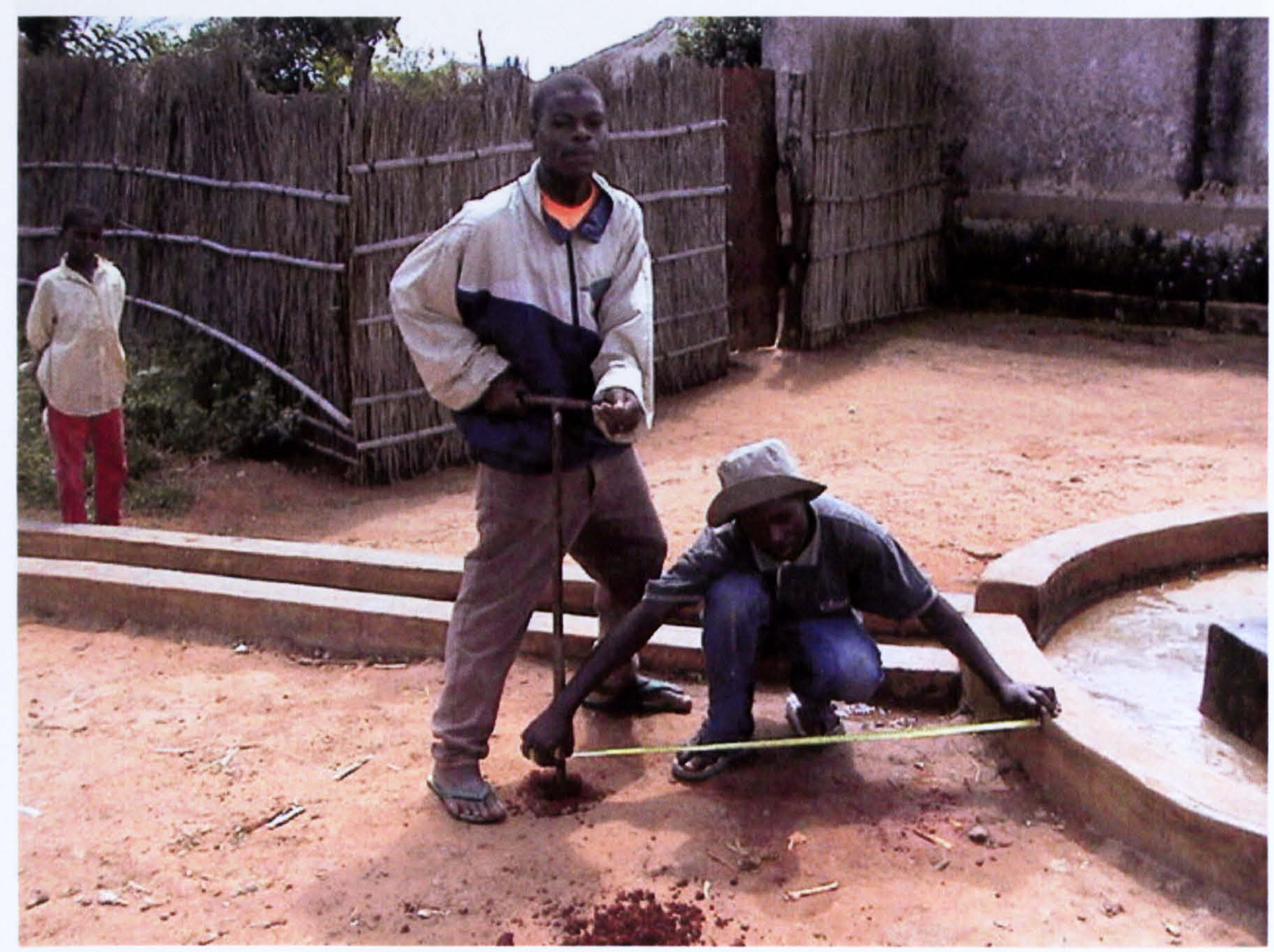

Figure 14: Enthusiastic community participation during soil sampling

The extracted sample was weighed using a 1 gram-accuracy field balance. It was then dried in an oven at $110^{\circ} \mathrm{C}$ for a period of 1 hour to give an oven dry mass of approximately 100 gram. The sample was then crushed into a powder form and mixed with 1 litre of mineral water. Bottled mineral water was selected for the experiment, as the only alternative was either highly turbid groundwater or highly chlorinated tap water. A dispersant of sodium hexametaphosphate was then crushed into a powder and made in a solution of 40g per 1 litre of mineral water (BS1377-2, 1990). This was selected as the soils in Lichinga contain a high clay fraction and are therefore highly cohesive. The solution was then agitated until mixed. $25 \mathrm{ml}$ of the dispersant was then added to the 1litre soil sample and left to settle for 1 hour with occasion agitation by hand. Figure 15 shows sieve analysis equipment used in the field. 


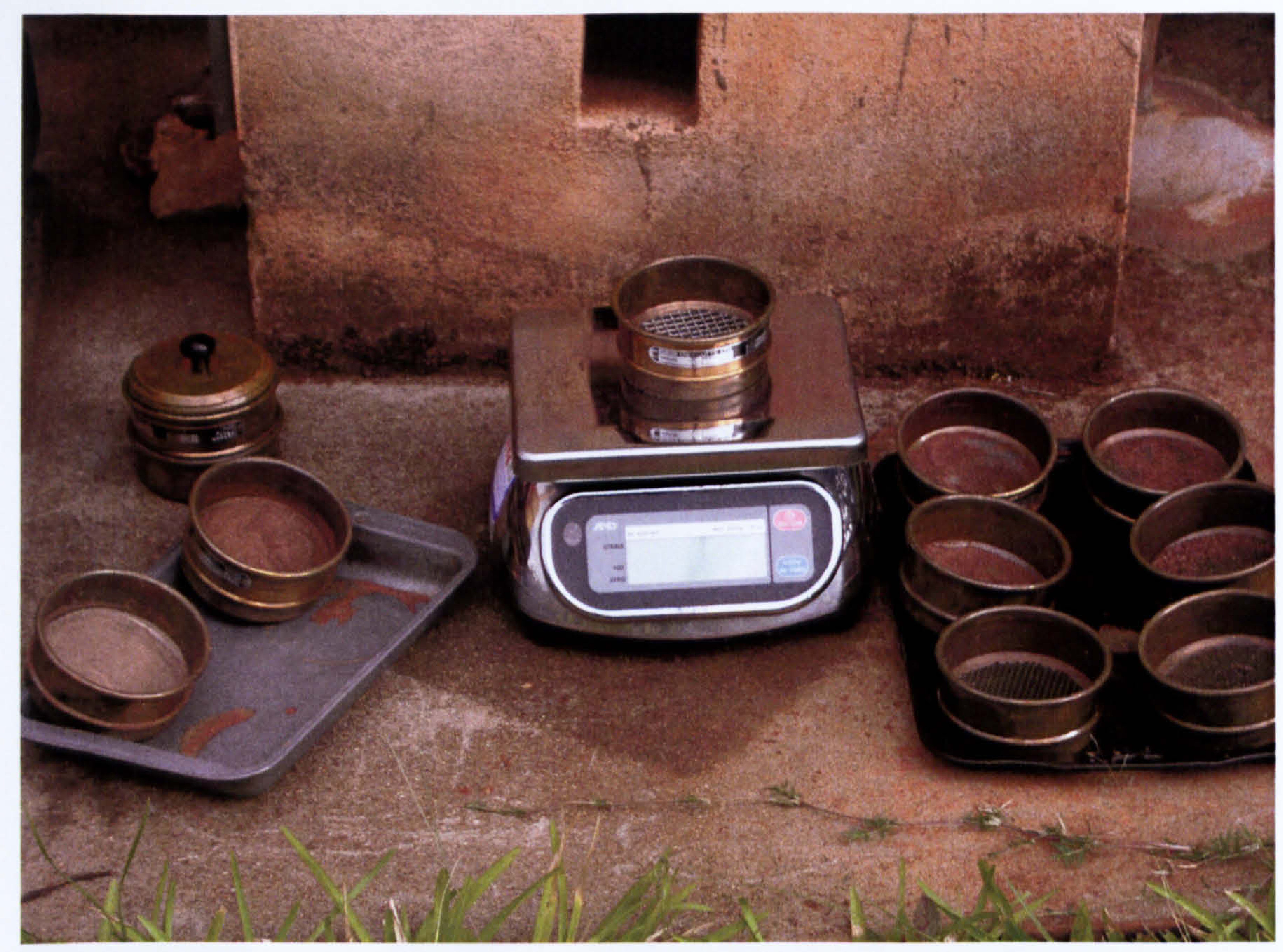

Figure 15: Sieve Analyses equipment

Samples were riffled through a set of 5 " sieves with sizes of $5 \mathrm{~mm}, 3.35 \mathrm{~mm}, 2 \mathrm{~mm}$, $1.18 \mathrm{~mm}, 600 \mu \mathrm{m}, 425 \mu \mathrm{m}, 300 \mu \mathrm{m}, 212 \mu \mathrm{m}, 150 \mu \mathrm{m}, 63 \mu \mathrm{m}$. A jet wash bottle containing water was used to manually wash the sample through the sieves. The material retained in each sieve was transferred into an evaporating tray and dried in the sun until completely dry. Samples were dried in a sheltered position, to avoid any particles blowing away. The material was then transferred onto glass watch glasses and weighed using the laboratory balance to 1-gram accuracy. Particles less than $63 \mu \mathrm{m}$ in size were recorded as clay particles.

For each sample, a grading curve was calculated using standard methods outlined in Barnes (2000). Results were recorded in a standard format outlined in Appendix 1. These were then converted into values for hydraulic conductivity. Full details of the analysis are outlined in chapter 5 . 


\section{Borehole camera}

In situ readings of the well geology were recorded using a borehole camera. A GeoVision borehole camera that linked to a miniature colour monitor was used (see figure 16).

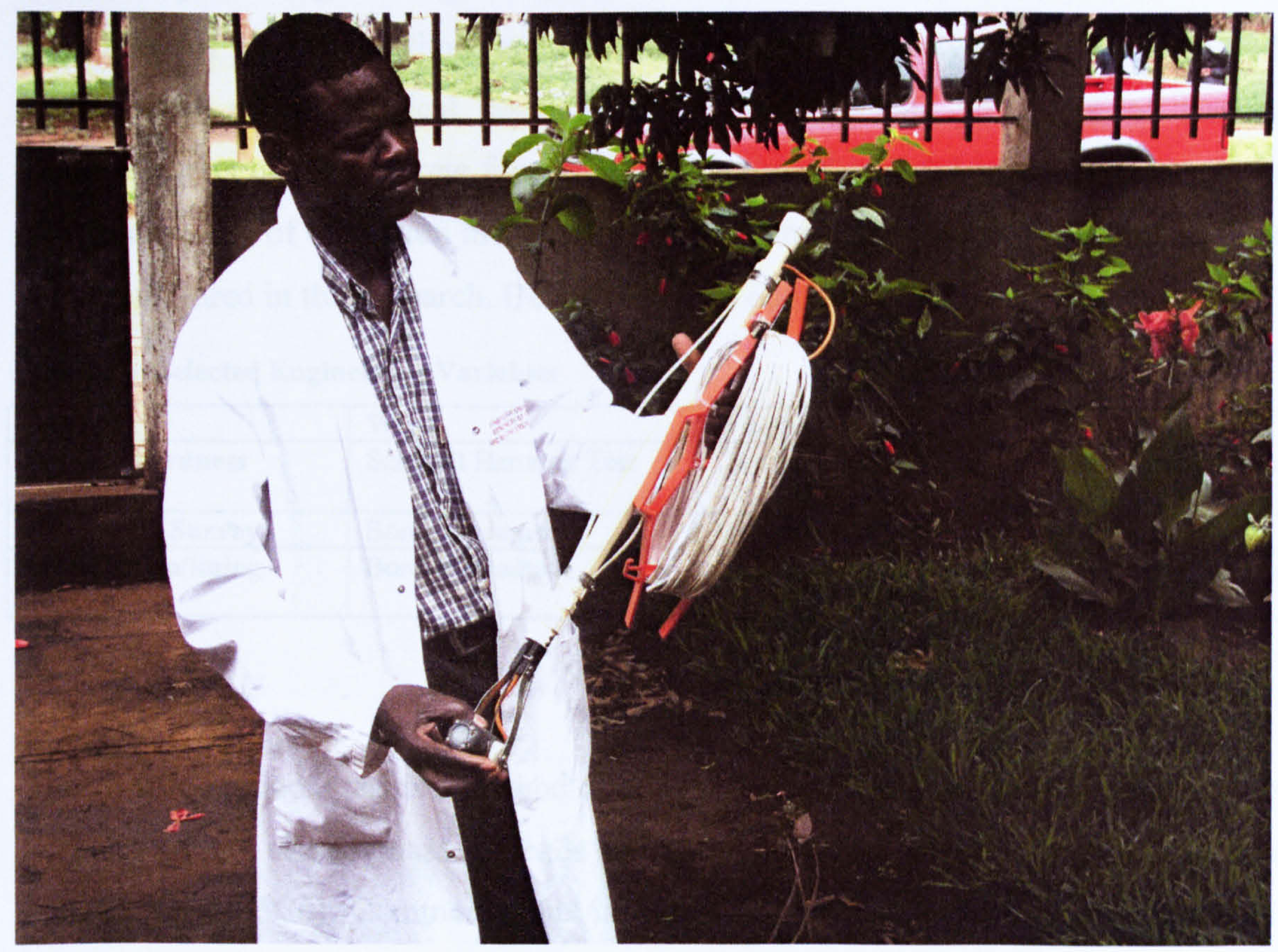

Figure 16: Geovision Borehole Camera

The GeoVision Borehole Camera provided a quick view of both the geological formation and level of sanitary protection afforded by the lining of the well. The camera was inserted into the well and images recorded at stratified depths. The images from the camera were used to compose well logs for each of the 25 sites. These included detail of the various geological formations, types of well lining (including identified failures), sanitary seals (where visible) and sanitary/structural condition of the well.

\section{Depth to Water Table}

Depth to water level was measured using a dipper tape on a monthly basis. The measurements were taken at the same time of day on each day's sampling. Field visits occurred between 7:30 and 12:00 to avoid early morning water collections in the communities. Due to the regime of testing and sample collection, the depth to water 
table was measured at the same time each day. Results were recorded with water quality outcomes in a standard format as metre (m) below ground (mbg).

\subsubsection{Receptor - Engineering Variables}

A number of physical methods are available to test the effectiveness of the wellhead in reducing microbiological contamination. These include validation of surface hardness, tests of the concrete formwork, validation of material and depth of sanitary seal and quality of extraction mechanism. Table 16 outlines the selected variables that were monitored in this research. Detail of each is outlined below.

Table 16: Selected Engineering Variables

\begin{tabular}{|l|l|l|l|}
\hline Receptor: & What & Where & Why \\
\hline Surface hardness & Schmidt Hammer Test & On site & $\begin{array}{l}\text { Level of concrete hardness and } \\
\text { quality of construction }\end{array}$ \\
\hline Headwork Survey & Borehole camera & On site & Design and construction survey \\
\hline Well Design/lining & Borehole camera & On site & $\begin{array}{l}\text { View of sanitary protection } \\
\text { afforded by well/lining type }\end{array}$ \\
\hline
\end{tabular}

\section{Surface Hardness}

The surface hardness test is a method of quality control based on the principle that the rebound of an elastic mass depends upon the hardness of the surface it strikes (BS1881-201, 1986). Commonly this is tested using a handheld spring loaded steel rebound hammer, commercially known as a Schmidt Hammer. The test is highly appropriate for this research as it relies on the use of an on-site durable instrument that records a rebound number. No chemicals or electrical sources are required and therefore the test can be undertaken in situ. Furthermore, British Standard No 1881 notes "the test is particularly suited to comparative surveys" (BS1881-201, 1986). 


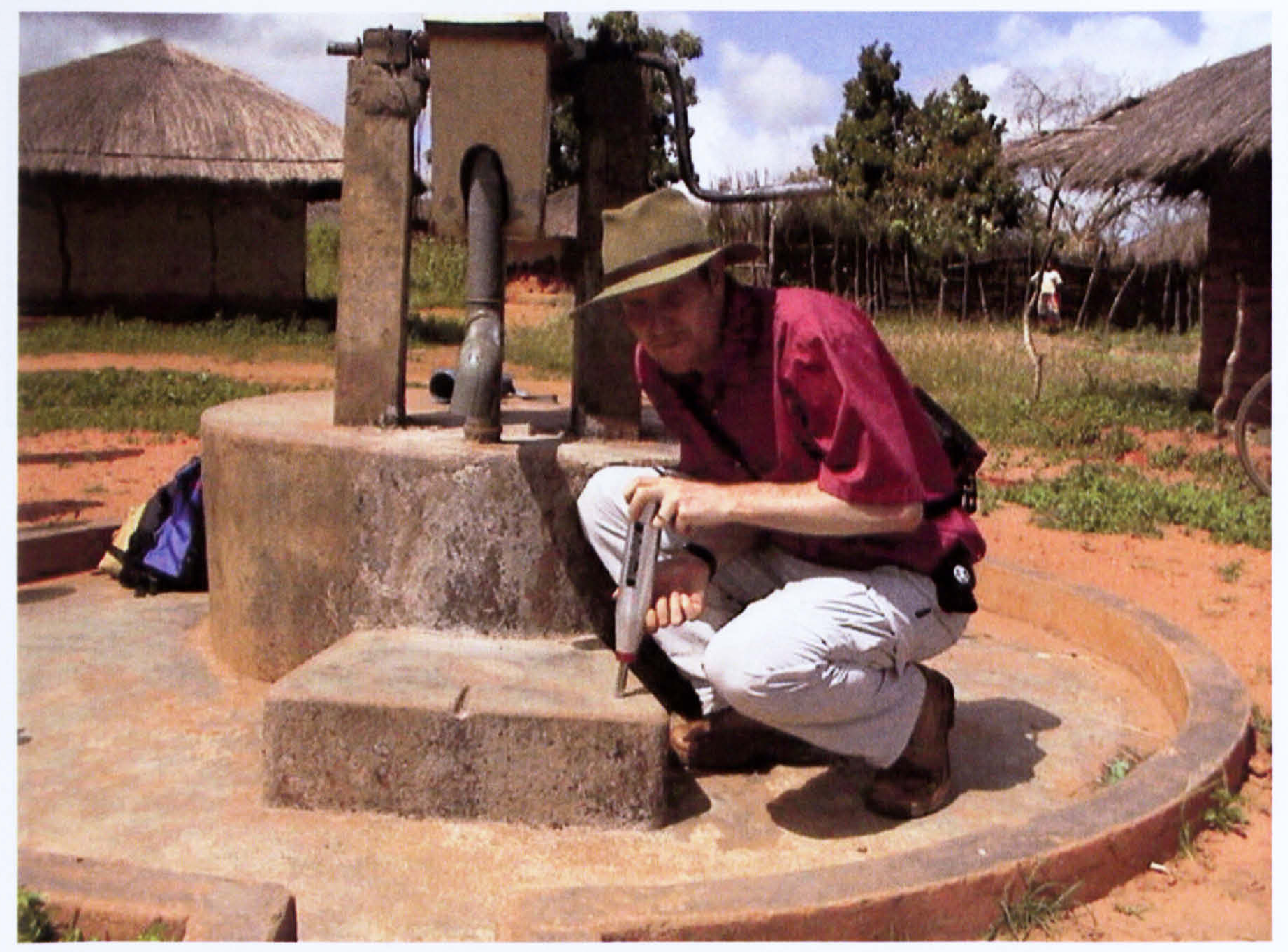

Figure 17: Surface Hardness testing by the author

Figure 17 shows the author using a Schmidt hammer to test the hardness of concrete at a well-head. Based on BS1881-201 (1986) 30 vertical rebound tests were done at each well site. The rebound numbers for each were recorded in the standard formats shown in Appendix 1. The author undertook all the tests to ensure that the same operator was used, to reduce potential errors associated with inconsistent measurement techniques. Limitations of this test are that results only relate to surface hardness for up to $30 \mathrm{~mm}$ depth and may be greatly affected by localised hardening (BS1881-201, 1986). Undertaking surface hardness testing on set concrete has a further limitation in that the concrete may be affected by localised carbonisation once the concrete is more than 3 months old (BS1881-201, 1986). Results from this test were therefore combined in this research with visual/survey observations outlined in section 4.4.4.

\subsubsection{End Product - Water quality variables}

Justification for the selected variables was discussed in detail in chapter 3 . The section outlines the methods used in the field to collect data on the variables outlined in table 17. 
Table 17: Selected water quality variables

\begin{tabular}{|l|l|l|l|}
\hline Water Quality & What & Where & Why \\
\hline $\begin{array}{l}\text { Turbidity } \\
\text { pH }\end{array}$ & $\begin{array}{l}\text { Turbidity tube } \\
\text { Handheld comparator }\end{array}$ & $\begin{array}{l}\text { On site } \\
\text { On site }\end{array}$ & $\begin{array}{l}\text { Surrogate for } \\
\text { microbiological } \\
\text { contamination }\end{array}$ \\
\hline thermotolerant coliforms & PotaFlex portable test kit & On site & $\begin{array}{l}\text { Bacterial } \\
\text { Contaminant }\end{array}$ \\
\hline Enterococci & Potaflex portable test kit & On site & $\begin{array}{l}\text { Bacterial } \\
\text { Contaminant }\end{array}$ \\
\hline Somatic Coliphage & Laboratory Test & United Kingdom & $\begin{array}{l}\text { Viral } \\
\text { Contaminant }\end{array}$ \\
\hline
\end{tabular}

\section{Physico chemical data}

Two physical parameters were tested once per month at each well for the duration of the research. These included turbidity and $\mathrm{pH}$.

- $\mathrm{pH}$ - Tested using a handheld $\mathrm{pH}$ meter, WagTech code PSCANWP2. The $\mathrm{pH}$ meter was calibrated on a monthly basis using buffer $\mathrm{pH} 4$ and buffer $\mathrm{pH} 7$. The parameter was selected as a surrogate parameter for the presence of organic growth in the well water.

- Turbidity - Turbidity was analysed using turbidity tubes calibrated against both the Nephelometric turbidity unit (NTU) and Jackson turbidity unit scales (JTU) (RCPEH, 2000). In this method, a black cross is marked on the base of the bottom tube and water added until it can no longer been seen. The turbidity was then read from the graduations on the tube. Where this fell between two graduations, an interpolated estimate was made. The tubes had a range of 5 to 2000NTU, results at extreme levels were recorded as $<5$ or $>2000$ as appropriate.

Equipment used for both $\mathrm{pH}$ and turbidity were calibrated by the manufacturer (WagTech) before use for maximum accuracy and precision (WagTech, 2003).

\section{Microbiological Analysis}

The Robens Institute undertook initial training of WaterAid project staff on water quality monitoring in 2002 over a two-week period. Further refresher training was provided by the author (one week) in November 2003. During this training, standard procedures for both the field and laboratory work were developed in Portuguese to be used by the local staff, and in-depth training given on the analysis of enterococci. These were field tested and quality controlled over a 3-week period in November 2003. 
Two microbiological parameters were tested: Presumptive (rather than confirmed) enterococci and thermotolerant coliforms. The author undertook sampling and analysis during the months of November/December 2003 and March/April 2004. The remainder of the sampling and analysis was done in collaboration with the technician from the Lichinga Agricultural Research centre who was trained and supervised by the author. Outlined below are the methods used during the research for testing the indicator bacteria and viruses.

\section{Sample Collection:}

Samples were collected by either the author or the trained laboratory technician from the Soil Research section of the Instituto Investigacoes de Agraria de Lichinga (Agricultural Research Centre on Lichinga). Standard aseptic procedures were followed (AWWA/APHA, 1998, WHO, 2004). These included sterilisation of the sampling cup through burning of methanol which inactivates bacteria through a combination of direct heat and the release of formaldehyde gas when methanol is burnt in restricted oxygen (RCPEH, 2000). This was used for collection of samples from open wells in order to prevent recontamination of well water. For water points with a handpump, the handpump was wiped clean with a paper towel and water collected directly in order to get a representative sample of the water consumed by the community. Samples were then collected using sterile $60 \mathrm{ml}$ plastic sampling bottles. These were stored in cool bags at $<4^{\circ} \mathrm{C}$ for a maximum of 6 hours whilst field sampling was undertaken. Samples were then analysed in a centralised WaterAid laboratory using hygienically/aseptic prepared apparatus. Two microbiological parameters were tested; enterococci and thermotolerant coliforms.

\section{Enterococci (EF):}

Presumptive enterococci were isolated using Azide Nutridiscs (pre-impregnated membranes) in deep plastic petri dishes supplied by Schleicher and Schuell (Product Reference Number 10433003) (WagTech, 2003). The Nutridiscs were selected due to their high selectivity and minimal fluctuation in colony growth under variable temperature and/or time (Godfrey et al 2005). To activate the agar, $3.5 \mathrm{ml}$ of distilled water was added to the Nutridiscs and a standing period of 10 minutes observed. $50 \mathrm{ml}$ samples were processed using membrane filtration (filter size of $45 \mu \mathrm{m}$ ) and applied to 
the Nutridiscs. During the rainy periods, excessive turbidity levels (>100NTU) meant 1:2, 1:5 and 1:10 dilutions with sterile de-ionised water were used accordingly.

A four-hour resuscitation period at ambient temperature was observed prior to incubation at $44^{\circ} \mathrm{C}\left( \pm 0.5^{\circ} \mathrm{C}\right)$ for 44 hours. As noted in the UK Methods for Examination of Water and Associated Materials "although incubation throughout at $37^{\circ} \mathrm{C}$ may yield a higher count, it allows some organisms to grow which do not confirm to the definition of enterococci...incubation at $44-45^{\circ} \mathrm{C}$ thus has a selective effect and produces fewer false-positive results" (ANON, 1994). The WagTech Potaflex was therefore selected as an appropriate test kit as it can be programmed to $44^{\circ} \mathrm{C}$ and will remain more stable $\left( \pm 0.1^{\circ} \mathrm{C}\right)$ than other field test kits and has the inbuilt advantage of a uniform internal temperature regulation (Godfrey et al. 2005). The kit was selected for incubating the more temperature sensitive enterococci. A constant electricity supply helped to maintain accurate temperature control. The Potaflex kit was powered by $3 \times 12$ volt solar powered batteries for the first 3 months of the research. After the trial period it was found that $1 \times 12$ volt battery was sufficient for the total incubation period.

Post incubation, all red, maroon and pink bacterial colonies that were smooth and convex were examined using a hand lens were recorded as presumptive enterococci (WagTech, 2003). Total plate counts were recorded per $100 \mathrm{ml}$ by multiplying the number of presumptive enterococci in $50 \mathrm{ml}$ by 2 . Post counts, all plastic Petri dishes were incinerated in Lichinga hospital due to the potentially harmful nature of the bacterial colonies and the Sodium Azide present in the Nutridiscs.

\section{thermotolerant coliforms (TTC):}

The isolation and enumeration of thermotolerant coliforms was carried out using membrane filtration (WagTech, 2003). $50 \mathrm{ml}$ samples were filtered through a Millipore $45 \mu \mathrm{m}$ nitro-cellulose filter. Membrane lauryl sulphate media was prepared in a specially developed membrane sulphate media measuring device (MMD) using $50 \mathrm{ml}$ batches with deionised water following standard methods (WagTech, 2003). $2 \mathrm{ml}$ of the solution was applied to each filter pad. The filtered membrane was then placed on a pad and incubated at an ambient temperature of $28^{\circ} \mathrm{C}$ for 4 hours to permit bacterial resuscitation, before transferring to $44^{\circ} \mathrm{C}$ for 14 hours incubation. Post 
incubation, all yellow colonies were counted using a hand lens and results recorded as TTC per $100 \mathrm{ml}$. The membrane pads and filters were also incinerated in Lichinga hospital.

\section{Somatic Coliphages}

Single samples were collected from each of the 25 wells by the author during April 2004. Duplicate samples were taken on the first and last sample collected during the day's sampling. In total 31 samples were analysed for somatic coliphage. Standard glass $10 \mathrm{ml}$ collection jars were used. These were dosed with $1 \mathrm{ml}$ of chloroform to assist the preservation of the sample. The samples were kept in a cool dry condition for 2 weeks prior to analysis. Due to time and logistic constraints, samples were transported from Mozambique to the UK. They were then analysed by qualified microbiologists at the Robens Institute of Environmental Health at Surrey University. The method followed ASTM Standard D4201-82 using E.coli as the host to grow the coliphages. The host culture was reconstituted using the instructions contained with the culturing. A sample of the organism was then frozen down using protec beads after culture. In order to obtain the host for the test, $10 \mathrm{mls}$ of Luria broth containing the E.coli was incubated overnight at $36^{\circ} \mathrm{C}$. This was then inoculated with $1 \mathrm{ml}$ into a new broth, incubated for 4 hours and then used as the host for bacteriophage identification.

\section{Quality Control}

For quality control, the testing kit was calibrated using a duplicate test on the first and last sample of each day's sampling as stated above. The duplicates were rotated for each month sampling to avoid repetition of control sites. For example Month 1 (November), wells 1 and 9 were replicates, Month 2 (December), wells 2 and 8 were replicates, Month 3 (January), 3 and 7, Month 4 (February), 4 and 6 were used and then back to wells from month 3 etc. Well 5 was not included due to the odd number of wells. See figure 18 for details. Blanks were taken from separate contaminated sources to test validity of equipment on a monthly basis. 
Figure 18: Duplicate sampling routine (duplicates shown as shaded area)

\begin{tabular}{|c|c|c|c|c|c|c|c|c|c|c|c|c|}
\hline $\begin{array}{l}\text { Sample } \\
\text { No. }\end{array}$ & Nov & Dec & $\operatorname{Jan}$ & Feb & March & April & May & June & July & Aug & Sept & Oct \\
\hline 1 & 4 & & & & & & 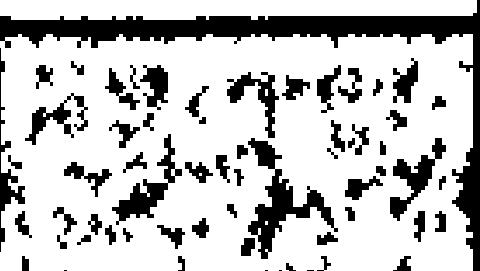 & & & & & \\
\hline$\overline{2}$ & & Wo & & & & (2) & & 45 & & & & $b_{3}+4$ \\
\hline 3 & & & 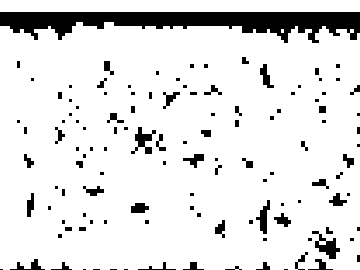 & & $6 \mathrm{O}$ & & & & mos & & $4+4,4$ & \\
\hline$\overline{4}$ & & & & 4 & & & & & & who & & \\
\hline 5 & & & & & & & & & & & & \\
\hline$\overline{6}$ & & & & 1 & & & & & & 6 & & \\
\hline$\overline{7}$ & & & 8 & & 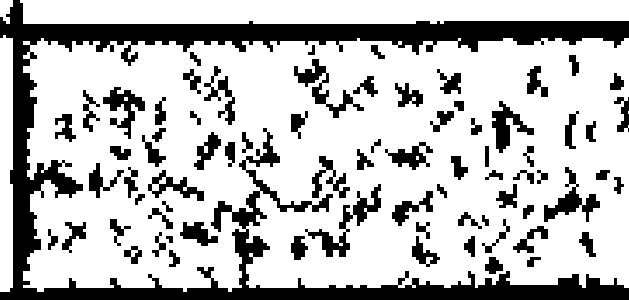 & & & & wing & & $6 x^{2}+x^{2}$ & \\
\hline 8 & & 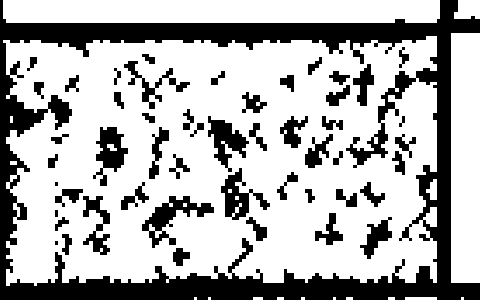 & & & & 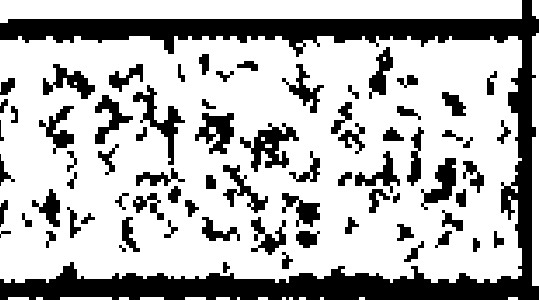 & & 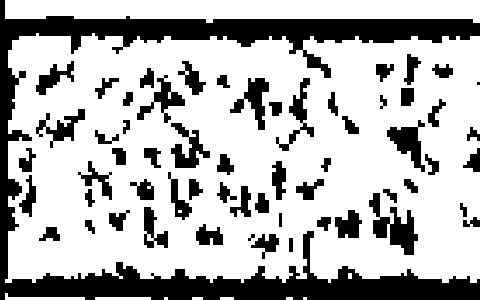 & & & & $x_{2} y^{2}$ \\
\hline 9 & $\sqrt{6}$ & & & & & & 3. & & & & & \\
\hline
\end{tabular}

Verification of plate counts was done on all samples by either the author or a qualified molecular biologist who had been working in Lichinga and was trained in the United States. The verification involved identification of thermotolerant and enterococci colonies as well as quality control of results for different dilutions. A $95 \%$ confidence interval was used to define variation in results. In addition, digital images were taken of each of the plates and sent through to the author each month for verification. The author undertook support supervision visits during 5 of the 12 monthly sampling periods (November, March, April, September, and October). These involved structured observation of the trained field technician by the author in Mozambique three times during the 12-month period.

\subsection{Summary}

This chapter has outlined the visual and physical methods used to collect complementary qualitative and quantitative data for this research. It has discussed the collection of data for both categorical and parametric variables. The methods involve the examination of soils, concrete and water quality as well as the measures to minimise the possible errors of uncertainty. Chapter 5 outlines the results from the data collection stage. 
Chapter 5: Data Analysis 


\subsection{Introduction:}

Chapter 4 outlined the data collection methodology for fieldwork undertaken in Lichinga, Mozambique between November 2003 and October 2004. This chapter reviews and analyses the data collected during the fieldwork. The chapter is divided into three sections:

- Section 5.2: Data Description

- Section 5.3: Data Mining

- Section 5.4: Data Analysis

Conceptually, each category contributes both individually and collectively to the potential risk of microbiological contamination of shallow groundwater (see Figure 19). As noted in chapter 1, the defined research problem in this research is How to assess the significance of variables affecting microbiological risk to shallow groundwater. This chapter uses selected statistical techniques to assess the significance of each of these variables to risk. Risk is defined as a combination of "the probability or frequency of a particular event occurring with the consequences of its occurrence" (microbiological contamination) (Dixon et al. 2001).

Figure 19: Conceptual framework

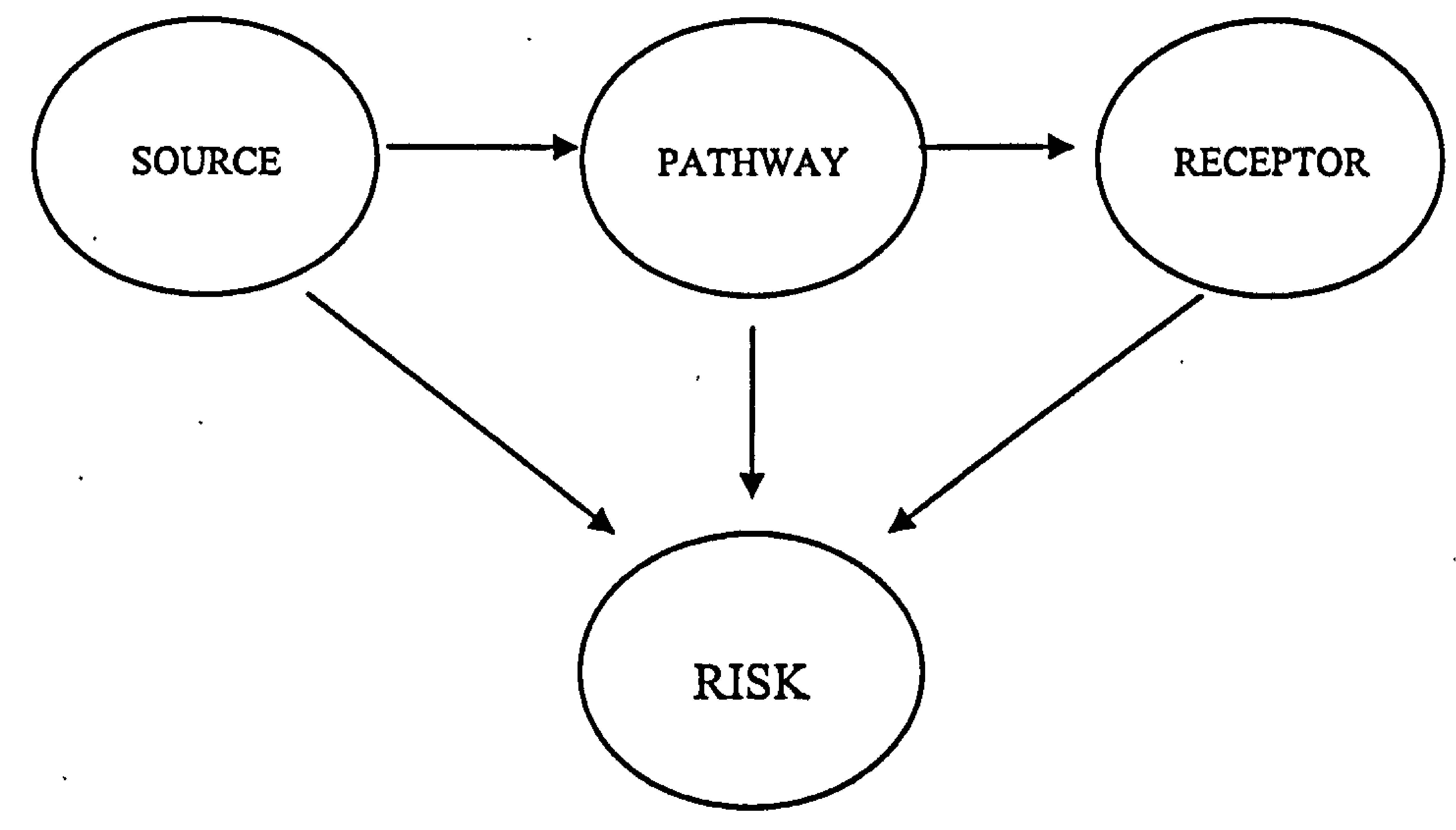

Categorical and parametric data are analysed on the basis of the categories of source, pathway and receptor. Due to the multivariate nature of the research there are numerous variates in each category of data. Results for each are therefore presented on the basis of the groupings of source, pathway and receptor. Sufficient data were 
collected from field research for the source and pathway variables. Variables defining source in this research are;

- hazard analysis: with quantitative data on hazard sources, and qualitative data on land use categorisations,

- pathway analysis: with data a combination of quantitative data on rainfall, depth to water table and soil analysis data combined with qualitative visual soil and geological categorisations, and,

- receptor analysis: quantitative data on surface hardness, inventory data and qualitative data from visual examinations.

Due to difficulties of assessing underground facilities (well shaft and intake), an additional method of data generation was used (Analytic Hierarchy Process-AHP) following the initial data collection period. The AHP method relies on expert judgement to provide data on specific variables in which there is an element of uncertainty. This will be discussed in detail in section 5.2.4.

Risk was then assessed on the basis of the quantitative water quality data. This included data on two indicator bacteria (thermotolerant coliforms and enterococci) as well as selected physico-chemical parameters. Although data were collected on somatic coliphage, it was withdrawn from further analysis as results were non conclusive (see section 5.2 .5 for details).

Due to the combination of both qualitative and quantitative data collected during this research, the initial requirement was to describe and then categorise data. This is outlined in section 5.2 and 5.3 and is then followed by statistical analysis in section 5.4. 


\subsection{Data Description}

\subsubsection{Introduction}

Data described in section 5.2 are sub divided into two categories:

1. Geographical data - data based on geographical areas (Nomba/Lulimile/Ceramica). Geographical data are selected to assess the source and pathway to contamination as these reflect identified anthropogenic and hydrogeological conditions (Figure 20 below).

2. Technological data - data based on well technology types (traditional well, upgraded well with windlass and improved well with handpump) are used to assess the effectiveness of the engineering barriers.

Figure 20: Geographical location of Lichinga

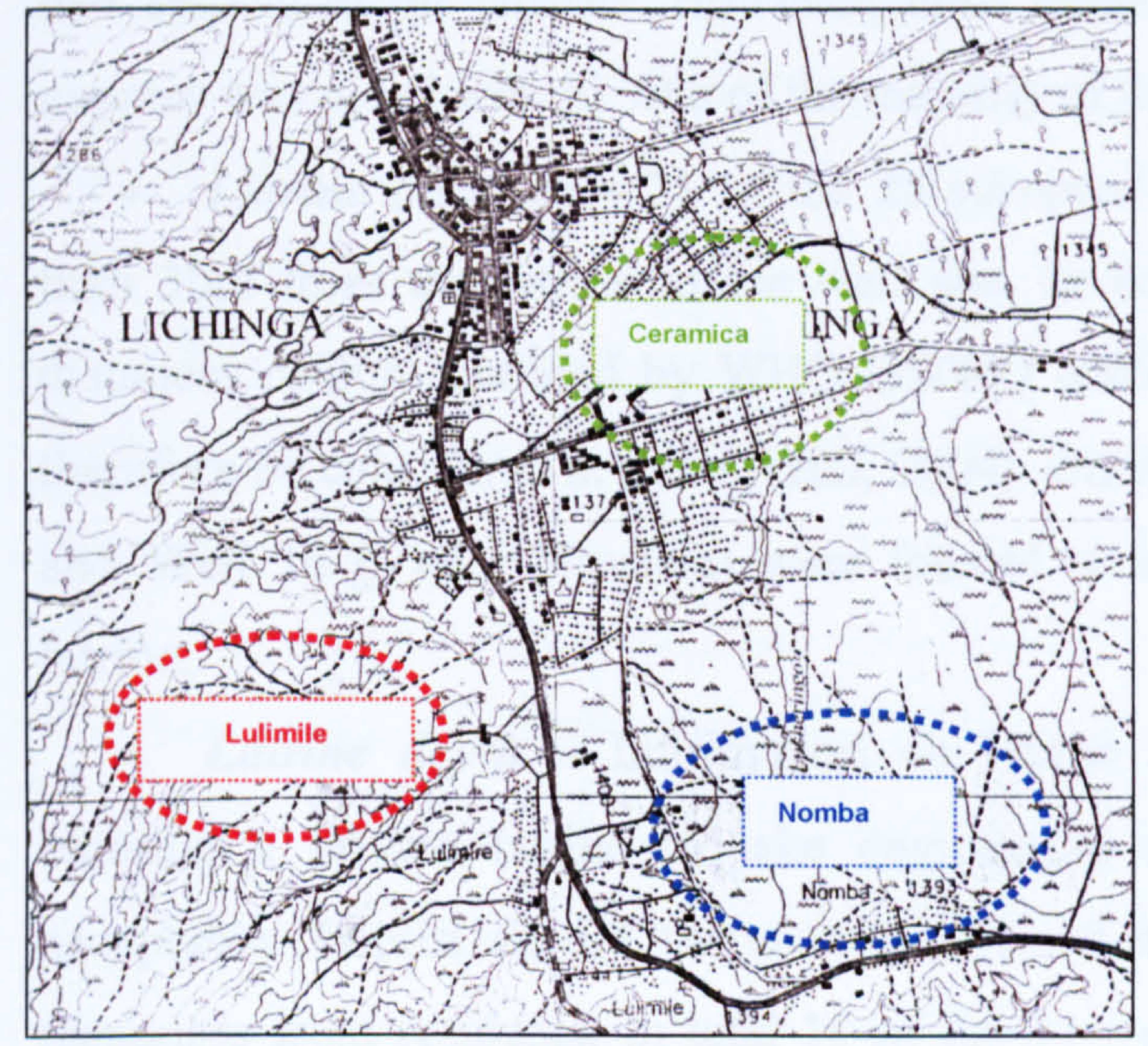

(Source: WaterAid Mozambique)

A combination of both geographical and technology sub groups was used to assess the microbiological and physico-chemical data. This combination was selected as it reflects both the technological and prevailing hydrogeological conditions. This section is divided into the source, pathway, receptor and risk categories, and will describe the data collected in each category.

\subsubsection{Source of anthropogenic contamination}

The first category described is the source of contamination. In total 325 sanitary inspections and 25-hazard analyses were undertaken between November 2003 and October 2004 in Lichinga to categorise sources of anthropogenic pollution at each of 
the 25 well sites. Data were collected during the hazard analysis from all wells except Well 19 where the owner denied access. Results of sanitary inspections were used in the case of well 19 to define hazard sources (see observations below).

- Population density - Using population density categorisations of Low $(<50$ people/hectare), Medium (50-100/hectare) and High (>100/hectare) (WHO, 2004). Table 18 indicates low levels of population density in 19 wells, medium in 3 and High in 2 wells. Using population density as a surrogate for faecal loading, it can be concluded that only low levels of human faecal loading are presented except at Well 6 (Health Centre - Lulimile) and Well 17 (Ceramica School).

- Sanitation type - Limited open defecation was noted. $100 \%$ of surveyed wells had associated pit latrines. However, open disposal of children's faeces and baby nappies was noted with in $30 \mathrm{~m}$ of the majority of the wells.

- Latrine distance - 21 of the 25 surveyed wells indicated a distance of less than $30 \mathrm{~m}$ from the latrine to the well site. In accordance with recommended safe distances of 30m outlined by WHO GDWQ edition 3, each of the 21 wells should therefore be considered at risk (WHO, 2004). Only Well 6 (Health Centre - Lulimile) and Well 10 (Victor Nuvaela) were located at a distance $>30 \mathrm{~m}$ from the nearest latrine.

- Latrine depth - Information on latrine depth was difficult to obtain, as entering a private latrine to take engineering measurements was culturally not acceptable. Depths should therefore be treated as approximation based on verbal responses from residents. In total 19 of the 24 wells were constructed at a depth of $<5 \mathrm{~m}$ with only well $12,13,14,17$ and 20 being constructed at $>5 \mathrm{~m}$. The deeper latrines are all located in the Ceramica sample area.

- Solid Waste - Broad definitions based on characterisations outlined in Barret et al (2000) were used. Minimal risk was noted from solid waste with low quantities present in the environment and the majority of solid waste dumps located $>30 \mathrm{~m}$.

- Solid waste depth - Low risk was noted as $100 \%$ of solid waste pits were recorded as having depths $<5 \mathrm{~m}$, therefore not penetrating the groundwater table.

- Animal Faeces - High risk was noted from animal faeces in 18 of the 25 wells. Evidence of cow, goat, chicken and dog faeces was evident in the close vicinity of the wells. Presence of animal faeces is linked to high prevalence levels of recorded 
enterococci in water samples analysed during the research (see section 5.2.4 for detail).

Interpretation of the level of contaminant loading from the field data was then undertaken using an adaptation of the POSH (Pollutant Origin and its Surcharge Hydraulically) method of load characterisation (Foster et al. 2002). The POSH method characterises the potential sources of subsurface contaminant load based on two characteristics:

1. Association of the likelihood of the presence of a groundwater-polluting substance with the type of anthropogenic activity

2. Estimation of associated hydraulic load (surcharge) on the basis of water use activities (Foster et al. 2002).

The POSH method provides three levels of "potential to generate a subsurface contaminant load" namely, REDUCED, MODERATE and ELEVATED. Precise characterisations outlined in Foster et al 2002, are based on experience in industrialised nations where sewered sanitation and high levels of industrial waste are the predominant pollution sources. These pollution sources differ from those in the study area in peri-urban and rural areas of Northern Mozambique. The author has therefore adapted the method outlined in Foster et al for the study site. Hazard sources have been identified from both the hazard inventory and hazard risks identified during monthly sanitary inspections at each of the 25 wells.

Table 18: Classification of pollution sources using an adapted POSH method

\begin{tabular}{|c|l|}
\hline Subsurface contaminant load potential & \multicolumn{1}{c|}{ Pollution Sources } \\
\hline ELEVATED & $\begin{array}{l}\text { On-site sanitation } \\
\text { High concentration of on-site sanitation associated } \\
\text { with population density }>100 \text { persons/ha }\end{array}$ \\
\hline MODERATE & $\begin{array}{l}\text { Livestock rearing, lower density on site sanitation } \\
\text { coverage, constructed sanitation facilities intersect } \\
\text { groundwater levels, washing in vicinity of well }\end{array}$ \\
\hline REDUCED & Leaching refuse tips \\
\hline
\end{tabular}

Table 19 applies the POSH method to the 25 well sites in Lichinga. The type of activity is based on the hazard inventory and sanitary inspection. The hydraulic surcharge is considered higher in traditional wells than protected wells and the soil zone by pass is based on results discussed in section 5.2.3. 
Table 19: Pollution load characterisation

\begin{tabular}{|c|c|c|c|c|c|c|}
\hline $\begin{array}{l}\text { Well } \\
\text { No }\end{array}$ & Type of Activity & $\begin{array}{c}\text { Character } \\
\text { of Pollutant } \\
\text { Load }\end{array}$ & & & & $\begin{array}{l}\text { Subsurface } \\
\text { contaminant } \\
\text { load potential }\end{array}$ \\
\hline & & $\begin{array}{l}\text { Distribution } \\
\text { category }\end{array}$ & $\begin{array}{l}\text { Main types } \\
\text { of pollutant }\end{array}$ & $\begin{array}{l}\text { Hydraulic } \\
\text { surcharge }\end{array}$ & $\begin{array}{l}\text { Soil bypass } \\
\text { zone }^{2}\end{array}$ & \\
\hline 1 & Leaching Refuse tips & r P-D & nfot & ++ & + & REDUCED \\
\hline 2 & $\begin{array}{l}\text { Leaching Refuse } \\
\text { tips/livestock rearing }\end{array}$ & r P-D & nfot & + & ++ & MODERATE \\
\hline 3 & Livestock rearing & r P-D & $\mathrm{nfot}$ & + & ++ & MODERATE \\
\hline 4 & Livestock rearing & r P-D & $\mathrm{nfot}$ & + & + & MODERATE \\
\hline 5 & Livestock rearing & r P-D & nfot & + & + & MODERATE \\
\hline 6 & $\begin{array}{l}\text { High density on site } \\
\text { sanitation }\end{array}$ & r P-D & $\mathrm{nfot}$ & + & + & ELEVATED \\
\hline 7 & Livestock rearing & r P-D & nfot & ++ & + & MODERATE \\
\hline 8 & Livestock rearing & r P-D & $\mathrm{nfot}$ & + & + & MODERATE \\
\hline 9 & Leaching Refuse tips & r P-D & nfot & + & + & REDUCED \\
\hline 10 & Livestock rearing & r P-D & nfot & + & ++ & MODERATE \\
\hline 11 & $\mathrm{LR}^{\prime}$ & r P-D & nfot & + & + & REDUCED \\
\hline 12 & Livestock rearing & r P-D & $\mathrm{nfot}$ & + & ++ & MODERATE \\
\hline 13 & Livestock rearing & r P-D & nfot & ++ & ++ & MODERATE \\
\hline 14 & Livestock rearing & r P-D & $n$ fot & + & + & MODERATE \\
\hline 15 & LR & r P-D & nfot & + & + & REDUCED \\
\hline 16 & LR & r P-D & $\mathrm{nfot}$ & ++ & + & REDUCED \\
\hline 17 & $\begin{array}{l}\text { High density on site } \\
\text { sanitation }\end{array}$ & r P-D & $\mathrm{n}$ fot & + & ++ & ELEVATED \\
\hline 18 & Livestock rearing & r P-D & nfot & ++ & ++ & MODERATE \\
\hline 19 & Livestock rearing & r P-D & $\mathrm{nfot}$ & + & ++ & MODERATE \\
\hline 20 & LR & r P-D & nfot & + & ++ & REDUCED \\
\hline 21 & Livestock rearing & r P-D & nfot & + & ++ & MODERATE \\
\hline 22 & LR & r P-D & nfot & + & ++ & REDUCED \\
\hline 23 & Livestock rearing & r P-D & nfot & + & ++ & MODERATE \\
\hline 24 & Livestock rearing & r P-D & nfot & + & ++ & MODERATE \\
\hline 25 & Livestock rearing & r P-D & nfot & ++ & ++ & MODERATE \\
\hline
\end{tabular}

\begin{tabular}{|l|l|}
\hline 'LR - Limited risk identified in well surroundings & $\mathrm{P}$ (point) D (diffuse) \\
\hline${ }^{2}$ Discussed in detail in section 5.2.2 & $\mathrm{n}$ (nutrient compounds) $\mathrm{f}$ (faecal pathogens) o (overall organic load) t (toxic micro-organisms) \\
\hline $\mathrm{r}$ (rural) & + Increasing significance \\
\hline
\end{tabular}




\section{Summary}

This section summarised the key findings from sanitary inventory and inspections undertaken during the study period. By combining the variables affecting subsurface contaminant load potential, it can be concluded that a MODERATE to REDUCED level of hazard is present in the study site. Only Wells 6 and 17 were noted to have ELEVATED load potential due to their high population density and proximity of latrines. Due to low population density, minimal livestock activity and better sanitary condition, wells $1,9,11,15,16,20$ and 22 have REDUCED load potential. These categorisations will be used in section 5.3 to determine the risk of microbiological contamination of shallow groundwater. 


\subsubsection{Pathways to contamination}

To assess the pathways to contamination, data were collected on both meteorological and hydrogeological variables. These included continuous data in the forms of daily rainfall recording in two fixed locations during the 12-month study and monthly water level testing. Categorical data in the form of detailed hydrogeological surveys were also included. This section will firstly discuss the meteorological findings and then the hydrogeological findings.

\section{Meteorological Variables:}

Rainfall records were collected on a daily basis during the 12 months of study. Readings were recorded in intervals of $0.1 \mathrm{~mm}$ but are presented in this section to the nearest $1 \mathrm{~mm}$ (Brassington, 1998). The results indicate a similar pattern of rainfall to the previous 8 years. Figure 21 outlines the median rainfall from 1995-2003 compared to median results from the two rain gauges (Estação Agraria de Lichinga and Quinta Capriconia) set up and monitored for this research period 2003-2004.

An average annual rainfall of $1157 \mathrm{~mm}$ was recorded over the years 1995 to 2003 . During the study period, the rain gauges recorded comparable results of $1047 \mathrm{~mm}$ and $1042 \mathrm{~mm}$ in the Quinta and EAL rain gauges respectively. Highest rainfall was noted during the months of the monomodal rains (November - April) with peak rainfall recorded in January. During the study period, heavier than average rainfalls were noted in December 2003 with 252 and $297 \mathrm{~mm}$ recorded in Quinta and EAL as compared to averages from the previous 8 years of $173 \mathrm{~mm}$. Rains were also more continuous during the study period with higher than average rainfall during the month of April.

Periods of extended heavy rainfall were noted between the 15th November and the 7th December, the 13th of December and 29th January and 4th to the 25th February. Highest rainfall was noted in November 15th at $20 \mathrm{~mm}$ in 24 hours, December 13th at $76 \mathrm{~mm}$ in 24 hours, January 19th, 29th at 80 and $44 \mathrm{~mm}$ and February 23rd at $54 \mathrm{~mm}$. Source errors were recognised during collection of rainfall data. These included:

- Variable collection times

- Scale reading errors

- Rounding off results to nearest $\mathrm{mm}$ 
In line with recommendations from Freeman, a scale reading error of \pm 0.2 times the smallest division of the scale was used as error margins to all readings (see Figure 21). For further analysis in section 5.3, average values for rainfall will be used.

Figure 21: Median rainfall

Median rainfall data (1995-2003) compared to rainfall (2003-4)

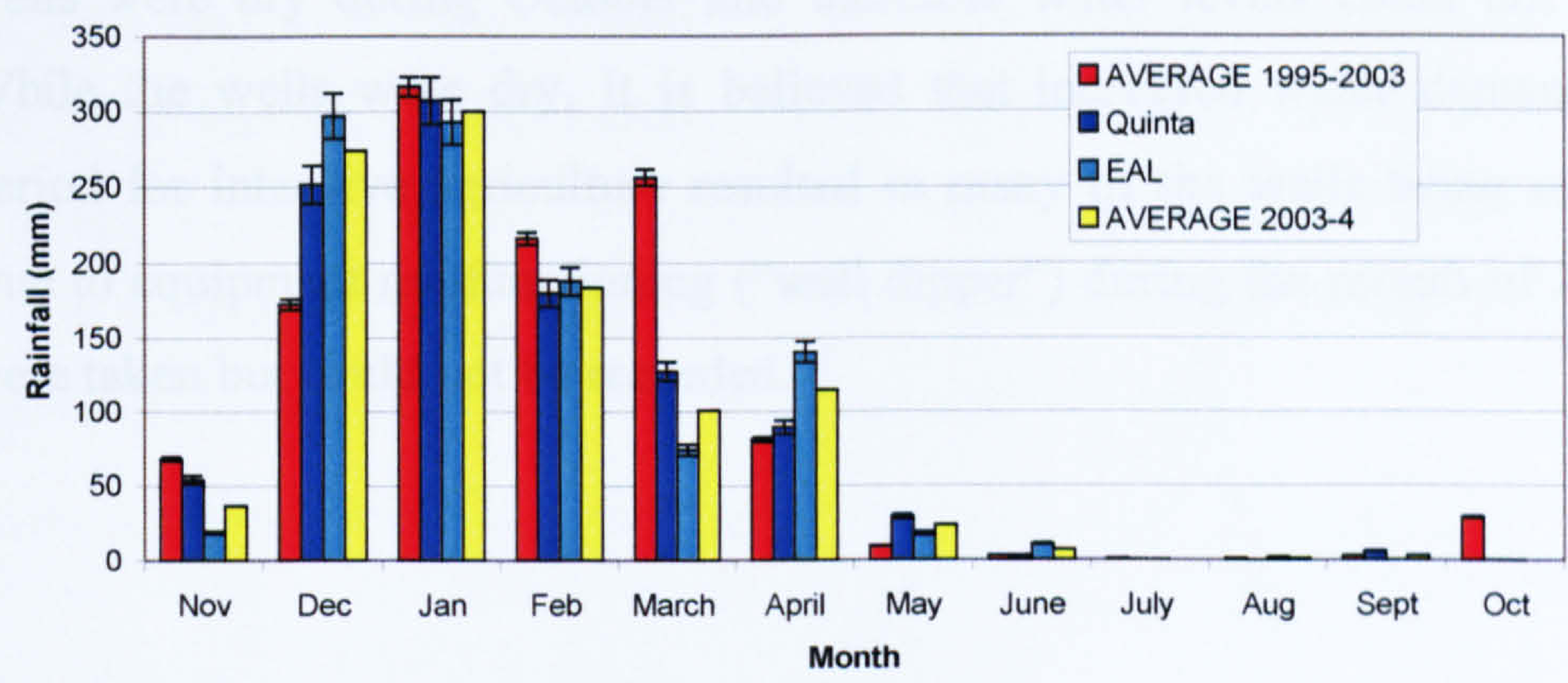

\section{Depth to Water Table}

Monthly water table readings were taken using a water level dipper. These were taken once per month on the same day as the water quality sample. Figure 22 outlines summary findings for wells located in the three geographical areas of the study (namely Nomba, Lulimile and Ceramica). As noted in Figure 22, deeper groundwater levels of between 8-10mbg were recorded in Lulimile than in Ceramica and Nomba, showing almost identical variations in groundwater levels during the study period.

Figure 22: Groundwater levels

\section{Comparison of average groundwater levels in Nomba, Lulimile and Ceramica (2003-4)}

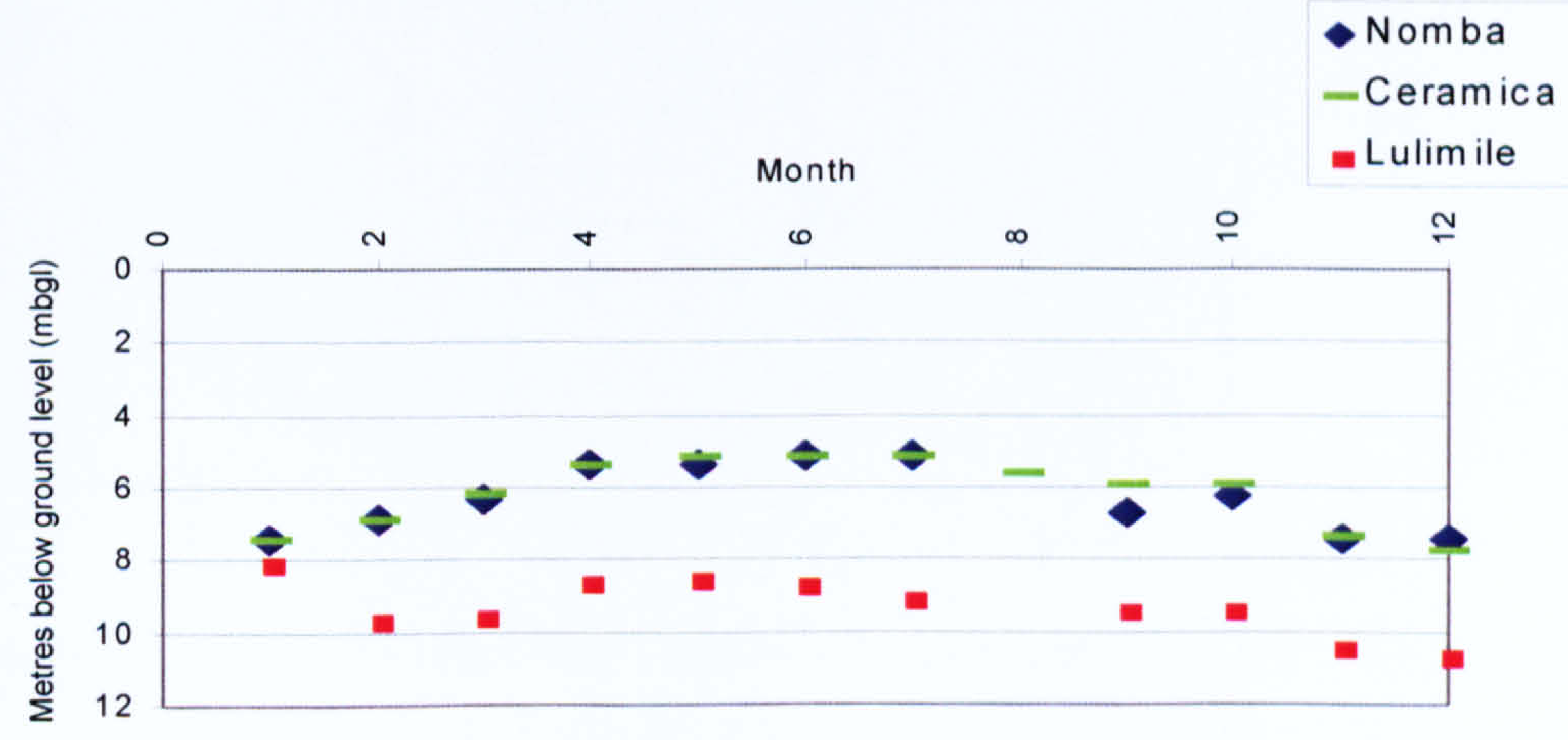


Naturally, seasonal fluctuations in the depth to the water table were noted. During the rainy season increased recharge results in shallow water levels during the months of April and May at $5.1 \mathrm{mbgl}$ at both locations. During the drier period, the water level drops to below $7.5 \mathrm{mbgl}$. Lowest recorded levels were noted in Well 13 (Traditional well owned by Luisa Juliasse) where levels dropped to $8.62 \mathrm{mbg}$ in October. In total 8 wells were dry during October and therefore water levels could not be collected. While the wells were dry, it is believed that increased water demand during this period for intensive agriculture resulted in many of the wells being over exploited. Due to equipment malfunctioning ("well dipper") during the month of June, readings were taken but could not be recorded. 


\section{Hydrogeological Variables}

The following methods were used to collect data on hydrogeological variables:

- Desk review

- Sub soil field descriptions

- Soil Particle Distribution analysis

- Geological survey (CCTV Borehole camera)

The desk review revealed limited data on the hydrogeological situation in Lichinga. Due to the underdeveloped nature of the town, limited investment has been made to map, log or record hydrogeological data. The only substantial available data were from a geological map dating to the Portuguese colonial period (see Figure 23 Lichinga is named as Vila Cabrel and highlighted in blue).

Figure 23: Geological Map of Mozambique

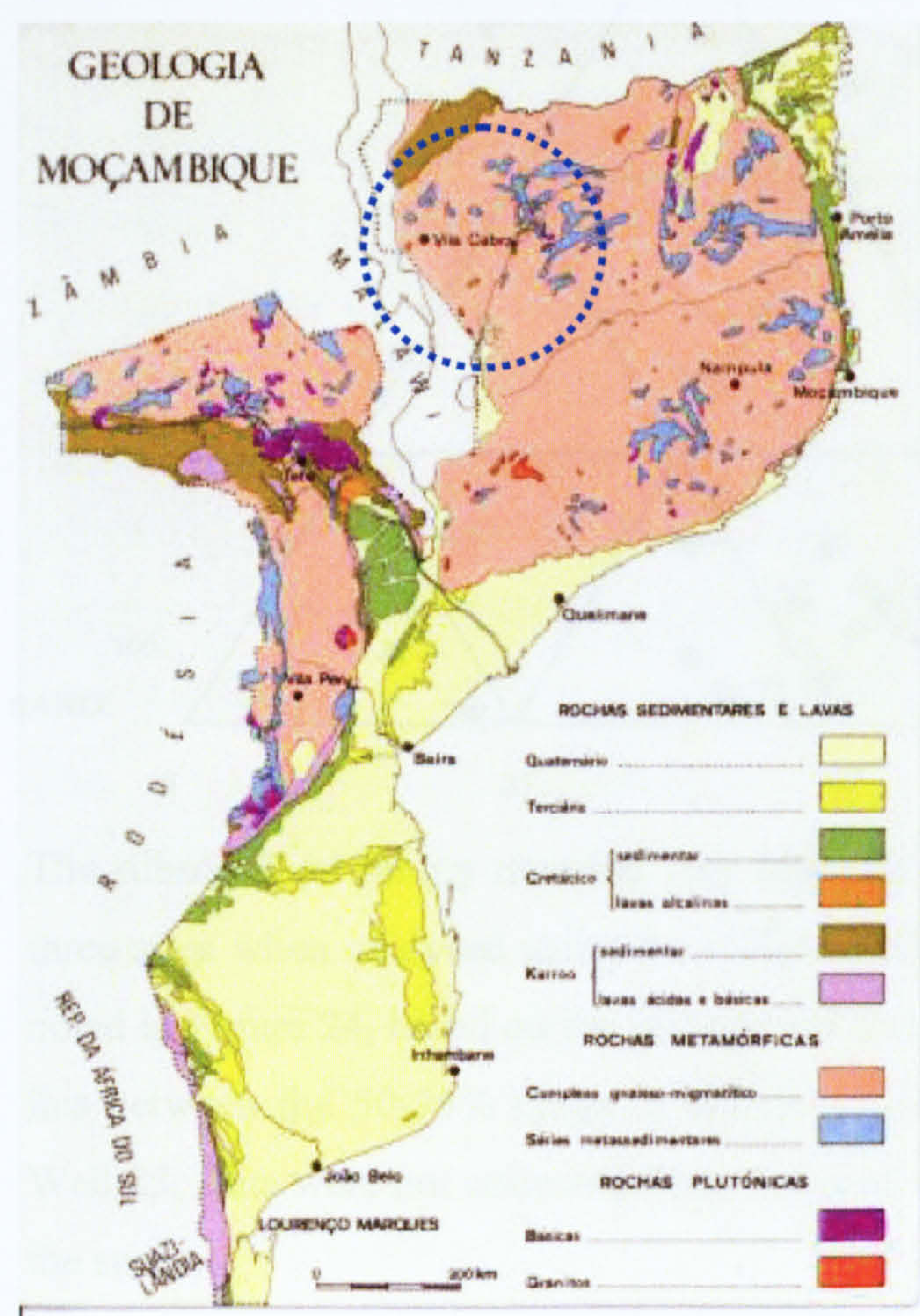

(Source: WaterAid)

The geological map indicates that Lichinga is underlain by metamorphic rock with overlying alluvial drift. Due to limited data on the hydrogeology of the area, subsoil 
field investigations were undertaken using the CIBAGEIGY classification method and soil particle distribution analysis. Findings of the soil particle distribution analysis are outlined in the ternary diagram in Figure 24: Readings for samples taken at $0.5 \mathrm{mgl}$.

\section{Figure 24: Soil Ternary diagram}

Illustrates range of particle sizes within the three study sites (Depths of 1 to $10 \mathrm{~m}-$ refer to Table 22 for detail for each geographical area)

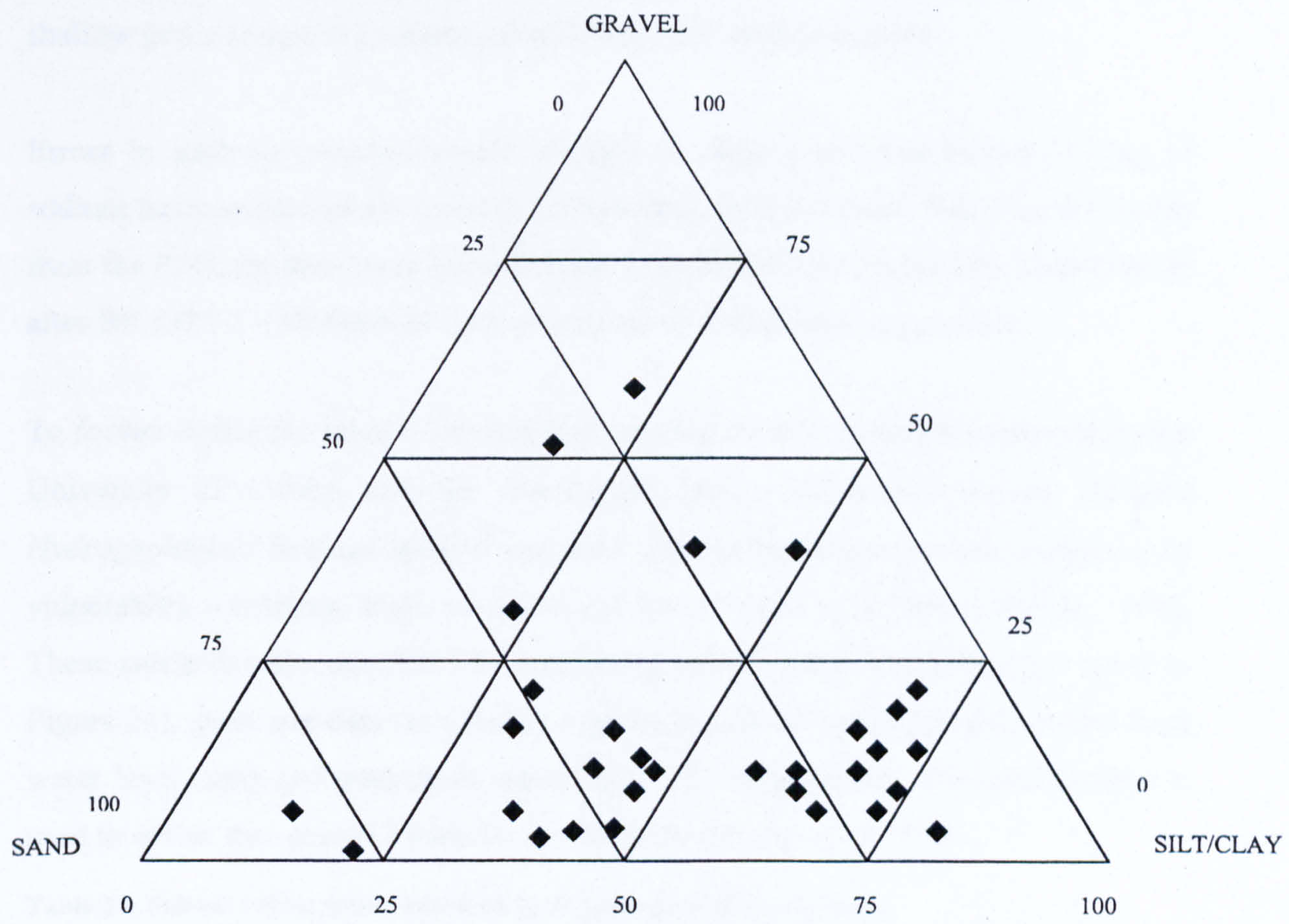

The subsoil field survey revealed very high silt and clay content in samples from all three sites when analysed using the CIBAGEIGY method (CIBAGEIGY, 1986). As noted in Figure 24, based on the soil particle size analysis, the greater size distribution lies between the 50-75\% range of silt/clay. Loamy sand was noted in Well 10 and Well 25. Data were not collected from Wells 18 and 19 as the owner denied access for the study.

Further findings from subsoil analyses using Particle Size Distribution (PSD) analysis for each of the three study areas are outlined in figure 26. The figure indicates similar grading curves in Nomba and Lulimile with slight variations in Ceramica. Medium 
clay percentages $(41 \%, 46 \%$ and $47 \%)$ in Ceramica, Nomba and Lulimile were noted. Very high fine sand/silt content was noted in all three samples with limited percentages of coarse materials. The $K$ permeability value for each of the samples suggest a moderate to low permeability range at $10^{-4}-10^{-8} \mathrm{~m} / \mathrm{s}$ (see Table 20 below). The medium to low permeability of the subsoil surrounding the well will limit the ingress of microbiological contaminants forcing higher attenuation and greater die off of pathogenic microorganisms. This in turn will reduce the vulnerability of the shallow groundwater to contamination through sub surface ingress.

Errors in analysis included erratic sunlight for drying and inconsistent mixing of sodium hexametaphosphate (used as a dispersant) in tepid water. Based on the results from the PSD, the soils were classified using the British system for Soil Classification after BS 1377-2 - Methods of tests of soils for civil engineering purposes.

To further define the subsoil vulnerability, an adaptation of methods developed by the University of Dublin and the Geological Survey of Ireland termed Adapted Hydrogeological Settings Method was used. The method considers four categories of vulnerablity - extreme, high, moderate and low (Swartz et al. 2003, Robins, 1998). These categories are calculated by combining subsoil field descriptions (as noted in Figure 24), grain size data (as noted in Figure 25), subsoil thickness (determined from water level data) and qualitative estimates of soil permeability. The permeability is used to define the specific hydraulic conductivity (Swartz et al. 2003).

Table 20: Subsoil vulnerability based on hydrogeological characteristics

\begin{tabular}{|c|c|c|c|c|}
\hline \multicolumn{5}{|c|}{ Hydrogeological Characteristics } \\
\hline \multirow[t]{2}{*}{$\begin{array}{c}\text { Subsoil } \\
\text { Thickness (m) }\end{array}$} & \multicolumn{3}{|l|}{ Subsoil Permeability } & \multirow{2}{*}{$\begin{array}{l}\text { Unsaturated Zone } \\
\text { (sand/gravel aquifers only) }^{2}\end{array}$} \\
\hline & $\begin{array}{l}\text { High Vulnerability } \\
\text { (e.g. Gravel/Sand) }{ }^{1}\end{array}$ & $\begin{array}{l}\text { Medium Vulnerability } \\
\text { (e.g. Sand, Sandy Silt) }{ }^{1}\end{array}$ & $\begin{array}{l}\text { Low Vulnerability } \\
\text { (e.g. Clay, peat) }^{1}\end{array}$ & \\
\hline $0-3$ & Extreme & Extreme & Extreme & Extreme \\
\hline 3-5 & Extreme-High & High & High & - \\
\hline $5-10$ & High & High-Moderate & Moderate & High \\
\hline$>10$ & Low -High & Moderate & Low & - \\
\hline
\end{tabular}

(Source: Swartz et al 2003)

\footnotetext{
'Example description based on BS5930

${ }^{2}$ Thickness of the unsaturated zone is only considered for sand/gravel aquifers such as Lichinga
} 
Figure 25: Coefficient of permeability $(\mathrm{m} / \mathrm{s})$

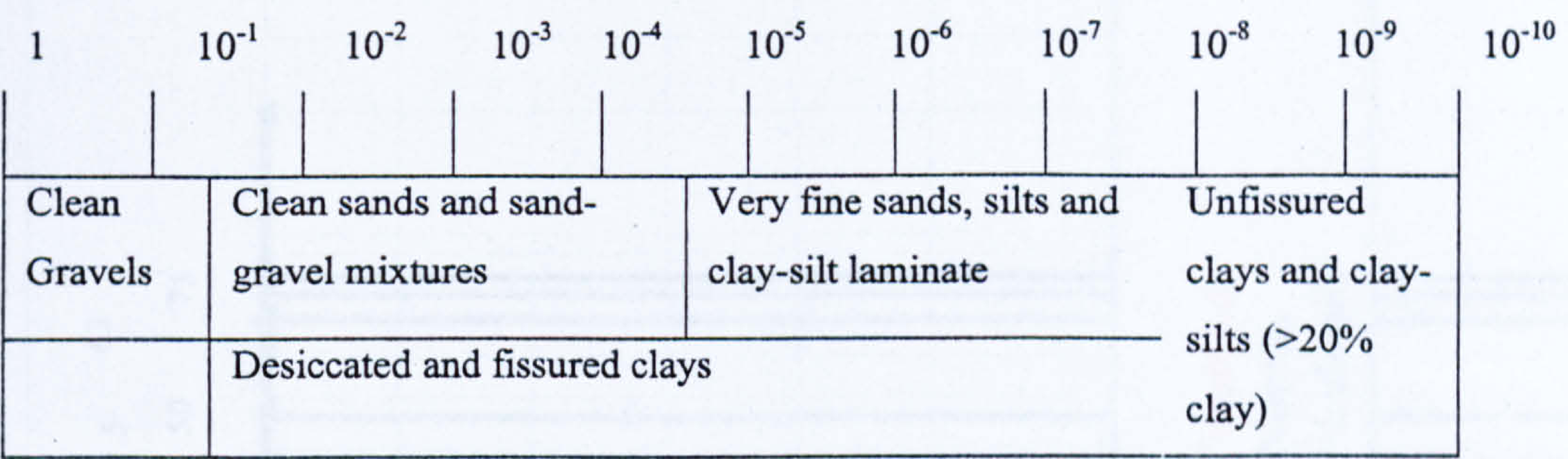

(Source: Swartz et al 2003)

Although the Hazens method was considered, the author selected definitions from Swartz et al to define permeability. This was due to both the high fraction of fine sands and clay in the sample and the smaller sample size (100g as opposed to the standard 200g soil sample) used for the particle size distribution analysis (BS1377-2, 1990). The difference in sample weights requires an error margin which is best interpreted using the modified Swartz method. The categorisations of permeability outlined in table 20 and table 21 were therefore applied to the study sites in table 22 (Craig, 1995).

Figure 26: Particle Size Distribution analysis for Lichinga. 

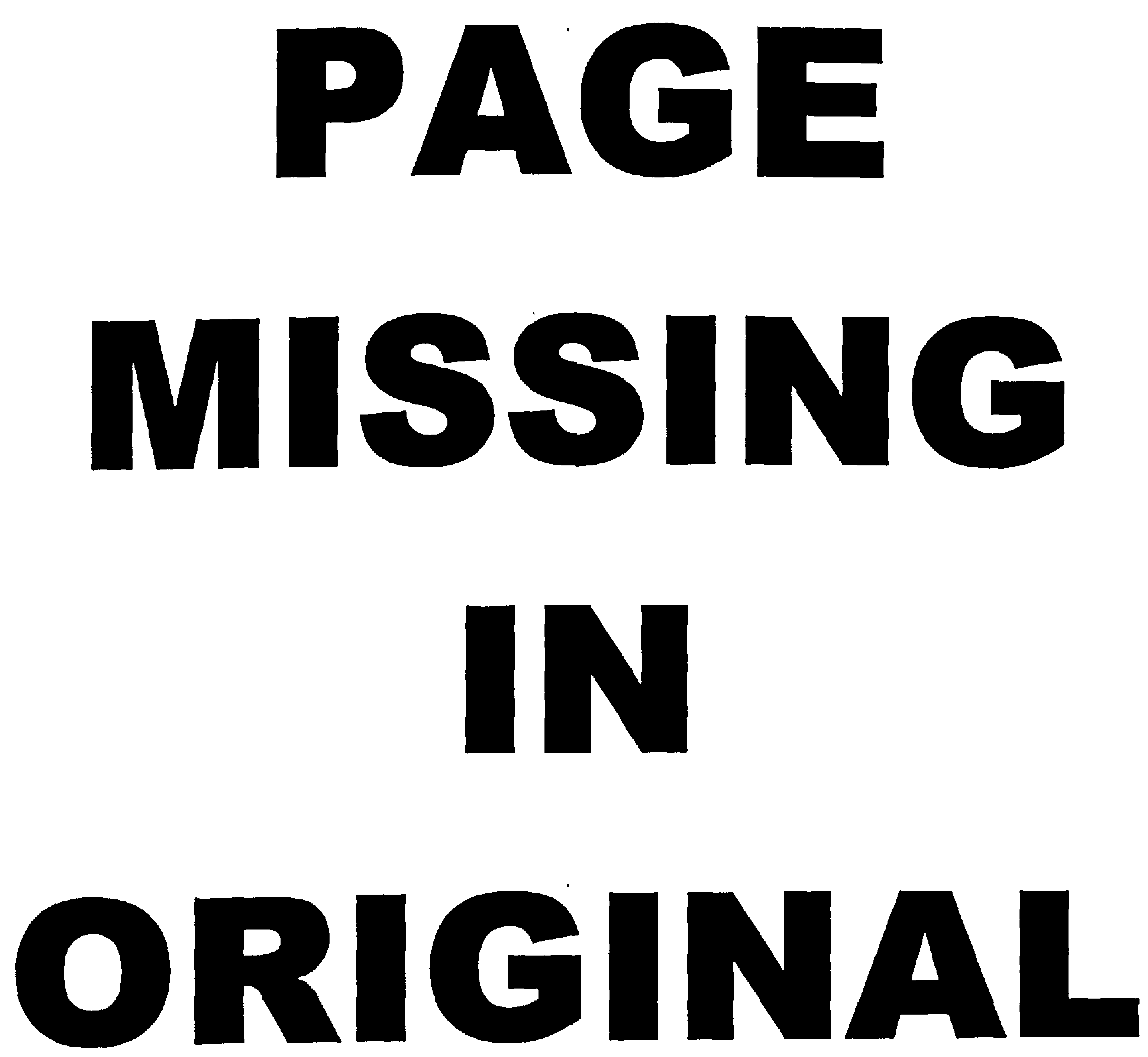


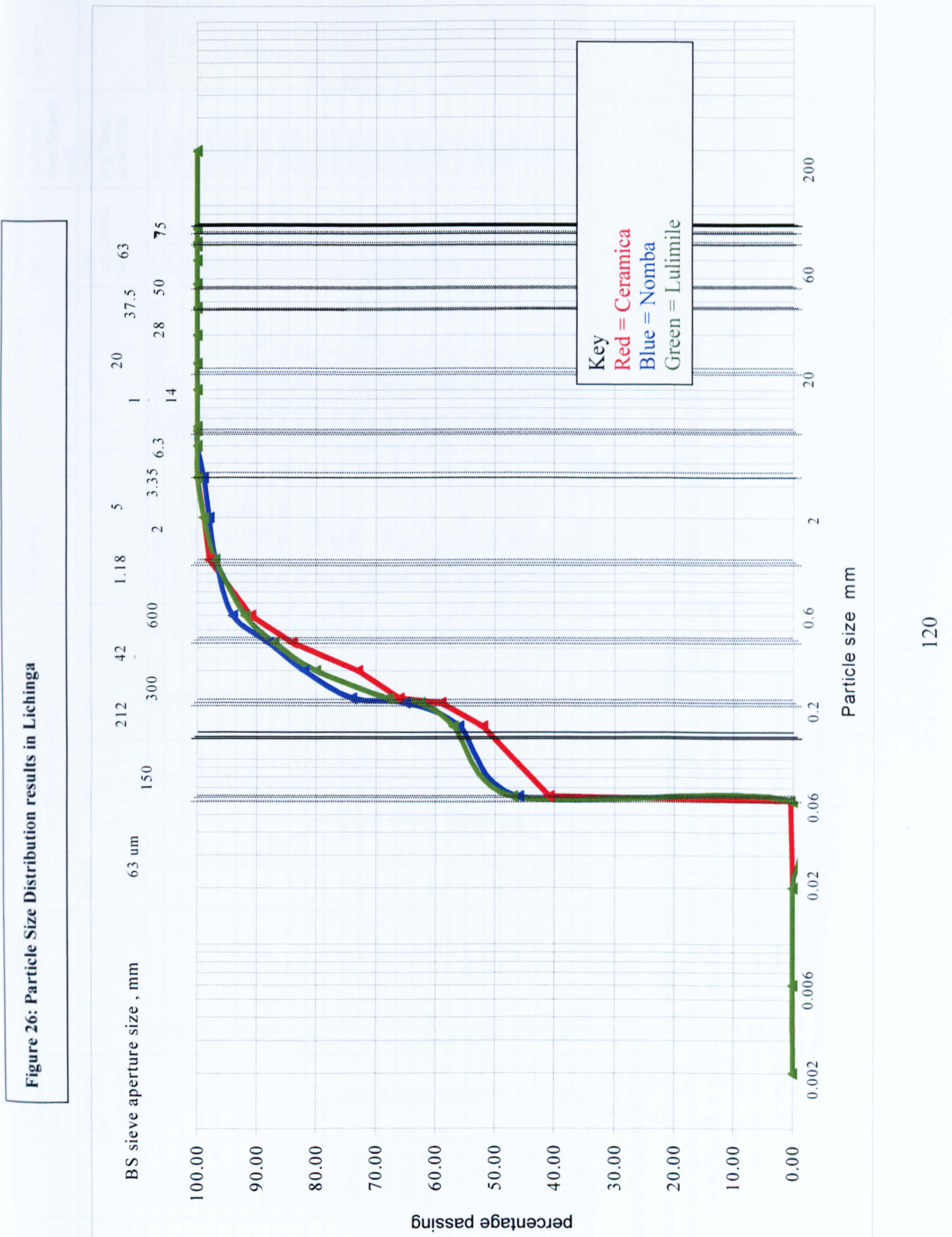




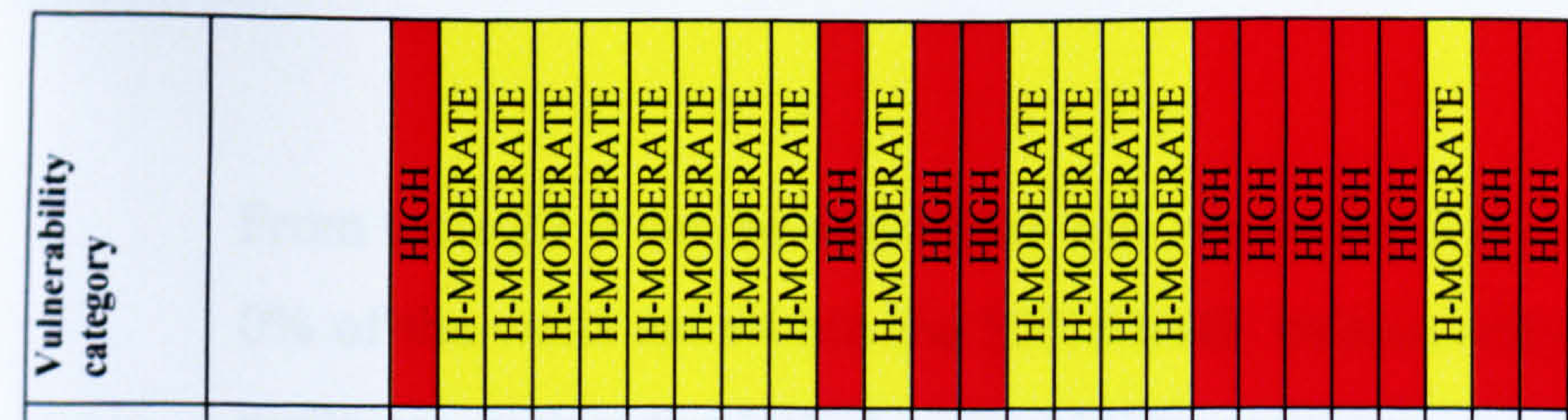

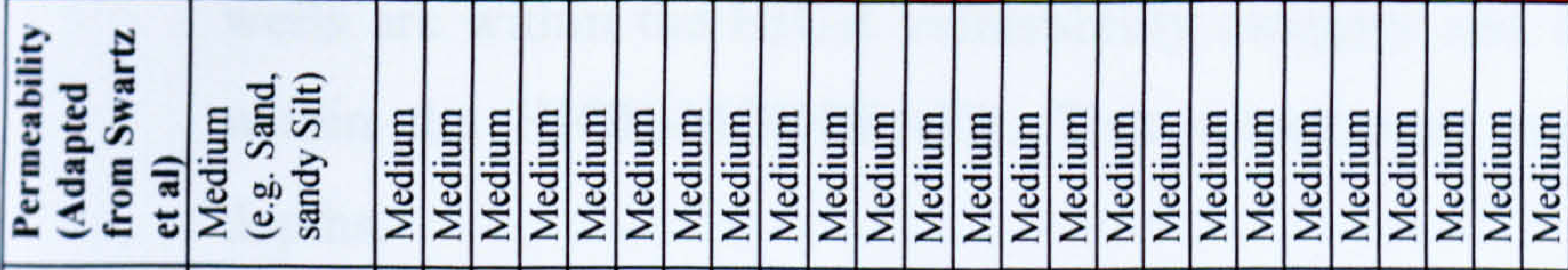

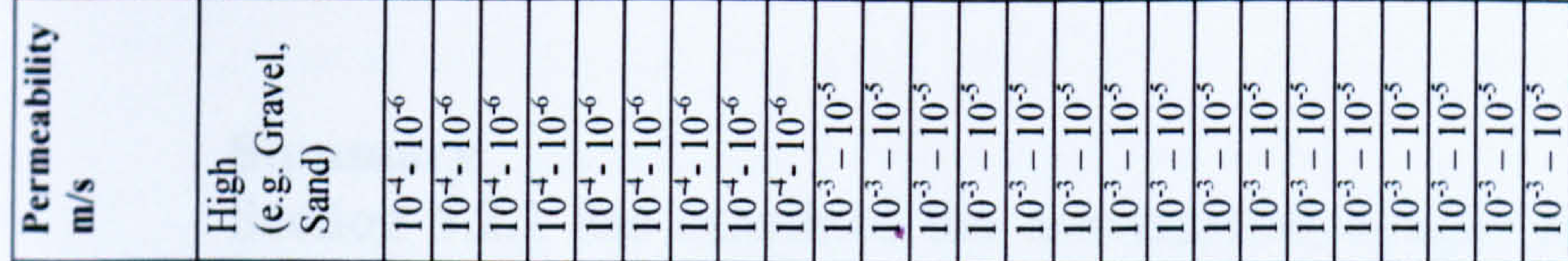

高

킁 틍

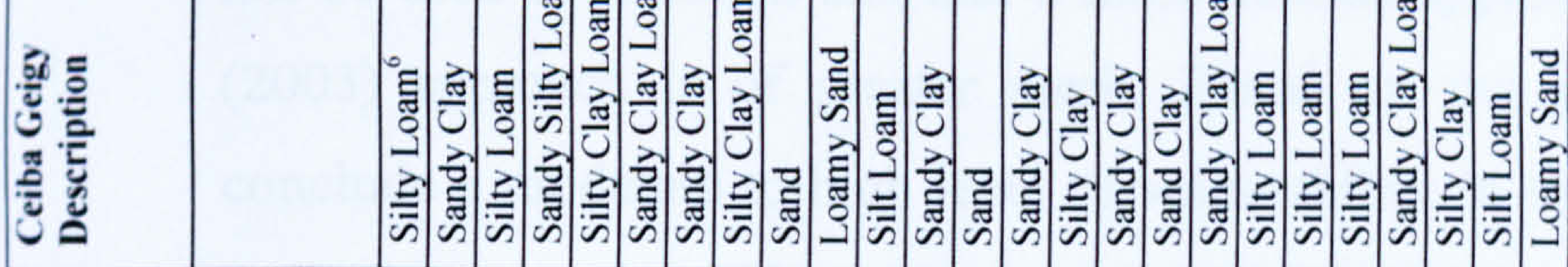

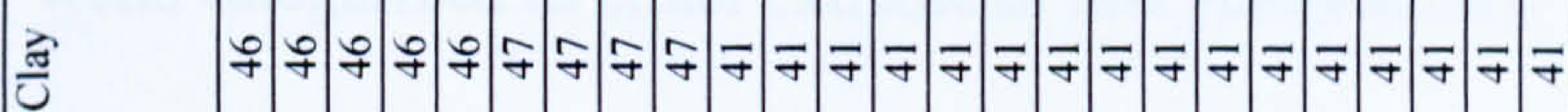

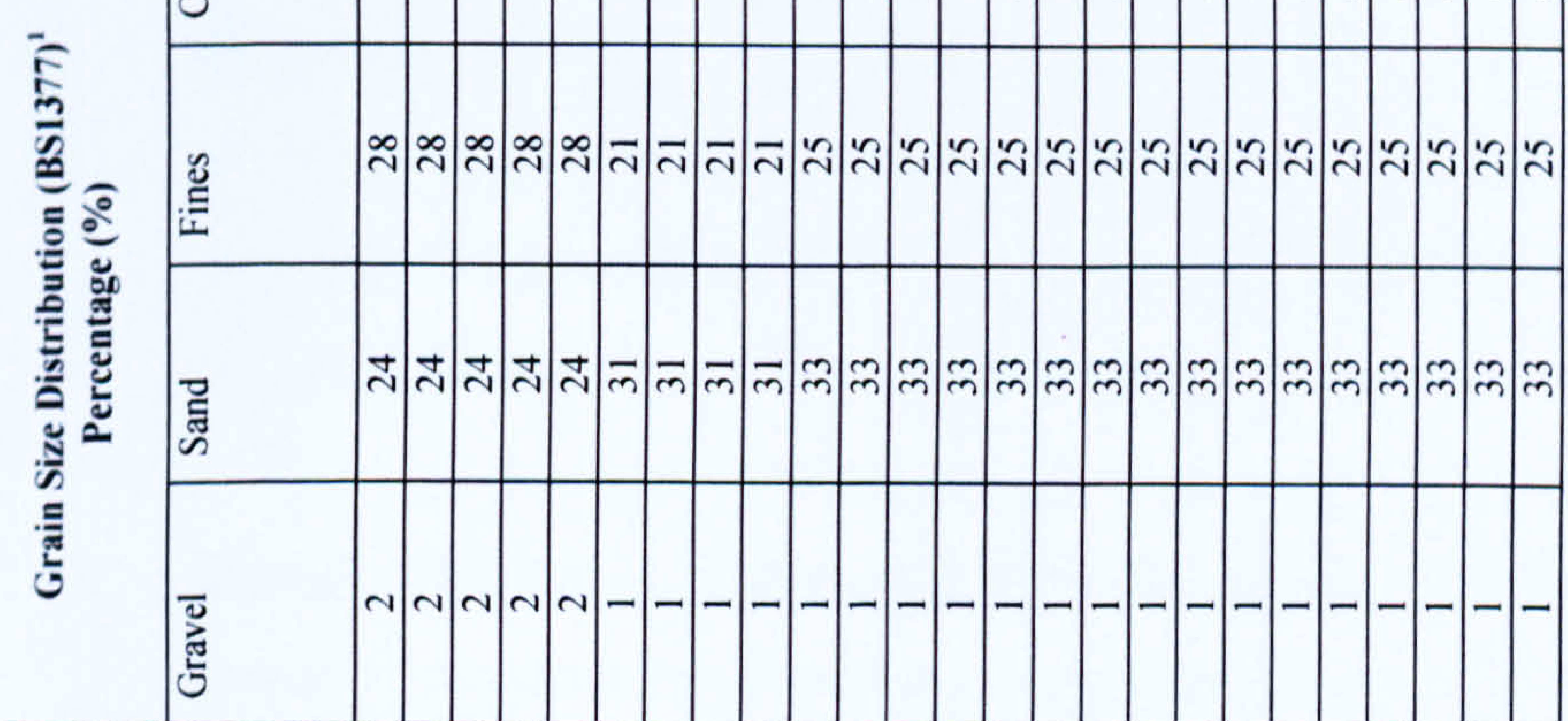

五

(1)

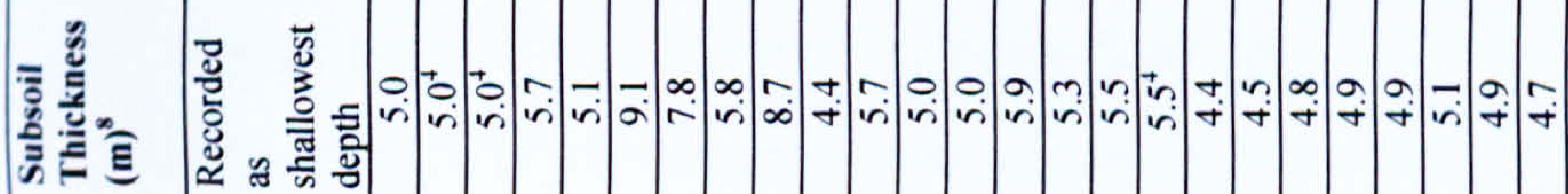

\begin{tabular}{|c|c|c|c|c|c|c|c|c|c|c|c|c|}
\hline 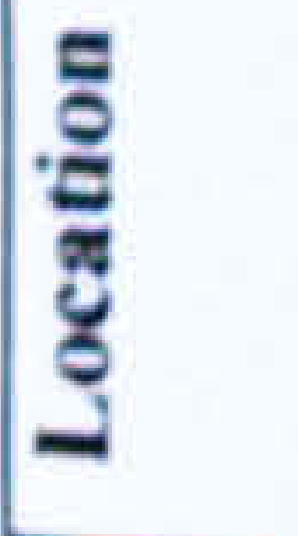 & 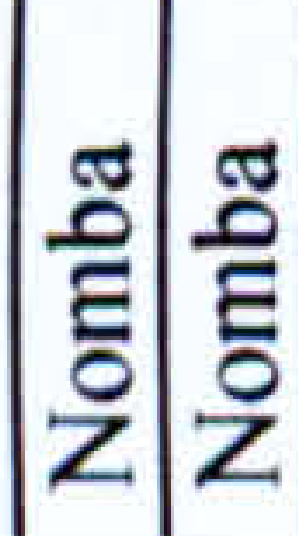 & & 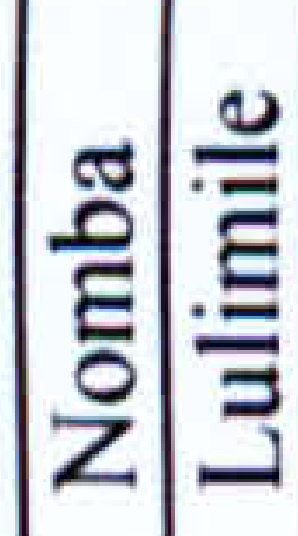 & & 章 & : & \begin{tabular}{c|c}
0 \\
0 \\
0
\end{tabular} & 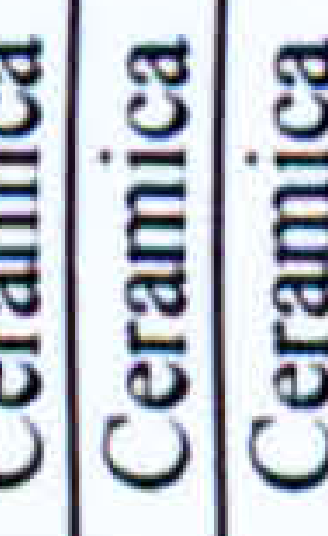 & 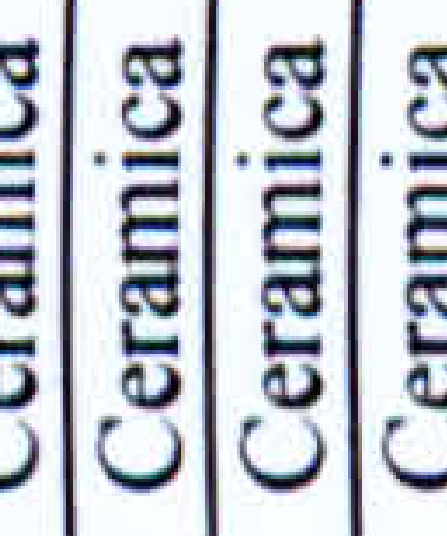 & 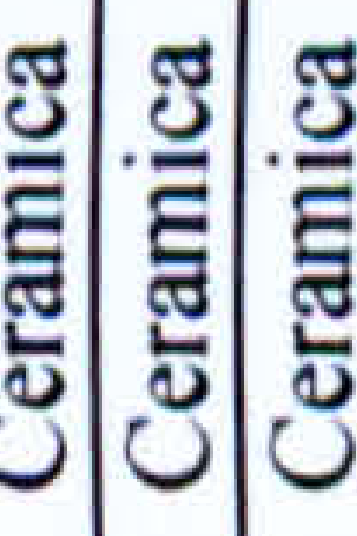 & 仓ี & 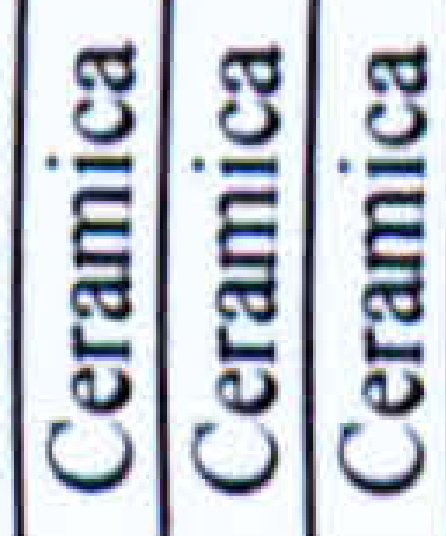 \\
\hline$\overline{\bar{g}}$ & & & & & & & & & & & & $\vec{N}: \mathscr{N}$ \\
\hline
\end{tabular}

言

ถูํำ

党

约

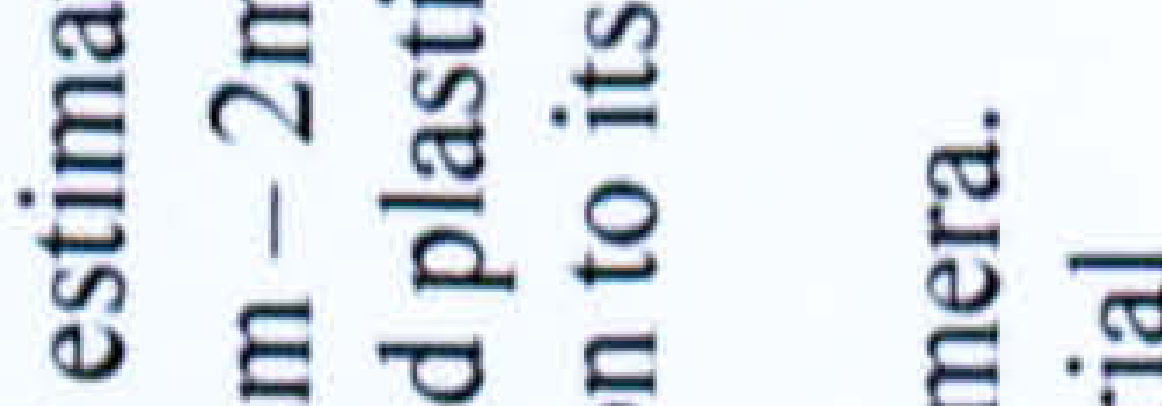

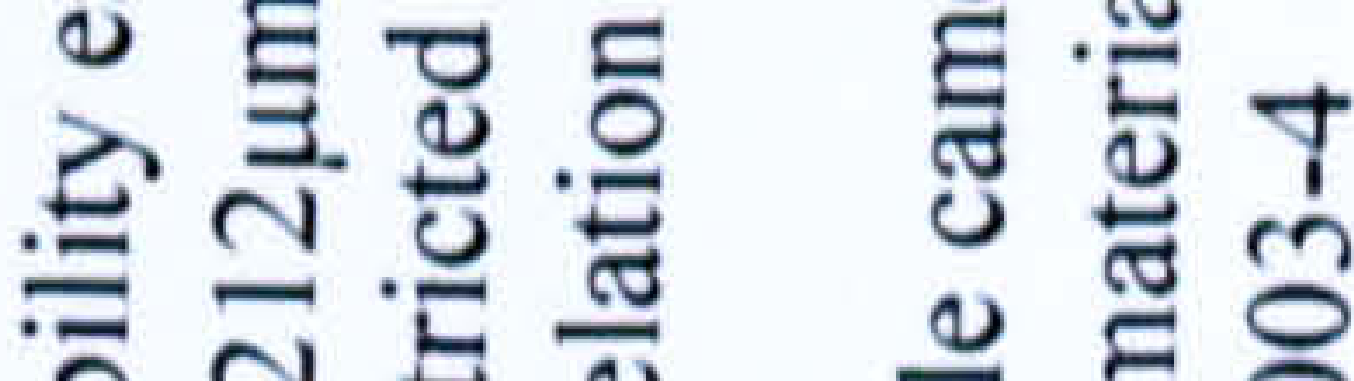

व

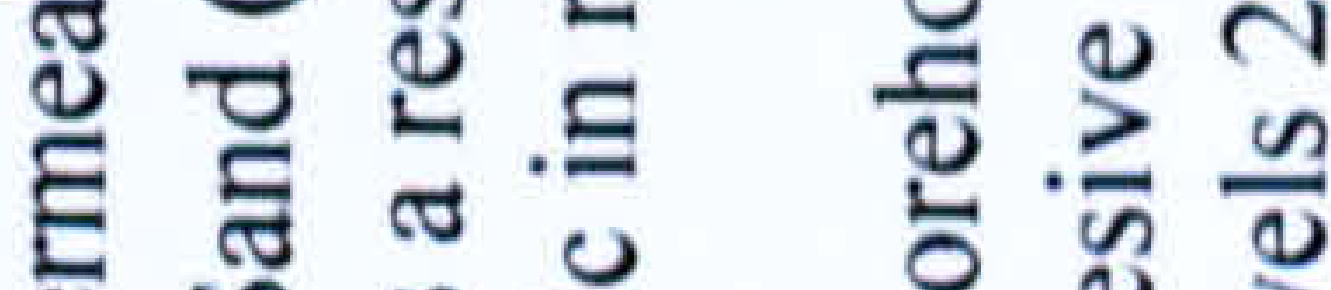

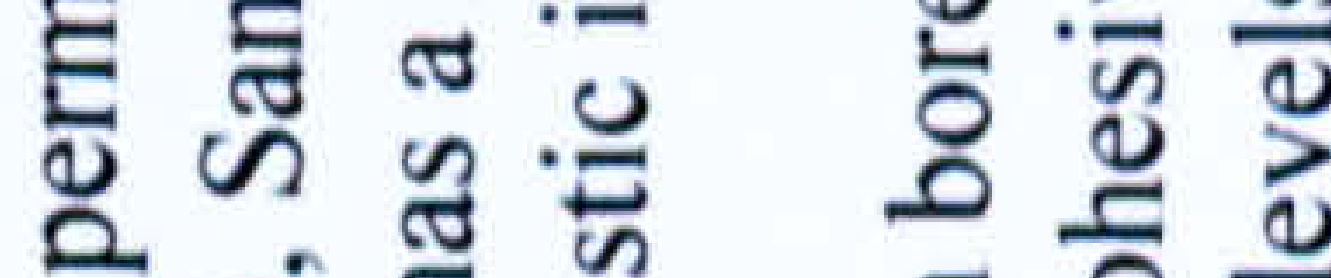

믈

ส है

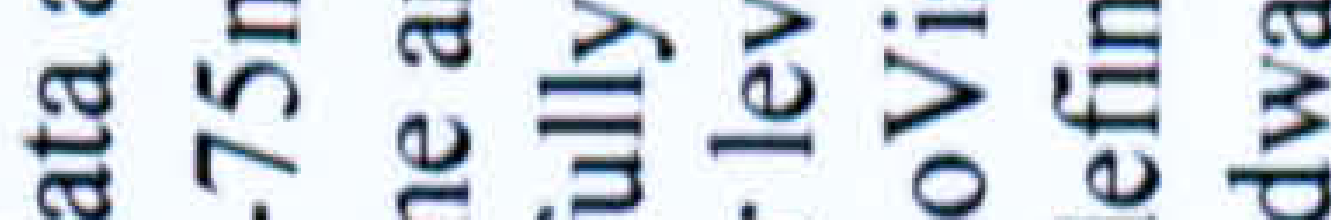

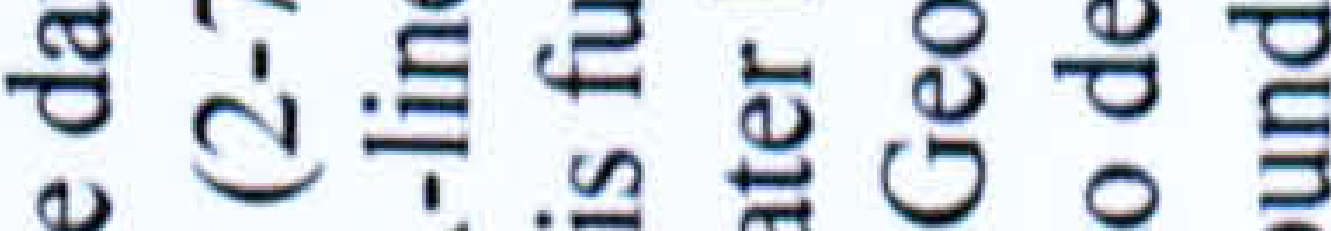

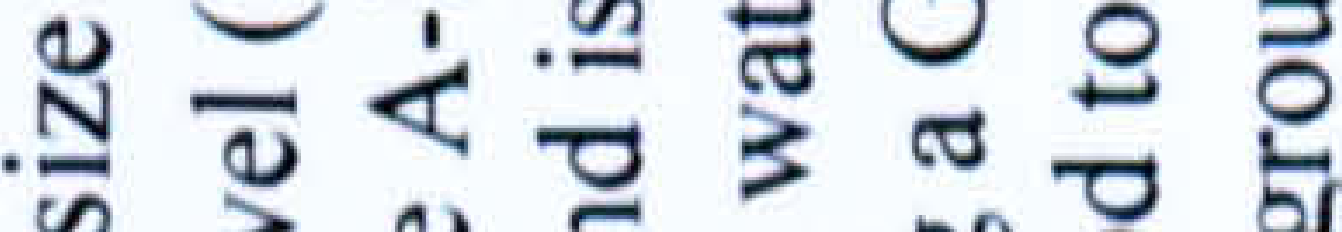

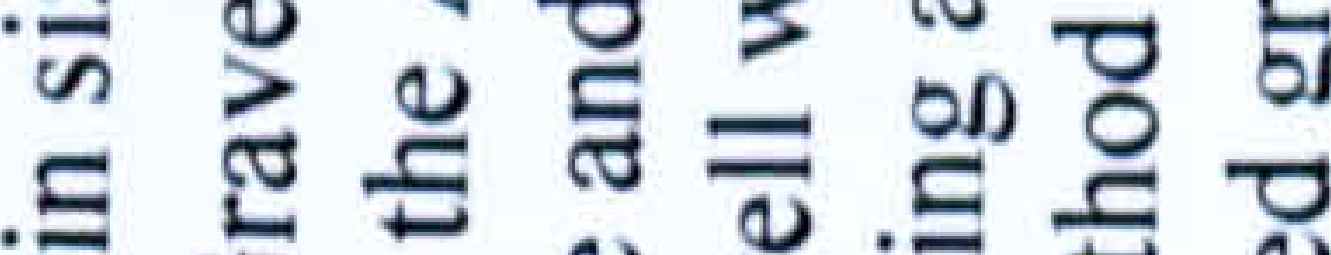

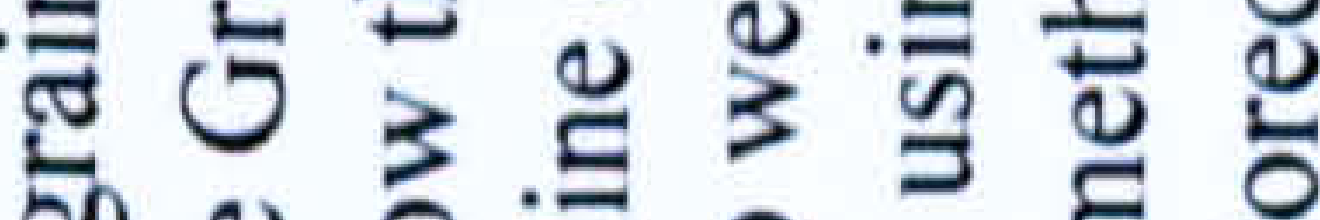

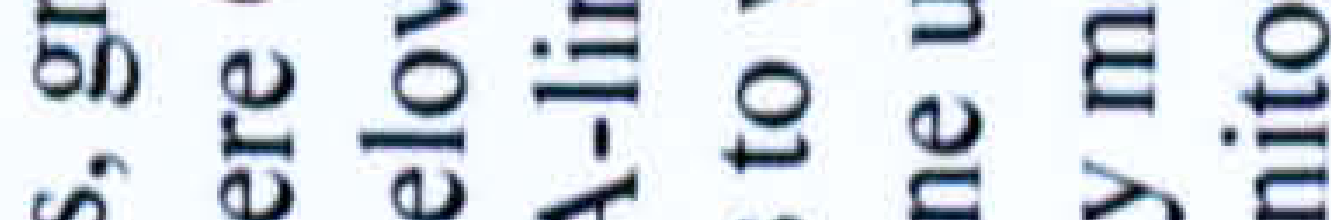

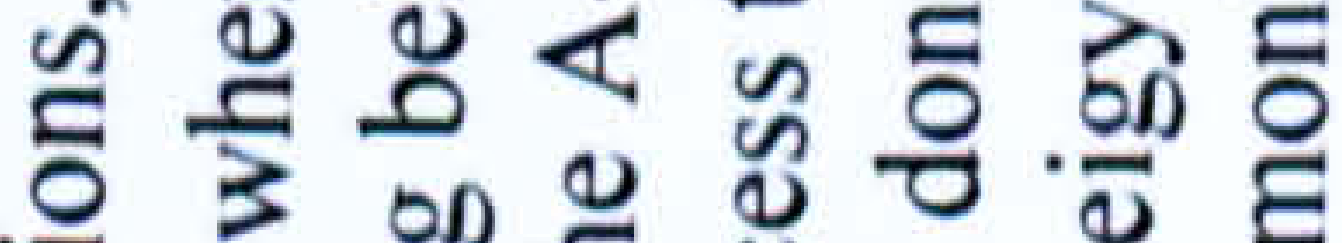

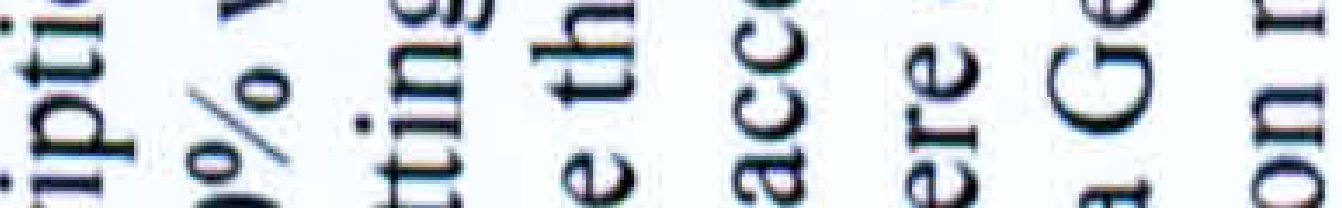

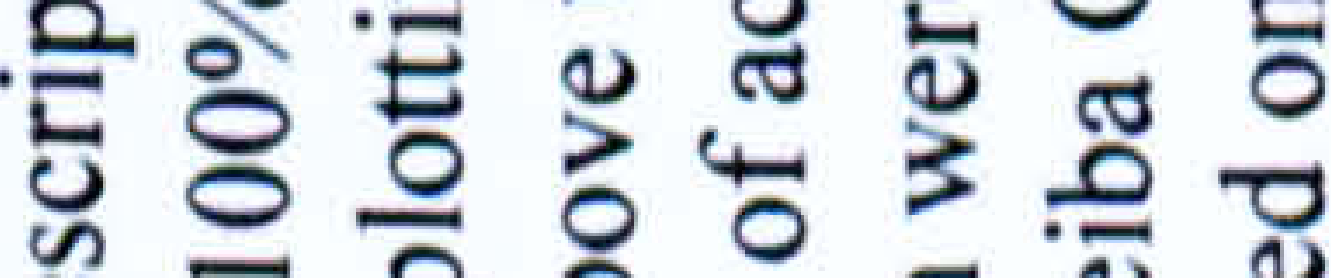
능

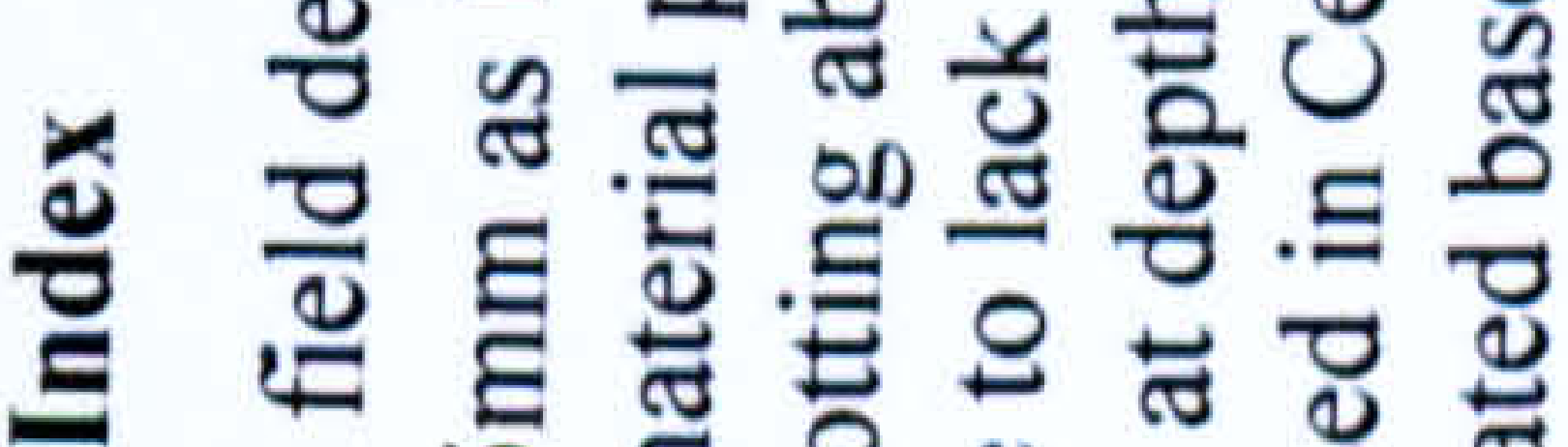
ว

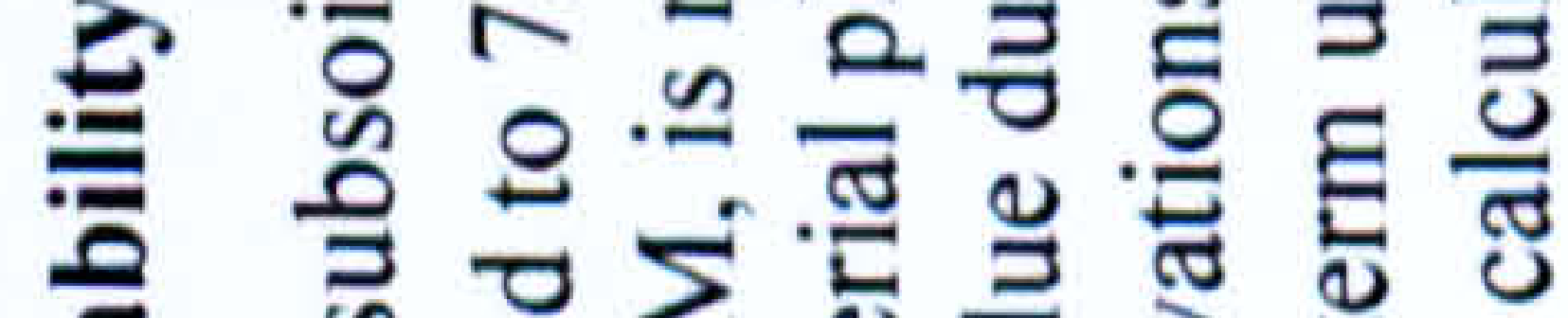

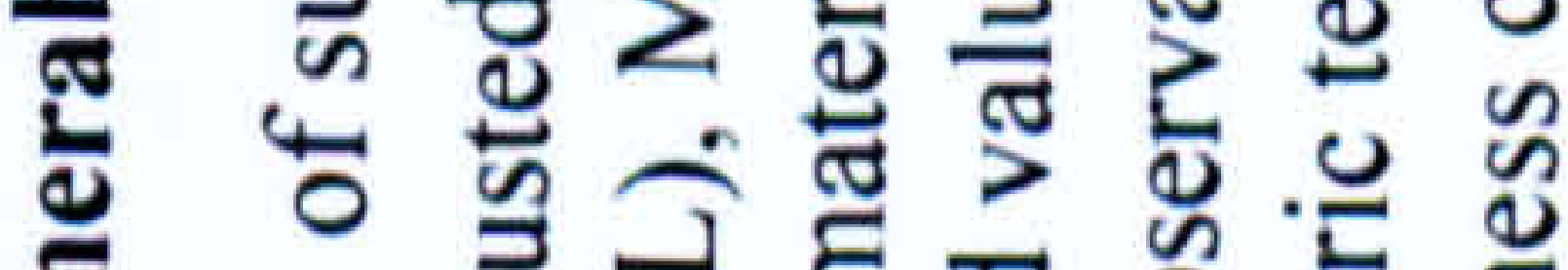

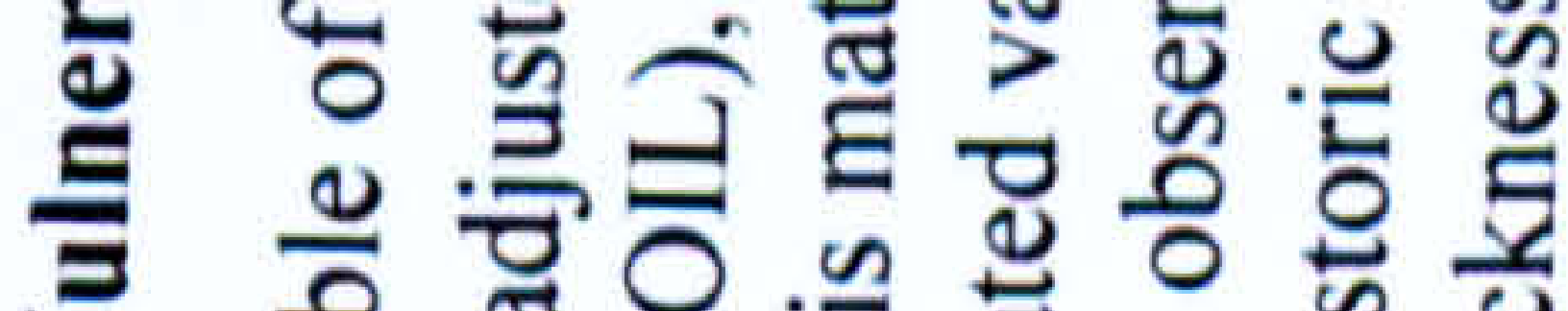

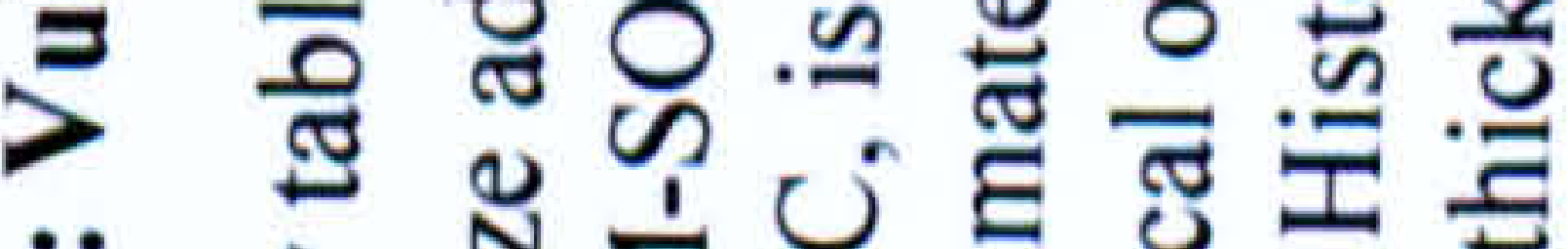

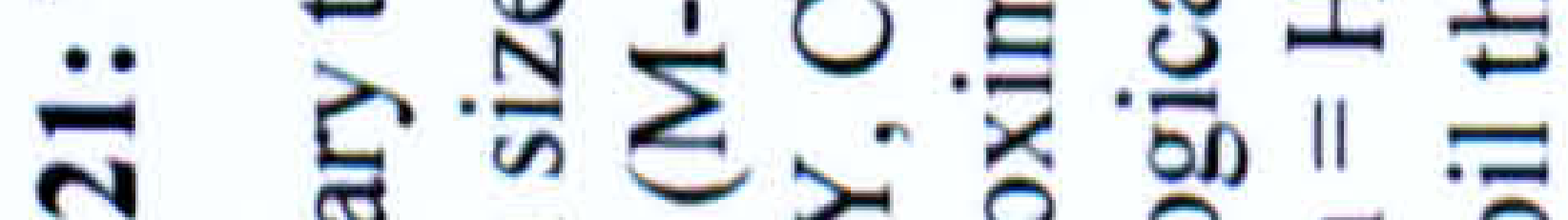

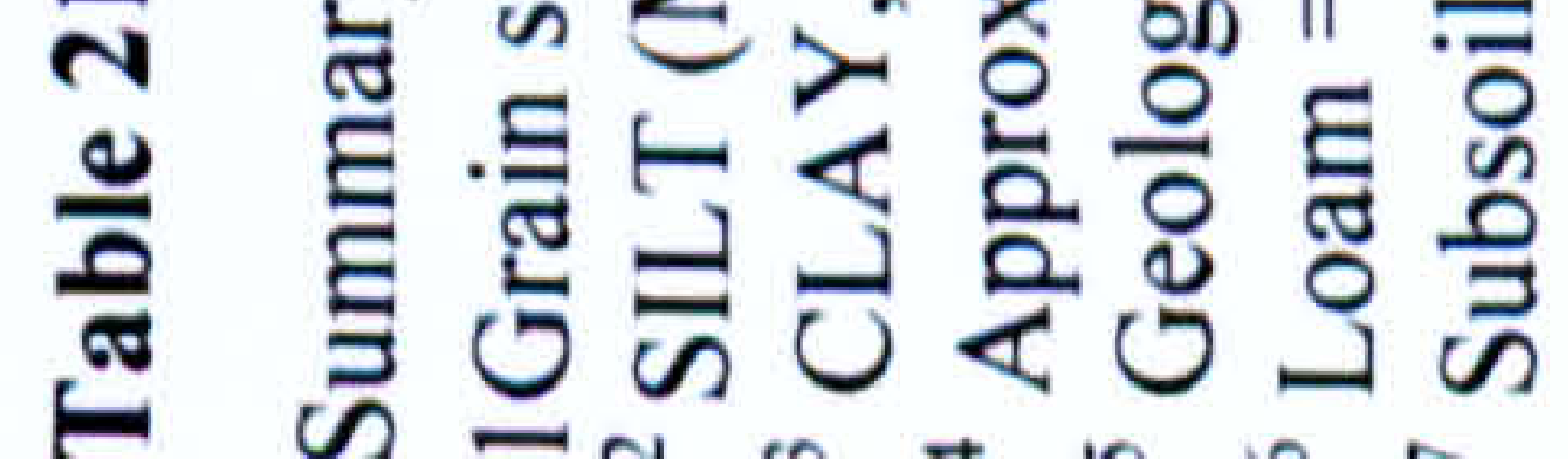


From table 22 it can be concluded with respect to soil conditions for the pathway that $0 \%$ of the wells are within the EXTREME vulnerability category. Eleven (11) of the wells are within the HIGH vulnerability category and fourteen (14) of the wells are within the HIGH-MODERATE. This corresponds with the shallow groundwater depths.

\section{Summary}

Section 5.2.2 has examined the conventional aquifer pathways to contamination of shallow groundwater considering factors such as rainfall, subsoil thickness, depth to water level, soil permeability and distance from source to receptor. Due to time and financial constraints, additional factors such as ambient temperature of soil microbes relative to physiologic temperature and specific porosity could not be researched. Literature however suggests that the use of any one indicator of vulnerability should not be used in isolation and that a more holistic approach such as the Swartz et al. (2003) approach is of greater merit. Based on the soil conditions, the findings conclude a moderate to high level of vulnerability in the selected well sites with no wells categorized as either extreme or low vulnerability. 


\subsubsection{Receptor to contamination}

Conventionally, hydrogeologists assess risk to groundwater based on pollutant source loading and vulnerability of aquifer pathways. This research also assesses the influence of the receptor in minimizing risk through localized pathways (e.g. shortcircuiting through the wellhead protection zone). The wellhead is defined in this context as the pipe and well structure, as opposed to the larger capture zone, where ingress of contaminants from diffuse surface faecal sources occurs due to poor workmanship through poorly sealed annuli of boreholes and cracks in surface aprons. The more effective the receptor is as a barrier, the fewer the localised pathways of contamination. To assess the risk of localised pathways through the barrier, this section will outline results from qualitative data collection from wellhead inventories and quantitative data from non-destructive tests on surface hardness.

\section{Well head inventory}

As noted in Chapter 3 the wellhead in this research is defined as "the underground and overground construction of the abstraction facility as well as the immediate area surrounding the abstraction point" (Howard et al. 2005). Inventories of the wellhead included:

- Qualitative visual examination

- Visual inspections

- Non destructive surface hardness tests

Designs outlined in Watt et al. (1979) and Collins (2000) were used to define standard codes of construction. Based on recommendations in Watt et al. (1979), wellhead can be divided into three components: the intake, the shaft and the headworks. Adequate data were obtained from fieldwork on the condition, type and quality of construction of the headworks. However, due to the limited accessibility of underground sections of constructed wells, limited data were collected for the shaft and the intake. To generate this data, alternative methods of data collected using the Analytic Hierarchy Process (AHP) based on expert judgement were used. Before discussing the AHP, this section will firstly outline findings from fieldwork associated with the headworks and then findings from the application of the AHP to the well intake and shaft. 


\section{Headworks}

Data were collected on the design and quality of workmanship of each well as well as the type and condition of the extraction (pumping) mechanism. Data were compared to both standard recommended design criteria and the authors' experience of apron construction outlined in Table 23 . Table 23 below outlines some key design criteria

Table 22: Wellhead design criteria

\begin{tabular}{|c|c|c|c|}
\hline $\begin{array}{l}\text { Wellhead } \\
\text { design }\end{array}$ & Category & Design Criteria & References \\
\hline \multirow{14}{*}{ Wellhead } & \multirow{12}{*}{$\begin{array}{l}\text { Workmanship } \\
\text { Design }\end{array}$} & $1.3 \mathrm{~m}$ sanitary seal of $50-100 \mathrm{~cm}$ wide & (Watt et al. 1979) \\
\hline & & $\begin{array}{l}\text { Headworks } 0.8 \mathrm{~m} \text { above ground level (open } \\
\text { with windlass) }\end{array}$ & (Collins, 2000) \\
\hline & & $\begin{array}{l}\text { Headworks } 0.2 \mathrm{~m} \text { above ground level (capped } \\
\text { with handpump) }\end{array}$ & (Collins, 2000) \\
\hline & & Apron foundation (clay/cement) & $($ Oxfam, 1998) \\
\hline & & Well cover of $15 \mathrm{~cm}$ thick & (Watt et al. 1979) \\
\hline & & Minimum $50 \times 50 \mathrm{~cm}$ inspection cover & (Watt et al. 1979) \\
\hline & & $\varnothing$ Apron $\geq 3 \mathrm{~m}$ diameter & $($ Oxfam, 1998) \\
\hline & & Drainage channel $=23 \mathrm{~m}$ in length & (Collins, 2000) \\
\hline & & $\varnothing$ Drainage channel $>0.1 \mathrm{~m}$ & (Oxfam-Angola, 2001) \\
\hline & & Drainage channel 1:50 slope & (Oxfam, 1998) \\
\hline & & Soak away pit should be present & $($ Oxfam, 1998) \\
\hline & & $<1 \mathrm{~m}$ depth filtration pit & (Oxfam-Angola, 2001) \\
\hline & \multirow{2}{*}{$\begin{array}{l}\text { Extraction } \\
\text { mechanism }\end{array}$} & Flange bolt spacing $\geq 22 \mathrm{~cm}$ & (ACME, 2002) \\
\hline & & uPVC and GI rising mains $>2$ years & (Collins 2000) \\
\hline
\end{tabular}

Full results of the well inventory are outlined in Appendix 1. Wells with construction and design criteria that are not in accordance with the recommended guidelines for construction are highlighted in red in Appendix 1.

When compared to guideline methods of construction, results in Appendix 1 indicate the following results for 25 researched wells:

- LOW RISK $=$ Wells $2,4,5,6,15$ and 16 (with 1 risk score),

- HIGH RISK = Wells 3, 8, 9, 10, 11, 12, 14, 20, 21,22, 23, 24 (with >1 risk score).

As the wells researched are operational wells, non-destructive tests of surface hardness and concrete strength were required. The Schmidt Hammer test was selected and 510 tests at four specific points on the apron were undertaken. Results of these tests and structural observations are outlined in Appendix 1. Source errors identified during data collection included:

- Poor quality of workmanship - Hand mixing of the cement resulted in poor compaction and aggregate distribution, 
- Poor aggregate washing - noted that the aggregate was poorly washed resulting in poor concrete cohesiveness (dust on the surfaces of aggregates weakened the bonding potential),

- Poor quality bricks - Poorly cured bricks were used for apron foundation and drainage,

- Sanitary seal - Wells were not properly sealed with filter material and were back filled with excavated debris of variable quality,

- Age of concrete - tests were undertaken on concrete older than 3 months which affects readings (BS1881-201, 1986).

Results of the Schmidt Hammer tests are detailed in Appendix 1. A summary of the four main findings is given below:

- Depth of concrete $-100 \%$ of wells were $>30 \mathrm{~mm}$ (recommended depth)

- Age of Concrete $-100 \%$ of wells were more than 3 months old as recommended in BS1881-201 (1986).

- Optimum levels of $\mathrm{R}$ (Rebound Coefficient) $=30$ were used as the lowest level recommended by the manufacturer (Mastrad, 2004) Using $R=30$, it can be concluded that only the pre-cast reinforced concrete capping beam produced results $\geq 30$ in wells 2,6 and 17 .

From the above list of compliance it can be concluded that the quality of concrete used in the headworks is poor. High levels of visible aggregate, suggesting poor mixing of concrete, by hand further reinforce this. It should also be noted that these are surface hardness readings and although considered indicative of concrete strength, are not alone a measure of concrete stability. Additionally therefore, a structural survey was undertaken. Results from the survey indicate high levels of surface cracking and dry jointing. Examination of these cracks and dry joints revealed high levels for risks of direct ingress of surface contaminants through unlined annuli of wells $11,14,17$ and 21 . 


\section{Below ground component (Intake and Shaft)}

The 25 wells assessed during this research were operational wells. Access to the well intake and shaft was therefore limited for the following reasons:

- Wells were sealed and capped,

- Culturally it is believed that foreigners entering a well may introduce disease (e.g. cholera),

- Limited well inspection equipment was available.

Although initial well inspections were undertaken using a CCTV Borehole camera, this yielded minimal results in sealed or capped wells such as the caisson lined wells fitted with handpumps. Due to these difficulties, four alternative options for data generation on the shaft and intake were considered:

1. Excavate and inspect the environ of wells,

2. Discard the shaft and intake as contributing variables,

3. Assume quality of construction as comparable to headworks,

4. Use "expert judgment" techniques to generate data.

Option 1 was considered practically and logistically unfeasible due to the constraints of the research site, and option 2 would have not been rigorous in its contribution to the research objectives. It was therefore decided to use a combination of Options 3 and 4, to assess the risk posed by the intake and shaft and apply it to the risk of the wells. To achieve this, various multi-criteria or multi-variate techniques were reviewed. These included the following methods as outlined in Triataphyllou et al. 1994, 1995 and 1997), Wang et al. (2002) and Ramanujam et al. (1981);

- REMBRANDT,

- The Weighted Sum Model,

- The Weighted Product Method,

- Analytic Hierarchy Process (AHP), and,

- Multi Attribute Utility Theory (MAUT).

This research selected the Analytic Hierarchy Process (AHP) as it is different from other decision making tools in that it requires the "simultaneous use of data and judgement as opposed to formal models" (Ramanujam et al. 1981). The AHP is a "multicriterion decision making approach that employs a method of multiple comparisons to rank order alternative solutions to a problem, formulated in a hierarchy" (Satty, 1980). It was developed "to solve a specific problem in 
contingency planning and a later major application was to design alternative futures for a developing country, the Sudan" (Satty, 1980). The AHP is Analytic (i.e. it uses numbers), Hierarchical (it structures the decision problems in levels) and is a Process (real decisions require a process of learning, debating and revising decisions) (Fatti et $a l, 1989)$. In comparison, the other methods required either data or judgment. The use of the other methods limits the validity of the approach.

Application of AHP as a method of forecasting appropriate technological choices in developing countries is well documented in (Ramanujam et al. 1981). Its application has also been successfully applied for decision making in the water engineering and water resources sector (Fatti et al. 1981). Also, and appropriately for this research, it has been applied in the groundwater sector by Thirumalaivasan et al. (2001 and 2003) in estimating specific aquifer vulnerability through use in conjunction with the DRASTIC model.

\section{AHP Method}

The AHP is decomposed into levels of criteria. The strength of influence between each of these criteria at different levels forms the basis for decision making. The AHP is an interactive process, where a group of decision makers relay their preferences to the researcher for specified technological options or outcomes. It is based upon the construction of Pairwise Comparison Matrices (PCMs). Satty, suggests a scale of 1-9 for PCM elements (see table 23 below). Justification for these scales based on psychological tests in number identification is provided in Triantaphyllou et al. (1994, 1995, 1997).

Table 23: Scale of measurement for AHP

\begin{tabular}{|l|l|}
\hline Numerical Values & Definitions \\
\hline 1 & Equally preferred \\
\hline 3 & Moderately preferred \\
\hline 5 & Strongly preferred \\
\hline 7 & Very strongly preferred \\
\hline 9 & Extremely preferred \\
\hline $2,4,6,8$ & Intermediate values to reflect compromise \\
\hline Reciprocals & Used to reflect dominance of the second alternative as compared with the first. \\
\hline
\end{tabular}

The AHP decomposes a given problem into a hierarchy structure. The hierarchy comprises different levels and the AHP compares the different criteria of the levels. using the PCM. To estimate the likelihood of the various scenarios, each actor first makes a pair-wise comparison of the relative importance of specific variables 
associated with engineering barriers to groundwater microbiological contamination. This yields a pair of weights for each variable.

The relationship between the $n$ criteria in the hierarchy is explained mathematically as:

$$
\left\lfloor\mathrm{A}_{(i))}\right\rfloor \mathrm{X}\left\lfloor\mathrm{W}_{(j)}\right\rfloor=\left\lfloor\mathrm{nW}_{(j)}\right\rfloor
$$

Where;

$$
\begin{array}{ll}
A & =\text { an } n \times n \text { PCM in terms of ratio of ratings/weights, } \\
W & =\text { the ratings or weights (priority rankings/weights) of criteria, } \\
n & =\text { is the order of the PCM matrix. } \\
i & =\text { index of physical conditions } \\
j & =\text { index of well linings } \\
l & =\text { index of candidate technologies }
\end{array}
$$

The input matrix is $A$ and the solution for equation (1) is the common eigenvalue problem. The AHP is founded upon a system of homogenous linear equations with a non trivial solution that only is incorrect if the determinant $A-n l$ (i.e. $n$ is an eigenvector of $A$ ) whose ultimate outcome is a principal eigenvector $\left(\lambda_{\max }\right)$ defined as the sum of the criteria divided by the number of criteria. The closer $\lambda_{\max }$ is to $n$ (the number of activities in the matrix), the more consistent the result.

\section{Application of AHP}

To apply the AHP to this research, the author developed an AHP specific questionnaire based on identified variables. As this research is specifically exploring groundwater contamination in Lichinga, Mozambique, only "experts" familiar with groundwater in Lichinga were selected. The author believed that the inclusion of actors not familiar with Lichinga would bias results. Three respondents from Lichinga were selected. These included engineers and managers from WaterAid as well as local government staff. It is acknowledged that this is a small sample size. However, these were the only water professionals available and they were confident with the subject matter. The author proposed the following hierarchical formulation to each of the actors: 


\section{GOAL}

- To provide judgement on the relative importance of various well linings in minimising microbiological risk to shallow groundwater

Each of the actors was requested to weight and produce pairwise comparisons for each criterion at a particular level of the hierarchy, with regard to the "contribution" it makes to criteria at the succeeding level of the hierarchy, by means of a procedure of paired comparisons. For this research, the actors weighted the physical criteria associated with well linings that affect the risk of microbiological contamination of shallow groundwater. Specifics of the types of contaminants were not a feature of this component of the research. Focus was solely on the effectiveness of the engineering barrier (i.e. the well lining) in reducing the risk of shallow groundwater to microbiological contamination. Finally, a "composite weight" was obtained for each of the "alternative well linings." This composite weight is the overall measure of importance for the particular criteria.

For this study a total of 11 independent characteristics were selected and compared in groups at two levels. The levels were divided between the critical influential variables; physical condition of well (i.e. depth/diameter and prevailing soil type) and type of well lining (age, soil type, quality of workmanship, materials). From a pairwise judgement, the most appropriate "candidate technology" was selected by each participant using the definitions outlined in Table 23. Figure 27 presents a diagrammatic representation of the decision tree used for the development of the AHP in this research.

Figure 27: Well Lining Hierarchy 


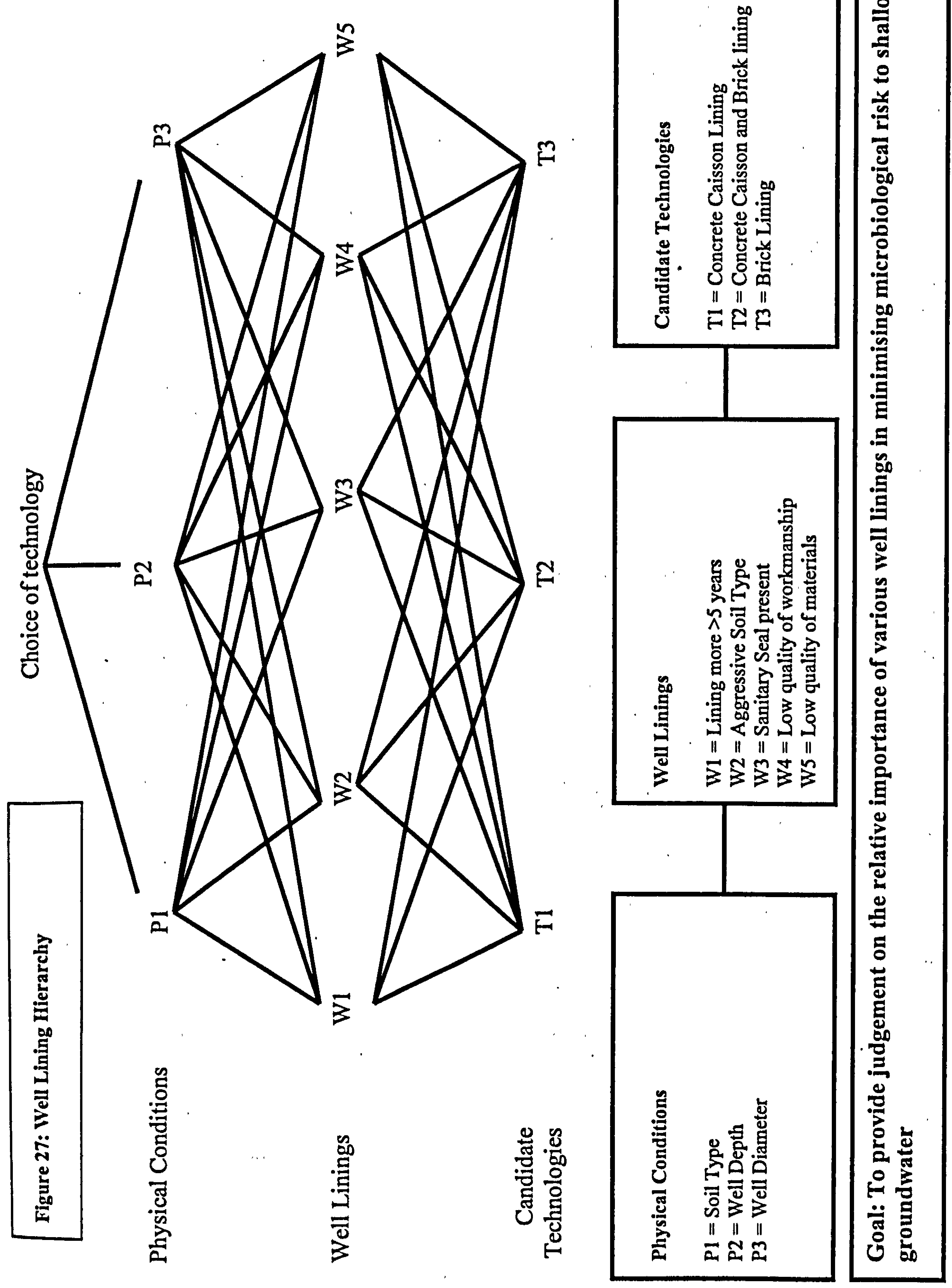




\section{AHP Results}

Data from respondents was coded in an EXCEL spreadsheet developed by the author to gain estimates of weightings for each of the contributing variables (see screen shot of spreadsheet in Appendix 2). These were then used to assign composite weightings to each of the actual well lining technologies used in Lichinga. A summary of the composite weighting results from the AHP questionnaire is outlined in table 24 below, with the shaded cells indicating the variable group considered most important.

Table 24: AHP Composite Weightings

\begin{tabular}{|c|c|c|c|c|}
\hline Group & Variable group & Respondent 1 & Respondent 2 & Respondent 3 \\
\hline $\mathbf{1}$ & Physical Conditions & 0.09 & 0.65 & 0.23 \\
\hline $\mathbf{2}$ & Well linings & 0.62 & 0.08 & 0.64 \\
\hline $\mathbf{3}$ & $\begin{array}{c}\text { Candidate } \\
\text { technologies }\end{array}$ & 0.30 & 0.27 & 0.13 \\
\hline
\end{tabular}

where 1 is maximum value

The results revealed a strong preference for the importance of the well lining group (group 2) over groups 1 and 3. Specifically, this included the methods and materials used for well lining over the specificity of the technology or the physical conditions in which the well lining is constructed. Interestingly, the responses to the questionnaire reflected the academic background of the respondent. For example, respondent 2 was a technician from the Lichinga Agricultural Research center. The respondent indicated that the physical conditions (i.e. soil/hydrogeological conditions) were the most critical variable group in contributing to the risk of contamination. In comparison, respondent 1 was a WaterAid engineer. The respondent indicated that the physical engineering barrier was most critical. Respondent 3 was a Public Health specialist and the WaterAid Country Representative. Responses gained from both respondents 1 and 3 identified well linings as the most critical variable group.

In summary, the AHP assigned greatest significance to the well lining variable group. This variable group includes the lining age, chemical properties of soil, absence of sanitary seal and low material quality and workmanship. Within this group, low quality of workmanship and low material quality were identified by all respondents as the two most important sub-variables.

\section{Uncertainty in AHP process}

The author noted uncertainties in the application of the AHP process. These included: 
1. Vagueness of how the attribute weights are assessed,

2. Link between the points on 1-9 scale and corresponding verbal descriptions.

These uncertainties or limitations correspond with difficulties noted in the use of the AHP method by the UK Office of the Deputy Prime Minister (ODPM 2001). It is therefore recommended that more precise numerical values be used during the composition and implementation of the AHP questionnaire, so that respondents are aware of the risk values being assigned to each of their responses.

\section{Application of AHP}

Results of the AHP questionnaire were then applied to each of the 25 well sites dependent on the type of receptor. Results were coded as High and Low depending on the candidate technology and variables affecting the use of the well lining. To gain a composite risk score, results of the AHP were combined with qualitative and quantitative data collected during the wellhead inventory (see Table 25 below). Table 25 combines results obtained on both the wellhead and the below ground components of each of the 25 wells to assign a High or Low risk score for the effectiveness of the receptor (the well structure). 
Table 25: Receptor Risk

\begin{tabular}{|c|c|c|c|c|c|c|}
\hline \multirow[t]{2}{*}{$\begin{array}{l}\text { Well } \\
\text { No }\end{array}$} & \multicolumn{2}{|c|}{$\begin{array}{l}\text { Headworks (including low } \\
\text { quality workmanship and } \\
\text { materials) }\end{array}$} & \multicolumn{3}{|c|}{ Below ground components } & \multirow[t]{2}{*}{$\begin{array}{l}\text { RISK TO } \\
\text { RECEPTOR }\end{array}$} \\
\hline & $\begin{array}{l}\text { Total risk } \\
\text { score }\end{array}$ & $\begin{array}{l}\text { Schmidt } \\
\text { Hammer }\end{array}$ & $\begin{array}{l}\text { Lining }>5 \\
\text { years }\end{array}$ & $\begin{array}{l}\text { Chemical Soil } \\
\text { properties }\end{array}$ & $\begin{array}{l}\text { Sanitary Seal } \\
\text { Absent }\end{array}$ & \\
\hline 1 & $5=\mathrm{H}^{1}$ & $\mathrm{H}^{2}$ & $\mathrm{H}^{3}$ & $\mathrm{H}^{4}$ & $\mathrm{H}^{5}$ & $\mathrm{HIGH}^{6}$ \\
\hline 2 & $3=\mathrm{L}$ & $\mathrm{L}$ & $\mathrm{H}$ & $\mathrm{H}$ & $\mathrm{H}$ & LOW \\
\hline 3 & $5=\mathrm{H}$ & $\mathrm{H}$ & $\mathrm{H}$ & $\mathrm{L}$ & $\mathrm{H}$ & $\mathrm{HIGH}$ \\
\hline 4 & $1=\mathrm{L}$ & $\mathrm{H}$ & $\mathrm{L}$ & $\mathrm{L}$ & $\mathrm{H}$ & LOW \\
\hline 5 & $1=\mathrm{L}$ & $\mathrm{H}$ & $\mathrm{L}$ & $\mathrm{L}$ & $\mathrm{H}$ & LOW \\
\hline 6 & $3=\mathrm{L}$ & $\mathrm{L}$ & $\mathrm{L}$ & $\mathrm{H}$ & $\mathrm{H}$ & LOW \\
\hline 7 & $5=\mathrm{H}$ & $\mathrm{H}$ & $\mathrm{L}$ & $\mathrm{H}$ & $\mathrm{H}$ & $\mathrm{HIGH}$ \\
\hline 8 & $2=\mathrm{L}$ & $\mathrm{H}$ & $\mathrm{L}$ & $\mathrm{H}$ & $\mathrm{H}$ & LOW \\
\hline 9 & $2=\mathrm{L}$ & $\mathrm{H}$ & $\mathrm{L}$ & $\mathrm{H}$ & $\mathrm{H}$ & LOW \\
\hline 10 & $3=\mathrm{L}$ & $\mathrm{H}$ & $\mathrm{L}$ & $\mathrm{L}$ & $\mathrm{H}$ & LOW \\
\hline 11 & $2=L$ & $\mathrm{H}$ & $\mathrm{L}$ & $\mathrm{L}$ & $\mathrm{H}$ & LOW \\
\hline 12 & $3=\mathrm{L}$ & $\mathrm{H}$ & $\mathrm{L}$ & $\mathrm{L}$ & $\mathrm{H}$ & LOW \\
\hline 13 & $5=\mathrm{H}$ & $\mathrm{H}$ & $\mathrm{L}$ & $\mathrm{L}$ & $\mathrm{H}$ & LOW \\
\hline 14 & $2=L$ & $\mathrm{H}$ & $\mathrm{L}$ & $\mathrm{L}$ & $\mathrm{H}$ & LOW \\
\hline 15 & $1=\mathrm{L}$ & $\mathrm{H}$ & $\mathrm{L}$ & $\mathrm{L}$ & $\mathrm{H}$ & LOW \\
\hline 16 & $5=\mathrm{H}$ & $\mathrm{L}$ & $\mathrm{H}$ & $\mathrm{L}$ & $\mathrm{H}$ & $\mathrm{HIGH}$ \\
\hline 17 & $2=L$ & $\mathrm{H}$ & $\mathrm{L}$ & $\mathrm{L}$ & $\mathrm{H}$ & LOW \\
\hline 18 & $5=\mathrm{H}$ & $\mathrm{H}$ & $\mathrm{H}$ & $\mathrm{L}$ & $\mathrm{H}$ & $\mathrm{HIGH}$ \\
\hline 19 & H estimate & $\mathrm{H}$ & $\mathrm{L}$ & $\mathrm{L}$ & $\mathrm{H}$ & LOW \\
\hline 20 & $3=\mathrm{L}$ & $\mathrm{H}$ & $\mathrm{L}$ & $\mathrm{L}$ & $\mathrm{H}$ & LOW \\
\hline 21 & $4=\mathrm{L}$ & $\mathrm{H}$ & $\mathrm{L}$ & $\mathrm{L}$ & $\mathrm{H}$ & LOW \\
\hline 22 & $3=\mathrm{L}$ & $\mathrm{H}$ & $\mathrm{L}$ & $\mathrm{L}$ & $\mathrm{H}$ & LOW \\
\hline 23 & $3=\mathrm{L}$ & $\mathrm{H}$ & $\mathrm{L}$ & $\mathrm{L}$ & $\mathrm{H}$ & LOW \\
\hline 24 & $3=\mathrm{L}$ & $\mathrm{H}$ & $\mathrm{L}$ & $\mathrm{L}$ & $\mathrm{H}$ & LOW \\
\hline 25 & $5=\mathrm{H}$ & $\mathrm{H}$ & $\mathrm{H}$ & $\mathrm{L}$ & $\mathrm{H}$ & $\mathrm{HIGH}$ \\
\hline
\end{tabular}

Where;

I $5=$ High Risk $(\mathrm{H})$ and $<5=$ Low Risk (L)

2 Wells with $\mathrm{R}$ value $<30=\operatorname{High} \mathrm{Risk}(\mathrm{H})$ and Wells with $\mathrm{R}$ value $>30=$ Low Risk (L)

${ }^{3}$ Well linings $<5$ years $=$ Low Risk $(\mathrm{L})$ and Well linings $>5$ years $=$ High Risk $(\mathrm{H})$

${ }^{4}$ Clay based soils (high acidity) $=$ High Risk $(\mathrm{H})$, Sandy soils $=$ Low Risk (L)

${ }^{5}$ Wells without sanitary seals $=$ High Risk $(\mathrm{H})$, Wells with sanitary seals $=$ Low Risk $(\mathrm{L})$

${ }^{6}$ Wells with total $\mathrm{H}$ of $1-3=$ Low Risk, Wells $4-5=$ High Risk 
The variables of low quality materials and workmanship could not be assessed in the below ground components. Results from the above ground components (as outlined in the total score in column one), were therefore taken as indicative of these variables. From Table 25, it is observed that 6 of the 25 wells are considered at high risk and 19 of the 25 wells are considered low risk.

\subsubsection{Risk Variables}

The parametric and categorical variables outlined for the source, pathway and receptor affect the severity of the microbiological contamination of shallow groundwater. The following sections describe the 12 months of data collected during the field study. The section begins by providing a summary of microbiological and physico-chemical results collected and then discusses key findings from sanitary inspections. Although sanitary inspections have been used in the preceding sections to determine contaminant loading at source, pathways to contamination and susceptibility of the receptor, this section will provide an overview of the key categorizations.

\section{Microbiological results:}

\section{Thermotolerant Coliform}

Figure 28 presents data in graphical form for presumptive thermotolerant coliform analysis. The samples size/total data set of 351 samples is divided into the three geographic locations. The total number of results for Ceramica $=208$, Nomba $=65$, Lulimile $=52$ (plus 26 duplicate samples). The three well technologies are indicated as:

- Traditional Wells in Red

- Upgraded Wells in Blue

- Improved Wells in Yellow 


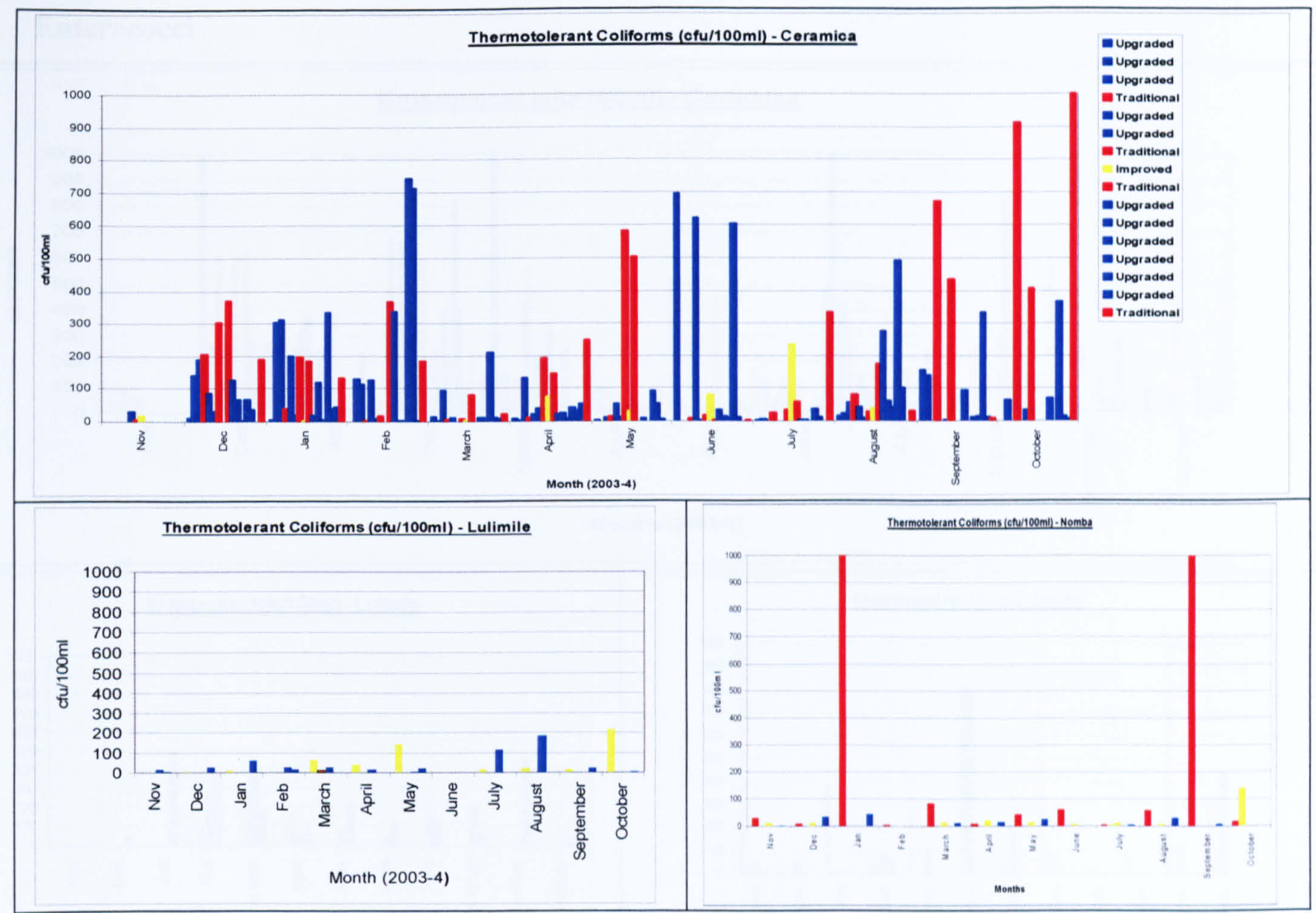

Figure 28: Thermotoloerant Coliform Data

The data indicates that in Nomba and Ceramic contamination levels were highest in traditional wells, followed by upgraded wells and then improved wells. Inconsistencies in results must be noted for Lulimile for the traditional wells as it was observed that the owner of Well 7 (Paulo Saide) admitted to chlorinating his well on a weekly basis. Additionally inconsistencies should also be noted for Improved Well 6 in Lulimile as during the months of February to June 2004, the handpump on the well was not functioning and abstraction of the water was being undertaken using potentially contaminated buckets. Despite these inconsistencies contamination levels were noted as less in Lulimile as compared to Ceramic in upgraded wells. Traditional wells in Nomba indicate increase in contamination immediately following the onset of rains in October 2003 and again in September 2004. 


\section{Enterococci}

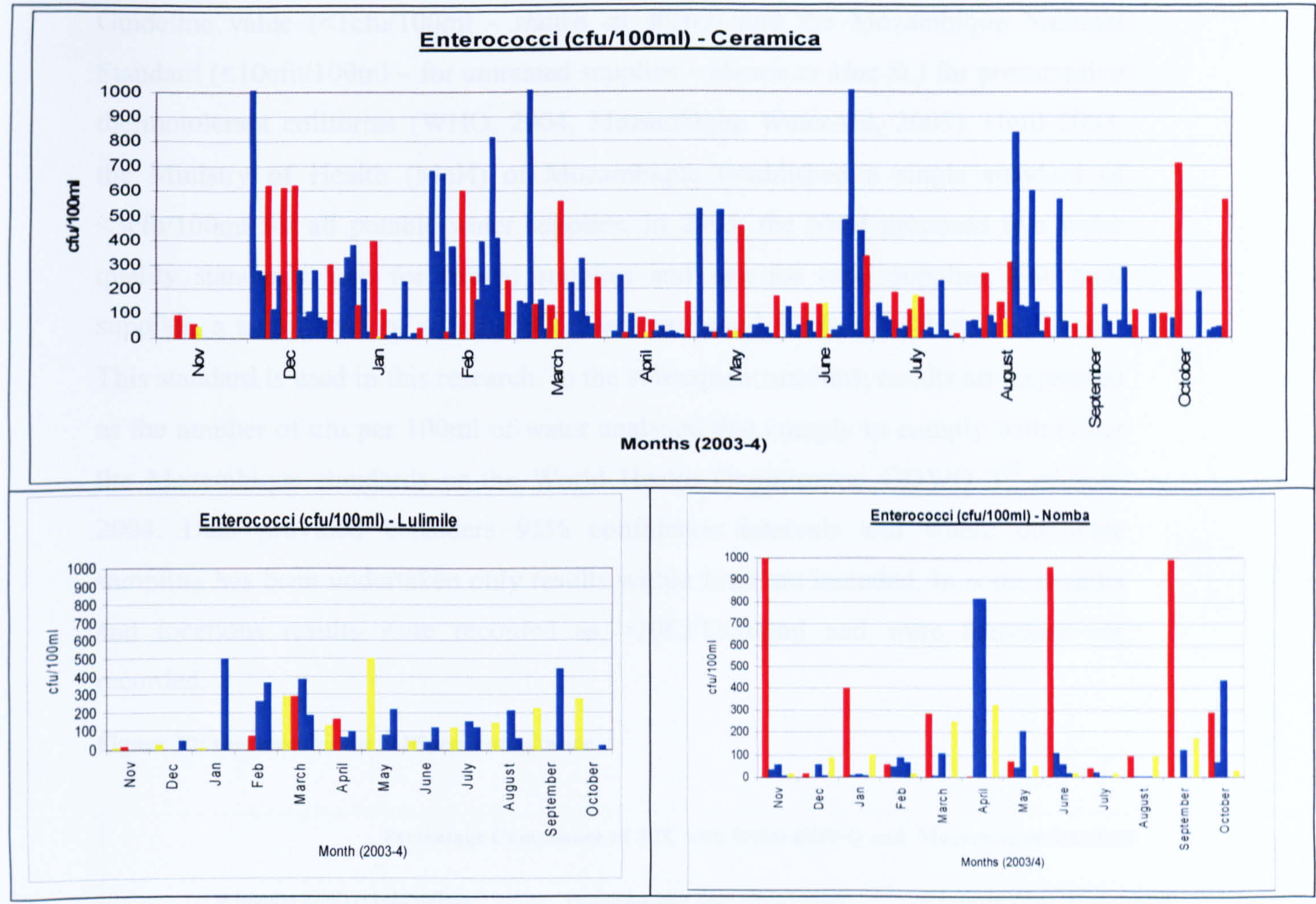

Figure 29: Enterococci data

Figure 29 uses the same colour coding as the previous Figure. Figure 29 indicates that in Ceramica and Lulimile, improved wells had consistently lower levels of microbial contamination than upgraded or traditional wells. Levels of contamination were noted as highest in upgraded wells in Ceramica. This may be due to the high presence of animal faeces in the environment in Ceramica. Additionally, in all geographic locations an increase in contamination was noted following the first flush of rainfall in November/December 2003. Inconsistencies were noted in Lulimile and Nomba where contamination increased during the months of April (Lulimile) and May (Nomba) in improved wells. This was because the handpumps broke down during these months and buckets were used for abstracting the water which provided a significantly increased risk of contamination. 
Figure 30 below outline the number of samples that fail to meet both the WHO Guideline value $(<1 \mathrm{cfu} / 100 \mathrm{ml}$ - shown as WHO) and the Mozambique National Standard $(<10 \mathrm{cfu} / 100 \mathrm{ml}$ - for untreated supplies - shown as Moz St.) for presumptive thermotolerant coliforms (WHO, 2004, Mozambique WaterAid, 2003). Until 2003, the Ministry of Health $(\mathrm{MoH})$ of Mozambique established a single standard of $<3 \mathrm{cfu} / 100 \mathrm{ml}$ for all potable water supplies. In 2003 , the $\mathrm{MoH}$ proposed two water quality standards, one for treated supplies and one for rural supplies. For rural supplies, a target level of $<10 \mathrm{cfu} / 100 \mathrm{ml}$ was proposed for thermotolerant coliforms. This standard is used in this research. In the subsequent sections, results are expressed as the number of cfu per $100 \mathrm{ml}$ of water analysed that comply to comply with either the Mozambique standards or the World Health Organization GDWQ $3^{\text {rd }}$ edition2004. Data provided considers $95 \%$ confidence intervals and where duplicate sampling has been undertaken only results within limit are included. In some months and locations results were recorded as $>10 \mathrm{CFU} / 100 \mathrm{ml}$ and were therefore not recorded.

Figure 30: thermotolerant coliform compliance

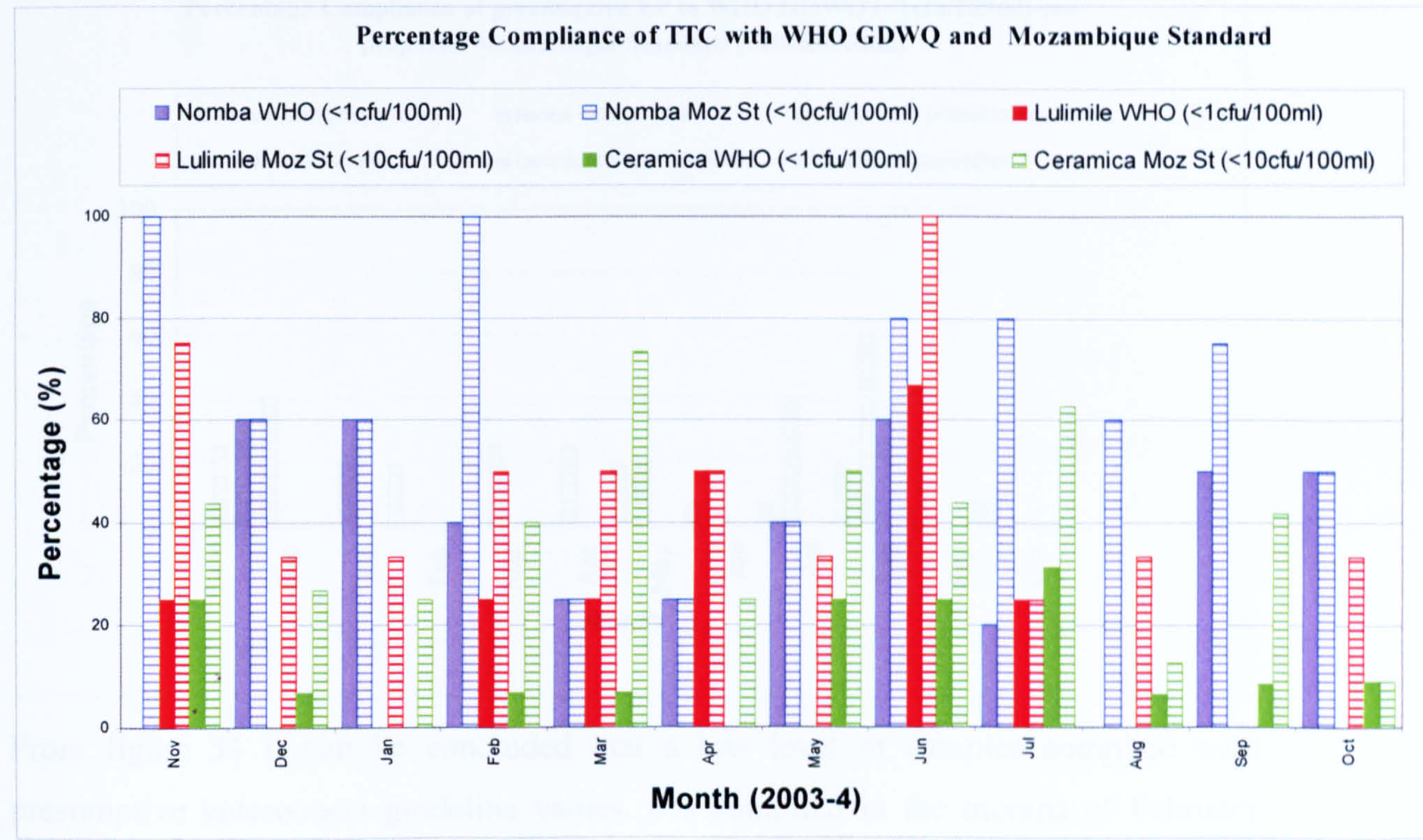

From Figure 30, it can be concluded that highest percentage compliance was achieved during the month of June with more than $25 \%$ of the total samples complying with 
both WHO GDWQ and Mozambique Standards. Low levels of compliance were achieved during the months of December, January, August, September and October. Highest levels of compliance were achieved in Nomba and lowest in Lulimile.

Summary of analysis of presumptive enterococci is outlined in Figure 31. It is important to note that currently the WHO GDWQ ( $3^{\text {rd }}$ edition) expresses a similar guideline value $(\mathrm{GV})$ of $<1 \mathrm{cfu} / 100 \mathrm{ml}$ for enterococci. It is noted that enterococci usually occur in lower numbers than thermotolerant coliforms (WHO, 2004). Results from the study in Lichinga note the opposite with only 1 sample within the WHO GDWQ GV $<1 \mathrm{cfu} / 100 \mathrm{ml}$. It is therefore recommended that a relaxation of the value is used in this study of $10 \mathrm{cfu} / 100 \mathrm{ml}$. The lack of compliance of data from rural water supplies to WHO GDWQ has been also been noted by Howard (2003) and Lloyd et al. (1991). The use of the WHO GDWQ GV $<1 \mathrm{cfu} / 100 \mathrm{ml}$ for monitoring microbiological contamination of shallow groundwater is therefore an area that requires significant further research.

Figure 31: Percentage compliance of enterococci

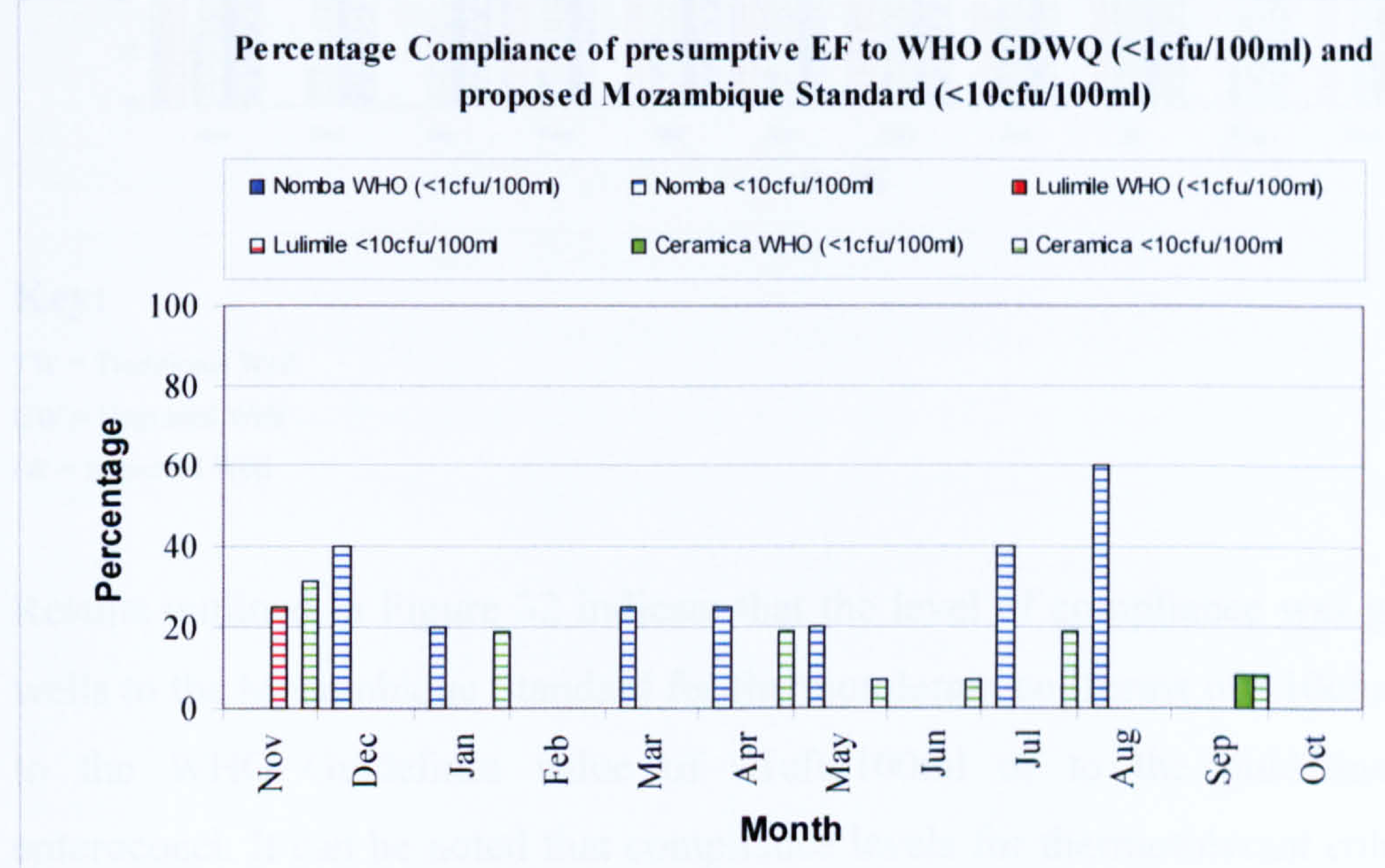

From figure 31 it can be concluded that a low level of samples complied with presumptive enterococci guideline values. $0 \%$ complied in the months of February and October and highest compliance noted in July and August. Overall, numbers of presumptive enterococci exceeded the enterococci guideline values at some stage in all wells over the 12 month period. 
Figure 32 below analyses results for EF and TTC for each technology type. Three technologies were considered in this research (traditional wells, upgraded wells with windlass, and improved well with handpump). Results indicate a very low level of compliance of traditional wells to both the WHO GDWQ and Mozambique standard for TTC and EF during the rainy season and greater compliance during the dry seasons.

Figure 32: EF and TTC results per technology

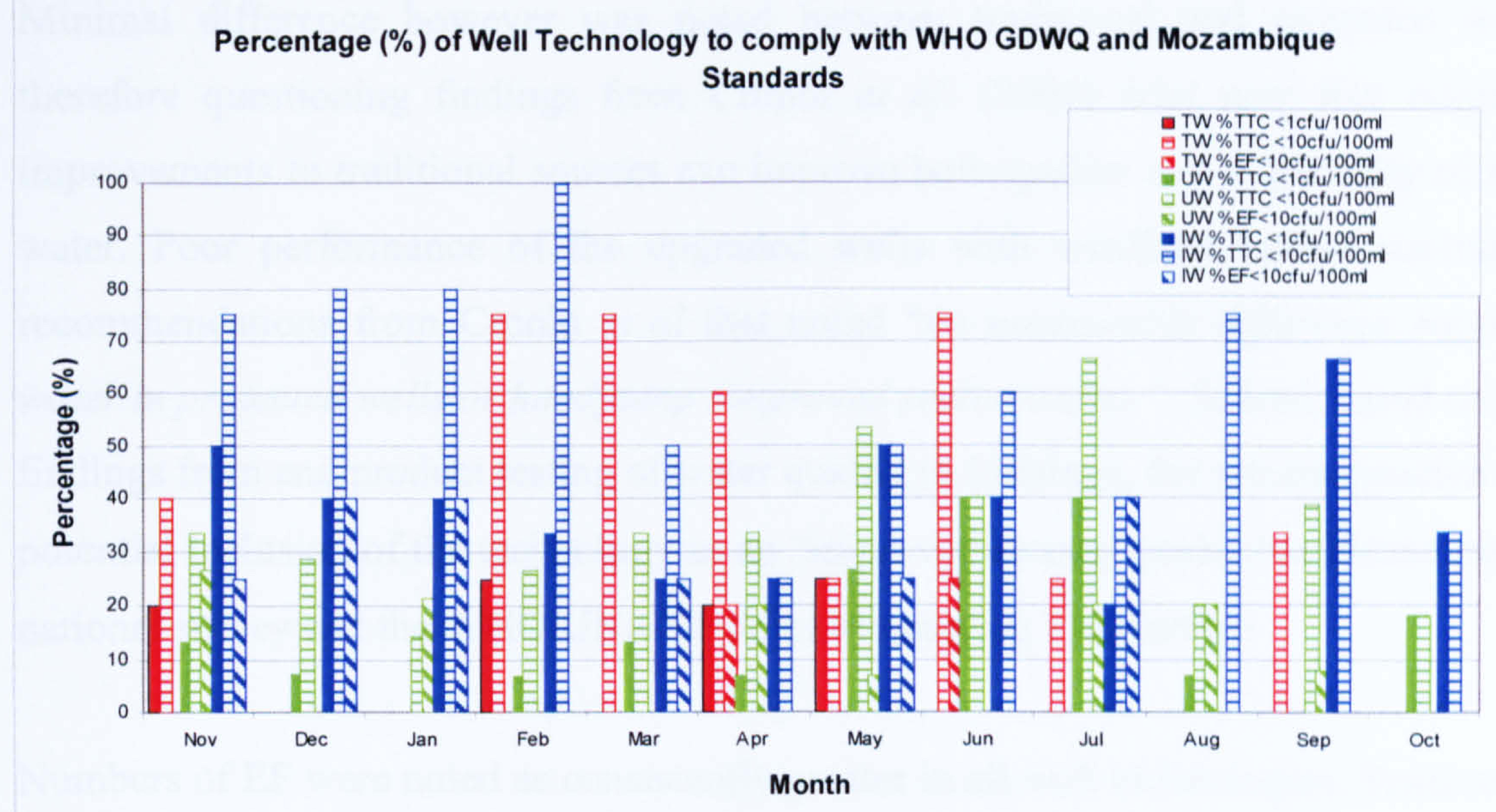

Key:

$\mathrm{TW}=$ Traditional Well

UW $=$ Upgraded Well

IW = Improved Well

Results outlined in Figure 32 indicate that the level of compliance was greater in all wells to the Mozambique Standard for thermotolerant coliforms of $<10 \mathrm{cfu} / 100 \mathrm{ml}$ than to the WHO Guidelines value of $<1 \mathrm{cfu} / 100 \mathrm{ml}$ or to the guideline value for enterococci. It can be noted that compliance levels for thermotolerant coliforms were highest in improved wells with handpumps, with $>60 \%$ compliance noted from November to February and in June and September. Lower levels of compliance were noted in improved wells with handpumps during the dry season. This may be explained by the increased demand on handpumps during this drier period. 
Importantly, frequently lower levels were recorded for improved wells than traditional wells. During the rainy season (November-March) very low levels of compliance were noted in both traditional wells and improved wells. This improved during the drier months of March to July and then deteriorated again in the lead up to the rains in August to September. It should be noted that increased demand on the wells during the later part of the year combined with minimal yield may have resulted in increased levels of contamination.

Minimal difference however was noted between traditional and upgraded wells therefore questioning findings from Cronin et al. (2002) who note that minimal improvements to traditional sources can improve both quality and availability of safe water. Poor performance of the upgraded wells with windlass further contradict recommendations from Cronin et al that noted "no measurable difference between water in protected wells or handpump (improved sealed wells)." Indeed, based on the findings from end product testing of water quality in Lichinga, the results question the potential inclusion of the technology as an "improved source" under the Mozambique national survey and the WHO/UNICEF Joint Monitoring Programme.

Numbers of EF were noted as consistently greater in all well technologies. Traditional wells indicated EF levels in excess of $10 \mathrm{cfu} / 100 \mathrm{ml}$ in all months except the dry period of April and June. Upgraded wells demonstrated $20 \%$ compliance in both the rain and the dry seasons and improved wells indicated 25, 40 and 40\% levels during the monomodal rains. Interestingly, higher counts of EF were recorded in wells at greater depth. This may be explained by the robustness of the organism and its ability to survive, but not multiply under environmental conditions at depth (Mara, 2003).

Numbers of TTC were more compliant with the Mozambique Standard $(<10 \mathrm{cfu} / 100 \mathrm{ml})$ than the WHO GDWQ $(<1 \mathrm{cfu} / 100 \mathrm{ml})$. A dramatic increase in TTC contamination levels was noted following the onset of the rains in November. This reduced towards the end of the rains (March/April) and then increased following the dry period (September). This was most pertinent in improved and traditional wells therefore suggesting minimal effectiveness of the engineering barrier in protecting the well during flushes of contamination from intense rainfall. Results for improved wells with handpumps, although following the trend, indicated less variability between 
seasons. More than $50 \%$ of the improved wells complied with Mozambique Standards during 7 of the 12 months.

Overall, the results suggest that a relaxation of the Mozambique Standard to $<10 \mathrm{cfu} / 100 \mathrm{ml}$ is a more realistic target for both improved and upgraded wells.

Although the above observations are of use, limited conclusions should be drawn from Figure 30 alone. In line with recommendations in the $3^{\text {rd }}$ edition of the WHO GDWQ (2004), reliance on end product testing alone is inadvisable and a more thorough risk based approach should be adopted. For this study, limitations of interpretation of end product results include: Limited sample size - due to time and financial constraints and technology distribution - a greater number of upgraded wells were monitored compared to traditional and improved wells. Additionally, the following errors were noted;

\section{Experimental errors -}

a. Analyses was done outside and so there was potential for either wind, dust or sunlight exposure to affect results,

b. MMD - Numbers of Media Making Devices (MMDs) were limited in January and February. Re-use of sterilised MMDs may have resulted in potential cross contamination.

c. Dilutions - Samples with high turbidity made colony identification difficult during the end of the dry and beginning of the wet season. 1:2, 1:5 and 1:10 dilutions with deionised water were undertaken.

d. Incubator tray - The removal of the incubator tray prior to incubation created minor fluctuations in the incubation temperature $\left( \pm 1^{0} \mathrm{C}\right)$. In many cases this equalled $-1^{\circ} \mathrm{C}$ over the first 10 minutes of incubation.

e. Availability of ice - Limited availability of ice for transporting samples resulted in minimal quantities being used during some months. Samples may not have remained at $<4^{0} \mathrm{C}$ during transportation.

\section{Human errors included:}

a. Timing - Although a stopwatch was used to control resuscitation and incubation times, potential human error may have occurred.

b. Colony identification - A handheld 5" magnifying lenses was used to identify both enterococci and thermotolerant coliforms. The size of 
some colonies made identification difficult and potential errors in colony vs. non-colony identification may have occurred.

c. Community - Potential threat of cholera made communities highly suspicious of the data collected at each well, and resulted in some community members denying access to the wells for research.

Due to these errors, duplicate results were taken on the first and last sample of the day and $95 \%$ confidence levels were used to define compliance of the microbiological results. In cases where $95 \%$ confidence levels were achieved a mean result was taken and computed. Where results were not within $95 \%$ confidence level, it was considered a statistical outlier and was removed from further analysis.

\section{pH}

$\mathrm{pH}$ was measured on a monthly basis at the same time as the microbiological analysis. Values ranges of recorded $\mathrm{pH}$ are outlined in Figure 33. $\mathrm{pH}$ values are constant with a median value of 6.1 . Well 7 varies from the norm. It is a traditional well, which was visited on a limited basis during the study period due to lack of access provided by the owner.

\section{Figure 33: pH results}

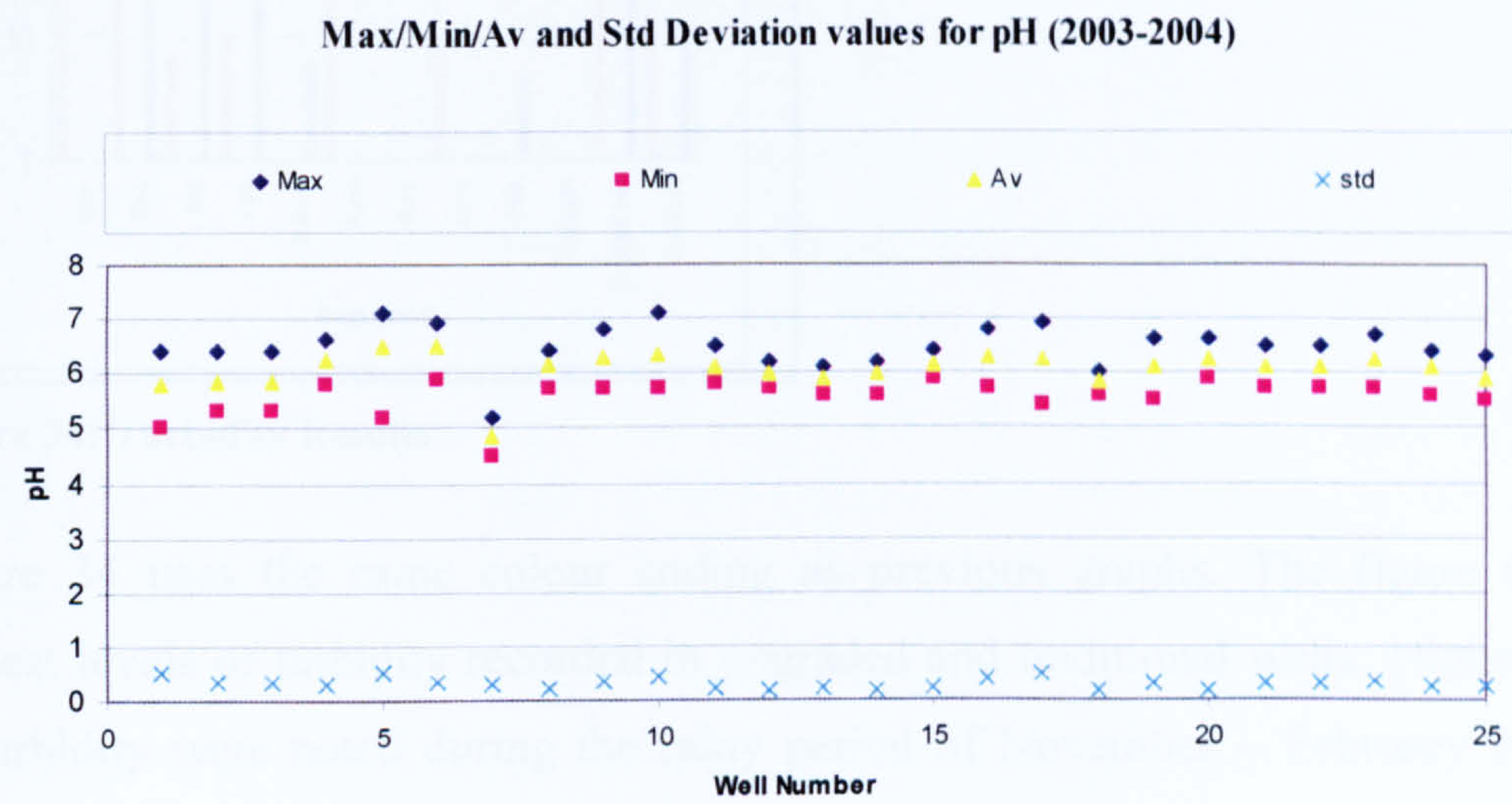

The author observed that the owners might have been chlorinating well 7 with hypochlorite during the study period. This would result in changes in $\mathrm{pH}$ due to the forming of hydroxyl ions. However low $\mathrm{pH}$ values may be naturally occurring and as 
noted by Stejmar reflect the metamorphic rock underlying the alluvial unconfined aquifer (Stejmar, 1998). Higher values may relate to increased organic material in samples water and increased turbidity which consequently results in higher $\mathrm{pH}$ values and greater alkalinity (WHO, 2004). However, due to the stability of the $\mathrm{pH}$ in the sample wells and the fact that treatment of water is not included in this study, the author decided to remove $\mathrm{pH}$ from any further data analysis at this stage.

\section{Turbidity}

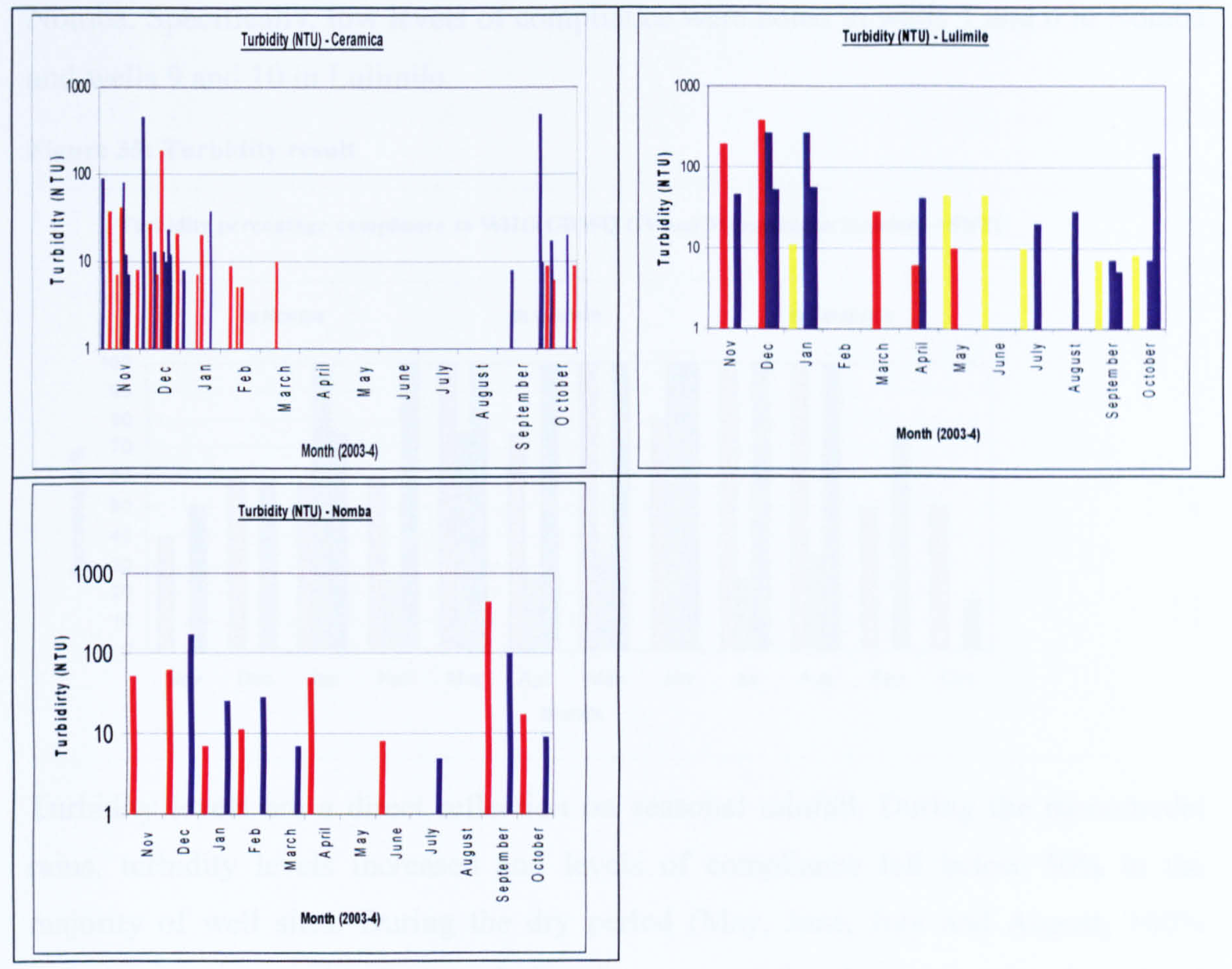

Figure 34: Turbidity Results

Figure 34 uses the same colour coding as previous graphs. The figure indicates highest levels of turbidity recorded in upgraded and traditional wells. Highest levels of turbidity were noted during the rainy period of November - February 2003 and then in September-October 2004. Inconsistencies were noted in Well 6 (Improved Well) of Lulimile where turbidity increased due to the removal of the handpump between February and June resulting in direct introduction of contamination. In general turbidity levels were higher in Lulimile than at the other two sites. This may be due to the higher percentage of clay in the topsoil in Lulimile as compared to 
Nomba and Ceramica. Very low levels of turbidity were noted in all wells in Ceramica during the dry season of March-August 2004 perhaps due to the high silt fraction in the soil resulting in higher filtration.

Percentage compliance rates for turbidity are based on the WHO GDWQ GV and Mozambique Standard of $<5$ NTU. Results indicated in Figure 35 below suggest high compliance levels in the Ceramica and Lulimile sample sites and less compliance in Nomba. Specifically, low levels of compliance were noted in wells 1 and 6 in Nomba and wells 9 and 10 in Lulimile.

\section{Figure 35: Turbidity result}

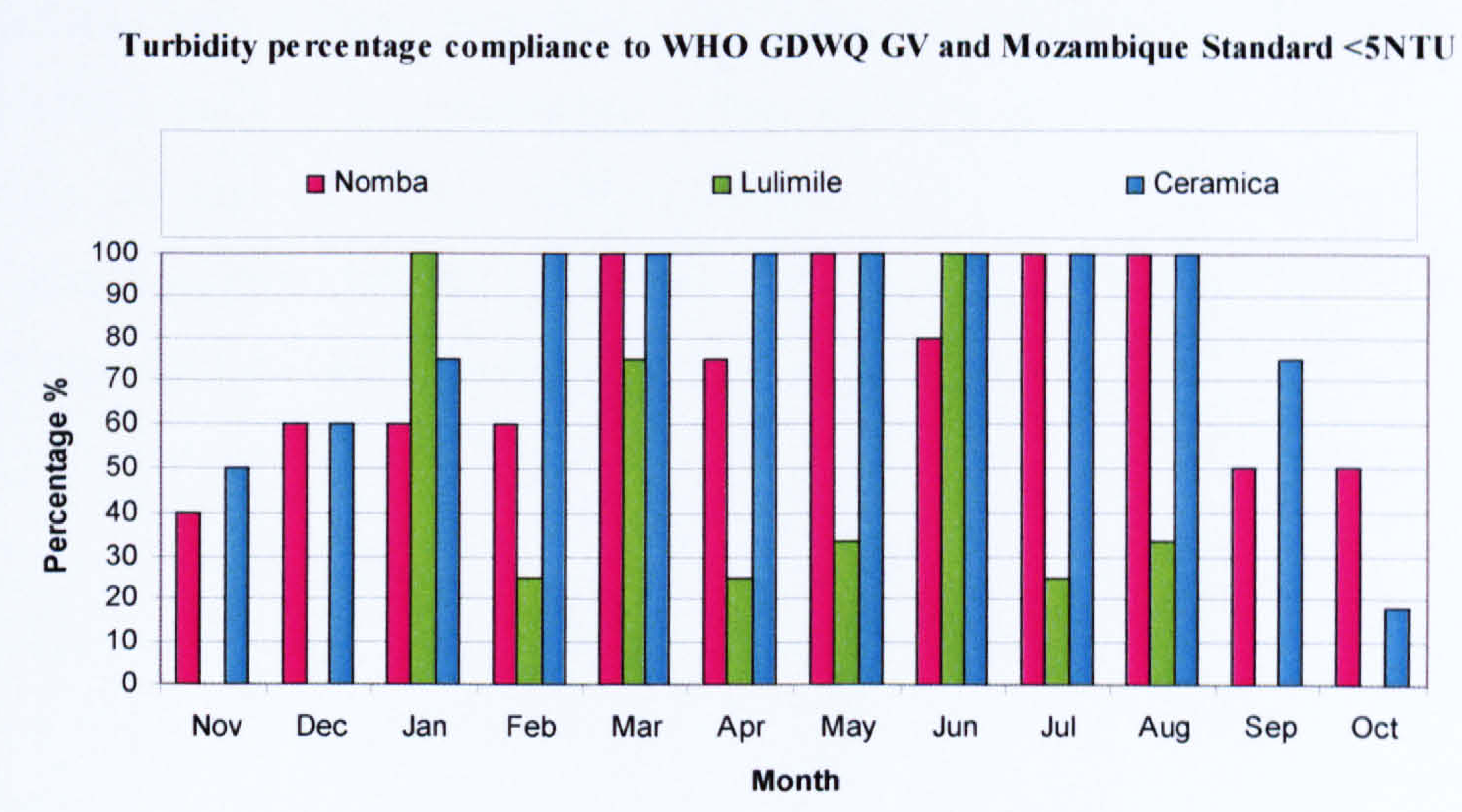

Turbidity levels are a direct reflection on seasonal rainfall. During the monomodal rains, turbidity levels increased and levels of compliance fell below $50 \%$ in the majority of well sites. During the dry period (May, June, July and August, 100\% compliance was noted in 2 of the 3 sites. It was noted that the community also related the increase in turbidity during the rainy season to the time of collection of water. During the rains, it is common for communities to collect water early in the morning (before afternoon or mid day rains). This disturbs sediment in the well and introduces turbidity. During the dry colder season, communities tend to collect water during the warmer late morning period causing higher turbidity rates at midday or later. As samples in this study were always taken between $7 \mathrm{am}$ and 12 noon, the period of collection by communities will affect turbidity levels. 


\section{Sanitary Inspection Data}

Sanitary inspection data were collected each time a water sample was taken. The forms were field trialed and then standardized by the author at the beginning of the research with local counterparts in Lichinga. A total of 12 questions were included on the improved well with handpump, 11 questions on the improved well with rope and washer pump and 10 questions for the upgraded and traditional well. In this research, results for sanitary inspection will be included during the next stage of data analysis. As noted in Chapter 4, the sanitary inspection forms were divided into SOURCE, PATHWAY and RECEPTOR (INDIRECT FACTORS). Results for each of these will be included in section 5.4 during the process of data analysis. Results will be used as parametric variables to complement established categorical variables. 


\subsection{Data Mining}

\subsubsection{Introduction}

This section will focus on the selection, cleaning and coding of data presented in section 5.2. It will follow the format of SOURCE-PATHWAY-RECEPTOR-RISK by selecting and coding the variables in preparation for multivariate statistical analysis in section 5.3.

To achieve this, a process of Data Mining was used. This can be defined as "mining knowledge from large amounts of data" (Han et al. 2001). It is more comprehensively described as "the exploration and analysis, by automatic or semiautomatic means, of large quantities of data in order to discover meaningful patterns and rules" (Helberg 2002). Data mining was first introduced by academics and industry to sort data electronically. It is a systematic means of coding data. There are a number of stages to data mining and each method varies according to the author of the method. Commonalities between methods however include an initial description and compilation of the data similar to that outlined in section 5.1. 


\subsubsection{Source Variables}

Due to the multivariate nature of this research, variables affecting pollutant loading at source have been "clustered" to provide a summary hazard rating. The variables considered in the definition of this hazard rating and links between the variables are outlined in figure 36.

Figure 36: POSH method variables

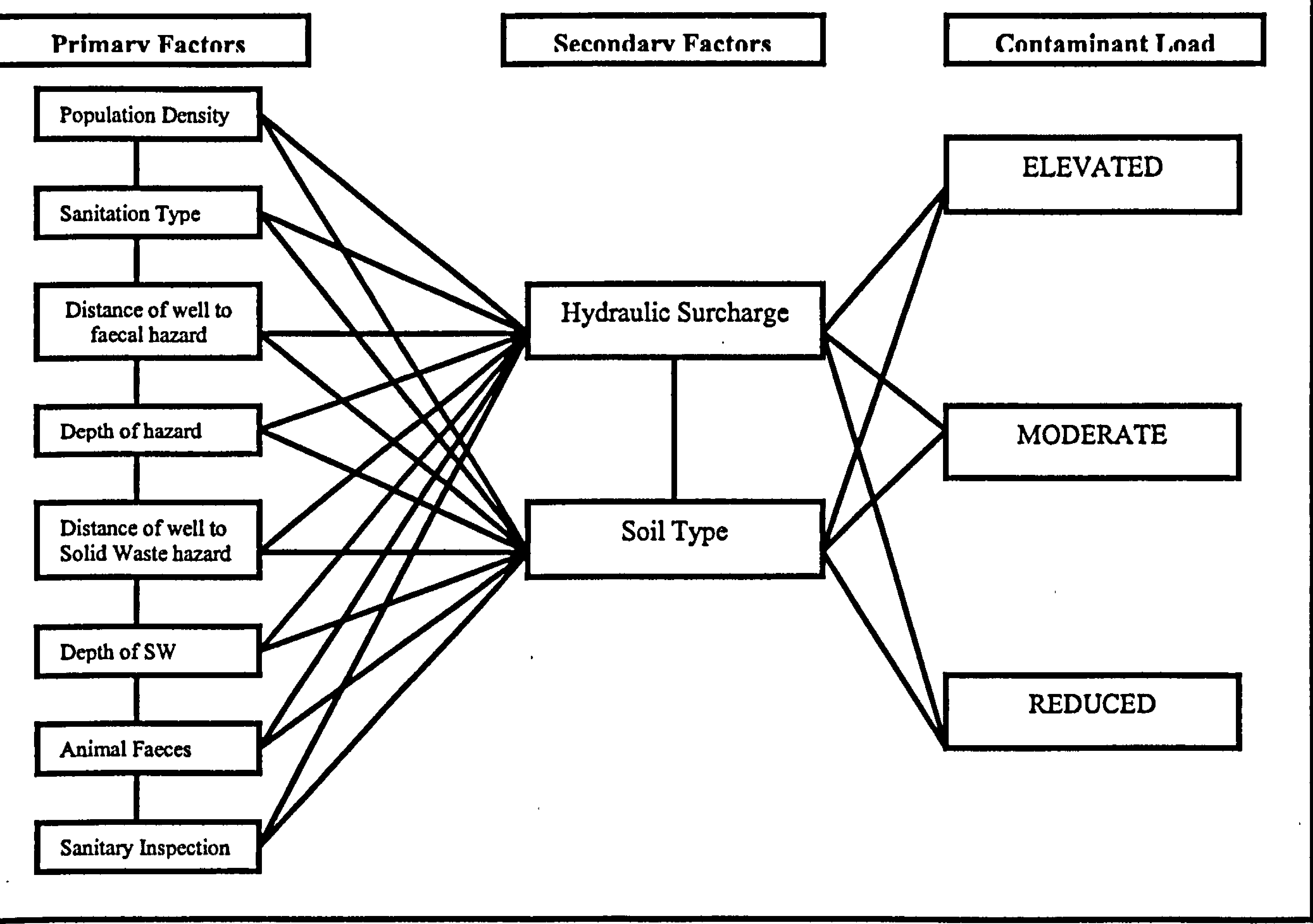

Categorisations based on the POSH method (discussed in section 5.2.2) are summarised in Table 26. In column three, binomial categorical value labels are presented. These are the codes used in the statistical analysis using the software package SPSS. Where no data are available, 9 is used in accordance with standard statistical methods (Coakes et al. 1999).

Potential errors were noted in historic data used for assessing population density. This is a common phenomenon in developing countries. As a result, a method of binomial coding was used that indicated 0 or 1 for presence or absence. This method was selected over a numerical weighting system due to potential discrepancies in margins 
between interpretations of Elevated to Moderate to Low due to these potential error margins.

Table 26: Subsurface contaminant load potential

\begin{tabular}{|l|l|c|c|}
\hline Category & Wells & Compliant & Non Compliant \\
\hline ELEVATED & 6,17 & 1 & 0 \\
\hline MODERATE & $2,3,4,5,7,8,10,12,13,14,18,19$ & 1 & 0 \\
\hline REDUCED & $1,9,11,15,16,20,22$ & 1 & 0 \\
\hline
\end{tabular}

The compliant or non-compliant coding forms the basis for the statistical analysis in section 5.4 .

\subsubsection{Pathway Variables}

Two variable sets were assessed in selecting vulnerability categories using a modified Swartz method as described in section 5.2.3. These included meteorological and hydrogeological variables. Initial data description revealed a strong correlation between rainfall and risk to microbiological contamination. Following the first flush of rainfall, levels of contamination (measured in both presumptive thermotolerant coliform and presumptive enterococci) indicator bacteria increased by a 5 and 10 order of magnitude compared to mean results from before the rains. Initial results indicate a pulse response to rainfall. However, due to limitations of this research it was not possible to quantify the precise travel time using tracer studies. These limitations included:

1. Funding constraints - limited funds for tracer studies

2. Social constraints - communities would not accept the addition of a tracer (regardless of type) into their water source,

3. Logistics - transport of the tracer material from the UK to Mozambique would have presented foreseen difficulties.

Direct pulse response graphs however indicate a correlation between increased rainfall and flushing of contaminants into wells. Particularly high contamination concentrations were noted in traditional wells and upgraded wells during the rainy season. Specifically, wells 1,18 and 22 were highly vulnerable to contamination during the rainy period. This is due to minimal protection afforded by well linings and drainage on headworks. Rainfall was therefore identified as a critical variable and, although considered as a variable of the pathway in section 5.2, has been removed 
during the data mining process and will be considered as an independent variable for purposes of data analysis in section 5.4. The "clustering" of variables for selection for coding is outlined in Figure 37.

Figure 37: Vulnerability categories based on modified Swartz method

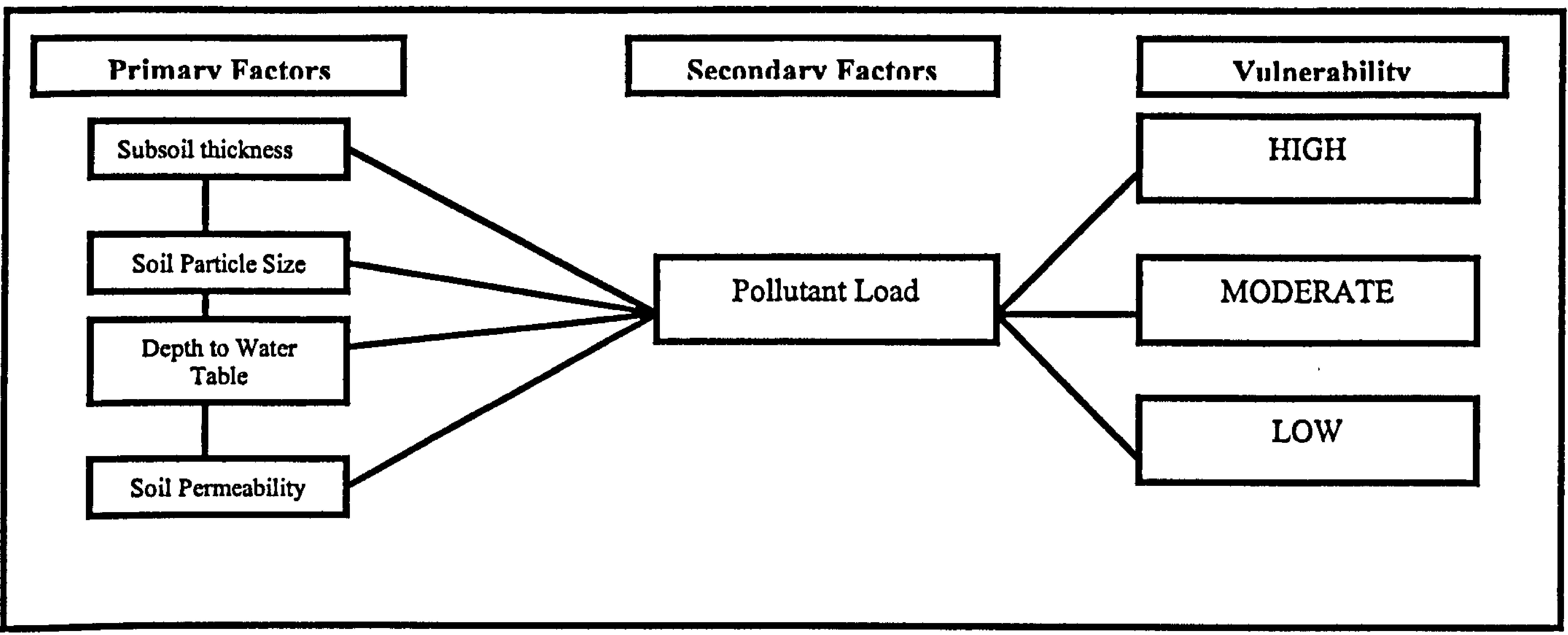

Results were clustered into HIGH, MODERATE and LOW vulnerability categories.

Results of these are summarised in Table 27. Binomial categorical value labels are presented in column three with the number 9 used for non-available data.

Table 27: Vulnerability ratings Lichinga

\begin{tabular}{|l|l|c|c|}
\hline Vulnerability & Well Nos & Compliant & Non Compliant \\
\hline HIGH & $1,10,12,13,18,19,20,21,22,24,25$ & 1 & 0 \\
\hline MODERATE & $2,3,4,5,6,7,8,9,11,14,15,16,17,23$ & 1 & 0 \\
\hline
\end{tabular}

Highest levels of vulnerability were noted in wells in Ceramica, with lower moderate levels noted for wells in Nomba and Lulimile. When combined with the pollutant source categorisation, it can be concluded that the Ceramica area contains greater hazards and is at higher vulnerability than Lulimile but that animal hazards are still evident in Lulimile (see Figure 38 below for details). The vulnerability categories outlined in Figure 35 will be used in the data classification section 5.4 to determine statistical correlations between vulnerability and risk. 
Figure 38: Vulnerability and source loading categorisations

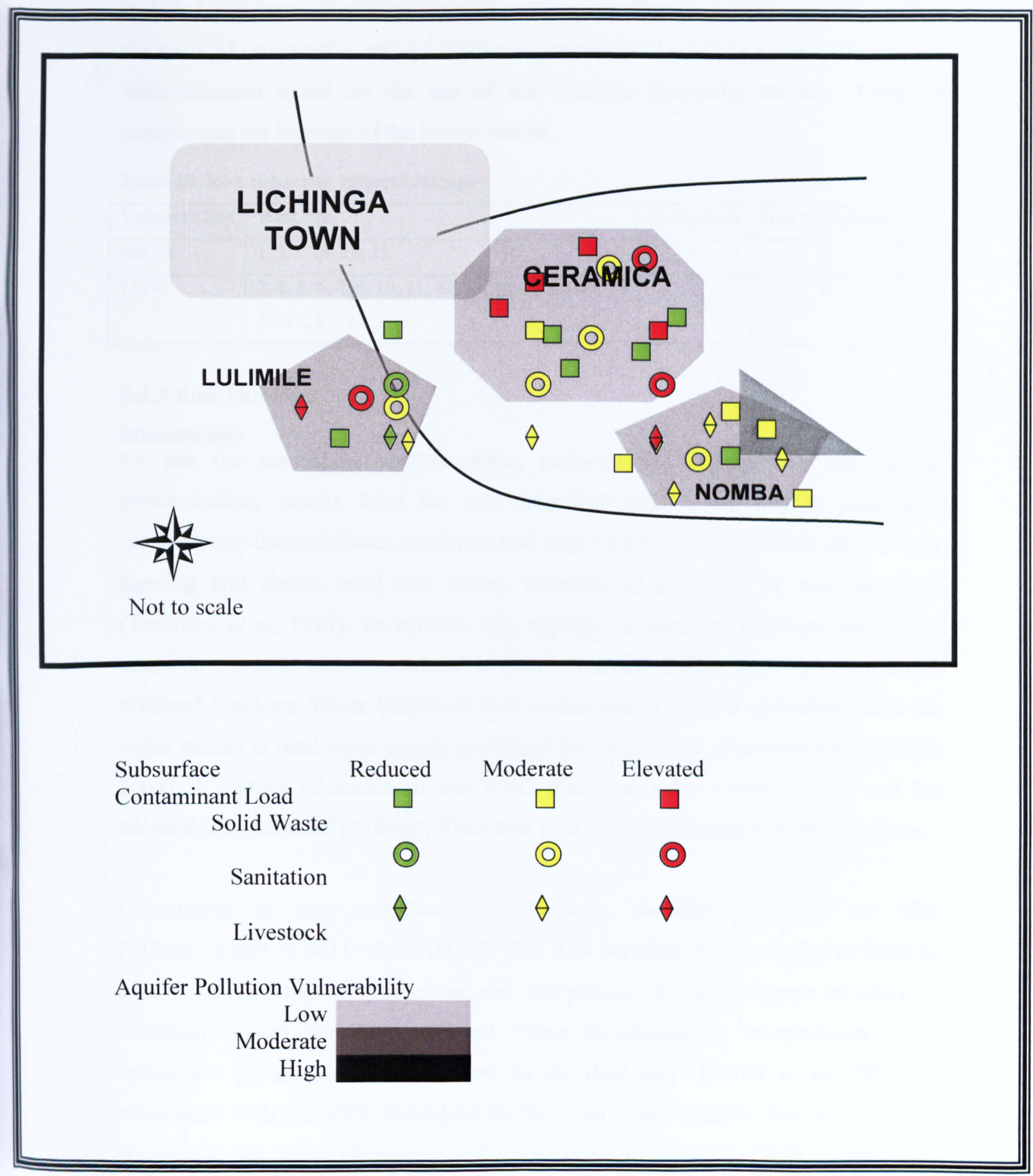




\subsubsection{Barrier Variables}

Two variable sets were used to assess the risk to each engineering barrier. These included; headworks and below ground components. The headworks were assessed on the basis of quantitative and qualitative assessments. The below ground components were assessed based on the use of the Analytic Hierarchy Process. Table 28 summarises the findings of the barrier results.

Table 28: Risk to barrier ratings Lichinga

\begin{tabular}{|l|l|c|c|}
\hline Vulnerability & Well Nos & Compliant & Non Compliant \\
\hline HIGH & $1,3,7,16,18,25$ & 1 & 0 \\
\hline LOW & $\begin{array}{l}2,4,5,6,8,9,10,11,12,13,14,15,17,19,20 \\
21,22,23,24\end{array}$ & 1 & 0 \\
& & & \\
\hline
\end{tabular}

\subsubsection{Risk Variables}

\section{Microbiology}

To test the assocation of the source, pathway and receptor on the risk of contamination, results from the two microbiological water quality parameters (presumptive thermotolerant coliforms and enterococci) were converted from colony forming unit counts (cfu) into binary variables of compliant or non compliant (Tesoriero et al. 1997). To achieve this, appropriate levels of cfu were established based on recommendations outlined in both Lloyd and Helmer and the Mozambique National Drinking Water Standards that recommend a relaxed guideline value for water quality in rural water supply systems (Lloyd et al 1991, WaterAid Mozambique 2003). A further relaxation of the WHO guideline value $(<1 \mathrm{cfu} / 100 \mathrm{ml})$ and the Mozambique Standard $(<10 \mathrm{cfu} / 100 \mathrm{ml})$ was used for the purposes of further analysis.

Compliance or non compliance results were therefore expressed as YES $(<10 \mathrm{cfu} / 100 \mathrm{ml})$ or NO $(>10 \mathrm{cfu} / 100 \mathrm{ml})$. This data was then dummy coded in SPPS as 1 or 0 representing compliance or non compliance. For the purpose of analysis, statistical outliers have been removed. These are defined as "observations whose values are quite different than others in the data set." (Helsel et al. 1992). In accordance with the WHO Guideline for Drinking Water Quality, this study defined statistically non valid outliers as microbiological results $>1000$ cfu (WHO, 2004). 


\section{Turbidity}

A further factor to be considered during the data analysis stage was turbidity. Limits placed on turbidity are based on WHO where low risk is defined as $<5 \mathrm{NTU}$ (WHO, 2004). Compliance or non-compliance ratings were assigned to each well as 1 or 0 for compliance to WHO risk factors associated with turbidity.

\section{Sanitary inspection}

Sanitary Inspection results were used to analyse the variable risk at each well during each month of sampling. The sanitary inspection form questions were divided into those affecting the source, pathway and receptor (See Appendix 1). The breakdown of the risk variables monitored in each well type is outlined in Table 29 where the indirect factor is equal to the barrier top contamination through either the receptor or aquifer.

Table 29: Sanitary inspection variables

\begin{tabular}{|c|l|l|l|l|}
\hline Question & Traditional well & $\begin{array}{l}\text { Upgraded well } \\
\text { with windlass }\end{array}$ & $\begin{array}{l}\text { Improved well } \\
\text { with rope and } \\
\text { washer pump }\end{array}$ & $\begin{array}{l}\text { Improved well } \\
\text { with handpump }\end{array}$ \\
\hline $\mathbf{1}$ & Source & Source & Source & Source \\
\hline $\mathbf{2}$ & Source & Source & Source & Source \\
\hline $\mathbf{3}$ & Source & Source & Source & Source \\
\hline $\mathbf{4}$ & Pathway & Pathway & Pathway & Pathway \\
\hline $\mathbf{5}$ & Indirect factor & Indirect factor & Indirect factor & Indirect factor \\
\hline $\mathbf{6}$ & Pathway & Pathway & Pathway & Pathway \\
\hline $\mathbf{7}$ & Indirect factor & Pathway & Pathway & Pathway \\
\hline $\mathbf{8}$ & Pathway & Pathway & Indirect factor & Indirect factor \\
\hline $\mathbf{9}$ & Pathway & Indirect factor & Indirect factor & Indirect factor \\
\hline $\mathbf{1 0}$ & Pathway & Indirect factor & Pathway & Pathway \\
\hline $\mathbf{1 1}$ & & & Pathway & Indirect factor \\
\hline $\mathbf{1 2}$ & & & & Pathway \\
\hline TOTAL RISKS & & $\mathbf{1 0}$ & $\mathbf{1 0}$ & \\
\hline
\end{tabular}

Results for each of the sanitary inspections for each category (Source, Pathway, Receptor) and for each technology were presented in SPSS as O or 1 (present or absent) for each category question. 


\section{Rainfall}

To consider rainfall separately, monthly mean rainfall results from both the EAL and

Quinta for 2003-4 were coded into binomial data. Limits were established for rainfall based on mean monthly results. These included:

- $<10 \mathrm{~mm} / \mathrm{month}=$ Low Risk $(0)$

- $>10 \mathrm{~mm} / \mathrm{month}=$ High Risk (1)

$10 \mathrm{~mm}$ was selected as an established limit based on evidence presented in the literature (see Godfrey et al. 2005, Gunston 1997). Compliance or non-compliance weightings were added at 1 and 0 . 


\subsection{Data Analysis \\ 5.4.1 Introduction}

Section 5.3 selected the variables selected for further analysis based on data mining. This section applies statistical methods to analyse the data. Based on results of trends outlined in section 5.2, it can be observed that low levels of compliance to both WHO GDWQ and Mozambique microbiological standards were achieved in upgraded wells and high levels of compliance were achieved in improved wells. This questions the inclusion of upgraded wells as an improved technology within the JMP data. In order to assess the specific variables affecting the increased risk of microbiological risk, this section uses detailed statistical analysis to compare both the Chi Square $\left(\chi^{2}\right)$ and significance weightings ( $p$-value) of a dependent variable to co-variates

To achieve this, section 5.4 is divided into four sets of analyses. Each of these was performed based on technology type where one dependent variable (risk of microbiological contamination using both thermotolerant coliforms and enterococci) is compared to one or more co-variates. For this research the co-variates are:

1. Hazard - source loading potential

2. Pathway - vulnerability of aquifer

3. Barrier - effectiveness of engineering barrier

4. Hazard Sanitary Inspection Result

5. Pathway Sanitary Inspection Result

6. Barrier Sanitary Inspection Result

7. Rainfall

8. Turbidity

Due to the large number of co-variates, four analyses were performed using logistic regression and Chi-Square. These include:

- Analysis 1: Monthly analysis of the significance weightings by comparing the source, pathway and receptor on microbiological risk.

- Analysis 2: Monthly analysis of source, pathway, receptor plus significance of specific sanitary inspection results to microbiological non compliance

- Analysis 3: Monthly analysis of source, pathway, receptor plus significance of specific sanitary inspection results and rainfall to microbiological non compliance 
- Analysis 4: Monthly analysis of source, pathway, receptor plus significance of specific sanitary inspection results, rainfall and turbidity to microbiological non compliance

\subsubsection{Statistical Analysis}

This research used multivariate statistical analysis due to the high number of variables to be analysed (Calder et al. 2001). This analysis involved both descriptive and quantitative statistics. Firstly, descriptive statistics were undertaken using Chi-Square analyses, and secondly logistic regression was applied.

\section{Chi-Square $\left(\chi^{2}\right)$.}

Chi-Square analysis was selected for this research as it provides descriptive statistics to determine the probability of a statistical relationship between variables. This probability ( $p$ value) is calculated based on the estimation of degrees of freedom outlined in a Chi-Squared distribution. Levels of precision are estimated based on the output p-value. This provides an estimate of precision that is statistically significant at $95 \%$ confidence. $95 \%$ confidence is equivalent to a p value of 0.05 , and. significant results are noted for p-values nearer to zero than 0.05 . The statistical models used are outlined in appendix 4.

\section{Logistic Regression}

Regression techniques were selected as they have the specific advantage of comparing variable weightings. From the regression family, the specific technique of Logistic regression was chosen for this research. It was selected for the following reasons:

1. An effective predictive technique - used extensively in the health sciences since the late 1960 s as a predictive statistical technique to predict binary response from explanatory variables (Tesoriero et al. 1997).

2. Power of analysing "the extent to which one variable can be predicted by another" (Calder et al. 1997).

3. Ability to handle binomial categorical data generated from sanitary inspection analysed against a dependent variable (Helsel et al. 1992).

4. Enables an innovative linguistic translation of binomial data into a decision making tool (Calder et al. 1997).

Logistic regression has also proved effective in: 
a) analysis of data sets which have large numbers of values - this research analyses source, pathway, receptor and risk data with unequal numbers of data sets and values,

b) identification of relations between water quality and explanatory variables this research aims to identify the relative level of risk posed by the source, pathway and receptor on the potential for shallow groundwater contamination.

Furthermore, logistic regression can establish which of the influences are strong and which are weak, to what extent the different independent variables are independent influences (or conversely, how much their influences overlap), and whether there are interaction effects between variables (Calder et al. 2001).

\section{Development of SPSS model}

For this research, data for the source, pathway, receptor and risk variables were dummy coded in SPSS 11 as 0 or 1 based on the compliance or non compliance with critical limits (Norusis, 1999). SPSS 11 was selected as it was the most current version at the time of research. Three models were developed;

1. Model $1=$ traditional well,

2. Model $2=$ improved well.

3. Model 3 = upgraded well

Data was dummy coded on a monthly basis for each well in each model. This included coded data on the source, pathway and receptor as well as parametric data on sanitary risk, microbiological water quality, turbidity and rainfall. Results for source, pathway and receptors were presented as values of 0 or 1 . For sanitary inspection data, values of 0 or 1 were entered monthly as YES or NO responses to each individual question. Where more than one assessment was made in a month (e.g. November 2003), results were given for the first sample visit only. Categorical data (rainfall, turbidity, microbiological results) were presented on a monthly basis as either in compliance (1) or non-compliance (0) with established limits. For this research, the following critical limits were used (see section 5.3.4 for justification).

- Rainfall: $>10 \mathrm{~mm}$ as high risk and $<10 \mathrm{~mm}$ as low risk,

- Turbidity: $>5 \mathrm{NTU}=$ high risk, $<5 \mathrm{NTU}=$ low risk,

- thermotolerant coliforms: $>10 \mathrm{cfu} / 100 \mathrm{ml}=$ high risk, $<10 \mathrm{cfu} / 100 \mathrm{ml}=$ low risk, 
- Enterococci: $>10 \mathrm{cfu} / 100 \mathrm{ml}=$ high risk, $<10 \mathrm{cfu} / 100 \mathrm{ml}=$ low risk.

\subsubsection{Analysis 1 - source, pathway, receptor}

Firstly the data was analysed using the descriptive statistical technique - Chi-Square. This section uses Chi-Square analysis to estimate the significance weightings of the source, pathway and receptor categories to microbiological risk. The objective of the analysis was to decipher which of the source, pathway or receptor variables was statistically more significant for each well technology type for both occurrence of thermotolerant coliforms (TTC) and Enterococci. Results are presented for each well technology beginning with traditional wells and followed by improved and upgraded wells.

\section{Traditional Well - Chi-Square Analysis}

In traditional wells, Chi-Squared analysis revealed four constant variables. These were;

1. Low source - low level of significance of hazard source on risk to shallow groundwater of microbiological contamination,

2. High source - high level of significance,

3. Low pathway - low level of significance,

4. Low receptor - low level of significance.

To determine the overall significance for the four variables Chi-Square analysis was undertaken. The results of this are summarised in the omnibus analysis below. The omnibus is a summary analysis to gain an overview of the statistical significance of the variables to non-compliance of thermotolerant coliforms.

Table 30: Omnibus - thermotolerant coliform Non Compliance

\begin{tabular}{|r|r|r|c|c|}
\hline & & $\begin{array}{r}\text { Chi- } \\
\text { square }\end{array}$ & Df & Sig. \\
\hline TTC & Model & 12.442 & 3 & 0.006 \\
\hline
\end{tabular}

Where:

$\mathrm{Df}=$ degrees of freedom

Sig = significance

The omnibus reveals medium levels of significance for all three remaining variables at 0.006 with a Chi-Square value of 12.442. To determine the influence of each individual variable, each covariate was compared to the dependent variable (non compliance TTC). These are summarized below:

- High Pathway - contributing 11.889 of 12.442 of Chi-Square with a high significance weighting of $\mathrm{p}=0.001$. 
- Medium Source -contributing 0.357 and a low significance weighting of $p=0.550$.

- Receptor - minimal significance with a Chi-Square distribution of 0.005 and a very low significance weighting of $p=0.941$.

The greater significance of pathway factors may be explained by the high presence of open wells in close proximity to many traditional wells.

Note that low numerical values of $p(p \leq 0.05)$ indicate high significance, with the significance reducing as numerical values of $\mathrm{p}$ approach 1.

In comparison, analysis of non-compliance of EF noted a lower Chi-Square value of 6.218. Influence of individual variables was noted using cross tabulation. These are summarized below:

- Pathway and Source - low $p$ value of $p=0.221$

- Receptor - high level of precision $(p=0.036)$. Chi-Square analysis further revealed a receptor contributory variable of 4.403 of total 6.218 .

The results therefore indicate that the receptor contributes most significantly to traditional well contamination of enterococci. The high level of significance of the receptor in the occurrence of enterococci can be explained by the unprotected design of traditional wells and the high risk of direct ingress of both animal and human derived contaminants following rainfall. As noted by Godfree et al (1997), enterococci are derived from a ratio of human and animal faeces. Due to high levels of false positives of specific Enterococcus genus groups, the precise ratio has been discredited as a means of determining the source of enterococci pollution. Nonetheless, the higher levels of enterococci in traditional wells may be related to washing in of both animal and human faeces through preferential flowpaths.

\section{Chi-Squared Analysis - Traditional Wells - Results Summary}

The results for traditional wells indicate:

1. For enterococci receptor (or localised pathways) are a significant risk to contamination of shallow groundwater,

2. For TTC, pathway is a significant due to presence of open wells,

3. Difference in findings for TTC and enterococci may be explained by the relative amount of animal and human excreta in the environment. 


\section{Improved Well with Handpumps - Chi Square Analysis}

In Improved wells, Chi-Square analysis revealed that the receptor was the greatest contributing variable. Table 31 below outlines the omnibus results from the ChiSquare analysis.

Table 31: Omnibus - Thermotolerant Non Compliance

\begin{tabular}{|l|l|r|c|c|}
\hline & & $\begin{array}{r}\text { Chi- } \\
\text { square }\end{array}$ & Df & Sig. \\
\hline TTC & Model & 10.446 & 1 & 0.001 \\
\hline
\end{tabular}

Where:

Df $=$ degrees of freedom

Sig $=$ significance

The omnibus indicates a Chi-Square value of 10.446 with only 1 degree of freedom. The results indicate a high level of probability that the relationship between the source, pathway and receptor are of statistical significance. Of the 10.446 , the data indicates that the receptor and source equate to a Chi Square contribution of 4.301 or $\mathrm{p}=0.111$.

\section{Chi-Squared Analysis - Improved Wells - Results Summary}

The results for improved wells therefore indicate:

1. TTC and EF - receptor is the most significant variable,

2. TTC - receptor is a highly significant variable,

3. TTC and EF - risk is dependent on the combination of source and receptor.

\section{Upgraded Well with Windlass - Chi Square Analysis}

In upgraded wells, Chi-Square analysis indicates a value of 1.814 with 3 degrees of freedom. The level of significance between variables is considered low at 0.612 .

Table 32: Omnibus - Thermotolerant Non Compliance

\begin{tabular}{|r|r|r|c|c|}
\hline & & $\begin{array}{r}\text { Chi- } \\
\text { square }\end{array}$ & Df & Sig. \\
\hline TTC & Model & 1.814 & 3 & 0.612 \\
\hline
\end{tabular}

Where:

$\mathrm{Df}=$ degrees of freedom

Sig $=$ significance

Within the Ch Square value of 1.814, the receptor indicates greatest statistical significance, contributing 1.124 to the total. This may indicate that the design and workmanship of the upgraded well is a significant factor in the risk of contamination. 
- Receptor is of greatest statistical significance,

- A combination of factors is required to cause microbial contamination.

\section{ANALYSIS 1 SUMMARY}

Findings and observations from analysis one include:

- For both EF and TTC, high levels of significance were noted of localized pathways in both traditional and upgraded wells,

- For both EF and TTC, a combination of variables is required for increased risk,

- For EF higher risk of direct ingress of both animal and human derived faecal matter was noted in traditional wells than other well technologies,

- For TTC and EF, the quality of the receptor of upgraded wells was of significance.

\subsubsection{Analysis 2 - Sanitary Inspection}

The second analysis involved monthly analysis of source, pathway, receptor plus significance of specific sanitary inspection results to microbiological noncompliance. The specific risks identified through the sanitary inspection forms are termed as hazards in Figure 39. Data were dummy coded as binomial data in SPSS Version 11 on a monthly basis. This considered variations in sanitary inspection results for each well technology in each month. Results are presented collectively for each well technology beginning with traditional wells, followed by upgraded and improved wells.

\section{Traditional Well}

Figure 39 below outlines results for significance weightings of individual sanitary inspection results and specific source, pathway and receptor variables for the noncompliance of EF and TTC. Greater levels of statistical significance were obtained in correlation of p-values for TTC as opposed to EF. 


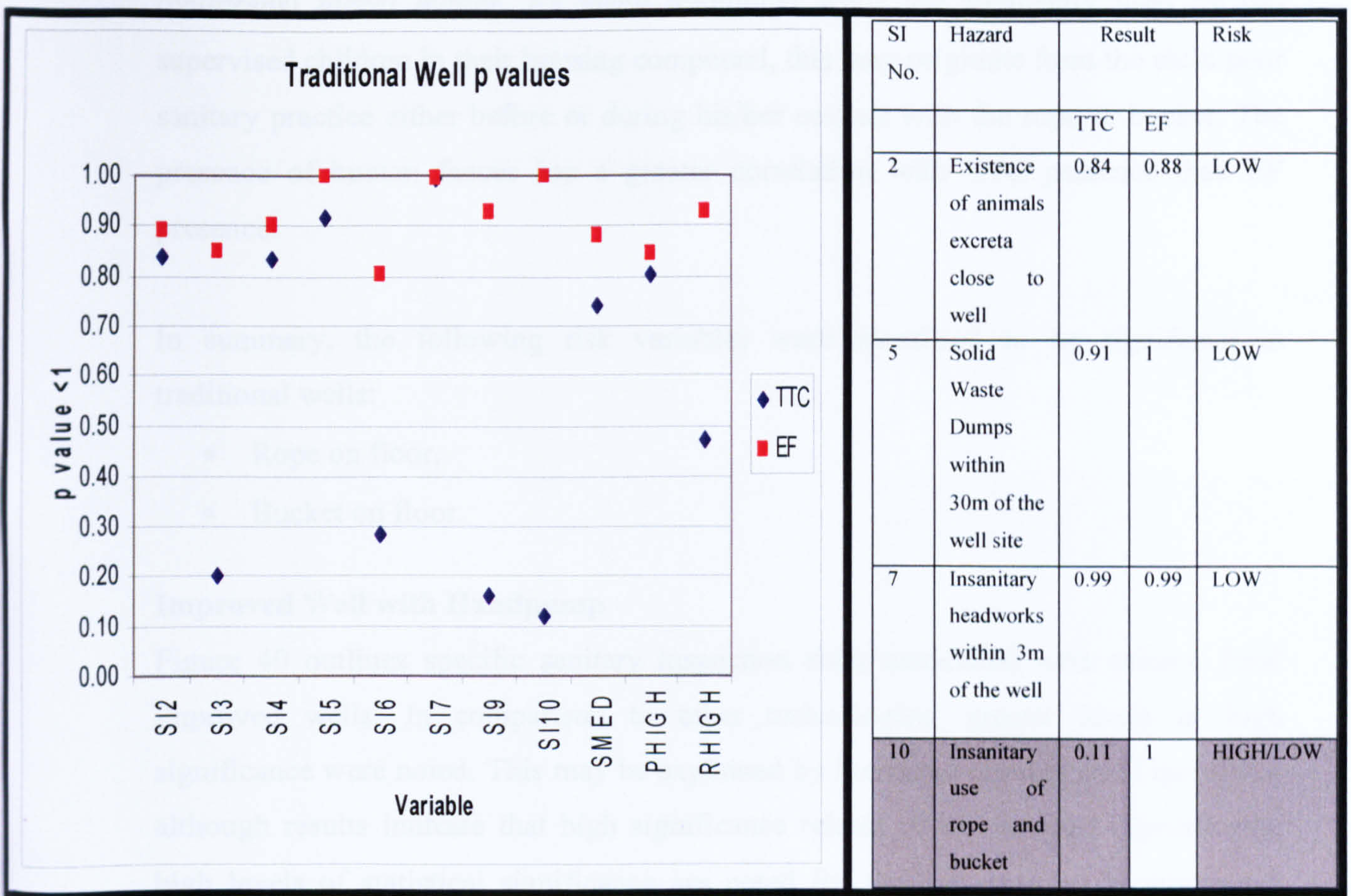

Where: Statistical Significance $=$ close to $<0.05$ shown as grey

Specifically, results indicate low levels of significance of sanitary risk scores 5 and 7 . Sanitary inspection point $5(\mathrm{p}=0.918$ and $\mathrm{p}=1$ for TTC and enterococci respectively). This equates to occurrence of solid waste dumps within $30 \mathrm{~m}$ of the well site. Sanitary inspection $7(\mathrm{p}=0.994$ and $\mathrm{p}=0.996$ for TTC and enterococci respectively) equates to Insanitary Headworks within $3 \mathrm{~m}$ of well. Low level of risk is further noted from sanitary inspection no. $2(\mathrm{p}=0.840 / 0.889)$, which refers to the existence of animal excreta close to well. As results refer to traditional unlined wells, specific shortcircuiting of aquifer pathways through preferential flow paths in the receptor appears common.

Results reveal a further high level of significance associated with cross contamination from the bucket or rope being present on the floor (SI Question 10). High levels of significance are noted for SI Question10 (Insanitary use of rope and bucket) in relation to non-compliance with TTC but very low correlation is noted for noncompliance of EF. This is explained by a combination of high presence of human 
(childrens) faecal matter. As many traditional wells are frequently used by unsupervised children in their housing compound, this may originate from the child poor sanitary practice either before or during his/her contact with the rope or bucket. The presence of human faeces has a greater correlation with TTC presence than EF presence.

In summary, the following risk variables were identified to be significant in traditional wells:

- Rope on floor,

- Bucket on floor.

\section{Improved Well with Handpump}

Figure 40 outlines specific sanitary inspection risks associated with caisson lined improved wells. In comparison to other technologies, greater levels of high significance were noted. This may be explained by increased number of SI questions, although results indicate that high significance relates to the receptor. Specifically, high levels of statistical significance are noted for the influence of SI question 8 (Deficient Drainage) or SI question 9 (Headwork's diameter $<2 \mathrm{~m}$ ) for both TTC and $\mathrm{EF}$. This indicates that the improved design of the headworks of the wells is not satisfactory. 


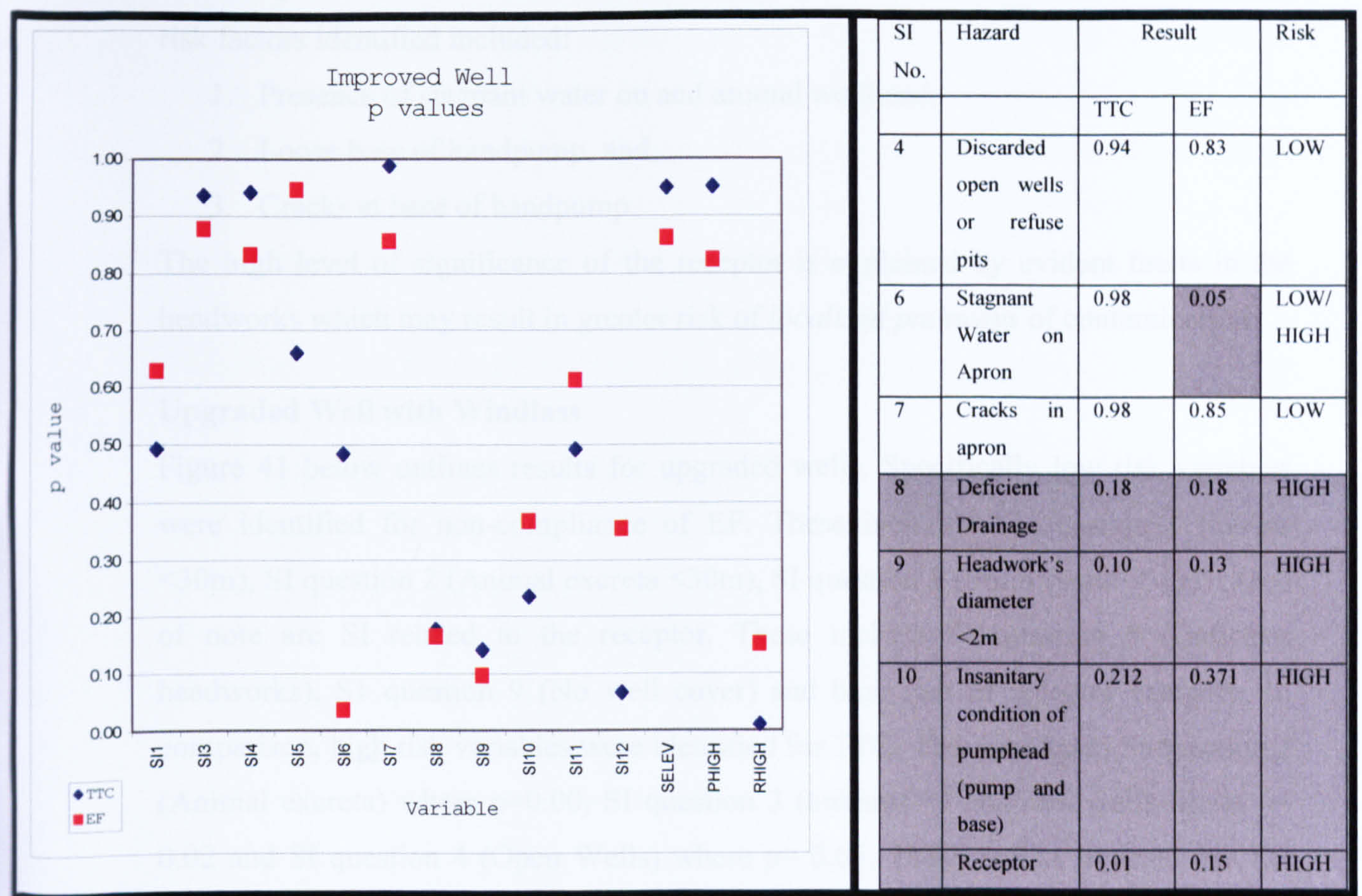

Where: Statistical Significance $=<0.05$ shown as grey

Lower significance was however noted in relation to the influence of cracks in the apron/headworks (SI 7) where $\mathrm{p}$ values of $\mathrm{p}=0.988$ and $\mathrm{p}=0.857$ were noted for TTC and EF non-compliance respectively. This may be explained by the age of the wells under study which were noted to be constructed during a period of high quality control. Equally, low levels of significance were noted for open wells or refuse pits within $30 \mathrm{~m}$ of the well at TTC $(\mathrm{p}=0.941)$ and $\mathrm{EF}(\mathrm{p}=0.831)$ respectively.

High level of significance was noted for both the presence of stagnant water (SI question 6) and for the insanitary condition of the pump head (connection between pump base and apron (SI question 10)). This is explained by the fact that $75 \%$ of wells studied had unsecured and cracked handpump bases. Greatest significance was noted for the receptor as a whole where $\mathrm{p}=0.01$ and $\mathrm{p}=0.15$ for TTC and EF respectively. The high level of significance of the receptor is explained by evident faults in the headworks which may result in greater risk of localised pathways of contamination. 
The receptor was identified as being the principal route of contamination. Specific risk factors identified included:

1. Presence of stagnant water on and around wellhead,

2. Loose base of handpump, and,

3. Cracks at base of handpump.

The high level of significance of the receptor is explained by evident faults in the headworks which may result in greater risk of localised pathways of contamination.

\section{Upgraded Well with Windlass}

Figure 41 below outlines results for upgraded wells. Specifically low risk variables were identified for non-compliance of EF. These included SI question 1 (latrine $<30 \mathrm{~m}$ ), SI question 2 (Animal excreta $<30 \mathrm{~m}$ ), SI question 5 (Solid waste $<30 \mathrm{~m}$ ). Also of note are SI related to the receptor. These include SI question 8 (Deficient headworks), S1 question 9 (No well cover) and high risk of receptor category. In comparison, high risk variables were identified for TTC. These included SI question 2 (Animal excreta) where $\mathrm{p}=0.00$, SI question 3 (animals $<10 \mathrm{~m}$ from well) where $\mathrm{p}=$ 0.02 and SI question 4 (Open Wells) where $p=0.05$. These results indicate that the source of contamination is of great significance for upgraded wells.

Figure 41 Upgraded wells sanitary inspection records

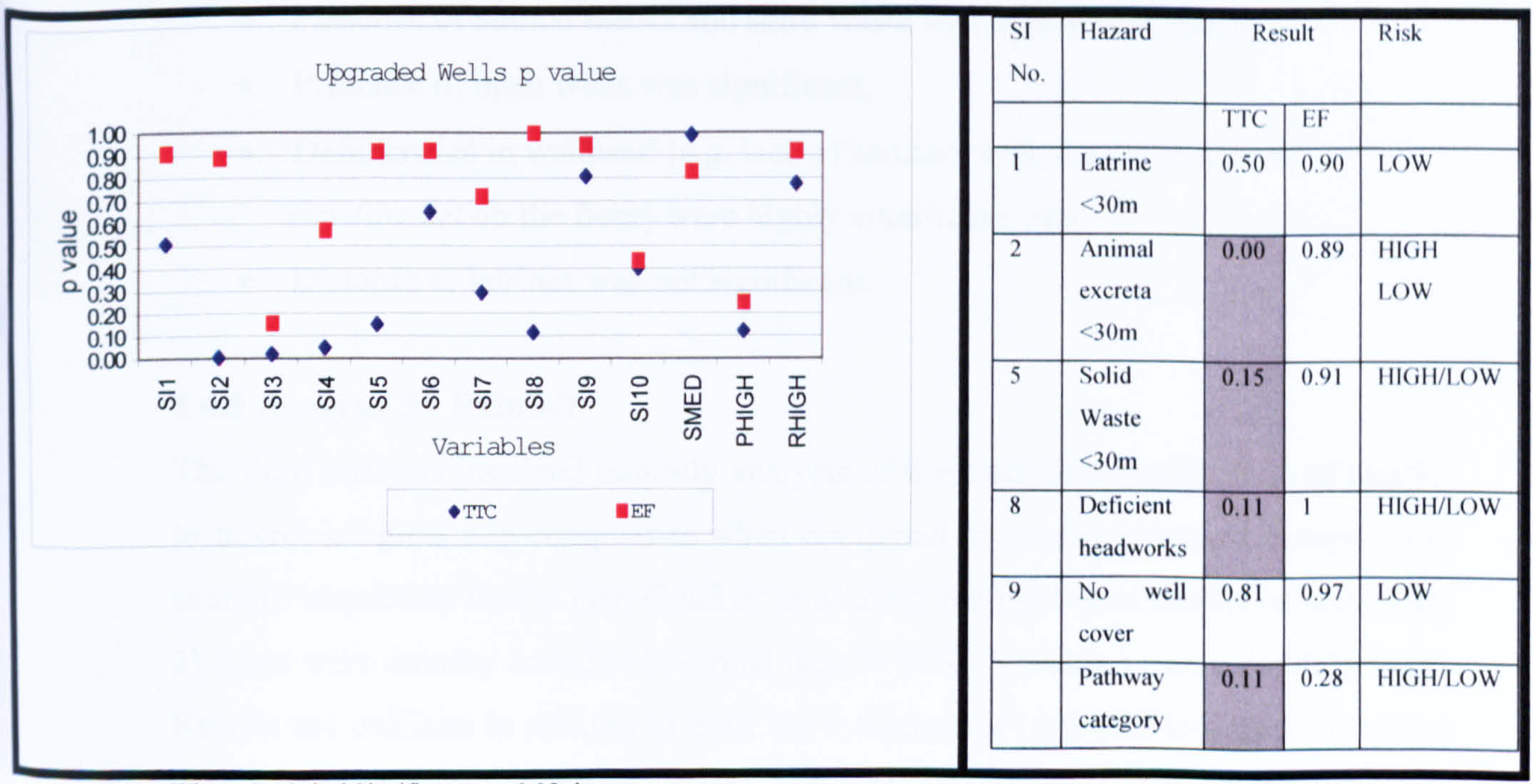

Where: Statistical Significance $=<0.05$ shown as grey 
In addition, medium levels of significance were noted for pathway factors $(p=0.12)$. This may be explained by the denser population in which the wells are located as well as the higher vulnerability of soil type. The combination of the high faecal source factors suggests that upgraded wells are more susceptible to microbiological contamination by TTC indicator organisms than EF organisms.

Specifically, the following risks were identified as being of significance for upgraded wells:

- Solid Waste $<30 \mathrm{~m}$

- Animal excreta $<30 \mathrm{~m}$

- Deficient headworks (No well cover)

\section{ANALYSIS 2 SUMMARY}

Analysis of specific sanitary inspection risks indicates the following:

- TTC is more numerous in traditional and upgraded wells than in improved wells,

- $\quad \mathrm{EF}$ is more numerous in improved sources than in traditional and upgraded wells,

- Presence of animal faeces and solid waste was highly significant,

- Presence of open wells was significant,

- Deficiencies in wellhead (e.g. lack of sanitary seal, cracks in aprons, rope/bucket on the floor) were highly significant, and,

- Distance to latrines was not significant.

\subsubsection{Analysis 3 - Rainfall}

The third analysis involved monthly analysis of the statistical significance of rainfall to microbiological non-compliance when compared to source, pathway, receptor and sanitary inspection results (see Godfrey et al 2005 for published results in Appendix 1). Data were dummy coded as binomial data in SPSS Version 11 on a monthly basis. Results are outlined in relation to both the influence of high and low rainfall (where low is defined as $<10 \mathrm{~mm}$ per month) and high rainfall (as defined as $>10 \mathrm{~mm}$ per month). For both traditional and upgraded wells, levels of non-compliance were noted as being of greatest significance during periods of low rainfall. For all well types, 
levels of microbiological non-compliance were noted as greatest during periods of high rainfall. Results are summarised in table 32 .

Table 33 Rainfall

\begin{tabular}{|l|c|c|c|c|c|c|}
\hline & \multicolumn{2}{|c|}{ Traditional Well } & \multicolumn{2}{c|}{ Improved Well } & \multicolumn{2}{c|}{ Upgraded Well } \\
\hline & TTC & EF & TTC & EF & TTC & EF \\
\hline Rain High & 0.472 & 0.527 & 0.014 & 0.147 & 0.297 & $\mathbf{0 . 9 3 5}$ \\
\hline Rain Low & $\mathbf{0 . 9 6 3}$ & $\mathbf{0 . 8 5 2}$ & & & $\mathbf{0 . 2 2 5}$ & $\mathbf{0 . 9 4 8}$ \\
\hline
\end{tabular}

Rainfall was only significant in improved wells during peak rains. High $\mathrm{p}$ values of $\mathrm{p}=0.014$ were noted for TTC indicating a high statistical correlation between TTC contamination and periods of rainfall. Equally, medium levels of compliance were noted for $\mathrm{EF}(\mathrm{p}=0.147)$. The higher than average levels of significance in improved wells indicate the presence of preferential pathways. Further Chi-Squared analysis noted a Chi Square value of 37.116. Analysis of variance based on individual rainfall variables contribute to 2.001 of distribution. This is in combination with the specific risk variables of SI question 12 (pump base unhygienic $\mathrm{p}=0.083$ ) and high risk receptor $(\mathrm{p}=0.005)$, with Rain High $\mathrm{p}=0.001$.

Rainfall is slightly less significant in upgraded wells than improved wells during peak rainy periods. However, both traditional and upgraded wells are affected by both high and low rains, whereas improved wells are not affected during periods of low rainfall. Chi Squared analysis of upgraded wells reveals a 24.138 total and significance of $\mathrm{p}=0.063$. Cross tabulation reveals that SI question 2 and 4 with animal faeces within $10 \mathrm{~m}$ of well contribute 13.589 of significance of 24.138 .

In traditional wells, rain alone is not of significance. However, when combined with high risk pathways or high risk sources in the environment, high risk occurs. All wells are highly susceptible to high rains from both TTC and EF bacteria following first "low" flush of rainfall. This is outlined in figure 42, where the bottom axis graph outlines daily rainfall records and the top axis graph outlines results from three separate water quality results $\left(13 / 14^{\text {th }}\right.$ November, $23 / 24^{\text {th }}$ November and $16 / 17^{\text {th }}$ December 2003). 


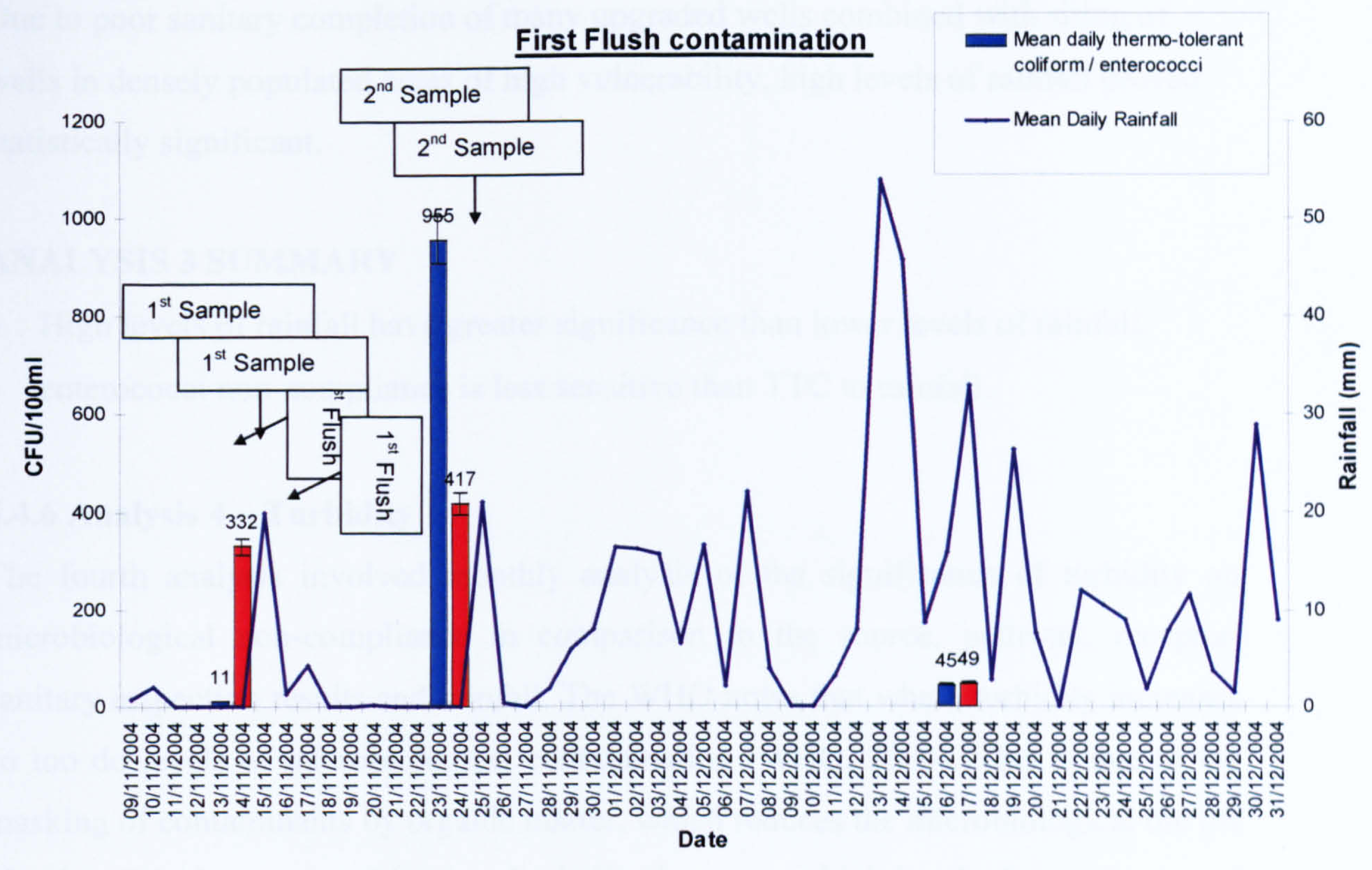

Figure 42 indicates rainfall as a blue line measured on a daily basis. TTC numbers are shown as red columns and Enterococci as blue columns. These (numbers of TTC and EF) were measured less frequently. Results in Figure 42 indicate that microbiological analysis was undertaken on $13 / 14^{\text {th }}, 23 / 24^{\text {th }}$ of December 2003 and on the $15 / 16^{\text {th }}$ of January 2004. The first significant rainfall of the season $(25 \mathrm{~mm})$ occurred on the $15^{\text {th }}$ of November 2003 and the next microbiological sample showed elevated numbers of TTC and EF. The assumption is that these elevated numbers are linked to the significant rainfall a eight days before. However, it was not possible to take microbiological samples at more frequent intervals. The further assumption that the first significant rainfall of the season produced a "first flush" is supported by the fact that subsequent higher rainfall incidents occurred, but numbers of TTC/EF reduced.

Further analysis of the data indicated that upgraded wells were more susceptible to contamination from the first flush. This occurred due to:

1. Greater proximity of upgraded wells to hazard sources,

2. Low permeability of soils in Ceramica where the majority of upgraded wells are located, 
3. Low levels of receptor protection.

Due to poor sanitary completion of many upgraded wells combined with siting of wells in densely populated areas of high vulnerability, high levels of rainfall proved statistically significant.

\section{ANALYSIS 3 SUMMARY}

- High levels of rainfall have greater significance than lower levels of rainfall,

- enterococci non-compliance is less sensitive than TTC to rainfall.

\subsubsection{Analysis 4 - Turbidity}

The fourth analysis involved monthly analysis of the significance of turbidity on microbiological non-compliance in comparison to the source, pathway, receptor, sanitary inspection results and rainfall. The WHO notes that where turbidity increases so too do levels of microbiological contamination (WHO, 2004). This is due to the masking of contaminants by organic matter, which reduces the microbiological die off kinetics. Results support this view by indicating a very high level of significance of turbidity in relation to microbiological non-compliance. Figure 43 below outlines results from Lulimile for monthly turbidity and thermotolerant coliform readings.

Figure 43: TTC v Turbidity

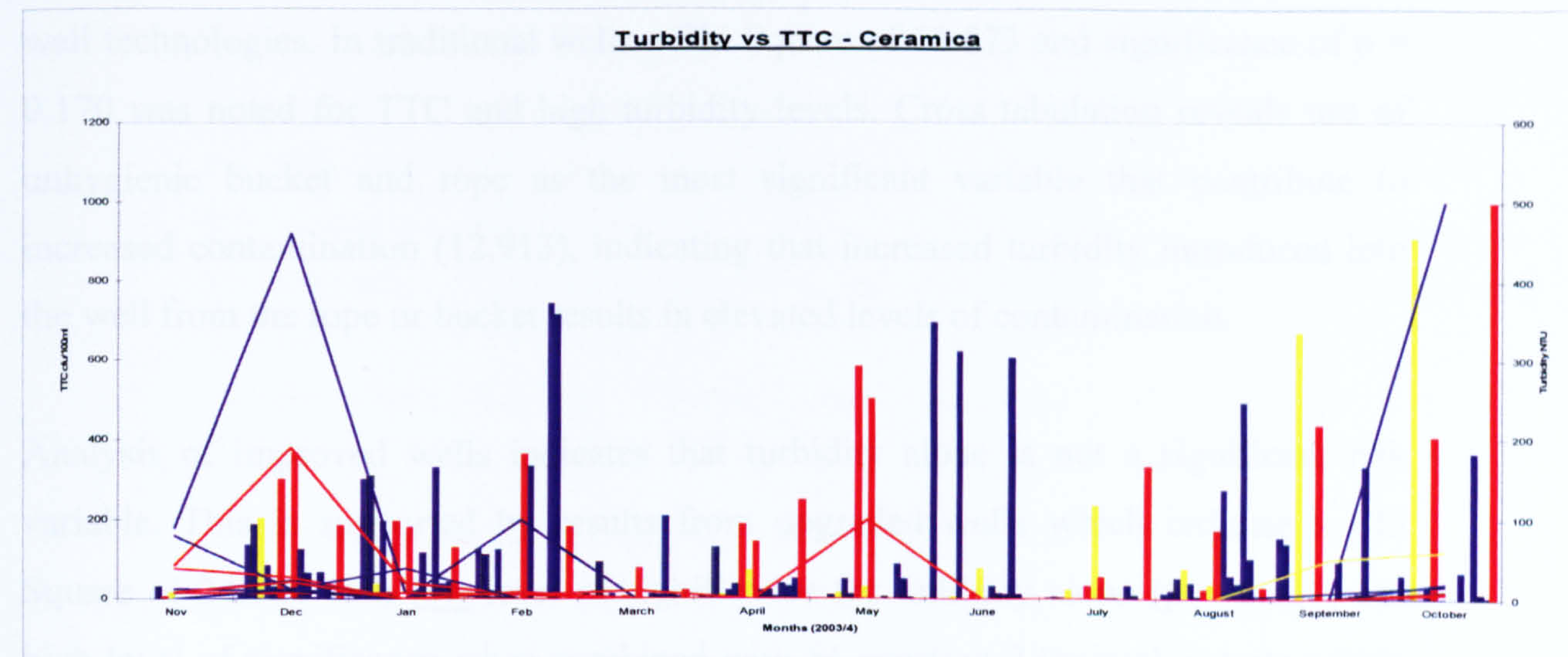



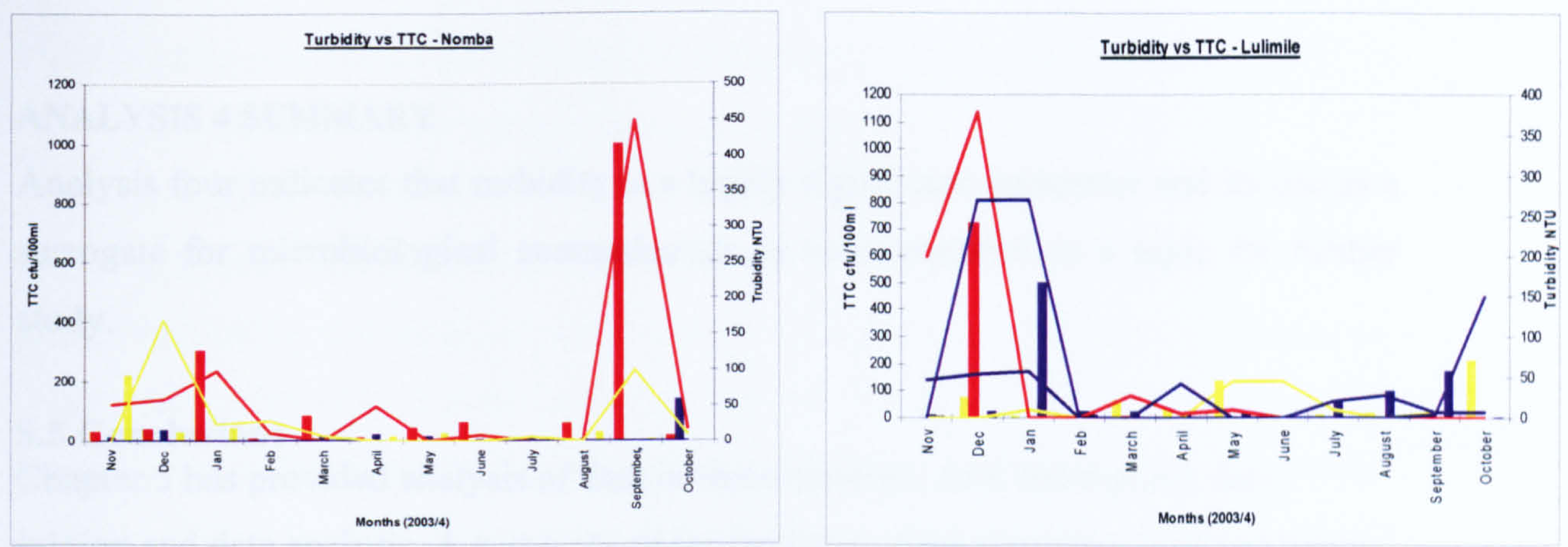

Figure 43 shows the monthly turbidity and TTC readings for the three study areas. The data is colour coded with Traditional Wells in Red, Upgraded Wells in Blue and The lines indicate the turbidity readings and the columns indicate the TTC readings. All data are shown as mean monthly data. From Figure 43 a trend can be observed with a correlation between an increase in turbidity and an increase in microbiological contamination. This is particularly evident in Nomba and Lulimile, and less so in Ceramica

To gain a better understanding, a Chi-Square analysis was undertaken. The results indicate a high level of statistical correlation between turbidity and TTC in all three well technologies. In traditional wells a Chi Square of 18.873 and significance of $\mathrm{p}=$ 0.170 was noted for TTC and high turbidity levels. Cross tabulation reveals use of unhygienic bucket and rope as the most significant variable that contribute to increased contamination (12.913), indicating that increased turbidity introduced into the well from the rope or bucket results in elevated levels of contamination.

Analysis of improved wells indicates that turbidity alone is not a significant risk variable. This is supported by results from upgraded wells which indicate a Chi Square of 24.184 with $\underline{\text { low }}$ level of significance for turbidity alone $(p=0.831)$ but high level of significance when combined with SI question 2 (animal excreta within $10 \mathrm{~m}$ of the well $(\mathrm{p}=0.002)$.

Analysis of trends of turbidity in the results suggests that contamination increases and decreases with levels of turbidity therefore supporting the view that turbidity is an effective surrogate of microbiological contamination. 


\section{ANALYSIS 4 SUMMARY}

Analysis four indicates that turbidity is a highly significant parameter and its use as a surrogate for microbiological contamination is recommended as a topic for further study.

\subsection{Conclusions}

Chapter 5 has provided analysis of data in three sections, data description, data mining and data analysis. A summary of the findings of the chapter is outlined below.

\begin{tabular}{|l|l|}
\hline \multicolumn{1}{|c|}{ SUMMARY OF FINDINGS } \\
\hline Feneral & $\begin{array}{c}\text { Sources of Contamination } \\
\text { 1. Animal Faeces major source of contamination. }\end{array}$ \\
& $\begin{array}{l}\text { 2. POSH method noted overall Moderate to Reduced levels of sources of contamination (2 } \\
\text { wells only with Elevated level). }\end{array}$ \\
& $\begin{array}{l}\text { Pathways of Contamination } \\
\text { 1. Rainfall significant in increasing contamination }\end{array}$ \\
& $\begin{array}{l}\text { Receptor of Contamination } \\
\text { 1. Headworks major pathway to contamination }\end{array}$ \\
2. High risk in 6 of the 25 wells
\end{tabular}

Section 5.2 provided a description of the data. The description was divided into a description of the source, pathway and receptor data collected. The source data were described using an adaptation of the POSH method where a moderate to reduced level of pollution loading was observed. The pathway was described using the Hydrogeological settings method. 
From the data description the following findings regarding the study site

1. It incurred heavy rainfall during study year 2003-4,

2. It comprised of a clay/silt soil with a low permeability of $10^{-4}$ to $10^{-8} \mathrm{~m} / \mathrm{s}$

3. It was moderate to high vulnerability.

Description of the barrier noted an innovative use of the Analytic Hierarchy Process (AHP) due to the lack of available information on the below ground components of the study wells. The AHP and quantitative assessments revealed the following results:

- Poor quality materials and workmanship combined with lack of sanitary seal resulted a high number of wells being at high risk to microbiological contamination.

Further analysis of water quality data supported this view and noted low levels of compliance for both thermotolerant coliforms and enterococci in improved and traditional wells.

Significantly, very low levels of compliance were noted in upgraded wells questioning the wells inclusion as an improved source. However, in line with recommendations from the WHO (2004), reliance on end product water quality results to determine "water safety" is inadequate. Therefore section 5.4 analysed the specific risk variables that contribute to these results. Data were analysed using logistic regression and Chi-Square. Analysis revealed:

1. High levels of significance of the receptor in contributing to microbiological non compliance.

2. Analysis 1 in section 5.4 .2 noted high levels of statistical significance for both EF and TTC due to localized pathways in both traditional and upgraded wells.

3. Greater risk was also noted based on a combination of variables and that although localized pathways appear predominant, there significance is dependent on the presence of other variables.

Further analysis (2) noted:

1. Distance to latrines was not a major risk variable.

2. Presence of animal faeces was a major risk,

3. Presence of open wells and deficiencies in wellhead (e.g. lack of sanitary seal, cracks in aprons, rope/bucket on the floor) were a major risk. 
Analysis 2 noted that TTC is more prominent in traditional and upgraded wells and that $\mathrm{EF}$ is more prominent in improved sources due its higher survival function at depth. Analysis 3 and 4 further noted the significance of rainfall and turbidity in contributing to the risk of microbiological contamination with higher levels of risk noted during high rainfall periods and during periods of peak turbidity. 
Chapter 6: Risk Management 


\subsection{Introduction}

Chapter 5 presented an analysis of data collected from Lichinga, Mozambique and provided answers to the defined research problem in this research of How to assess the significance of variables affecting microbiological risk to shallow groundwater. Chapter 5 identified specific variables associated with microbiological risk to shallow groundwater as well as specific weaknesses in sole reliance on end product (water quality) results. Having assessed the significance of each of these variables, this chapter (Chapter 6) presents potential methods of both managing and communicating risk. In line with global initiatives in the water quality sector, this chapter firstly presents a conceptual background to recent initiatives in the water risk management sector and then presents a model risk management strategy for each of the well technologies studied.

\subsection{Background}

As noted in detail in Chapter 2, fundamental weaknesses of reliance on end product testing in the water sector have been identified. In summary these include;

- Presence of indicator bacteria is not definitive evidence of pathogen presence,

- Minimal link between bacteria and corrective actions,

- Testing provides limited warning regarding water quality deterioration,

- Testing is likely to be "Too little-too late" as once bacteria are identified, they have often already been consumed.

Within the water and public health sectors, recognition of the weakness of the indicator bacteria system has led to increasing work to develop more effective methods of monitoring and controlling water safety.

Similar problems with end-product testing were noted in the 1980s in the food industry. These in turn, led to the development of HACCP ( Critical Control Points). HACCP originated as a risk management tool for food safety but has its origins in the NASA programme. It is now widely accepted and is recommended through the FAO/WHO Codex Alimentarius as an effective risk management tool for managing food safety.

In 1994, Havelaar proposed the transferral of the principles of HACCP to the water sector (WHO, 2004). Following its proposal, various initiatives have been undertaken 
to trial HACCP in the water sector. These include work by Deere et al. (2001) in applying to piped water supplies in Australia, by Howard (2002) in application for small water supply systems and by the author in applying the principles to water supplies in developing countries (Godfrey et al. 2005).

In light of these developments, the WHO (2004) proposed a more global application of HACCP for water supplies in the $3^{\text {rd }}$ edition of the WHO Guidelines for Drinking Water Quality. The WHO GDWQ $3^{\text {rd }}$ edition proposed a fundamental shift in the approach to water safety. The process, termed Water Safety Framework, outlines a globally applicable method for assessing and managing microbiological risk founded upon the principles of quality assurance as opposed to quality control. Quality assurance in this context is defined as a thorough understanding of the risk associated with a groundwater supply, which is then verified through microbiological quality control.

This framework has a number of components. These include (see figure 44):

1. Setting up health based water quality targets based on health concerns,

2. Undertaking system assessments to determine the safety of the water supply,

3. Establishing operational monitoring of control measures in the water supply,

4. Developing management plans to document the system assessment and monitoring, and,

5. Providing an independent surveillance and verification system.

Due to time and financial limitations, this research focuses on the main components of the Water Safety Framework known as Water Safety Plans (WSPs). The research does not address the health based water quality targets (using Quantitative Risk Assessment tools) outlined in red in figure 44. The principles of WSPs are:

- to prevent contamination of source waters;

- to treat the water to reduce or remove contamination that could be present to the extent necessary to meet the water quality targets; and

o to prevent re-contamination during storage, distribution and handling.

(Davison et al, 2005) 
Figure 44: Framework for safe drinking water (WHO 2004)

FRAMEWORK FOR SAFE DRINKING-WATER
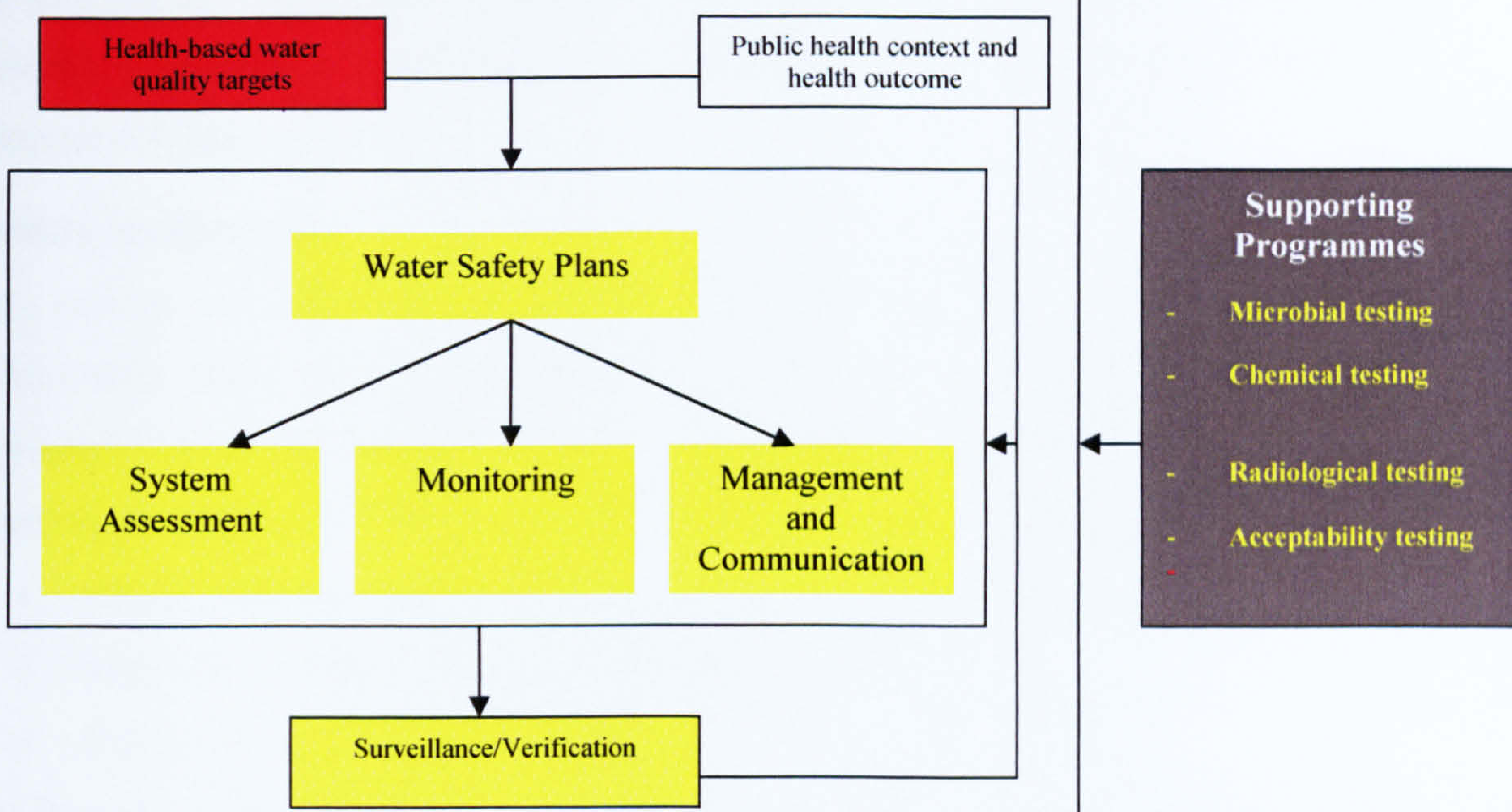

Conceptually, the WSP varies from historical approaches, where water quality was controlled solely through end product testing (Godfrey et al. 2005).

Figure 45: Historical and WSP approach

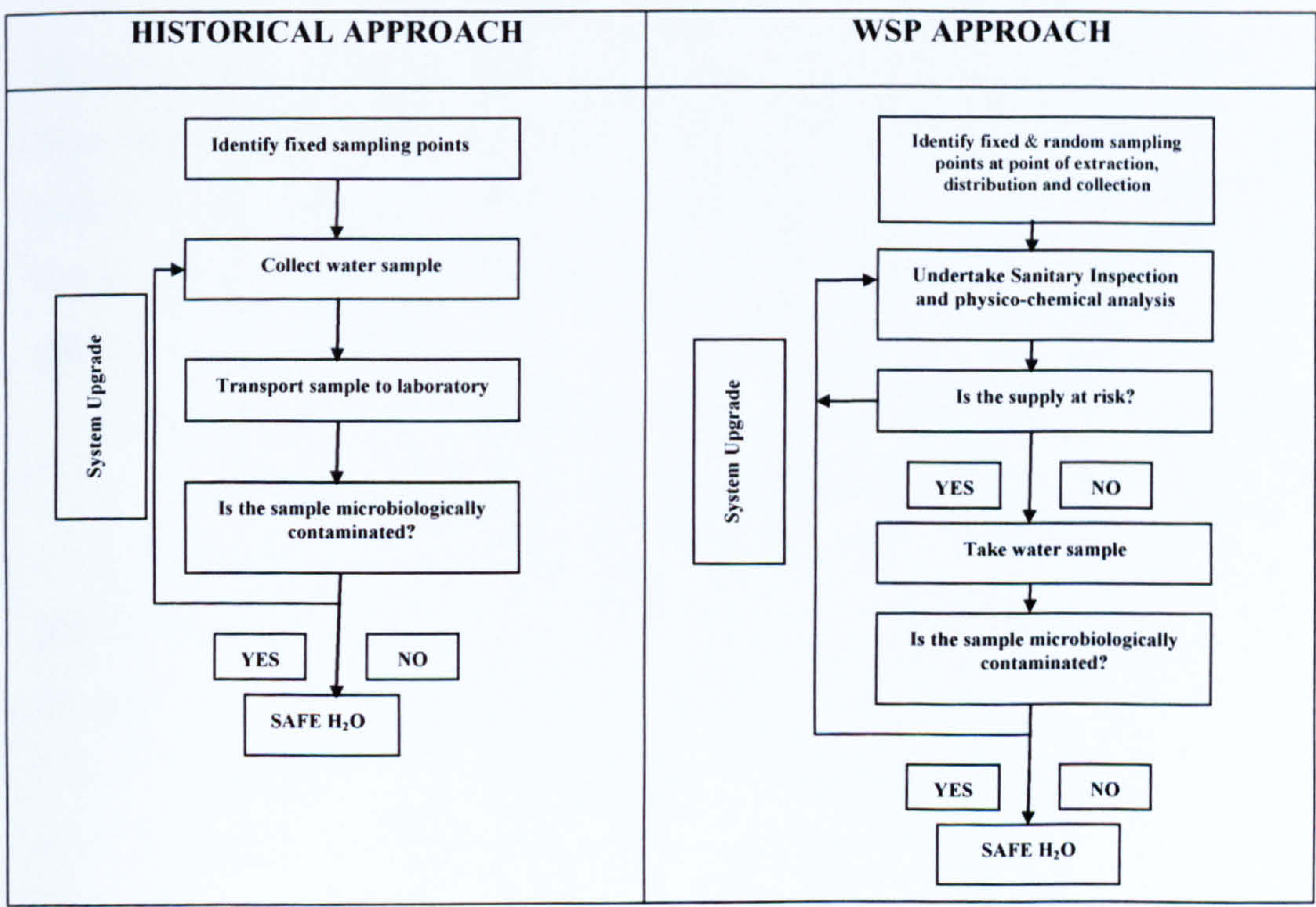


As noted in Figure 45, historically, sole reliance was placed on testing of indicator bacteria. The WSP approach identifies control points and control measures throughout the process of abstraction, distribution and collection of groundwater and then provides a means of monitoring and verification for each plus suggestions for potential corrective actions.

\subsection{Risk management}

This section describes the application of the WSP principles to the three well technologies under study in this research. Central to the understanding of the WSP application is an appreciation of the hydrogeological model used throughout this research, namely the SOURCE-PATHWAY-RECEPTOR relationship. Is:

- Source = hazard event/environment (e.g. latrine/animal faeces/solid waste),

- Pathway = vulnerability of the media (e.g. soil type), and

- Receptor= receiving water infrastructure (e.g. hand dug well).

The first step in applying WSPs to the wells studied is to identify specific hazard events that affect the risk to each well technology at each of the three stages outlined above. Where these relate to particular points within the receptor (e.g. apron or extraction mechanisms), control points are identified on the basis of information gained about the system during the field study.

Consideration is then given to how to monitor these points with emphasis on simple frequently repeatable methods (e.g. sanitary inspection or turbidity monitoring). Based on the information from this monitoring, control measures are established at the source, pathway and receptor. Critical limits are assigned to each control measure and consist of two levels;

- target level - state in which the well should be operated to ensure safety

- action level - state in which remedial action is required immediately to bring well back into compliance (WHO, 2004).

Microbiological testing is then undertaken as a means of verifying the compliance of the system to the control measure. The combination of these factors is known as a Water Safety Plan. The definition of the specific risk associated with each hazard event is based on definitions outlined in Davison et al. (2005) and WHO (2004). Both recommend an approach based on the identification of potential sources of hazards and then the pathways into water supply (receptor). Data from Chapter 5 are used to 
assess the potential frequency of each event. The severity of impact of each of these events is based on a combination of the frequency of occurrence and extent and severity of impact of a specific risk. The weightings presented are based on those developed for the WHO (2004). These are outlined in table 33 below with a high weighting indicating greater significance.

Table 34: Condition and weighting of hazard events (WHO 2004)

\begin{tabular}{|l|l|l|c|}
\hline & \multicolumn{1}{|c|}{ Description } & \multicolumn{1}{|c|}{ Definition } & Weighting \\
\hline Frequency of occurrence & Almost certain & Once per day & 5 \\
\cline { 2 - 4 } & Likely & Once per week & 4 \\
\cline { 2 - 4 } & Moderate & Once per month & 3 \\
\cline { 2 - 4 } & Unlikely & Once per year & 2 \\
\cline { 2 - 4 } & Rare & Once every 5 years & 1 \\
\hline \multirow{5}{*}{$\begin{array}{l}\text { Extent and severity of } \\
\text { impact }\end{array}$} & Catastrophic & Potentially lethal to large population & 5 \\
\cline { 2 - 4 } & Major & Potentially lethal to small population & 4 \\
\cline { 2 - 4 } & Moderate & Potentially harmful to large population & 3 \\
\cline { 2 - 4 } & Minor & Potentially harmful to small population & 2 \\
\cline { 2 - 4 } & Insignificant & No impact or not detectable & 1 \\
\hline
\end{tabular}

The severity of impact of an individual hazard event occurring is then estimated on the basis of the product of a combination of the frequency of the conditions and these are outlined in table 34 below.

Table 35 Final risk ratings for potential combinations (WHO 2004)

\begin{tabular}{|l|c|c|c|c|c|}
\hline \multirow{2}{*}{$\begin{array}{l}\text { Frequency of } \\
\text { occurrence }\end{array}$} & \multicolumn{5}{|c|}{ Severity/extent of impact } \\
\cline { 2 - 6 } & Catastrophic & Major & Moderate & Minor & Insignificant \\
\hline $\begin{array}{l}\text { Almost } \\
\text { certain }\end{array}$ & 25 & 20 & 15 & 10 & 5 \\
\hline Likely & 20 & 16 & 12 & 8 & 4 \\
\hline Moderate & 15 & 12 & 9 & 6 & 3 \\
\hline Unlikely & 10 & 8 & 6 & 4 & 2 \\
\hline Rare & 5 & 4 & 3 & 2 & 1 \\
\hline
\end{tabular}

The use of this aids the management of risk at identified control points. Outlined below are model Water Safety Plans for traditional wells, upgraded wells and improved wells. It is acknowledged that these are only model plans developed for this research. In order to apply them other "supporting programmes" would be required which may include community and water quality training, hygiene promotion and logistic supply. However, these are beyond the scope of this research and therefore focus is only given to model or conceptual risk management plans.

Information provided in the model WSPs is based on specific risk variables identified in Chapter 5. For example, means of verification are identified based on levels of statistical correlation (established in Chapter 5) to individual risk variables. Similarly, 
means of monitoring are outlined based on effectiveness of turbidity monitoring and specific sanitary inspection results. It is recognised that although the monitoring may be feasible for community leaders, the means of verification (microbiology) must be done by external expertise such as by government staff or Non Government Organizations (NGOs).

The tables below outline model water safety plans. Table 35 presents a Water Safety Plan for traditional wells, Table 36 for Improved Wells with a handpump and Table 37 for Upgraded Wells with windlass. 


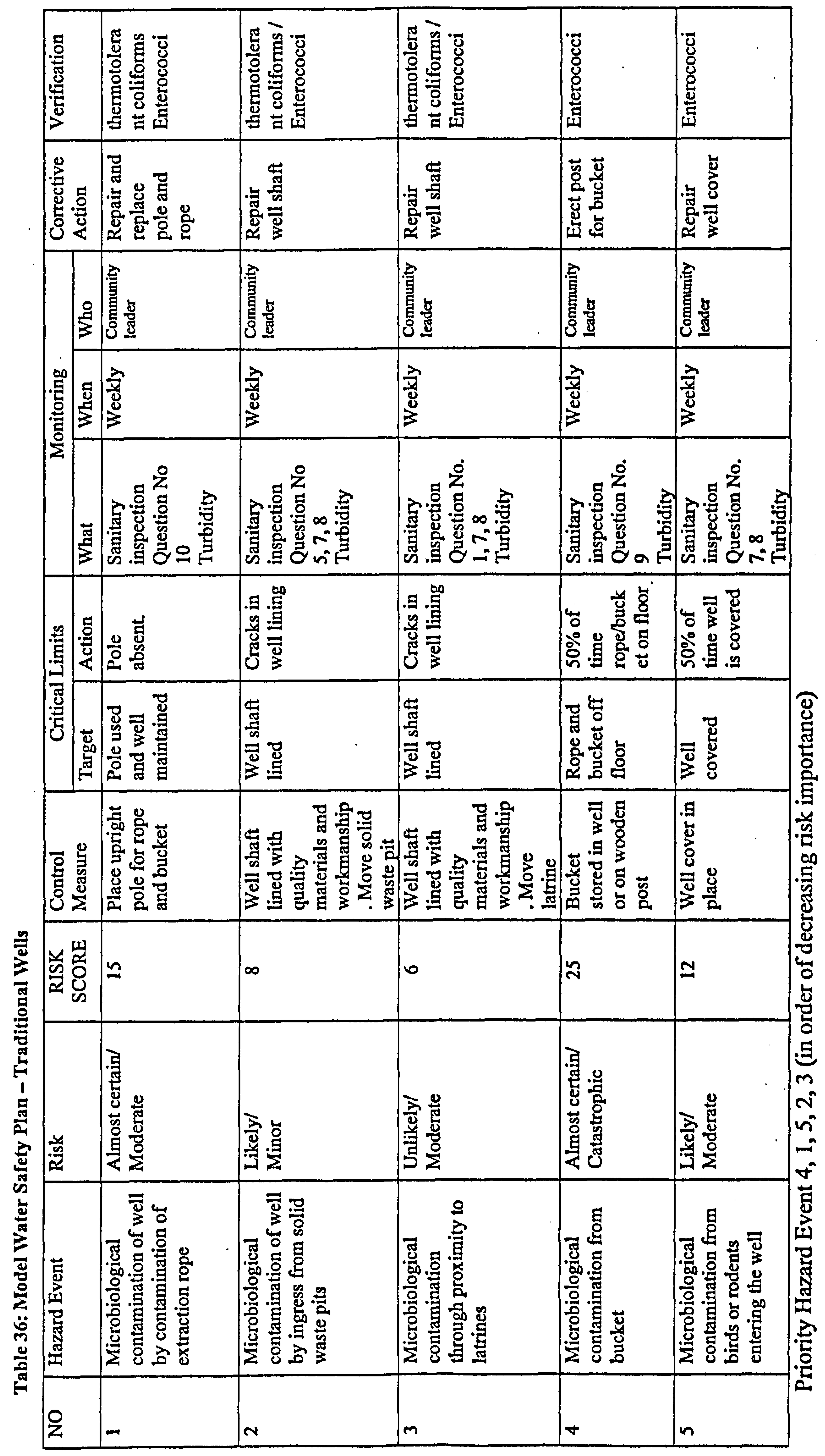




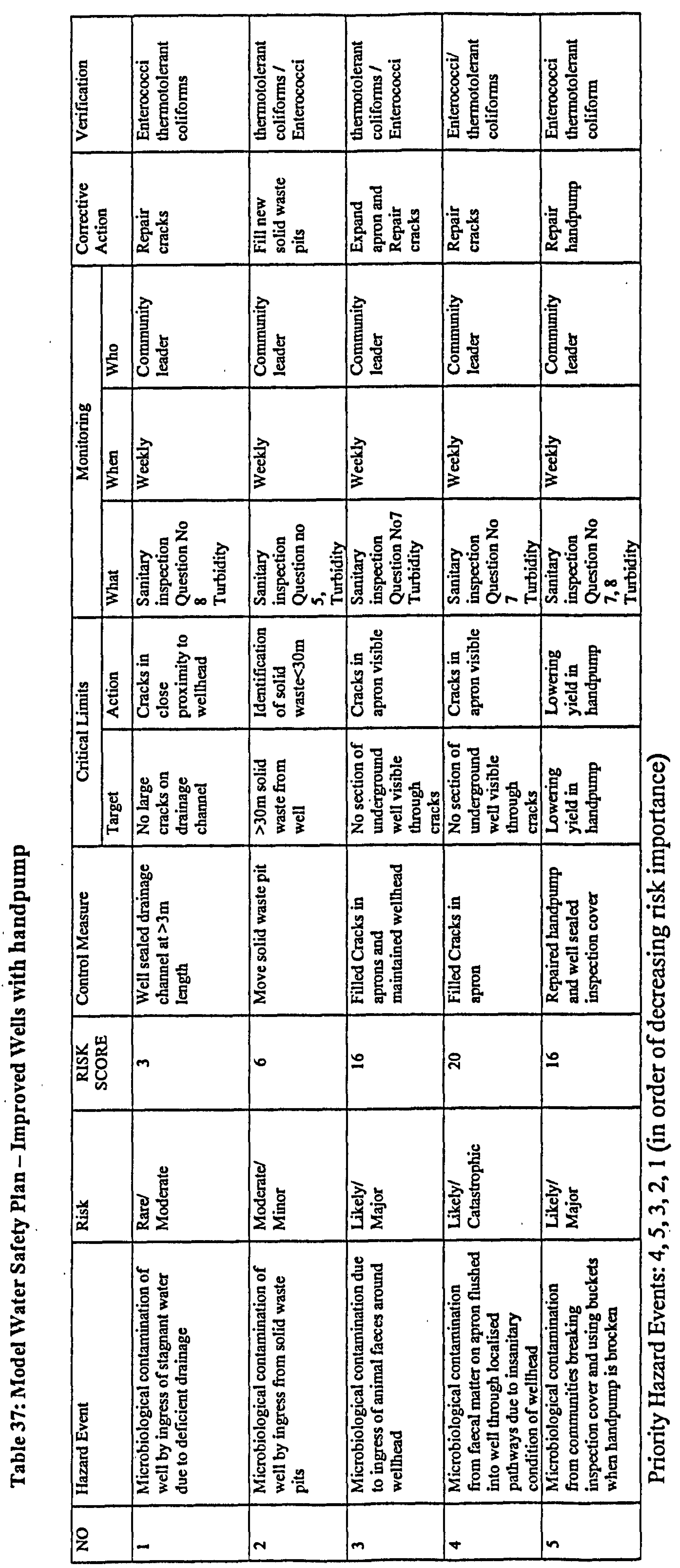




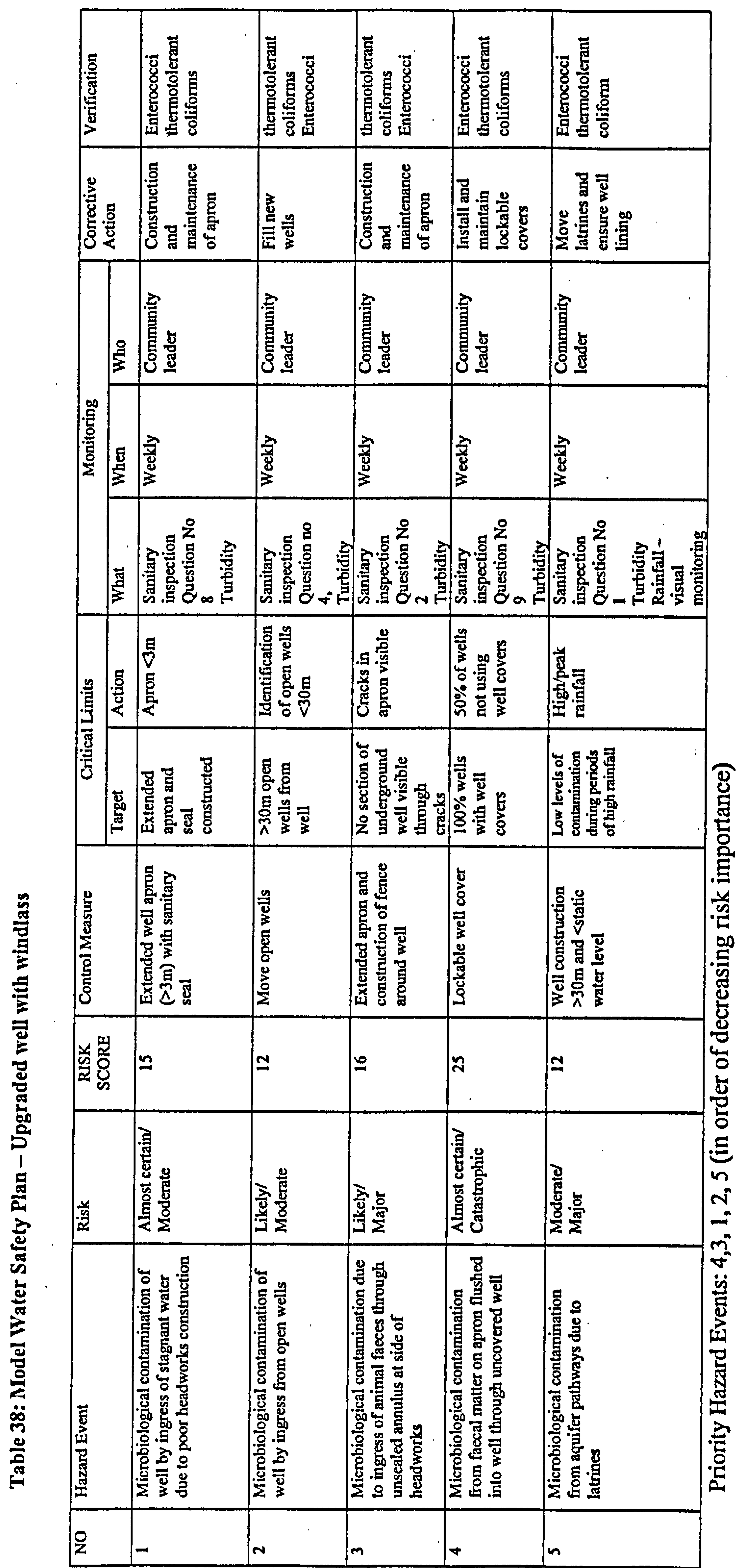


Tables 36-38 outline Water Safety Plans for the three technology types. Five specific hazard events for each technology have been identified based on results outlined in analyses 1 to 4 in section 5.4. Using the matrix developed by WHO (2004) based on the severity of impact and frequency of occurrence of a specific hazard, risk weightings have been applied to each of the five risks per technology (see Table 39).

Table 39 Risk Scores by technology

\begin{tabular}{|l|c|c|c|}
\hline Risk & Traditional Well & Improved Well & Upgraded Well \\
\hline Animal & & 16 & 16 \\
\hline Latrine & 6 & & 12 \\
\hline Deficient drainage & 15 & 3 & 12 \\
\hline Open Wells & 8 & 6 & \\
\hline Rope and bucket & 25 & 16 & 15 \\
\hline Missing well cover & 12 & & 25 \\
\hline Unsealed apron & & 20 & 16 \\
\hline Cracked apron Mean & 13.2 & 12.2 & \\
\hline \multicolumn{1}{|c|}{ Mear } \\
\hline
\end{tabular}

The following can be observed from the table above:

- Upgraded Wells = HIGH RISK $($ mean $=16)$

- $\quad$ Traditional Wells = MEDIUM RISK $($ mean $=13.2)$

- Improved Wells = LOW RISK $($ mean $=12.2)$

From the assessment it can be observed that upgraded wells are the most at risk well technology, followed by traditional wells and then improved wells. This corresponds with results outlined in Chapter 5 which it state that upgraded and traditional wells recorded higher mean levels of microbiological contamination.

\subsection{Conclusions}

This chapter developed Water Safety Plans for each well technology. Each provides risk management practices designed to manage specific risks associated with risk variables identified in Chapter 5. Based on the combination of frequency of occurrence and the extent and severity of impact of each risk, it is observed that upgraded wells with windlass in the study are at greater risk than traditional or improved wells. This is followed in order of risk magnitude by traditional and then improved wells. 
Chapter 7: Conclusions and Recommendations 


\subsection{Introduction}

This thesis has followed an experimental research design where the defined research problem was repeated throughout the research. For this thesis, the defined problem in this research was;

- How to assess the significance of variables affecting microbiological risk to shallow groundwater?

In response to the defined research problem, the thesis has identified improved methods for both the assessment and management of specific risk variables affecting microbiological safety of shallow groundwater.

Specific hypotheses of this research (Section 1.2) were:

- Hypotheses 1: It is possible to determine the relative risk to microbiological groundwater quality by study of the source, pathway and receptor

- Hypotheses 2: It is possible to quantify the overall risk to microbiological groundwater quality by study of the collective risks from source, pathway and receptors.

These were supported by the objectives to:

- Objective 1: Assess the sources, pathways and receptors that present greatest risk to shallow groundwater,

- Objective 2: Analyse levels of significance of individual risk variables,

- Objective 3: Propose appropriate Water Safety Plans (WSPs) to manage existing and probable risk.

\subsection{Conclusions}

To address these aims and objectives, the thesis has identified methods of improving risk assessment and risk management of microbiological contamination of shallow groundwater. Specifically, the research has addressed each hypotheses as outlined below:

- Hypotheses 1: It is possible to determine the relative risk to microbiological groundwater quality by study of the source, pathway and receptor

This thesis supports the view that groundwater risk can be effectively determined based on a study of the source, pathway and receptor. The thesis concludes that this requires a combination of both qualitative and quantitative assessment using selected hydrogeological assessment tools such as POSH and the Hydreogeological Settings 
method (see Section 5.2.2 and 5.2.3). The research however concludes that in many developing countries limited data on groundwater is available. The use of expert judgement methods such as the Analytic Hierarchy Process to determine "unknown" variables associated with underground groundwater barriers, proved to be highly effective. Furthermore, the incorporation of "human factors" such as poor workmanship and selection of poor quality materials are as important as the source, pathway and receptor variables in effectively assessing the risk to shallow groundwater. The study notes that despite investment and good engineering, the barriers are not "fool proof" and that close quality assurance and quality control is required at all stages of construction (Section 5.2.4).

- Hypotheses 2: It is possible to quantify the overall risk to microbiological groundwater quality by study of the collective risks from source, pathway and receptors.

The use of a logistic regression and Chi-Square models were appropriate in the analysis of the collective risk. The use of these statistical models identified specific risk factors. These included

- Traditional wells - rope and bucket (Section 5.4.4),

- Improved wells - deficiency of drainage, the headworks diameter and insanitary condition/presence of stagnant water (Section 5.4.4)

- Upgraded wells - presence of animal faeces / solid waste and no well cover (Section 5.4.4).

Analysis of specific pathways to contamination supported the view that localised pathways are significant in Northern Mozambique. The study indicates that they an important route of contamination This supports earlier studies by BGS and the Robens Institute. In traditional wells localised pathways were a significant variable in the presence of EF contamination. In improved and upgraded wells, localised pathways were significant for both TTC and EF. Difference in findings for TTC and EF may be explained by the relative amount of animal and human excreta in the environment close to the traditional wells studied. Logistic regression indicates that analysis based on a combination of variates provides better statistical correlation than analysis based on one variate. However, the significance of localised pathways may be more or less significant depending on specific geological formations. 
The use of rainfall and turbidity indicates a promising trend a may be considered as "proxy indicators of microbial water quality." Greater levels of risk of contamination were noted during periods of high rainfall and at times of high turbidity. These scientific findings support the need for further research work to establish whether rainfall and turbidity can be used as proxy indicators of microbial water quality.

As well as addressing the above hypotheses, the study further concludes that enterococci are the more robust organisms than thermotolerant coliforms in shallow groundwater systems. In agreement with studies by Massa et al this study concludes that evidence from analysis of polluted groundwater waters suggest that $E F$ may be "a more reliable indicator of faecal pollution than faecal coliforms in raw water" (Massa et al. 2001). Enterococci displayed a higher survival rate and were less susceptible to die-off, dilution or filtration (Bitton et al. 1983, Melian et al. 1999, Macler et al. 2000, Massa et al. 2001). Their greater survival at depth in this study suggests that there is good evidence to support further work on using Enterococci as an appropriate indicator organisms..

To manage the identified risk in the selected wells, the Water Safety Plan (WSP) was a very useful too to identify risk. In adapting the WSP principles to the study, it can be concluded that in Northern Mozambique, Upgraded Wells with Windlass are at greater risk of contamination than Improved wells and Traditional Wells. These results therefore suggest that improvement in management and design are necessary for their inclusion as a technology to address the Millennium Development Goals (MDGs).

\subsection{Recommendations}

However, despite these clear conclusions, the methods developed and applied in this research suggest that further research is still required in selected areas. Outlined below are recommendations for future research. 


\subsubsection{Future Research}

The methods adopted in this research remain too data dependent. There is a need to adapt rapid assessment methods for drinking water quality to incorporate "risk" variables. These may include statistical methods of calculating sample size based on cluster statistics, $10 \%$ sampling or randomisation and should be based on analysis of "risk" as opposed to quality. This will aid specific programmes in assessing the relative level of safety of "improved" water supplies identified in the WHO/UNICEF Joint Monitoring Programme (JMP).

Further work may also be appropriate in the adaptation and simplification of the Analytic Hierarchy Process (AHP) for use by practitioners. The AHP proved to be a useful tool in this research in identifying risk variables for underground components of groundwater systems. It was furthermore appropriate as a decision making tool. Nonetheless, further research may be required into the determination of the minimal statistical number of respondents required for the AHP as well as its application at "field" level requires simplification.

Further research is required into the derivation of pollutant sources for enterococci and thermotolerant coliforms. Although qualitative and quantitative (methods) estimates are provided in this research to establish a relationship between bacteria numbers and the characterisation of a pollutant source, further "laboratory based" research is required to develop simplified methods that can be used at field level.

Turbidity proved to be a highly appropriate proxy indicator for faecal contamination. Further statistical research is required to determine the statistical relationship between turbidity and specific indicator organisms. This may include the use of Poisson distribution simulation models using control experiments.

The research identified that "human" factors are important in the failure of engineering barriers. These include poor workmanship and user behaviour. Further sociological research is required into risk communication, motivations, causes and frequencies of human actions or failures in affording adequate supervision and varied levels of quality of workmanship. 
The WSP approach proved to be an appropriate method of risk management. However, the development of WSPs for all individual wells is not practical. Further research is therefore required into the development of "model Water Safety Plans" that include appropriate methods of monitoring, verification and corrective actions, which can be carried out at community level. Field trials into the effectiveness of use of different approaches to WSPs for small systems are recommended. This may include development of WSPs with community members (using pictorial rather than matrix style WSPs) and monitoring trials of various parameters. A critical component of this is the simplification and integration of Quantitative Microbiological Risk Assessments.

\subsection{Summary}

This research supports the fundamental changes outlined in the $3^{\text {rd }}$ edition of World Health Organization (WHO) Guidelines for Drinking Water Quality (GDWQ) which state that "The most effective means of consistently ensuring the safety of a drinkingwater supply is through the use of comprehensive risk assessment and risk management approaches that encompass all steps in water supply from catchment to consumer." The study has selected methods to improve current understanding of microbiological risk assessment and risk management that enhance the understanding of risk outlined in WHO 2004. 


\section{Bibliography}

1. ACME Alloys (2002) Handpump Specifications, New Delhi, India

2. Allison, B. (1998) Research Skills for Students, Kogan Page Press, London, UK

3. Amuzu, A. (1993). Sanitary aspects of groundwater supplies in Ghana. Presented at 19th WEDC conference - Water, Sanitation, Environment and Development, Accra, Ghana.

4. ANON (1994) "The bacteriological examination of drinking water supplies," in Reports on Public Health and Medical Subjects No. 71 Methods for Examination of Waters and Associated Materials, UK Drinking Water Inspector, London

5. ARGOSS (2002). Guidelines for Assessing the Risk to Groundwater from OnSite Sanitation. British Geological Survey Commissioned Report CR/01/142.

6. Auge, M. (2004) Vulnerabilidade de acuiferors, Concepts y Métodos, (Aquifer Vulnerability - Methods and Concepts),, International Association of Hydrogeologists (IAH) E book, Argentina

7. AWWARF (2002) "Chapter 7: Recommended control strategies". In Pathogen Intrusion into the distribution system. AWWARF, USA

8. AWWA/APHA (1998) Standard Methods for the Examination of Water and Wastewater, $20^{\text {th }}$ Edition, United Book Press, USA

9. Ball, P. (2001). Drilled wells. SKAT Publications, St Gallen, Switzerland,

10. Barnes, G. (2000) Soil Mechanics - Principles and Practice - Part 2, Pelgrave, New York, USA

11. Barrel, R. and Rowland, M. (1979) The relationship between rainfall and well water pollution in a West African (Gambian) village. Journal of Hygiene Vol. 83, pp. $143-150$

12. Barret, M. Johal, K. Howard, G. Pedley, S. and Nalubega M. (2000). "Sources of faecal contamination of shallow groundwaters in Kampala," in Groundwater: Past Achievements and Future Challenges. Balkema Press, Rotterdam, Netherlands.

13. Barret, M., M. Nalubega, et al. (1999). On site sanitation and urban aquifer systems in Uganda. Waterlines Vol. 17, No. 4, pp. 10-22. 
14. Bartram, J. (1996) Optimising the Monitoring and Assessment of Rural Water Supplies. Ph.D Thesis, University of Surrey, UK

15. Baumann, E. (2003). Discussion with Sam Godfrey on Handpump base plates, May 2004

16. Bengtsson, M. and Gustafson, G. (1996) Assessment of groundwater using hydrogeological settings. Pilot study in Western Sweden, Department of Geology CTH Publication No B426, Gothenburg

17. BGS (1994) Impact of wastewater use and disposal on groundwater, BGS Publications, Nottingham, UK

18. Bitton, G. Farrah, S. Ruskin, R. Butner, J. and Chou, Y.(1983) Survival of Pathogenic and Indicator Organisms in Groundwater. Groundwater Vol. 21, No. 4. pp. $405-410$

19. Brassington, J. (1998) Field Hydrogeology, Willey Publications, Chichester, UK

20. Breslin, N. (2002). The case for protected wells - Lessons learnt from Niassa. Maputo, Mozambique, WaterAid Series of Case Studies. No 8.

21. Brown, K. Wolf, H. Donnely, K. and Slowey, J. (1979). "The movement of faecel coliforms and coliphages below septic lines." Journal of Environmental Quality, Vol. 8, pp. 121-125.

22. BS1377-2 (1990) BS 1377-2 Methods of testing for soils for Civil Engineering Purposes - Part 2 Classification Tests. British Standards Institution (BSI), London, UK

23. BS1881-201 (1986) Testing concrete - Part 201: Guide to the use of nondestructive methods of test for hardened concrete, British Standards, London

24. Calder, J. and Sapsford, R. (2001) "Multivariate Analysis" In Data Collection and Analysis, UK

25. Cave, B. and Kolsky, P. (1999). "Groundwater, latrines and Health" WELL studies in Water, Sanitation and Environmental Health. Loughborough University, UK.

26. Chidavaenzi, M. Bradley, M. Jere, M. and Nhandara, C. (2001) Pit latrine effluent infiltration into groundwater - The Epworth Case Study IWA Publishing, London, UK

27. Chilton, J. and Seiler, K. (2003) "Chapter 2: Groundwater: Hydrological and Hydrogeological Processes," In Oliver Schmoll, Ingrid Chorus, Jamie 
Bartram, WHO Groundwater Monograph, WHO Publication, Geneva, Switzerland.

28. CIBAGEIGY (1986) Guide to soil identification. CIBAGEIGY Agrochemicals, UK

29. Clark, L. (1992) The field guide to water wells and boreholes. London, John Wiley.

30. Coakes, S. and Steed, L. (1999) SPSS Analysis without anguish, Milton Press, Australia

31. Cogger, C. (1988). "On site septic systems - The risk of groundwater contamination" Journal of Environmental Health, Vol. 51, No. 1, pp.12-18

32. Collins, S. (2000). Hand dug shallow wells. SKAT, St Gallen, Switzerland

33. Craig, R. (1995) Soil mechanics, London, UK

34. Creswell, J. (2003) Research design, qualitative, quantitative and mixed method approaches, Sage Publications, UK

35. Cronin, A. Breslin, N. Taylor, R. and Pedley, S. (2002). Assessing the risks to groundwater quality from unsanitary well completion and on-site sanitation. Presented at ECOSAN - closing the loop Proceedings of the second international conference of ecological sanitation, Lubeck, Germany.

36. Daly, D. Dassargues, A. Drew, D. Dunne, S. Goldscheider, N. Neale, S. Popescu, I. and Zwahlen, F. (2002) Main concepts of the European Approach to Karst-groundwater vulnerability assessment and mapping. Hydrogeology Journal Vol. 10, pp. 340-345

37. Davison, A. Howard, G. Stevens, M. Fewtrell, L. Deere., D. Callan, P. and Bartram, J. (2005) Water Safety Plans, WHO Publication, Geneva, Switzerland

38. Deere, D. and Stevens, M. (2001). Management Strategies. Water Quality: Guidelines, Standards and Health Ed. Fewtrell and Bartram, Water Sanitation and Health, IWA Publication, London, UK.

39. Deere, D. Stevens, M. Davison, A. Helm G. and Dufour, A. (2001) Management Strategies, IWA Publishing, London, UK

40. Dixon, $\cdot$ K. Blakey, G. Whiter, J. and Hope, V., (2001). "GIS based risk analysis of ferrous water mains." In Dixon Underground Infrastructure Research Municipal Industrial and Environmental Applications, London, UK 
41. Doerfliger, N. Jeanin, P. and Zwahlen, F. (1999) Water vulnerability assessment in karst environments: a new method of defining protection areas using a multi attribute approach and GIS tools (EPIK method), Environmental Geology Vol. 39, No 2, pp. 165-176.

42. Driscoll, F. (1995). Groundwater and wells. Johnson Screens, St Paul, Minnesota, USA

43. Dziegielewski, B. Opitz, E. Maidment, D. (1996) Water Resources Handbook, New York, USA

44. Esrey, S. Potash, J. Roberts, L. and Shiff, C. (1990) Health benefits from improvements in water supply and sanitation: survey and analysis of the literature on selected diseases, WASH Technical Report, No. 66. Water and Sanitation for Health Project

45. Fatti, P. (1989) Water Research Planning in South Africa, The Analytic Hierarchy Process - Applications and Studies, Vol. 122

46. Fewtrell, L. and Macgil, M. (2001). "Uncertainties in risk assessment for the determination of drinking water pollutant concentrations: Cryptosporidium case study" Water Research, Vol. 35, No. 2, pp. 441-447.

47. Foster, S. and Hirata, R. (1991) Groundwater Pollution Risk Assessment - a methodology using available data, Pan American Centre for Sanitary Engineering and Environmental Science (CEPIS), Peru

48. Foster, S. Hirata, R. Gomes, D. D'Elia, M. and Paris, M. (2002) Groundwater quality protection - a guide for water utilities, municipal authorities and environment agencies. World Bank Publication, Washington DC, USA

49. Fourie, A. and Van Ryneveld, M. (1995). "The fate in the subsurface of contaminants associated with on-site sanitation: A review." Water $S A$, Vol. 21, No. 2, pp. 101-111

50. Fujioka, R. Ueno, A. and Narikawa, O. (1984) Recovery of false positive faecal streptococcus on KF agar from marine recreational waters University of Hawaii Report, USA

51. Gale, P. (2001). Microbiological risk assessment. "Risk assessment for environmental professionals". In CIWEM Risk Assessment and Management Manual, CIWEM, London 
52. Gelinas, Y. Randall, H. Robidoux, L. and Schmit, J. (1996) Well water survey in two districts of Conakry (Republic of Guinea) and comparison with the piped city water. Water Research Vol. 30, No. 9, pp. 2017-2026

53. Gerba, C., P, Wallis, C, Melnick, J, L, (1975). "The fate of wastewater bacteria and viruses in soil." Journal of the Irrigation and Drainage Division, American Society of Civil Engineers, Vol. 101, No. IR3, pp. 157-175.

54. Godfree, A. Kay, D. and Wyer, M. (1997) Faecal Streptococci as indicators of faecal contamination in water, Journal of Applied Microbiology Supplement, Vol. 83. pp 110

55. Godfrey, S. (2004) Quality clay bricks for lining wells, Journal of Appropriate Technology, Vol. 31, No. 1

56. Godfrey, S. and Ball, P. (2003). Making boreholes work - remedial measures for siltation of boreholes. Presented at 29th WEDC conference - Towards the Millennium Development Goals (MDGs), Abuja, Nigeria, WEDC

57. Godfrey, S. and Howard, G. (2005) Water Safety Plans (WSP) - Book 1 planning water safety for urban piped water supplies in developing countries. WEDC Loughborough University, UK

58. Godfrey, S. and Smith, S. (2005) Improved microbial risk assessment of groundwater. Hydrogeology Journal, Vol. 13, pp. 321-324

59. Godfrey, S. McCaffrey, L. Obika, A. and Becks, M. (2003). "The effectiveness of point source chlorination in improving water quality in IDP communities in Angola" Journal Chartered Institution of Water and Environmental Management, Vol. 17, No. 3, pp. 149-151

60. Godfrey, S. Timo, F. and Smith, M., (2005) Relationship between rainfall and microbiological contamination of shallow groundwater in Northern Mozambique, Water $S A$, Vol. 31, No. 4. pp. 609-614

61. Godfrey, S. Watkins, J. Toop, K. and Francis, C. (2005) Analysis of enterococci using portable equipment for developing countries - variance of Azide NutriDisk medium under variable time and temperature, Presented at WATERMICRO 2005 Conference, Swansea, UK

62. Gogu, R. and Dassargues, A. (2000) Current trends and future challenges in groundwater vulnerability assessment using overlay and index methods Environmental Geology Vol. 39, No. 6, pp. 549-559

63. GoM (2003) WaterAid Country Report, Maputo, Mozambique 
64. Gorter, A. and Alberts, H. (1995). "A randomized trial of the impact of rope pumps on water quality" Journal of Tropical Medicine and Hygiene, Vol. 98, pp. 247-255

65. Greenfield, T. (2000) Research Methods - Guidance for postgraduates. Arnold Press London, UK.

66. Gunston, H. (1997) Field hydrology in tropical countries - a practical introduction. Intermediate Technology Publications, UK

67. Han, J. and Kamber, M. (2001) Data Mining - Concepts and Techniques, Simon Fraser University, USA

68. Hartley, S. (2000) The development of a protocol to manage the potential of groundwater contamination from on site sanitation. IWA Publishing, London, UK

69. Helberg, C. (2002) Data Mining with confidence - SPSS, SPSS Inc. USA

70. Helsel, D. and Hirsch, R. (1992) Statistical Methods in Water Resources, Elsevier Science Press, Amsterdam, The Netherlands

71. Hepworth, N. (2001). Groundwater quality in Dar Es Salaam, Tanzania - a scoping study. WaterAid Report, Tanzania

72. Hoffman, J. (1994). Diffuse (non point) source pollution in the Hennops Valley. Presented at First Conference on Environmental Management, Technology and Development, South Africa

73. Horold, S. and Baur, R. (1997). Modelling sewer and deterioration for selective inspection planning - case study, Presented at 13th European Junior Scientist Workshop, Rathen, Dresden, Germany

74. Howard, G. (2000). Distinguishing human and animal faecal contamination in shallow groundwater. DFID commissioned Report, London, UK

75. Howard, G. (2002) Water supply surveillance - a practical guide. WEDC Loughborough University, UK

76. Howard, G. (2003) Monitoring and Surveillance of urban water supplies in developing countries, $\mathrm{Ph} . \mathrm{D}$, University of Surrey, UK

77. Howard, G. Godfrey, S. and Boonyakarnkul, T. (2005) "Chapter 18: Wellhead protection/sanitary completion," In Oliver Schmoll, Ingrid Chorus, Jamie Bartram, WHO Groundwater Monograph, WHO Publication, Geneva, Switzerland. In press 
78. Howard, G. Pedley, S. Barret, M. Nalubega, M. and Johal, K. (2003) Risk factors contributing to microbiological contamination of shallow groundwater in Kampala, Uganda. Water Research Vol. 37, pp. 3421-3429

79. Hrudey, S. Huck, P. Payment, P. Gillham, R. and Hrudey, E. (2002). "Walkerton: Lessons learnt in comparison with Waterborne outbreaks in the developed world" Journal of Environmental Engineering Science, Vol. 1, pp. 397-407.

80. Haas, C. and Eisenberg, N. (2001). Risk assessment In Water Quality: Guidelines, Standards and Health, Ed. Fewtrell and Bartram, Water Sanitation and Health, IWA Publication, London, UK

81. Ibe, K. Nwankwor, G. and Onyekuru, S. (2001) Assessment of groundwater vulnerability and its application to the development of protection strategy for the water supply aquifer in Owerri, Southeastern Nigeria Environmental Monitoring and Assessment. Vol. 67, pp. 323-360

82. Jenkins, D. (1984) "Using off-set handpumps - a cost effective method to protect drinking water in rural villages" Waterlines, Vol. 2, No.4, pp 25-27.

83. Kinsey, G. Paterson, R. and Kelley, J. (2003) Filamentous fungi in water systems. Academic Press, USA

84. Koegel, R. (1977) Self Help Wells. FAO Publications, Rome, Italy.

85. Langenegger, O. (1981). "High nitrate concentrations in shallow aquifers in a rural areas of central Nigeria caused by random deposits of domestic refuse and excrement." In Quality of Groundwater, Elsevier Scientific Publishing Company, Norway.

86. Lee, Y. Dahab, M. and Bogardi, I. (1992) Nitrate risk management under uncertainty Journal of Water Resources Planning and Management, Vol, 118, No. 2 pp. 151-165

87. LeGrand, H. (1970) Comparative Hydrogeology; An example of its use Geological Society American Bulletin. Vol. 18, pp. 1243-1248

88. Lewis, W. Foster, S. and Draser, B. (1980) The risk of groundwater pollution by on-site sanitation in developing countries - a literature review, BGS, UK

89. Lloyd, B. and Helmer, R. (1991) Surveillance of drinking water quality in rural areas, UK 
90. MacDonald, D. Ahmed, K. Islam, M. Lawrence, A. and Khandker, Z. (1999) Pit latrines - A source of contamination in peri urban Dhaka? Waterlines Vol. 17, No. 4, pp. 6-9

91. Macler, B. and Merkle, J. (2000) Current knowledge on groundwater microbial pathogens and their control Hydrogeology Journal Vol. 8, pp. 29-40

92. Mara (2003) "Indicator Organisms," In Mara and Horan Handbook of Water and Wastewater Microbiology, Elsevier Press, UK

93. Massa, S. Brocchi, G. Peri, G. Altieri, C. and Mammina, C. (2001) Evaluation of recovery methods to detect feacal streptococci in polluted waters Letters in Applied Microbiology Vol. 32, pp. 298-302

94. Mastrad (2004) Mastrad Speedy Moisture Testers Mastrad, UK

95. Melian, R. Myrlian, N. Gouriev, A. Mouraru, C. and Radstake, F. (1999) Groundwater quality and rural drinking water supplies in the republic of Moldova, Hydrogeology Journal, Vol. 7, pp. 171-188.

96. Mertens, T. Fernando, M. Cousens, S. Kirkwood, B. Marshall; T. and Feachem, R. (1990). "Childhood diarrhoea in Sri Lanka: a case-control study of the impact of improved water sources." Tropical medicine and parasitology Vo. 41, pp. 98-104

97. Morgan, P. (1990). Rural water supply and sanitation - a text from Zimbabwe Blair Research Laboratory, MacMillan Press, London, UK

98. Mozambique WaterAid (2003) WaterAid Country Report, Unpublished Report, London, UK

99. Murray, C. and Lopez, A. (1996). Global burden of disease and injury. In Global health statistics, Cambridge MA, Harvard School of Public Health on behalf of World Health Organization and the World Bank.

100. Nola, M. Njine, T. Djuikom, E. and Foko, V. (2002) Faecal coliform and faecal streptococci community in the underground water in an equatorial area in Cameroon (Central Africa): the importance of some environmental chemical factors. Water Research Vol. 36, pp. 3289-3297

101. Norusis, M. (1999) SPSS Regression Models 10, Chicago, USA

102. Nyanchaga, E. (1994). "Rehabilitation of hand dug wells and springs." Aqua, Vol. 43, No. 5, pp. 233-237 
103. ODPM (2001) ODPM Multi Criteria Analysis: A manual - Office of the Deputy Prime Minister, Delivering thriving, inclusive and sustainable communities in all regions http://www.odpm.gov.uk// (11 November 2004)

104. Olanrewaju, D. (1990). "Soak away systems and possible groundwater pollution problems in developing countries" Journal of the Royal Society of Health, Vol. 110, No. 3, pp.108-112.

105. Oxfam (1998) Well digging pack. Oxfam GB, Oxford, UK.

106. Oxfam Angola (2001) Oxfam GB Angola Standard Procedures for Apron Construction, Luanda, Angola

107. Pang, L. Close, M. Goltz, M. Sinton, L. Davies, H. Hall, C. and Stanton, G. (2003) Estimation of septic tank setback distances based on transport of E.coli and F-RNA phages. Environment International Vol. 29, pp. 907-921

108. Payment, P. (2003) "Health effects of water consumption and water quality" In Mara and Horan Handbook of Water and Wastewater Microbiology, Elsevier Press, London, UK.

109. Payment, P. Richardson, L. Siemiatycki, J. Dewar, R. Edwardes, M. and Franco, E. (1991). "A randomized trial to evaluate the risk of gastrointestinal disease due to consumption of drinking water meeting current microbiological standards." American Journal of Public Health Vol. 81, No. 6, pp. 703-708

110. Pedley, S. Howard, G. (1997). "The public health implications of microbiological contamination of groundwater." Quarterly journal of . Engineering Geology, Vol. 30, pp. 179-188.

111. Pedley, S. Yates, M. West, M. Barret, M. and Howard, G. (2005) "Chapter 3: Pathogens: Health Relevance, transport and attenuation," In Oliver Schmoll, Ingrid Chorus, Jamie Bartram, WHO Groundwater Monograph, WHO Publication, Geneva, Switzerland. In press

112. Petrivicova, A. Simkova, A. and Cervenka, J. (1988) Entero viruses and coliphage in different water ecosystems Z. Gesamte Hygiene Vol. 34, pp. 522523

113. Powell, K. Taylor, R. Cronin, A. Barret, M, Pedley, S. Sellwood, J. Trowsdale, S. and Lerner, D. (2003). "Microbial contamination of two urban sandstone aquifers in the UK." Water Research, Vol. 37, No. 2, pp 339-352 
114. Preene, M. and Brassington, J. (2003). "Potential groundwater impacts from civil engineering works." Journal Chartered Institution of Water and Environmental Management, Vol. 17, No. 1, pp. 59-64.

115. Rajani, B. and Kleiner, Y. (2001). "Comprehensive review of structural deterioration of water mains - physically based models." Urban Water, Vol. 3, pp. 151-164.

116. Ramanujam, V. and Saaty, T. (1981) Technology choice in less developed countries: an Analytic Hierarchy Approach (AHP), Technological Forecasting and Social Change, Vol. 19, pp. 81-91

117. RCPEH (2000) DelAgua kit operation manual, University of Surrey, UK

118. Regli, S. and Rose, B. (1991). "Modelling the risk from giardia and viruses in drinking water." Journal of the American Water Works Association (AWWA) pp. 76-84

119. Reynolds, J. and Barret, M, (2003). "A review of the effects of sewer leakage on groundwater quality" Journal Chartered Institution of Water and Environmental Management, Vol. 17, No. 1, pp. 34-39

120. Robertson, J. and Edberg, S. (1997) Natural protection of spring and well drinking water against surface microbial contamination-Hydrogeological parameters CRC Press, pp. 143-177

121. Robins, N. (1998). "The quality of groundwater in Northern Ireland." Journal of the Chartered Water and Environmental Management, Vol. 12, pp. 163169.

122. Rupert, M. G. (2001) Calibration of the DRASTIC groundwater vulnerability mapping method. Groundwater Vol. 39, No. 4. pp. 625-630

123. Satty, T. (1980) The analytical hierarchy process, Sage Publications, USA

124. Schwartz, J. Levin, R. an Hodge, K. (1997) "Drinking water turbidity and pediatric hospital use for gastrointestinal illness in Philadelphia," Epidemiology, Vol. 8, pp 615-620

125. Secunda, S. Collin, M. and Melloul, A. (1998) Groundwater vulnerability. assessment using a composite model combining DRASTIC with extensive agricultural land use in Israel's Sharon region. Journal of Environmental Management Vol. 54, pp. 39-57 
126. Sivaborvorn, K. and Dutka, B. (1989) Coliphage presence in various types of potable water in Thailand Water Pollution Research Journal Canada Vol. 24 No. 4, pp. 583-588

127. Snow, J. (1854) On the mode of communication of cholera, John Churchill, London

128. Stejmar, H. (1998) "Assessment of groundwater quality using hydrogeological settings." In Gambling with Groundwater - Physical, Chemical and Biological Aspects of Aquifer-Stream Relations, USGS Publication, Las Vegas, USA,

129. Sutton, S. (1994). "Microbiological quality of groundwater supplies in rural Zambia" In Nash, H. and McGall, G. Groundwater Quality, BGS, UK

130. Swartz, M. Misstaer, B. Daly, D. and Farrell, E (2003) Assessing subsoil permeability for groundwater vulnerability. Quarterly journal of Engineering Geology Vol. 36, pp. 173-184

131. Taylor, H. (2003) Surface water, In Mara and Horan Handbook of Water and Wastewater Microbiology, Elsevier Press, UK

132. Tesoriero, A. and Voss, F. (1997) Predicting the probability of elevated nitrate concentrations in the Puget Sound Basin: Implications for aquifer susceptibility and vulnerability, Groundwater, Vol. 35, No. 6, pp 1026

133. Thirumalaivasan, D. (2001) Aquifer vulnerability assessment using analytical hierarchy process and GIS for upper palar water shed, Presented at 22nd Asian Conference on Remote Sensing, 5-9 November 2001, Singapore

134. Thirumalaivasan, D. Karmegam, M. and Venugopal, K. (2003) AHPDRASTIC: software for specific aquifer vulnerability assessment using DRASTIC model and GIS, Environmental Modelling and Software, Vol. 18, pp. 645

135. Triantaphyllou, E. and Lootsma F. (1994) On the evaluation and application of different scales for quantifying pairwise comparisons in fuzzy sets, Journal of Multicriteria decision analysis, Vol. 3, pp. 645

136. Triantaphyllou, E. and Mann, S. (1995) Using the Analytic Hierarchy Process (AHP) for decision making in engineering applications: some challenges, International Journal of Industrial Engineering: Applications and Practice, Vol. 2, No. 1, pp. 35 
137. Triantaphyllou, E. and Sanchez, A. (1997) A sensitivity analysis approach for some deterministic multicriteria decision making methods, Decision Sciences, Vol. 28, No. 1, pp. 151

138. UN (1977) Mar Del Plata - Planning for the water decade, UN report.

139. UN (2005) UN Millennium Development Goals (MDG) http://www.un.org/millenniumgoals// (31 August 2005)

140. USEPA (1994). Groundwater and Wellhead protection. Washington DC, United States Environment Protection Agency.

141. USEPA (2001) Pathogen load estimation, USEPA Publication, Colorado, USA

142. Van Ryneveld, M. and Fourie, B. (1997) "A strategy for evaluating the environmental impact of on-site sanitation systems." Water $S A$, Vol. 23, No. 4, pp. 279-291

143. WAGTECH (2003) Portable Water Testing Laboratory Kit - The Potaflex, Operational Manual, WagTech International, UK

144. Wang, Q. Wee, Y. and Ofori, G. (2002) DSSDSS: A decision support system for dewatering system selection, Building and Environment, Vol. 37, pp 625

145. Watt, S. and Wood, E. (1979). Hand dug wells and their construction, IT publications, UK

146. WHO (2004) Guidelines for Drinking Water Quality - Recommendations. $3^{\text {rd }}$ edition, WHO Publication, Geneva, Switzerland

147. WHO/UNICEF (2004a) The Joint Monitoring Programme: Definitions. WHO Publication, Geneva, Switzerland

148. WHO/UNICEF (2004b) Meeting the MDG drinking-water and sanitation target: A mid-term assessment of progress. WHO Publication, Geneva, Switzerland

149. Woodward, C. Ta, T. and Whiter, J. (2001). "Risk analysis related to water mains bursts". In Computing and Control for the Water Industry, Research Studies Press Ltd, UK.

150. Wright, R. (1986) The seasonality of bacterial quality of water in a tropical developing country (Sierra Leone) Journal of Hygiene Vol. 96, pp.75-82

151. Yates, M. and Yates, S. (1989). "Septic tank setback distances: A way to minimize virus contamination of drinking water" Groundwater, Vol. 27, No. 2, pp. 202-208 
152. Zoller, U. (1993). "Groundwater contamination by detergents and polycyclic aromatic hydrocarbons - A global problem of organic contaminants: Is the solution locally specific?" Water, Science and Technology, Vol. 27, No. 7-8, pp. 187-194. 
Appendix 1: Results 


\begin{tabular}{|c|c|c|c|c|c|c|c|c|c|c|}
\hline & $\approx$ & $x$ & & $|x|$ & $1 x$ & 4 & & & $|x| x \mid$ & $x$ \\
\hline & $\pi$ & $x$ & & $x \mid$ & $x$ & & & & $|x| x \mid$ & $|x|$ \\
\hline & 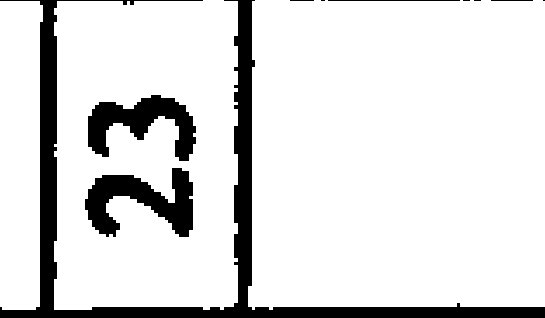 & $|x|$ & & $x \mid$ & $x$ & & & & $|x| x \mid$ & $|x|$ \\
\hline & $|\tilde{\mid}|$ & $|x|$ & & $|x|$ & $x$ & & & & $|x|$ & 1 \\
\hline & $\bar{N}$ & $x$ & & $x$ & $x$ & & & & $|x|$ & $x$ \\
\hline & i & $x$ & & $x$ & $x$ & & $x$ & 4 & $x \mid x$ & $x$ \\
\hline & 2 & $x$ & & $x$ & $x$ & & $x$ & 4 & $|x| x \mid$ & $7 x$ \\
\hline & $\infty$ & $|x|$ & & $x$ & $x$ & & & & $|x|$ & $|x|$ \\
\hline & $\equiv x$ & 1 & & $x$ & . & $x$ & $4 x$ & 4 & $x \mid x$ & $D x$ \\
\hline & \begin{tabular}{|l|l|} 
\\
\end{tabular} & $x$ & & $x$ & $x$ & & $x$ & & $x|x|$ & $x$ \\
\hline & $\approx$ & $x$ & & $x$ & $x$ & 4 & $x$ & & $|x| x \mid$ & $x$ \\
\hline & \pm & $x$ & & $x$ & $x$ & & $1 x$ & $x$ & $x|x|$ & $|x|$ \\
\hline & $\approx$ & $x$ & & $x$ & $x$ & & $x$ & $4 x$ & $x \mid x$ & $x$ \\
\hline & $\approx$ & $x$ & & $x$ & $x$ & $\varepsilon$ & $x$ & $5 x$ & \begin{tabular}{|c|c|}
$x$ & $x$ \\
\end{tabular} & $x$ \\
\hline & $\Rightarrow$ & $x$ & & $x$ & $x$ & & 11 & & $x \mid x$ & $x$ \\
\hline & 인 & $x$ & & $x$ & & & $4 x$ & & $x \mid x$ & $x$ \\
\hline & $a$ & \begin{tabular}{|l|l|}
$x$ & \\
\end{tabular} & & $x$ & $x$ & & $x$ & $x$ & \begin{tabular}{|l|l|}
$x$ & $x$ \\
\end{tabular} & $x$ \\
\hline & $\infty$ & $x$ & & $x$ & $x$ & & $x$ & & $|x| x \mid$ & $x$ \\
\hline & -1 & $x$ & & $x$ & $x$ & $\leq$ & $x$ & & \begin{tabular}{l|l|}
$x$ \\
\end{tabular} & $x$ \\
\hline & $0 x$ & & & $x$ & & & $x$ & & $|x| x \mid$ & $x$ \\
\hline & $n$ & $x$ & & $x$ & $x$ & & $x$ & & $x|x|$ & $x$ \\
\hline & $\sigma$ & $x$ & & $x$ & $x$ & & $x$ & & $x|x|$ & $x$ \\
\hline & $\mathrm{m}$ & $|x|$ & & $x \mid$ & $x$ & & 11 & & $|x| x \mid$ & $x$ \\
\hline & $N$ & \begin{tabular}{|l|l}
$x$ & \\
\end{tabular} & & $x$ & $x$ & & $x$ & $x$ & $4 x$ & $x$ \\
\hline & - & $x$ & & $x$ & $x$ & & $x$ & $x$ & $x$ & $x$ \\
\hline & 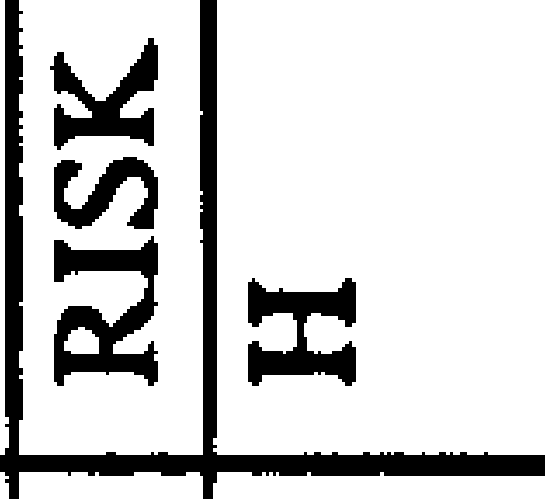 & $\Sigma+$ & & $\Sigma$, & $\Sigma$ & & $\Delta$ & & 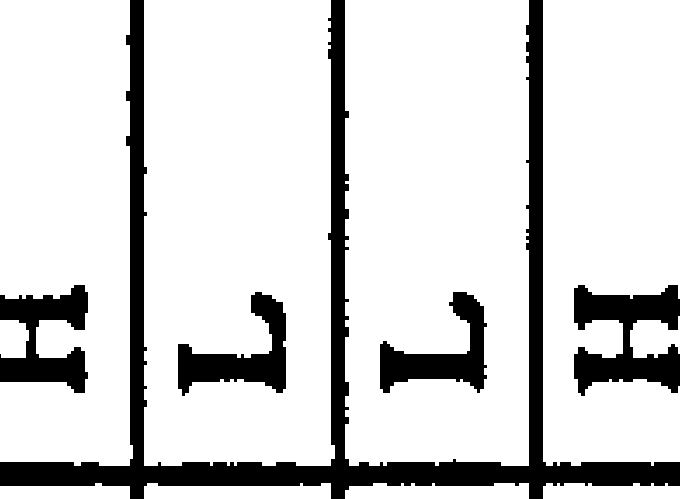 & \pm \\
\hline & \pm & $\Sigma \mid-2$ & & 点: & & & 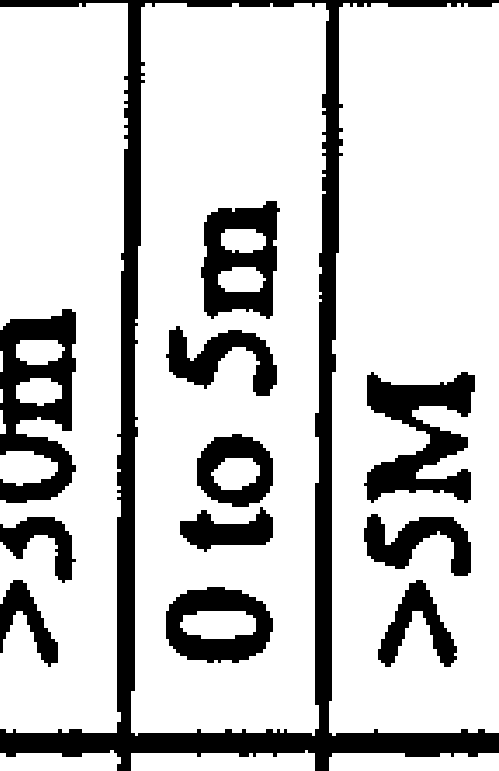 & & 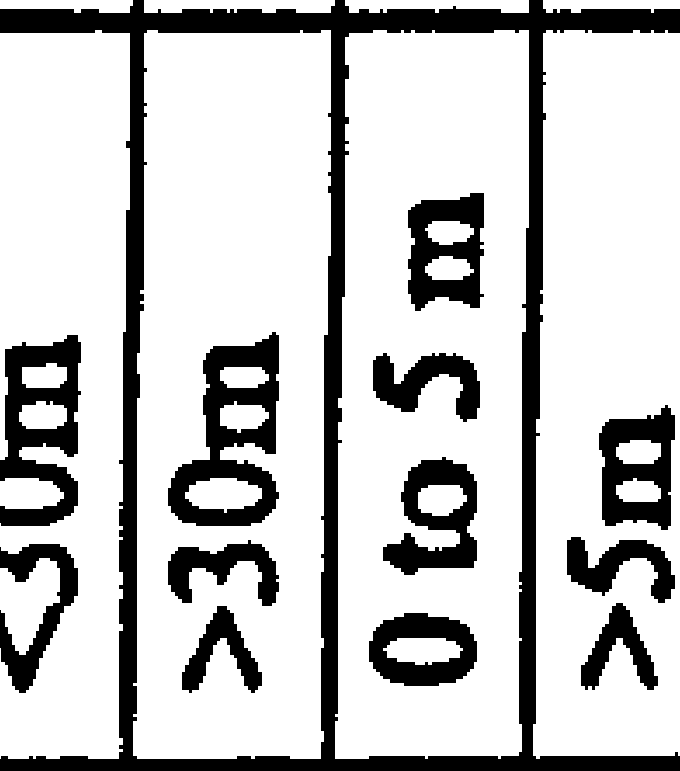 & \begin{tabular}{|l|l|} 
& $\frac{g}{8}$ \\
\end{tabular} \\
\hline $\begin{array}{l}0 \\
\frac{0}{5} \\
\frac{5}{7}\end{array}$ & 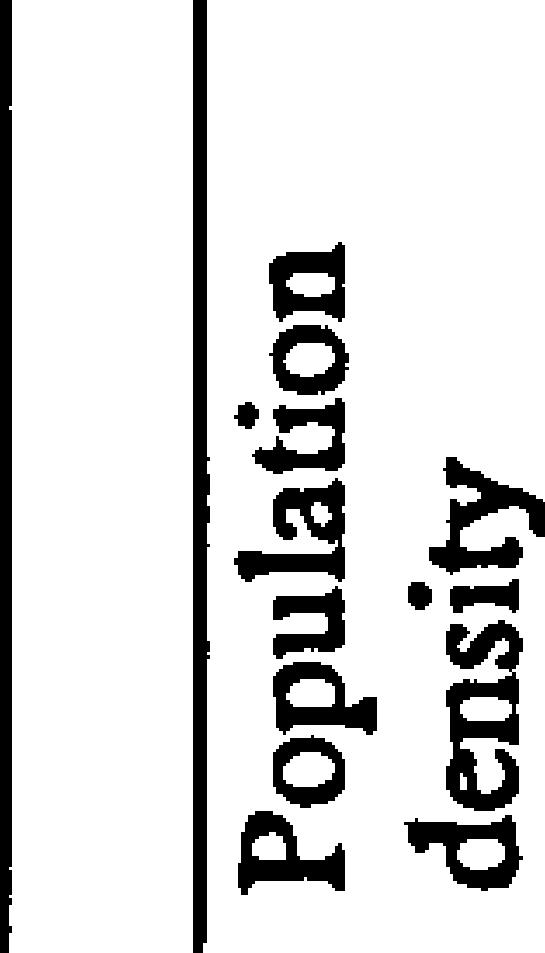 & & 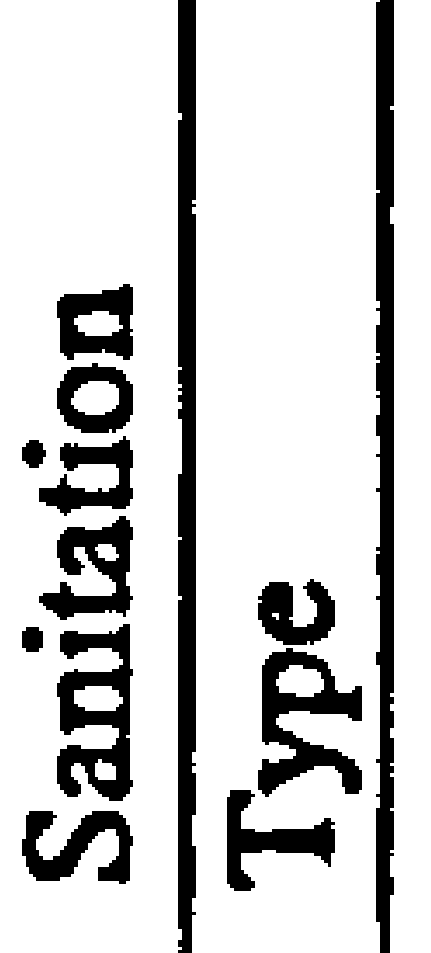 & & 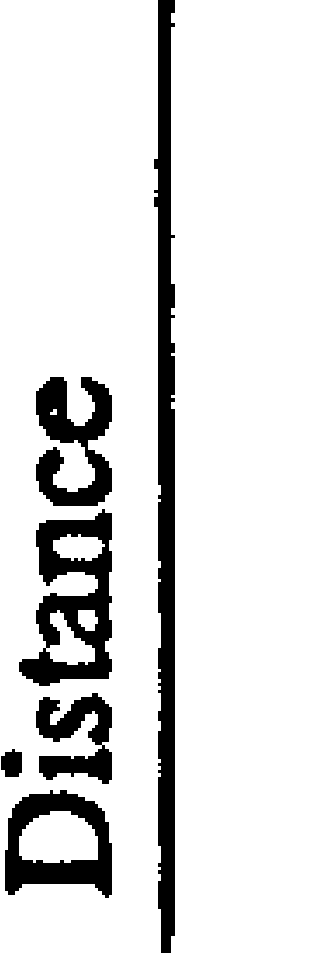 & & 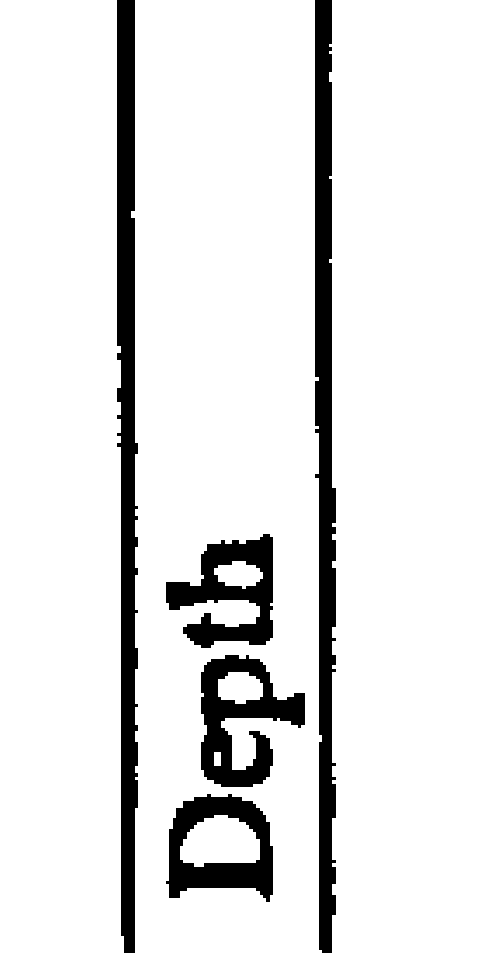 & 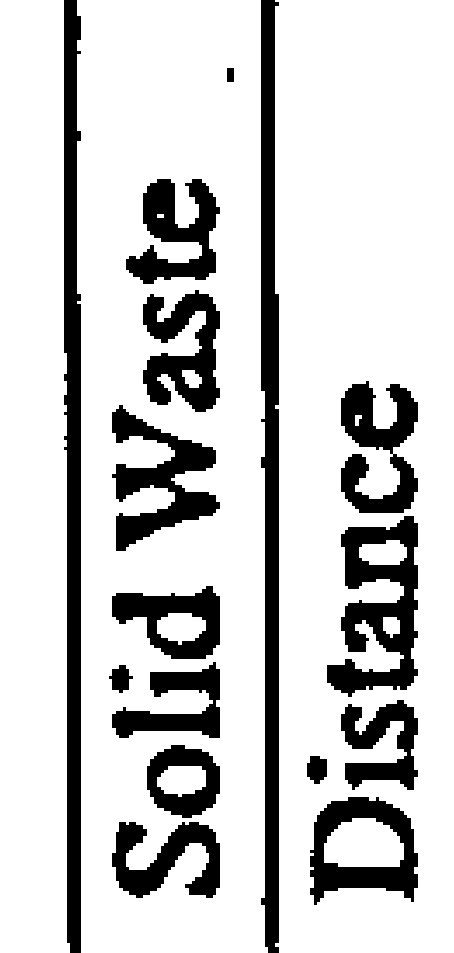 & 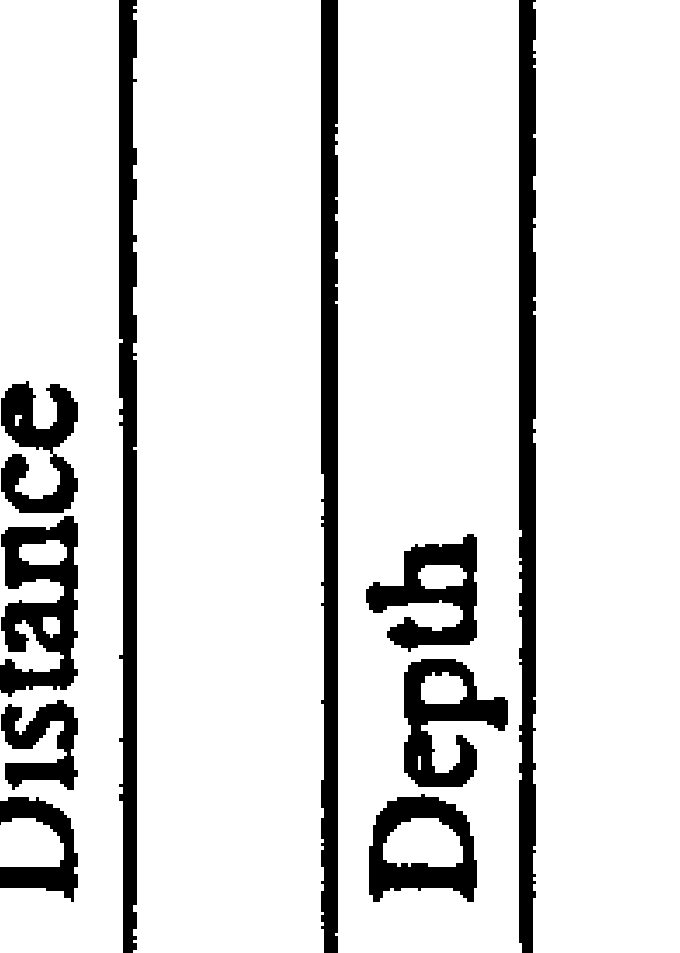 & 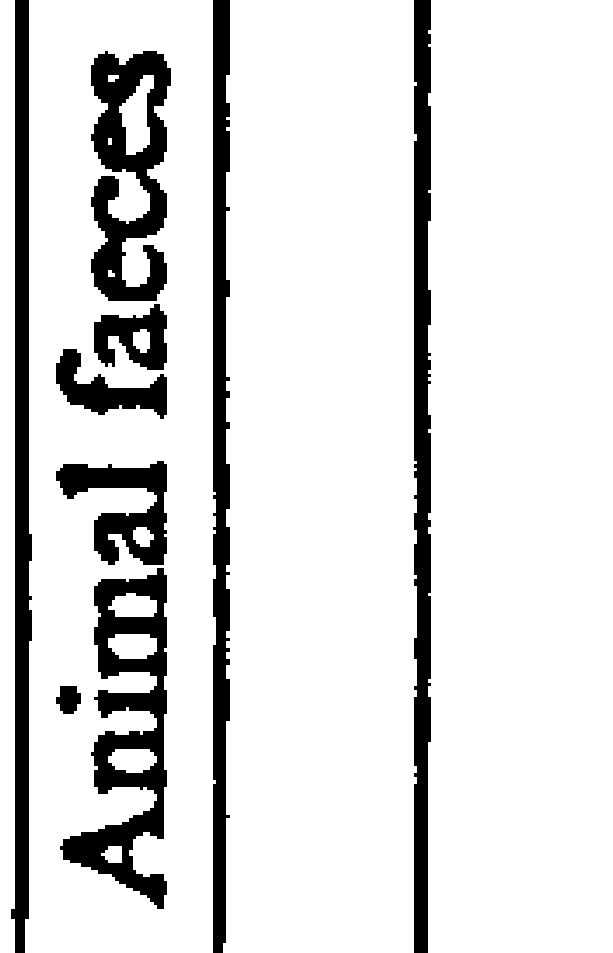 \\
\hline
\end{tabular}




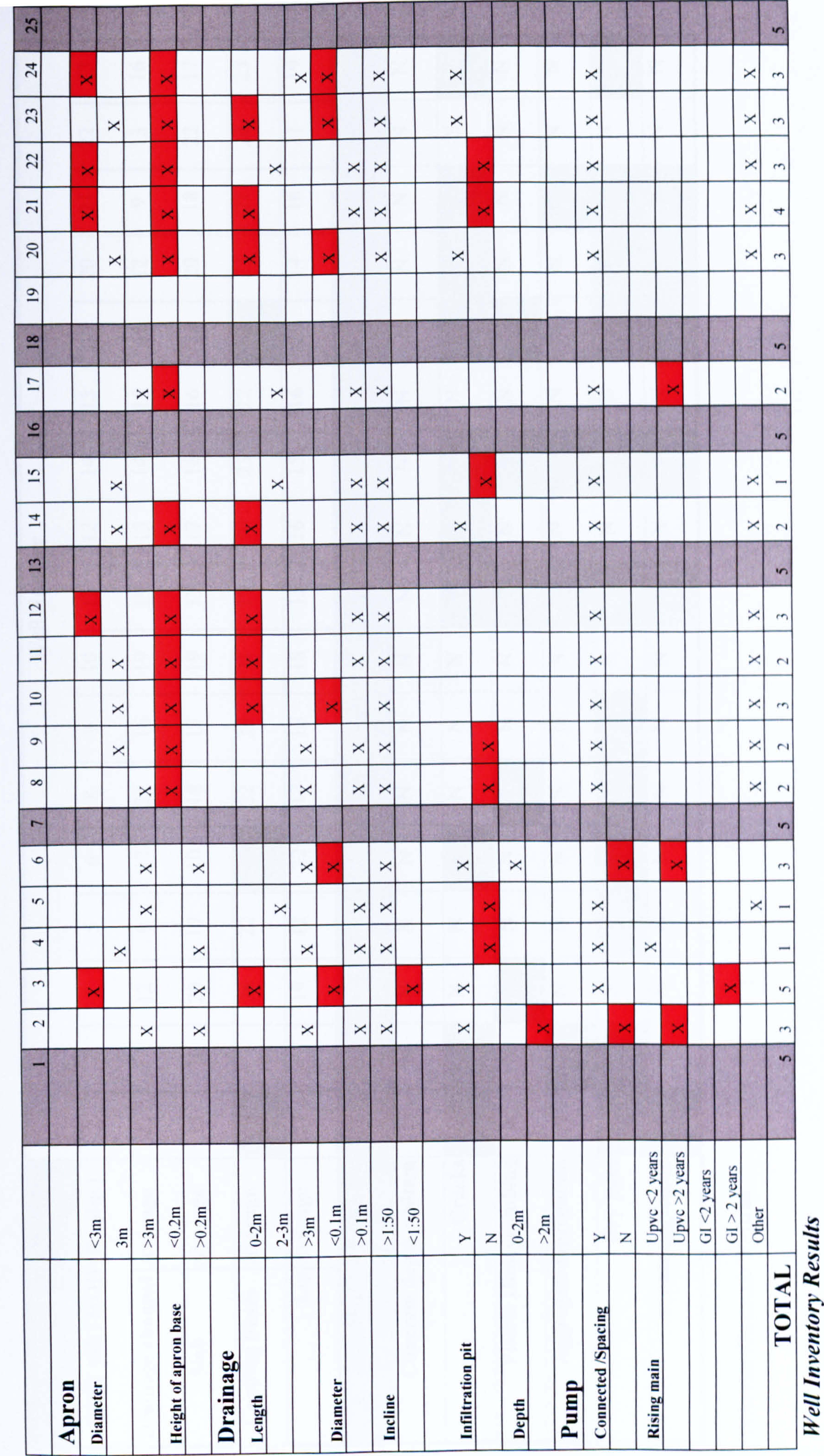




\begin{tabular}{|c|c|c|c|c|c|c|c|c|c|c|c|c|}
\hline \multirow{17}{*}{ 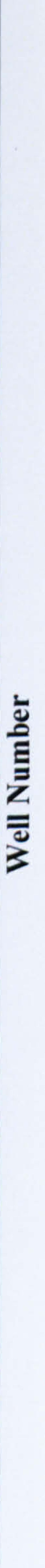 } & $\widehat{\curvearrowright}$ & $\underline{0}$ & 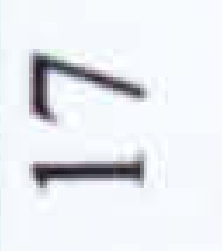 & $\widehat{\curvearrowright}$ & a & & Z & $>$ & Z & Z & $\gamma$ & Z \\
\hline & $\mathcal{N}$ & $\cong$ & त & $\stackrel{\sim}{\sim}$ & $\bar{\sim}$ & & Z & Z & Z & Z & 乙 & Z \\
\hline & $\bar{\sim}$ & $a$ & $\infty$ & $\bar{\sim}$ & $\underline{0}$ & & z & $>$ & Z & $>$ & $\gamma$ & $>$ \\
\hline & ণ & $\simeq$ & 이 & 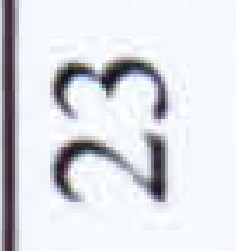 & $\Xi$ & & Z & $>$ & Z & Z & $>$ & $>$ \\
\hline & $\simeq$ & $\underline{-}$ & $\stackrel{\infty}{\sim}$ & i & 유 & & Z & $>$ & $>$ & Z & $>$ & $>$ \\
\hline & $\cong$ & $\underline{n}$ & $\underline{0}$ & N & $\underline{0}$ & & Z & Z & Z & Z & Z & Z \\
\hline & $\Xi$ & \pm & $\underline{0}$ & $\tilde{\sim}$ & $\underline{n}$ & & Z & $>$ & $>$ & $\lambda$ & $>$ & $>$ \\
\hline & $\simeq$ & $\cong$ & 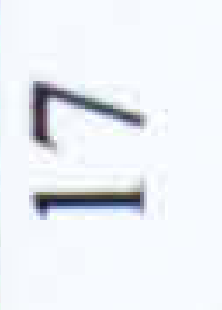 & 9 & $\underline{0}$ & & Z & $>$ & Z & Z & Z & Z \\
\hline & $=$ & 9 & 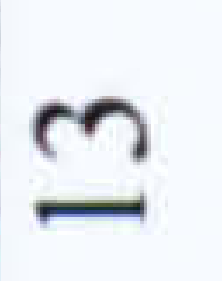 & I & $\cong$ & & z & $>$ & $>$ & $>$ & $>$ & $>$ \\
\hline & 으 & 9 & 9 & $\bar{\sim}$ & $\infty$ & & z & Z & Z & Z & Z & Z \\
\hline & $a$ & $\underline{0}$ & 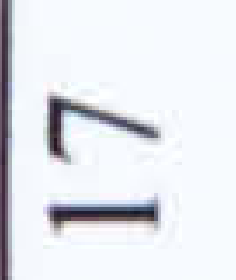 & ते & $\infty$ & & z & Z & Z & Z & $>$ & Z \\
\hline & $\infty$ & N & $\infty$ & N & 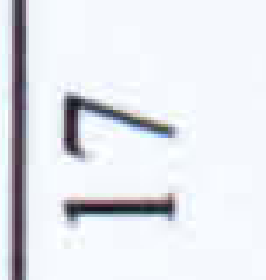 & & z & Z & $>$ & Z & $>$ & Z \\
\hline & 6 & 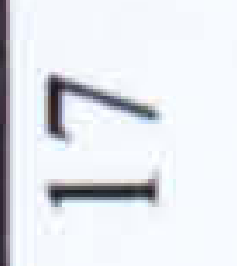 & 으 & 요 & $\tilde{N}$ & & z & $\lambda$ & Z & Z & $>$ & Z \\
\hline & in & $a$ & 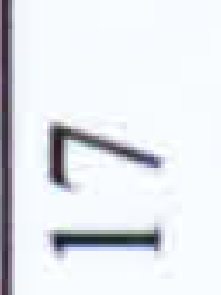 & $\tilde{N}$ & $\simeq$ & & z & Z & Z & Z & $>$ & Z \\
\hline & $\nabla$ & I & i & $\stackrel{\sim}{N}$ & 9 & & Z & Z & $>$ & Z & Z & Z \\
\hline & $m$ & & సి & & & & z & $\gamma$ & Z & $>$ & $>$ & 乙 \\
\hline & $\sim$ & $\tilde{\curvearrowright}$ & $\because$ & $\bar{m}$ & $\hat{\sim}$ & & z & $>$ & Z & Z & $>$ & $>$ \\
\hline 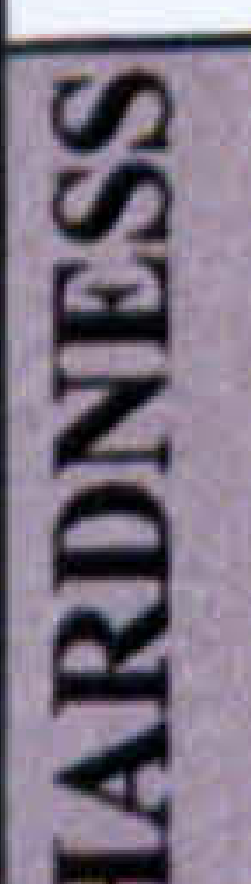 & 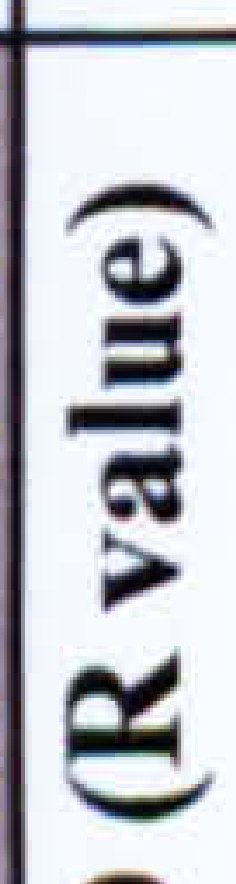 & 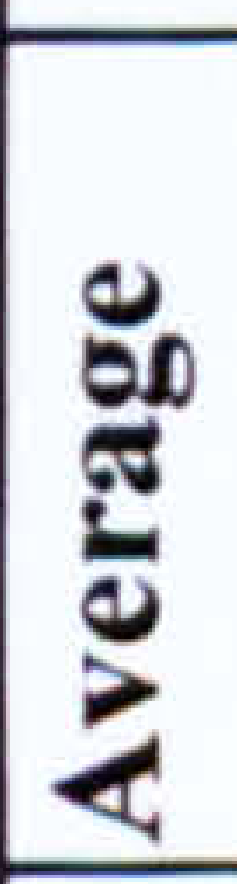 & 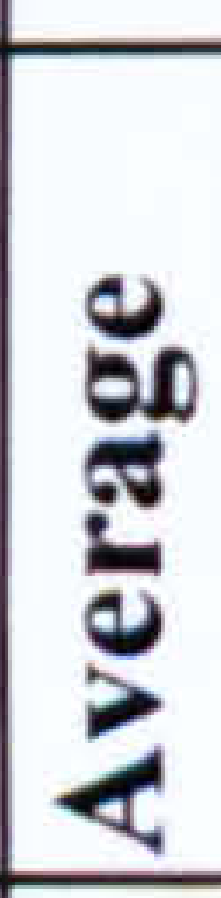 & 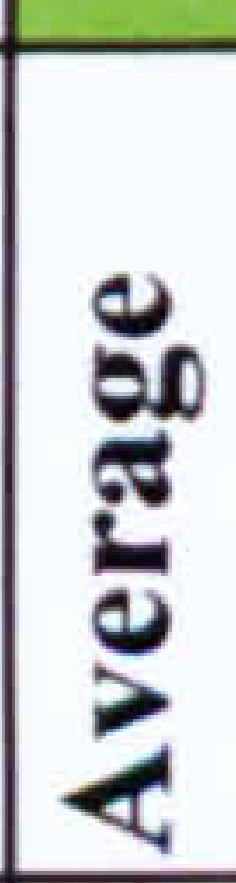 & 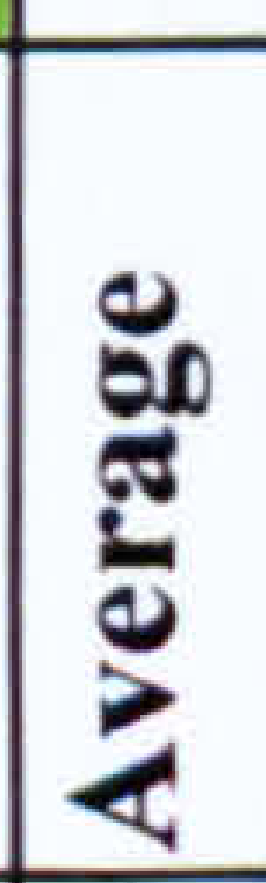 & 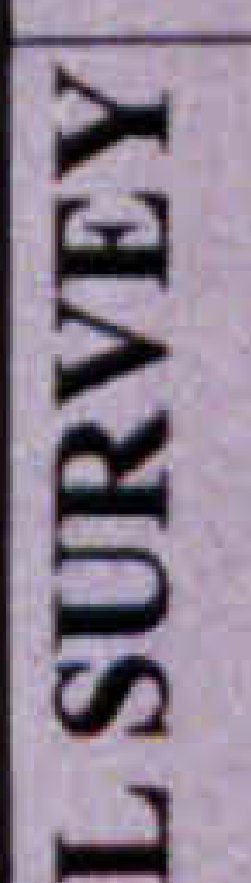 & 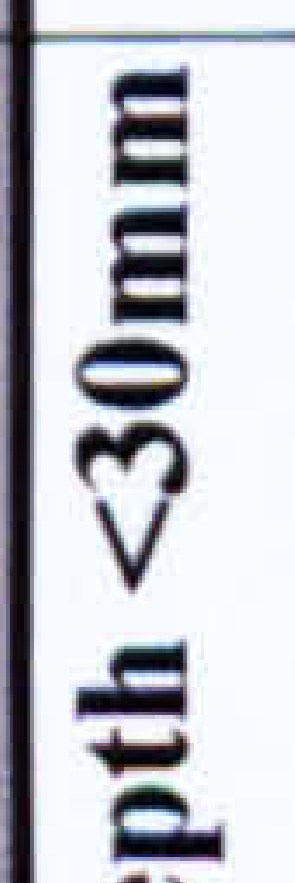 & ن & 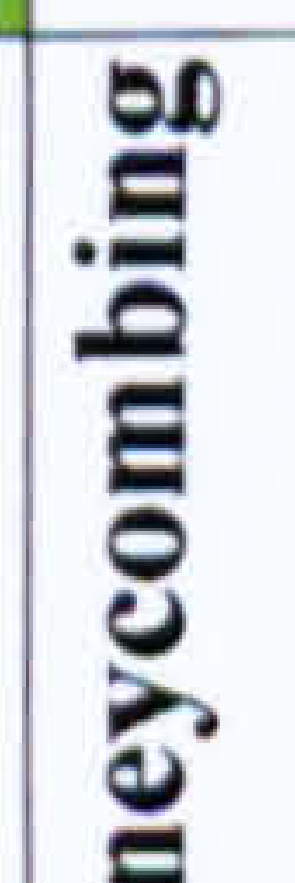 & 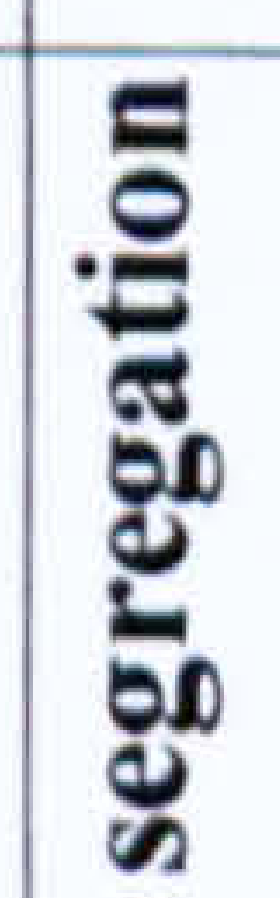 & 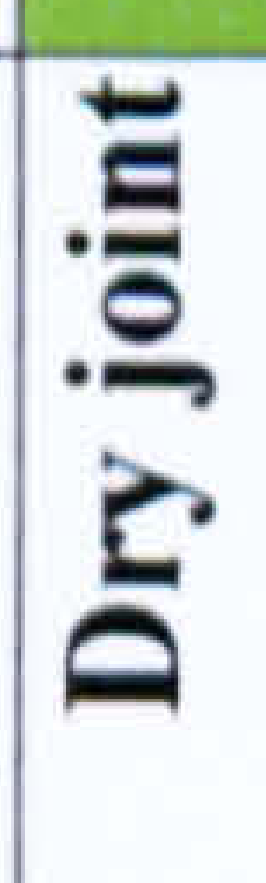 & 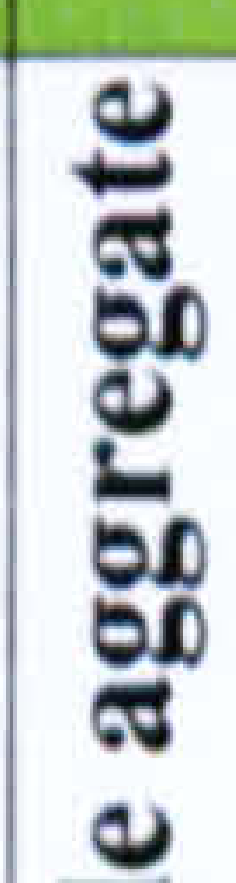 \\
\hline$\frac{\pi}{0}$ & 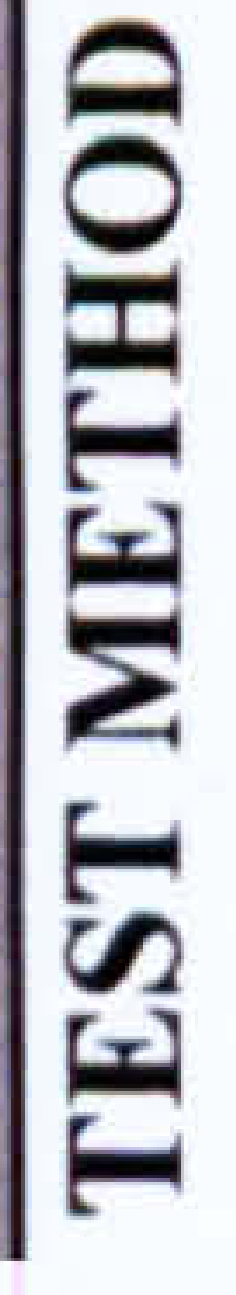 & 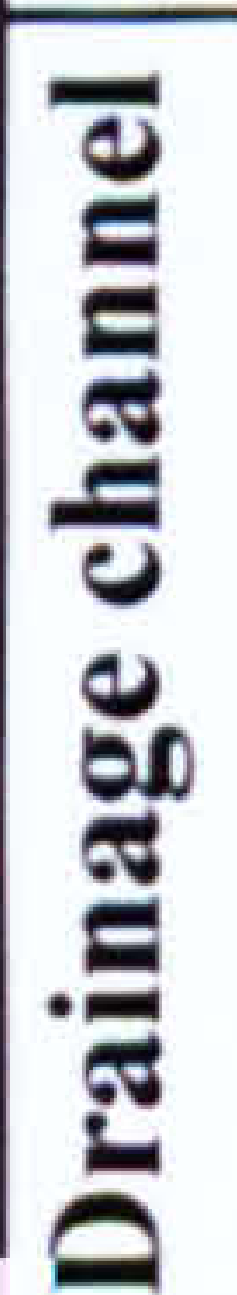 & $\frac{\hat{\sigma}}{\omega}$ & 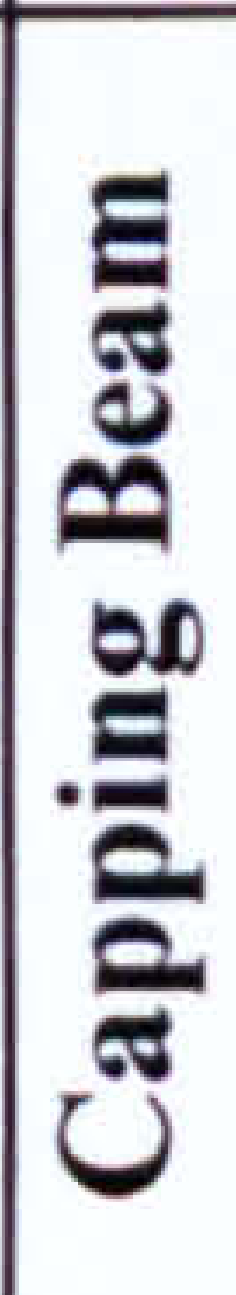 & $\hat{\jmath}$ & 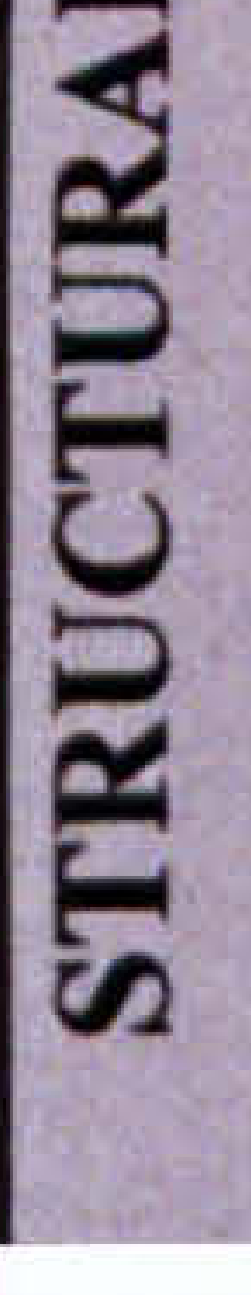 & 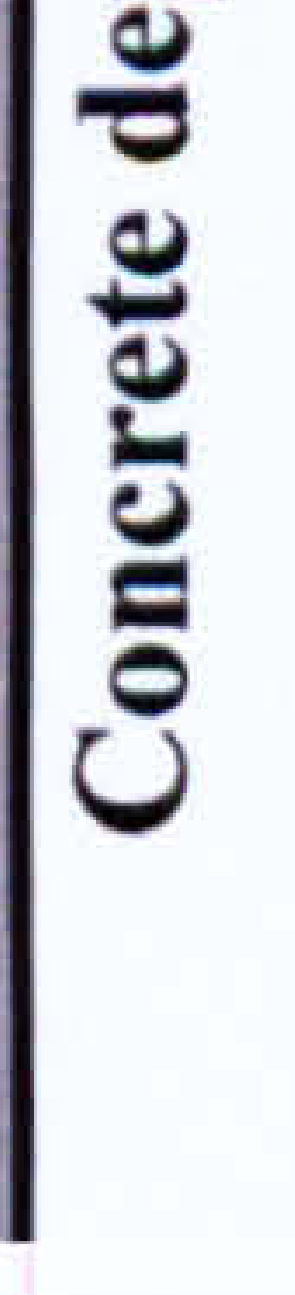 & & $\begin{array}{l}\frac{0}{1} \\
\frac{0}{0} \\
\frac{0}{0} \\
\frac{0}{2}\end{array}$ & 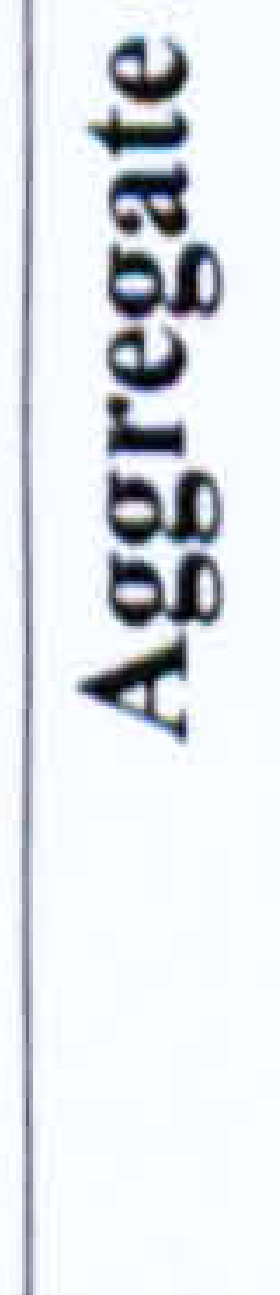 & & $\frac{\overline{0}}{\overline{2}}$ \\
\hline
\end{tabular}


Appendix 2: Analytic Hierarchy Process (AHP) 


\section{Instruction}

For a group under consideration, two variables are compared separately and then compared to the other variables in the group. The questionnaire therefore consists of two columns for each comparison. The respondents are required to tick the choice of preference in the column $\mathbf{1}$ and tick the degree of preference in the column 2 of each comparison.

For example in case of Questionnaire-1, to compare the two variables of soil permeability and well depth in the physical condition group, if the respondent feels soil permeability is a greater contributory variable to microbial contamination than that of well depth, respondent should tick 'soil permeability' in the column-1 of the table and then go to column-2. If the respondent thinks that 'soil permeability' is a 'stronger contributory' than 'well depth' to microbial contamination, then 'strongly preferred' should be ticked in the column-2 of the table. In this way the respondent is required to complete all the pair-wise comparisons for each group at different levels. At the beginning of Questionnaire there are notes describing how each variable contributes to the final output.

\section{Level 1 - Physical Condition Group}

\section{Soil permeability - Well depth}

\begin{tabular}{|l|ll|}
\hline Column-1 & Column-2 & \\
\hline $\begin{array}{l}\text { Soil permeability } \\
\text { Well depth }\end{array}$ & $\begin{array}{l}\text { Equally preferred } \\
\text { Moderately preferred } \\
\text { Strongly preferred }\end{array}$ & Very strongly preferred \\
& Extremely preferred \\
\hline
\end{tabular}

\section{Soil permeability - Well diameter}

\begin{tabular}{|l|ll|}
\hline Column-1 & Collumn-2 & \\
\hline $\begin{array}{l}\text { Soil permeability } \\
\text { Well diameter }\end{array}$ & $\begin{array}{l}\text { Equally preferred } \\
\text { Moderately preferred } \\
\text { Strongly preferred }\end{array}$ & Very strongly preferred \\
\hline
\end{tabular}




\begin{tabular}{|c|c|c|c|c|c|}
\hline Level & Group & Indicators & $\begin{array}{l}\text { Weights } \\
\text { R } 1\end{array}$ & $\begin{array}{l}\text { Weights } \\
\text { R2 }\end{array}$ & $\begin{array}{l}\text { Weights } \\
\text { R3 }\end{array}$ \\
\hline \multirow[t]{11}{*}{1} & 1 & Soil Permeability & 0.58 & 0.07 & 0.640 .11 \\
\hline & & Well depth & 0.14 & 0.52 & 0.25 \\
\hline & & Well diameter & 0.28 & 0.41 & \\
\hline & 2 & Lining $>5$ yrs old & 0.06 & 0.04 & $\begin{array}{l}0.09 \\
0.19\end{array}$ \\
\hline & & $\begin{array}{l}\text { Chemical soil } \\
\text { properties }\end{array}$ & 0.07 & 0.12 & 0.05 \\
\hline & & $\begin{array}{l}\text { Sanitary seal } \\
\text { absent }\end{array}$ & 0.18 & 0.11 & 0.50 \\
\hline & & $\begin{array}{l}\text { Low quality of } \\
\text { workmanship }\end{array}$ & 0.37 & 0.30 & 0.17 \\
\hline & & $\begin{array}{l}\text { Low material } \\
\text { quality }\end{array}$ & 0.32 & 0.44 & 0.71 \\
\hline & 3 & $\begin{array}{l}\text { Concrete Caisson } \\
\text { lining }\end{array}$ & 0.81 & 0.06 & 0.22 \\
\hline & & $\begin{array}{l}\text { Concrete Caisson } \\
\text { and brick lining }\end{array}$ & 0.13 & 0.16 & 0.07 \\
\hline & & Brick lining & 0.06 & 0.78 & 0.23 \\
\hline \multirow[t]{3}{*}{1} & 1 & $\begin{array}{l}\text { Physical } \\
\text { condition } \\
\end{array}$ & 0.09 & 0.65 & 0.23 \\
\hline & & Well linings & 0.62 & 0.08 & 0.64 \\
\hline & & $\begin{array}{l}\text { Candidate } \\
\text { technologies }\end{array}$ & 0.30 & 0.27 & 0.13 \\
\hline
\end{tabular}


Appendix 3: Paper Publications 


\title{
Microbiological risk assessment and management of shallow groundwater sources in Lichinga, Mozambique
}

\author{
S. Godfrey MCIWEM' ${ }^{1}$, F. Timo ${ }^{2}$ \& M. Smith MCIWEM ${ }^{3}$ \\ 'UNICEF Bhopal, India; ${ }^{2}$ Estaçăo Agraria de Lichinga, Lichinga, Mozambique; and ${ }^{3}$ Water, Engineering and Development Centre MEDC, \\ Loughborough University, Loughborough, UK
}

\section{Keywords}

bacteria; groundwater, hydrogeology; localised pathways; Mozambique; risk; wells.

\section{Correspondence}

S. Godfrey, Water and Environmental Sanitation Project Officer, UNICEF Bhopal, India. Email: sgodfrey@unicef.org

Winner of the UK Water Conservators Society and CIWEM Tony Drake Scholarship 2003-2004. Findings presented from author's PhD.

"Research cofinanced by the UK Water Conservators Society Tony Drake Scholarship and Loughborough University.

doi:10.1111/1.1747-6593.2006.00040.x

\begin{abstract}
The principal water target of the Millennium Development Goals (MDG) is to ensure environmental sustainability by halving the proportion of people with. out access to safe water by 2015. Although great strides have been made in meeting this challenge since the year 2000, the safety of many of these water supplies remains unknown. Acknowledging the weaknesses of current water quality and hydrogeological means of assuring microbial safety, this paper has the objective of developing improved methods for the assessment and management of microbiological water safety based on a 'risk' paradigm. This paper provides evidence for the risk assessment of both conventional aquifer pathways and localised (short circuiting) pathways to 25 wells of three well technology types in Mozambique between 2002 and 2005." Findings from the research outline improve methods of risk assessment and management by demonstrating that (1) the predominant source of contamination was from animal faeces rather than from latrines/septic tanks, (2) short circuiting is a significant risk to shallow groundwater in developing countries, (3) the use of altemative indicator organisms (e.g. enterococci) may improve risk understanding and (4) the World Health Organisation Water Safety Plans are recommended as an appropriate method of risk management.
\end{abstract}

\section{Introduction}

Because of rising populations in developing countries, many surface water resources are becoming highly vulnerable to anthropogenic chemical and microbial pollution. Consequently, many low-income communities have become increasingly reliant on shallow groundwater resources defined in this research as the water bearing materials that are strongly influenced by physical and chemical processes on the ground surface (Melian et al. 1999). These shallow groundwater sources are often exploited using low-cost technology facilities such as wells or tubewells, where the water quality is monitored based on 'end-product testing' of selected microbiological and chemical parameters and controlled through the establishment of groundwater catchment protection zones (Watt \& Wood 1979; Collins 2000).

Fundamental weaknesses in both the 'end-product testing' and groundwater catchment approach have been highlighted in the third edition of the World Health Organisation (WHO) Guidelines for Drinking Water
Quality and the British Geological Survey (BGS) study of Associated Risks to Groundwater from On-Site Sanitation (ARGOSS) (ARGOSS 2002; WHO 2004). Limitations highlighted by WHO include analysis based on a restricted range of indicator organisms and overreliance on a nonrepresentative sample volume (Payment et al. 2003; WHO 2004). Similar limitations in conventional approaches to groundwater catchment protection zones for developing countries have also been highlighted recently. Studies by the BGS on the ARGOSS suggest a high risk of short circuiting of the wellhead protection zone through localised pathways such as poorly sealed annuluses of boreholes or cracks in surface aprons (associated with construction faults and inadequate maintenance of wells) (Gelinas et al. 1996; ARGOSS 2002).

To counteract these weaknesses, the WHO propose a fundamental shift away from end-product testing towards alternative risk-based approaches termed Water Safety Plans (WSPS), where risk is defined as a combination of the probability or frequency of a particular event occurring with the consequences of its occurrence (Dixon et al. 
2001; Godfrey \& Howard 2005; Godfrey \& Smith 2005; Godfrey et al. 2005). This is supported by the ARGOSS study, which concludes that effective groundwater risk assessment and management must include two main pathways of contamination:

(a) aquifer pathway. migration of pathogens from the base of a pit latrine to the water table and then into intake of a well or a screen:

(b) localised pathway: developed through poor design, construction and/or operation and maintenance of the water supply.

In light of this debate, the objective of this paper is to develop improved methods for the assessment and management of microbiological water safety based on a 'risk' paradigm. The conceptual basis of risk is defined in this context by the source pathway receptor model, where the source is defined as the hazard event/environment (e.g. septic tank), the pathway as the vulnerability of the media (e.g. soil type) and the receptor as the receiving water infrastructure (e.g. hand-dug well).

\section{Materials and methods}

This study was undertaken in Niassa province in northern Mozambique through joint research between the UK Water, Engineering and Development Centre (WEDC), the Mozambique Estação Agraria de Lichinga (Agricultural Research (entre) and the UK charity WaterAid. The precise study area selected was the town of Lichinga (population 110000), the capital of Niassa province, located at $13^{\circ} 18^{\prime} \mathrm{S}, 35^{\circ} 15^{\prime} \mathrm{E}$. Three sample communities (Nomba, Lulimile and Ceramica) were selected from within Lichinga based on practical/logistical criteria to achieve a statistically valid sample size (i.e. number of statistically valid water points). To calculate $n$ water points for a population of size $N$ within these communities, the Student's $t$-test was selected (Helsel \& Hirsch 1992; Driegielewski et al. 1996). For a statistically valid sample of the total 362 water points in Lichinga, 20 water points would be required (plus five control 'traditional wells' at $25 \%$ of the sample size). Categorical (nonchanging) and parametric (continuous) data were collected at each of the 25 well sites over a 12 -month period from November 2003 to October 2004. Historical data were made available to the researcher from August 2002 to October 2003. The methods selected for each variable are outlined in Table 1.

\section{Results and data analysis}

Data analysis was conducted for the source, pathway, receptor and water quality data in three stages:

- data description (based on geographical and technological data).
Table 1 Methods of analysis

\begin{tabular}{|c|c|c|}
\hline Varlable & Method & Frequency \\
\hline \multicolumn{3}{|l|}{ SOURCE } \\
\hline Hazard/vulnerability analysis & Sanitary survey & Monthly \\
\hline Distance from latrines & Field survey & Monthly \\
\hline Depth of latrine & Field survey & Annual \\
\hline Land use & Field survey & Annual \\
\hline \multicolumn{3}{|l|}{ PATHWAY } \\
\hline Rainfall/precipitation & DipFlex manual rain gauge & Dally \\
\hline $\begin{array}{l}\text { Depth to water/water } \\
\text { level }\end{array}$ & HORON dip test & Monthly \\
\hline \multirow[t]{4}{*}{ Aquifer media } & $\begin{array}{l}\text { Clba-Geigy agrochemicals } \\
\text { gulde to soil identification }\end{array}$ & Annual \\
\hline & $\begin{array}{l}\text { GEO-VISION borehole } \\
\text { camera }\end{array}$ & Annual \\
\hline & Field survey & Annual \\
\hline & $\begin{array}{l}\text { Particle slze distribution } \\
\text { (BS1377-2) }\end{array}$ & Annual \\
\hline Hydrogeological survey & Field survey & Annual \\
\hline & Visual soll classification & Annual \\
\hline & Subsoll thickness & Annual \\
\hline & Geological obsenvations & Annual \\
\hline \multicolumn{3}{|l|}{ RECEPTOR } \\
\hline Surface hardness & $\begin{array}{l}\text { MASTRAD Schimdt } \\
\text { Hammer (BS1881-201) }\end{array}$ & Annual \\
\hline Water lifting & Structured survey & Annual \\
\hline Headwork survey & $\begin{array}{l}\text { Borehole camera } \\
\text { Structured survey }\end{array}$ & $\begin{array}{l}\text { Annual } \\
\text { Annual }\end{array}$ \\
\hline Well designulining & $\begin{array}{l}\text { Borehole camera } \\
\text { Structured survey }\end{array}$ & $\begin{array}{l}\text { Annual } \\
\text { Annual }\end{array}$ \\
\hline \multicolumn{3}{|l|}{ WATER QUALITY } \\
\hline Turbidity & Turbidity tube & Monthly \\
\hline $\mathrm{pH}$ & Handheld comparator & Monthly \\
\hline $\begin{array}{l}\text { Presumptive thermotolerant } \\
\text { coliforms }\end{array}$ & $\begin{array}{l}\text { UK methods for } \\
\text { examination of water and } \\
\text { assoclated materlals }\end{array}$ & Monthly \\
\hline Presumptive enterococel & $\begin{array}{l}\text { UK methods for examination } \\
\text { of water and associated } \\
\text { materials }\end{array}$ & Monthly \\
\hline
\end{tabular}

Note: Source is defined as the hazard eventenvironment (e.g. latrine). Pathway is defined as the vulnerability of the media (e.8. soll type). Receptor is defined as the recelving water infrastructure (e.g. hand-dug well).

- data mining (statistical extraction of data) and - data analysis [statistical analysis using logistic regression and chi-square $\left(\chi^{2}\right)$ significance weightings $(P$ values)].

\section{Data description}

\section{Hazard varlables}

Results from 325 sanitary inspections indicated high usage of latrines by adults and low usage by children. resulting in the high presence of children/babies and livestock faeces in the wellhead catchment. 


\section{Pathway variables}

A total of 1047 and $1042 \mathrm{~mm}$ of rainfall were collected in the two rain gauges during the 12 -month study. The highest rainfall was noted during the months of monomodal rains (November-April) (see Godfrey et al. 2005). Additionally, water table depths were collected monthly in each well over the 12-month period. During the rainy season, increased recharge resulted in shallow water levels to $5.1 \mathrm{mbgl}$ (metres below ground level) at both locations. During the dryer period, the water level dropped to below $7.5 \mathrm{mbgl}$. Lowest recorded levels were noted as $8.62 \mathrm{mbgl}$ in October.

Rainfall- and water-level data were linked to hydrogeological data, which indicated that Lichinga is underlain by metamorphic rock with overlying alluvial drift. Because of limited available data on the hydrogeology of the area, subsoil field investigations were undertaken using the Ciba-Geigy classification method and soil particle size distribution (PSD) analysis (see Fig. 1). The CibaGeigy method relies on visual examination and physical behaviour of the soil when handled without using analytical equipment. The Ciba-Geigy survey revealed very high silt and clay content in samples from all three sites (CIBAGEIGY 1986). In comparison, PSD results indicated a very high fine sand/silt content with a limited percentage of coarse materials. The $K$ permeability value for each of the samples suggested a moderate to low permeability range at $10^{-4}-10^{-8} \mathrm{~m} / \mathrm{s}$ (BS1377-2 1990).

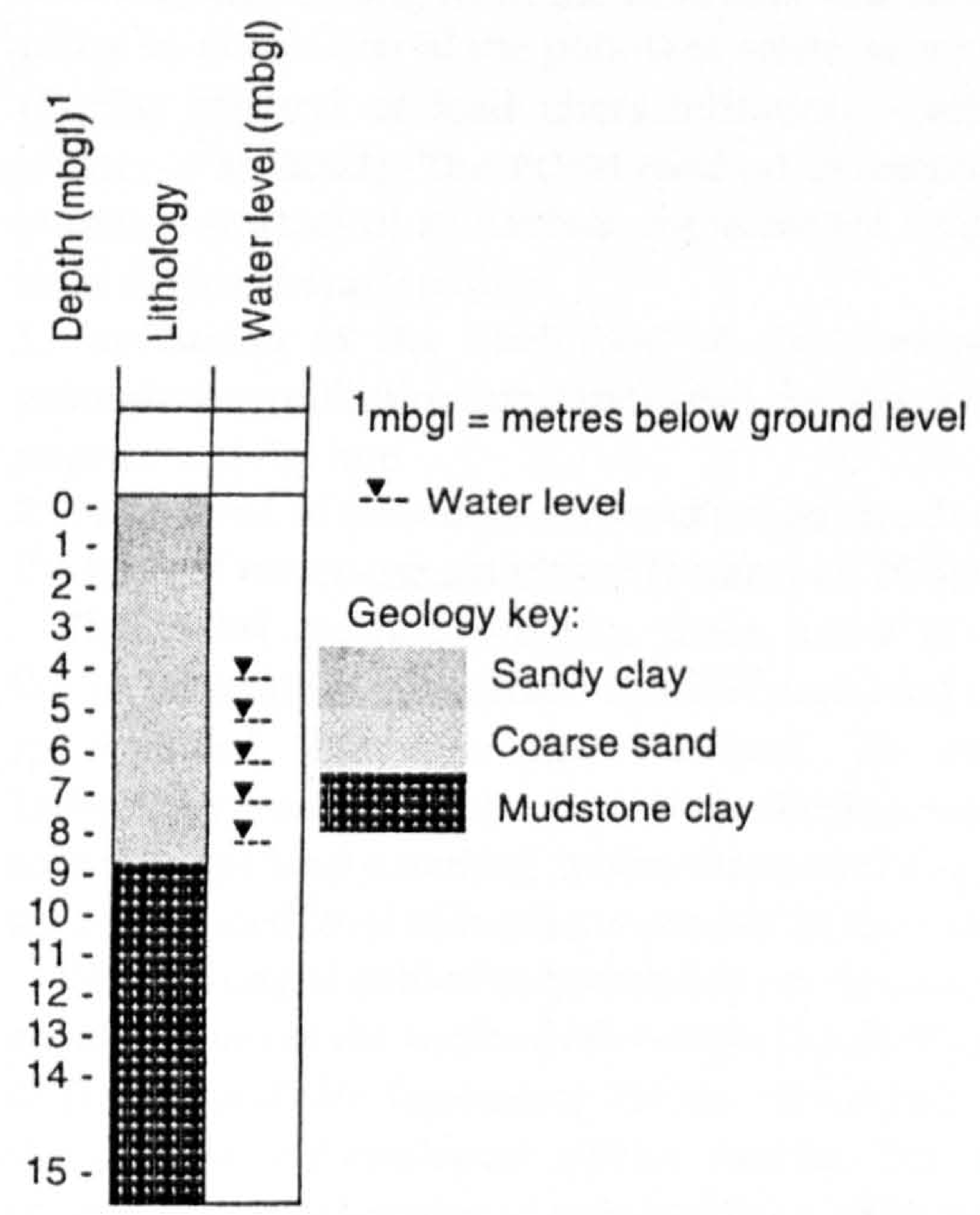

Fig. 1. Subsurface geology.

\section{Receptor variables}

Conventionally, hydrogeologists assess risk to groundwater based on pollutant source loading and vulnerability of aquifer pathways. This research also assesses the influence of the receptor in minimising risk through localised pathways (e.g. short circuiting through the wellhead protection zone). The wellhead is defined as the underground and overground construction of the abstraction facility as well as the immediate area surrounding the abstraction point (Howard et al. 2003a).

The headworks of the wellhead were assessed using 510 Schmidt Hammer surface hardness tests at four specific points on the apron of each well and a qualitative headworks inventory. For the Schmidt Hammer tests, optimum levels of $R=30$ were used as the lowest levels as recommended by the manufacturer for concrete products (Mastrad 2004) Using $R=30$, it can be concluded that only the precast reinforced concrete capping beam produced results $\geq 30$ and that the quality of concrete used in all the headworks was poor. Visual inventories revealed high levels of visible aggregate (suggesting poor mixing of concrete by hand) and surface cracking and dry jointing. Examination of these cracks and dry joints revealed high levels of risks of direct ingress of surface contaminants through the unlined annuluses of wells to the well reservoir.

\section{Water quality}

\section{Microbiological results}

As outlined in Fig. 2, low levels of compliance to the WHO guideline values for thermotolerant coliforms (TTC) were noted in both traditional wells and improved wells during the rainy season (November-March). This improved during the drier months of March to July and then deteriorated again in the leadup to the rains in August to September. It should be noted that increased demand on the wells during the later part of the year, combined with minimal yield, may have resulted in increased levels of contamination. Minimal difference, however, was noted between traditional and upgraded wells. Levels of enterococci (EF) were noted as being consistently greater in all well technologies. Higher counts of EF were recorded in wells at greater depth. This is explained by the robustness of the organism and its ability to survive, but not multiply under environmental conditions at depth (Mara 2003).

\section{Data mining}

In order to then refine the data, a process of data mining was undertaken. Data mining is described as the 
- TW $\% T T C<1 \mathrm{cfu} / 100 \mathrm{~mL}=U W \% T T C<10 \mathrm{cfu} / 100 \mathrm{~mL}$

a TW $\% T T C<10 \mathrm{cfu} / 100 \mathrm{~mL}$ \& UW $\% E F<10 \mathrm{cfu} / 100 \mathrm{~mL}$

$\triangle T W \% E F<10 \mathrm{cfu} / 100 \mathrm{~mL} \quad \mathrm{IW} \% \mathrm{TTC}<1 \mathrm{cfu} / 100 \mathrm{~mL}$

UW $\%$ TTC $<1 \mathrm{cfu} / 100 \mathrm{~mL} \quad \square \mathrm{IW} \% \mathrm{TTC}<10 \mathrm{cfu} / 100 \mathrm{~mL}$

v IW \%EF $<10 \mathrm{cfu} / 100 \mathrm{~mL}$

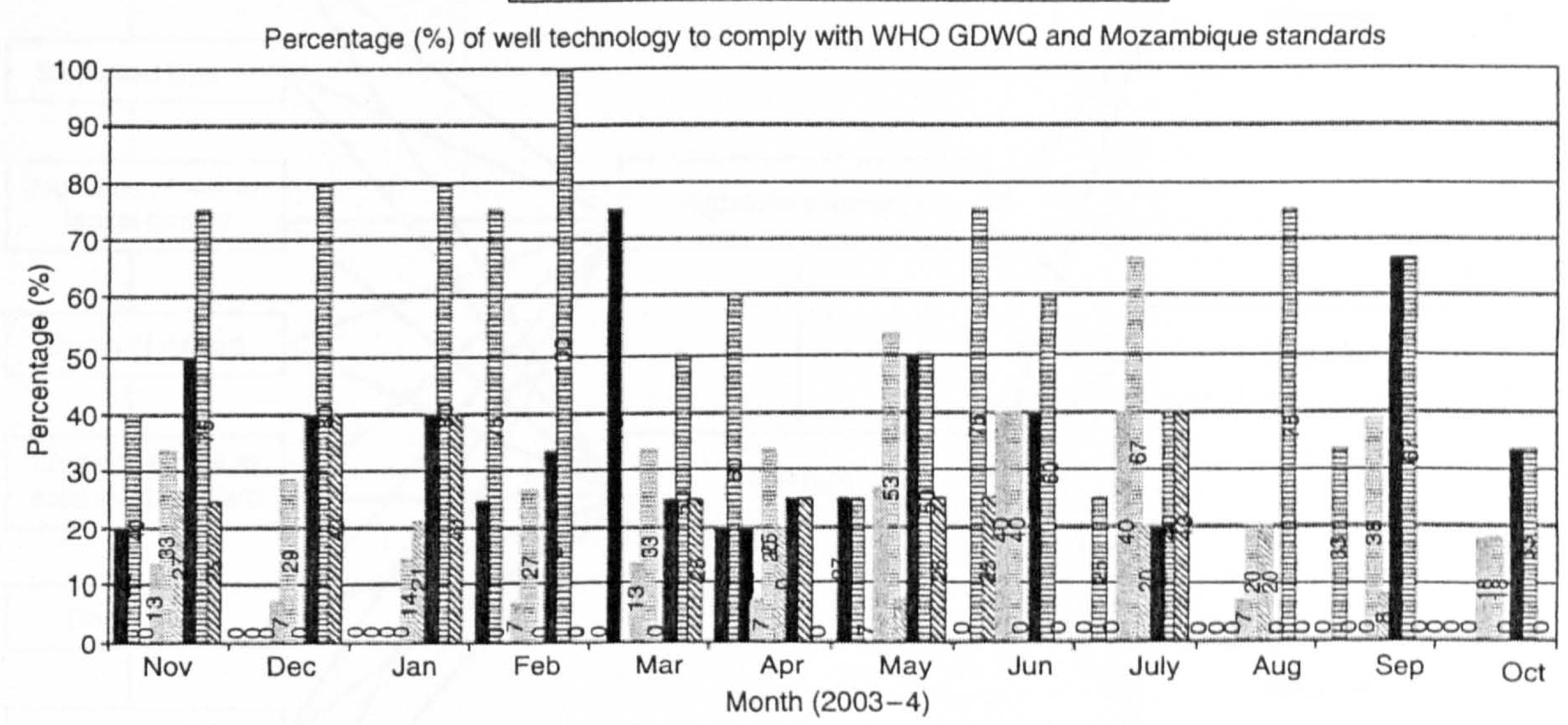

Fig. 2. Percentage compliance to World Health Organisation GDWQ third edition 2004. TW, traditional wells; UW, upgraded wells; IW, improved wells; $E F$, enterococci; TTC, thermotolerant coliforms.

exploration and analysis, by automatic or semiautomatic means, of large quantities of data in order to discover meaningful patterns and rules (Helberg 2002). For this research, data mining of the source variable level of contaminant loading from the field data was undertaken using an adaptation of the pollutant origin source hazard (POSH) method of load characterisation - see Fig. 3 (Foster et al. 2002). The POSH method characterises the potential sources of subsurface contaminant load on the basis of two characteristics:

1. association of the likelihood of the presence of a groundwater-polluting substance with the type of anthropogenic activity and

2. estimation of associated hydraulic load (surcharge) on the basis of water-use activities (Foster et al. 2002).

The POSH method provides three levels of 'potential to generate a subsurface contaminant load', namely, Reduced, Moderate and Elevated. As noted in Table 2, by combining the variables affecting subsurface contaminant load potential, it was observed that a Moderate to Reduced level of hazard is present in the study site.

Data mining of subsoil vulnerability was analysed using an adaptation of the methods developed by the University of Dublin and the Geological Survey of Ireland, termed the adapted hydrogeological settings method. The method considers four categories of vulnerablity - extreme, high, moderate and low (Robins 1998; Swartz et al. 2003). As noted in Table 3, these categories are calculated by combining subsoil field descriptions, grain size data, subsoil thickness (determined from waterlevel data) and qualitative estimates of soil permeability. The permeability is used to define the specific hydraulic conductivity (Swartz et al. 2003).

From the hydrogeological settings method, it was observed that $0 \%$ of the wells were within the Extreme vulnerability category. Fifty per cent of the wells were within the High vulnerability category and $50 \%$ of the wells were within the Moderate. Because of lack of available data, three wells had no vulnerability category. Because of time and financial constraints, additional factors such as ambient temperature of soil microbes relative to physiologic temperature and specific porosity have not been researched. The literature, however, suggests that any one indicator of vulnerability should not be used in isolation and that a more holistic approach such as the adapted hydrogeological settings method is of greater use (Stejmar 1998). A moderate to high level of vulnerability was found in the selected well sites, with no wells categorised as having either extreme or low vulnerability.

\section{Data analysis}

Statistical analysis was undertaken using logistic regression. This technique was selected because of its successful use 


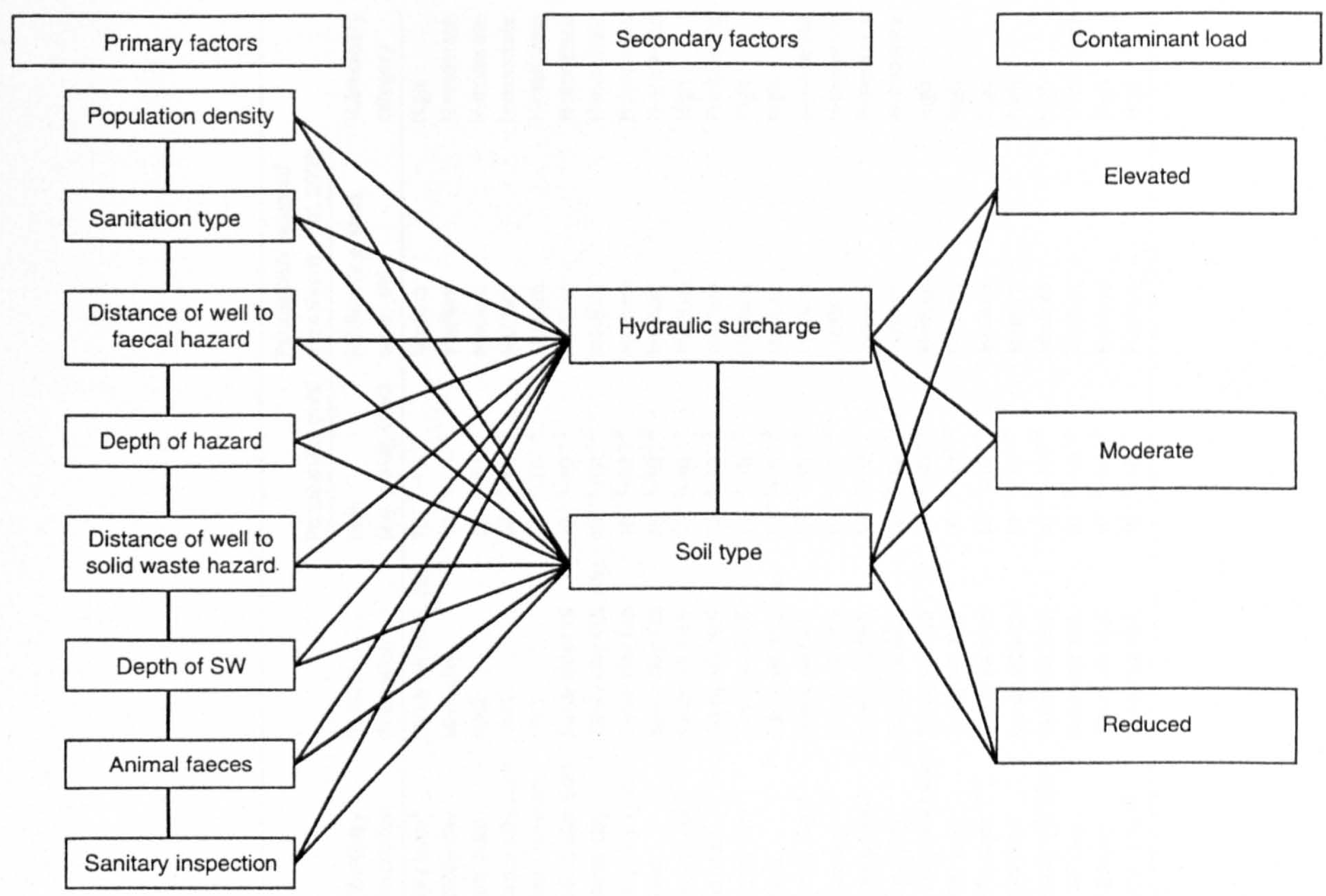

Fig. 3. Pollutant origin source hazard data mining.

Table 2 Source variable - subsurface contaminant load potential

\begin{tabular}{ll}
\hline Category & Wells \\
\hline Elevated & 6,17 \\
Moderate & $2,3,4,5,7,8,10,12,13,14,18,19$ \\
Reduced & $1,9,11,15,16,20,22$ \\
\hline
\end{tabular}

in other studies (Howard et al. 2003b; Tesoreiro et al. 2003). Because of the large number of covariates, four analyses were performed using logistic regression. This paper will focus on one of the analyses, namely

- monthly analysis of source, pathway, receptor and significance of specific sanitary inspection results to microbial noncompliance.

Data were dummy coded as 0 or 1 in SPSS 11 based on compliance or noncompliance with the selected critical limits below for each well technology:

- TTC $>10 \mathrm{cfu} / 100 \mathrm{~mL}=$ high risk, $<10 \mathrm{cfu} / 100 \mathrm{~mL}=$ low risk;

- $\mathrm{EF}>10 \mathrm{cfu} / 100 \mathrm{~mL}=$ high risk, $<10 \mathrm{cfu} / 100 \mathrm{~mL}=$ low risk.

Outlined below are the results for significance weightings of individual sanitary inspection results and specific source, pathway and receptor variables for the noncompliance of EF and TTC in three well types:

- traditional wells,

- improved wells and

- upgraded wells.

For each, the categories along the $x$-axis (SI2-SII0 inclusive) refer to specific individual questions on the sanitary inspection form used. Each sanitary inspection (SI) number presented is a statistically generated number based on the mean of 12 months data. The $y$-axis presents the statistical weighting represented as a $P$-value at $95 \%$ confidence or 0.05 .

\section{Traditional wells (Fig. 4)}

Results summary: traditional wells

Statistical significance $\leq 0.05$,

Statistical significance $>0.05$.

Two risk variables were identified to be significant in traditional wells:

- rope on floor and

- bucket on floor. 


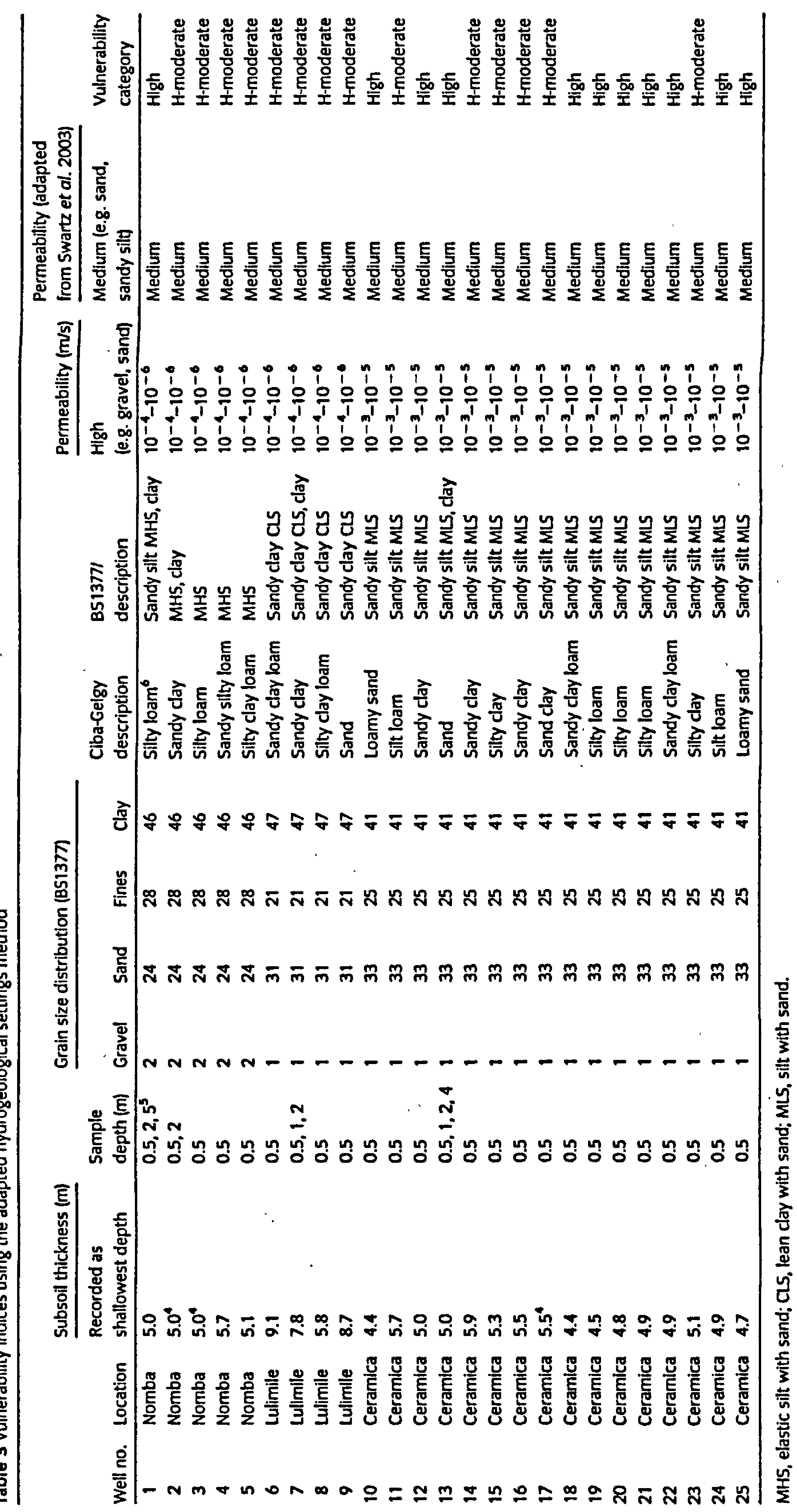




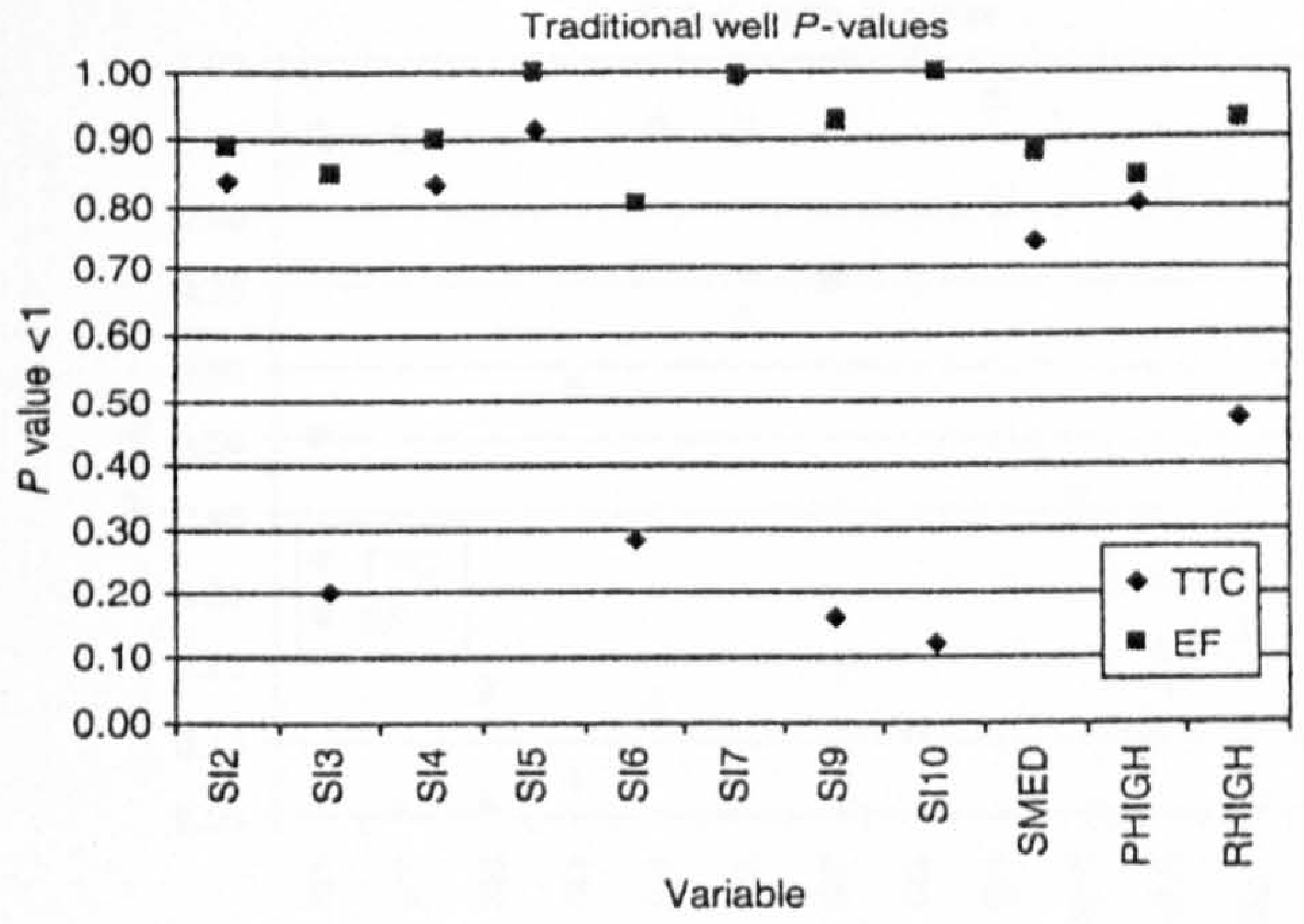

\begin{tabular}{|l|l|l|l|l|}
\hline SI no. & Hazard & \multicolumn{2}{|c|}{ Result } & Risk \\
\hline & & TTC & EF & \\
\hline 2 & $\begin{array}{l}\text { Existence of animais excreta } \\
\text { close to well }\end{array}$ & 0.84 & 0.88 & Low \\
\hline 5 & $\begin{array}{l}\text { Solid waste dumps within } \\
30 \text { m of the well site }\end{array}$ & 0.91 & 1 & Low \\
\hline 7 & $\begin{array}{l}\text { Insanitary head works within } \\
3 \text { m of the well }\end{array}$ & 0.99 & 0.99 & Low \\
\hline 10 & $\begin{array}{l}\text { Insanitary use of rope and } \\
\text { bucket }\end{array}$ & 0.11 & 1 & High/Low \\
\hline
\end{tabular}

Fig. 4. Traditional well sanitary inspection results. EF, enterococci; TTC, thermotolerant coliforms.

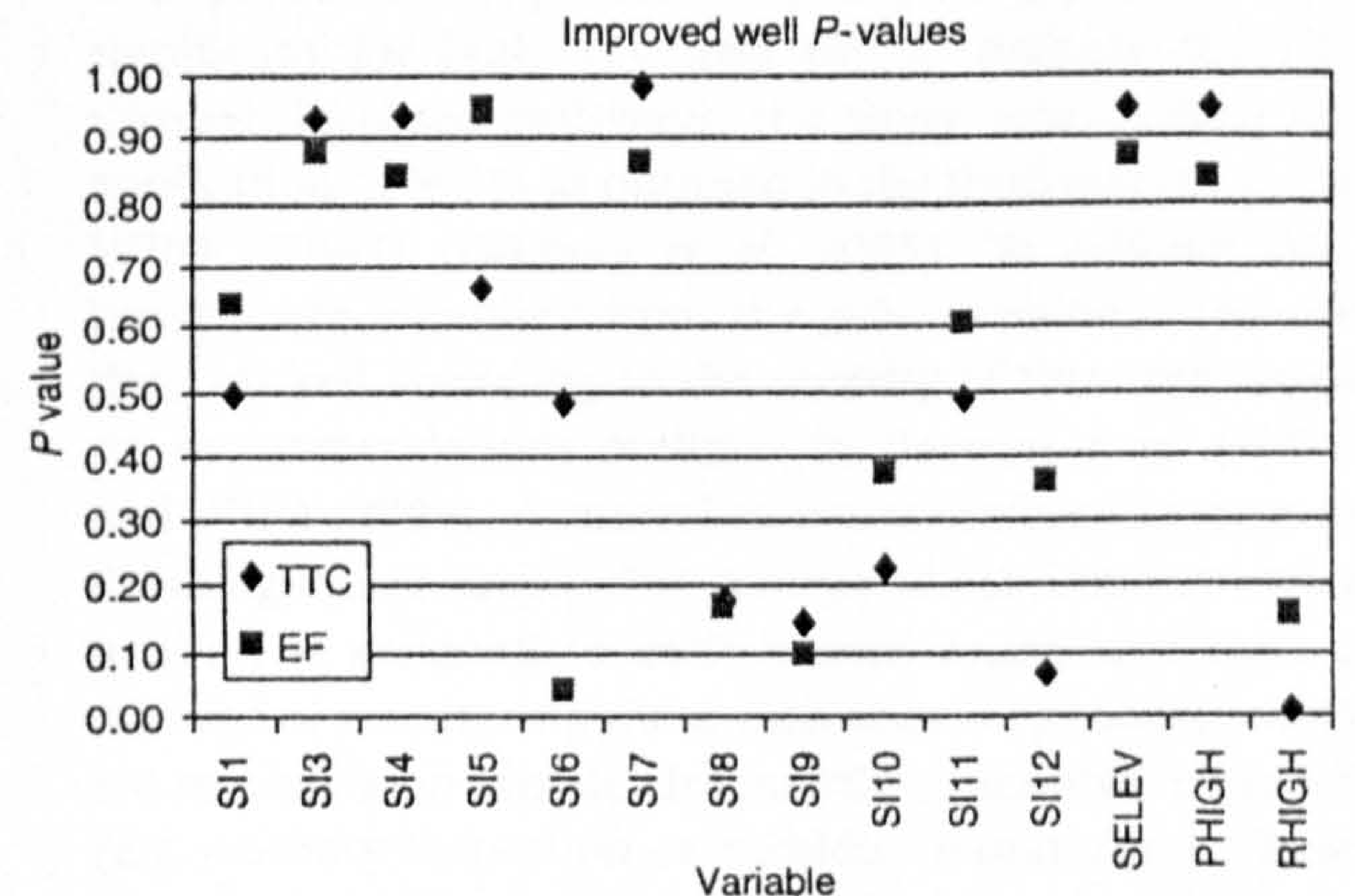

\begin{tabular}{|l|l|l|l|l|}
\hline SI no. & Hazard & \multicolumn{2}{|c|}{ Result } & Risk \\
\hline & & TTC & EF & \\
\hline 4 & $\begin{array}{l}\text { Discarded open wells or } \\
\text { refuse pits }\end{array}$ & 0.94 & 0.83 & Low \\
\hline 6 & Stagnant water on apron & 0.98 & 0.05 & Low/High \\
\hline 7 & Cracks in apron & 0.98 & 0.85 & Low \\
\hline 8 & Deficient drainage & 0.18 & 0.18 & High \\
\hline 9 & Headwork's diameter <2 m & 0.10 & 0.13 & High \\
\hline 10 & $\begin{array}{l}\text { Insanitary condition of } \\
\text { pumphead (pump and base) }\end{array}$ & 0.212 & 0.371 & High \\
\hline & Receptor category & 0.01 & 0.15 & High \\
\hline
\end{tabular}

Fig. 5. Improved well sanitary inspection records. EF, enterococci; TTC, thermotolerant coliforms.

\section{Improved wells (Fig. 5)}

In comparison, in caisson-lined improved wells, evidence of high risk relates to the receptor (receiving water infrastructure).

Results summary: improved wells

The receptor was identified as being the principal route of contamination. Three specific risk factors were identified:

1. presence of stagnant water on and around the wellhead,

2. loose base of the handpump and

3. cracks at the base of the handpump.

The high level of significance of the receptor is explained by evident faults in the headworks, which may result in greater risk of localised pathways of contamination.

\section{Upgraded wells (Fig. 6)}

Results summary: upgraded wells

Three risks were identified as being of significance for upgraded wells:

- solid waste $<30 \mathrm{~m}$,

- animal excreta $<30 \mathrm{~m}$ and

- deficient headworks (no well cover).

\section{Discussion}

Analysis of specific pathways to contamination supports the view that localised pathways are significant in northern Mozambique. This supports earlier studies by BGS and Robens (ARGOSS 2002). In traditional wells, localised pathways or direct ingress of contamination were a significant variable in the presence of $\mathrm{EF}$ contamination. 


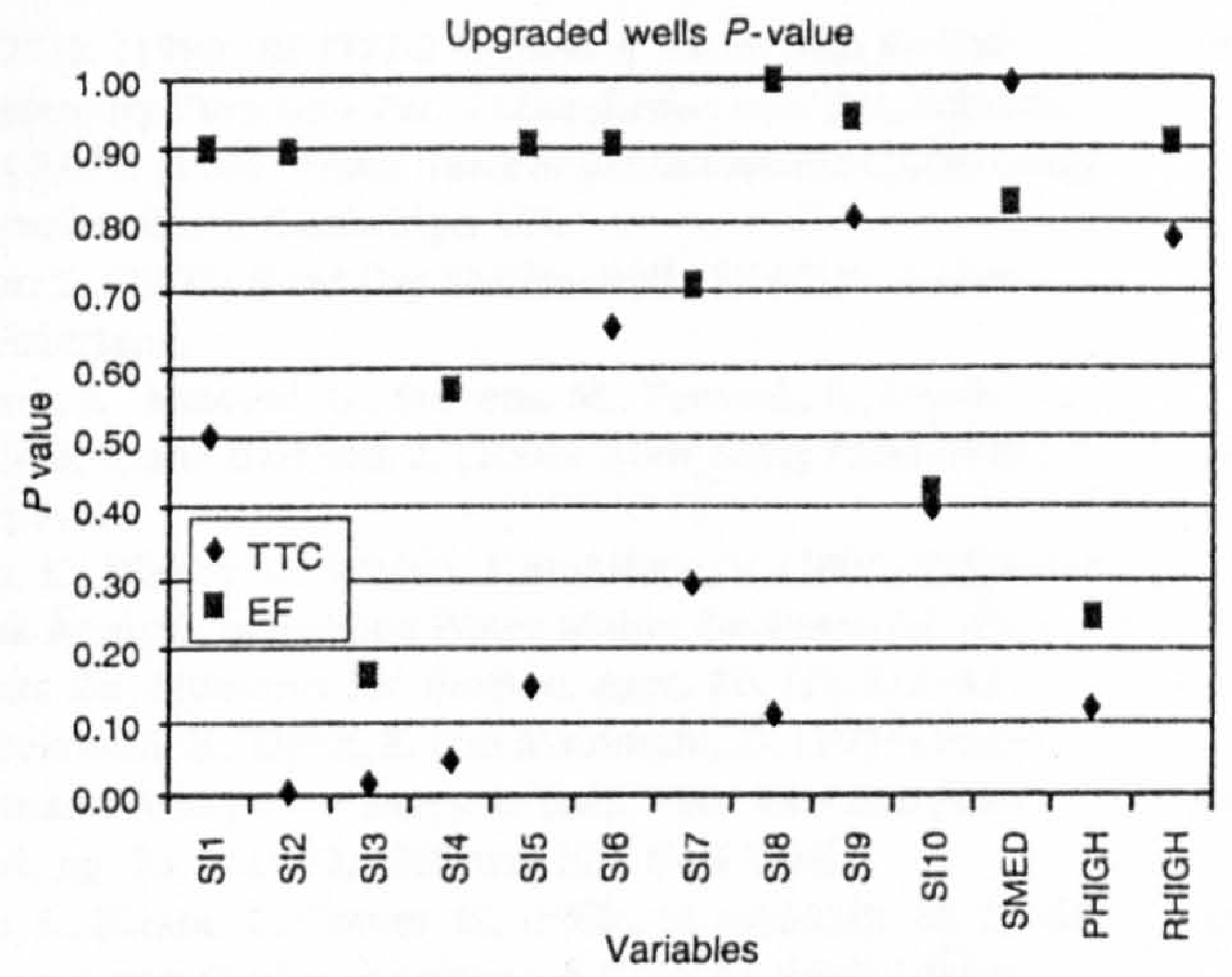

\begin{tabular}{|l|l|c|l|l|}
\hline SI no. & Hazard & \multicolumn{2}{|c|}{ Result } & Risk \\
\hline & & TTC & EF & \\
\hline 1 & Latrine $<30 \mathrm{~m}$ & 0.50 & 0.90 & Low \\
\hline 2 & Animal excreta $<30 \mathrm{~m}$ & 0.00 & 0.89 & High/Low \\
\hline 5 & Solid waste $<30 \mathrm{~m}$ & 0.15 & 0.91 & High/Low \\
\hline 8 & Deficient headworks & 0.11 & 1 & High/Low \\
\hline 9 & & & & \\
\hline & No well cover & 0.81 & 0.97 & Low \\
\hline & Pathway category & 0.11 & 0.28 & High/Low \\
\hline
\end{tabular}

Fig. 6. Upgraded well sanitary inspection records. EF, enterococci; $\Pi \mathrm{CC}$, thermotolerant coliforms.

In improved and upgraded wells, localised pathways were significant for both TTC and EF. To manage the risk through localised pathways, the study recommends the application of WSPs as outlined in the third edition of the WHO GDWQ (Godfrey et al. 2005). To achieve this, hazards are identified from the risk assessment and are then ranked according to the severity of their risk based on recommendations outlined in Davison et al. (2004) and WHO (2004). A control measure (defined as steps in drinking-water supply that directly affect drinking water quality) is assigned to each hazard event, and then a method of monitoring these measures is considered with an emphasis on simple, frequently repeatable methods (e.g. sanitary inspection or turbidity monitoring). These control measures are then verified using microbial indicator organisms.

Furthermore, the findings in Mozambique indicate that, statistically, EF would be a more appropriate indicator for all three well types studied than TTC. In agreement with studies by Massa et al. (2001), this study notes that evidence from analysis of polluted groundwater waters suggests that EF may be 'a more reliable indicator of faecal pollution than faecal coliforms in raw water' (Massa et al. 2001). EF displayed a higher survival and was less susceptible to die-off, dilution or filtration (Bitton et al. 1983; Melian et al. 1999; Macler \& Merkle 2000; Massa et al. 2001). Their greater survival at depth in this study suggests that EF may be a more appropriate means of verifying the compliance of the system to the control measure.

\section{Conclusions}

The objective of this paper was to develop improved methods for the assessment and management of microbiological water safety based on a 'risk' paradigm. To achieve this objective, this paper concludes that the following points are critical for the effective assessment and management of groundwater microbiological risk.

(1) Localised pathways are significant pathways in the risk of contamination of shallow groundwater in northern Mozambique. Contamination through aquifer pathways from latrines/septic tanks was not as insignificant as contamination from animal faeces.

(2) The use of alternative indicator organisms (e.g. EF) may improve risk understanding associated with short circuiting. The findings indicated that although TTCs are more prominent in traditional and upgraded wells, EFs are a more detectable organism at depth in improved wells.

(3) The study recommends the WHO WSPs as an appropriate method of risk management.

\section{Acknowledgements}

This study was only possible because of the financial support of the UK Water Conservators Company Tony Drake Scholarship 2003-2004. The authors acknowledge this and the technical and logistical support provided by Dr. Guy Howard (DFID), Rebecca VanDer Meulen and James Gibson from WaterAid Mozambique. The views expressed in this paper are solely those of the authors and should not, however, be taken as representing the views of WaterAid.

\section{References}

ARGOSS. (2002) Guidelines for assessing the risk to groundwater from onsite sanitation. CR/01/142, ed. B.G.S.C. Report.

Bitton, G., Farrah, S.R., Ruskin, R.H., Butner, J. and Chou, Y.J. (1983) Survival of Pathogenic and Indicator Organisms in Groundwater. Groundwater, 21 (4), 405-410. 
BS1377-2. (1990) BS 1377-2 Methods of Test for Soils for Civil Engineering Purposes - Part 2 Classification tests. BSI, London. CIBAGEIGY. (1986) Pocket Guide to Soil Identification. Ciba Geigy Agrochemicals, Cambridge, UK.

Collins, S. (2000) Hand Dug Shallow Wells. SKAT, St. Gallen, Switzerland.

Davison, A., Howard, G., Stevens, M., Fewtrell, L., Deere, D., Callan, P. and Bartram, J. (2004) Water Safety Plans. WHO. Geneva.

Dixon, K., Blakey, G., Whiter, J. and Hope, V. (2001) GIS Based Risk Analysis of Ferrous Water Mains. Underground Infrastruct. Res. Municipal Ind. Environ. Appl., 20, (1), 312-322.

Dziegielewski, B., Opitz, E. and Maidment, D. (1996) Water Demand Analysis. In Mays, I. (ed). Water Resources Handbook, pp. 23.1-23.62. McGraw-Hill, New York.

Foster, S., Hirata, R., Gomes, D., D'Elia, M. and Paris, M. (2002) Groundwater Quality Protection - A Guide for Water Utilities, Municipal Authorities and Environment Agencies. The World Bank, Washington, DC, USA.

Gelinas, Y., Randall, H.o Robidoux, I. and Schmit, J. (1996) Well Water Survey in Two Districts of Conakry (Republic of Guinea) and Comparison with the Piped Water Supply. Wat. Res., 30, 2017-2026.

Godfrey, S. and Howard, G. (2005) Water Safety Plans - Planning Water Safety Management for Urban Piped Water Supplies in Developing Countries. WEDC, UK.

Godfrey, S. and Smith, M. (2005) Improved Microbial Risk Assessment of Groundwater. Hydrogeol. J., 13, 321-324.

Godfrey, S., Tino, F. and Smith, M. (2005) Relationship Between Rainfall and Microbiological Contamination of Shallow Groundwater in Northem Mozambique. WATERSA, 31 (4), 609-614.

Helberg. C. (2002) Data Mining with Confidence - SPSS (2nd edn). SPSS Inc, Chicago, Illinois.

Helsel, D.R. and Hirsch, R.M. (1992) Statistical Methods in Water Resources. Elsevier Science, Amsterdam, the Netherlands.

Howard, G., Godfrey, S. and Boonyakamkul. T. (2003a) Chapter 18: Wellhead Protection/Sanitary Completion. In Schmoll, O. and Chorus, I. (eds) Groundwater Monograph. pp. 200-230. WHO, Geneva.
Howard, G., Pedley, S., Barret, M., Nalubega, M. and Johal, K. (2003b) Risk Factors Contributing to Microbiological Contamination of Shallow Groundwater in Kampala, Uganda. Wat. Res., 37, 3421-3429.

Macler, B. and Merkle, J. (2000) Current Knowledge on Groundwater Microbial Pathogens and Their Control. Hydrogeol. J., 8, 29-40.

Mara, D.D. (2003) Faecal Indicator Organisms. In Mara, D. and Horan, N. (eds). Handbook of Water and Wastewater Microbiology, p. 819. Elsevier, London.

Massa, S., Brocchi, G., Peri, G., Altieri, C. and Mammina, C. (2001) Evaluation of Recovery Methods to Detect Faecal Streptococd in Polluted Waters. Lett. Appl. Microbiol., 32, 298-302.

MASTRAD. (2004) Mastrad Speedy Moisture Testers. Mastrad Limited, Douglas, Isle of Man, UK.

Melian, R., Myrlian, N., Gouriev, A., Mouraru, C. and Radstake, P. (1999) Groundwater Quality and Rural Drinking Water Supplies in the Republic of Moldova. Hydrogeol. J., 7. 171-188.

Payment, P., Waite, M. and Dufour, A. (2003) Introducing Parameters for the Assessment of Drinking Water Quality. In Dufour, A. et al. (eds). Assessing the Microbial Safety of Drinking Water. IWA, London.

Robins, N. (1998) The Quality of Groundwater in Northern Ireland. J. Ch. Water Environ. Manage., 12, 163-169.

Stejmar, H. (1998) Assessment of Groundwater Quality Using Hydrogeological Settings. In Gambling with Groundwater Physical, Chemical and Biological Aspects of Aquifer-Stream Relations, pp. 1-10. USGS Publication, Las Vegas, USA.

Swartz, M., Misstaer, B., Daly, D. and Farrel, E. (2003) Assessing Subsoil Permeability for Groundwater Vulnerability. Quart. J. Eng. Geol., 36, 173-184.

Tesoreiro, A.o Inkpen, E. and Voss, F. (2003) Assessing groundwater vulnerability using logistic regression. Water Resources Division, US Geological Survey.

Watt. S. and Wood, E. (1979) Hand Dug Wells and Their Construction. IT Publications, UK.

WHO. (2004) Guidelines for Drinking Water Quality. Volume I Recommendations (3rd edn). World Health Organisation. Geneva, Switzerland. 


\title{
Relationship between rainfall and microbiological contamination of shallow groundwater in Northern Mozambique
}

\author{
S Godfrey ${ }^{4 *}$ F Tino ${ }^{2}$ and M Smith ${ }^{3}$ \\ ' Water and Environmental Sanitation Project Officer, UNICEF Bhopal, India (formerly WEDC, UK) \\ ${ }^{2}$ Estação Agraria de Lichinga, Lichinga, Mozambique \\ ${ }^{3}$ Water, Engineering and Development Centre (WEDC), Loughborough University, UK
}

\begin{abstract}
Outbreaks of contamination events in many developing countries occur during periods of peak rainfall. This study presents evidence of direct pulse response of shallow groundwater contamination events to rainfall in Northern Mozambique. The objective of the paper is to establish both a statistical relationship between rainfall and contamination and to analyse the pathways through which runoff resulted in contamination. To achieve this, data from 25 wells were monitored over a 12-month period in Lichinga, Northern Mozambique, and then compared to historical rainfall from the previous 8 years. Categorical (soil survey) and parametric (water quality, rainfall, depth-to-water-table) data were further collected before, during and after the 4-month monomodal rains. Using logistic regression statistics, three distinct conclusions were drawn from the study. Firstly, the study demonstrated a direct pulse response between increased numbers of presumptive thermotolerant coliforms and enterococci bacteria. Secondly, the study observed high risk of contamination through localised, as opposed to aquifer pathways and thirdly, the study noted a higher survival function and stability of presumptive enterococci bacteria as compared to presumptive thermotolerant coliforms in the environment and at depth.
\end{abstract}

Keywords: rainfall/runoff, contamination, groundwater monitoring, microbiological processes

\section{Introduction}

Studies of shallow groundwater contamination in developing countries have demonstrated a direct pulse-response between trends of rainfall and microbiological contamination (Barrel, 1979; Lewis et al.., 1980; Lewis et al.,1984; Wright, 1986). A recent study of springs in the weathered crystalline aquifers of Kampala, Uganda by Barret (2000) and Howard et al. (2003) demonstrated a significant deterioration in microbiological groundwater quality within 12 hours of a rainfall event (Barret et al., 2000; Howard et al., 2003). This study is supported by further evidence from studies undertaken in Peru, Gambia, Sierra Leone and Zambia regarding the seasonality of groundwater quality (Barrel, 1979; Wright, 1986; Utkilen et al., 1989; Bartram, 1996). For example, in a study of wells in rural villages in the Gambia, Barrel (1979) noted an increase of approximately 10 orders of magnitude of faecal contamination following the onset of the rains over a period of 6 days (Barrel, 1979). Further studies by Utkilen et al. (1989) in Zambia concluded that peaks in faecal contamination of wells were associated with rainfall as a result of surface flushing of faecal material (Utkilen et al., 1989).

However, in contrast to these views, studies of the seasonality of water quality in Sierra Leone noted decreasing rates of contamination during the wet season (Wright, 1986). The study examined levels of selected faecal indicator bacteria and incidence of Salmonella spp. over a one-year period. The study concluded that counts were generally increasing during the dry season culminating in peaks at the transition from dry to wet season. This increase was attributed to a lack of sanitation devel-

* To whom all correspondence should be addressed

$\boldsymbol{\nabla}+91755$ 2466568; fax: +91 7552463623

e-mail: sgodfrey@unicef.org

Received 21 January 2005; accepted in revised form 9 June 2005 opment and the sporadic nature of rainfall patterns in the study area. Consequently, the human and animal waste was deposited at the soil surface and flushed into the water sources during the rains. Additionally, due to the water sources diminishing in the dry season, a lower level of dilution or concentration effect of faecal contamination was observed in the dry season resulting in higher detection levels (Wright, 1986).

Studies by Howard et al. (2003), although solely focused on spring contamination, provide a significant background to the development of the study presented in this paper. Their study highlights the importance of contamination of shallow springs by short-circuiting of sanitary headworks through "localised pathways" (Howard et al., 2003) It explores this alternative localised pathway by examining the microbiological contamination levels in wells with varied levels of sanitary protection during periods of high and low rainfall.

This paper widens the Howard et al. (2003) research to investigate microbiological contamination of 25 shallow wells over 12 months (November 2003 to October 2004) in Lichinga, Northern Mozambique. The aim of the study outlined in this paper was to identify the influence of rainfall and localised pathways on groundwater contamination. Based on the source-pathwayreceptor model of groundwater contamination, "localised" and "aquifer" pathways of contamination are defined as follows;

- Localised pathways - a rapid bypass mechanism where pathogens enter the intake of the water supply due to poor design and/or construction, the microbes having limited residence time in the saturated zone as a consequence.

- Aquifer pathways - where pathogens migrate through the subsoil from a faecal source to the water table (ARGOSS, 2002).

Field workers report that localised pathways are considered of high significance in Mozambique, where poor quality materials, limited quality control in construction and high levels of 


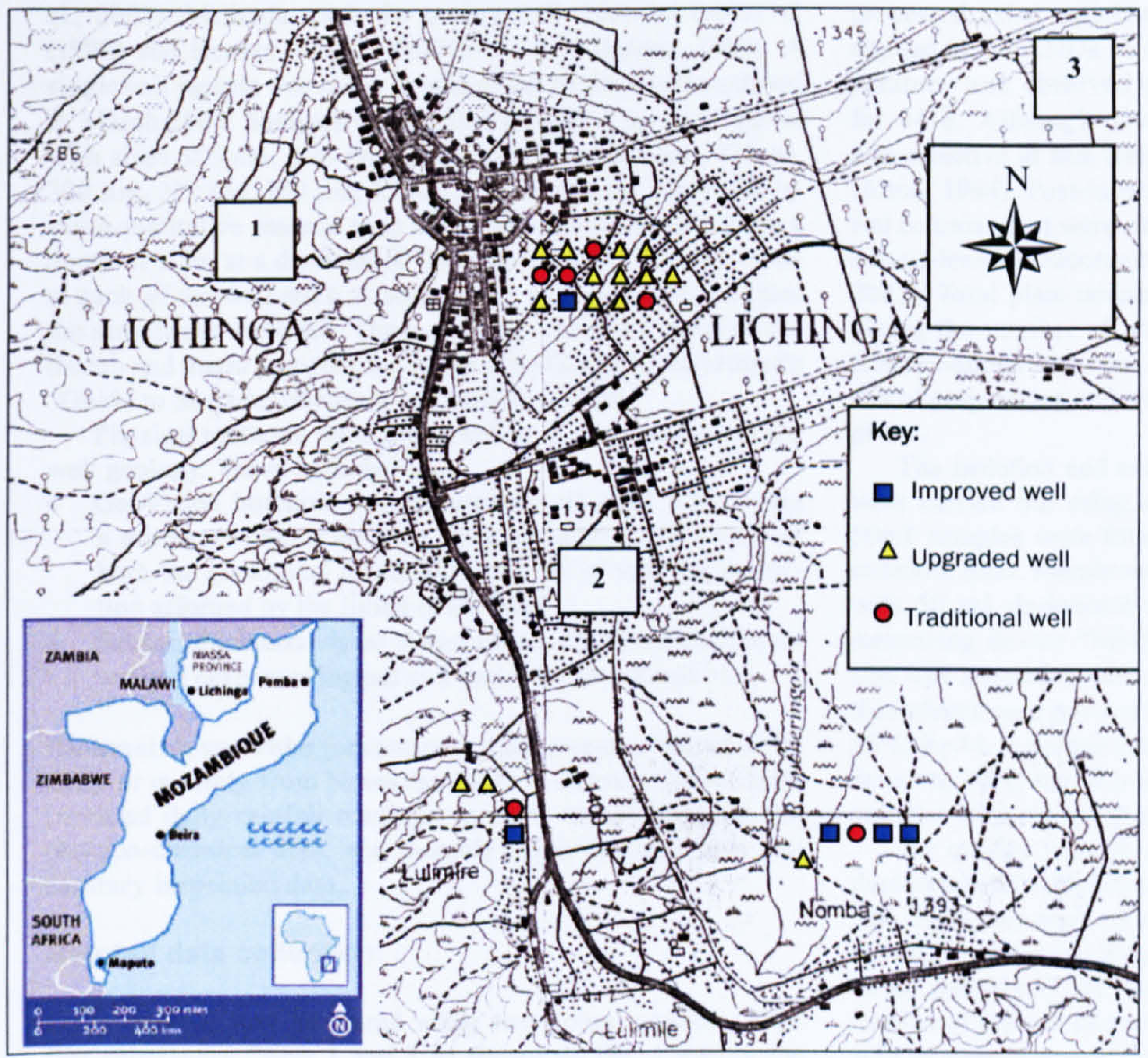

Figure 1

Location of sample points and rain-gauges in Lichinga

where:

improved well = concrete caisson lined well with mechanised pump upgraded well = brick lined well with windlass

traditional well = unlined well with rope and bucket

Note: Raingauges 1, 2, 3 are identified by white squares in Fig. 1

faeces in the environment result in high levels of microbiological ingress (Tino, 2003). This paper discusses the relationship between rainfall and contamination in three well types with respect to the contamination pathways.

\section{Experimental}

The study was undertaken in the town of Lichinga, the capital of Niassa Province in Northern Mozambique, located at $13^{\circ} 18^{\prime} \mathrm{S}, 35^{\circ} 15^{\prime} \mathrm{E}$, through joint research between the UKbased Water, Engineering and Development Centre (WEDC), the Mozambique Estação Agraria de Lichinga (Agricultural Research Centre) and the UK charity WaterAid. Twenty five groundwater sources were selected using the statistical t-test based on 2 comparable means from 2 variables; existing levels of contamination (water quality) and population served. Using the t-test, the number of water points required with $95 \%$ confidence level of estimating average levels of contamination within $2 \%$ of the true value was calculated using Eqs.(1) and (2):

$$
\mathrm{n}_{\mathrm{o}}=\frac{\{t \mathrm{~S}\}^{2}}{r \mathrm{Y}^{2}}
$$

where:

\footnotetext{
$\mathrm{n}_{\mathrm{o}}$ : first approximation of sample size

$t$ : confidence probability (t statistics). This value is $1.64,1.96$ and 2.58 for confidence probabilities of 90 , 95 and $99 \%$ respectively

$\mathrm{S}:$ population standard deviation

$r$ : relative error

$\mathrm{Y}$ : population mean.
}
where: $\quad \mathrm{n}=\frac{\mathrm{n}_{\mathrm{o}}}{\left(1+\frac{\mathrm{n}_{\mathrm{o}}}{\mathrm{N}}\right)}$
$\mathrm{n}$ : sample size
$\mathrm{N}$ : population size
$\mathrm{n}_{\mathrm{o}}$ : first approximation sample size (see Eq.(1)).

For a statistically valid sample, 20 water points would be required. These were selected from the communities outlined in Map 1 based on logistics, practicalities, ease of access, available water quality data and inclusion in an existing monitoring framework.

Data were initially collected from 20 water sources in three communities in Lichinga with an additional five traditional wells used as control sites (at least one of each located within a given sampling area). Sampling was undertaken twice per month immediately before the rains and at monthly intervals after their arrival to gauge the potential "pulse response" of levels of contamination in the shallow groundwater to rainfall. Stratified data collection was done on both categorical and parametric variables.

Categorical variables (or non-changing data) were single measurements. These included geographic positioning system (GPS) readings, a soil characterisation study based on particle size distribution (PSD) and soil classification tests and an engineering assessment. For the purpose of this paper, the soil characterisation methods will be discussed. The method for collecting soil characterisation data included the particle size distribution method and manual soil classification tests (Swartz et 
al., 2003). Methods used for testing PSD followed BS1377-2 (1990) and Barnes (2000) (BS1377-2, 1990; Barnes, 2000). A single soil sample was taken at each of the 25 wells and analysed in March 2004. Samples were riffled through a set of 5 " sieves with sizes of $5 \mathrm{~mm}, 3.35 \mathrm{~mm}, 2 \mathrm{~mm}, 1.18 \mathrm{~mm}, 600 \mu \mathrm{m}, 425 \mu \mathrm{m}$, $300 \mu \mathrm{m}, 212 \mu \mathrm{m}, 150 \mu \mathrm{m}, 63 \mu \mathrm{m}$. PSD tests were supported by semi-qualitative manual tests using an augured sample from a depth of $0.5 \mathrm{~m}$ at a distance of $1 \mathrm{~m}$ from the well. This was done at each of the well sites. A segment of soil was extracted from the sample and analysed. The sample was classified based on the thumb and finger test outlined in the Ciba-Geigy Agrochemicals "Guide to Soil Identification." (CibaGeigy, 1986).

Physical methods were supported by in situ readings of the well geology. These included:

- GeoVision borehole camera readings of lined wells using a miniature colour monitor. This provided a quick view of both the geological formation and level of sanitary protection afforded by the lining of the well.

- Subsoil thickness visual observations of unlined traditional wells. These were logged as $0-1 \mathrm{~m}, 1-3 \mathrm{~m}, 4-5 \mathrm{~m}$ and $>5 \mathrm{~m}$.

Parametric variables (or continuous data) were collected either daily or monthly from November 2003 to October 2004. These included daily rainfall readings, monthly microbiological and physico-chemical data, and monthly depth-to-water-table and sanitary inspection data.

\section{Rainfall data collection}

Daily rainfall was measured using two $40 \mathrm{~mm}$ capacity Dipflex raingauges (Sites 1 and 2 as shown on Fig. 1 during the 12-month period to understand the correlation between rainfall and contamination. This data was then compared to historical rainfall for the proceeding 8 years. Number 1 raingauge was located to the west of the city in a low lying area for data comparison to rainfall measurements at a higher altitude. Number 2 raingauge was located in the Agricultural Research Centre of Lichinga approximately 500 to $1000 \mathrm{~m}$ from the project site. Each was positioned on a 1.5 to $2.0 \mathrm{~m}$ high pole in an open area with a clear distance between the gauge and the nearest and tallest tree being twice the height of that tree (Gunston, 1997). The rainfall was measured at 17:00 on a daily basis during the 12month data collection period (Gunston, 1997). Historical data from 1995 to date were also collected from the Meteorological Centre of Lichinga (marked as Number 3 on Map 1). Monthly average rainfall measured at Lichinga Airport for the period 1995 to 2003 was also obtained from the Meteorological Centre of Lichinga (refer Fig. 1). However, it is possible that not all rainfall was measured during this period, the reasons for which are discussed within a later section.

\section{Water quality data collection}

Monthly water quality samples were tested at a centralised laboratory established in Lichinga following standard aseptic procedures (WHO, 2004) Samples were collected using sterile $60 \mathrm{mC}$ plastic sampling bottles. These were stored in cool bags at $<4^{\circ} \mathrm{C}$ for a maximum of $6 \mathrm{~h}$ whilst field sampling was undertaken.

Two microbiological parameters were tested; Presumptive (rather than confirmed) enterococci and thermotolerant coliforms. Presumptive enterococci were isolated using azide Nutridiscs (AND), pre- impregnated membranes with sodium azide supplied by Schleicher and Schuell "Product Reference Number 10433003;" (WagTech, 2003). $50 \mathrm{mC}$ samples were processed using membrane filtration (filter size of $45 \mu \mathrm{m}$ ) and applied to the ANDs. A 4 h resuscitation period at ambient temperature was observed prior to incubation at $44^{\circ} \mathrm{C}\left( \pm 0.5^{\circ} \mathrm{C}\right)$ for $44 \mathrm{~h}$. Although enterococci grow best at $37^{\circ} \mathrm{C}$, they are less selective at this temperature than when incubated at $44^{\circ} \mathrm{C}$ (Anon, 1994). Post-incubation, all red, maroon and pink bacterial colonies that were smooth and convex were identified using a hand-lens and recorded as presumptive enterococci (WagTech, 2003). Total plate counts were recorded per $100 \mathrm{me}$ by multiplying the number of presumptive enterococci in $50 \mathrm{mC}$ by 2 . Confirmations were not possible at field level due to difficulties of preparation and storage of kanamycin aesculin azide agar plates.

The isolation and enumeration of thermotolerant coliforms were carried out using membrane filtration (WagTech, 2003). $50 \mathrm{ml}$ samples were filtered through a Millipore $45 \mu \mathrm{m}$ nitrocellulose filter. Membrane lauryl sulphate medium was prepared with $50 \mathrm{ml}$ de-ionised water in a membrane sulphate media measuring device "MMD" (WagTech, 2003). 2 mCof the solution was applied to each filter pad. The filtered membrane was then placed on a pad and incubated at an ambient temperature of $28^{\circ} \mathrm{C}$ for $4 \mathrm{~h}$ to permit bacterial resuscitation, before being transferred to $44^{\circ} \mathrm{C}$ for $14 \mathrm{~h}$ incubation. Post-incubation, all yellow colonies were recorded using a hand-lens as TTC per $100 \mathrm{ml}$.

For quality control, the testing kit was calibrated using a duplicate test on the first and last sample of each day's sampling. The duplicates were rotated for each month's sampling to avoid repetition of control sitcs. Verification of plate counts was done on all samples by the authors. The verification involved identification of thermotolerant coliforms and enterococci colonics as well as quality control of results for different dilutions. A $95 \%$ confidence level interval was used to define variation in results. Due to elevated levels of colonies on some plates, a wider statistical variability was noted and a $95 \%$ confidence level could not always be achicved.

\section{Water lovel data collection}

Depth-to-water level was tested using dipper tape on a monthly basis. The measurements were taken at the same time of day on each day's sampling. Field visits occurred between 7:30 and 12:00 to avoid early morning water collections in the communities. Results were recorded with water quality outcomes in a standard format as metre $(m)$ below ground (mbg).

\section{Results}

Three forms of analysis are presented. These include logistical regression analysis of rainfall to "non-compliance" of microbiological quality as well correlations between the first of flush of rainfall and contamination and the soil type and contamination. Results from the study are presented to demonstrate:

- total rainfall received during the study period

- pathways to contamination following the first flush rains

- correlation between rainfall and contamination levels using regression analysis.

For the purpose of analysis, statistical outliers have been removed from further analysis and are not indicated in this paper. These are defined as 'observations whose values are quite different than others in the data set.'(Helsel et al., 1992). In accordance with the WHO Guideline for Drinking Water Quality, this study defined statistically 'non- valid' outliers as microbiological results $>1000 \mathrm{cfu}$ (WIIO, 2004). 
Median rainfall data (1995-2003) compared to rainfall (2003-4)

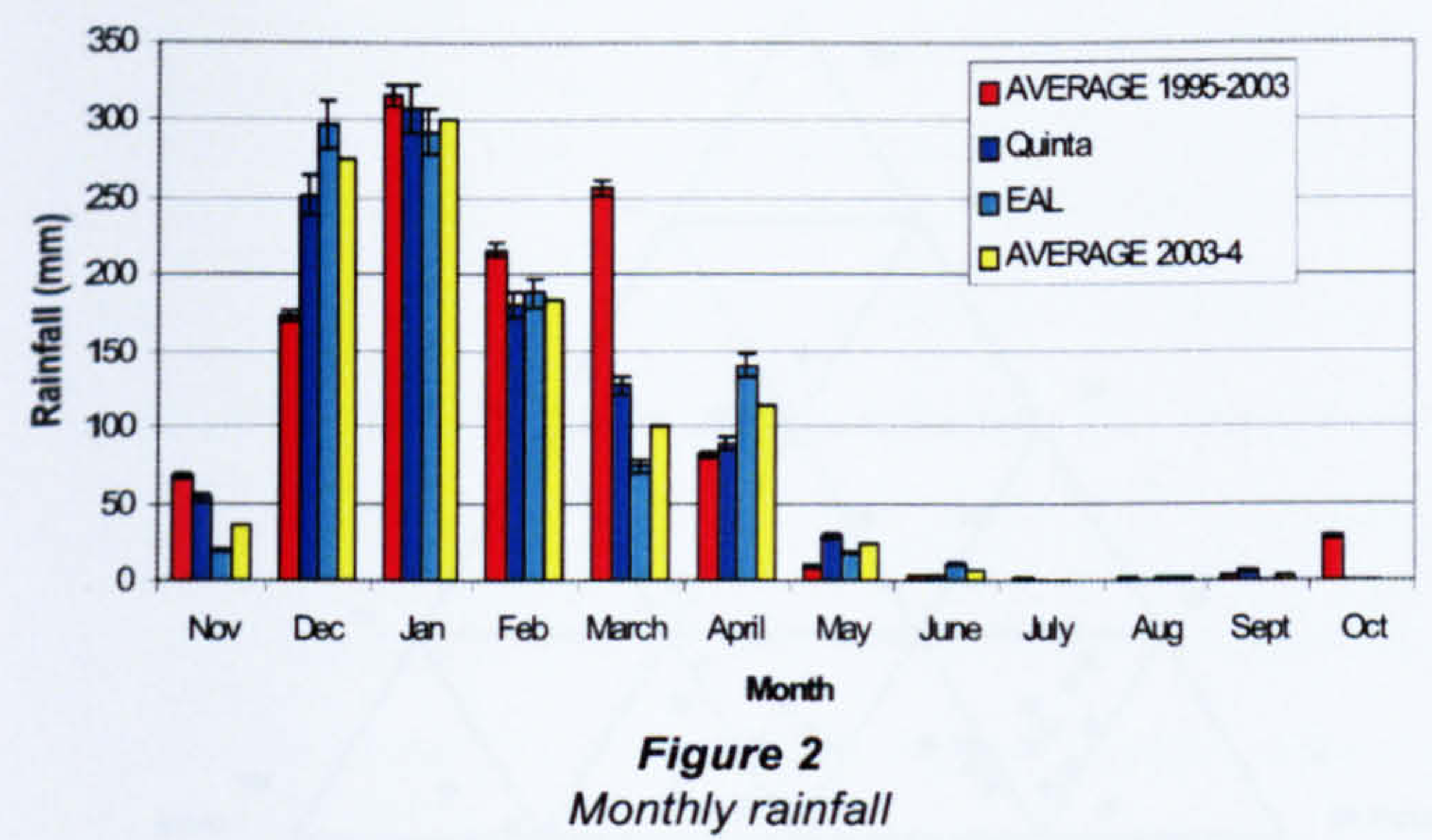

\section{Rainfall}

The rainfall distribution during the study was 'typical' with peak periods of rainfall falling between summer period of November 2003 and April 2004. Figure 2 outlines the mean monthly rainfall measure at Raingauge 3 for the period between 1995 and 2003 is compared with data collected from Raingauges 1 and 2 between 2003 and 2004. The average rainfall at each of the three sites in 2003 and 2004 is also shown

Both Raingauges 1 (Quinta) and 2 (EAL) provide higher average monthly rainfall figures than rainfall recorded at Raingauge 3 over the previous 8 years. The histogram in Fig. 2 illustrates a higher pattern rainfall from Raingauge 2 located on higher ground than Raingauge 1 (located in lower ground). This may be due to the closer proximity of tree cover, "non- readings" during school holidays, location of a Raingauge on lower ground and/or rigour of the data collection undertaken in each gauge.

\section{Rainfall and microbiological contamination}

Prior to November 2003, contamination levels were noted as $<10$ $\mathrm{cfu} / 100 \mathrm{m \ell}$. Analysis 1 indicates increased levels of microbiological contamination (noted as $>10 \mathrm{cfu} / 100 \mathrm{~m} \ell$ ) following the first flush of rainfall. Over the 12-month period, levels of microbiological contamination increased at the beginning of the rains during the month of November where direct pulse response of contamination to rainfall was observed. Figure 3 outlines results obtained for thermotolerant coliforms and enterococci during the start of the rains in November 2003 and December 2004. The results are illustrated as blocks for improved, upgraded and traditional wells. Figure 3 indicates results from samples collected twice during November $\left(14^{\text {th }} / 15^{\text {th }}-\right.$ before the rains and $\left.23^{\text {rd }} / 24^{\text {th }}\right)$ and then once during December $\left(16^{\text {th }} / 17^{\text {th }}\right)$. Rainfall records were collected daily through November and December with the first rains recorded on $15^{\text {th }}$ November microbiological samples were collected.

Statistical outliers, defined in this research as the upper band limit of the WHO Guidelines for Drinking Water Quality of $>1000 \mathrm{cfu} / 100 \mathrm{m \ell}$ are excluded from all data analyses in this paper (WHO, 2004). An average of 2 outliers was recorded in microbiological results per month. These results are accorded to initial errors due to cross-contamination during laboratory analysis, they have not been discarded as errors but are considered as outliers (described in this context as observations whose values are quite different to others in the data set) (Helsel et al., 1992).

Figure 3 indicates that the levels of recorded contamination increased dramatically following the first flush of heavy rainfall on $15^{\text {th }}$ November. Prior to the rains, low contamination levels

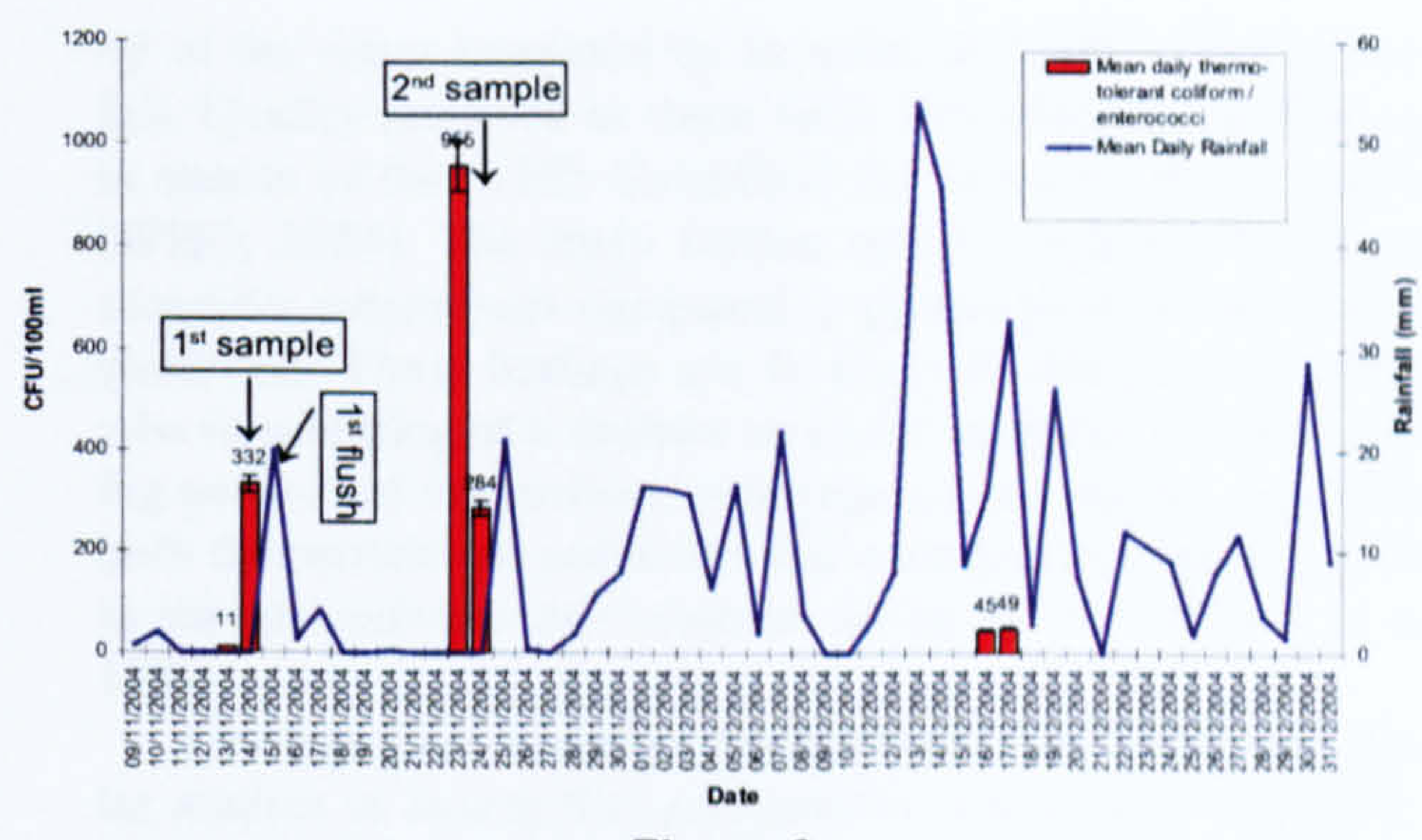

Figure 3

First flush contamination in Lulimile and Nomba

(Nov-Dec 2003)

were recorded in all wells before the peak contamination rates equalled 5 and 10 orders of magnitude for thermotolerant coliforms and enterococci between the first and second sample in November This is believed to be due to a combination of factors including use of unwashed and highly contaminated buckets for water extraction resulting from limited quantity of water in the wells during this dry period, cross contamination from dirt/ dust entering the wells, possible errors in analysis methods and raised turbidity/total dissolved solids (TDS) masking contaminants and reducing die-off periods. Figure 3 further highlights a rapid "pulse response" of levels of contamination to rainfall with Result 1 on 14/15 November at less than $24 \mathrm{~h}$.

Due to limitations in this paper, annual trends are not outlined in detail. In summary however, a contamination reduced slightly during further rains in December and the trend was reflected in the following months, where contamination levels increased following torrential downfalls at the end of January/ February and then began to reduce at the end of the rains in April.

\section{Pathways to contamination}

Analysis 2 involved the determination of the hydrogeological correlation between soil types surrounding the researched wells and contamination. Data were collected using particle size distribution analysis and soil classification tests - see Fig. 3 (CibaGeigy, 1986).

Results indicate a lithology of very high silt and clay content with interspersed impermeable clay layers located at depth to bedrock. The $K$ permeability value for each of the samples suggest a moderate to low permeability range at $10^{-4}-10^{-8} \mathrm{~m} / \mathrm{s}$ (BS5930, 1999) (Taylor et al., 2004). The findings suggest that direct ingress of bacterial contaminants through the study soils to the well receptor is prevented due to the low permeability and depth to water table ( $>8 \mathrm{mbgl}$ ) (Yates, 1989; Robertson et al., 1997; ARGOSS, 2002; Foster et al., 2002). Results therefore suggest that contamination of the wells has occurred through alternative localised pathways. These include identified weaknesses in the engineering headworks such as cracks at base of hand-pumps, inadequate drainage, seepage through annulus of concrete caissons or ingress through pumping mains.

\section{Regression models of contamination}

The third analysis involved monthly analysis of the statistical significance of rainfall to microbiological non-compliance at $>10 \mathrm{cfu} / 100 \mathrm{m \ell}$. Data was "dummy coded" as binomial data in 


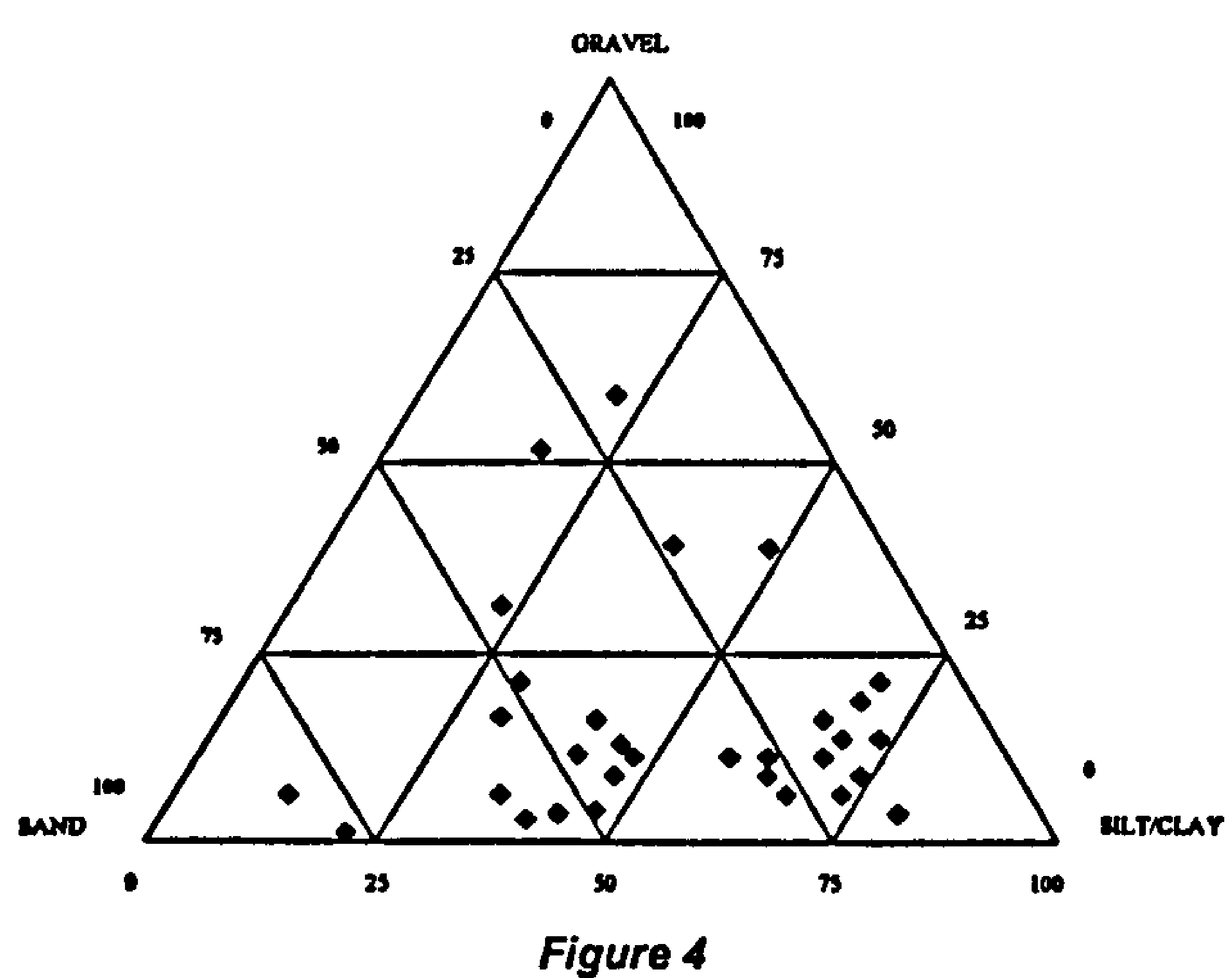

Ternary diagram showing range of particle sizes within the three study areas of Lichinga (depths of 1 to $10 \mathrm{~m}$ )

SPSS Version 10 on a monthly basis. Results were outlined in relation to both the influence of high and low rainfall (where low is defined as $<10 \mathrm{~mm}$ per month) and high rainfall (as defined as $>10 \mathrm{~mm}$ per month) for the three well technology types.

Levels of precision are presented in Table 1 and are estimated based on the output p-value. This provides an estimate of precision that is statistically significant at $95 \%$ confidence or 0.05 . Significant results are noted at a p-value nearer to zero than 0.05 .

\begin{tabular}{|l|l|l|l|l|l|l|}
\hline \multicolumn{9}{|c|}{$\begin{array}{l}\text { TABLE 1 } \\
\text { Rainfall }\end{array}$} \\
\hline & $\begin{array}{l}\text { Traditional } \\
\text { Well }\end{array}$ & \multicolumn{2}{l|}{$\begin{array}{l}\text { Improved } \\
\text { Well }\end{array}$} & \multicolumn{2}{l|}{$\begin{array}{l}\text { Upgraded } \\
\text { Well }\end{array}$} \\
\hline & TTC & EF & TTC & EF & TTC & EF \\
\hline Rain High & 0.472 & 0.527 & 0.014 & 0.147 & 0.297 & 0.935 \\
\hline Rain Low & 0.963 & 0.852 & & & 0.225 & 0.948 \\
\hline
\end{tabular}

For both traditional and upgraded wells, levels of non-compliance were noted as being of greatest significance during periods of low rainfall. For all well types, levels of microbiological non-compliance were noted as greatest during periods of high rainfall. Rainfall was however only significant in improved wells during peak rains. High $p$ values of $p=0.014$ were noted for TTC indicating a high statistical correlation between TTC contamination and periods of rainfall. Equally, medium levels of compliance were noted for EF $(p=0.147)$. Rainfall is slightly less significant in upgraded wells than improved wells during peak rainy periods. However, both traditional and upgraded wells are affected by both high and low rains; whereas improved wells are not affected during periods of low rainfall. In traditional wells, rain alone is not of significance. However, when combined with high risk pathways or high risk sources in the environment, high risk occurs.

All wells are therefore highly susceptible to high rains from both TTC and EF bacteria following first "low" flush of rainfall. Due to poor sanitary completion of many upgraded wells combined with siting of wells in densely populated areas of high vulnerability, high levels of rainfall proved statistically significant.

\section{Discussion}

The analysis of groundwater quality at 25 sites in Lichinga, Northern Mozambique indicates that the microbiological qual- ity of the water increased by an order of 10 after $24 \mathrm{~h}$ of rainfall. Quality recorded in these wells following the rainfall was in excess of the WHO Guidelines for Drinking Water Quality (WHO, 2004). The study further noted a higher level of presumptive enterococci compared to presumptive thermotolerant coliforms. These findings are in line with Bitton et al. (1983) who in sampling of 6 shallow wells for bacterial indicators during periods of intermittent sewerage contamination, noted that both thermotolerant coliforms and enterococci remained stable in the groundwater environment for up to $70 \mathrm{~d}$ (Bitton et al., 1983)

Findings from Lichinga, Mozambique further support similar studies in noting that presumptive enterococci displayed a higher survival function than presumptive thermotolerant coliforms and did not multiple under polluted environments (Bitton et al., 1983; Melian et al., 1999; Macler et al., 2000). The findings indicate that enterococci were consistently higher than thermotolerant coliforms both at shallow and deeper depths. This finding supports the opinion that enterococci may be 'a more reliable indicator of faecal pollution than faecal coliforms in raw water' (Massa et al., 2001) The greater survival of enterococci both in the environment and at depth in this study suggests that enterococci may be an ideal additional or alternative indicator organism for bacterial contamination of shallow groundwaters.

\section{Conclusions}

Three conclusions can be drawn from this study. Firstly, the study demonstrates a direct pulse response of microbiological contamination to the first flush of rainfall. Levels of microbiological contamination identified in the selected well sites indicate increased levels of contamination of an order of 10 within $24 \mathrm{~h}$ of rainfall suggesting that contamination is occurring through preferential or localised pathways. Secondly, that localised, as opposed to aquifer pathways, may be responsible for rapid contamination following first flush and thirdly that enterococci demonstrated a higher survival rate, both in the environment, at deeper depths than thermotolerant coliforms.

\section{Acknowledgement}

The authors wish to acknowledge the support provided by Rebecca van der Meulen, WaterAid Mozambique, Quinta Capriconia and the Lichinga Agricultural Research Centre. The views expressed in this paper are solely of the authors.

\section{References}

ANON (1994) The bacteriological examination of drinking water supplies 1994. Reports on Public Health and Medical Subjects No. 71: Methods for Examination of Woters and Associated Materials. UKDrinking Water Inspector, London.

ARGOSS (2002) Assessing Risk to Groundwater from on Sile Sanitation: Scientific Review and Case Studies.

Publisher?

BARNES GE (2000) (2) Soil Mechanics - Principles and Practice. Pelgrave, New York.

BARREL RAE and ROWLAND MGM (1979) The relationship between rainfall and well water pollution in a West African (Gambian) village. J. Hyg. 83143.

BARRET $M$ JOHAL $K$ HOWARD G PEDLEY $S$ and NALUBEGA $M$ (2000) Sources of faecal contamination of shallow groundwaters in Kampala. Groundwater: Past Achievements and Future Challenges. DFID, UK.

BARTRAM J (1996) Optimising the monitoring and assessment of rural water supplies. Robens Centre of Environmental Health. University of Surrey, UK. 
BITTON G, FARRAH SR, RUSKIN RH, BUTNER J and CHOU YJ (1983) Survival of pathogenic and indicator organisms in groundwater. Groundwater 21 (4) 405.

BS1377-2 (1990) BS 1377-2 Methods of Test for Soils for Civil Engineering Purposes - Part 2 Classification Tests. British Standards Institution (BSI), London, UK.

BS5930 (1999) Code of Practice for Site Investigation. British Standards Institution. (BSI), London, UK.

CIBAGEIGY (1986) Guide to Soil Identification. Ciba Geigy Agrochemicals. UK.

FOSTER S, HIRATA R, GOMES D, D'ELIA M and PARIS M (2002) Groundwater Quality Protection - A Guide for Water Utilities, Municipal Authorities and Environment Agencies. Washington DC, USA.

GUNSTON H (1997) Field Hydrology in Tropical Countries - A Practisher? cal Introduction.

HOWARD G, PEDLEY S, BARRET M, NALUBEGDA M and JOHAL $K$ (2003) Risk factors contributing to microbiological contamination of shallow groundwater in Kampala, Uganda. Water Res. 37 3421.

LEWIS WJ, FOSTER SD and DRASER BS(1980) The Risk of Groundwater Pollution by On-Site Sanitation in Developing Countries - A Literature Review. DFID, UK.

LEWIS WJ and CHILTON P J (1984) Performance of sanitary completion measures of wells and boreholes used for rural water supplies in Malawi. Challenges in Afr. Hydrol. Water Resour. .235 235-247.

MACLER BA and MERKLE JC (2000) Current knowledge on groundwater microbial pathogens and their control. Hydrogeol. J. 829.
MASSA S, BROCCHI GF, PERI G, ALTIERI C and MAMMINA C (2001) Evaluation of recovery methods to detect feacal streptococci in polluted waters. Lett. Appl. Microbiol. 32298.

MELIAN R, MYRLIAN N, GOURIEV A, MOURARU C and RAD. STAKE F (1999) Ground water quality and rural drinking water supplies in the republic of Moldova. Hydrogeol. J. 7171.

ROBERTSON JB and EDBERG SC (1997) Natural protection of spring and well drinking water against surface microbial contamination 1. Hydrogeological parameters. CRC Press 143 143-177.

SWARTZ M, MISSTAER BDR, DALY D and FARRELL ER (2003) Assessing subsoil permeability for groundwater vulnerability. $Q . J$. Eng. Geol. 36 (173-184).

TAYLOR R (2004) The implications of groundwater velocity variations on microbial transport and wellhead protection - Review of field evidence. Published report, University of Surrey.

TINO F (2003) Personal communication. Agricultural Engineer, EAL Lichinga.

UTIKLEN $\mathrm{H}$ and SUTTON S (1989). Experience and results from a water quality project in Zambia. Walcrlines 7 (3) 6.

WAGTECH (2003) Portable Water Testing Laboratory Kit - The Potaflex, Operational Manual.

WHO (2004) (3) Guidelines for Drinking Water Quality. Geneva, Switzerland.

WRIGHT R (1986) The seasonality of bacterial quality of water in a tropical developing country (Sierra Leone). J. Hyg. 9675.

YATES MV and YATES SR (1989) Septic tank setback distances: A way to minimize virus contamination of drinking water. Ground. water 27 (2) 202. 


\title{
Improved microbial risk assessment of groundwater
}

\author{
S. Godfrey • M. Smith
}

Keywords Risk - Groundwater - Microbial - Localised pathways $\cdot$ Developing countries

\section{Introduction}

The World Health Organisation (WHO) and the United Nations Children's Fund (UNICEF) estimate that at the beginning of the year 2000 , one-sixth (1.1 billion) of the world's population lacked access to a safe water supply (WHO/UNICEF 2000). Despite global efforts made in the decade between 1980-1990, the majority of the worlds' population with access to safe water remains in developed countries (see Fig. 1).

To address the inadequate level of coverage of safe water supply in developing countries, the United Nations established various initiatives including the Millennium Development Goals (MDGs) and the development of a Global Rapid Assessment of Drinking Water Quality Methodology (WHO/UNICEF 2000). The principal target of the MDGs is to Ensure environmental sustainability by halving the proportion of people without access to safe water by 2015 - where safe water is defined as a water supply that is devoid of disease-producing pathogenic bacteria/viruses and highly toxic substances (WHO/ UNICEF 2000; Howard et al. 2001).

Due to the high cost and questionable sustainability of piped water supply in developing countries, many rural and peri-urban communities are solely reliant on water supply from shallow groundwater. This essay discusses appropriate methods for assessing and managing the "safety" of this shallow groundwater in developing countries. It will:

Received: 26 April 2004 / Accepted: 11 November 2004 Published online: 25 February 2005

\section{- Springer-Verlag 2005}

S. Godfrey $(\square) \cdot$ M. Smith

Water, Engineering and Development Centre (WEDC). Loughborough University, LE113TU, UK

e-mail: s.e.n.godfrey@lboro.ac.uk

Tel.: +44-1509-222398

Fax: +44-1509211079
1. Acknowledge the increasing global importance of chemical contamination,

2. Highlight the significance of assessment of the vulnerability of groundwater to microbial contamination,

3. Emphasise the specific challenges faced by hydrogeologists in assessing microbial risk in the future.

\section{Background}

The WHO/UNICEF 2000 Global Water Supply and Sanitation Assessment stated that $47 \%$ of the population of rural areas in Africa, $62 \%$ in Latin America and $75 \%$ in Asia do not have access to improved water (WHO/UNICEF 2000). The predominant source of improved water in many of these rural areas is shallow groundwater where water is extracted using shallow boreholes or protected hand dug wells with mechanised or hand powered pumps. However, increasing global concern over the safety of these water supplies has arisen due to the increased detection of toxic organic chemicals and high levels of pathogenic microorganisms. For example, recent studies by the WHO have identified elevated levels of arsenic $(>0.01 \mathrm{mg} / \mathrm{l})$ and fluoride $(>1.5 \mathrm{mg} / \mathrm{l})$ in shallow groundwater in Argentina, Bangladesh, Cambodia, China, Mongolia and Tanzania (WHO 2004). This is combined with increased concern throughout developing countries of high nitrate contamination from human and agricultural sources (WHO 2004).

Of greater global concern however is the adverse health effect associated with the consumption of microbially contaminated shallow groundwater in developing countries. Since the work of John Snow (1854) in the United Kingdom, there has been increasing recognition of the importance of microbial contamination of drinking water and its risk to public health. This is of particular importance in developing countries where, due to limited access to improved sanitation combined with poor hygiene practices, many shallow groundwater sources are highly susceptible to microbial contamination. Indeed, epidemiological studies by Esrey et al. (1990) have indicated a strong correlation between improved water and sanitation and reduced levels of gastroenteric disease. A key component of this diarrhoea-transmission model for low-income communities in developing countries is the control of water quality in shallow groundwater through a 


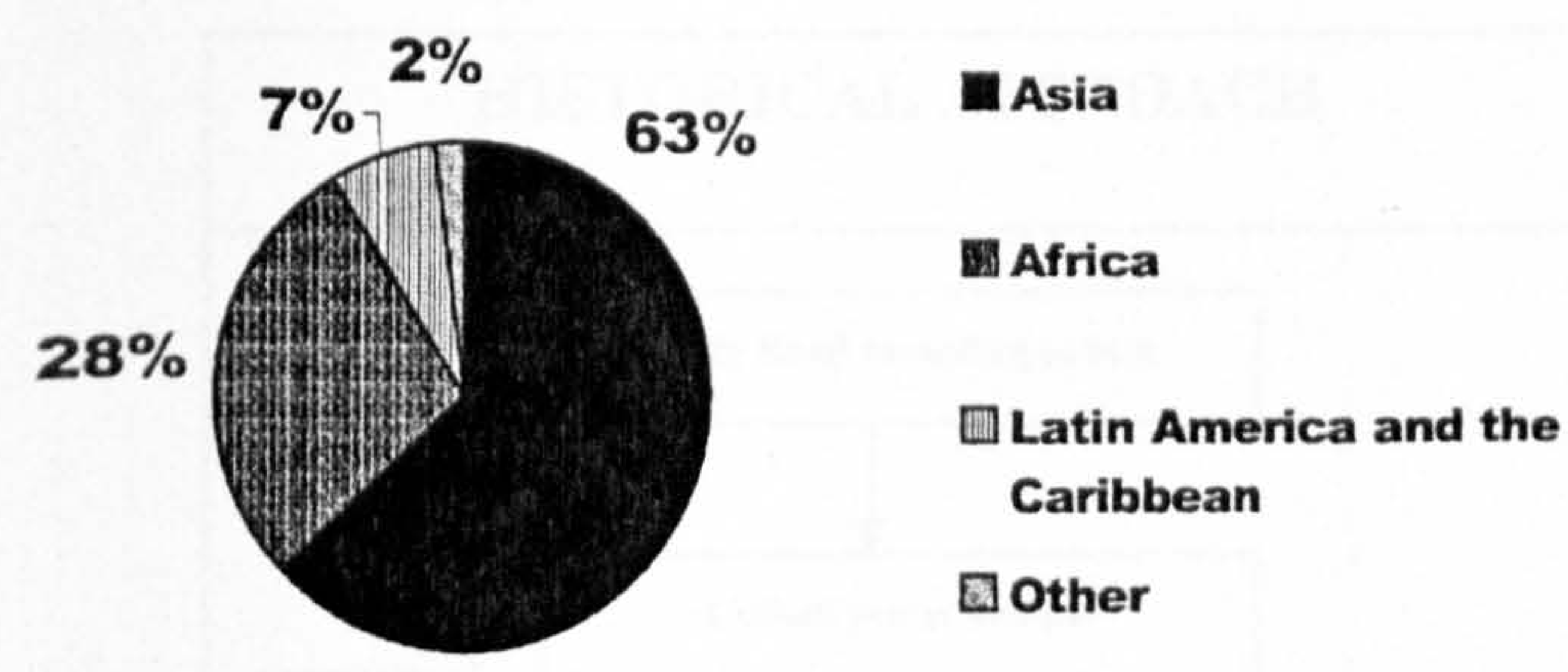

Fig. 1 Distribution of the global population not served with improved water supply, by region (WHO/UNICEF 2000)

reduction in pathogenic microorganisms that include, in order of functional complexity, viruses, bacteria, protozoa and helminths (WHO 2004). The remainder of this essay will therefore discuss improved methods of assuring microbially safe, as opposed to chemically safe, shallow groundwater.

\section{Risk assessment and management}

The assurance of microbially safe water from shallow aquifers has historically relied upon good engineering practice with an understanding that "increased infrastructure" equals "increased safety" (i.e. the more expensive the design and construction, the more effective the treatment and protection). This essay challenges this viewpoint, arguing that the determination of "safe" water in developing countries cannot rely on good engineering practice alone. Indeed, to understand the safety of shallow groundwater in developing countries, a thorough understanding of the "risk" associated with the supply must be achieved. Central to the understanding of microbial risk to shallow groundwater is an appreciation of the hydrogeological SOURCE-PATHWAY- RECEPTOR relationship where the source is defined as the hazard event/environment (e.g. septic tank), the pathway as the vulnerability of the media (e.g. soil type) and the receptor as the receiving water infrastructure (e.g. hand dug well).

\section{Aquifer pathways}

Historically, understanding of risk has focussed on the assessment of faecal sources to a water supply receptor through movement of microbial pathogens through aquifer pathways. These have considered factors such as contaminant loading, soil permeability and porosity, ambient temperature of soil microbes relative to physiologic temperature and distance from source to receptor. A number of multivariate groundwater vulnerability index tools have been developed to assess this risk including DRASTIC, EPIK, GOD and LE GRAND (Auge 2004). These tools are reliant on data, and can be used to delineate the boundaries of groundwater supply protection areas (Foster et al. 2002). In a developing country context this may result in establishing safe distances between a faecal source (e.g. septic tank/pit latrine) and a water receptor (e.g. well/borehole). There are however limitations in providing guidance on supplying protection zones in developing countries including; limited data availability, complex and dynamic traditional land tenure practices and adoption of unrealistic distances for siting water supply points from domestic dwellings (Godfrey 2003).

\section{Localised pathways}

Recent research in developing countries compared the significance of aquifer pathways to other pathways of contamination (Gelinas et al. 1996; BGS 2001; Howard et al. 2003). The studies found that poor well completion practice combined with high risk of surface faecal loading resulted in short circuiting through the wellhead protection zone (defined in this context as the piping and well structure as opposed to the larger capture zone). They noted ingress of contaminants along localised pathways from diffuse surface faecal sources (associated with inadequate sanitation conditions), and through poorly sealed annuluses of boreholes and cracks in surface aprons (associated with construction faults and inadequate maintenance of wells) (Howard et al. 2003). The studies further noted that to reduce risk of contamination of shallow groundwater, a more thorough understanding of the mechanisms affecting the formation of preferential flow paths through localised pathways is required. It was concluded that these localised pathways were of higher significance in increasing the risk of contamination in developing countries than aquifer pathways.

\section{Future challenges}

The challenge therefore facing hydrogeologists is how to effectively assess and manage microbial risk to ensure the provision of "safe" drinking water in developing countries. In the 3rd edition of the WHO Guidelines for Drinking Water Quality (2004), a fundamental shift in the approach to water safety has been proposed (WHO 2004). The process, termed Water Safety Plans (WSP), outlines a globally applicable method for assessing and managing microbial risk founded upon the principles of quality assurance as opposed to quality control. Quality assurance in this context is defined as a thorough understanding of the risk associated with a groundwater supply, which is then verified through microbial quality control. The WSP differs from historical approaches, where water quality was controlled solely through end product testing (see historical and WSP approach outlined in Fig. 2).

The WSP approach is a useful method to identify control points and control measures throughout the process of abstraction, distribution and collection of groundwater. It is applicable for both the assessment of localised and aquifer pathways and uses sanitary inspection to identify the distance and extent of the hazard loading from the water source. This is then monitored using selected physico-chemical parameters (e.g. temperature, $\mathrm{pH}$ and turbidity, conductivity) to assess the risk of each control point to contaminant ingress. At each control point this is then verified using selected microbial organisms. The degree of compliance of the occurrence of 


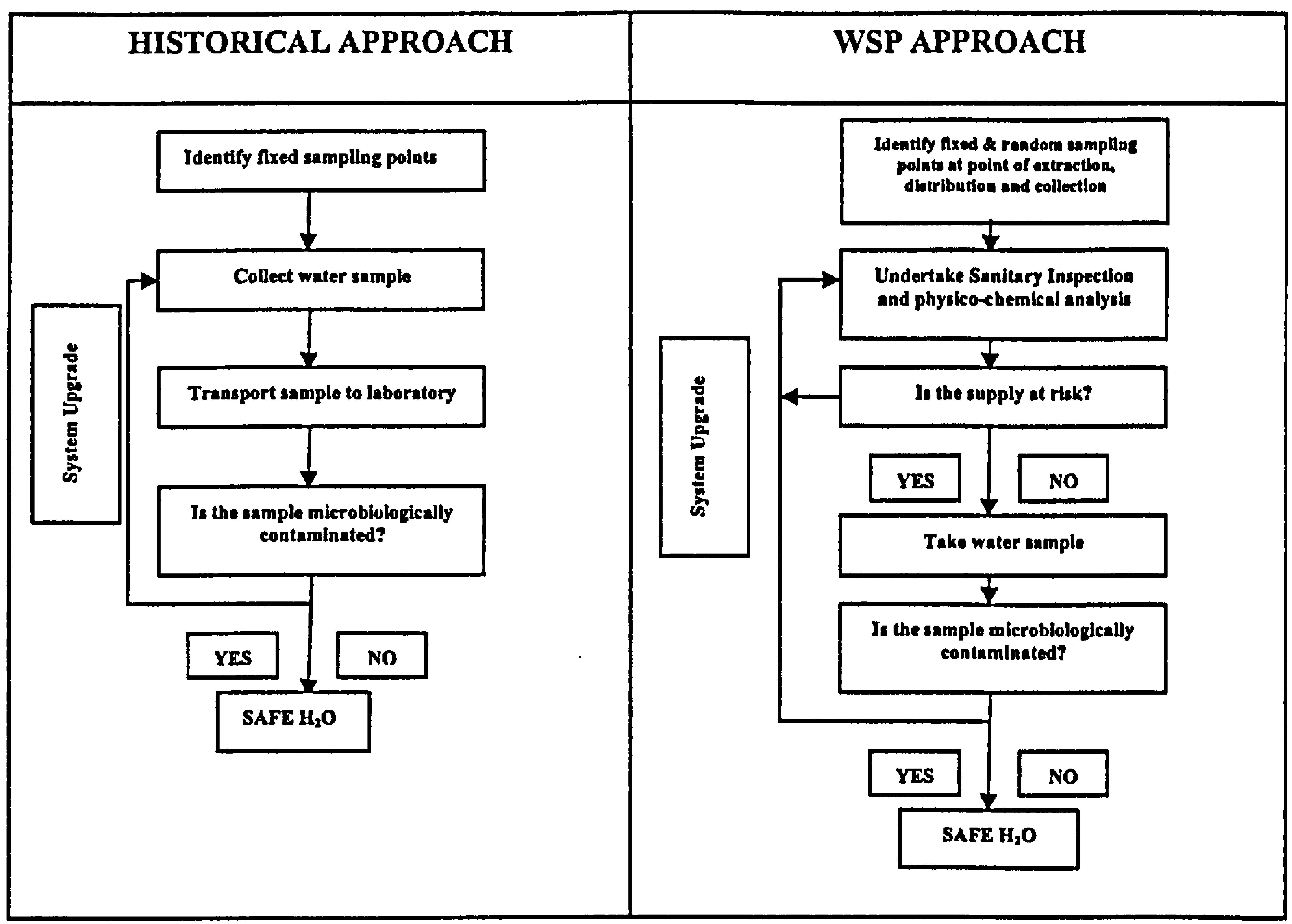

Fig. 2 Summary of approaches to assuring safe drinking water (Godfrey et al. 2004)

these organisms (e.g. Enterococci) to numerical guideline values is an area that requires further research.

Since 1998, the UK Water, Engineering and Development Centre (WEDC) has implemented various research projects in Bangladesh, Ghana, India, Mongolia, Mozambique and Uganda to assess the applicability of the approach in developing countries. Results from the research indicate that, although applicable, the WSP methodology still remains too data dependent. In rural areas in developing countries where protected groundwater sources are dispersed over a large area, there is a need for rapid methods of assessing groundwater vulnerability through localised pathways. Due to limited access to data about prevailing hydrogeological, hydrological and geological conditions in many rural areas in developing countries, there is a need to develop the use of simple surrogate measures of assessment. The challenge therefore facing hydrogeologists is to develop rapid risk assessment methods for localised pathways of shallow groundwater contamination in remote areas of developing countries.

\section{Conclusions}

To address the global targets outlined in the Millennium Development Goals (MDGs), hydrogeologists require more appropriate tools for assessing microbial safety in developing countries. The current method of assuring safety based on groundwater protection zones is questionable because other pathways have also proved to be of significance in developing countries. There is a need to develop methods for assessing and managing risk through localised pathways. The application of the WSP methodology is a good first step. However, greater attention needs to be given to the use of surrogate measures.

Acknowledgements The authors wish to acknowledge the support provided by the UK Department for International Development (DFID) and the UK charity WaterAid in the field research work in Africa and Asia. The views expressed in this essay are solely those of the authors and should not be taken as representing the views of DFID or WaterAid

\section{References}

Auge M (2004) Vulnerabilidade de acuiferors - Concepts y Métodos [Aquifer Vulnerability-Methods and Concepts], E book. Argentina

British Geological Survey (BGS) (2001) Guidelines for assessing the risk to groundwater from on-site sanitation, UK

Esrey SA, Potash JB, Roberts L, Shiff C (1990) Health benefits from improvements in water supply and sanitation: survey and analysis of the literature on selected diseases, WASH Technical Report No. 66, Water and Sanitation for Health Project 
Foster S, Hirata R, Gomes D, D'Elia M, Paris M (2002) Groundwater quality protection - a guide for water utilities, municipal authorities and environment agencies. The World Bank, Washington, DC, USA

Gelinas Y, Randall H, Robidoux Ln Schmit J-P (1996) Well water survey in two districts of Conakry (Republic of Guinea) and comparison with the piped city water. Water Res 30(9):20172026

Godfrey S (2003) Improved microbial risk assessment of shallow groundwater, PhD Thesis submission Yr 1. Water, Engineering and Development Centre (WEDC), UK

Godfrey S, Howard G (2004) Water safety plans for piped urban systems in developing countries. Water, Engineering and Development Centre (WEDC,) UK
Howard G, Ince M, Smith M (2001) Rapid assessment of drinking water quality handbook. Water, Engineering and Development Centre (WEDC,) WHO/UNICEF, UK

Howard G, Pedley S, Barret M. Nalubega M. Johal K (2003) Risk factors contributing to microbiological contamination of shallow groundwater in Kampala, Uganda. Water Res 37:34213429

Snow J (1854) On the mode of communication of cholera. John Churchill, London

World Health Organisation (WHO) (2004) Guidelines for drinking water quality, 3rd edn, vol 1, Recommendations, Geneva, Switzerland

WHO/UNICEF (2000) Global water supply and sanitation assessment 2000 report, Geneva, Switzerland 


\section{Groundwater microbial risk assessment using Analytical Hierarchy Process (AHP) in data poor environments in developing countries}

Sam Godfrey ${ }^{1}$, Felix Agosto Tino ${ }^{2}$ Mike Smith ${ }^{3}$

${ }^{1}$ UNICEF, Water and Environmental Sanitation (WES) section, Bhopal, India sgodfrey@unicef.org

${ }^{2}$ Estação Agraria de Lichinga (EAL), Lichinga, Mozambique

${ }^{3}$ Water, Engineering and Development Centre (WEDC), Loughborough University, LE11 3TU, UK

\section{Abstract:}

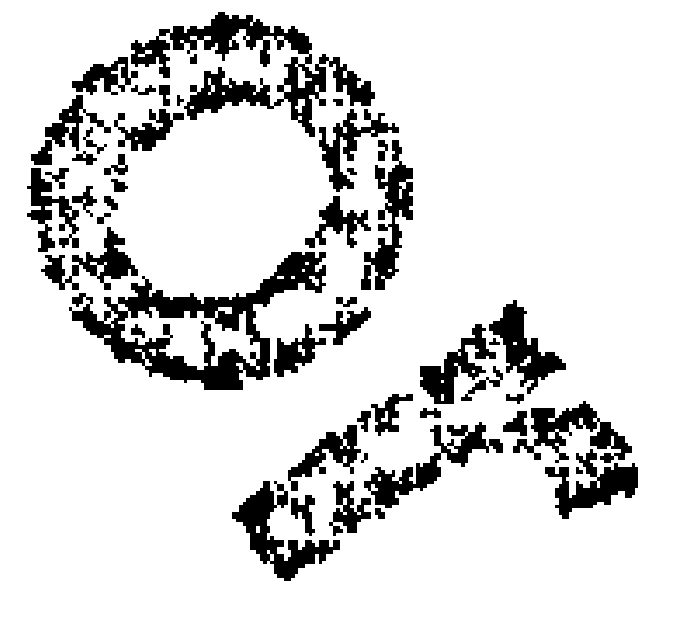

It is commonly known that hydrogeologists and water quality professionals have failed to reach a consensus on definitions, reference terms and methods of effective groundwater microbial risk assessment, For hydrogeologists, the understanding of microbial risk has historically focussed on the source-pathway-receptor relationship. In comparison, water quality professionals ass ssment of safety of groundwater supplies has historically relied upon results from microbiological or chemical analysis. Recent research identifies weaknesses in ${ }^{k}{ }^{\circ}$ th approaches. Central to all critiques for developing countries is the fundamental lack of available data to support quantitative decision making in the risk assessment (process. To improve these methods, this paper explores the use of the Analytic Hierarchy Process (AHP) decision making tool as a means of determining relative risk associated with the below ground engineering barriers (receptor). The study was applied to 25 wells in Northern Mozambique in 2004. Results indicate that AHP is an effective tool in decision making in data poor environments and conclude that the AHP should be explored as an effective alternative mechanism to groundwater microbial risk assessment for developing countries. 


\section{(1) Hournal Jeology Springer}

Groundwater microbial risk assessment using Analytical Hierarchy

Process (AHP) in data poor environments in developing countries

\begin{tabular}{|c|c|}
\hline Journal: & Hydrogeology Journal \\
\hline Manuscript ID: & draft \\
\hline Category: & Paper \\
\hline $\begin{array}{r}\text { Date Submitted by the } \\
\text { Author: }\end{array}$ & $n / a$ \\
\hline Complete List of Authors: & $\begin{array}{l}\text { Godfrey, Sam; UNICEF, Water and Sanitation } \\
\text { Smith, Mike; WEDC, Civil and Building Engineering }\end{array}$ \\
\hline Keywords: & $\begin{array}{l}\text { analytical solutions, Africa, groundwater monitoring, microbial } \\
\text { processes, water supply }\end{array}$ \\
\hline
\end{tabular}

Manuscript Central ${ }^{\mathrm{m}}$ 


\section{Introduction:}

It is commonly known that hydrogeologists and water quality professionals have failed to reach a consensus on definitions, reference terms and methods of effective groundwater risk assessment [1]. Terms such as vulnerability, hazard and risk are commonly used, but commonly misunderstood. Indeed, due to the numerous variables that contribute to groundwater risk various, overlay and index tools have been developed. For hydrogeologists, the understanding of risk has historically focussed on the assessment of faecal sources to a water supply receptor through movement of microbial pathogens through aquifer pathways [1]. Hydrogeologists consider factors such as contaminant loading, soil permeability and porosity, ambient temperature of 数

soil microbes relative to physiologic temperature and distance from source to receptor to develop overlay and index risk-based tools. Many of these tools are heavily reliant on data and are used to delineate the boundaries of groundwater supply protection areas [2].

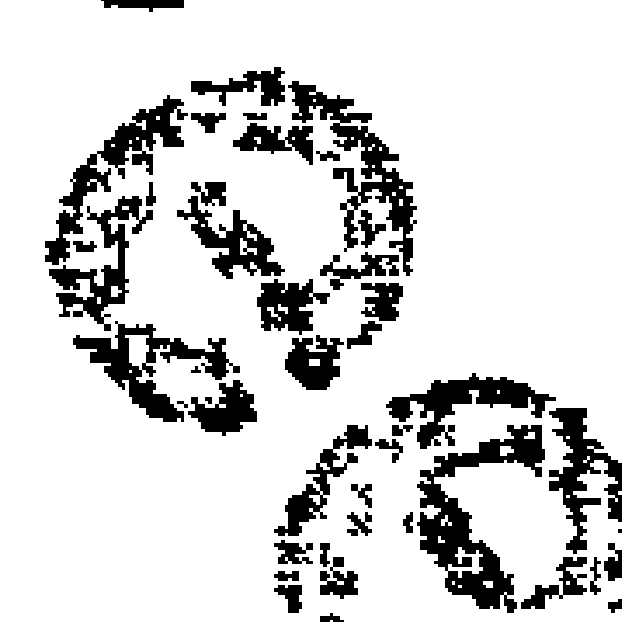

Weaknesses in this approach were identified by the British Geological Survey (BGS) and Robens on the Associated Risks to Groundwater from On Site Sanitation (ARGOSS) who identified "engineering" variables such as poor workmanship as primary pathways to the short circuiting of the wellihead protection zone $[3,4]$. The ARGOSS study noted ingress of contaminants through localised pathways (short circuiting). These originated from diffuse surface faecat sources (associated with inadequate sanitation conditions) and through poorly sealed annuluses of boreholes or cracks in surface aprons (associated with construction faults and inadequate maintenance of wells). This resulted in higher levels of microbiological contamination than the conventional aquifer pathways [5]. The studies further noted that to improve risk assessment, a more thorough understanding of the mechanisms affecting the formation of preferential flow paths through localised pathways is required.

In comparison to hydrogeologists, water quality professionals' assessment of safety of groundwater supplies has historically relied upon results from microbiological and chemical analysis. However, fundamental weaknesses in this approach have resulted in changes in recommended practices to water safety. In the World Health Organisation Guidelines for Drinking Water Quality (GDWQ) edition 3, there is a 
move away from the reliance on end product testing of water quality as a means of assuring water safety and towards a risk based approach termed Water Safety Framework $[6,7]$.

Central to all these approaches is the availability of data. In many groundwater environments in developing countries limited data collection and data management is undertaken. As a result, many groundwater systems lack detailed lithological and engineering records. In line with recommendations outlined in the third edition of the WHO GDWQ this paper explores the application of risk assessment for data poor environments in developing countries as a means of improving understanding of microbial risk. Central to the risk assessment methodological development is an acknowledgement of the need for alternative methods of data generation. This paper explores the application of the Analytic Hierarchy Process (AHP) as a means of generating this data. The $\mathrm{AHP}$ " is "multicriterion decision making approach that employs a method of multiple comparisons to rank order alternative solutions to a problem, formulated in a hierarchy" "[8] It was developed "to solve a specific problem in contingency planning and a later major application was to design alternative futures for a developing country, the Sudan" [8]. The AHP is Analytic (i.e. uses numbers), Hierarchical (structures the decision problems in levels) and is a Process (real decisions require a process of learning, debating and revising decisions) [9]

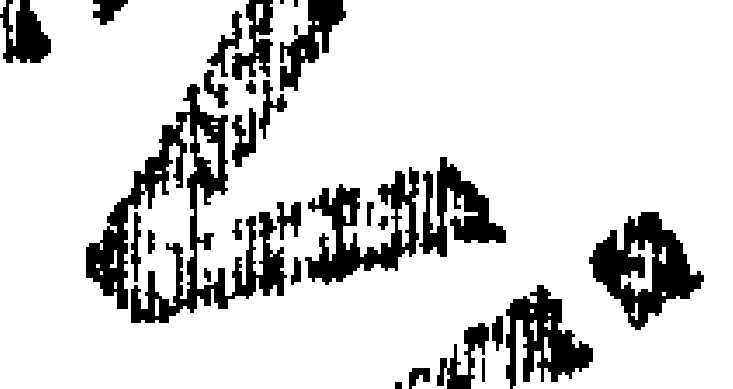

Application of AHP as a method of forecasting appropriate technological choices in developing countries is well documented in [10]. Its application has also been successfully applied for decision making in the water engineering and water resources sector $[9,11]$ Also appropriately for this research, it has been applied in the groundwater sector by Thirumalaivasan et al $(2001,2003)$ in estimating specific aquifer vulnerability through a combination use with the DRASTIC model $[12,13]$.

\section{Materials and Methods:}

Conventional methods of assessing risk to groundwater follow the source, pathway, receptor relationship of contaminant transport based on the movement of the contaminant from SOURCE through a geological PATHWAY to a groundwater RECEPTOR. This source pathway receptor relationship is commonly used in the hydrogeological field to assess risk of groundwater to pollution. It is however a 
complex process and one that involves a number of key data sets ranging from the key characteristics of the microbe or source (i.e. size, inactivation - die off - rate and surface electrostatic properties), the physical determinants of the aquifer or pathway (i.e. the flow velocity, porosity, temperature and aquifer grain pore size) and the type of receptor (i.e. lined/unlined well, tubewell or spring) [14, 15]. The theoretical justification for using this model as the methodological basis of this research relates to its acknowledgement of the multivariate nature of risk reduction in shallow groundwater. Other risk models used in the groundwater sector include establishing groundwater protection zones based on theoretical travel distances and multivariate vulnerability models (e.g. DRASTIC/EPIK) that assume the presence and concentration of a hazard source [16].

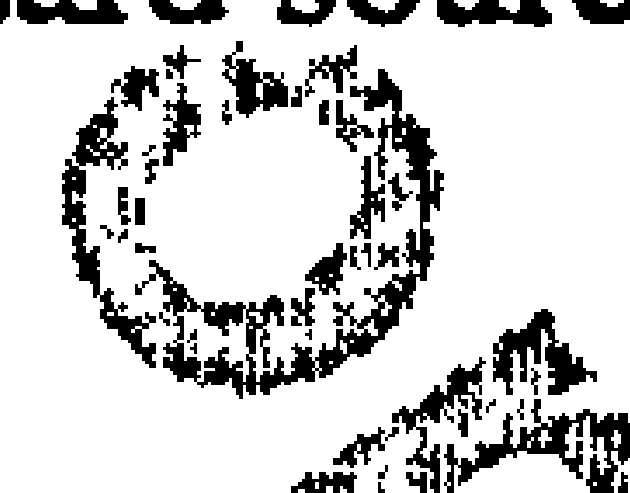

Although qualitative and quantitative assessments are feasible for the source and pathway variables, the assessment of the pathway requires alternative approaches. Data is often limited on the type condition of the receptor due to the lack of availability of the data and the limited access to the well intake and shaft are limited. Due to these difficulties, expert judgment techniques are required to assess the microbial risk associated with the well structure. To achieve this, various multicriteria or multi-variate techniques exist. These included;

- REMBRANDT [17]

- The Weighted Sum Model [18],

- The Weighted Product Method [18]

- Analytic Hierarchy Process (AHP) $[10,13]$

- Multi Attribute Utility Theory (MAUT) [19]

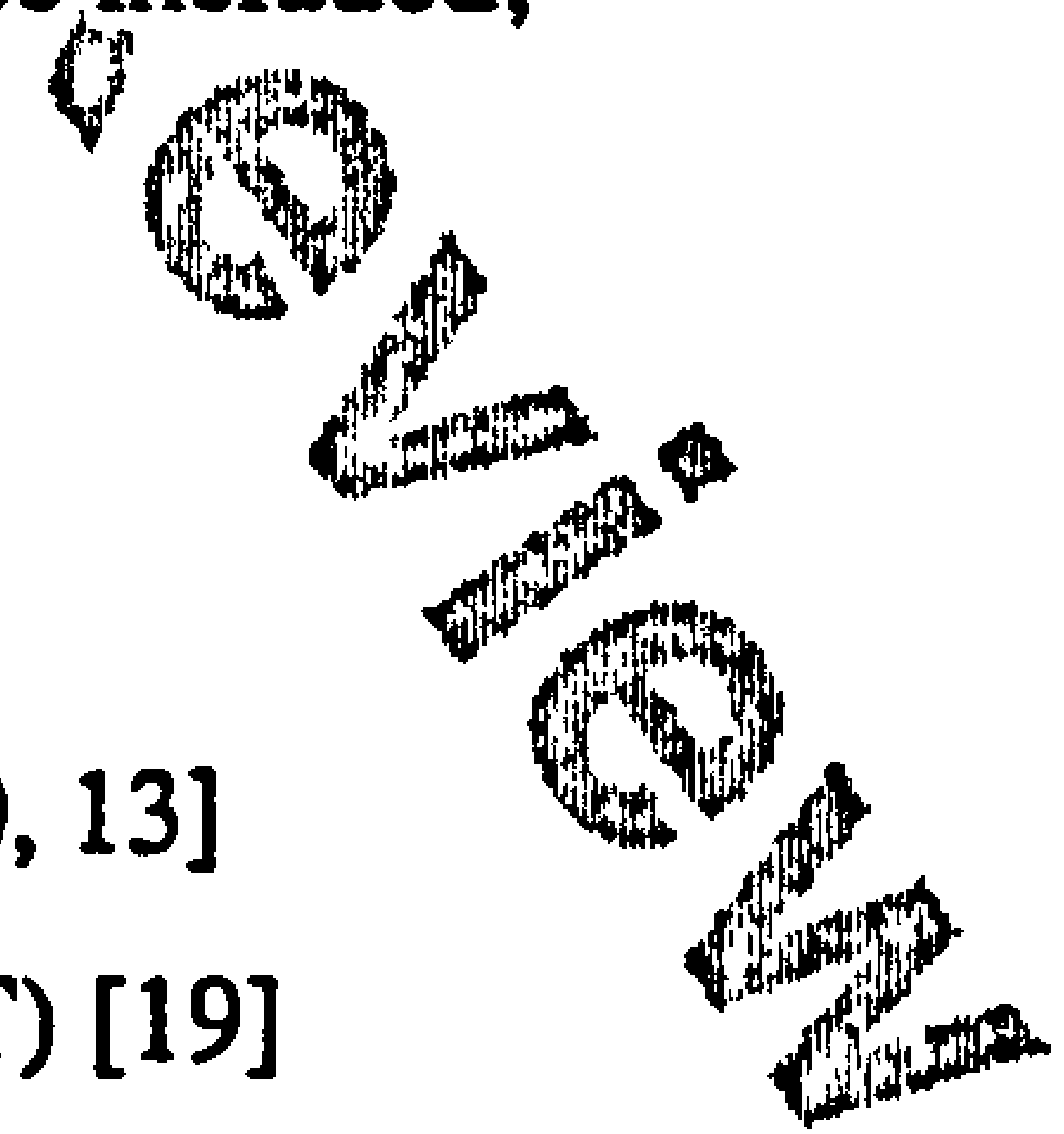

This research selected the Analytic Hierarchy Process (AHP) as it is different from other decision making tools in that it requires the "simultaneous use of data and judgement as opposed to formal models" [10] The AHP is a mathematical technique for multicriteria decision making (Saaty 1977; Saaty 1980; Saaty 1994). The AHP allows the analyst to structure a problem hierarchically and guide themselves through a sequence of pairwise comparison judgements. 
The AHP is conducted in six steps:

1. Setting up the hierarchy (goal, factors and alternatives)

2. Perform pairwise comparisons for factors

3. Prepare a matrix (judgement matrix) for factors

4. Compute the priority vector for factors

5. Assess consistency of pairwise judgments

6. Compute the relative weights/ranks

The procedure used in obtaining the relative weights for each factor is described below and in Flowchart of Figure **1.

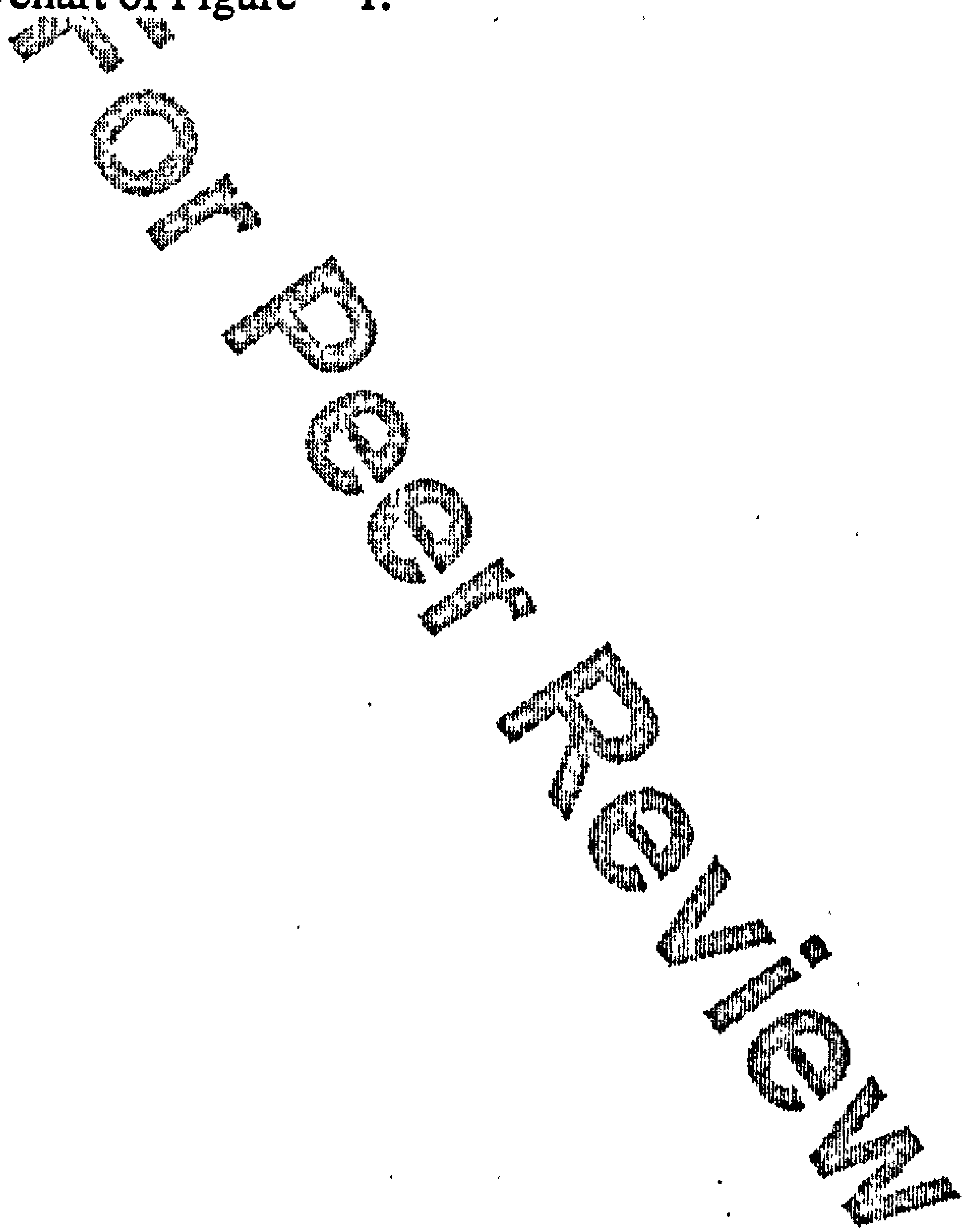




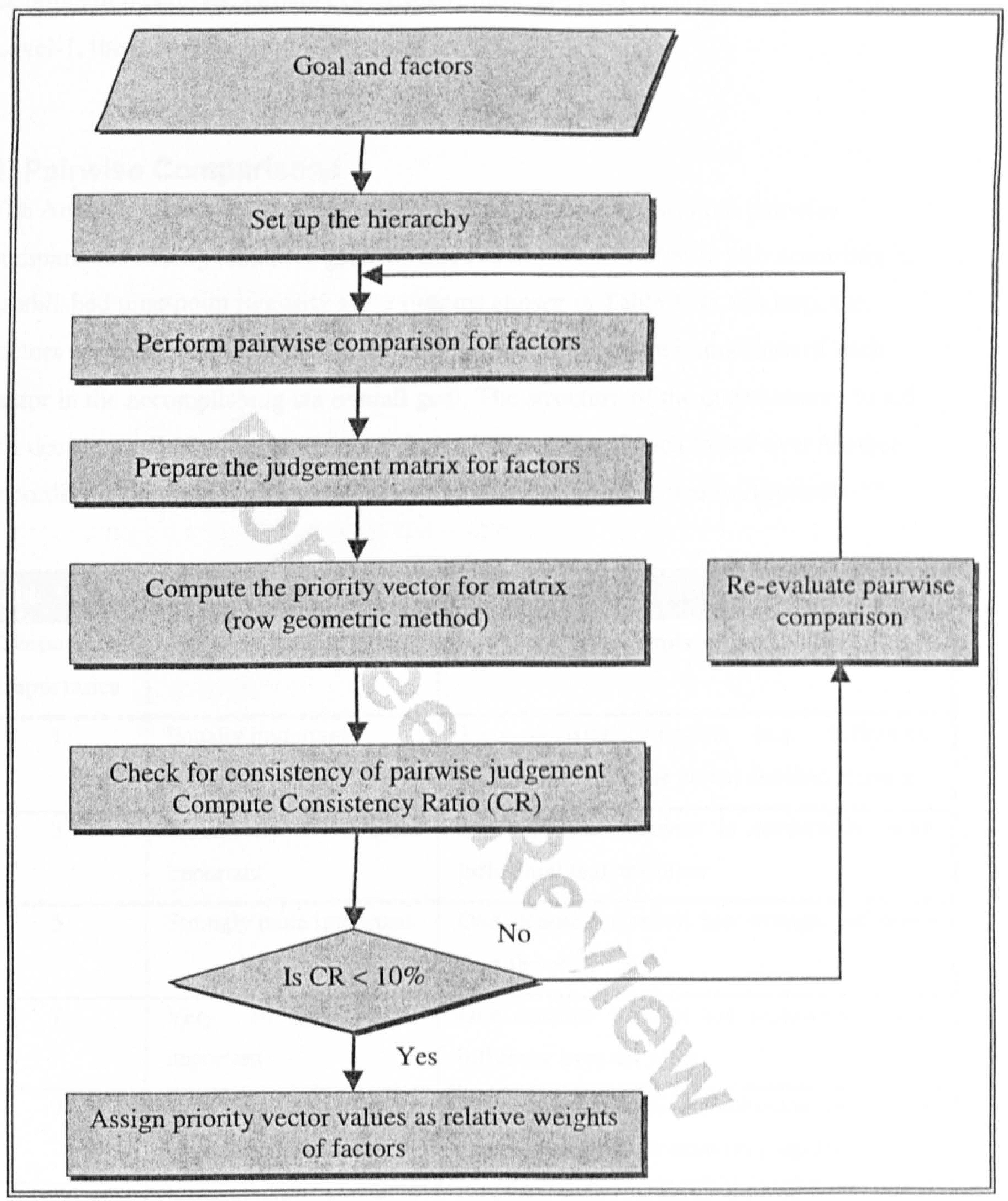

Figure 1: The procedure for obtaining the relative weights for each factor.

\section{Setting up the hierarchy}

The problem is structured into a hierarchy. The first level denotes the overall goal of the decision-maker. The second level consists of several different factors that contribute to this goal. The number of factors involved can vary from case to case, for 
example in this thesis, Group-1 of Level-1, these are three whereas in Group-2 of Level-1, these are five.

\section{Pairwise Comparisons}

The Analytic Hierarchy Process (AHP) method requires to carry out pairwise comparisons among factors to give the relative importance of each pair according to established nine-point intensity scale systems shown in Table 1. In this step, the factors are compared with each other to determine the relative importance of each factor in the accomplishing the overall goal. The structure of the questionnaire to aid the decision maker to determine the relative importance of each factor over another according to Scale system (modified to 5 point scale) is presented in Appendix-**

\section{Table 1. scales for pair-wise comparisons}

\begin{tabular}{|c|l|l|}
\hline $\begin{array}{c}\text { Comparative } \\
\text { Importance }\end{array}$ & \multicolumn{1}{|c|}{ Definition Explanation } \\
\hline 1 & Equally important & $\begin{array}{l}\text { Two decision elements (e.g., indicators) } \\
\text { equally influence the parent decision element }\end{array}$ \\
\hline 3 & $\begin{array}{l}\text { Moderately more } \\
\text { important }\end{array}$ & $\begin{array}{l}\text { One decision element is moderately more } \\
\text { influential than the other }\end{array}$ \\
\hline 5 & Strongly more important & $\begin{array}{l}\text { One decision element has stronger influence } \\
\text { than the other }\end{array}$ \\
\hline 9 & $\begin{array}{l}\text { Very strongly more } \\
\text { important }\end{array}$ & $\begin{array}{l}\text { One decision element has significantly more } \\
\text { influence over the other }\end{array}$ \\
\hline $2,4,6,8$ & $\begin{array}{l}\text { Intermediate judgment } \\
\text { values }\end{array}$ & $\begin{array}{l}\text { Judgment values between equally, moderately, } \\
\text { decision elements is extremely significant } \\
\text { strongly, very strongly, and extremely. }\end{array}$ \\
\hline Reciprocals & & $\begin{array}{l}\text { If } \mathrm{v} \text { is the judgment value when i is compared } \\
\text { to } \mathrm{j}, \text { then } 1 / \mathrm{v} \text { is the judgment value when } \mathrm{j} \text { is } \\
\text { compared to i. }\end{array}$ \\
\hline
\end{tabular}




\section{Matrix for Factors}

A matrix with the factors (in our example soil permeability, well depth and well diameter) listed at the top and on the left is prepared. Based on individually surveyed information and the resulting informed judgement of the decision-maker (Step-2), the matrix is then filled with numerical values denoting the importance of the factor on the left relative to the importance of the factor on the top. A high value means that the factor on the left is relatively more important than the factor at the top.

Table 2 provides an example where soil permeability is considered to be three times as important as well depth, whereas well depth is only one third as important as the well diameter. When a factor is compared with itself the ratio of importance is one (1), resulting in a diagonal line across the matrix. The resulting matrix is known as the judgement matrix.

\begin{tabular}{|l|l|l|l|}
\hline \multicolumn{3}{|l|}{ Table *:/2. The judgement matrix for the factors } \\
\hline & $\begin{array}{l}\text { Soil } \\
\text { permeability }\end{array}$ & Well depth & $\begin{array}{l}\text { Well } \\
\text { diameter }\end{array}$ \\
\hline $\begin{array}{l}\text { Soil } \\
\text { permeability }\end{array}$ & 1 & 3 & 2 \\
\hline $\begin{array}{l}\text { Well depth } \\
\text { Well } \\
\text { diameter }\end{array}$ & $1 / 2$ & 1 & $1 / 3$ \\
\hline
\end{tabular}

\section{Priority vector for factors}

In this step the decision-maker uses the matrix in Table 2 to get an overall priority value for each factor. AHP computes a overall priority value or weight for each decision element based on the pairwise comparisons using mathematical technique $\mathrm{m}$ of Row Geometric Mean

The geometric mean of each row (i.e., the elements in each row are multiplied with each other and then the $n$th root is taken, where $n$ is the number of elements in the 
row) is calculated. This forms the vector of geometric mean. The elements of this vector are then normalized by dividing them with the sum. The resulting normalized vector is an approximated maximum eigenvector, herein named as priority vector.

\section{The Priority vector}

Soil permeability $\quad 0.53$

Well depth $\quad 0.14$

Well diameter $\quad 0.33$

\section{Consistency of Pairwise Judgments}

If all the comparison are perfectly consistent, then the following expression should hold true for any combination of comparisons of the judgement matrix.

$a_{i j}=a_{i k} \times a_{k j}$

where $a_{i j}=$ relative importance factor (tabulated values in Table $* * 2$ ) of decision criteria $i$ to $j$.

However, perfect consistency rarely occurs in practice. Consistency ratio (CR) is commonly used to reflect the degree of consistency of judgment matrix. The CR is calculate as follow:

$C I=\frac{\lambda_{\max }-n}{(n-1)}$

$C R=\frac{C I}{R C I}$

where $C I=$ consistency index; $\lambda_{\max }=$ maximum eigenvalue of judgement matrix; $R C I=$ Random Consistency index as given in Table $3 ; n=$ the number of factor . 


\section{Table 3. RCI values for different values of $\boldsymbol{n}$}

\begin{tabular}{|l|l|l|l|l|l|l|l|l|l|}
\hline $\mathrm{N}$ & 1 & 2 & 3 & 4 & 5 & 6 & 7 & 8 & 9 \\
\hline $\mathrm{RCI}$ & 0 & 0 & 0.58 & 0.90 & 1.12 & 1.24 & 1.32 & 1.41 & 1.45 \\
\hline
\end{tabular}

Maximum eigenvalue $\left(\lambda_{\max }\right)$ is obtained by adding the columns in the judgment matrix and multiplying the resulting vector by the vector of priorities (i.e., the approximated eigenvector) obtained earlier.

The pairwise comparisons in a judgement matrix in AHP are considered to be adequately consistent if its CR is less than certain predefined values say 10\% (Saaty 1980). If CR is greater than predefined value, there is a need for further evaluation of the pairwise comparison in judgement matrix.

\section{Computing the Relative Weights}

If the CR of the judgement matrix is satisfactory, the priority vector values will be assigned as relative weights of factors. This weighting is used to assign to each variable group.

The AHP is decomposed into levels of criteria. The strength of influence between each of these criteria at different levels forms the basis for decision making. The AHP is an interactive process, where a group of decision makers relay their preferences to the author for specified technological options or outcomes. It is based upon the construction of Pairwise Comparison Matrices (PCMs). Saaty (1990), suggests a scale of 1-9 for PCM element (see table 1 below). Justification for these scales based on psychological tests in number identification is provided in Triantaphyllou et al (1994) [20]

Table 1: Scale of measurement for AHP

\begin{tabular}{l|l} 
Numerical Values & Definitions \\
\hline $\mathbf{1}$ & Equally preferred \\
$\mathbf{3}$ & Moderately preferred \\
$\mathbf{5}$ & Strongly preferred \\
$\mathbf{7}$ & Very strongly preferred
\end{tabular}


\begin{tabular}{l|l}
9 & Extremely preferred \\
$\mathbf{2 , 4 , 6 , 8}$ & Intermediate values to reflect compromise \\
Reciprocals & Used to reflect dominance of the second alternative as compared with the first.
\end{tabular}

The AHP decomposes a given problem into a hierarchy structure. The hierarchy comprises of different levels and the AHP compares the different criteria of the levels using the PCM. To estimate the likelihood of the various scenarios, each actor first makes a pair wise comparison of the relative importance of specifics variables associated with engineering barriers to groundwater microbial contamination. This yields a pair of weights for each variable.

The relationship between "the $n$ criteria in the hierarchy is explained mathematically as:

$$
\left\lfloor\mathrm{A}_{(i j)}\right\rfloor \mathrm{X}\left\lfloor\mathrm{W}_{(j)}\right\rfloor=\left\lfloor\mathrm{nW}_{(j)}\right\rfloor
$$

Where;

A : an $n \times n$ PCM in terms of ratio of ratings/ (

$W \quad$ : the ratings or weights (priority rankings/weights) of criteria,

$n \quad=$ is the order of the PCM matrix.

The input matrix is $A$ and the solution for E.g. (1) is the commone eigenvalue problem. The AHP is founded upon a system of homogenous linear equations with a non trivial solution that only is incorrect if the determinant $A-n l$ (i.e. $n$ is an eigenvector of $A$ ) whose ultimate outcome is a principle eigenvector $\left(\lambda_{\max }\right)$ defined as the sum of the criteria divided by the number of criteria. The closer $\lambda_{\max }$ is to $n$ (the number of activities in the matrix), the more consistent the result [10].

The author developed an AHP specific questionnaire based on identified variables. As this research is specifically exploring the receptor variables of groundwater contamination in Lichinga, Mozambique, only "experts" familiar with groundwater in Lichinga were selected. The author believed that the inclusion of actors not familiar 
with Lichinga would bias results. Respondents from Lichinga were selected. These included engineers and managers from WaterAid as well as local government staff. The author proposed the following hierarchical formulation to each of the actors

\section{GOAL}

- To provide judgement on the relative importance of various well linings in minimising microbial risk to shallow groundwater

Each of the actors were requested to weight and produce pairwise comparisons for each criteria at a particular level of the hierarchy, with regard to the "contribution" it makes to criteria at the succeeding level of the hierarchy, by means of a procedure of paired comparisons. For this research, the actors weighted the physical criteria associated with well linings that affect the risk of microbial contamination of shallow groundwater. Specifics of the types of contaminants were not a feature of this component of the research. Focus was solely on the effectiveness of the engineering barrier (i.e. the well lining) in reducing the risk of shallow groundwater to microbial contamination. Finally, a "composite weight" was obtained for each of the "alternatives well linings." This composite weight is the overall measure of importance for the particular criteria.

For this study a total of 11 independent characteristics were selected and compared in three groups at two levels (see figure 1). The pair-wise judgement matrices developed for each of the relationships are outlined in table [21].

Figure 1: Well lining hierarchy 


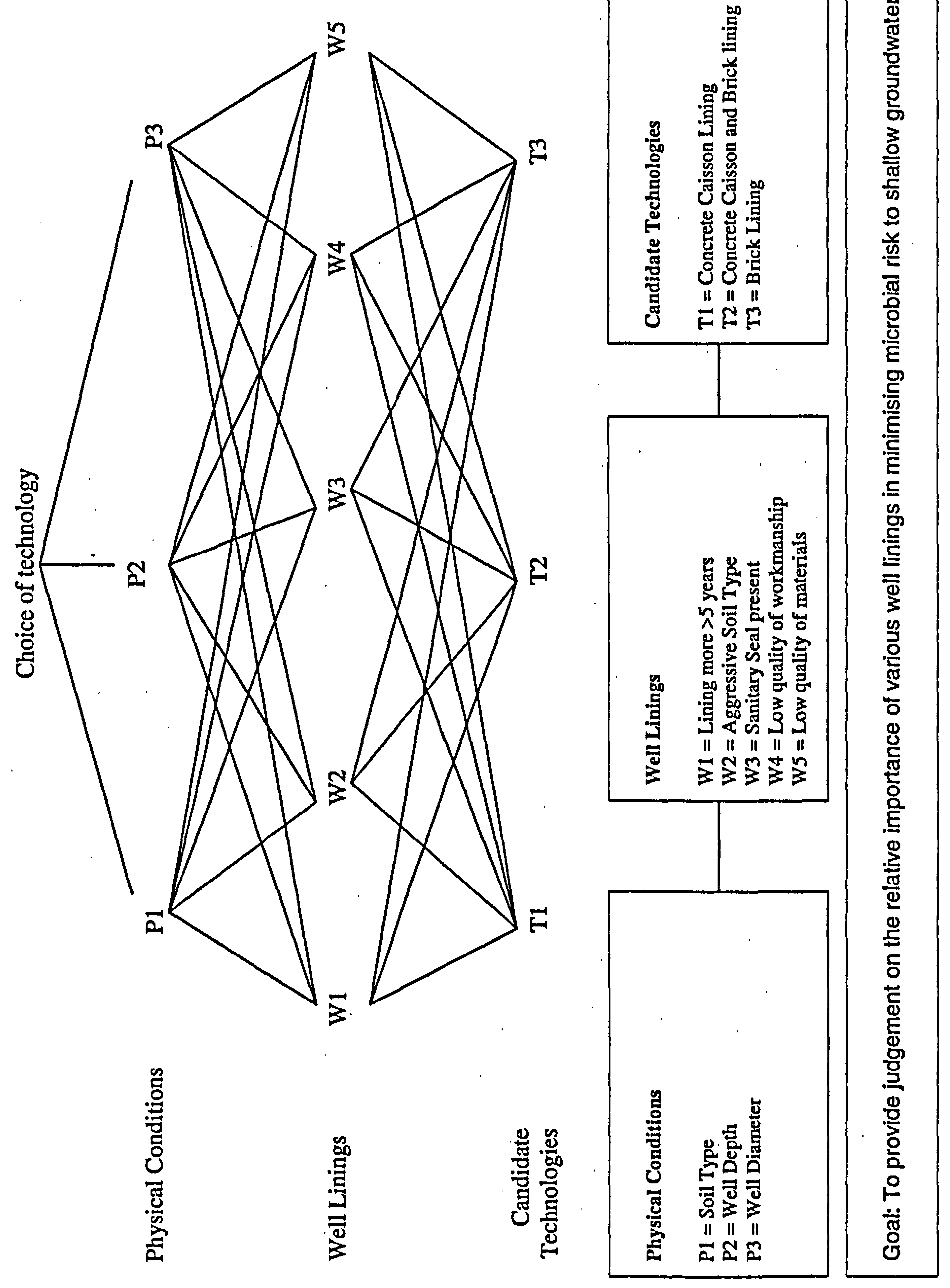




\section{Results and Discussion}

Data from respondents was coded in an EXCEL spreadsheet developed to gain estimates of weightings for each of the contributing variables. These were then used to assign composite weightings to each of the actual well lining technologies. A summary of the composite weighting results from the AHP survey are outlined in table 2 .

Table 2: AHP Composite Weightings

\begin{tabular}{c|c|ccc} 
Group & Variable group & Respondent 1 & Respondent 2 & Respondent 3 \\
\hline $\mathbf{1}$ & Physical Conditions & $0.09^{1}$ & 0.65 & 0.23 \\
$\mathbf{2}$ & Well linings & 0.62 & 0.08 & 0.64 \\
$\mathbf{3}$ & $\begin{array}{c}\text { Candidate } \\
\text { technologies }\end{array}$ & 0.30 & 0.27 & 0.13 \\
& & & &
\end{tabular}

The results revealed a strong preference for the importance of the well lining group (group 2 - marked as shaded above) over group 1 and 3. Specifically, this included the methods and materials used for well lining over the specificity of the technology or the physical conditions in which the well lining is constructed. Interestingly, the responses to the questionnaire reflected the academic background of the respondent. For example, respondent 2 was a technician from the Lichinga Agricultural Research center. The respondent indicated that the physical conditions (i.e. soil/hydrogeological conditions) were the most critical variable group in contributing to the risk of contamination. In comparison, respondent 1 was a WaterAid engineer. The respondent indicated that the physical engineering barrier was most critical. Respondent 3 in comparison was a Public Health specialist and the WaterAid Country Representative. Responses gained from both respondent 1 and 3 both identified well linings as the most critical variable group.

In summary, the AHP assigned greatest significance to the well lining variable group. This variable group includes the lining age, chemical properties of soil, absence of sanitary seal and low material quality and workmanship. Within this group, low quality of workmanship and low material quality were identified by all respondents as the two most important sub variables. 
Results of the AHP questionnaire were then applied to each of the 25 well sites dependent on the type of receptor. Results were coded as high and low dependent on the candidate technology and variables affecting the use of the well lining. To gain a composite risk score, results of the AHP were combined with qualitative and quantitative data collected during a wellhead inventory. Table 3 combines results obtained on both the wellhead and the below ground components of each of the 25 wells to assign a High or Low risk score for the effectiveness of the receptor.

Table 3: Risk Variable Table

\begin{tabular}{|c|c|c|c|c|c|c|}
\hline \multirow[t]{2}{*}{$\begin{array}{l}\text { Well } \\
\text { No }\end{array}$} & \multicolumn{2}{|c|}{$\begin{array}{l}\text { Headworks (including low } \\
\text { quality workmanship and } \\
\text { materials) }\end{array}$} & \multicolumn{3}{|c|}{ Below ground components } & \multirow[t]{2}{*}{$\begin{array}{l}\text { RISK TO } \\
\text { RECEPTOR }\end{array}$} \\
\hline & $\begin{array}{l}\text { Total risk } \\
\text { score (see } \\
\text { annex 3) }\end{array}$ & $\begin{array}{l}\text { Schmidt } \\
\text { Hammer (see } \\
\text { annex 4) }\end{array}$ & $\begin{array}{l}\text { Lining }>5 \\
\text { years }\end{array}$ & $\begin{array}{l}\text { Chemical Soil } \\
\text { properties }\end{array}$ & $\begin{array}{l}\text { Sanitary Seal } \\
\text { Absent }\end{array}$ & \\
\hline 1 & $5=\mathrm{H}^{1}$ & $\mathrm{H}^{2}$ & $\overline{\mathrm{H}^{3}}$ & $\mathrm{H}^{4}$ & $\overline{\mathrm{H}^{5}}$ & $\mathrm{HIGH}^{6}$ \\
\hline 2 & $3=\mathrm{L}$ & $\mathrm{L}$ & $\mathrm{H}$ & $\mathrm{H}$ & $\mathrm{H}$ & LOW \\
\hline 3 & $5=\mathrm{H}$ & $\mathrm{H}$ & $\mathrm{H}$ & $\mathrm{L}$ & $\mathrm{H}$ & HIGH \\
\hline 4 & $1=\mathrm{L}$ & $\mathrm{H}$ & $\mathrm{L}$ & $\mathrm{L}$ & $\mathrm{H}$ & LOW \\
\hline 5 & $1=\mathrm{L}$ & $\mathrm{H}$ & $\mathrm{L}$ & $\mathrm{L}$ & $\mathrm{H}$ & LOW \\
\hline 6 & $3=\mathrm{L}$ & $\mathrm{L}$ & $\mathrm{L}$ & $\mathrm{H}$ & $\mathrm{H}$ & LOW \\
\hline 7 & $5=\mathrm{H}$ & $\mathrm{H}$ & $\mathrm{L}$ & $\mathrm{H}$ & $\mathrm{H}$ & HIGH \\
\hline 8 & $2=\mathrm{L}$ & $\mathrm{H}$ & $\mathrm{L}$ & $\mathrm{H}$ & $\mathrm{H}$ & LOW \\
\hline 9 & $2=\mathrm{L}$ & $\mathrm{H}$ & $\mathrm{L}$ & $H$ & $\mathrm{H}$ & LOW \\
\hline 10 & $3=\mathrm{L}$ & $\mathrm{H}$ & $\mathrm{L}$ & $\mathrm{L}$ & $\mathrm{H}$ & LOW \\
\hline 11 & $2=\mathrm{L}$ & $\mathrm{H}$ & $\mathrm{L}$ & $\mathrm{L}$ & $\mathrm{H}$ & LOW \\
\hline 12 & $3=\mathrm{L}$ & $\mathrm{H}$ & $\mathrm{L}$ & $\mathrm{L}$ & $\mathrm{H}$ & LOW \\
\hline 13 & $5=\mathrm{H}$ & $\mathrm{H}$ & $\mathrm{L}$ & $\mathrm{L}$ & $\mathrm{H}$ & LOW \\
\hline 14 & $2=\mathrm{L}$ & $\mathrm{H}$ & $\mathrm{L}$ & $\mathrm{L}$ & $\mathrm{H}$ & LOW \\
\hline 15 & $1=\mathrm{L}$ & $\mathrm{H}$ & $\mathrm{L}$ & $\mathrm{L}$ & $\mathrm{H}$ & LOW \\
\hline 16 & $5=\mathrm{H}$ & $\mathrm{L}$ & $\mathrm{H}$ & $\mathrm{L}$ & $\mathrm{H}$ & HIGH \\
\hline 17 & $2=\mathrm{L}$ & $\mathrm{H}$ & $\mathrm{L}$ & $\mathrm{L}$ & $\mathrm{H}$ & LOW \\
\hline 18 & $5=\mathrm{H}$ & $\mathrm{H}$ & $\mathrm{H}$ & $\mathrm{L}$ & $\mathrm{H}$ & HIGH \\
\hline 19 & $\mathrm{H}$ estimate & $\mathrm{H}$ & $\mathrm{L}$ & $\mathrm{L}$ & $\mathrm{H}$ & LOW \\
\hline 20 & $3=\mathrm{L}$ & $\mathrm{H}$ & $\mathrm{L}$ & $\mathrm{L}$ & $\mathrm{H}$ & LOW \\
\hline 21 & $4=\mathrm{L}$ & $\mathrm{H}$ & $\mathrm{L}$ & $\mathrm{L}$ & $\mathrm{H}$ & LOW \\
\hline 22 & $3=\mathrm{L}$ & $\mathrm{H}$ & $\mathrm{L}$ & $\mathrm{L}$ & $\mathrm{H}$ & LOW \\
\hline 23 & $3=\mathrm{L}$ & $\mathrm{H}$ & $\mathrm{L}$ & $\mathrm{L}$ & $\mathrm{H}$ & LOW \\
\hline
\end{tabular}




\begin{tabular}{l|llllll}
$\mathbf{2 4}$ & $3=\mathrm{L}$ & $\mathrm{H}$ & $\mathrm{L}$ & $\mathrm{L}$ & $\mathrm{H}$ & LOW \\
$\mathbf{2 5}$ & $5=\mathrm{H}$ & $\mathrm{H}$ & $\mathrm{H}$ & $\mathrm{L}$ & $\mathrm{H}$ & HIGH
\end{tabular}

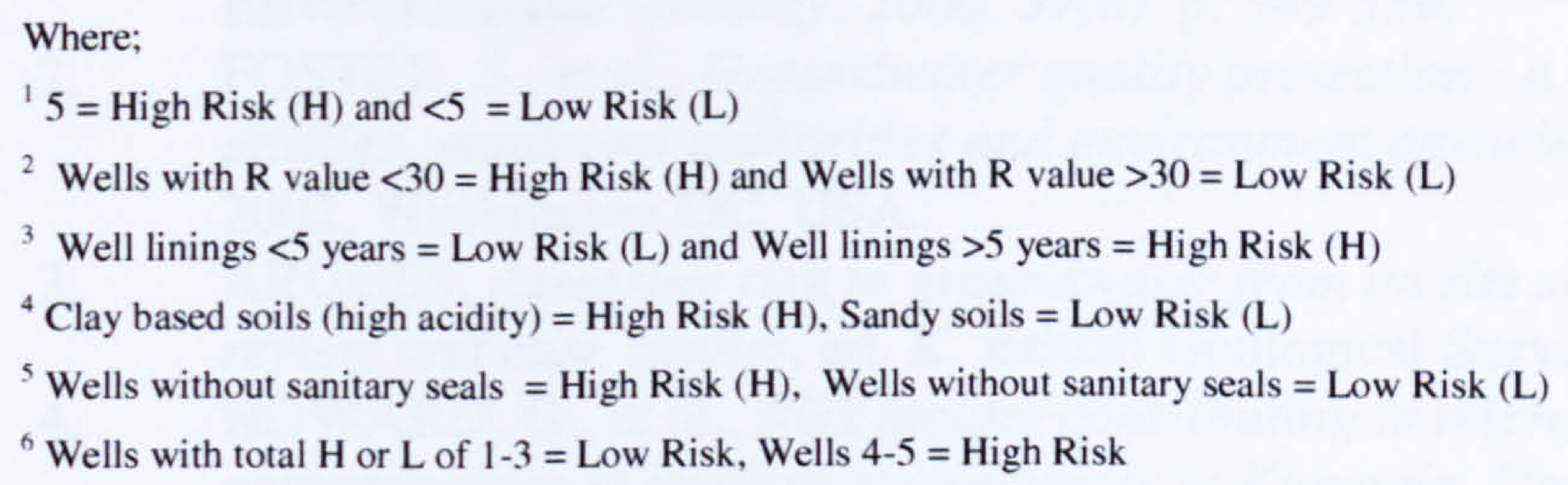

The variables of low quality materials and workmanship could not be assessed in the below ground components. Results from the above ground components (as outlined in the total score in column one), were therefore taken as indicative of these variables. From table 3, it is observed that 6 of the 25 wells are considered at high risk and 19 of the 25 wells are considered low risk.

\section{Discussion}

The author noted uncertainties in the application of the AHP process. These included:

1. Vagueness of how the attribute weights are assessed,

2. Link between the points on 1-9 scale and corresponding verbal descriptions. These uncertainties or limitations correspond with difficulties noted in the use of the AHP method by the UK Office of the Deputy Prime Minister [22]. It is therefore recommended that more precise numerical values be used during the composition and implementation of the AHP questionnaire, so that respondents are aware of the risk values being assigned to each of their responses.

\section{Conclusions}

The study indicates that the AHP is a useful tool in assigning risk rankings in data poor environments. Specifically, the AHP provides a method for identifying and ranking the risk associated with below ground components of a groundwater system. 


\section{Bibliography}

1. GOGU, R., C., and A. DASSARGUES, Current trends and future challenges in groundwater vulnerability assessment using overlay and index methods. Environmental Geology, 2000. 39(6): p. 549-559.

2. FOSTER, S., et al., Groundwater quality protection - a guide for water utilities, municipal authorities and environment agencies, ed. T.W. Bank. 2002, Washington DC, USA.

3. ARGOSS, Assessing risk to groundwater from on site sanitation: Scientific review and case studies, ed. K. British Geological Survey, UK. 2002.

4. HOWARD, G., et al., Risk factors contributing to microbiological contamination of shallow groundwater in Kampala, Uganda. Water Research, 2003. 37: p. 3421-3429.

5. HOWARD, G., S. GODFREY, and T. BOONYAKARNKUL, Chapter 18: Wellhead protection/sanitary completion, in Groundwater Monograph, WHO, Editor. 2003: Geneva.

6. GODFREY, S. and G. HOWARD, Water Safety Plans (WSP) for urban piped water supplies in developing countries. 2004, Loughborough, UK: WEDC.

7. DAVISON, A., et al., Water Safety Plans. 2004, WHO, Geneva.

8. SATTY, T.L., The analytical hierarchy process, McGraw Hill Inc, Editor. 1980. p. pp. 17-34.

9. FATTI, P., Water Research Planning in South Africa, in The Analytic Hierarchy Process - Applications and Studies, B. Golden, L.,. E. Wasil, A.," and P. Harker, T.,, Editors. 1989," Springer-Verlag: New York. p. 122-137.

10. RAMANUJAM, V. and T.L. SAATY, Technological choice in less developed countries: an Analytic Hierarchy Approach (AHP). Technological forecasting and social change, 1981. 19:

11. TRIANTAPHYLLOU, E. and S.H. MANN Using the analytic hierarchy process for decision making in engineering applications: some challenges. inter'l Journal of Industrial Engineering: Applications and practice, 1995. 2(1): p. 35-44.

12. THIRUMALAIVASAN, D. Aquifer vulnerability assessment using analytical hierarchy process and gis for upper palar water shed. in 22nd Asian Conference on Remote Sesnsing, 5-9 November 2001 2001. Singapore: Asian Association on Remote Sensing (AARS).

13. THIRUMALAIVASAN, D., M. KARMEGAM, and K. VENUGOPAL, AHP. DRASTIC: software for specific aquifer vulnerability assessment using DRASTIC model and GIS. Environmental Modelling and Software, 2003. 18: p. 645-656.

14. FOURIE, A., B, VAN RYNEVELD, M,B, The fate in the subsurface of contaminants associated with on site sanitation: A review. Water SA, 1995. 21(2): p. 101-111.

15. VAN RYNEVELD, M., B., FOURIE, A, B.,, A strategy for evaluating the environmental impact of on-site sanitation systems. Water SA, 1997. 23(4): p. 279-291.

16. FOSTER, S., HIRATA, R, GOMES, D, D'ELIA, M, PARIS, M, Groundwater quality protection - a guide for water utilities, municipal authorities and environment agencies, ed. T.W. Bank. 2002, Washington DC, USA.

17. LOOTSMA, F., A.,, The REMBRANDT system for multi criteria decision analysis via pair wise comparisons or direct rating. 1992, Faculty of 
Technical Mathmatics and Informatics, Delft University of Technology: Delft, Netherlands.

18. TRIANTAPHYLLOU, E. and A. SANCHEZ, A sensitivity analysis approach for some deterministic multi-criteria decision making methods. Decision sciences, 1997. 28(1): p. 151-194.

19. WANG, Q., W., Y. WEE, and G. OFORI, DSSDSS: a decision support system for dewatering systems selection. Building and Environment, 2002. 37: p. 625-645.

20. TRIANTAPHYLLOU, E. and F. LOOTSMA, A.,, On the evaluation and application of different scales for quantifying pairwise comparisons in fuzzy sets. Journal of Multi criteria decision analysis, 1994. 3: p. 645-656.

21. BOULTER, J., The Analytical Hierarchy Process. 2002, USA.

22. ODPM, Multi criteria analysis: A manual - Office of the deputy prime minister. Delivering thriving, inclusive and sustainable communities in all regions. 2001

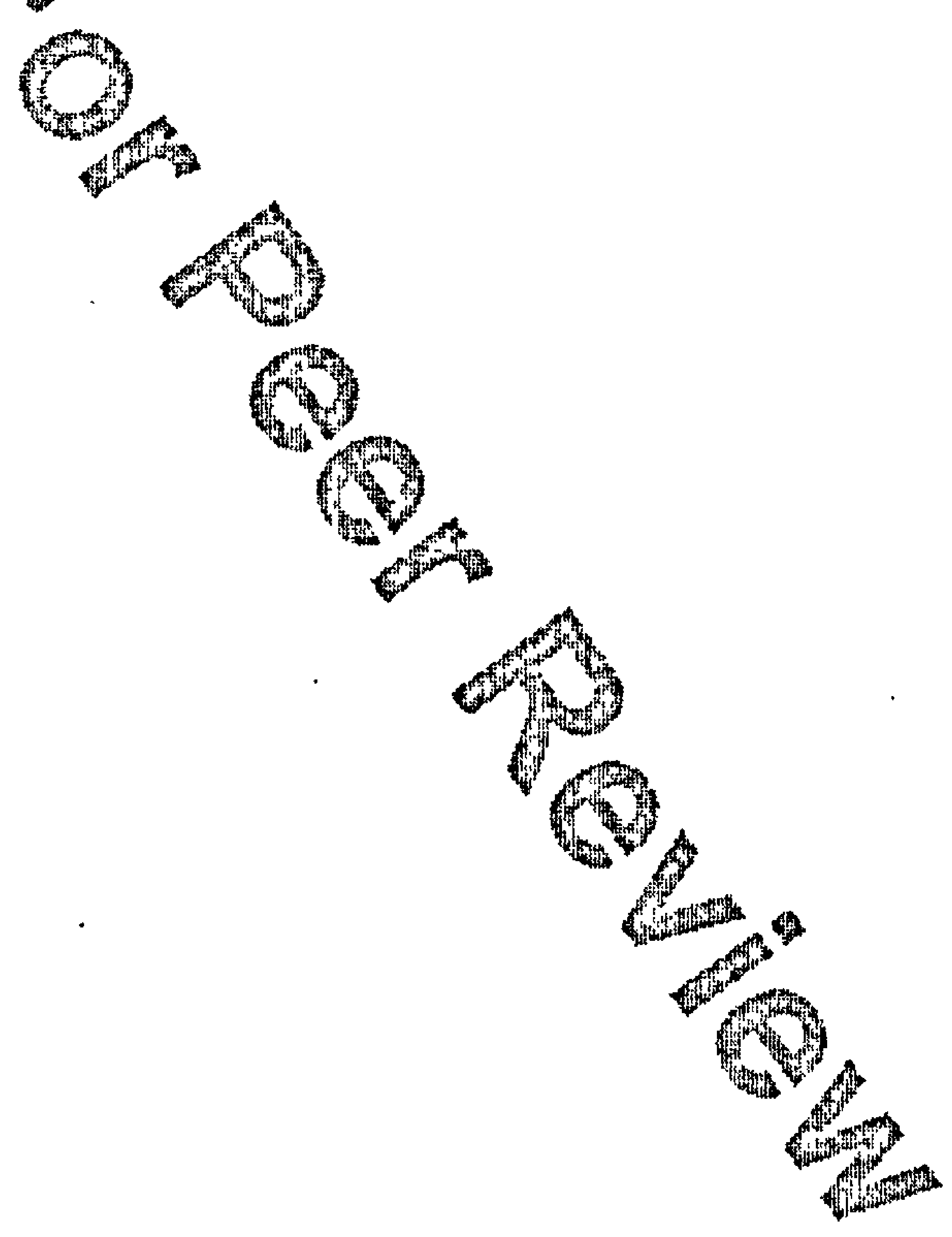




\section{Water 05
Micro 05}

Paper 46: Analysis of enterococci using portable testing equipment for developing countries - variance of Azide NutriDisk medium under variable time and temperature

\section{S Godfrey ${ }^{* 1}, \mathbf{J}$ Watkins ${ }^{2}, \mathrm{~K} \mathrm{Toop}^{3}$ \& C Francis ${ }^{2}$}

${ }^{I}$ Water \& Environmental Sanitation Project, UNICEF Bhopal Field Office, E7/650 Area Colony, Shahpura, Bhopal, Madhya Pradesh/Chhattisgarh, India; ${ }^{2}$ CREH Analytical Ltd, Horsforth, Leeds, UK, ${ }^{3}$ Water, Engineering \& Development Centre, University of Loughborough, Loughborough, UK

\section{sgodfrey@unicef.org}

This report evaluates the appropriateness of pre-impregnated Azide NutriDisks (ANS) medium (sterile, dehydrated culture medium) for use in field water quality testing kits in developing countries. Findings are presented from two experiments designed to (a) evaluate the accuracy of enterococci analysis using AND medium compared to AWWA/APHA Standard Method 9230B \& C, most probable number (MPN) and membrane filtration (MF) and (b) examine the recovery of enterococci on AND and SB media with respect to variable incubation times and temperatures.

Experiment 1 compared AND to presumptive controls based on inoculation of a series of tubes with Azide Dextrose broth using a multiple tube technique and transferral of Millipore filters on Slanetz \& Bartley (SB) agar. Experiment 2 compared incubation temperature, time and combination of the two using membrane filtration. Presumptive counts were observed at (i) $37^{\circ} \mathrm{C}, 41^{\circ} \mathrm{C}, 46^{\circ} \mathrm{C}$ and $47^{\circ} \mathrm{C}$ and (ii) at $20,24,28$ and 48 hours. These were compared to the AWWA/AHPA Standard Method $9230 \mathrm{C}\left(44^{\circ} \mathrm{C}, 44\right.$ hours $)$. Confirmations were performed on Kanamycin Aesculin Azide agar (KAA). Statistical analysis was done based on $95 \%$ confidence intervals, Friedman's ANOVA and student $t$-test in EXCEL.

Results from Experiment 1 indicated significant correlation $(p=0.85)$ between enumeration by AND medium and standard methods using SB agar with minimal correlation $(p=0.071)$ compared to MPN. $100 \%$ of presumptives were confirmed as enterococci on both media types. Results from Experiment 2 indicated higher enumeration using AND $(p=0.45)$ than with $\mathrm{SB}(\mathrm{p}=<0.001)$ at all temperatures with a survival threshold of $47^{\circ} \mathrm{C}$. Significant results for AND medium was noted 
at $20(p=0.021), 24(p=0.278)$ and $28(p=0.543)$ hours.

The study concluded that AND was an appropriate medium for use in developing countries for identification of presumptive enterococci due to its accuracy at a greater time and temperature range. Significant findings from the study indicated the need to develop sterile, dehydrated culture media with the ability to provide confirmed enterococci. The study further concluded that AND provided flexibility in incubator technology making it an appropriate alternative to SB agar for monitoring drinking water using field testing kits in developing countries.

This article is from WaterMicro

http://www.watermicro.cactusbob.org/ 


\title{
Sanitary completion of protection works around groundwater sources
}

\author{
G. Howard, S. Godfrey and T. Boonyakarnkul
}

The proper sanitary completion of groundwater sources is of particular relevance to the microbial quality of water. It is essential to prevent the direct contamination of groundwater at the point of abstraction or resulting from rapid recharge pathways close to the source. Where contamination is allowed to directly enter the groundwater source or reach groundwater close to the point of abstraction, the travel time may be too limited to ensure adequate die-off and the processes of attenuation may not be effective in reducing the numbers of pathogens (Robertson and Edberg, 1997).

Sanitary completion is also important in preventing direct chemical contamination, but often does not provide the same degree of protection. The subsurface leaching and transport of mobile and persistent chemical contaminants means that land use controls will be required to limit risks. This is illustrated, for instance, by studies in a small town in Uganda that showed little contamination by microbial contaminants, but significant increases in nitrate derived from faecal sources (Barrett et al, 2000a). Large-scale protection measures, such as designation of groundwater protection zones, are discussed in Chapter 17.

Sanitary completion refers to the protection works at the abstraction point and the immediate surrounding areas. It is sometimes also referred to as wellhead protection, although this would usually cover a wider area around the well than covered in this

2006 World Health Organization. Protecting Groundwater for Health: Managing the Quality of Drinking-water Sources. Edited by O. Schmoll, G. Howard, J. Chilton and I. Chorus. ISBN: 1843390795. Published by IWA Publishing, London, UK. 
chapter. In this chapter, sanitary completion includes the underground and above ground construction of the abstraction facility as well as the immediate area surrounding the abstraction point.

\begin{tabular}{ll}
\hline NOTE & This chapter introduces options for controlling risks through \\
sanitary completion. The information presented supports defining \\
control measures in the development of a Water Safety Plan \\
(Chapter 16).
\end{tabular}

\subsection{SANITARY COMPLETION AND HEALTH}

The direct contamination of groundwater sources resulting from poor sanitary completion has been linked to both endemic disease and outbreaks. Such contamination is present in both developed and developing countries. For instance, Olson et al. (2002) describe an outbreak of Ecoli 0157:H7 in Alpine, Wyoming, including cases of haemolytic uraemic syndrome, which was related to consumption of water from a poorly protected spring which sanitary surveys had identified as being at risk from contamination by surface water. Poor sanitary completion measures also appear to have played a role in the Walkerton outbreak in Canada (O'Connor, 2002). In developing countries, the use of poorly protected groundwater sources has been linked to acute diarthoeal disease (Trivedi et al., 1971; Nasinyama et al., 2000). Good sanitary completion measures have been shown to be necessary to maintain the quality of water and protect public health (US EPA, 1993; Pedley and Howard, 1997; Robertson and Edberg, 1997).

The effectiveness of sanitary completion in reducing risks of pathogens is profound as it provides a barrier to direct contamination of the source (Robertson and Edberg, 1997). The degree to which risks will be reduced, however, varies between pathogen types and aquifer types and there is a need for multiple interventions to act as barriers to most pathogen types.

For many aquifers, good sanitary completion measures will control the majority of risks posed by protozoa. Sanitary completion will greatly reduce the risks from bacteria in alluvial aquifers, but significant risks will remain in fracture flow aquifers where the enforcement of protection zones and, possibly, disinfection will be required. Sanitary completion measures will in general provide much less protection against risks posed by viruses, with protection zones and disinfection being required to reduce risks.

Most sanitary completion measures do not significantly add costs onto good standard design practice. There are cost implications, however, in ensuring that effective maintenance is performed to prevent basic protection measures from deteriorating and becoming ineffective. In some cases, cost considerations may be important with regard to selecting whether improvement of sanitary completion measures or altemative interventions will be the preferred option. For instance, where an aquifer is subjected to 
low-level or intermittent microbial contamination, it may be more cost effective to chlorinate the water prior to distribution than to try to deepen the borehole.

\subsection{THE NEEDS FOR EFFECTIVE CONTROL MEASURES IN SANITARY COMPLETION}

Sanitary completion typically includes a number of essential control measures to prevent the contamination of groundwater. Failures in such control measures have been reported from a variety of situations in both developed and developing countries (Lewis and Chilton, 1984; Lloyd and Helmer, 1991; Platenberg and Zaki, 1993; Daly and Woods, 1995; Gelinas et al., 1996; Howard et al., 2003). In addition to the immediate protection works at the abstraction point, the appropriate sealing of abandoned wells is also noted as essential to protect functioning groundwater sources (Rojas et al., 1995; Robertson and Edberg, 1997).

Failures in sanitary completion measures may result from poor construction and in particular lack of adherence to basic quality standards. For example poor jointing on casings of boreholes, incorrect selection and placement of grouting, poor selection and installation of gravel packs, poorly mixed concrete used for linings and aprons may all result in seepage of contaminated water into groundwater sources (Howsam, 1990; US EPA, 1993).

Some drilling techniques lead to increased risks because they do not allow for grouting around the casing to be used (ARGOSS, 2001). Failure to consider the $\mathrm{pH}$ of the groundwater may lead to corrosion and rapid deterioration of rising mains, resulting in loss of water and abandonment of the supply (Leake and Kamal, 1990). In addition, methods of water lifting can present a direct route of contamination such as through the priming of handpumps with contaminated water (MacDonald et al.,1999).

Failures in sanitary completion may also result from poor maintenance (Lloyd and Bartram, 1991; Lloyd and Helmer, 1991; Platenberg and Zaki, 1993; US EPA, 1993; Daly and Woods, 1995; Howard et al., 2003). In many cases specific measures constructed to protect a groundwater source fail because other measures, such as fences and diversion ditches, have not been maintained. The failure to maintain ditches and fences can result in increased access to the groundwater source, increased stress and erosion on the other protection measures and increased likelihood of inundation by surface water.

Control measures as part of sanitary completion should be identified and implemented in the planning, design, construction, operation and maintenance of an abstraction facility. As the risks to groundwater sources can be described using the source-pathway-receptor model (see Table 8.8 in Chapter 8.5.2), control measures can be categorised as: controlling the source of hazards, e.g. faecal material from a pit latrine overlying an aquifer and close to an abstraction point, and controlling pathways to avoid direct or very rapid ingress of contaminated water, e.g. through cracks in the casing of boreholes, improperly sealed apron surrounding the headwall of a dug well or borehole, eroded backfilled area of a protected spring, abandoned dug wells and borrow pits.

Control measures both for sources and for pathways include indirect measures to decrease the likelihood of a hazard or pathway developing, such as a fence around the 
water source to prevent access of animals or humans which could be a source of hazard (through defecation) or cause a pathway (through causing damage to the source or the immediate surrounding area).

In many cases, a combination of control measures addressing hazard sources and contamination pathways is necessary. Sanitary completion provides one barrier to contamination from such sources, but should be integrated with proper pollution containment practices and other environment engineering interventions (such as improved drainage) to be effective.

\subsection{CONTROL MEASURES IN SANITARY COMPLETION: PLANNING AND DESIGN}

The initial design of a groundwater abstraction facility is crucial in determining how protected the source will be. Some background information and a number of basic considerations should be taken into account at this stage.

\section{Planning site and design in relation to the hydrogeological environment}

The first step in sanitary completion is to understand the nature of the hydrogeological environment - where and how many aquifers exist, what type of aquifers exist, expected yields, depth and nature of the overburden and the degree of interconnection between different aquifers (Chapter 8). It is also important to assess how the water will be abstracted - are there springs or must the groundwater be abstracted through sinking a well or borehole into the ground? This information can then be used to make basic decisions such as the type of technology to be used, the depth of abstraction and additional protection measures required.

Where aquifers are deep or multiple aquifers are found, setting the intake deeper is likely to improve the microbial quality of water. In many aquifers, in particular relatively fine-grained aquifers, there is far less vertical movement of water (and therefore pathogens) than horizontal movement. The increase in travel times for relatively small increases in depth may be many tens or hundreds of days (ARGOSS, 2001). This increases the potential for die-off of pathogens and potentially greater dispersion; although in the latter case sophisticated models may be required to predict this. It may also increase the potential for attenuation, although this cannot be relied upon.

Sinking tubewells into deeper (usually older) aquifers may also be an important way of avoiding chemical contamination in shallow groundwater, as is the case in relation to arsenic contamination in Bangladesh (Ahmed et al, 2002). Where tubewells are deepened it is important that shallower layers are cased off to prevent ingress. Often the incremental cost of deepening a well is relatively low in comparison to the overall capital investment and thus yields a significant cost-benefit. Deepening tubewells requires ascertaining whether there is no or very limited hydraulic connection between contaminated shallow and uncontaminated deeper aquifers. Hydraulic connection between aquifers is relatively common in aquifers found in weathered basement rocks and may also occur in alluvial aquifer sequences with no defined aquitard or aquiclude. Where hydraulic connections exist, deepening a tubewell may limit the improvement of water quality, as induced leakage from shallow aquifers may still lead to contamination. 
Planning control measures in designing abstraction may be hampered by lack of hydrogeological information. For example in fracture aquifers it may be difficult to determine the level of risk posed to a deep aquifer by a contaminated shallow aquifer. Geophysical investigation and detailed assessment may provide some, but possibly not all, the answers required during the design stage. In such cases, monitoring as part of validation of the design chosen is particularly important.

\section{Planning site, design and operational control measures in relation to the outcome of hazard assessment}

As discussed in Section II and Chapter 14 of this book, a critical step before embarking on the design of a groundwater source is to evaluate what hazards exist close to the proposed site and their potential to be attenuated or diluted. This includes determining whether particular aquifers are contaminated and therefore whether their use as a drinking-water supply is justified.

Where the situation assessment identifies existing contamination of a well or spring, or a high potential for pollution from activities and conditions too close to the abstraction facility, control measures can either be identified towards removing the cause of the hazard(s) (see also Section V), or towards changing the site or depth of the well. While removing hazards would be the preferable, in practice population density and/or severity of contamination may make relocation of wells more feasible.

Whilst an emphasis should be placed on ensuring microbial quality of water, attention should be paid to the chemical quality of different groundwaters. Assessing whether particular aquifers contain toxic levels of chemicals (e.g. arsenic) or whether the levels of chemicals will affect the acceptability of water to consumers (e.g. high iron or manganese levels) or cause unacceptable operational problems (e.g. very hard waters) is critical in the design process. The acceptability of water is a particular problem as this may lead households to reject the use of an otherwise safe source and use contaminated sources for drinking. This not only fails to meet basic health needs for low-risk drinkingwater, but also represents a significant waste of resources.

In cases where the hazard only represents a risk under certain pumping conditions, the pumping regime could be defined as control measure in order to reduce the influence of the hazard. This is unlikely to be satisfactory, however, as there may be considerable uncertainty both in the abstraction model used as basis for decisions, and in operational monitoring and corrective action to ascertain that this pumping regime is always adhered to.

If the hazard cannot be removed and changes in design of the source are not possible, post-abstraction disinfection is likely to be an effective control measure. In some cases, it will be more effective to use a lower microbial quality of water and then apply treatment at household or community level and/or implement a health education programme dealing with steps available at the household level to reduce the risks. Also, a residual risk may have to be retained if contamination is relatively low, other routes of disease transmission are more significant than water and are therefore other interventions are a greater public health priority where resources are insufficient to simultaneously improve drinking-water quality. 


\subsubsection{Drainage and fencing}

Control measures are important to protect abstraction facilities against the potential for inundation by contaminated surface water or damage by animals or overland flows caused by heavy rainfall by diverting surface water away from the headworks. For protected springs this diversion should be located above the protection works and should direct the water into a drainage ditch downstream and away from the spring. For dug wells and boreholes, diversion ditches should circle the headworks and drain the water away from the source. In designing the ditch, the topography and likely overland flows should be evaluated to ensure that the depth of the ditch is adequate to remove all stormwater.

Diversion ditches should be located some way from the groundwater source, but not so far that significant overland flow will be generated within the area between the ditch and the headworks. A general rule of thumb is a minimum of $6 \mathrm{~m}$ and preferably $10 \mathrm{~m}$ for boreholes and dug wells and up to $20 \mathrm{~m}$ for protected springs (Morgan, 1990).

Restricting access by both humans and animals to the headworks is also important to reduce risks of contamination and thus, where possible, water sources should be enclosed by a fence. However, this needs to be balanced against cultural norms, for instance fencing of community water sources in Bangladesh is often not practiced because this may be interpreted as restricting the use of the source.

The wellhead of boreholes serving a piped distribution system should be located within a locked building which only the operation staff of the water supplier should have access to. Where users must collect water directly at the borehole or dug well source, fencing is still required and access should be restricted to only one or two entrances. For springs, the whole backfilled area should be fenced and inaccessible as users will collect water from outlets on the spring box. Where the spring feeds a gravity piped water system, the whole spring protection works should be fenced off and access limited to the community operator. All valve and junctions boxes should have concrete lined sides and a lockable lid.

\subsubsection{Design of boreholes}

Boreholes or tubewells may be shallow (5-45 m) or deep (up to several hundred metres). The choice of pump (hand, mechanized or electric submersible) to withdraw the water will depend on the hydraulic (or pumping) head in the pump, with handpumps being typically constrained to depths of $45 \mathrm{~m}$ or less. Where confined or semi-confined aquifers are used, the water table may rise considerably higher than the depth of the well and a handpump may still be used despite the well being physically relatively deep. Where mechanized or electric submersible pumps are used, they are typically linked to a distribution system. An example of a shallow borehole is shown in Figure 18.1. Selection of appropriate design such as the use of geotextile stockings, telescopic screen or external gravel packs can improve filtration and reduce potential sanitary risk (Driscoll, 1986). 


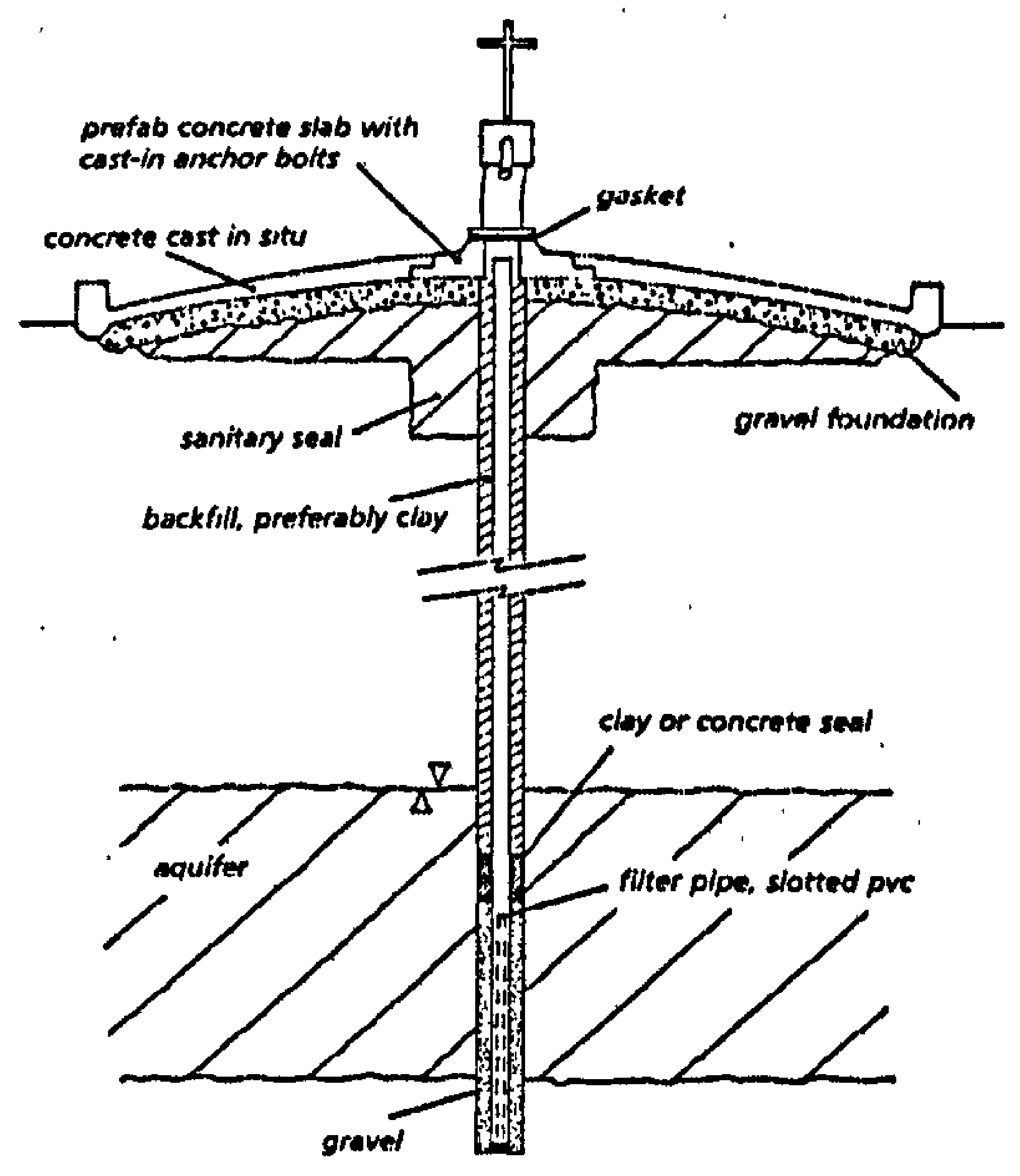

Figure 18.1. Design of a shallow borehole with handpump (Howard et al., 2001)

For all boreholes or tubewells ensuring proper sanitary completion of the above ground infrastructure is essential to prevent direct ingress of contaminated surface water. Key components are to provide a casing over the unsaturated zone and over the upper part of the aquifer which may be expected to dewater during pumping. It is important to provide a bentonite grout seal for at least the top $1-3 \mathrm{~m}$, which should be continuous with a concrete apron surrounding the top of the borehole (Driscoll, 1986). The apron must be in good condition with cracks and faults repaired rapidly.

Sanitary completion of tubewells/boreholes will be dependent on the method of drilling. For instance, MacDonald et al. (1999) note that the use of the sludger method commonly employed in the alluvial aquifers in Bangladesh increases susceptibility to contamination via routes close to the tubewell because it precludes sealing the annulus between the casing and drilled tubewell. However, as the formation typically collapses around the casing, the susceptibility can be reduced (Ahmed et al., 2002).

Boreholes are usually fully developed prior to commissioning to ensure adequate flow using a variety of techniques. Well development is not typically designed to improve water quality, but care is needed when using some techniques (notably hydrofracturing and acidization) to avoid the creation of preferential flow paths in consolidated formations that could allow rapid transport of contaminants.

\subsubsection{Design of dug wells}

Most hand-dug wells are shallow (typically $20 \mathrm{~m}$ or less in depth) although wells as deep as $120 \mathrm{~m}$ have been constructed (Watt and Wood, 1977). They are often more vulnerable 
to contamination than boreholes, thus while some shallow dug wells have mechanized pumping, the majority (particularly those in developing countries) have water abstraction through some form of handpump, windlass or rope and bucket system. A typical design is shown in Figure 18.2.

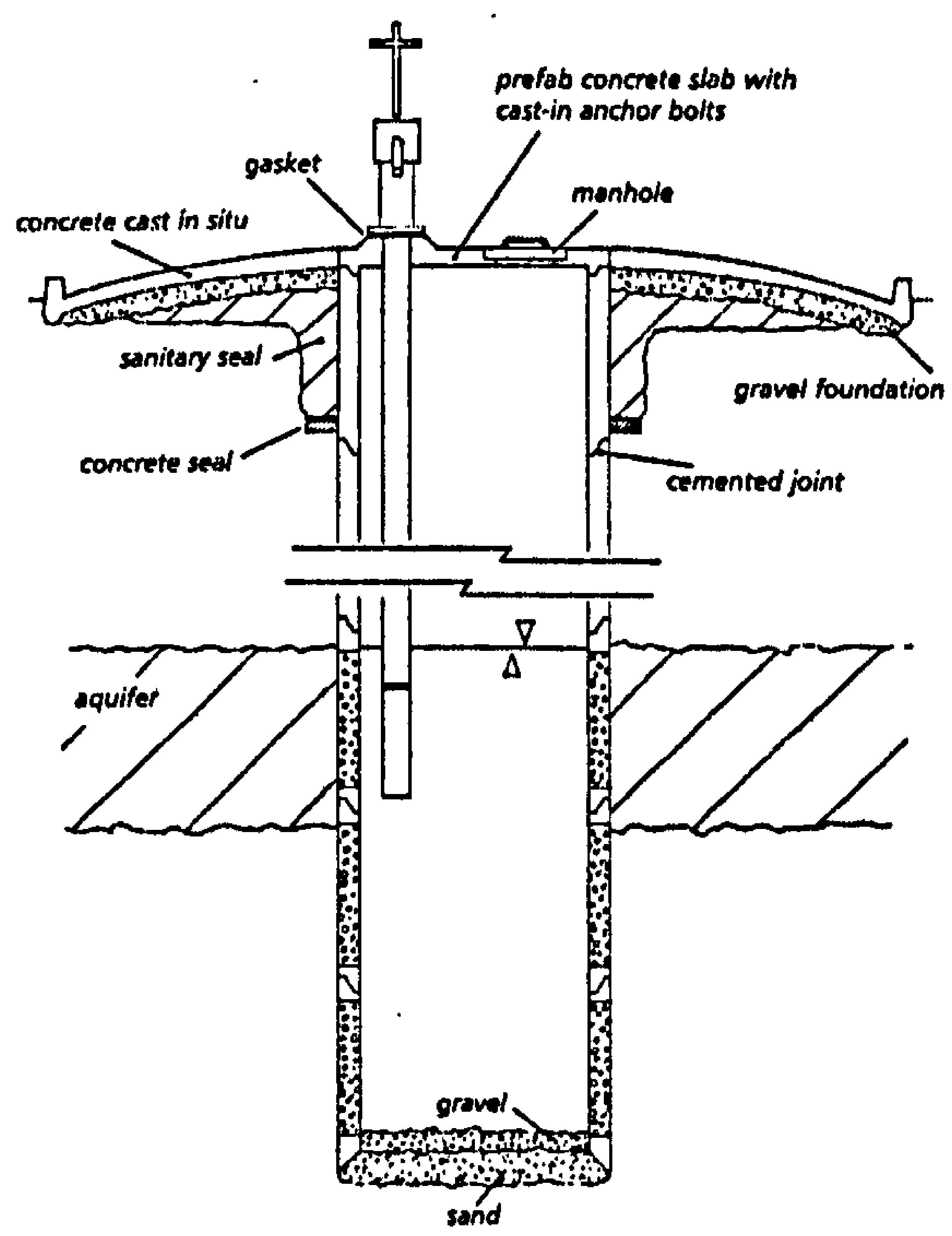

Figure 18.2. Design of a dug well with handpump (ARGOSS, 2001)

Hand-dug well designs usually have some form of lining over the unsaturated zone. In order to secure a year-round supply, caissons may be sunk below the water table to prevent drying. The design should include an apron surrounding the top of the well (usually of $1.3 \mathrm{~m}$ radius) with lining extended $30-50 \mathrm{~cm}$ above the top of the apron to provide protection against direct ingress of surface water. It is preferable that a cover is put on the well to prevent direct contamination of the water (Collins, 2000).

Studies by Lewis and Chilton (1984) note that the design, construction, operation and maintenance of the apron results in a direct reduction in levels of contamination. Dug wells can be backfilled with a sanitary seal of between $1-3 \mathrm{~m}$, which increases travel time resulting in increased die off rates of pathogens. However, backfilling of wells is difficult if deepening of the well is required during drought periods. Alternative techniques such as curbing (attachment of section stabilizers) can be used to prevent movement of the shaft section of well and therefore not disturb the sanitary seal (Watt and Wood, 1977).

The means of abstraction should minimize the potential for introducing contamination from dirty containers. This may include using a handpump or other sanitary means of 
withdrawing water from the well such as a rope and washer pump, which have been shown to be effective in reducing levels of contamination (Gorter et al., 1995). (See Section 18.5.1 for more detail about risks associated with pumps.) Where a windlass, rope and pulley system with a bucket is used, then only one bucket should enter the well and hygiene education should emphasize the need to keep the well bucket from coming into contact with the ground.

Hand dug wells often represent particular problems for sustaining good quality water, as it is difficult to ensure that very shallow water cannot enter the lining during wet periods. There are a number of different linings that may be used, including precast concrete, concrete cast in-situ and brick linings (Collins, 2000). Each of these methods gives varying degrees of sanitary protection.

Where water quality is difficult to maintain, additional improvements have been made to dug wells. These include the addition of a small sand filter set inside a box at the base of the well, a permeable base plate or ongoing chlorination of the water in the well (Lloyd and Helmer, 1991; WHO, 1997; Godfrey et al., 2003). Chlorination has proven to be effective in post-emergency situations where other technology alternatives are unavailable but its effectiveness in terms of sustainability is questionable (Rowe et al., 1998; Godfrey, 2003).

\subsubsection{Design of protected springs}

A spring is a natural groundwater source which is protected by providing a concrete headwall or spring box around the eye of the spring (where water emerges) that prevents direct contamination (WHO, 1997; Howard et al., 2001; Meuli and Wehrle, 2001). There are a number of designs for protected springs, all of which utilize some form of retaining wall or spring box with an excavated area backfilled with loose material to encourage spring flow towards the outlet. A protective cover usually overlies the excavated area and the area is fenced for some distance to prevent direct access by humans and animals. One design that has been used in periurban areas is shown in Figure 18.3.

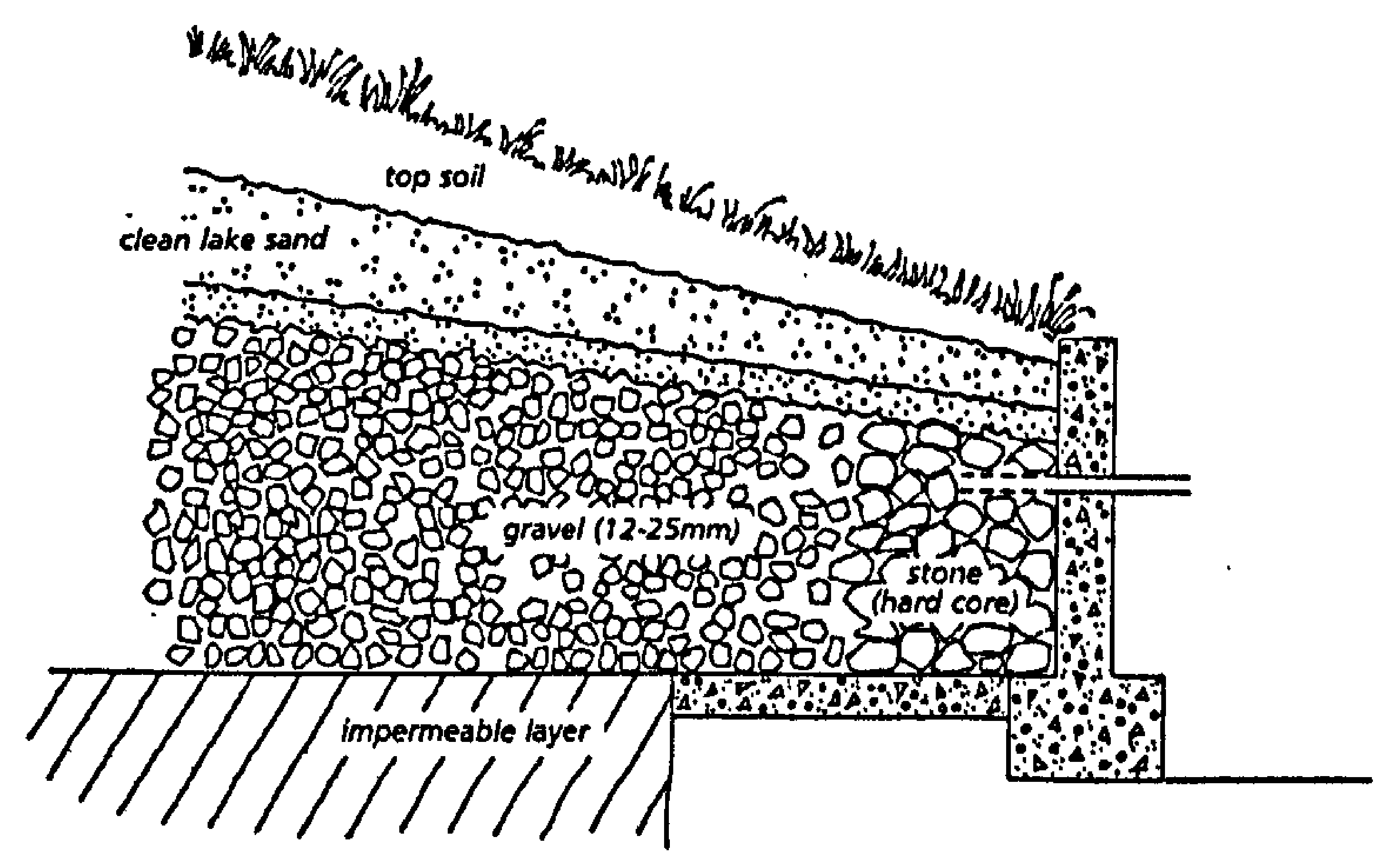

Figure 18.3. Cross-section of the backfill of a protected spring (Howard et al., 2001) 
Where protection is poor, contamination may occur at the point of emergence due to recharge by contaminated water in the immediate area. Thus the proper protection of the spring eye becomes vital. At most springs, the eye of the spring is excavated and the area backfilled with loose material. The filter media should be sufficiently fine to provide reasonable filtration of the groundwater entering from the spring eye and any surface water percolating through the immediate area: usually gravel although finer media may be required in more polluted areas.

It is important that this filter is overlain by an impermeable layer, commonly clay but can be a concrete cover, to reduce direct infiltration of surface water, and the whole area grassed (Howard et al., 2001; Meuli and Wehrle, 2001). The filter media should be placed in the backfill area from the base of the excavation up to the expected highest level of wet season water table rise (only applicable in gravity springs).

\subsubsection{Design of infiltration galleries}

Infiltration galleries come in a variety of forms - they may run alongside rivers or other surface water bodies or may tap a spring line. They can be used as a part of a treatment train or may provide water directly via a shallow well or from a gravity-fed piped water supply. Infiltration galleries have been used in many countries and often have long life spans, for instance an infiltration gallery has been in operation in Lima, Peru for over 100 years and still provides high quality water with limited maintenance (Rojas et al., 1995).

When using an infiltration gallery it is important to ensure that the collector pipe is laid at an adequate depth to ensure a year-round supply. The collector pipe should be surrounded by a gravel pack designed to reduce the velocity of water entering the drain to ensure that suspended sediments are removed. It is preferable that the intake holes be on the underside of the collector pipe to increase the flow path length. However, it is recognized that in most cases inlet holes will be required on the full pipe for hydraulic reasons and that the gravel pack must be laid properly. The interior of infiltration galleries will be self-cleaning if the velocity is at least $1 \mathrm{~m}$ per second.

\subsection{CONTROL MEASURES IN SANITARY COMPLETION: CONSTRUCTION AND MATERIALS}

The construction process and materials used are critical in ensuring that proper sanitary completion is achieved. Substandard work should be rejected. Poor construction quality allows faults to develop at the abstraction point. It is essential that technicians undertaking water source construction are properly trained and that guidelines for construction (for instance concrete mixes, rising main materials, etc.) are provided and followed.

The materials used can be critical to prevent water quality deterioration. Cement should be of good quality and within the recommended date of use. Sand and gravel should be clean and mixed in the proportions specified in the design. Reinforcing materials should be free of rust and dirt to ensure that a firm bond is formed with the concrete and care should be taken in selecting the gauge of reinforcing materials. 
An important part of the construction process is quality control. This requires periodic checking and auditing of field practices to ensure that they are consistent with stated quality goals and objectives that the construction agency has set itself. Such quality control is necessary in all situations, whether construction is undertaken by the public or private sector. In all cases, but particularly where work is contracted to a third party, it is essential that there is evidence that the quality of construction is adequate. This may take the form of inspection and signing off a contract prior to full payment, or unannounced site visits.

\subsubsection{Pumps and rising mains}

For dug wells and tubewells, the selection of the rising main material is important. Galvanized iron rising mains should be avoided where water is relatively acid water because they are likely to corrode and lead to abandonment of the use of the handpump or the source. Where suction pumps are used, it is important that pumps are selected which have a non-return foot valve and do not require priming water to be added. As priming water is often taken from surface water or other stored household water, it may be contaminated (ARGOSS, 2001). Where priming water must be used, then it is important that only water collected from the well and stored in a covered container is used.

\subsubsection{Cleaning of facilities prior to commissioning}

For boreholes and dug-wells, good hygiene should be practiced by the team during construction. However, as some contamination will almost always remain, the wells should be thoroughly cleaned and disinfected prior to use and after maintenance tasks within the well.

For dug wells, the lining and caisson walls should be scrubbed with a chlorine solution prior to commissioning; after this washing down with chlorinated water should be sufficient. Where a handpump is installed on a dug well, the rising main should be filled with a chlorine solution and left to stand for at least one hour and preferably overnight.

Disinfection of boreholes requires filling the casing with a chlorine solution and leaving it to stand for at least one hour and preferably overnight. In both cases, the chlorinated water should be pumped to waste before use.

\subsection{CONTROL MEASURES IN SANITARY COMPLETION: OPERATION AND MAINTENANCE}

Whilst good design and construction will do much to ensure that wellhead protection is adequate, ensuring that it remains in good condition through ongoing preventative maintenance and repair is essential. This applies equally to springs and wells of large utilities and to small community or household supplies. The inspection routine should be defined in a management plan and include the recording of any deterioration detected and the action to be taken by whom and when. 
For example, where pumps are used (whether handpump or mechanized), a stock of tools and spares should be kept by the operator so that repairs can be carried out quickly. Inherent to this is developing an effective supply chain for spares. In South Asia this has been successful as the small-scale private sector has been able to meet demand. In Africa, developing adequate supply chains has been more problematic, leading to relatively large numbers of boreholes being non-functional. In more developed countries, operators would normally have a store of the requisite tools and spares or would be able to source these quickly.

Proper training of operators of a supply is of critical importance for them to have and have the skills and knowledge to undertake at least basic preventative maintenance and perform minor repairs. More than one operator per source should be trained to ensure that maintenance and repairs can still be undertaken even if an operator moves away from the area or cannot undertake work at a particular time. For utility supplies, a number of operators may be identified who work at the supply on a rotational basis. Operators should have access to guidance and information about maintenance and repairs - e.g. specifying frequencies for replacement or worm parts and giving detailed information of repair procedures.

Where possible, the operators of water supplies should receive ongoing support from technical or professional support staff. Very often, even limited support in terms of regular visits to a supply to undertake an inspection and to meet with the operators of the supply can be very effective in sustaining good operation. This is particularly important for sustaining good quality small water supplies in both developed and developing countries and in rural and urban areas (Bartram, 1999; Holden, 1999).

In addition to basic maintenance and repairs of equipment, it is important that basic cleaning tasks are routinely undertaken. This involves cleaning and repairing diversion ditches, ensuring that wastewater ditches from springs do not become blocked and allowed to flood the source and ensuring the fence remains in good condition. Such tasks are best defined in management plans and usually are not onerous if done regularly. They can make a crucial difference in water quality control. Such activities should be supported by inspections of the site by the operator.

Experience shows that in order to sustain operation and maintenance some form of contribution from the users for the upkeep of the water source is very effective. In rural areas of low-income countries this may involve the contribution of labour. Other communities, particularly those in wealthier countries and those in urban areas of developing countries, may rely on payment by the users for the water services supplied. Most communities are willing to pay for water services providing the charges are realistic and the service meets the demands of the users. Routine payment is often preferred, as systems that operate solely on the collection of fees once a breakdown has occurred will mean that faults take longer to repair, although the latter approach has been found to work in some communities, for example in Eastern Uganda.

In both cases, community organization is often key to ensuring that maintenance procedures are supported. This may take the form of a committee that oversees the operation of the water supply. In many low-income countries, such a committee may be specific to the water source and it is preferable to ensure that the members are representative of the different interest groups in the community and in particular that 
women's concerns are adequately addressed. In higher-income countries such a committee may be a subcommittee from a local council or government at the local level. For instance in Chile user committees have been set up for all water supplies constructed by the regional water supply company using subsidies from the Government. These committees are supported by training programmes provided by the regional water supply companies who provide training to managers and operators of the supplies.

\subsection{ASSESSMENT OF SANITARY COMPLETION AND ESTABLISHING PRIORITY RISK FACTORS}

The state of sanitary completion can be assessed using inspection methodologies, as described further below. These are particularly important in the context of system assessment to determine risks and priorities for upgrading abstraction facilities as well as for defining control measures in the context of developing a Water Safety Plan (WSP). Sanitary inspections may also be used in verification via a surveillance programme using standardised approaches (Howard, 2002; WHO, 1997). Examples of such forms are commonly available, for instance in Volume 3 of the Guidelines for Drinking-water Quality (1997). In both cases, water quality data would also typically be collected to allow combined analysis of the effectiveness of the control measures.

Sanitary inspection methods may also be used in the routine operational monitoring of the water source as part of a WSP. Sanitary inspection approaches for routine monitoring in developed countries are likely to be the same as those used in assessment. In developing countries, other tools such as simple pictorial monitoring tools may be more effective. Routine monitoring may include some analysis of basic water quality parameters, particularly if chlorination is practiced, but this is dependent on the skill of the operators and funds for supporting such analysis.

\subsubsection{Sanitary inspection}

Sanitary inspection provides an easy but effective means of both assessing and monitoring sanitary completion, particularly when this employs a standardized and quantifiable approach (Lloyd and Bartram, 1991; Lloyd and Helmer, 1991; WHO, 1997). Unless a standardized approach is adopted, problems are commonly found in comparing the findings between different inspectors (WHO, 1997; Howard, 2002). This leads to inaccurate and unreliable results and limits the potential for subsequent analysis of the data. A quantified approach allows an overall risk score to be calculated in order to assess the state of supply systems and to identify priorities for action. It also permits comparisons between different source types once the data is converted into a percentage risk.

Sanitary inspections should be undertaken frequently, at least as often as samples are analysed for verifying water quality and in some cases more often. Risks are not static, they change over time as new development occurs in the area and are sometimes due to poor maintenance practices. Certain risks may also be important only seasonally, for instance the collection of surface water uphill of a groundwater source may only occur during wet periods. Therefore inspections may be required in both wet and dry seasons. 
Most sanitary inspections involve a series of simple questions with Yes/No answers. As the questions are usually framed in such a way that a positive answer indicates the presence of a risk, typically a score is allocated for a positive answer and no score for a negative answer. Adding up the positive answers provides an overall sanitary risk score. An example of a sanitary inspection form is given in Box 18.1 below. Other examples are available from volume 3 of the Guidelines for Drinking-water Quality (WHO, 1997).

In the form in Box 18.1, questions 7, 8 and 10 refer to potential sources of faeces in the environment; questions 1,2 and 3 refer to direct pathway factors; and, questions 4,5, 6 and 9 refer to indirect factors. The analysis of these factors in relation to water quality provides useful information regarding which remedial and preventative actions are required for the specific water source. Data collected this way can further be aggregated and evaluated across a range of abstraction facilities of a given region in order to identify key risk factors.

Box 18.1. Example of a sanitary inspection form

I. Type of Facility: PROTECTED SPRING

1. General Information: Division: Parish:

2. Code Number:

3. Date of Visit:

4. Water sample taken? Sample No.: Faecal Coliform $/ 100 \mathrm{ml}$ :

II. Specific Diagnostic Information for Assessment

1. Is the spring unprotected?

Risk

2. Is the masonry protecting the spring faulty? $\quad \mathrm{Y} / \mathrm{N}$

3. Is the backfill area behind the retaining wall eroded? YIN

4. Does spilt water flood the collection area? $\quad Y / N$

5. Is the fence absent or faulty? $\quad Y / N$

6. Can animals have access within $10 \mathrm{~m}$ of the spring? $\mathrm{Y} / \mathrm{N}$

7. Is there a latrine uphill and/or within $30 \mathrm{~m}$ of the spring? YN

8. Does surface water collect uphill of the spring?

9. Is the diversion ditch above the spring absent or non-functional? YN

10. Are there any other sources of pollution uphill of the spring (e.g. solid waste)?

Total Score of Risks: $/ 10$ (Risk score 0-3=low; 3-5=medium; 6-8=high; 9$10=$ very high)

\section{Results and Recommendations}

The following important points of risk were noted (list nos. 1-10):

Comments:

Signature of Health Inspector/Assistant: 


\subsubsection{System assessment through sanitary inspection as a management tool}

Sanitary inspections provide a useful management tool for communities, water supply agencies and surveillance bodies. The value of the sanitary inspection is that it provides a longer-term perspective on the risks of contamination, gives an overview assessment of how effective operation and maintenance has been and which system upgrade is needed. Such information can help in directing resources for improvement of the infrastructure and for improved training of water supply operators. Sanitary inspections also provide an additional means of assessing the differences in water quality from different types of water sources thus helping overall national and regional planning and policy-making (Bartram, 1999; Howard, 2002). This type of analysis is likely to be undertaken by a utility or surveillance body rather than an operator of a supply.

In a number of countries, the combined analysis of sanitary risk scores and level of contamination has proved to be an effective way of prioritizing which water supplies receive investment (Lloyd and Helmer, 1991; WHO, 2004). In many cases there is a broad relationship between the overall sanitary risk score and level of contamination (Lloyd and Bartram, 1991; Lloyd and Helmer, 1991). However, such approaches do not necessarily identify which are the most important specific factors to address as the system of sanitary inspection provides each risk factor with equal weighting, despite awareness that this is unlikely to be the case.

It is often useful to be able to determine the importance of different risk factors in order to direct investment and action on those improvements in the source that will yield the greatest improvements in water quality. Such an approach is often particularly useful in order to assess whether microbial contamination of groundwater derives from poorly sited and constructed sanitation facilities or from poor maintenance of sanitary completion measures. Leaching from on-site sanitation has been identified in some cases to be the major cause (Boonyakarnkul and Lloyd, 1994; Rahman, 1996; Massone et al., 1998; Melian et al., 1999). Other research from a number of countries indicates that poor sanitary completion was more important in microbial contamination than subsurface leaching from hazards such as pit latrines (Gelinas et al., 1996; Cronin et al., 2002; Howard et al., 2003) as described further in Section 18.6 .3 below. This is particularly the case in situations where there are a number of sources of human faecal matter in the environment such as refuse pits and dumps, open defecation and widespread occurrence of animal faecal matter (Barrett et al., 2000b; Chidavaenzi et al., 2000). Furthermore, it is often important to determine the influence of other factors such as rainfall and population density, which may affect contamination risks (Wright, 1986; Gorter et al., 1995; Barrett et al., 2000a; Howard, 2002).

\subsubsection{Establishing the importance of different risks due to poor sanitary completion}

There are a number of approaches that have been used to investigate the relationships between individual risks identified through sanitary inspection and water quality outcomes using statistical methods to analyse the data. These approaches range from the 
use of simple reporting of the frequency of risks in relation to specified water quality targets to the use of contingency tables and logistic regression. In order to undertake such analysis, it is important that water quality data and sanitary inspection data are available and can be paired.

In undertaking analysis of the relationship between sanitary risk factors and water quality outcomes, it is useful to compare risks in relation to water quality targets, as the failure to meet specified targets would trigger action. Cronin et al. (2002) present the analysis of data from two sites in Kenya and Mozambique, where the frequency of reporting of individual risks identified in inspections of sanitary completion measures were compared against samples with results above and below the median concentration of thermotolerant coliforms. This is shown in Table 18.1 below. This analysis indicated that poor sanitary completion of wells was more important in leading to contamination than subsurface leaching from sources of faecal material.

Table 18.1. Risk factors relating to higher levels of microbial contamination in dug wells in Kisumu, Kenya (Cronin et al., 2002)

\begin{tabular}{|c|c|c|c|}
\hline Risk factor & $\begin{array}{l}\text { Percent of samples } \\
\text { < median TTC/100 ml }\end{array}$ & $\begin{array}{l}\text { Percent of samples } \\
>\text { > median TTC/100 } \mathrm{ml}\end{array}$ & Difference \\
\hline Plinth $<1.5 \mathrm{~m}$ & 83 & 100 & +17 \\
\hline Well wall sealed & 83 & 91 & +8 \\
\hline Surface waste within $30 \mathrm{~m}$ & 83 & 91 & +8 \\
\hline Ponding on plinth & 50 & 55 & +5 \\
\hline Drainage channel inadequate & 100 & 100 & 0 \\
\hline Well cover unsanitary & 92 & 91 & -1 \\
\hline Latrines within $10 \mathrm{~m}$ & 55 & 58 & -3 \\
\hline Open water within $20 \mathrm{~m}$ & 64 & 67 & -3 \\
\hline Ponding within $3 \mathrm{~m}$ & 92 & 82 & .10 \\
\hline
\end{tabular}

Other analyses have used concentrations of indicator organisms in water to define a water quality target based on international guidelines or national standards. In this approach, for each risk factor the difference in frequency of reporting of each risk factor is compared between when the target is met and when it is exceeded with the difference providing an indication of whether there is a relationship and the strength of relationships found. Howard et al. (2003) describe such an analysis of water quality and sanitary risks in shallow protected springs in Kampala, Uganda shown in Table 18.2.

It is often useful to undertake further analysis of the data to assess the strength of the relationships between risk factors and water quality. In studies from Thailand, Boonyakarnkul and Lloyd (1994) developed a Sanitary Hazard Index (SHI), which related the intensity of faecal contamination associated with individual risk factors identified from sanitary inspection. These authors were able to identify which factors had the highest $\mathrm{SHI}$ and concluded that this should provide direction in relation to the priority accorded to reducing the presence of individual risk factors. The authors noted that there was a difference between those factors with the highest SHI and those that were most commonly reported. 
Combined analysis of water quality and sanitary inspection data can also be undertaken using a range of non-parametric tests, which is common in the analysis of water resources data (Helsel and Hirsch, 1992). The use of dedicated software packages will assist in undertaking such analysis, but are not essential. Such analysis often incorporates other data such as rainfall and population density that are considered important in controlling quality.

Table 18.2. Sanitary inspection and water quality data for protected springs in Uganda (Howard et al, 2003)

\begin{tabular}{llll}
\hline Risk factor & $\begin{array}{l}\text { Percent reported when } \\
<1 \text { cfu/100 ml }\end{array}$ & $\begin{array}{l}\text { Percent report when } \\
21 \text { cfu/100 ml }\end{array}$ & Difference \\
\hline Masonry defective & 8 & 17 & +9 \\
Backfill eroded & 29 & 67 & +38 \\
Collection area flooded & 79 & 83 & +4 \\
Fence faulty & 83 & 100 & +17 \\
Animal access within $10 \mathrm{~m}$ & 79 & 100 & +21 \\
Latrine less than 30 m uphill & 4 & 0 & -4 \\
Surface water collects uphill & 46 & 100 & +54 \\
Diversion ditch faulty & 79 & 100 & +21 \\
Other pollution uphill & 46 & 83 & +37 \\
\hline
\end{tabular}

One example of non-parametric statistical tests is a contingency table of odds ratios. To make this analysis, variables with continuous data (e.g. water quality, rainfall and population density) must be converted into binomial categorical data. In the case of water quality targets the resulting variable will be whether the target was complied with or was exceeded (often simply expressed as either Yes or No). For rainfall data, a new variable may be whether rain was recorded within a specified time period or whether a certain depth of rainfall occurred.

An example of a contingency table is given below in Table 18.3 taken from analysis performed by Howard et al. (2003), which combines analysis of sanitary risks and water quality objectives for faecal streptococci and thermotolerant coliforms in protected springs in Uganda.

In the example of Table 18.3, two water quality objectives have been selected to allow the data to be analysed: the absence of faecal streptococci and less than $10 \mathrm{cfw} / 100$ $\mathrm{ml}$ thermotolerant coliforms, the latter being a more realistic target for non-chlorinated community-managed water supplies. Odds ratios exceeding 1 show a positive relationship between the risk factor and exceeding the water quality target.

For both water quality targets the analysis demonstrates that localised pathways combined to sources of pollution and rainfall lead to contamination. Furthermore, in this setting thermotolerant coliform contamination appears to result from a more complex set of factors than faecal streptococci but is still primarily linked to poor sanitary completion.

This data can be further analysed through logistical regression (Howard et al., 2003). Using the same data shown in Table 18.3, logistic regression models were developed and are shown in Table 18.4. The regression models included all co-variates where odds ratios showed relationships significant at least to the 95 per cent level. Although not 
significant at least to the 95 per cent level for faecal streptococci, latrine proximity within $30 \mathrm{~m}$ was forced into the model as this was still deemed a plausible route of contamination.

Table 18.3. Contingency table for protected springs in Uganda (Howard et al., 2003)

\begin{tabular}{|c|c|c|c|c|c|c|}
\hline \multirow[t]{2}{*}{ Variable } & \multicolumn{3}{|c|}{ FS $>0 \mathrm{cfu} .100 \mathrm{mr}^{1}$} & \multicolumn{3}{|c|}{ TTC $>10 \mathrm{cfu} .100 \mathrm{mr}^{1}$} \\
\hline & $\begin{array}{l}\text { Odds } \\
\text { ratio }\end{array}$ & $\mathbf{p}$ & $95 \% \mathrm{CI}$ & Odds ratio & p & $\begin{array}{l}95 \% \\
\mathrm{Cl}\end{array}$ \\
\hline Faulty masonry & 1.216 & 0.475 & 2.42 & 1.506 & 0.075 & 1.4 \\
\hline Backfill area eroded & 4.135 & 0.000 & 5.8 & 2.762 & 0.000 & 2.73 \\
\hline Collection area floods & 0.619 & 0.085 & 0.71 & 0.603 & 0.035 & 0.53 \\
\hline Fence absent or faulty & 9.492 & 0.008 & 48.26 & 3.496 & 0.138 & 17.64 \\
\hline Animal access $<10 \mathrm{~m}$ & 3.627 & 0.202 & 25.73 & 1.366 & 0.756 & 9.64 \\
\hline Surface water uphill & 2.203 & 0.014 & 2.95 & 3.933 & 0.000 & 4.36 \\
\hline Diversion ditch faulty & 0.755 & 0.369 & 0.98 & 1.324 & 0.263 & 1.35 \\
\hline Other pollution uphill & 3.75 & 0.041 & 12.3 & 5.728 & 0.029 & 26.23 \\
\hline Latrine $<30 \mathrm{~m}$ uphill of spring & 1.938 & 0.057 & 2.85 & 1.759 & 0.036 & 1.94 \\
\hline Latrine $<50 \mathrm{~m}$ uphill of spring & 0.838 & 0.531 & 0.98 & 0.738 & 0.198 & 0.17 \\
\hline High population density & 4.49 & 0.000 & 5.43 & 4.708 & 0.000 & 4.75 \\
\hline Waste $<10 \mathrm{~m}$ uphill of spring & 1.971 & 0.028 & 2.53 & 2.557 & 0.000 & 2.63 \\
\hline Waste $<20 \mathrm{~m}$ uphill of spring & 2.437 & 0.001 & 2.78 & 3.085 & 0.000 & 3.03 \\
\hline Waste $<0 \mathrm{~m}$ uphill of spring & 1.547 & 0.191 & 2.17 & 1.896 & 0.031 & 2.4 \\
\hline Rainfall within previous 2 days & 4.966 & 0.000 & 6.29 & 3.827 & 0.000 & 3.75 \\
\hline
\end{tabular}

Table 18.4. Logistic regressions for protected springs in Uganda (Howard et al., 2003)

\begin{tabular}{lllllll}
\hline Model & $\begin{array}{l}\text { Model log } \\
\text { estimate }\end{array}$ & Variables & $\begin{array}{l}\text { Log } \\
\text { estimate }\end{array}$ & $\begin{array}{l}\text { Standard } \\
\text { error }\end{array}$ & df & p-value \\
\hline Faecal & 343.27 & Constant & 2.63 & 0.36 & 1 & 40.001 \\
streptococci & & Eroded backfill & -0.8 & 0.29 & 1 & 0.006 \\
$>0$ cfu/100 $\mathrm{ml}$ & & Faulty fence & -1.94 & 0.88 & 1 & 0.027 \\
& & Surface water uphill & -1.07 & 0.32 & 1 & 0.001 \\
& & Rainfall within 2 days & -1.34 & 0.27 & 1 & 4.001 \\
Thermotolerant & \multirow{2}{*}{338.11} & Constant & 2.06 & 0.37 & 1 & $<0.001$ \\
coliforms & & Eroded backfill & -0.72 & 0.34 & 1 & 0.034 \\
$>10$ cfu/100 ml & & Collection area flooded & 0.57 & 0.29 & 1 & 0.047 \\
& & Surface water uphill & -0.7 & 0.32 & 1 & 0.031 \\
& & High population density & -1.02 & 0.35 & 1 & 0.003 \\
& & Rainfall within 2 days & -1.64 & 0.29 & 1 & 40.001 \\
\hline
\end{tabular}

Both regression models indicate contamination resulting from rapid recharge close to the springs and suggest that it is poor sanitary conditions at the spring itself that represent the greatest problems for the microbial quality of water. It is likely that this occurs through both direct inundation and very rapid recharge through preferential flow paths. 
In both cases, the principal sources appear to be waste dumps and surface water rather than latrines. This agrees with other studies that point to the importance of refuse dumps for the presence of indicator organisms (Chidavaenzi et al., 2000). In a study of wells in rural Mozambique, Godfrey et al., (2005) found that there was a pulse response of microbial contamination to rainfall events. Soil and engineering studies indicated that localised pathways were likely to be the primary cause of contamination rather than contamination due to aquifer pathways (Godfrey et al., 2005).

The findings of Howard et al., (2003) and Godfrey et al., (2005) are in agreement with other studies into the causes of microbial contamination of shallow groundwater supplies, which have tended to emphasize direct ingress rather than subsurface leaching of contaminants in causing contamination (Rojas et al., 1995; Gelinas et al., 1996). These findings emphasise the importance of sanitary completion of groundwater sources.

The influence of sanitary completion on controlling quality may vary with different technologies and areas. For instance, studies in Thailand by Boonyakarnkul and Lloyd (1994) concluded that on-site sanitation factors led to the greatest Sanitary Hazard Index and were therefore priority risks to resolve. In Uganda, the major control on quality in tubewells appeared to be the proximity and location of on-site sanitation rather than wellhead completion (Howard et al., 2003). By contrast, studies in Bangladesh reported that wellhead completion was more important than subsurface leaching from on-site sanitation (MacDonald et al., 1999; Ahmed et al., 2002).

The results of these studies support the validation of control measures, an essential step within a WSP (see Chapter 16). The performance of a WSP may be assessed by repeating the above analysis after upgrading sanitary completion to address faults. identified.

\subsection{CONTROL MEASURES FOR SANITARY COMPLETION OF GROUNDWATER SOURCES}

The design, construction, operation and maintenance requirements for groundwater sources can be translated into a series of control measures or points at the wellhead or spring protection works. Key control measures for different types of groundwater source are shown in Table 18.5 below. Planning measures to control the presence of hazards in the catchment area or immediate vicinity of a well or spring are discussed in more detail in Chapters 18-25.

NOTE In water supplies developing a Water Safety Plan (Chapter 16), system assessment would identify which control measures exist, their effectiveness and which need to be upgraded or newly introduced Management plans would document why specific control measures were chosen, how their performance is monitored and which corrective action should be taken both during normal operations and during incident conditions when monitoring indicates loss of control. 
Table 18.5. Examples of control measures for sanitary completion and options for their monitoring and verification

\begin{tabular}{|c|c|c|}
\hline $\begin{array}{l}\text { Process } \\
\text { step }\end{array}$ & Examples for control measures in sanitary completion & $\begin{array}{l}\text { Options for their monitoring } \\
\text { and verification }\end{array}$ \\
\hline 要, & $\begin{array}{l}\text { Plan site and depth of abstraction to avoid presence of hazards and } \\
\text { pathways for their ingress into the water source, e.g. prevent } \\
\text { presence of faecal material within set-back distance } \\
\text { Plan pumping regime to avoid leaching of contaminants into the } \\
\text { aquifer by providing sufficient distance from sources of } \\
\text { contaminants }\end{array}$ & $\begin{array}{l}\text { Review (applications for) } \\
\text { permits for construction of new } \\
\text { abstraction facilities or for } \\
\text { reconstruction and upgrade of } \\
\text { existing ones }\end{array}$ \\
\hline 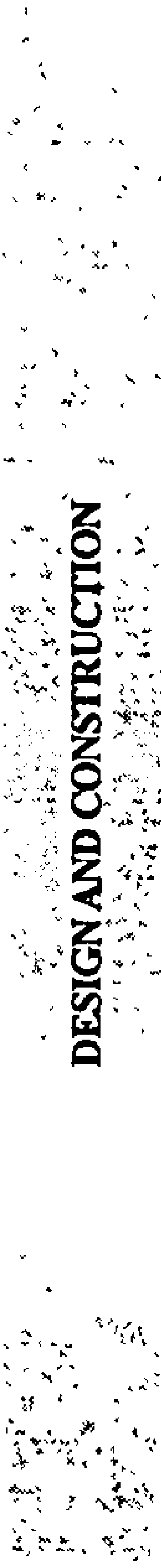 & $\begin{array}{l}\text { Ensure good drainage around wellhead or spring, e.g. } \\
\text { - with ditches to divert runoff away from the wellhead or backfill } \\
\text { area of a spring } \\
\text { - for wells with an apron to direct spills away from the wellhead } \\
\text { - for springs with good drainage of wastewater away from the } \\
\text { spring area } \\
\text { Design wellhead or spring area protection to prevent direct } \\
\text { contamination, e.g. with } \\
\text { - Fencing to exclude animals from wellhead or spring backfill } \\
\text { area } \\
\text { - apron extending around the wellhead at least } 1 \text { - } 1.5 \mathrm{~m} \text { from } \\
\text { casing } \\
\text { - for boreholes ensure that join between apron and casing or lining } \\
\text { is sound } \\
\text { - for dug wells ensure wellhead is raised by at least } 0.3 \mathrm{~m} \text { and } \\
\text { covered by slab } \\
\text { - for springs ensure backfill area behind spring box or retaining } \\
\text { wall is protected, e.g. with grass cover } \\
\text { Ensure sanitary completion of lining, e.g. } \\
\text { - with lining extending at least } 30 \mathrm{~cm} \text { above the apron } \\
\text { - with seal sufficiently extended below ground level: at least } 1.5 \\
\text { m for boreholes with handpump and } 5 \mathrm{~m} \text { for mechanised } \\
\text { boreholes } \\
\text { - for boreholes with rising main in good condition } \\
\text { - for dug wells by proper construction and use of mortar seal on } \\
\text { lining, ensure lining stays in good condition (no weep holes } \\
\text { during rainfall !) } \\
\text { Ensure adequate choice and good condition of structures, e.g. } \\
\text { - for boreholes that pumps are firmly attached to the wellhead } \\
\text { - for dug wells install handpump or other sanitary means of } \\
\text { abstraction }\end{array}$ & $\begin{array}{l}\text { Sanitary inspection of design } \\
\text { and condition }\end{array}$ \\
\hline 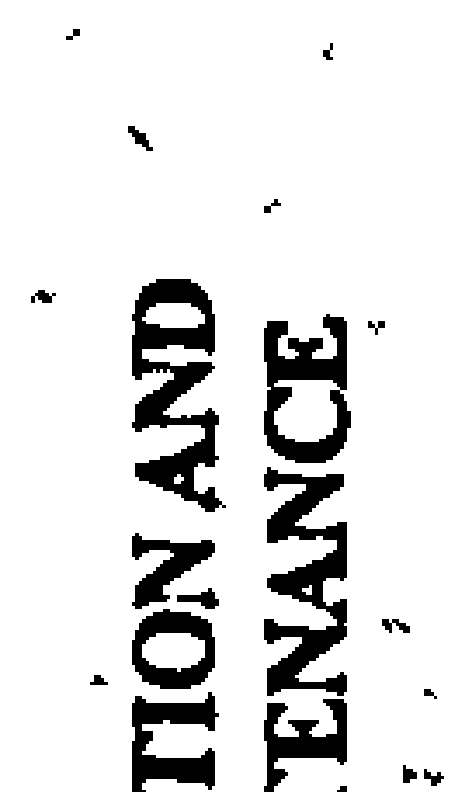 & $\begin{array}{l}\text { For boreholes and wells, ensure pumping regime does not exceed } \\
\text { amounts allowed for during planning } \\
\text { For dug wells ensure hygienic use of handpump or other means of } \\
\text { withdrawing water }\end{array}$ & $\begin{array}{l}\text { Meter or estimate amount of } \\
\text { water abstracted } \\
\text { Regular inspection of condition } \\
\text { and of use. Periodic analysis of } \\
\text { microbial indicators. }\end{array}$ \\
\hline 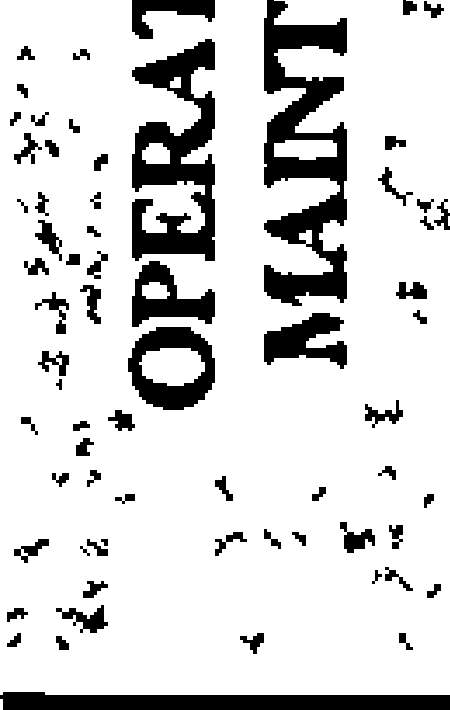 & $\begin{array}{l}\text { Ensure regular maintenance and cleaning of well or spring } \\
\text { environment, e.g. removal of debris blocking diversion ditches or } \\
\text { those removing wastewater from the vicinity of springs; repair of } \\
\text { fences; repair of structures such as aprons, covering flaps, } \\
\text { handpumps }\end{array}$ & $\begin{array}{l}\text { Review inspection reports for } \\
\text { compliance to management } \\
\text { plans. Periodic analysis of } \\
\text { microbial indicators. }\end{array}$ \\
\hline
\end{tabular}


Table 18.5 focuses on control measures for the design and construction of wells and springs which are specific to sanitary completion. For the operation of abstraction facilities, maintenance and repairs are crucial control measures for keeping contaminants out, and management plans to define the scope and timescales of such activities are important to support that they are regularly carried out.

Regardless of whether or not any of these control measures are part of a WSP, their monitoring and verification is crucial to ensure that they are in place and are effective. Table 18.5 therefore includes options for surveillance and monitoring of the control measure examples given. As most of the control measures for sanitary completion involve issues of design and maintenance, many of them are most effectively monitored by regular inspections and through reviewing inspection and maintenance reports. The periodic analysis of microbiological indicator organisms is also crucial to the verification and validation of protection measures. In this context, management plans are an important tool to ascertain that inspection and maintenance activities are regularly carried out. This aspect of monitoring focuses on checking whether the controls are operating as intended, rather than on contaminant concentrations in groundwater.

NOTE $>$ Options for monitoring suggested in Table 18.5 focus on the control measures rather than on groundwater quality.

Comprehensive groundwater quality monitoring programmes are a supplementary aspect of verification of the efficacy of sanitary completion.

\subsection{REFERENCES}

Ahmed, K.M., Khander, Z.Z., Lawrence, A.R., MacDonald, D.M.J. and Islam, M.S. (2002) An investigation of the impact of on-site sanitation on the quality of groundwater supplies in two peri-urban areas of Dhaka, Bangladesh. In ARGOSS Assessing risk to groundwater from onsite sanitation: scientific review and case studies, BGS Commissioned Report CR/02/079N, pp. 37-67, BGS, Keyworth.

ARGOSS (2001) Guidelines for assessing the risk to groundwater from on-sile sanitation, BGS Technical Report, BGS, Wallingford.

Barrett, M., Howard, G., Pedley, S., Taylor, R. and Nalubega, M. (2000a) A comparison of the extent and impacts of sewage contamination on urban groundwater in developed and developing countries. In Water, Sanitation and Health, (eds. I. Chorus, U. Ringelband, G. Schlag and O. Schmoll) pp. 179-186, IWA, London.

Barrett, M.H., Johal, K., Howard, G., Pedley, S. and Nalubega, M. (2000b) Sources of faecal contamination in shallow groundwater in Kampala. In Groundwater: Past achievements and future challenges, (eds. O. Sililo, S. Appleyard and M. Barrett), pp. 691-696, Balkema, Rotterdam.

Bartram, J. (1999) Effective monitoring of small drinking water supplies. In Providing Safe Drinking Water in Small Systems, (eds. J.A. Cotruvo, G.F. Craun and N. Hearne), pp. 353365, Lewis, Washington, DC. 
Boonyakarnkul, T. and Lloyd, B.J. (1994) The Impact of Rehabilitation on Tubewell Water Quality Using Combined Sanitary Inspection and Bacteriological Analysis. Paper presented at the Second Asian Regional Workshop on Groundwater Contamination, Adelaide.

Chidavaenzi, M., Bradley, M., Jere, M. and Nhandara, C. (2000) Pit latrine effluent infiltration into groundwater: the Epworth case study. Water, Sanitation and Health, (eds. I. Chorus, U. Ringelband, G. Schlag and O. Schmoll) pp. 171-178, IWA, London.

Collins, S. (2000) Hand-dug Shallow Wells. SKAT Publications, St. Gallen.

Cronin, A., Breslin, N., Taylor, R.G. and Pedley, S. (2002) Assessing the risks to groundwater quality from on-site sanitation and poor sanitary well completion, in 'Eocsan-closing the loop'. In Proc. Second International Conference of Ecological Sanitation, pp. 431-436, Lubeck, April 2003.

Daly, E.P. and Woods, L. (1995) Groundwater quality in the Nore River Basin in the southeast of Ireland. In Groundwater Quality, (eds. H. Nash and G.J.H. McCall), pp. 131-144, Chapman and Hall, London.

Driscoll, F.G. (1986) Groundwater and Wells, Johnson Screens, St Paul, Minnesota.

Gelinas, Y, Randall, H., Robidoux, L. and Schmit, J-P. (1996) Well water survey in two Districts of Conakry (republic of Guinea) and comparison with the piped city water. Water Res., 30(9), 2017-2026.

Godfrey, S. (2003) Appropriate chlorination techniques for wells in Angola. Waterlines, 21(4), 6-9.

Godfrey, S., McCaffrey, L., Obika, E.U. and Becks, M. (2003) The effectiveness of point source chlorination in improving water quality in IDP camps in Angola. JCWEM, 17(3), 149-152.

Godfrey, S., Timo, F. and Smith, M. (2005 Relationship between rainfall and microbiological contamination of shallow groundwater in Northem Mozambique. Water SA, 31(4), 609-614.

Gorter, A.C., Alberts, J.H., Gago, J.F. and Sandiford, P. (1995) A randomised trial of the impact of rope-pumps on water quality. J. Trop. Med. and Hygiene, 98, 247-255.

Helsel, D.R. and Hirsch, R.M. (1992) Statistical Methods in Water Resources, Elsevier Science, Amsterdam.

Hix, G.L. (1993) Using mud rotary to drill monitoring and remediation wells. Water Well J., 47(5), 80-85.

Holden, R.M.L. (1999) Circuit rider training program in first nation communities. In Providing Safe Drinking Water in Small Systems, (eds. J.A. Cotruvo, G.F. Craun and N. Heane), pp. S13521, Lewis, Washington, DC.

Howard, G. (ed.) (2002) Urban Water Supply Surveillance - A reference mamual. WEDC, Loughborough University.

Howard, G., Mutabazi, R. and Nalubega, M. (2001) Rehabilitation of protected springs in Kampala, Uganda. In Water, Sanitation and Hygiene: challenges of the millennium, Proc. of the 26th WEDC Conference, Dhaka, Bangladesh, pp. 20-23.

Howard, G., Pedley, S., Barrett, M., Nalubega, M. and Johal, K. (2003) Risk factors contributing to microbiological contamination of shallow groundwater in Kampala, Uganda. Water Res., 37(14), 3421-3429.

Howsam, P. (1990) Well performance deterioration: an introduction to causes. In Water Wells: Monitoring, maintenance and rehabilitation, (ed. P. Howsam), pp. 19-24, E\&F Spon, London.

Leake, C.C. and Kamal, T. (1990) Well deterioration in Sindh, Pakistan. In Water Wells: Monitoring, maintenance and rehabilitation, (ed. P. Howsam), pp. 59-71, E\&F Spon, London.

Lewis, W.J. and Chilton, P.J. (1984) Performance of sanitary completion measures of wells and boreholes used for rural water supplies in Malawi. In Challenges in African Hydrology and Water Resources, p. 235, LAHIS, Harare.

Lloyd, B. and Bartram, J. (1991) Surveillance solutions to microbiological problems in water quality control in developing countries. Water, Sci. Technol., 24(2), 61-75.

Lloyd, B. and Helmer, R. (1991) Surveillance of Drinking Water Quality in Rural Areas, Longman, London.

Macdonald, D., Ahmed, K.M., Islam, M.S., Lawrence, A. and Khandker, Z.Z. (1999) Pit latrines - a source of contamination in peri-urban Dhaka? Waterlines, 17(4), 6-8. 
Massone, H.E., Martinez, D.E., Cionchi, J.L. and Bocanegra, E. (1998) Suburban areas in developing countries and their relationship to groundwater pollution: a case study of Mar del Plata, Argentina. Environ. Man., 22(2), 245-254.

Melian, R., Myrlian, N., Gouriev, A., Morau, C. and Radstake, F. (1999) Groundwater quality and rural drinking-water supplies in the Republic of Moldova. Hydrogeology J., 7, 188-196.

Meuli, C. and Wehrle, K. (2001) Spring Catchment, SKAT, St Gallen.

Michael, A.M. and Khepar, S.D. (1989) Water Well and Pump Engineering. TATA Press, New Delhi.

Morgan, P. (1990) Rural water supplies and sanitation - A text from Zimbabwe's Blair Research Laboratory, Macmillan Publishers, London.

Nasinyama, G.W., McEwen, S.A., Wilson, J.B., Walter-Toews, D., Gyles, C.L. and Opuda-Asibo, J. (2000) Risk factors for acute diarthoea among inhabitants of Kampala District Uganda. $S$. African Med. J., 90(9), 891-898.

O'Connor, R. (2002) Report of the Walkerton Enquiry, Part One: The events of May 2000 and related issues (a summary). Ontario Ministry of the Attorney General, Ontario.

Olsen, S.J., Miller, G., Breuer, T., Kennedy, M., Higgins, C., Walford, J., McKee, G., Fox, K., Bibb, W. and Mead, P. (2002) A Waterbome Outbreak of Escherichia coli 0157:117 Infections and Hemolytic Uremic Syndrome: Implications for Rural Water Systems. Emerging Infectious Diseases, 8(4), 370-375.

Pedley, S. and Howand, G. (1997) The Public Health Implication of Groundwater Microbiology. $Q$ J. Eng. Geology, 30(2), 179-188.

Platenberg, R.J.P. and Zaki, M. (1993) Patterns of water quality in rural areas of Assyut Govemate, Egypt. Water Sci. Technol., 27(9), 55-66.

Rahman, A. (1996) Groundwater as source of contamination for water supply in rapidly growing megacities in Asia: case of Karachi, Pakistan. Water Sci. Technol., 34(7-8), 285-292.

Robertson, J.B. and Edberg, S.C. (1997) Natural protection of spring and well drinking water against surface microbial contamination. Critical Reviews in Microbiology, 23(2), 143-178.

Rojas, R, Howard, G. and Bartram, J. (1995) Groundwater Quality and Water Supply in Lima. In Groundwater Quality, (eds. H. Nash and G.J.H. McCall), AGID Report No. 16, pp. 159-167, Chapman and Hall, London.

Rowe, A., Angulo, F., Roberts L. and Tauxe, R. (1998) Chlorinating well water with liquid bleach was not an effective water disinfection strategy in Guinea Bissau. Internat. J. Environ. Health Res., 8, 339-340.

Trividi, B.K., Gandhi, H.S. and Shukla, M.K. (1971) Bacteriological water quality and incidence of waterborne diseases in a rural population. Indian J. Med Sci., 25, 795-801.

US EPA (1993) Wellhead Protection: A guide for small communities, US EPA, Washington, DC.

Watt, S.B. and Wood, W.E. (1977) Hand-Dug Wells and Their Construction, Intermediate Technology Publications, London.

WHO (1997) Guidelines For Drinking-water Quality: Surveillance and control of community water supplies, 2nd edn, vol. 3, WHO, Geneva

WHO (2004) Guidelines For Drinking-water Quality: Recommendations 3rd edn, vol. 1, WHO, Geneva.

Wright, R.C. (1986) The seasonality of bacterial quality of water in a tropical developing country (Sierra Leone). J. Hygiene, 96(1), 75-82. 
Appendix 4: Statistical Methods 


\section{Logistic Regression}

With advances in computer technology, logistic regression has largely replaced discriminate analysis as the predominant form of multivariate analysis (Coates et al, 2003). A standard linear regression model contains continuous and dependent variables taking ranges of values since the errors are normally distributed. In logistic regression, the dependent variable takes one of two values (typically the values of 0 or 1). The form of the logistic regression model is outlined in equations 2 and 3 :

$$
P=\frac{e^{(b 0+b \mathrm{X})}}{1+\mathrm{e}^{(\mathrm{bo}+\mathrm{bX})}}
$$

Where,

$\mathrm{P}=$ = probability that microbiological contamination is present at a count $>10 \mathrm{cfu} / 100 \mathrm{ml}$

$\mathbf{X}=$ vector of $\mathrm{n}$ explanatory variable values

$\mathrm{b}_{0} \quad=$ scalar interceptor parameter

b = vector of slope coefficient values, so that $b X=b_{1} X_{1}+b_{2} X_{2}+\ldots b_{n} X_{n}$

e $\quad$ error margin

$$
L u \frac{P}{1-P}=b_{o}+b \mathbf{X}
$$

Note P divided by 1-P as the odds ratio which equals the "success" to "failure."

\section{Chi-Square $\left(\chi^{2}\right)$.}

Chi-Square is a mathematical distribution that enables researchers to equate the calculated $\mathrm{X}^{2}$ values to $\chi^{2}$ (see equation 4 ).

$\sum_{i=1}^{n} \frac{\left(O_{i}-E_{i}\right)^{2}}{E_{i}}$

\section{Where}

$\mathrm{O}_{i}=$ observed frequencies

$E_{i}=$ expected frequencies for $i=1,2, \ldots, n$

Chi-Square analysis was selected for this research as it provides descriptive statistics through the estimation of degrees of freedom outlined in a Chi-Squared distribution. The method is used to generate a significance level of $p$-value. Levels of precision are estimated based on the output $\mathrm{p}$-value. This provides an estimate of precision that is statistically significant at $95 \%$ confidence or 0.05 . Significant results are noted at a $\mathrm{p}$ value nearer to zero than 0.05 . 